\title{
Kai Matuszkiewicz
}

\section{Zwischen Interaktion und Narration}

Ein Kontinuumsmodell zur Analyse hybrider digitaler Spiele. Modellbildung - Funktionalisierung Fallbeispiel (The Legend of Zelda: Ocarina of Time)

Dissertation zur Erlangung des philosophischen Doktorgrades an der Philosophischen Fakultät der Georg-August-Universität Göttingen 



\section{Inhaltsverzeichnis}

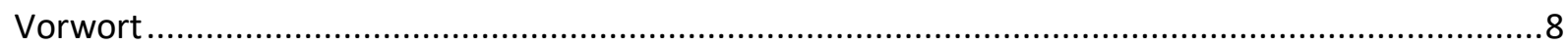

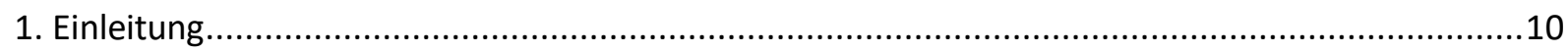

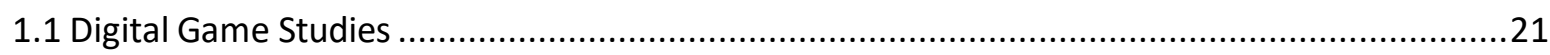

1.1.1 Wissenschafts(kurz)geschichte der Digital Game Studies .....................................22

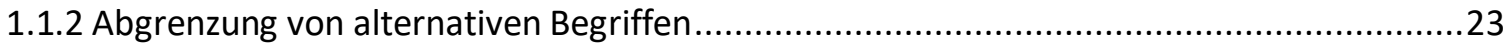

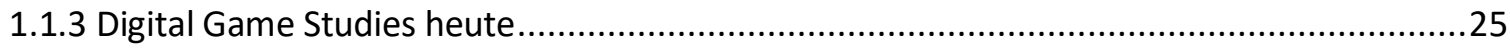

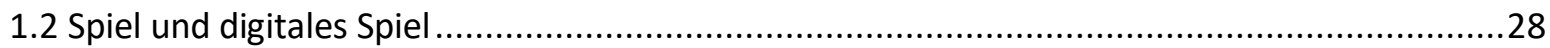

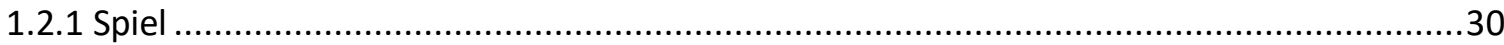

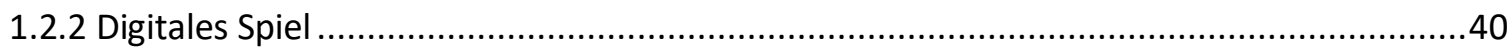

2. Das Kontinuumsmodell zur Analyse interaktiv-narrativer digitaler Spiele ................................46

2.1 Die Narratologen-Ludologen-Debatte.................................................................

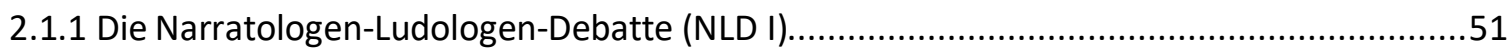

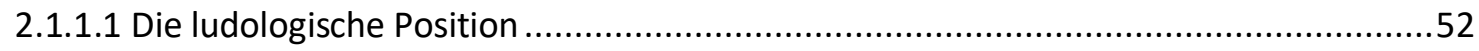

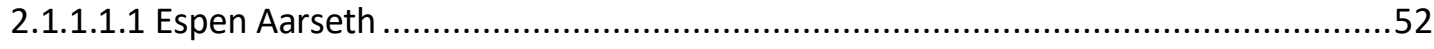

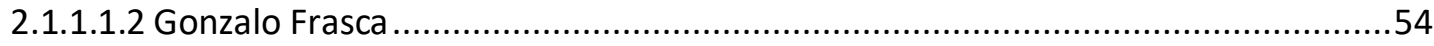

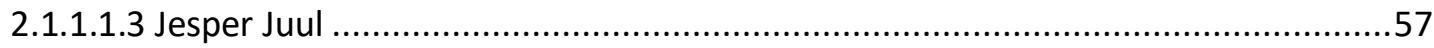

2.1.1.1.4 Markku Eskelinen ......................................................................60

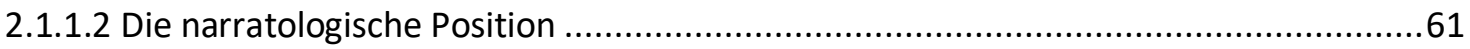

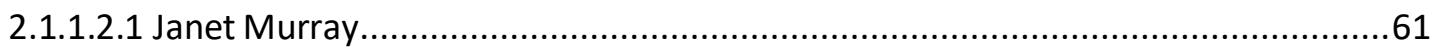

2.1.1.2.2 Marie-Laure Ryan und Henry Jenkins...................................................64

2.2 Hybridtheorien in den Digital Game Studies ...........................................................67

2.2.1 Hybridität in digitalen Spielen - zwischen medialer und attributiver Hybridisierung.........67

2.2.2 Von der Narratologen-Ludologen-Debatte zu den, vermittelnden' Hybridtheorien ...........72

2.2.2.1 Exkurs: Beispiele für Formen der Interaktivität-Narrativität in gegenwärtigen digitalen

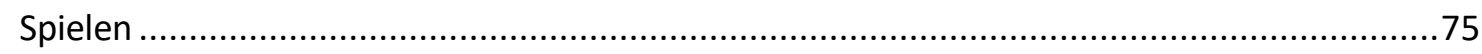

2.2.1.1 Das Quick Time Event.

2.2.1.2 Simultane Verschmelzung zwischen Interaktion und Narration in interaktivnarrativen digitalen Spielen jenseits des Quick Time Events.

2.2.2.1.3 Spielerische Interaktion und ,narrative Rezeptionsangebote' in interaktivnarrativen digitalen Spielen ...................................................................... 78

2.2.2.1.4 Fließende Übergänge zwischen interaktiven und narrativen Phasen..................79

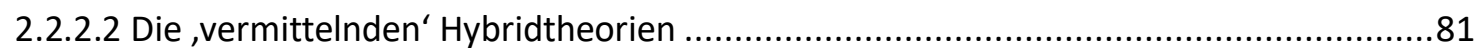


2.2.2.1 Von den dichotomischen zu den Hybridansätzen.

2.2.2.2.2 Hybridtheoriebildungen in den Digital Game Studies.................................82

2.3 Interaktivität, Interaktion, Interaktiv - Ausführungen zum ,interaktiven` Begriffsfeld .............91

2.3.1 Interaktivität und Interaktion - eine erste Annäherung.........................................94

2.3.2 Interaktivität und Interaktion in Medien - zwischen Kritik und Zuspruch .....................97

2.3.3 Interaktivität und Interaktion in digitalen Spielen ................................................ 105

2.3.4 Das Interaktiv in digitalen Spielen ................................................................. 117

2.3.5 Reale und virtuelle Interaktionen in digitalen Spielen ........................................119

2.4 Narrativität, Narration, Narrativ - Ausführungen zum , narrativen Begriffsfeld' ....................121

2.4.1 Narrativität und Narration in der literaturwissenschaftlichen Narratologie..................124

2.4.2 Narrativität und Narration in den Digital Game Studies..................................... 127

2.4.3 Narrative als Ordnungsprinzip und Grundmuster ........................................... 129

2.4.4 Mediale und personale Narrationen ......................................................... 134

2.5 Profilierung des Kontinuumsmodells .................................................................. 140

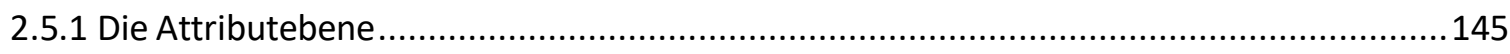

2.5.1.1. Die Makroperspektive.................................................................. 147

2.5.1.2 Die Mesoperspektive ...................................................................... 150

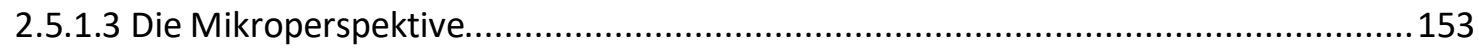

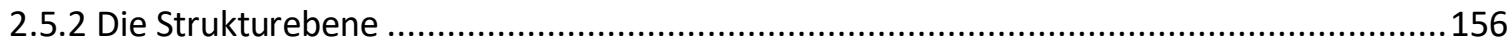

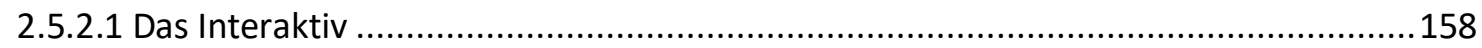

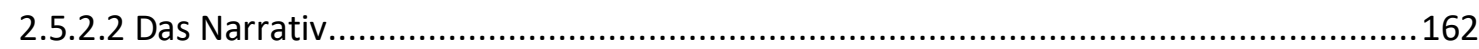

2.5.2.3 Das interaktiv-narrative Figurendesign................................................... 166

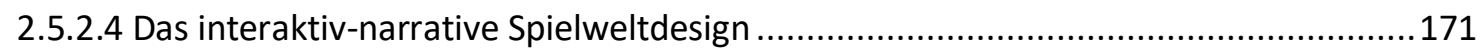

2.5.2.5 Das interaktiv-narrative Strukturdesign.................................................. 173

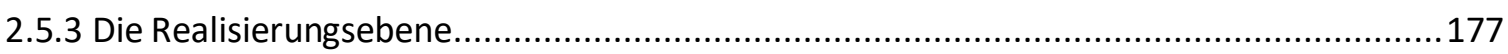

2.5.3.1 Der interaktive Spielertyp ............................................................. 182

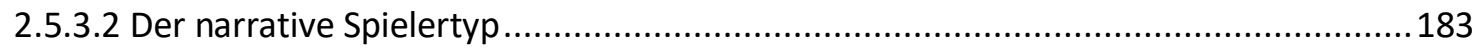

2.5.3.3 Der interaktiv-narrative Spielertyp ................................................... 186

3. Mythos und interaktiv-narrative digitale Spiele ..................................................... 190

3.1 Ansätze der modernen Mythenforschung - eine Skizze ......................................... 194

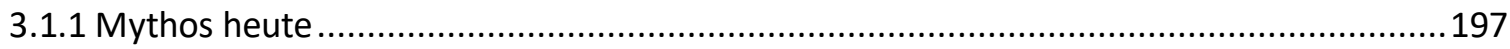

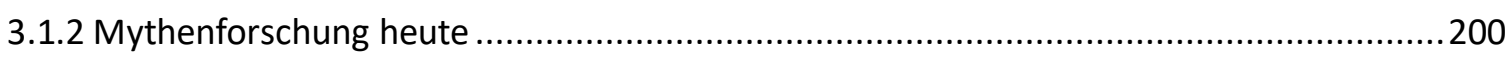

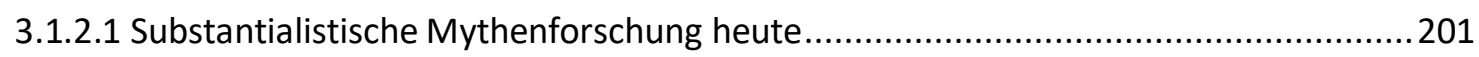

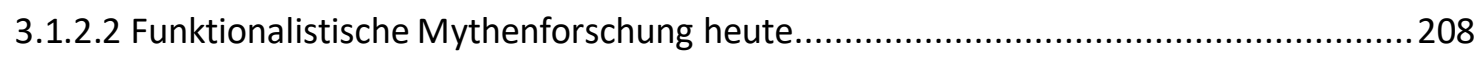


3.2 Der Mythos als Narrativ - das mythologische Narrativ.

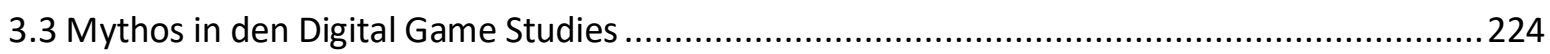

3.4 Mythos als Interaktiv-Narrativ in digitalen Spielen..............................................230

3.4.1 Funktionalistische Aspekte des Mythos in interaktiv-narrativen digitalen Spielen ..........233

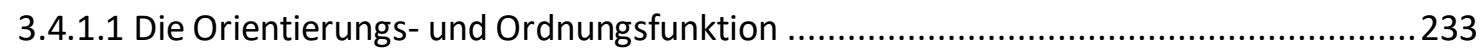

3.4.1.1.1 Strukturierung durch den Mythos .......................................................233

3.4.1.1.2 Deutung und Sinnstiftung durch den Mythos ........................................... 236

3.4.1.1.3 Vorbild- und Nachahmungsfunktion..................................................243

3.4.1.2 Die Entrückungsfunktion................................................................ 249

3.4.2 Substantialistische Aspekte des Mythos in interaktiv-narrativen digitalen Spielen .........252

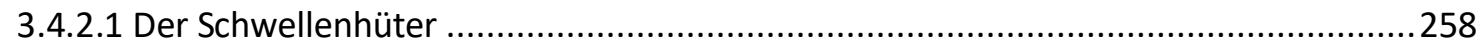

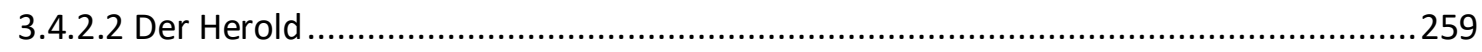

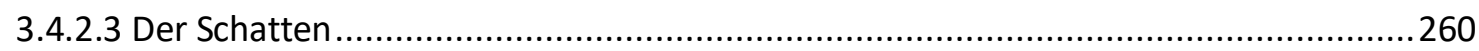

3.4.2.4 Modifikation des Modells der Heldenreise für die Analyse interaktiv-narrativer digitaler Spiele ........................................................................................... 261

3.4.2.4.1 Erster Akt der Heldenreise ..............................................................263

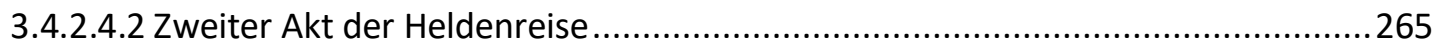

3.4.2.4.3 Dritter Akt der Heldenreise ...........................................................267

4. Eine Analyse von The Legend of Zelda: Ocarina of Time (1998) anhand des Kontinuumsmodells .269 4.1 Einführung in die transmediale Welt von The Legend of Zelda ....................................271

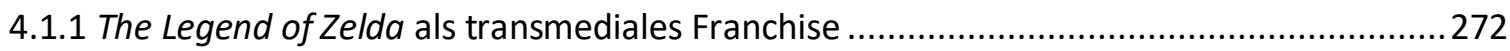

4.1.2 The Legend of Zelda als transmediale Erzählung(?) ............................................2276

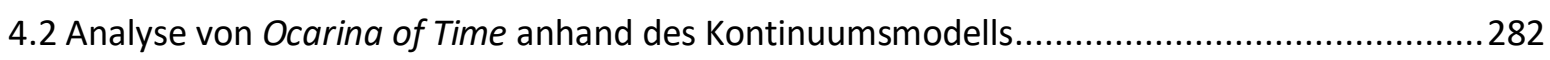

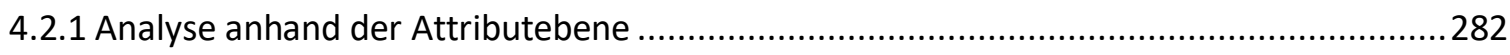

4.2.1.1 Interaktivität und Agency in Ocarina of Time .............................................284

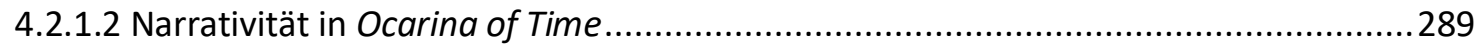

4.2.1.3 Attributive Hybridität in Ocarina of Time.....................................................294

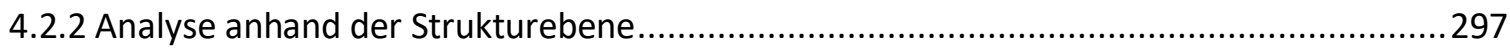

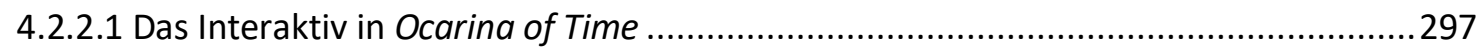

4.2.2.1.1 Handlungsoptionen und Interaktionsdesign ............................................ 298

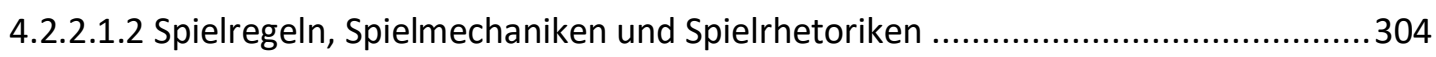

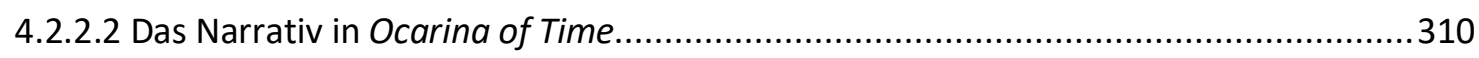

4.2.2.2.1 Der Monomythos als ordnende Instanz .............................................. 313

4.2.2.2.2 Das (modifizierte) Reisemodell des Helden........................................ 316

4.2.2.3 Das mythologische Interaktiv-Narrativ in Ocarina of Time ................................326 


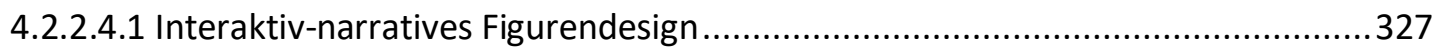

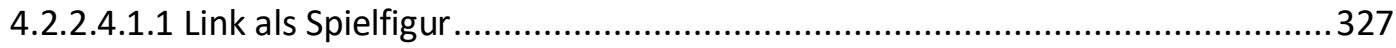

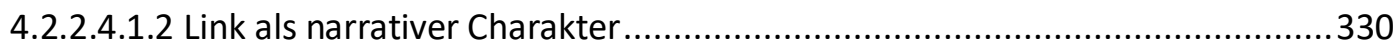

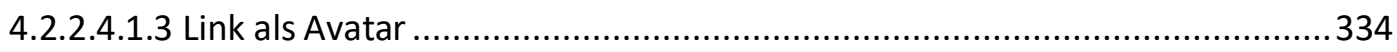

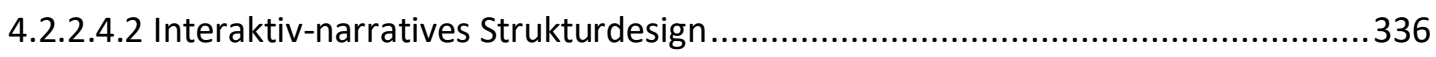

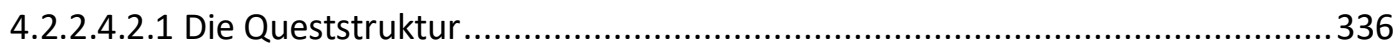

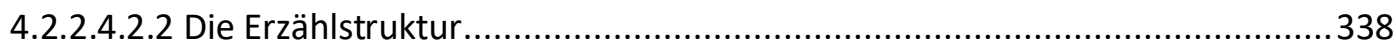

4.2.2.4.2.3 Die interaktiv-narrative Spielstruktur.........................................................340

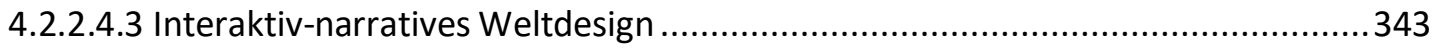

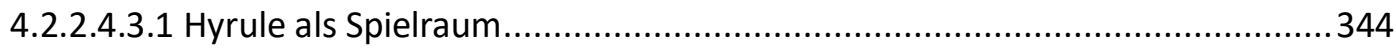

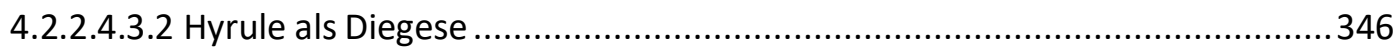

4.2.2.4.3.3 Hyrule als interaktiv-narrative Spielwelt ....................................................348

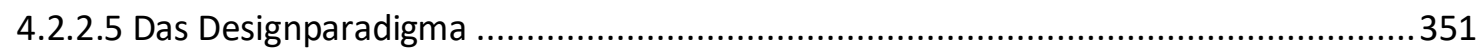

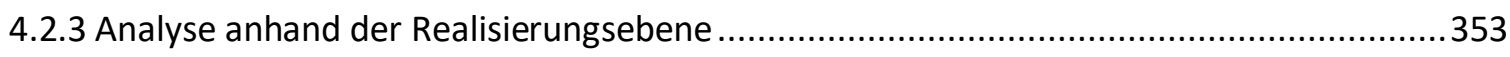

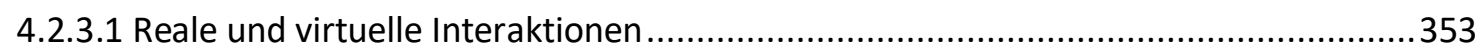

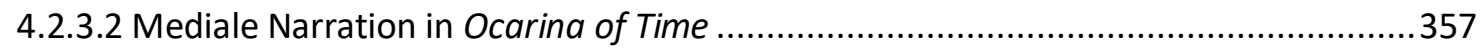

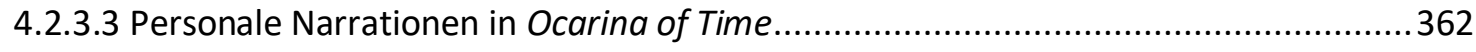

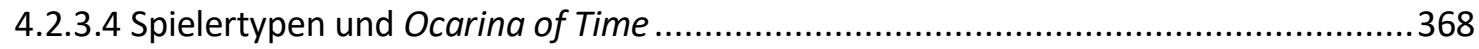

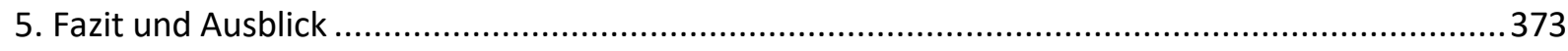

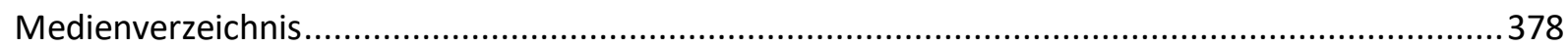

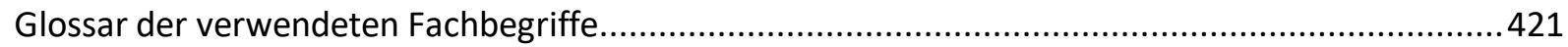

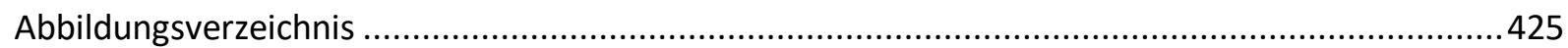





\section{Vorwort}

Dieses Buch behandelt das Verhältnis zwischen interaktiven und narrativen Elementen digitaler Spiele und fragt danach, inwiefern grundlegende Narrative wie das ,Reisemodell des Helden' geeignet sind, um diese beiden unterschiedlichen Wirkmächte ästhetisch und ontologisch zusammenzuführen. Dabei glich meine Forschung im Rahmen meiner Dissertation, meine Arbeit an dem hierbei entworfenen ,Kontinuumsmodell ${ }^{\star}$ selbst einer Reise - einer Reise, die mich nicht nur in die facettenreiche Welt der digitalen Spiele, sondern auch in die faszinierende Welt der Wissenschaft führte. Auf dieser Reise wurde mir schnell klar, dass die Gegenstände meiner Forschung wie ein Spiegelbild des Forschungsprozesses selbst sind. Ich befand mich auf meiner eigenen Heldenreise, ich interagierte mit meinen treuen Reisegefährten und erzählte immer neue Geschichten meiner Forschungsergebnisse. Es liegt in der Natur der Heldenreise, dass es um den Helden und fast ausschließlich um diesen geht, fast nie wird die Geschichte der Verbündeten erzählt, die die Reise des Helden überhaupt erst ermöglichen. Deshalb möchte ich nun mit dieser Tradition brechen und kurz die Geschichte meiner Reisegefährtinnen und -gefährten erzählen, ohne deren Zutun meine Reise bereits im ersten Akt beendet gewesen wäre. Dies ist für Euch!

Ich danke meinen Doktoreltern Prof. Dr. Claudia Stockinger, Prof. Dr. Simone Winko und Prof. Dr. Fotis Jannidis dafür, dass Sie mich auf meinen Weg brachten und mich auf meiner Reise auf die Art und Weise unterstützten, die es mir erlaubte, meine Arbeit optimal auszuführen. Ihre Ermutigungen, ihr Zuspruch, ihre Anregungen und ihre Kritik waren für mich unerlässliche Hilfestellungen. Mein Dank gilt aber auch dem Graduiertenkolleg 1787 „Literatur und Literaturvermittlung im Zeitalter der Digitalisierung“ an der Georg-AugustUniversität Göttingen und insbesondere jenen Menschen, die maßgeblich zu jener kreativen und konstruktiven Arbeitsatmosphäre beitrugen, die mir mehr als einmal ein ruhiger Hafen war, wenn die Reise stürmisch zu werden drohte. Für ihre inspirierende Zusammenarbeit danke ich insbesondere Sebastian Böck, Christian Dinger, Nicole Gabriel, Julian Ingelmann, Bogna Kazur, Lena Lang, Stefanie Lange, Franziska Weidle und Anna-Christine Zapf.

Mein Dank gebührt nicht zuletzt meinen Freundinnen und Freunden, die sich auch im Angesicht eines penetranten Diskutanten unermüdlich zeigten, mich immer wieder dazu bewegten, zu schnell verfestigte Erkenntnisse erneut aufzubrechen. So trugen Christian Wilhelm und Stephan Köhler, um nur einige wenige namentlich zu nennen, mit ihrer 
Begeisterung für Spiele und Medien, mit ihrem wachen Geist und ihrer wertvollen Kritik zum Gelingen dieses Buches bei. Florian Pahlke erwies sich für mich als ein anregender und unnachgiebiger Diskurspartner, dessen kritische und strenge Augen diese Arbeit bis zum ihrem Ende begleiteten. Zudem möchte ich alle jenen kreativen Köpfen danken, die mir auf Konferenzen, in Kolloquien oder anderen Zusammenhängen wertvolle Anregungen mit auf den Weg gaben. Dies umfasst nicht zuletzt meine Studierenden, mit denen ich gemeinsam meine Ideen und Modelle diskutierte und erprobte.

Die Geschichte des Helden als Erzählung beginnt meistens mit einem paradigmatischen Ereignis, jedoch ist der Held - zumindest außerhalb von Geschichten - nicht einfach so da; vielmehr wird er zu dem, der er ist, gewissermaßen auf einer Reise vor der Reise. Und auch auf dieser wird er begleitet. In diesem Zusammenhang gilt mein besonderer Dank Prof. Dr. Frank Rexroth, der in mir nicht nur die Begeisterung für die Wissenschaft weckte, er vermittelte mir auch, was Wissenschaft handwerklich letztlich bedeutet und schulte mein kritisches Denken ungemein. Ebenso muss an dieser Stelle Nikolas Helm erwähnt werden. Ohne unsere unzähligen nachmittäglichen Diskurse bei Kaffee, in denen wir sozial- und kulturwissenschaftliche Theorien und Modelle lebhaft diskutierten, wäre ich sicher nicht da, wo ich heute bin - ich danke Dir!

In ganz besonderem Maße gilt mein Dank meinen Eltern, Angela und Peter, sowie Daniel, meinem Bruder. Eure Geduld, Ermunterung und Unterstützung waren oftmals die Säule, auf der ich ruhte. Den allerherzlichsten Dank dafür! 


\section{Einleitung}

Before 1973, if you had said something like sgames are a storytelling medium<, just about anyone would have looked at you as if you were mad - and anyone knowledgeable about games would have assumed you knew nothing about them. Before 1973, the world had essentially four game styles: classic board games, classic card games, mass-market commercial board games, and the board wargame. None of these had any noticeable connection to story: There is no story in chess, bridge, Monopoly, or Afrika Korps. (COSTIKYAN 2007)

Der US-amerikanische Spieldesigner Greg Costikyan hebt mit dieser (etwas überspitzten) Feststellung auf einen Wandel der Medienkultur ab, der sich seit dem Beginn der Geschichte digitaler Spiele mit der Veröffentlichung des Spielhallenspiels Pong im Jahr 1972 zunehmend vollzieht. ${ }^{1}$ Gemeint ist die Hybridisierung der Phänomene des Spiels und der Erzählung im neuen Medium² des digitalen Spiels. Bis zum Aufkommen digitaler Spiele waren, abstrahiert man Costikyans Gedankengang, zwei Dinge offenbar vollkommen klar: Erstens werden Spiele im Allgemeinen von interaktiven Elementen bestimmt, narrative spielen keinerlei Rolle und zweitens haben Erzählungen recht wenig mit Interaktionen zu tun. Das Phänomen des Spiels und das der Erzählung schienen einander gegenseitig auszuschließen.

Allerdings, und hierauf hebt auch Costikyan indirekt ab, hat die mittlerweile 45-jährige Geschichte digitaler Spiele mit Textadventures wie dem genreprägenden Adventure (1976) oder Zork (1980), ${ }^{3}$ mit Grafikadventures wie Day of the Tentacle (1993) oder Simon the

\footnotetext{
${ }^{1}$ Die digitalen Spielhallenspiele der 1970er Jahre wie Pong oder Space Invaders (1978) haben in der westlichen Welt wie auch im südostasiatischen Kulturkreis maßgeblich dazu beigetragen, digitale Spiele nicht nur im Markt der Unterhaltungsindustrie zu etablieren, sondern diese leiteten zugleich den Prozess ein, der dieses Medium als gesellschaftsfähige Freizeitbeschäftigung legitimierte. Vgl. dazu MÄYRÄ (2010), 52 ff. Zum digitalen Spiel als Massenphänomen vgl. WIMMER (2013).

${ }^{2}$ Der Begriff ,Medium' wird in dieser Arbeit rein medienwissenschaftlich gebraucht. So gesehen sind zwei Bedingungen kennzeichnend für ein Medium - die technische Produktion und die Vermittlung. Das bedeutet, dass unter einem Medium ein technisch erzeugtes Vermittelndes verstanden wird. Das schließt bspw. Sprache aus, die sich kulturwissenschaftlich durchaus als Medium begreifen lässt. Da die kulturwissenschaftlichen Begriffsbestimmungen von Medium aber tendenziell extensional weiter ausgreifen, was im Rahmen dieses Projektes kontraproduktiv wäre, werden sie in dieser Arbeit nicht verwendet. Zudem wird eine Ergänzung vorgenommen, die die technische Erzeugung betrifft. So wird im Folgenden nur jenes technisch Erzeugte als Medium angesehen, das bei der Produktion auch als solches intendiert gewesen ist. Abhängig von der jeweiligen Definition von Technik könnte man durchaus eine Mauer als Medium begreifen, wenn auf sie Nachrichten geschrieben werden. Da die primäre Intenion und Funktion der Mauer aber nicht in der Vermittlung, sondern in der Abgrenzung oder dem Abstützen von etwas liegt, ist eine Mauer in diesem Sinne kein Medium. Eine derart technozentrische Mediendefinition bietet gerade Vorhaben wie dem vorliegenden, die sich mit hybriden Entitäten beschäftigen, die notwendige analytische Trennschärfe. Zusammengefasst heißt dies: Ein Medium ist eine technisch erzeugte Entität, deren primäre Intention und Funktion in der Vermittlung von Informationen oder kommunikativen Akten besteht.

${ }^{3}$ Mit dem Textadventure begann die medienästhetische Zusammenführung interaktiver und narrativer Elemente im digitalen Spiel, die bereits früh das Interesse der Forschung weckte, auch wenn sie erst mit der Jahrtausendwende in Gestalt der viel diskutierten ,Narratologen-Ludologen-Debatte‘ endgültig dazu führte, dass Game Studies oder Digital Game Studies als interdisziplinäres Forschungsfeld breiteren Forschungskreisen bekannt wurden. Eine der ersten (kulturwissenschaftlichen) Arbeiten zu Textadventures ist bspw. Anthony
} 
Sorcerer (1993), mit Action-Adventures wie The Legend of Zelda (1986 ff.) oder Assassin's Creed (2007 ff.), mit japanischen digitalen Rollenspielen wie Final Fantasy (1987 ff.) oder Persona (1996 ff.), mit interaktiven Filmen wie Heavy Rain (2010) oder The Wolf Among Us (2013 f.) bewiesen, dass die Ludizität in digitalen Spielen nicht nur interaktiv definiert wird. Neben Spielmechaniken, Spielregeln und Spielrhetoriken als konstitutiven Bestandteilen von Spielen im Allgemeinen treten narrative Elemente wie Erzählstrukturen oder narrative Figuren im digitalen Spiel im Besonderen hinzu. Die hier nur exemplarisch aufgerufenen digitalen Spiele verweisen bereits auf ein Grundlagenproblem bei der Analyse digitaler Spiele - die Auflösung der Bestimmbarkeit oder Unterscheidbarkeit von interaktiven und narrativen Elementen. Konnte man vor dem Aufkommen digitaler Spiele noch eindeutig festlegen, dass das Spielen von Schach, Fußball oder Fangen nichts mit dem Erzählen einer Geschichte zu tun hat, so verschwammen die Grenzen in der Folge zunehmend. Durch die Übertragung des Spiels aus dem analogen in den digitalen, virtuellen Raum entstand ein vollkommen neues Medium, das sich - bedingt durch seine mediale Form - den bis dahin bekannten medialen Konventionen entzog. Das Spiel war als digitales Spiel zu einem Hybridmedium geworden, das neben dem spielerischen Erlebnis nun zudem eine Geschichte erzählen konnte. (vgl. dazu

Die (medienwissenschaftliche) Forschung diskutiert seit der Entstehung digitaler Spiele oft, ob diese ein Hybridmedium sind und wie sich diese Hybridität (im Falle der Bejahung dieser Frage) darstellt. Die vorliegende Arbeit verortet sich im Kontext jener Forschungsarbeiten, die digitale Spiele als Hybridmedien ansehen und die von dem Gedanken getragen werden, dass diese Hybridität sowohl die Ontologie als auch die Ästhetik dieses ,Neuen Mediums` erheblich bestimmt. Daraus ergibt sich für die vorliegende Studie aber zugleich die Notwendigkeit einer hybriden Theoriebildung, an deren Ende ein Modell stehen soll, das eine möglichst, ganzheitliche ${ }^{4}$ Analyse digitaler Spiele ermöglicht, deren Form und Wirken sich sowohl aus interaktiven als auch aus narrativen Komponenten speist. Dieses derart entwickelte sog. ,Kontinuumsmodell‘ hat aber freilich seine Grenzen, sollte keinesfalls als ,Weltformel' der Analyse digitaler Spiele angesehen werden, denn als solche ist es auch keineswegs intendiert. Für die Reichweite des Kontinuumsmodells gilt dasselbe, was der Literaturwissenschaftler Stefan Neuhaus mit Blick auf Theorien und Modelle im Allgemeinen

Niesz' und Norman Hollands bereits 1984 veröffentlichter Aufsatz Interactive Fiction, der sich mit der Bedeutung erzählender digitaler Spiele im Kontext der Literaturtheorie befasst. Vgl. NIESz/HoLland (1984).

${ }^{4}$ Ein auf Ganzheitlichkeit angelegtes Analysemodell derartiger digitaler Spiele kann bisher als ein Desiderat der Digital Game Studies angesehen werden. 
bemerkt. Neuhaus konstatiert, „dass es Paradigmen wie Supertheorien nach dem heutigen Verständnis von Wissenschaft nicht gibt. Natürlich können Forscher bestimmte Theoriemodelle als allein seligmachend präsentieren und sich darauf beschränken, Wirklichkeit mit diesem einen Modell erklären zu wollen. Doch die angesprochene Pluralität von Erklärungsmodellen entlarvt dies als u[n]zulässigen Versuch, eine dafür viel zu komplexe Wirklichkeitsstruktur auf einen Nenner bringen zu wollen.“ (NEuHAus 2009, 23) In diesem Sinne ist das Kontinuumsmodell freilich nicht ,allein seligmachend“, es ist nur ein weiterer Versuch, der Lösung eines Problems näherzukommen, das nicht nur die Digital Game Studies beschäftigt, sondern auch Gegenstand der ,New Media Studies“ ist, zumindest dann, wenn sie sich mit dem Zusammenspiel von interaktiven und narrativen Elementen auseinandersetzt. (vgl. dazu WARDRIP-Fruin/MONTFORT 2003 sowie MANOVICH 2001)

Diese epistemologischen Grenzen des Kontinuumsmodells schlagen sich im hier gegebenen Fall u.a. in der Tatsache nieder, dass nicht alle digitalen Spiele (medial) narrativ sind. Die Vermittlung vieler digitaler Spiele läuft nicht narrativ $a b$, wie auch keine Bestandteile dieser narrativ dargestellt werden oder es gar strittig ist, ob eine Darstellung überhaupt stattfindet. (vgl. dazu 2.1.1) Diese nicht-narrativen digitalen Spiele sind vom Kontinuumsmodell nicht zu erfassen, stattdessen kapriziert es sich auf jene digitalen Spiele, die ich, interaktiv-narrativ ${ }^{\star}$ nenne. Diese versucht das Kontinuumsmodell auf drei verschiedenen Ebenen zu betrachten: der Attribut-, der Struktur- und der Realisierungsebene.

Auf der Attributebene geht es dem im Rahmen meines Dissertationsprojektes entwickelten Modell darum, aus verschieden gewichteten (und extensional unterschiedlich weit ausgreifenden) Perspektiven $\mathrm{zu}$ beschreiben, wie interaktive und narrative Elemente in interaktiv-narrativ digitalen Spielen ausgeprägt sind. ${ }^{5}$ Alle drei Ebenen des Modells werden dabei grundsätzlich als ein Spannungsfeld zwischen interaktivem auf der einen und narrativem Pol auf der anderen Seite verstanden. Das Verhältnis zwischen dem interaktiven und dem narrativen Pol wird als ein graduationsfähiges begriffen, d.h. es gibt verschiedene mögliche Abstufungen zwischen diesen Polen. Die mittels Attributebene diskursiv ermittelten interaktiv-narrativen Charakteristika von bspw. digitalen Spielgenres lassen sich auf den beiden anderen Ebenen präziser untersuchen. So geht es auf der Strukturebene darum, wenn man auf der Attributebene z.B. ein digitales Spiel ermittelt hat, das sich in seiner interaktiv-

\footnotetext{
${ }^{5}$ So ist es möglich, Genres interaktiv-narrativer digitaler Spiele bzw. deren einzelne Genrevertreter relational auf dem Kontinuum zu verorten. Ebenfalls gestattet es die extensional am weitesten gefasste Untersuchungsperspektive gar, verschiedene Medien oder Phänomene in Bezug auf ihre durch die Attributebene erkennbare ,Interaktivität-Narrativität‘ zueinander in Beziehung zu setzen.
} 
narrativen Ausgestaltung signifikant von anderen Genrevertretern zu unterscheiden scheint, dieses unter designerischen Aspekten konkret zu analysieren. Die Strukturebene konzentriert sich somit auf die Produzentenseite ${ }^{6}$ digitaler Spiele und nimmt allgemein in den Fokus, welches Narrativ einem digitalen Spiel zugrunde gelegt wird und welche Spielregeln, Spielmechaniken und Spielrhetoriken im Designprozess Anwendung gefunden haben. Im Besonderen wird dabei betrachtet, wie Figuren, Spielwelt und die Spielstruktur im Spiel unter hybriden Gesichtspunkten angelegt sind, um den ,Möglichkeitsraum“7 des Spiels zu erschaffen.

Die Realisierungsebene fokussiert sich schließlich auf den Rezeptions- resp. Spielprozess. Entscheidend ist dabei die Frage, wie die Spieler ${ }^{8}$ mit den auf der Strukturebene offengelegten designerischen Anlagen interagieren, wie sie den Möglichkeitsraum interaktiv-narrativ digitaler Spiele nutzen, um ihr subjektives Spielerlebnis im Rahmen der ,InteraktionNarration‘ zu konkretisieren. Dabei lassen sich tendenziell drei Spielertypen unterscheiden, die sich durch ihre Genrepräferenzen voneinander abheben und die die designerischen Anlagen abweichend interpretieren. ${ }^{9}$ Damit Interaktion und Narration (unabhängig vom Spielertyp) mit ihren widerstrebenden Charakteristika (freie Wählbarkeit der Handlung vs. narrative Geschlossenheit des Plots) nicht zur Zersetzung des hybriden Mediums digitales Spiel führen, bedarf es einer strukturierenden Kraft, die Interaktion und Narration nicht nur miteinander synchronisiert, sondern auch Synergien produziert. Problematisch ist an der Kombination dieser beiden Prozesse, dass die Selektion innerhalb dieser unterschiedliche Rollen vom Rezipienten verlangt. Die Rezeption von interaktiv-narrativen digitalen Spielen schwankt zwischen der Präsentation von Ausgewähltem (Narration) und dem eigenständigen

\footnotetext{
${ }^{6}$ Neben der Frage nach dem Produzenten ist aber auch die Frage nach dem Produkt entscheidend. Diese ist dabei, mit Blick auf das Modell, nicht in dem Sinne zu beantworten, dass man das Produkt eindeutig auf einer der drei Ebenen verorten kann. Es ist eher so, dass sich das Produkt interaktiv-narratives digitales Spiel auf allen drei Ebenen entfaltet, dass aber stets andere Aspekte fokussiert werden. Auf der Attributebene geht es um die qualitativen Eigenschaften des Produkts, auf der Strukturebene geraten, ausgehend von der Attributebene, Machart und Produzentenhandeln in den Blick und auf der Realisierungsebene kommt die mediale Wirkung jenes Produkts sowie dessen Nutzung ins Spiel.

${ }^{7}$ Der Möglichkeitsraum ist ein von den Gamedesignern Katie Salen und Eric Zimmerman in den Digital Game Studies popularisierter Terminus, den sie in ihrer einflussreichen Gamedesign-Einführung Rules of Play (2004) verwenden, um die Kontexte und möglichen Handlungsoptionen von Spielern in (digitalen) Spielen zu beschreiben. Vgl. SALEN/ZiMMERMAN (2004), 67.

${ }^{8}$ In dieser Arbeit werden durchweg generische Maskulina verwendet. In Fällen, in denen es um bestimmte Personen mit einem bestimmbaren Geschlecht geht, wird dieses explizit durch die passende Endung ausgewiesen. Die Praxis der Verwendung des generischen Maskulinums in dieser Studie resultiert keineswegs aus einer patriarchialischen Gesinnung des Verfassers, sondern ist dem Primat der Kürze geschuldet. Grundsätzlich werden alle unspezifischen Personen- oder Gruppenbezeichnungen geschlechtsneutral und im Sinne der Diversität gedacht.

${ }^{9}$ Diese drei sind der interaktive, der interaktiv-narrative und der narrative Spielertyp. Vgl. dazu 2.5.3.
} 
Auswählen (Interaktion) hin und her. Die narrativen Phasen üben dabei eine steuernde und fokussierende Funktion aus, währenddessen die interaktiven Phasen den Rezipienten zur Selbsttätigkeit auffordern. Somit wird ein Rezeptionserlebnis kreiert, das eine Fluktuation zwischen monotoner (narrativer) Präsentation und (über-)fordernder Interaktion ist.

Für das Gelingen dieser Symbiose sind die vom Designteam im Designprozess eingesetzten Narrative von entscheidender Bedeutung, die über ein Figurenpersonal verfügen, dessen Handlungsspielraum bzw. dessen Handlungen recht klar definiert sind und die Spieler dazu anregen können, die Figur im Sinne des Narrativs auszuagieren. Besonders häufig ist dabei in digitalen Spielen (wie auch anderen populärkulturellen Medien) das ,mythologische Narrativ ${ }^{10}$ bzw. der ,Monomythos` im Sinne von Joseph CAMPBELls (2011) ,Heldenreise“ anzutreffen, dessen implizite performative Anlagen genutzt werden können, um im Rahmen des Interaktions- und User Experience Designs (UX Design) auf den Spieler einzuwirken. In diesem Zusammenhang sind aber nicht nur die funktionalen Aspekte des Mythos entscheidend, sondern auch, wie Inhalte, Themen und Motive von historischen Mythen im Designprozess eines interaktiv-narrativen digitalen Spiels eingesetzt werden können, um Interaktionen oder Erfahrungen zu designen.

Um all dies leisten zu können, gilt es im ersten der drei großen Kapitel dieser Studie, die Narratologen-Ludologen-Debatte ${ }^{11}$ zu diskutieren, da diese gewissermaßen den Ausgangspunkt für Arbeiten wie die vorliegende bildet. (2.1) Deshalb schließen sich hieran auch die Ausführungen zu den bereits bestehenden Hybridtheorien in den Digital Game Studies unmittelbar an, welche oftmals entstanden sind, um zwischen beiden Positionen dieser Debatte zu vermitteln. (2.2) Die beiden folgenden Teilkapitel sind einerseits der Klärung des interaktiven und andererseits des narrativen Begriffsfeldes gewidmet. (2.3 sowie 2.4) Abgeschlossen wird dieses Kapitel von jenem Abschnitt, in welchem das Kontinuumsmodell profiliert wird. (2.5) Im zweiten Großkapitel geht es dann um den Mythos. Eingangs werden die Ansätze der modernen Mythenforschung erörtert und hierbei wird sowohl auf die substantialistischen als auch die funktionalistischen Aspekte Bezug genommen. (3.1) Dem folgt ein Teilkapitel zum Mythos als Narrativ, (3.2) ehe die bisherige Mythenforschung in den Digital Game Studies näher beleuchtet wird. (3.3) Da für das Verständnis der Wirkungsweisen des Mythos in digitalen Spielen v.a. dessen strukturierende und ordnende

\footnotetext{
${ }^{10}$ Vgl. dazu auch Todorov (1971).

${ }^{11} \mathrm{Zu}$ den bekanntesten Vertretern werden auf Seiten der Narratologen Janet Murray, Marie-Laure Ryan und Henry Jenkins sowie auf Seiten der Ludologen Espen Aarseth, Gonzalo Frasca, Jesper Juul und Markku Eskelinen gerechnet.
} 
Aspekte von Bedeutung sind, ist das Augenmerk insbes. auf das ,Interaktiv-Narrativ', jene Struktureinheit des Gamedesigns zu legen, anhand derer der Mythos im Designprozess in den spielerischen Anlagen des jeweiligen Spiels implementiert wird. (3.4)

Die Funktionsweise des Kontinuumsmodells soll abschließend anhand eines Beispiels im dritten Großkapitel illustriert werden, das für interaktiv-narrative digitale Spiele, die dem Monomythos folgen, paradigmatisch ist. Als Analysegegenstand wurde das Action-Adventure The Legend of Zelda: Ocarina of Time (1998) ausgewählt. Trotz der großen Bedeutung, die das gesamte transmediale Franchise für die populärkulturelle Medienkultur im Allgemeinen und für die digitale Spielkultur im Besonderen hat und dem immensen ökonomischen Erfolg v.a. der ,Hauptserie‘ sowie der immer wieder angeführten genreprägenden Signifikanz, hat sich die Forschung bisher kaum mit The Legend of Zelda befasst. Diesem Desiderat der westlich dominierten Digital Game Studies, die sich, so muss man konstatieren, bisher größtenteils eher Untersuchungsgegenständen zuwendet, die aus dem eigenen Kulturkreis stammen, möchte diese Arbeit anhand des ausgewählten Analysebeispiels entgegentreten. The Legend of Zelda ist für interaktiv-narrative digitale Spiele bis heute medienästhetisch wegweisend und besonders unter mythologischen Gesichtspunkten hochinteressant. ${ }^{12}$ Das dritte Großkapitel bietet deshalb zum einen einen Überblick über das transmediale Franchise ${ }^{13}$ von The Legend of Zelda, (4.1) widmet sich dann aber größtenteils der Analyse von Ocarina of Time anhand des Kontinuumsmodells. (4.2) Da es sich bei dieser Arbeit aber im Wesentlichen um einen Beitrag zur Theoriebildung der Digital Game Studies handelt, ist der analytische Teil weniger ausgeprägt, als dies für eine Arbeit üblich ist, die einen bisher eher vernachlässigten Untersuchungsgegenstand in den Fokus der Forschung rücken möchte. Die Analyse von Ocarina of Time fördert zwar gegenstandsbezogene Erkenntnisgewinne zutage, sie dient aber primär dazu, von der Applizierbarkeit des Kontinuumsmodells zur Analyse interaktiv-narrativer digitaler Spiele zu zeugen. Insofern sollten die durch die streiflichtartige Analyse herausgearbeiteten Erkenntnisse lediglich als ein erster Schritt zu einem tieferen

\footnotetext{
12 Zudem spricht für die Auswahl dieses interaktiv-narrativen digitalen Spiels ein weiterer banaler heuristischer Grund. Als Einzelspielerspiel ist es analytisch weitaus handhabbarer als Mehrspielerspiele, die nicht nur die Interaktionen zwischen Spieler und System umfassen, sondern auch zwischen Spielern. Durch eine entsprechende Modifikation kann das Kontinuumsmodell diese zwar auch untersuchen, allerdings muss dies aufgrund des Rahmens dieser Arbeit unterlassen werden.

${ }^{13}$ Die Erschließung des transmedialen Franchise, zumindest in groben Zügen, ist dabei notwendig, da die seriellen und transmedialen Bezugnahmen verschiedener (medialer) Artefakte dieses Franchise aufeinander derart vielzählig, weitreichend und signifikant sind, dass sie für das Verständnis auch eines einzelnen Artefaktes unerlässlich sind. Vor allem, wenn man sich dem weiten Feld der Fankultur zuwendet, kommt man ohne eine tiefgreifende Kenntnis des Franchise nicht aus, da diese Subkulturen derart eklektizistisch und referentiell sind, dass sie ohne diese Wissensbestände nicht adäquat untersuchbar sind.
} 
Verständnis von The Legend of Zelda im Allgemeinen wie Ocarina of Time im Besonderen verstanden und nicht mit einer, ausschöpfenden` Analyse gleichgesetzt werden.

Da sich das zugrundeliegende Erkenntnisinteresse durchaus vielgestaltig und komplex zeigt, scheint es wenig ratsam, dieses auf eine Hypothese oder Fragestellung zu verengen, die dem Umfang des Projektes freilich niemals ganz entsprechen kann. Stattdessen wurde ein Set aus vier Leitfragen entworfen, welche auch nicht lediglich Stück für Stück ,abgearbeitet` bzw. beantwortet werden. Vielmehr sind sie als ein Gerüst zu verstehen, das das argumentative Rückgrat dieser Arbeit darstellt. Sie lauten wie folgt:

1. Wie stellt sich das Verhältnis zwischen Interaktivität und Narrativität auf der attributiven Ebene digitaler Spiele dar?

2. Auf welche Weisen können Designer die interaktiv-narrative Hybridität digitaler Spiele im Designprozess digitaler Spiele nutzen bzw. anlegen?

3. Auf welche Weisen können Spieler die designerischen Anlagen interaktiv-narrativer digitaler Spiele im Spielprozess digitaler Spiele realisieren?

4. Inwiefern können Inhalte und Funktionen von historischen und modernen Mythen dazu beitragen, die interaktiv-narrative Hybridität digitaler Spiele umzusetzen?

Eine Frage, die sich zudem im Kontext der Theoriebildung immer wieder stellt, die auch immer wieder gestellt werden muss, ist die nach dem Nutzen und den Grenzen eines neu entworfenen Modells. Was bietet es, das bisherige Modelle nicht geboten haben? Es wurde bereits betont, um es nochmals unmissverständlich $\mathrm{zu}$ sagen, dass das Kontinuumsmodell nicht geeignet ist, um alle digitalen Spiele zu analysieren, sondern nur eine bestimmte Gruppe, die ich als ,medial narrativ‘ bezeichne. (vgl. dazu 2.4.4) Mediale Narrativität ist dementsprechend eine Grundvoraussetzung für Interaktivität-Narrativität und ohne diese nicht vorhanden. Auf den ersten Blick mag eine derartige Einschränkung widersinnig erscheinen, da sich nicht zuletzt die Forschung intensiv mit dem Spieler als Erzähler seiner eigenen Geschichte in digitalen Spielen befasst hat, um mehr oder weniger die (medienenthusiastische) Befreiung des Konsumenten aus dem Joch des Produzenten zu feiern, die sich in Konstrukten wie dem ,Prosumer ${ }^{\star}$ oder ,Wreader ${ }^{6}$ ausdrückt. ${ }^{14}$ Es soll damit aber keinesfalls das Phänomen bestritten oder kritisiert werden. Es soll auch nicht die Bedeutung von ,personalen“ Narrationen für die Digital Game Studies heruntergespielt werden. (vgl. ebd.) Es soll vielmehr darum gehen, eine heuristische und pragmatische Trennung

\footnotetext{
${ }^{14}$ Eine der wohl bekanntesten Hochpreisungen (medienenthusiastischer Couleur) der soziokulturellen Effekte digitaler Spiele, wenn auch ohne primären Bezug auf deren narrative Potenziale, hat Jane MCGoNIGAL mit ihrem Buch Besser als die Wirklichkeit! Warum wir von Computerspielen profitieren und wie sie die Welt verändern (2012) vorgelegt.
} 
einzuführen, die es ermöglicht, den Ursprung, die Erzeugung, den Ablauf, die Wirkungen und Reichweiten von Narrationen voneinander unterscheiden zu können.

Problematisch bei personalen Narrationen ist, dass nahezu jedes Ereignis, Phänomen oder Objekt narrativiert werden kann, sodass es wenig Aussagewert besitzt, festzustellen, dass etwas personal narrativierbar ist. Entscheidender ist es, zu beschreiben, inwiefern sich die Fähigkeit von bspw. Medien unterscheidet, Narrationen induzieren zu können. Werner Wolf hat bereits darauf hingewiesen, dass (nicht genuin narrative) Medien stark bzw. schwach ,narrationsinduzierend“ wirken können. (vgl. WOLF 2002) Diese Einsicht auf digitale Spiele anwendend, gehören diese wohl relativ unzweifelhaft $\mathrm{zu}$ den stark narrationsinduzierenden Medien. Hieraus ergibt sich dann aber auch die Frage, was diese Induktion in digitalen Spielen bewirkt und wie sich diese induzierenden Faktoren von den Faktoren anderer Medien unterscheiden, die den Rezipienten ebenso stärker zu personalen Narrationen anhalten als andere. Einen Vorstoß in diese Richtung hat Markus Engelns unternommen, der den Begriff des ,narrativen Rezeptionsangebots“ geprägt hat. Engelns definiert ein ,narratives Rezeptionsangebot“ als ,[s]pielseitiges Angebot, das die Rezeption des Spielers explizit oder implizit auf narrative Teilelemente von Computerspielen fokussiert. Dem Spieler ist es somit möglich, einzelne Teilelemente narrativ zu rezipieren und diesen Gesamteindruck auch auf andere Elemente von Computerspielen zu übertragen.“ (ENGELNS 2014, 393) Dies bedeutet aber, dass ,narrative Rezeptionsangebote“ nur bei digitalen Spielen auftreten, die medial narrativ sind. Mit Blick auf Werner Wolfs Idee der narrativen Induktion ergibt sich die berechtigte Frage, ob personale Narrationen auch von Angeboten evoziert werden können, denen selbst keine Narrativität inhärent ist.

Diesem Gedanken möchte ich im Folgenden nachgehen, sodass ich unter dem ,narrativen Rezeptionsangebot' einerseits Texte oder Dialoge fasse, denen eine, wenn auch schwach ausgeprägte, mediale Narrativität nicht abzusprechen ist. Andererseits subsumiere ich unter dem Aspekt des ,narrativen Rezeptionsangebotes' aber auch Elemente, die Narrativität induzieren können, ohne selbst narrativ zu sein wie bspw. eine agonale Ausprägung des Ludus, Spielmechaniken oder bestimmte (charakterliche) Eigenschaften der Spielfigur. (vgl. dazu 1.2) Bedeutend sind ,narrative Rezeptionsangebote als personale Narrationen induzierende Elemente in digitalen Spielen im Kontext dieser Arbeit, da sie die mediale Narrativität ergänzen und hierdurch zu einer Intensivierung des narrativen Erlebens digitaler Spiele durch den Spieler beitragen können. Personale Narrationen sind somit für die Profilierung des Kontinuumsmodells von Belang, aber nur soweit, wie sie mit medialen 
Narrationen in Verbindung stehen. Zweifelsfrei sind mögliche personale Narrationen von nicht-narrativen digitalen Spielen wie Fruit Ninja (2010), die sich als Beiträge in Wikis, als Fanfictions in den entsprechenden Foren oder als Let's Plays auf Youtube manifestieren, ein interessanter Untersuchungsgegenstand, sie liegen aber nicht im Fokus des entwickelten Modells.

Unter dem Aspekt der (starken) medialen Narrativität geraten besonders Genres wie das Adventure, das Action-Adventure, das Role Playing Game oder der Interaktive Film in den Blick. Andere Genres wie das Survival Game oder das Beat'em up sind zwar auch zu einem nicht unerheblichen Teil medial narrativ, aber dennoch deutlich schwächer als die vorhergehende Gruppe. Diese (diskursive) Beobachtung legt eine Vermutung nahe: Wenn man so will, so scheint es, dann kann man digitale Spiele anhand ihrer (medialen) Narrationsaffinität in drei verschiedene Kategorien einteilen. ${ }^{15}$ (vgl. dazu auch MAtusZKIEWICZ 2015a) Die Spielgenres der ersten Gruppe sind dabei so narrationsaffin, dass sie als ,narrationsnah`zu bezeichnen sind, wohingegen die Spiele der zweiten Gruppe durch ihre geringere Nähe zur medialen Narrativität als ,narrationsoffen“ bezeichnet werden. Digitale Spiele dieser beiden Kategorien lassen sich mithilfe des Kontinuumsmodells, wenn auch in unterschiedlichem Maße und mit abweichendem Nutzen, untersuchen. Neben diesen beiden Kategorien gibt es aber noch eine dritte, in die all jene digitalen Spielgenres einzuordnen sind, die gar nicht oder kaum medial narrativ sind. Diese sind als ,narrationsfern“ zu klassifizieren. Zur Analyse dieser digitalen Spiele kann das Kontniuumsmodell kaum etwas beitragen. Damit bleiben viele Genres, die durch Mobile und Online Gaming in den letzten Jahren einen fulminanten Aufstieg erlebt haben, ebenso ausgeschlossen wie traditionell überaus populäre und kommerziell erfolgreiche Genres wie das Sportspiel (mit all seinen Subgenres) oder das Maze und Puzzle Game.

Damit kann die berechtigte Frage gestellt werden, wozu man ein Modell benötigt, das derart viele digitale Spiele, ganze Genres wie die Multiplayer Online Battle Arena (MOBA), die mit League of Legends (2009 ff.) oder Dota 2 (2013 ff.) Millionen von Spielern weltweit in ihren Bann ziehen, im Voraus ausschließt? Die banale Antwort lautet: da es ebenso viele einschließt, die zudem eine signifikante kulturelle, ökonomische und künstlerische Bedeutung haben. So weisen neben den narrationsnahen Spielgenres, die sich im Massenmarkt etabliert haben, auch avantgardistische Indie-Produktionen wie The Stanley Parable (2011) eine

\footnotetext{
${ }^{15}$ Damit werden bspw. Modelle wie jenes von Werner Wolf ausdifferenziert, der die genuin narrativen im Unterschied zu den ,narrationsinduzierenden“ Medien nicht weiter untergliedert. Vgl. WoLf (2002), 96.
} 
deutlich ausgeprägte mediale Narrativität aus und lassen sich mit dem Kontinuumsmodell untersuchen.

Außerdem kann das Kontinuumsmodell einen Beitrag zur Erforschung interaktiv-narrativer Medien und Phänomene im Allgemeinen leisten, auch wenn es im Besonderen an digitalen Spielen entwickelt wurde. Als mögliche weitere Anwendungsfelder erscheinen bspw. Hypermedia bzw. Neue Medien geeignet zu sein. Man denke neben Hypertext-Erzählungen ${ }^{16}$ wie Michael Joyces Afternoon. A Story (1987), an Enhanced E-Books, digitale Literatur oder interaktive Medienkunst. Darüber hinaus könnte man das Kontinuumsmodell auch auf Phänomene anwenden, die keine oder nur sekundär relevante Beziehungen zu digitalen Technologien unterhalten. Naheliegend erscheinen diesbezüglich freilich die Pen-\&-PaperRollenspiele, aber auch Erscheinungen wie Trading Card Games à la Magic: The Gathering (1993 ff.) entwickeln im Kontext transmedialer Welten ${ }^{17}$ zunehmend neue interaktiv-narrative Verfahren, die spielerisch-interaktive Tätigkeiten mit narrativen Komponenten auf vielfältige Weise verbinden.

Die Fokussierung auf die mediale Narrativität schränkt den Gegenstand ein, was zwar heuristisch vorteilhaft ist, dem Modell aber schnell den Vorwurf einbringen kann, zu kurz zu greifen. Diesem Nachteil stehen jedoch einige Vorteile gegenüber, die, neben der möglichen Anwendbarkeit auf andere Gegenstandsbereiche, den Nutzen herausstellen und das Modell somit rechtfertigen. So ist es durch das Modell möglich, sich von dichotomischen Denkmustern zu lösen und das Spannungsfeld interaktiv-narrativer digitaler Spiele stattdessen antonym (im linguistischen Sinne) zu denken, ohne sich in Pauschalaussagen über Hybridität $\mathrm{zu}$ verlieren. Das Modell strebt somit eine differenziertere Betrachtung hybrider digitaler Spiele an. ${ }^{18}$ Deshalb versucht das Modell einerseits, das Zusammenspiel zwischen der Produzentenseite (Strukturebene) und der Rezipientenseite (Realisierungsebene) ebenso abzubilden, wie es aus verschiedenen, weit gefassten Perspektivierungen Aussagen über die ontologische und ästhetische Dimension zulassen soll. Um dies leisten zu können, geht das Modell ein Wagnis ein, da es versuchen muss, komplexe Prozesse und Zusammenhänge klar beschreibbar zu machen, dies aber nur vermag, wenn es eine gewisse Flexibilität behält.

\footnotetext{
${ }^{16}$ Vgl. zur historischen Entwicklung dieser in den 1990er Jahren RETTBERG (2015).

${ }^{17}$ Vgl. zum Konzept transmedialer Welten GABRIEL et al. (2015).

${ }^{18}$ Letztlich lässt sich Hybridität durch solche Modelle allgemein differenzierter denken, was ein durchaus nicht unerheblicher Vorteil in Gesellschaften und Kulturen ist, die durch paradigmatische Prozesse wie Globalisierung und Digitalisierung sowie durch Berührungen mit anderen (als andersartig empfundenen) Gesellschaften und Kulturen stets komplexer und hybrider werden.
} 
Insofern befindet sich das Modell in einem permanenten Ausgleich zwischen Prägnanz und Flexibilität, zwischen Klar- und Wagheit.

Zudem sei angemerkt, dass andere Modellbildungen, die ähnlich verfahren, andere Gegensatzpaare wählen als das hier dargebotene. So existieren bspw. Dichotomien wie Simulation vs. Text oder Spiel vs. Erzählung, die nicht zuletzt durch die NarratologenLudologen-Debatte in der Forschung popularisiert wurden. Die Gründe, die dafür sprechen, die Konzepte der Interaktivität und Narrativität zu verwenden, sollen skizzenhaft umrissen werden. Simulation ist zwar ein zentraler Aspekt der meisten digitalen Spiele, da es kaum ein digitales Spiel gibt, das nicht ein größeres System $^{19}$ in einem kleineren abbildet und erfahrsowie manipulierbar macht. Allerdings würde es zu kurz greifen, Spiel und Simulation gleichzusetzen, auch wenn es viele Gemeinsamkeiten gibt. (vgl. dazu 1.2.1) Ähnliches gilt für das Verhältnis zwischen Spiel als allgemeinem Phänomen und digitalem Spiel als besonderer Form. (vgl. ebd.) Durch die Bindung an ein digitales Medium hat das digitale Spiel ganz andere Möglichkeiten aber auch Limitierungen, die es von den meisten anderen Spielen abhebt.

Zusammenfassend kann man also sagen, dass sich der Nutzen des Kontinuumsmodells nicht nur auf die Analyse digitaler Spiele beschränkt. Es wurde zwar an diesen entwickelt, kann aber durchaus auch Beiträge zu vergleichbaren Medien oder Phänomenen leisten, wie sie bspw. die Digital Humanities betreffen. Darüber hinaus kann es sich aber auch durchaus fruchtbar für die Medienwissenschaft(en) erweisen oder für die (digitale) Literaturwissenschaft, die sich im Kontext digitaler Technologien und Medien immer mehr mit der Unvereinbarkeit zwischen den neuen Untersuchungsgegenständen und den etablierten Theorien und Modellen konfrontiert sieht. Als digitales Medium löst sich die Literatur bspw. von ihrem bisher erfolgreichsten Medienträger - dem Codex - und erreicht ontologisch wie

\footnotetext{
${ }^{19}$ Der Terminus ,System ' wird in dieser Arbeit in zweierlei Hinsich verwendet. In einem weiteren Sinne bezeichnet System eine Enität, die aus Operationen erzeugt und von diesen aufrechterhalten wird. Insofern werden Systeme als autopoietisch und operational geschlossen betrachtet, was dieses Systemverständnis in die Nähe von Niklas Luhmanns Systemtheorie rückt. Vgl. dazu LuHMANN (2009). Im Unterschied zu diesem wird die Differenz zwischen System und dessen Umwelt in der Folge aber weniger zentral sein. Diese Auffassung des Systems schlägt sich v.a. im Spiel als System nieder. In einem engeren Sinne wird unter System eine technischinformatische Einheit verstanden, wie sie elektronische und digitale Medien betrifft. Diese Verwendungsweise des Systembegriffs bezieht sich in dieser Arbeit auf das System als maschinelle Einheit und Gegenpart des menschlichen Subjekts in der Interaktion zwischen Spieler und System mit Blick auf digitale Spiele. Der zweite Systembegriff liegt im Folgenden also Ausführungen zugrunde, die sich auf die technische Seite digitaler Spiele bzw. die Interaktion mit einem automatisierten System beziehen, wohingegen die erste Auffassung von System dann Verwendung findet, wenn es um das Systemische des Spiels an sich geht. Mit anderen Worten: Der erste Systembegriff liegt eher in selbstreferenziellen Zusammenhängen vor und der zweite eher in fremdreferenziellen, die die systeminternen Grenzen verlassen.
} 
ästhetisch neue Dimensionen. Es entsteht eine neues digitales Hypermedium, ${ }^{20}$ das durch die Synthese mehrerer Medien auch neue Formen des Erzählens ebenso mit sich bringt wie neue dramatische Erscheinungen, die sich mit den traditionellen Werkzeugen nur bedingt fassen lassen. Ontologisch gesehen ,remedialisieren“ digitale Medien u.a. Film, Fotografie, Theater, Spiel, Literatur und interaktive Medienkunst, zeichnen sich durch eine ,Hypermedialität‘ aus. (vgl. BOLTER/Grusin 2000) Ästhetisch geht damit die Zunahme der Bild- und Filmhaftigkeit, der Interaktivität und der synergetischen Effekte durch digitale Hypermedialität genauso einher wie die Steigerung des Partizipations- und Immersionsgrades. Das interaktiv-narrative digitale Spiel kann als ein solches literarisches Hypermedium aufgefasst werden, das in höchstem Maße remedialisiert, interaktiv und partizipativ ist. ${ }^{21}$ Solche Fragen liegen aber außerhalb des Forschungsdesigns dieser Arbeit und werden deshalb nicht eingehender betrachtet. Was aber im Rahmen dieser Arbeit liegt, ist die Analyse interaktiv-narrativer digitaler Spiele anhand des Kontinuumsmodells. Um das in diesem Teilkapitel Proklamierte zu einlösen, soll dieses Kapitel mit einigen Ausführungen zu den Digital Game Studies (1.1) sowie dem Spiel im Allgemeinen und dem digitalen Spiel im Besonderen (1.2) vollendet werden, die das Folgende kontextualisieren, bevor die Arbeit wie oben beschrieben verfährt.

\subsection{Digital Game Studies}

Der folgende Abschnitt soll den Begriff Digital Game Studies, wie er in dieser Arbeit gebraucht wird, näher erläutern. ${ }^{22}$ Die Ausführungen erstrecken sich ausgehend von einem sehr kurzen wissenschaftshistorischen Abriss über die Abgrenzung von alternativen Begriffen bis zu den Digital Game Studies als aktuellem Forschungsfeld. Von vornherein sollte aber der Unterschied zum Gamedesign bedacht werden; beide dürfen keinesfalls gleichgesetzt werden, auch wenn es einige signifikante Überschneidungen gibt. Im Unterschied zu den Digital Game Studies sind die Ansätze des Gamedesigns (stark verkürzend gesprochen) oft pragmatischer und anwendungsbezogener als die der Digital Game Studies. Ein Dozent für

\footnotetext{
${ }^{20}$ Der Begriff ,Hypermedium` geht ebenso wie der Terminus ,Hypertext` auf Theodor Holm NELSON (2003) zurück.

21 Darüber hinaus gehören digitale Spiele nicht bloß zum Gegenstandsbereich einer digitalen Literaturwissenschaft, weil sie für eine neue Form digitaler Literatur stehen, sondern auch, weil sie traditionelle literarische Inhalte vermitteln und verarbeiten, deren Kenntnis sich sonst (wahrscheinlich) den meisten Rezipienten entziehen würde. Ein Spieler von Dante's Inferno (2010) ist mit grundlegenden Ereignissen und Figuren von Dante ALIGHIERIs Göttlicher Komödie (1980) vertraut, ohne dass er wissen muss, dass es einst einen Autoren im spätmittelalterlichen Italien gab, der besagtes Werk schrieb. Gleiches gilt für die zahlreichen Spiele, die die Bibel als Inspirations- und Themenquelle nutzen wie Dark Siders (2010 ff.). Auch hier werden literarische (und religiöse) Inhalte vermittelt, ohne dass es den Rezipienten oft bewusst wird, dass es sich um literarische Stoffe handelt. Vgl. dazu auch INGELMANN/MATUSZKIEWICZ (2017), 305 ff.

${ }^{22}$ Empfehlenswerte Einführungen in das Forschungsfeld bieten RAESSENS/GOLDSTEIN (2005); RUTTER/BRYCE (2006); EIGENFELDT-NIELSEN et al. (2008); FROMME/UNGER (2012) sowie GAMESCOOP. (2012).
} 
Gamedesign, um ein anschauliches Exempel zu verwenden, lehrt seine Studierenden, wie man digitale Spiele produziert, wohingegen der Dozent im Bereich Digital Game Studies seine Studierenden lehrt, wie man digitale Spiele analysiert. Dass es allerdings verfehlt ist, hieraus eine reflektierende Überlegenheit der Digital Game Studies gegenüber dem Gamedesign abzuleiten, wie man es zuweilen in kulturwissenschaftlichen Kontexten erlebt, zeigen dankenswerterweise neuere Arbeiten wie die von Gundolf S. FREYERMUTH (2015a sowie 2015b). Im Gegenteil: Eine Öffnung der Digital Game Studies hin zum Gamedesign ist aus epistemologischen und wissenschaftspolitischen Gründen wünschenswert.

\subsubsection{Wissenschafts(kurz)geschichte der Digital Game Studies}

Allgemein wird die letzte Jahrtausendwende ${ }^{23}$ als Beginn der Digital Game Studies angesehen. ${ }^{24}$ Die Anzahl an wissenschaftlichen Konferenzen sowie die Präsenz digitaler Spiele als Forschungsgegenstand an Universitäten (v.a. in Skandinavien und Nordamerika) nimmt in dieser Zeit zu. (vgl. AARSETH 2001)25 Die Anzahl an Publikationen in Sammelbänden steigt ebenso, wie die Veröffentlichungen in wissenschaftlichen Zeitschriften zunehmen, was größtenteils mit der Gründung neuer E-Journals mit Hauptaugenmerk auf digitale Spiele einhergeht. ${ }^{26}$ In den Anfangsjahren traten v.a. literatur-, medien- und filmwissenschaftliche Arbeiten hervor, in deren Kontext die Narratologen-Ludologen-Debatte

\footnotetext{
${ }^{23}$ Mark J.P. Wolf und Bernard Perron identifizieren drei Gründe für das deutlich zunehmende Interesse an digitalen Spielen in dieser Zeit: Erstens erreicht die erste Generation von Spielern digitaler Spiele die Universität als Forscher. Zweitens intensivieren die Attentate von Columbine und Erfurt den wissenschaftlichen Kontakt mit digitalen Spielen und drittens wird das Spiel als kulturelles Phänomen interessanter. Vgl. WoLf/PerRon (2003), $12 \mathrm{f}$.

${ }^{24}$ Dass die Digital Game Studies noch eine relative junge Disziplin sind, liegt nicht zuletzt an der recht kurzen Existenz des digitalen Spiels als Medium. Als Beginn der Geschichte digitaler Spiele wird heute im Allgemeinen das Spiel Pong (1972) von Atari angesehen. Zwar gab es erste digitale Spiele wahrscheinlich schon ab Ende der 1940er Jahre, jedoch sind von diesen aber erstens nur Überlieferungen und nicht mehr die Spiele an sich erhalten. Zweitens fehlt diesen digitalen Spielen (wie in den 1960er Jahren noch SpaceWar! (1962)) ein entscheidender Aspekt - die Rezeption durch ein größeres Publikum. Jene massenhafte Rezeption ist erst durch die Veröffentlichung von Pong als Spielhallenspiel gegeben. Insofern gelten für die Bestimmung des Beginns der Mediengeschichte beim digitalen Spiel dieselben Bedingungen wie für die Anfänge der Filmgeschichte. Auch hier liegen erste ,Filme' bereits Ende der 1880er Jahre vor, werden aber noch nicht von einem größeren Publikum simultan rezipiert. Dies geschieht erst im Jahr 1895 mit den Filmaufführungen der Brüder Lumière in Paris und der Brüder Skladanowsky in Berlin. Wie der Film wird auch das digitale Spiel erst in dem Moment zu einem Medium, in dem es ein publikumswirksames kulturelles Phänomen mit steigender sozialer Relevanz und somit öffentlich rezipiert wird. Zur Geschichte des digitalen Spiels vgl. Kent (2001), WOLF (2008) sowie BAER (2005). Zur Geschichte japanischer digitaler Spiele bzw. zu Nintendo, die im Kontext dieser Arbeit zentral sind, vgl. KOHLER (2005) sowie SHEFF (1999).

${ }^{25}$ Dieser Aufsatz ist in zweifacher Hinsicht für die Digital Game Studies in ihren Anfangsjahren, aber auch z.T. heute noch bezeichnend. So zeigt die Apologetik des Artikels zum einen den immensen Rechtfertigungsdruck, unter dem die Digital Game Studies zuweilen noch bis heute stehen. Zum anderen grenzt Espen Aarseth die Digital Game Studies (wie er sie versteht, also als Ludologie) von narratologisch geprägten Disziplinen wie der Filmwissenschaft ab und wehrt sich gegen deren, Okkupationsversuche‘.

${ }^{26}$ Als bekannteste dieser Zeitschriften kann bis heute Game Studies $(30.06 .2018)$ gelten, die v.a. von Espen Aarseth maßgeblich geprägt wurde und wird.
} 
paradoxerweise gleichzeitig zum Katalysator und zur ,Katastrophe“ des jungen ,Faches“ wurde. ${ }^{27}$ Nachdem man diesen Diskurs 2005 für beendet erklärt hatte, (vgl. dazu MURRAY 2005) auch wenn er dies bis heute de facto in vielerlei Hinsicht nicht wirklich ist, trat eine erhebliche Ausdifferenzierung der Erkenntnisinteressen, Fragestellungen und damit auch des Gegenstandsbereichs ein, von der die gegenwärtige Publikationsvielfalt in den Digital Game Studies zeugt.

Allerdings haben es die Leistungen der Digital Game Studies einerseits sowie die zunehmende soziokulturelle und ökonomische Signifikanz digitaler Spiele andererseits bis heute nicht vermocht, zu einer intensiven Verankerung der Digital Game Studies als Fach an (deutschen) Universitäten beizutragen. Man muss konstatieren, dass es bis dato kaum Möglichkeiten gibt, Digital Game Studies in Deutschland zu studieren und dass es fernerhin sehr wenig Professuren gibt, deren Inhaber sich schwerpunktmäßig mit digitalen Spielen befassen, dass es ferner bis heute keine Professur an einer deutschen Universität gibt, die „digitale Spiele“, „Digital Game Studies“ oder Ähnliches in ihrer Titulatur führt. ${ }^{28}$ Digital Game Studies als Fach, für das u.a. Espen Aarseth plädiert, (vgl. AARSETH 2001) sind bis zum gegenwärtigen Zeitpunkt an deutschen Universitäten nicht existent. ${ }^{29}$

\subsubsection{Abgrenzung von alternativen Begriffen}

Aktuell kursieren viele Bezeichnungen, die dazu dienen, wissenschaftliche Auseinandersetzungen mit dem Phänomen des Spiels zu benennen. So wird von Game Studies, Ludologie, Computer Game Studies, Video Game Studies, Digital Game Studies und vielen weiteren gesprochen. Diese Begriffsverwendungen unterscheiden sich extensional jedoch erheblich. Computer Game Studies und Video Game Studies heben zwar ebenso eine Fokussierung auf digitale Spiele als Medium hervor wie der Terminus Digital Game Studies, greifen von ihrer Reichweite aber deutlich kürzer als letzterer. Computer Game Studies

\footnotetext{
${ }^{27}$ Ein großes Problem der Anfangsjahre bestand darin, dass keine terminologische Einheitlichkeit in den Digital Game Studies vorherrschte. Vgl. dazu Wolf/Perron (2003), 16 f. sowie Jahn-SudMann/Stockmann (2008), $\mathrm{XV}$.

${ }^{28}$ Die deutsche universitäre Landschaft schneidet hier im internationalen Vergleich nicht sonderlich gut ab. Vorreiter sind hier nach wie vor die nordamerikanischen und skandinavischen Universitäten. Anders als an Universitäten stellt sich die Lage mit Blick auf deutsche Fach- oder Kunsthochschulen dar, die sehr wohl Professuren für Game Design oder Game Studies aufweisen wie die TH Köln, die aber bisher eher weniger von der universitären Forschung in Deutschland wahrgenommen wurden.

${ }^{29}$ Der Aufsatz von Randi GunZENHÄUSER (2003) zum Stand der Erforschung digitaler Spiele an deutschen Universitäten liest sich auch heute noch sehr treffend und aktuell. „Allerdings besteht gerade auf dem Gebiet der Populärkulturen eine auffällige Diskrepanz zwischen der massenhaften Verbreitung, die Computerspiele zu einem bedeutenden kulturellen und wirtschaftlichen Faktor macht, und der mangelnden Akzeptanz von Seiten der deutschen Wissenschaft." Ebd., 111. Eine neuere, umfassende Skizze des Forschungsfeldes bieten Benjamin BEIL et al. (2015a) in ihrem Sammelband.
} 
beschränkt die Analyse auf digitale Spiele, die auf einer bestimmten Plattform spielbar sind, Video Game Studies limitiert den Gegenstand auf einen Wahrnehmungskanal, den zwar die meisten digitalen Spiele bedienen, aber eben nicht alle, da bspw. der wachsende Bereich auditiver Spiele ausgeblendet wird. Der Ausdruck Digital Game Studies hat hingegen den Vorteil, dass er alle digitalen Spiele umfasst, unabhängig von der Plattform, auf der sie gespielt werden, und losgelöst von kognitiven Beschränkungen.

Im Unterschied zu den ersten drei Begriffen sind die Bezeichnungen Ludologie und Game Studies deutlich weiter gefasst, da sie prinzipiell eine Beschäftigung mit dem Phänomen des Spiels im Allgemeinen suggerieren und nicht unbedingt mit digitalen Spielen im Besonderen. So können (,reale`) Fußballspiele zwar Gegenstand der Game Studies sein, aber nicht der Digital Game Studies (es sei denn, dass es sich um eine digitale Fußballspieladaption wie FIFA (1993 ff.) handelt). Zudem unterliegen die Game Studies wie die Ludologie wissenschaftsgeschichtlichen Implikationen, die sie sehr stark geprägt haben. Mit dem Begriff Game Studies werden so auch die Anfänge der kulturwissenschaftlichen Auseinandersetzung mit dem Phänomen des Spiels bezeichnet, die von Johan Huizinga eingeleitet und von Roger Caillois weiterentwickelt wurden, um schließlich zusammen mit Ludwig Wittgenstein sowie Elliot M. Avedon und Brian Sutton-Smith so etwas wie den ,Kanon` der Game Studies zu bilden. (vgl. Huizinga 1991; CAillois 1960; WitTGENSTEIn 1980; Avedon/SuTton-SMith 1979a und SuTton-Smith 2001) In diesem Sinne verwendet auch diese Arbeit den Begriff Game Studies. ${ }^{30}$ Populäre Ansätze der Game Studies finden sich bspw. in der Philosophie, der Dramentheorie, der Soziologie oder den Performance Studies. Die Game Studies sind also weniger ein wissenschaftliches Fach als ein interdisziplinäres Methoden- und Theoriebündel, das verschiedene Disziplinen mehr oder weniger locker verbindet. ${ }^{31}$

Unter Ludologie wird im Allgemeinen eine Schule innerhalb der medien- und kulturwissenschaftlichen Ausrichtung der Digital Game Studies verstanden, die Bekanntheit im Kontext der Narratologen-Ludologen-Debatte erlangte. ${ }^{32}$ Prominente Vertreter dieser Schule sind Espen Aarseth, Gonzalo Frasca, Jesper Juul oder Markku Eskelinen. Den Begriff

\footnotetext{
30 Game Studies wird häufig auch synonym zu Ludologie verwandt. Die wahrscheinlich populärste Manifestation dieser Begriffsverwendung stellt das bereits erwähnte E-Journal Game Studies dar.

${ }^{31}$ Die Verwendung des Ausdrucks Game Studies für diesen Forschungszweig vermeidet auch die Hinzunahme von Bezeichnungen wie Spieltheorie, die leicht zu Konfusionen mit der mathematischen Spieltheorie führen können.

${ }^{32}$ Die Mehrdeutigkeit des Ausdrucks Ludologie bringt Espen Aarseth treffend auf den Punkt: „Ludology is an ambiguous term in game studies and game research in general. It can refer to (1) the study of games in general, or (2) to a particular apporach to game research, or (3) to a movement active in the years 1998-2001." AARSETH (2014a), 185.
} 
Ludologie zu verwenden, hieße, sich in dieser bestimmten Forschungstradition zu verorten, was aber nicht mit dem Erkenntnisinteresse dieser Arbeit zu vereinen ist, das gerade eine Hybridisierung bestehender theoretisch-methodischer Ansätze profiliert.

\subsubsection{Digital Game Studies heute}

Man kann kaum davon sprechen, dass mittlerweile eine Disziplin mit dem Namen Digital Game Studies existiert, und wissenschaftlich ist es wahrscheinlich auch nicht notwendig, dass Institute für Digital Game Studies aufgebaut und die Digital Game Studies als Fach eine institutionelle Manifestation an Universitäten auf der ganzen Welt erhalten. ${ }^{33}$ Aktuell Digital Game Studies zu betreiben, heißt demnach nicht, einer bestimmten wissenschaftlichen Disziplin anzugehören, ihr institutionell zugeordnet zu sein, es bedeutet vielmehr, ein kritischreflektiertes Bewusstsein für dieses Medium wie seine Potenziale in einer interdisziplinären Perspektive zu schaffen. ${ }^{34}$ In diesem Sinne sind Digital Game Studies ein ,interdisziplinäres Feld“ für Forscher verschiedener wissenschaftlicher Provenienz. (SACHS-HOMBACH/THON 2015a, 11) Somit ist es eher von peripherem Interesse, ob sich die Literatur- und Medienwissenschaften, ${ }^{35}$ die Kultur- und Geisteswissenschaften, die Wirtschafts- und Sozialwissenschaften, die Rechtswissenschaft und Informatik, die Neurologie und Psychologie oder die Pädagogik und die Medizin mit digitalen Spielen beschäftigen. ${ }^{36}$

${ }_{33}$ Dennoch kann man mittlerweile an recht vielen deutschen Fach- und Kunsthochschulen immer mehr Studiengänge im Bereich digitaler Spiele belegen. Einen Überblick bieten BARTHOLDY et al. (2017). Diese haben aber zumeist eine eher künstlerische Ausrichtung.

${ }^{34}$ Bisher sind die Digital Game Studies primär von ,westlichen Einflüssen' geprägt worden, woraus sich auch eine regionale wie genrebezogene Festlegung ergibt. Viele digitale Spiele aus dem südostasiatischen Raum, der eigentlich zu den wichtigsten der globalen digitalen Spielindustrie gehört, sind fast gänzlich ignoriert worden. Die Digital Game Studies sahen ihren Gegenstand bisher zumeist im ,westlichen Kulturkreis‘ beheimatet. Diese Einseitigkeit bedingt auch die Auswahl der zu analysierenden digitalen Spiele aus einem exklusiven Kreis weniger Genres. Das Adventure und seine hybride Weiterentwicklung des Action-Adventures sind z.B. auffallend häufig von, westlichen' Forschern (mit erzähltheoretischem Fokus) untersucht worden, wohingegen Genres wie der Survival-Horror, das Beat'em up oder das Maze Game selten betrachtet worden sind, obwohl sie mit Spielen wie der Resident Evil-Reihe (1996 ff.), der Tekken-Reihe (1994 ff.) oder Pac-man (1980) die Entwicklung digitaler Spiele maßgeblich vorangetrieben und nachhaltig beeinflusst haben. Wenige Forscher wie Mark J.P. Wolf oder Bernard Perron betonen bisher, dass es sich bei digitalen Spielen um ein globales Phänomen handele, welches demzufolge auch global zu betrachten sei. Vgl. WOLF/PERRON (2003), 20.

${ }^{35}$ Der Sammelband von Klaus Sachs-Hombach und Jan-Noël Thon bietet einen umfassenden Überblick über die gegenwärtigen Tendenzen der Digital Game Studies in den Medienwissenschaften, der sich nicht nur etablierten Ansätzen in den Digital Game Studies wie Genretheorie oder Narratologie widmet, sondern auch einen Blick in benachbarte Disziplinen wie die Medienpsychologie oder die Mediensoziologie wagt, wie er sich bisher eher weniger beachteten Fächern wie der Geschichtswissenschaft oder der Medienökonomie zuwendet. Vgl. SACHSHOMBACH/THON (2015b).

${ }^{36} \mathrm{Im}$ soziologischen Bereich sind u.a. Arbeiten von Jeffrey Wimmer zu nennen, welcher sich mit der Nutzung von digitalen Spielen auseinandergesetzt hat. Vgl. WIMMER (2013) sowie QUANDT et al. (2009). Im Kontext kognitionswissenschaftlicher Ansätze sei exemplarisch auf die Forschergruppe um Daphne Bavelier und deren aktive Publikationstätigkeit hingewiesen. Vgl. dazu die Website des Bavelier Labs (30.06.2018). Zudem haben die neurologischen Arbeiten von Klaus Mathiak und Rene Weber eine größere Aufmerksamkeit erfahren. Vgl. MATHIAK/Weber (2006) sowie WEBER et al. (2006). Diese untersuchen mittels fMRI, welche neurologischen 
Relevant ist lediglich die Bereitschaft $\mathrm{zu}$ interdisziplinärem Arbeiten und somit ein fächerübergreifendes Bewusstsein für die Spezifika digitaler Spiele. Um die Vielseitig- und Vielgestaltigkeit der Digital Game Studies aber dennoch anzudeuten, folgt ein kurzer Abriss der diversen Erkenntnisinteressen der unterschiedlichen wissenschaftlichen Disziplinen und Fachbereiche.

Die Soziologie interessiert sich bspw. für die Nutzung von digitalen Spielen durch den Spieler und untersucht u.a. Massively Multiplayer Online Games (MMOs) oder ähnliche digitale Spiele, nimmt so das technisch vermittelte Interagieren zwischen realen Personen in den Blick. Die Medienwissenschaft interessiert sich für die medialen Besonderheiten digitaler Spiele, die v.a. die Form und die Ästhetik betreffen sowie die Kommunikationssituation zwischen Spieler und System (Einzelspielermodus) oder zwischen Spielern sowie zwischen Spielern und System (Mehrspielermodus). Die Kulturwissenschaft fragt nach der kulturellen Bedeutung digitaler Spiele, sieht digitale Spiele zum einen als Ausdruck einer bestehenden Kultur sowie andererseits als kulturprägende Kraft. Die Informatik fokussiert Programmcode, Algorithmen, Interface- oder Interaktionsdesign aus einer technologischen Perspektive. Die Wirtschaftswissenschaften beobachten die wirtschaftliche Entwicklung der digitalen Spielindustrie, den Wandel innerhalb des Marktes (wie bspw. den Umsatzrückgang im Bereich des Hardcore Gamings ${ }^{37}$ und den simultan verlaufenden Aufstieg des Casual Gamings durch das zunehmende Mobile Gaming als Folge der permanenten Verfügbarkeit transportabler digitaler Spielgeräte wie Tablets oder Smartphones) oder die stetige Verbreitung neuer Vermarktungskonzepte für z.B. MMOs oder MOBAs wie ,Free-to-Play“ ${ }^{68}$ Für die Rechtswissenschaft stellen sich neben den komplexen Problemstellungen des

\footnotetext{
Prozesse im menschlichen Gehirn während einer Gamesession eines gewalthaltigen digitalen Spiels ablaufen. Derartige Studien entstanden nicht zuletzt als Resultat der soziokulturellen Auseinandersetzungen in der Folge der Attentate von Erfurt und Columbine. Die Spannbreite informatischer Forschungsprojekte verdeutlichen u.a. die Arbeiten Maic Masuchs, der sich mit Gamedesign und digitaler Spielentwicklung auch aus sozialen und didaktischen Richtungen nähert, wenn es bspw. um die Erforschung digitaler Lernspiele (im Besonderen für Kinder), von Serious Games, User Interface-Design oder sozialem Spieldesign geht. Vgl. dazu die jüngere Publikationsliste von Maic Masuch (30.06.2018). Die Medizindidaktik der Charité setzt mittlerweile diverse eLearning-Verfahren ein, bei denen (angehende) Mediziner am digitalen Objekt lernen sollen. So z.B. beim Lernspiel TRACY (30.06.2018), das es dem Lerner ermöglichen soll, Notfall- und Gefahrensituationen virtuell zu erproben.

${ }^{37}$ Der Begriff ,Hardcore Gamer‘ bezeichnet i.d.R. Spieler, die viel Zeit und Geld in digitale Spiele investieren, in deren Alltagsleben digitale Spiele ein bestimmender Faktor der Mediennutzung sind. Unter ,Casual Gamern` versteht man demgegenüber Spieler, die eher gelegentlich spielen, die zwar auch digitale Spiele und andere Medien nutzen, diese sind aber in deren Alltagsleben nicht derart dominant wie beim Hardcore Gamer. Es handelt sich bei beiden Termini aber nicht um trennscharfe Konzepte, weshalb sie durchaus nicht unumstritten sind.

${ }^{38} \mathrm{Zu}$ neuen Trends in der digitalen Spielindustrie oder aktuellen Marktzahlen vgl. für den deutschsprachigen Raum insbes. die Website (30.06.2018) von ,Game. Verband der deutschen Games-Branche ‘.
} 
Urheberrechts auch Fragen nach dem Eigentümer. Wer ist der Eigentümer eines MMOs wie World of Warcraft (2004 ff.)? Der Entwickler Blizzard (Commercial Ownership) oder die Community (Social Ownership ${ }^{39}$ )? Die Neurologie und Psychologie interessieren sich für die kognitiven Aspekte digitaler Spiele und was sie mit den spielenden Subjekten sowie deren Gehirnen machen. Hierbei korrespondieren die Forschungsinteressen der Neurologie und Psychologie stark mit denen der Pädagogik und der Didaktik, die digitale Spiele zum Lernen und Lehren als Teil des E-Learnings hervorheben wollen. Ähnliche Interessen verfolgt auch die Spielwissenschaft, die aber zudem das Ludische digitaler Spiele intensiver betrachtet als andere Disziplinen, indem sie nach den Spielregeln, ${ }^{40}$ der Spielmechanik $^{41}$ oder dem Gameplay $^{42}$ fragt.

,Die‘ Digital Game Studies definieren sich demnach durch ihren gemeinsamen Gegenstand und nicht über eine gemeinsame institutionelle Zugehörigkeit. Dies betont auch Frans Mäyrä: „[Digital] game studies is a multidisciplinary field of study and learning with games and related phenomena as its subject matters.“ (MÄYRÄ 2010, 6; Herv.i.O.) Insofern ähneln sich die gegenwärtigen Erscheinungsformen der Game Studies und der Digital Game Studies sehr, auch wenn sie sich durch die Reichweite ihres Spielbegriffs voneinander unterscheiden beide bündeln diverse Disziplinen, Methoden, Theorien und letztlich auch Wissenschaftsphilosophien zu einem vielseitigen interdisziplinären Forschungsfeld. Dennoch wäre es wünschenswert, diese fächerübergreifende Zusammenarbeit (neben der eingangs bereits erwähnten Öffnung in Richtung des Gamedesigns) noch weiter auszubauen, um die Ausdifferenzierung des Forschungsfeldes voranzutreiben. In diesem Zusammenhang würde sich auch eine intensivere Zuwendung der Forschung in Richtung der Praxis, in Richtung der digitalen Spiel- und Unterhaltungsindustrie anbieten, um neue Perspektiven auf den Gegenstandsbereich zu gewinnen und bestehende zu erweitern.

\footnotetext{
${ }^{39} \mathrm{Zu}$ den Begriffen vgl. MäYrÄ (2010), 129.

${ }^{40}$ Hierunter verstehe ich die für Spiele im Allgemeinen fixierten, verbindlichen, intersubjektiv erfahrbaren und den Handlungsraum absteckenden Regeln, die die formale Struktur von Spielen bilden. Vgl. dazu ausführlich SALEN/ZimMERMAN (2004), 118-297.

${ }^{41}$ Dieser Begriff wird in den meisten Diskursen in Fach- wie Fankreisen mit extensional wie intensional sehr unterschiedlichen Bedeutungen verwendet. Gemeinsam ist ihnen allen jedoch zumeist, dass der Ausdruck oft interaktive oder prozedurale Prozesse erfasst bzw. beschreibt. Im Folgenden wird deshalb unter einer Spielmechanik (weit gefasst) eine charakteristische interaktiv-prozedurale Prozesshaftigkeit eines Spiels verstanden, die das Spielen des Spiels umfassend beeinflusst. Das Aufspüren und Fangen von ,Verbrechern“ in Räuber und Gendarm-Spielen wären demgemäß Spielmechaniken.

${ }^{42}$ Frans Mäyrä fasst unter dem Begriff ,Gameplay' das, was sich zwischen Spieler und Spielsystem beim Akt des Spielens ereignet. Vgl. Mäyrä (2010), 16. Insofern ist Gameplay eine Kategorie, die sich auf das Erfahren und Erleben eines Spiels fokussiert. Problematisch ist an dem Begriff jedoch, dass er oft als ein Synonym für Interaktivität oder Interaktion und Handlung verstanden wird.
} 


\subsection{Spiel und digitales Spiel}

Es ist bemerkenswert, wie sehr beim Spiel dessen immense Präsenz in unserer Lebenswelt und die konkrete (terminologische) Fassbarkeit auseinandertreten. Diesen Umstand hat kaum jemand derart nachhaltig auf den Punkt zu bringen verstanden wie Ludwig Wittgenstein in seiner Aphorismensammlung Philosophische Untersuchungen:

Man kann sagen, der Begriff `Spiel〈 ist ein Begriff mit verschwommenen Rändern. -»Aber ist ein verschwommener Begriff überhaupt ein Begriff?« - Ist eine unscharfe Photographie überhaupt ein Bild eines Menschen? Ja, kann man ein unscharfes Bild immer mit Vorteil durch ein scharfes ersetzen? Ist das unscharfe nicht oft gerade das, was wir brauchen? Frege vergleicht den Begriff mit einem Bezirk und sagt: einen unklar begrenzten Bezirk könne man überhaupt keinen Bezirk nennen. Das heißt wohl, wir können mit ihm nichts anfangen. - Aber ist es sinnlos zu sagen: »Halte dich ungefähr hier auf!«? Denk dir, ich stünde mit einem Anderen auf einem Platz und sagte dies. Dabei werde ich nicht einmal irgend eine Grenze ziehen, sondern etwa mit der Hand eine zeigende Bewegung machen - als zeigte ich ihm einen bestimmten Punkt. Und gerade so erklärt man etwa, was ein Spiel ist. Man gibt Beispiele und will, daß sie in einem gewissen Sinn verstanden werden. - Aber mit diesem Ausdruck meine ich nicht: er solle nun in diesen Beispielen das Gemeinsame sehen, welches ich - aus irgend einem Grunde nicht aussprechen konnte. Sondern: er solle diese Beispiele nun in bestimmter Weise verwenden. Das Exemplifizieren ist hier nicht ein indirektes Mittel der Erklärung, - in Ermanglung eines Bessern. Denn, mißverstanden kann auch jede allgemeine Erklärung werden. So spielen wir eben das Spiel (Ich meine das Sprachspiel mit dem Wort »Spiel«.) (WITTGENSTEIN 1980, 60) ${ }^{43}$

Wittgenstein begreift die terminologisch diffizile Fassbarkeit des Spiels gar nicht als Schwierigkeit, hält die Ungenauigkeit der Spieldefinition für unproblematisch. Stattdessen plädiert er dafür, dass man auch Termini verwenden könne, deren Extension nicht exakt bestimmt werden kann, da es weniger darauf ankomme, zu wissen, wo etwas liege, wo etwas ende (um im Kontext der Raummetapher zu bleiben), sondern darauf, dass man ein geistiges Bild des Objektes im Kopf habe. ${ }^{44}$ Problembehaftet scheint nicht primär die gedankliche Erfassung, sondern der sprachliche Ausdruck eines Phänomens zu sein, wobei nach Wittgenstein die Gründe dieses Scheiterns des direkten sprachlichen Ausdrucks aber nicht an der Mangelhaftigkeit der Sprache liegen müssen. Die Verwendung von Beispielen zur Explikation von Sachverhalten, das Ringen um die sprachliche Genauigkeit des gedanklichen Ausdrucks sind Teile jenes spielerischen Lernprozesses, den Wittgenstein als „Sprachspiel“ versteht. Der Gebrauch von Worten, indem man auf Dinge zeigt und das Wort sagt, das diese

\footnotetext{
${ }^{43}$ Vgl. dazu auch HuIZINGA (1991), 14; Herv.i.O.: „Der Begriff Spiel bleibt ständig in merkwürdiger Weise abseits von allen übrigen Gedankenformen, in denen wir die Struktur des Geistes- und Gemeinschaftslebens ausdrücken können."

${ }^{44}$ Vgl. dazu auch aktuellere philosophische Debatten wie Markus GABRIELs (2015) populäres Buch über ,Welt ${ }^{`}$ Konzepte und ,Sinnfelder'.
} 
Dinge benennen soll, ist ein Spiel, welches auch Mutter und Kind zum Erlernen der Sprache spielen - dies nennt Wittgenstein Sprachspiel. (vgl. ebd., 19)

Insofern ist Spielen auch ein kommunikativer Prozess, der ohne das Vorhandensein von sprachlichen Fähigkeiten funktioniert, was sich weiterhin dadurch untermauern lässt, dass das Spiel auch eine bedeutende Kommunikationsform unter Tieren sei. (vgl. ebd., 30) Hieraus erklärt sich auch, warum sich Wittgenstein nicht an der Unabgeschlossenheit des Spiels stört. „Wie ist denn der Begriff des Spiels abgeschlossen? Was ist noch ein Spiel und was ist keines mehr? Kannst du die Grenzen angeben? Nein. Du kannst welche ziehen: denn es sind noch keine gezogen. (Aber das hat dich noch nie gestört, wenn du das Wort »Spiel « angewendet hast.)“ (ebd., 58) Spiele funktionieren als Systeme, die dem Spieler sukzessive in der Interaktion mit diesem die Spielregeln vermitteln. Hieraus resultiert aber keinesfalls eine Abgeschlossenheit des Regelsystems und damit des Spiels, manche Regeln müssen nicht explizit artikuliert werden und dennoch verstößt der Spieler nicht in einer Weise gegen diese, dass es die Grenzen des Spiels überschreiten würde. Als Beispiel führt Wittgenstein an, dass man beim Tennis auch keine Regel brauche, die festlege, wie hoch man den Ball werfen dürfe. Man kann Tennis auch ohne solche Regeln als Spiel spielen. (vgl. ebd., 58)

Dies führt Wittgenstein letztlich zu seiner, illustrativen“ Strategie der Spielbeschreibung, die exakte Grenzziehungen überflüssig macht. Grenzen solle man nur unter einem bestimmten Aspekt ziehen. „Wie gesagt, wir können - für einen besonderen Zweck - eine Grenze ziehen. Machen wir damit den Begriff erst brauchbar? Durchaus nicht! Es sei denn für einen besonderen Zweck.“ (ebd., 59) ${ }^{45}$ Allgemein sind Spiele nach Wittgenstein somit undefinierbar, da sie nicht exakt extensional bestimmbar sind, allerdings kann es Sinn ergeben, für bestimmte Zwecke eine bestimmte Grenze zu ziehen, eine bestimmte Definition aufzustellen, eine Arbeitsdefinition. In diesem Sinne unterscheidet sich der Spielbegriff kaum von anderen zentralen soziokulturellen Termini wie Literatur, Medium, Kultur oder Religion. Von allen haben wir gedankliche Vorstellungen, die auf intersubjektiven Gemeinsamkeiten beruhen, die wir allerdings nicht in dem Sinne sprachlich explizieren können, dass sie auch ausgesprochen oder geschrieben auf (ungeteilte) intersubjektive Zustimmung stoßen. Auf diese Weise erhalten sich aber bedeutende kulturelle und soziale Phänomene eine Polysemie, die sie in vielen Bereichen und somit auch wissenschaftlichen Disziplinen applizierbar macht.

\footnotetext{
${ }^{45}$ Hiermit macht Wittgenstein darauf aufmerksam, dass Definitionen allgemein Realität in ihrer Komplexität reduzieren, um sie überhaupt erst fassbar zu machen. Insofern sind alle Definitionen Verkürzungen, die eine Diskrepanz zwischen Bezeichnung und Bezeichnetem aushalten müssen.
} 
So können wir eine Theateraufführung ebenso als Spiel verstehen, wie das Jonglieren von Bällen, Sportarten wie Golf, das Abzählen von Kacheln am U-Bahnhof, während man auf die nächste U-Bahn wartet, das Spielen eines digitalen Spiels wie Pac-Man, den spielerischen (Lern-)Erwerb von neuen Fertigkeiten, das Mama-grinst-Baby-lacht-Spiel mit dem Kind, das spielerische Tollen und Kabbeln von Tieren, ein Brettspiel wie Schach, ein Kartenspiel wie Skat, das Glückspiel, die Spekulation am Finanzmarkt, karnevaleske Rauschzustände, Masken- und Rollenspiele oder das komplexe Zusammenspiel mancher Akteure innerhalb von Systemen, bei dem es um Sieg oder Niederlage geht, sodass nicht selten die umgangssprachliche Rede davon ist, dass sich jemand (spieltheoretisch betrachtet) ,verzockt ${ }^{\star}$ habe.

Diese Arbeit begrenzt den Spielbegriff für einen „besonderen Zweck“ im Sinne einer Arbeitsdefinition auf zweierlei Weise. Erstens erfolgt eine Grenzziehung des Spiels als kulturelles Phänomen, was den Spielbegriff für kulturwissenschaftliche Betrachtungen erst zugänglich macht. In einem zweiten Schritt erfolgt dann eine weitere Begrenzung, die den Fokus auf das digitale Spiel (in einem weiteren Sinne) präzisiert.

\subsubsection{Spiel}

Jenseits von sprachphilosophischen Überlegungen haben sich in den Kulturwissenschaften v.a. jene Ansätze etabliert, die in der Folge der Studien Johan Huizingas entstanden sind. Dieser macht das u.a. von Friedrich Schiller verwendete Konzept des ,homo ludens' stark und stellt diesen gleichwertig neben den ,homo sapiens' oder den ,homo faber‘. Dabei gehen Huizingas Überlegungen von der folgenden These aus: „Seit langer Zeit hat sich bei mir die Überzeugung in wachsendem Maße befestigt, daß menschliche Kultur im Spiel - als Spiel aufkommt und sich entfaltet.“ (HUIZINGA 1991, 7) Das Spiel ist damit nicht nur darauf limitiert, ein kulturelles Phänomen zu sein, vielmehr avanciert es zur präkulturellen Kraft, die Kultur spielerisch (mit-)formt. Ausgangspunkt dieser These ist (wie bei Wittgenstein), dass Spielen kein genuin menschliches Verhalten ist.

Tiere spielen genauso wie Menschen. Alle Grundzüge des Spiels sind schon im Spiel der Tiere verwirklicht. Man braucht nur junge Hunde beim Spielen zu beobachten, um in ihrem munteren Balgen alle diese Züge zu erkennen. Sie laden einander durch eine Art von zeremoniellen Haltungen und Gebärden ein. Sie beobachten die Regel, daß man seinem Bruder das Ohr nicht durchbeißen soll. Sie stellen sich so, als ob sie fürchterlich böse wären. Und das Wichtigste ist: an alledem haben sie offensichtlich ungeheuer viel Vergnügen und Spaß. (ebd., 9) 
Auch wenn es sich beim Spiel der Tiere um eine eher simple Form des Spiels handele, so lasse sich dennoch konstatieren, so Huizinga, dass Spiele immer einen Sinn ${ }^{46}$ haben. (vgl. ebd.) Dieser Sinn kann in vielerlei Gestalt zutage treten, so auch in Form von sozialen Ausund Neuaushandlungsprozessen. Victor Turners Überlegungen zum Wesen von Ritualen (im Anschluss an Arnold van Gennep) ${ }^{47}$ weisen eine bemerkenswerte Ähnlichkeit zum Spiel auf.

In der ersten Phase (der Trennung) verweist symbolisches Verhalten auf die Loslösung des Einzelnen oder einer Gruppe von einem früheren fixierten Punkt der Sozialstruktur, von einer Reihe kultureller Bedingungen (einem »Zustand«) oder von beidem gleichzeitig. In der mittleren »Schwellenphase« ist das rituelle Subjekt (der »Passierende«) von Ambiguität gekennzeichnet; es durchschreitet einen kulturellen Bereich, der wenig oder keine Merkmale des vergangenen oder künftigen Zustands aufweist. In der dritten Phase (der Angliederung oder Wiedereingliederung) ist der Übergang vollzogen. Das rituelle Subjekt - ob Individuum oder Kollektiv - befindet sich wieder in einem relativ stabilen Zustand und hat demzufolge anderen gegenüber klar definierte, sozialstrukturbedingte Rechte und Pflichten. Man erwartet von ihm, daß es sein Verhalten an traditionellen Normen und ethischen Maßstäben ausrichtet, die alle Inhaber sozialer Positionen in ein System solcher Positionen einbindet. (TURNER 2005, 94 f.)

Der dreigliedrige Aufbau des Rituals nach Turner lässt sich auf den Ablauf von Spielen übertragen. In der Trennungsphase, verlässt $^{\star}$ der Spieler seinen herkömmlichen sozialen Raum, wenn das Spiel beginnt. Er tritt in die Schwellenphase ein, in der sich das Spiel als Prozess eigentlich abspielt, welche in die Angliederungsphase übergeht, wenn das Spiel endet und das Spielergebnis ausgewertet wird. Sieger und Verlierer werden ermittelt und alle Spieler kehren in ihre soziale Realität ${ }^{48}$ zurück, wenn auch zuweilen mit einer hierarchischen Aufwertung innerhalb dieser als Resultat des Spiels. Darüber hinaus fallen in der Schwellenphase, der „Liminalität“ (ebd., 95) u.a. andere Kleidungsstile auf und somit Aspekte des Spiels, die Roger Caillois als ,Mimicry“ bezeichnet, wodurch die Parallelen zwischen Turners Arbeiten und diejenigen von Spielforschern deutlich werden. So ist die Ambiguität ebenfalls ein Aspekt, den sich Spiel und Ritual teilen, wie weiter unten bei Brian Sutton-Smith zu erläutern sein wird.

Mit dem Ritual bei Turner teilt sich das Spiel bei Huizinga einen zentralen Aspekt, der heute im Wesentlichen mit dem Namen Johan Huizinga in den Game Studies verbunden ist die Abgeschlossenheit und Abgrenzung. So zeichnet sich das Spiel nach Huizinga u.a. dadurch aus, dass es „sich vom gewöhnlichen Leben durch seinen Platz und seine Dauer“

\footnotetext{
${ }^{46}$ Diese Auffassung hat auch in den Digital Game Studies bis heute eine dominante Stellung. So erheben bspw. SALEN/ZiMMERMAN (2004) das „Meaningful Play“ zu einem Kernkonzept von Spielen im Allgemeinen wie digitalen Spielen im Besonderen. Vgl. ebd., $30 \mathrm{ff}$.

${ }^{47}$ Vgl. dazu van GENNEP (2005).

${ }^{48}$ Zum Verhältnis von sozialer Realität und (digitalen) Spielen vgl. KAMINSKI/LORBER (2006).
} 
abhebt. (HuIZINGA 1991, 18) Dies ist der berühmte und Huizinga zugeschriebene ,Zauberkreis'49 und ein wesentlicher Aspekt seiner Definition des Spiels, die sich in modifizierter Form bei Caillois wiederfindet.

Der Form nach betrachtet, kann man das Spiel also zusammenfassend eine freie Handlung nennen, die als »nicht so gemeint « und außerhalb des gewöhnlichen Lebens stehend empfunden wird und trotzdem den Spieler völlig in Beschlag nehmen kann, an die kein materielles Interesse geknüpft ist und mit der kein Nutzen erworben wird, die sich innerhalb einer eigens bestimmten Zeit und eines eigens bestimmten Raums vollzieht, die nach bestimmten Regeln ordnungsgemäß $\beta$ verläuft und Gemeinschaftsverbände ins Leben ruft, die ihrerseits sich gern mit einem Geheimnis umgeben oder durch Verkleidung als anders von der gewöhnlichen Welt abheben. (ebd., 22; Herv.i.O.)

Demnach ist ein Spiel eine, Als-ob'-Handlung, die von den Spielern als solche wahrgenommen wird, aber dennoch eine starke immersive Wirkung hat. ${ }^{50}$ Es liegt ein ,liminaler' Zustand vor, der die Spieler aus ihren sozialen Kontexten vorübergehend herausnimmt und sie in eine Spielwelt mit eigenen zeitlichen Ausmaßen versetzt. Zentral sind für Spiele die Regeln, die für sie konstitutiv sind. Spiele sind eine soziale Aktivität (deshalb geht Huizinga in seinen Beispielen fast immer von Mehrspielerspielen aus), die ihre Teilnehmer auch dadurch zusätzlich von ihrer gewöhnlichen Welt abschottet, dass bestimmte Formen des Insiderwissens notwendig sind, um sozial in dieser Gruppe handeln zu können. Anschauliche Beispiele hierfür lassen sich in der gegenwärtigen digitalen Spielkultur finden, v.a. im Kontext von Mehrspieler-Onlinespielen, die eine erhebliche Tendenz zur Fachsprachlichkeit offenbaren. Problematisch ist an Huizingas Definition, dass sie von einer Abstinenz irgendeiner Form des Nutzens oder materiellen Interesses ausgeht. So zählen dann alle spielerisch-ritualen Aushandlungsprozesse im Sinne Turners ebenso nicht zum Spiel, wie der Profisport oder das Glücksspiel. ${ }^{51}$ Selbst der Sieg bei den Olympischen Spielen in der Antike wäre problematisch, da die Sieger zwar keine unmittelbare materielle Gratifikation für ihren Sieg erhielten, aber viel symbolisches Kapital akkumulierten, welches in ihrer Heimatstadt auch in ökonomisches Kapital konvertierbar war. ${ }^{52}$ Ferner zersetzt das Definitionskriterium der Abwesenheit eines Nutzens streng genommen die Spieldefinition Huizingas, da Spiele immer einen Nutzen, einen Zweck haben. ${ }^{53}$ Mag es um das Eintauchen in eine andere ,Welt‘ jenseits der gewöhnlichen gehen oder darum, als häufiger Sieger eines

\footnotetext{
${ }^{49}$ Vgl. dazu SALEN/ZiMMERMAN (2004).

50 Zum ,make believe' bzw. ,Als-ob'-Charakter und dessen Verhältnis zur Darstellung vgl. allgemein auch Kendall WALTON (1990).

${ }^{51}$ Dies kritisiert bereits Roger Caillois an Huizingas Arbeit. Vgl. CAILlOIS (1960), 11.

${ }^{52} \mathrm{Zu}$ den Kapitalsorten nach Pierre Bourdieu vgl. FUCHS-HeInRITZ/KÖNIG (2011), 159 ff.

${ }^{53}$ Zur , Intentionalität‘ vgl. SEARLE (2001).
} 
(bestimmten) Spiels symbolisches Kapital innerhalb seiner Gruppe zu erwerben, wie groß diese auch immer sein möge. Digitale Spielgemeinschaften, die sich in Internetforen und Wikis zu bestimmten Spielen (digital oder nicht) oder auf Twitch und Youtube beobachten lassen, ${ }^{54}$ wie sie kommunizieren, wie sie Inhalte teilen, wie sie soziale Ordnungen innerhalb der Gruppe aushandeln, zeigen, dass eine hohe hierarchische Positionierung oft mit hohem spielerischen Können einhergeht. ${ }^{55}$ Das immer stärkere Interesse am E-Sport sowie die Verehrung besonders erfolgreicher Spieler verdeutlichen dies zudem. ${ }^{56}$

„Although Johan Huizinga [...] is generally recognized as the instigator of modern studies of play, Caillois [...] should be given credit for being the first to attempt an ontological study of games.“ (AARSETH 2014b, 485; Herv.i.O.) Espen Aarseth hebt damit einen zentralen Aspekt der Erforschung von Spielen hervor, den Huizinga in Homo ludens nicht in diesem Sinne fokussiert, einen Unterschied, den die deutsche Sprache nicht au sdrücken kann. Es geht (sehr verkürzt gesprochen) einerseits um das Spiel als Prozess, Handlung, Akt oder Tätigkeit (Play) und andererseits um das Spiel als Objekt (Game). Diese Differenz zwischen Huizingas Studie und seiner eigenen betont Caillois ebenfalls zu Beginn seines Buches, allerdings weniger klar als Aarseth. Caillois lobt zwar die Verdienste Huizingas, weist zugleich aber darauf hin, dass Huizinga nicht die Spiele an sich (Game) untersucht habe, sondern die „fruchtbaren Auswirkung[en]“ des „Spielgeist[s] auf dem Gebiet der Kultur“ (Play). (CAILloIs 1960, 8) Dennoch kann Caillois' Spieldefinition ihren Ursprung in Huizingas Begriffsbestimmung des Spiels nicht verleugnen. Denn Caillois definiert Spiel erstens als „eine freie Betätigung, zu der der Spieler nicht gezwungen werden kann“, zweitens als „eine abgetrennte Betätigung, die sich innerhalb genauer und im voraus festgelegter Grenzen von Raum und Zeit vollzieht“, drittens als „eine ungewisse Betätigung, deren Ablauf und deren

\footnotetext{
${ }^{54}$ Zur Untersuchung von Communities im Internet bietet sich das Modell der Netnography an, wie es Robert V. Kozinets durch eine Anwendung ethnografischer Ansätze auf die Feldforschung im Internet entwickelt hat. Vgl. KoZINETS (2010).

${ }^{55}$ Eines der interessantesten Exempel diesbezüglich ist aktuell das MOBA League of Legends, das über ein spielinternes Rankingsystem verfügt, welches Spieler anhand ihrer spielerischen Erfolge und des damit unterstellten spielerischen Könnens in eine Liste aus insgesamt sechs Ligen und bis zu fünf Divisionen einordnet. Umso höher das Ranking eines Spielers ist, umso mehr symbolisches Kapital besitzt er in der Regel in den Augen der meisten anderen Spieler, die niederer ,gerankt" sind. Diese Kluft zwischen Spielern steigert sich nochmals, wenn es sich bei dem bewunderten Spieler um einen Profi-E-Sportler handelt. Ein ,Pentakill`, d.h. wenn ein Spieler alle Spieleravatare des gegnerischen Teams direkt eliminiert, kann in Foren oder Chats schnell zahlreiche ekstatische Äußerungen nach sich ziehen, die belegen, wie massiv sich Spiele bzw. deren Ausgänge auf soziale Strukturen (wenn auch in subkulturellen Bereichen) auswirken können.

${ }^{56}$ Der immer größer werdende Interessentenkreis des E-Sports in Deutschland lässt sich nicht zuletzt auch daran verdeutlichen, dass mittlerweile bekannte deutsche Fernsehsender wie Sport1 oder ProSieben Maxx regelmäßig E-Sport-Großevents übertragen oder renommierte Sportmagazine wie der Kicker eine eigene Rubrik für E-Sport haben.
} 
Ergebnis nicht von vornherein feststeht“, viertens als „,eine unproduktive Betätigung, die weder Güter noch Reichtum noch sonst ein neues Element erschafft und die, [...] bei einer Situation endet, die identisch ist mit der zu Beginn des Spiels“, fünftens als „eine geregelte Betätigung, die Konventionen unterworfen ist, welche die üblichen Gesetze aufheben“ und sechstens als „eine fiktive ${ }^{57}$ Betätigung, die von einem spezifischen Bewußtsein einer zweiten Wirklichkeit oder einer in bezug auf das gewöhnliche Leben freien Unwirklichkeit begleitet wird.“(ebd., 16)

Wie Huizinga betont Caillois die Handlungsfreiheit des Spielers, das Vorhandensein des ,Zauberkreises', die Entkopplung von materiellen Vorteilsgewinnen, die Regelhaftigkeit des Spiels, die in ihrer Liminalität die bestehenden Gesetze der gewöhnlichen Welt außer Kraft setze sowie den ,Als-ob-Charakter'. Ebenso wie Huizinga blendet er Spiele als soziale Aushandlungsprozesse aus, die den sozialen Status der Spieler auch in der gewöhnlichen Welt nachhaltig verändern können, indem er eine Wiederherstellung des Anfangszustandes in der Angliederungsphase annimmt, wie er vor der Trennungsphase bestanden habe. Caillois erweitert die Definition Huizingas aber um einen entscheidenden Punkt - die Offenheit des Spiels in Bezug auf das Ergebnis des Spiels. Je nachdem, wie die Spieler im Spielverlauf spielen, ergeben sich unterschiedliche Spielausgänge.

Indem sich Caillois der ontologischen Ebene des Spiels zuwendet, geht er deutlich über Huizinga hinaus. Er teilt das Spiel in vier Hauptrubriken ein, ,je nachdem, ob innerhalb des jeweiligen Spiels das Moment des Wettstreits, des Zufalls, der Maskierung oder des Rausches vorherrscht. Ich bezeichne sie als Agôn, Alea, Mimicry und Ilinx.“ (ebd., 19) Agonale ${ }^{58}$ Spiele beruhen auf dem Prinzip der Rivalität zwischen Spielern, die ihren Konflikt auf Grundlage (möglichst) gleicher Bedingungen austragen können. Beispiele für agonale Spiele sind Polo, Tennis, Fußball, Boxen, Fechten, Golf, Wettschießen etc. (vgl. ebd., 21) Beim Alea-Spiel entscheidet (im Vergleich zum Agôn) nicht primär das Können der Spieler über den Sieg, sondern das Schicksal, der Zufall. Anstelle eines menschlichen Kontrahenten gilt es

\footnotetext{
${ }^{57}$ Dieser Ausdruck erfährt bei Caillois eine (für die Literatur- und Medienwissenschaften) sehr weite Begriffsverwendung. Die Fiktion ist für ihn das Gegenteil der Regel und meint das, was bei Huizinga den ,Alsob-Charakter' des Spiels bezeichnet. Dabei überschreitet die Fiktion aber ihren klassischen Gegenstandsbereich und tritt in Sphären ein, die im Anschluss an Jean BAUDRILLARD (2010) als Simulation verstanden werden. Eine derartige Ausdehnung des Fiktionsbegriffs im Zusammenhang mit Spielen und die daraus abgeleitete Frontstellung zwischen Regel und Fiktion, da Spiele „entweder geregelt oder fiktiv“ seien, findet sich auch noch vierzig Jahre später in den Auseinandersetzungen zu Beginn der Digital Game Studies in Form der NarratologenLudologen-Debatte wieder. CAILLOIS (1960), 14.

${ }^{58}$ Sehr lesenswert zur agonalen Struktur von digitalen Spielen sind die Bücher von INDERST/JUST (2011) und KACZMAREK (2010).
} 
somit, das Schicksal selbst zu bezwingen. Der Sieger ist nicht (zwangsläufig) der bessere Spieler (wie meistens beim Agôn), sondern der glücklichere. Beispiele für Schicksals-, Glücks- oder Zufallsspiele sind Roulette, Würfelspiele, Bakkarat, Lotterie etc. (vgl. ebd., 24) Dadurch, dass der Spieler bei Zufallsspielen weniger Können benötigt als bei Wettstreitspielen, kommt dem Training eine marginale Bedeutung $\mathrm{zu}$, wodurch sich die Aktivität des Spielers stark verringert. (vgl. ebd., 25)

Beim Mimicry geht es um das Spiel mit einer anderen Identität, um die Täuschung eines anderen, den man davon zu überzeugen versucht, dass man jemand anderes sei, indem man eine andere Rolle annimmt, die sich von der eigenen Identität und Persönlichkeit unterscheidet. Zentral ist hierbei die Imitation. (vgl. ebd., 28 f.) Klassische Beispiele für Maskenspiele sind das Theater und modernere Exempel finden wir in Rollenspielen jeder Art, ob analog oder digital. Beim Ilinx geht es um das Erreichen eines Rauschzustandes, wie ihn Kinder beim Drehen um die eigene Achse oder Partizipierende mancher mexikanischer Volksfeste erlangen. ${ }^{59}$ Dieser körperliche Rauschzustand wird oft von einem Drang zur Zerstörungswut begleitet, der zu brutalen Form der „Selbstbehauptung“ ausufern kann. (ebd., 33 f.) Diese rauschhaften Zustände weisen erhebliche Ähnlichkeiten zu den Folgen exzessiven Konsums von Rauschmitteln wie Alkohol oder Drogen auf. ${ }^{60}$ Der Rausch eines Ilinx-Spiels kann sich, so Caillois, bis zur Verwirrung steigern. (vgl. ebd., 34) Allerdings treten diese vier Spielformen nicht streng getrennt voneinander auf. Beim Spielen von Monopoly (1933 ff.) benötigt ein Spieler Würfelglück, findet sich in einem Wettstreit mit anderen Spielern wieder, maskiert sich als Immobilientycoon und kann bei dementsprechenden Spielverlauf auch erfolgsberauschte Zustände erfahren, sodass alle vier Spielformen in nur einem Spiel zu finden sind. Ähnlich ist dies bei einem digitalen Rollenspiel wie The Elder Scrolls IV: Oblivion (2006). Der Spieler schlüpft in eine andere Rolle, kämpft in Person feindlicher Non-Player-Characters (NPCs) gegen das System und kann das Spiel aufgrund seiner zahlreichen Freiheiten auch als Ilinx spielen. Allerdings fokussieren Spiele, die zur Hybridisierung der vier Spielformen neigen, diese unterschiedlich

\footnotetext{
${ }^{59}$ So steht bspw. der mexikanische ,Día de Muertos‘ in dem Ruf, bei den Feiernden eskstatische Zustände zu evozieren.

${ }^{60}$ Solche Rauschzustände können beim Spieler einerseits durch Endorphinausschüttung im Erfolgsfall sowie andererseits durch den entgegengesetzten Misserfolgsfall ausgelöst werden. Bei spielerischem Scheitern kann sich die Entladung des Rausches neben verbalen Ausfällen auch körperlich manifestieren, indem andere Objekte beschädigt werden. Auf Plattformen wie Youtube haben sich nicht zuletzt deshalb ,Gamer Rage Compilations zu einem beliebten und verbreiteten Phänomen entwickelt, das neben der Dokumentation tatsächlicher Rages auch zunehmend inszenierte Rages aufweist. Vgl. dazu exemplarisch das folgende Video von AJCARABELLO95 https://www.youtube.com/watch?v=iqu-fPkqQao (30.06.2018).
} 
stark, sodass es zu erheblichen graduellen Unterschieden kommen kann. Zudem beinhaltet freilich nicht jedes Spiel alle vier Formen.

Neben diesen vier Spielformen, die nach Caillois allerdings nur Sektoren bilden, in deren Bereich sich die dazugehörigen Spiele stufenweise in Reihen anordnen, existieren zwei Pole bzw. Spielarten, die er ,paidia‘ und ,ludus` nennt. Der Pol der Paidia-Spiele wird durch Vergnügen, freie Improvisation und unbekümmerte Lebensfreude gekennzeichnet, wohingegen der Pol des Ludi durch sein fortwährendes Streben nach Konventionalisierung der „anarchischen und launenhaften Natur“ des Spiels bestimmt wird. (ebd., 19 f.) Weniger abstrakt gesprochen handelt es sich dabei um den Gegensatz zwischen freiem und strikt reglementiertem Spiel. Im Unterschied zur deutschen Sprache kann die englische diesen Unterschied in Form von Play (Paidia) und Game (Ludus) fassen. ${ }^{61}$ Gonzalo Frasca merkt hierzu an:

Usually, play activities are associated with children, while games are thought to be more adult activities. The reason is that games have a strong social component, and young children need first to be socialized in order to perform that kind of activities. ${ }^{62}$ After that period, games start to be played, and they continue through adulthood. However, both play and game activities remain present during adult life (tough in different proportions). (FRASCA 1999)

Die Unterscheidung zwischen dem Spiel der Kinder und dem Spiel der Erwachsenen, dem Spiel des Menschen und dem Spiel der Tiere suggeriert eine hierarchische Ordnung, die den Game Studies seit Huizinga und Caillois eigen ist. Allerdings sollte sie einen nicht zu der Annahme verleiten, dass Paidia-Spiele dadurch weniger komplex wären oder freie Spiele immer regellose Spiele. Der Anthropologe Daniel Vidart betont, dass auch ,Play` auf Regeln beruhe. (vgl. ebd.) Ein simples Beispiel: Ein Kind spielt im Garten Flugzeug. Es handelt sich hierbei eindeutig um ein Paidia-Spiel, es hat aber auch Regeln - zumindest eine. Um nämlich Flugzeug spielen zu können, wird das Kind in der Regel seine Arme ausbreiten, laufend versuchen die Flugbahn eines Flugzeugs zu imitieren und das Mimicry-Spiel durch lautliche Nachahmung des Turbinengeräusches intensivieren. Dabei muss das Kind aber wenigstens

\footnotetext{
${ }^{61}$ Vgl. hierzu auch Perron (2003). Perron reflektiert am Beispiel des Interaktiven Films (er bevorzugt den Begriff „,movie games“) die englischen Begriffe Play und Game und damit verbunden Player und Gamer mit Rückgriff auf Caillois' Termini Paidia und Ludus. Ebd., 242; zum Gamer vgl. ebd., 242-244, zum Player vgl. 244-250 und zum Gameplayer vgl. 251-253. Perron setzt Paidia und Play sowie Ludus und Game gleich; ebenso ist das Gameplay für ihn eine Angelegenheit des Ludi.

${ }^{62}$ Erik Erikson erkennt die Rolle des Spiels bei der (kindlichen) Identitätsbildung an, misst ihr aber eine kleinere Rolle bei als Frasca, da es sich nur um eine Halluzination der Ich-Beherrschung handele: „Das Spiel ist also eine Funktion des Ich, ein Versuch, die körperlichen und die sozialen Prozesse mit dem Selbst in Einklang zu bringen [...] Eine Ichbeherrschung zu halluzinieren ist der Zweck des Spieles - aber das Spiel ist, wie wir gleich sehen werden, unwidersprochener Herr nur eines sehr schmalen Randgebietes der Existenz." ERIKSON (1971), 206 f.
} 
eine Regel einhalten: sich wie ein Flugzeug zu verhalten. Wo liegt dann aber der Unterschied zwischen Paidia und Ludus? Dazu Frasca:

Paidea is prodigality of physical or mental activity which has no immediate useful objective, nor defined objective, and whose only reason to be is based in the pleasure experimented by the player. [...] Ludus is a particular kind of paidea, defined as an activity organized under a system of rules that defines a victory or a defeat, a gain or a loss. (ebd.)

Unter Rückgriff auf André Lalande modifiziert Frasca Caillois’ Konzept dahingehend, dass sich die Freiheit des Paidia-Spiels vornehmlich darin ausdrücke, dass es nicht auf ein fest definiertes, vorher bestimmtes und exakt ermittelbares Spielziel hinausläuft, wie dies beim Ludus der Fall ist, sondern dass das Wesen des Paidia-Spiels in einer lustvollen Prokrastination liege. Somit sind Paidia-Spiele weniger auf Regeln angewiesen als LudusSpiele, woraus sich freilich aber keine Regelfreiheit, sondern lediglich eine Regelreduktion ableitet.

Gregory Bateson betont in seinen sprachphilosophisch geprägten Arbeiten einen Aspekt des Spiels, den die Game Studies oft nur implizieren - das Spiel als Kommunikation. Dabei dient das Spiel aber nicht nur als Kommunikationsraum der Spieler, sondern Kommunikation in Form eines deklarativen Sprechaktes etabliert erst das Spiel als solches. ${ }^{63}$ Ein Spiel kommt nur dann zustande, wenn sich die Spieler auf einen Quasi-, Vertrag“ einigen, der besagt, ,[t]his is play“. (BATESON 2007, 145) Spiel ist ein kommunikatives System, welches selbst erst durch Kommunikation entsteht. Huizingas Zauberkreis wird somit erst existent, wenn Spieler sich freiwillig in diesen hinein begeben oder - mit dem englischen Romantiker Samuel Taylor Coleridge gesprochen - sie freiwillig ihren Zweifel aufgeben und sich der Illusion und Immersion des Spiels ergeben. (vgl. CoLERIDGE 1997, 179) Zentraler an der Auffassung des Spiels als Kommunikation ist für eine Spieldefinition aber, dass somit die Interaktion zwischen Spielern in den Mittelpunkt des Interesses rückt. Spiele sind eine soziale Handlung, weil soziale Interaktionen zwischen Spielern (und dem Spiel als System) ablaufen, die die soziale Dimension des Spiels und des Spielens an sich somit erst möglich machen. Interaktivität ist deshalb immer ein Kernbestandteil von Ludizität, auch im Bereich digitaler Spiele.

Ein Aspekt an Spielen, der in den Digital Game Studies immer wieder von ludologischer Seite stark gemacht worden ist, ist das Spiel als System:

${ }^{63} \mathrm{Zu}$ den Sprechakten vgl. SEARLE (2000). 
At its most elementary level then we can define a game as an exercise of voluntary control systems in which there is an opposition between forces, confined by a procedure and rules in order to procedure a disequilibrial outcome. (AVEDON/SUTTON-SMITH 1979b, 7)

Spiele basieren auf Handlungen, sind freiwillig, agonal, regelgeleitet und haben ein Ergebnis. Insofern unterscheidet sich Elliot Avedons und Brian Sutton-Smiths Spielbegriff kaum von denen ihrer Vorgänger, allerdings betonen sie im Unterschied zu diesen, dass Spiele prozedurale Systeme sind. Einen Ansatz, den v.a. Ian Bogost aufgegriffen hat, wenn er (digitale) Spiele als durch ihre Prozeduralität ${ }^{64}$ gekennzeichnet sieht und hieraus sein Modell der , prozeduralen Rhetorik' ableitet:

I suggest the name procedural rhetoric for the new type of persuasive and expressive practice at work in artifacts like Tenure. Procedurality refers to a way of creating, explaining, or understanding processes. And processes define the way things work: the methods, techniques, and logics that drive the operations of systems, from mechanical systems like engines to organizational systems like high schools to conceptual systems like religious faith. Rhetoric refers to effective and persuasive expression. Procedural rhetoric, then, is a practice of using processes persuasively. More specially, procedural rhetoric is the practice of persuading through processes in general and computational processes in particular. [...] Procedural rhetoric is a technique for making arguments with computational systems and for unpacking computational arguments others have created. (BOGOST 2010, 2 f.; Herv.i.O.)

(Digitale) Spiele sind Systeme, die durchweg prozesshaft ablaufen, sodass man sie nur als solche - also prozedural - verstehen kann. Alle Operationen des Systems und die Logiken wie Abläufe, auf denen diese basieren, sind prozessbestimmt. Rhetorik ist dabei als eine Strategie effektiver (oder eher: effizienter) und überzeugender Ausdrucksfähigkeit zu verstehen, die mit dem Ziel des Überzeugens, Überredens, Überwältigens im Sinne eines Ilinx-Spiels eingesetzt wird. ,Persuasive Games‘ sind dabei jene digitalen Spiele (und hier wird deutlich, dass sich Bogosts Überlegungen auf digitale Spiele als Vertreter ,Neuer Medien“65 beziehen), ,that mount procedural rhetorics effectively“. (ebd., 46) Ansätze, die (in den Game wie Digital Game Studies) Rhetorik als Komponente von Spielen herausstellen, weisen tendenziell (bei Bogost nur bedingt) eine engere Beziehung zu Brian Sutton-Smiths grundlegendem Werk The Ambiguity of Play auf.

The ambiguity is most obvious, however, in the multiple forms of play and the diversity of the kinds of play scholarship they have investigated. Obviously the word play stands for a category of very diverse happenings, though the same could be said about omnibus categories, such as, for example, religion, art, war, politics and culture. (SUTTON-SMITH 2001, 3)

\footnotetext{
${ }^{64}$ Zur Kritik an Ian Bogosts Konzept der Prozeduralität bzw. Ansatz vgl. SICART (2011).

${ }^{65} \mathrm{Zu}$ digitalen Spielen als ,Neuen Medien` vgl. DoveY/KenNEDY (2011).
} 
Diese Ambiguität des Spiels drückt sich nach Sutton-Smith auch in verschiedenen Spielarten aus. So unterscheidet er: Das „Mind or subjective play“ (bspw. träumen), das „Solitary play“ (Hobbies), die „Playful behaviors“ (tricksen), das „Informal social play“ (scherzen), das „Vicarious audience play“ (fernsehen), das „Performance play“ (Klavier spielen), die „Celebrations and festivals“ (Geburtstage), die „Contests“ (Athletik) und „Risky or deep play“ (Bungee-jumping). ${ }^{66}$ (ebd., 4 f.) Nun kann aber nicht nur das Spiel an sich mehrdeutig sein, sondern auch diejenigen, die es spielen, je nachdem, welche Spielintention diese vertreten. (vgl. ebd., 5 f.) Es ist Sutton-Smiths Anliegen, eine neue terminologische und methodologische Klarheit in die Game Studies zu bringen. Dabei lenkt er sein Augenmerk v.a. auf ,popular cultural rhetorics that underlie the various play theories and play terms“. (ebd., 7 f.) Rhetorik wird hier in einer modernen Bedeutung gebraucht, d.h. in Abgrenzung zu den Rhetoriktheorien der griechisch-römischen Antike und als „persuasive discourse“ oder „implicit narrative“ bezeichnet, das bewusst oder unbewusst von Mitgliedern eines Kulturkreises verwendet wird, um andere zu überzeugen. ${ }^{67}$ (ebd., 8) Insofern zeigen sich hier deutliche Parallelen zu Bogost, allerdings - und hier unterscheiden sich beide dann wieder -, identifiziert Sutton-Smith im Spiel sieben Rhetoriken, die sich in dieser Form nicht bei Bogost wiederfinden lassen.

Dabei unterteilt er diese wiederum in antike und moderne Rhetoriken. Die antiken Spielrhetoriken (Schicksal, Macht, Identität und Frivolität) sind heute von den modernen (Fortschritt, Vorstellungskraft, das Selbst) in den Hintergrund gedrängt worden. Die modernen, seit der Aufklärung entstandenen Rhetoriken des Spiels sind heute durch ihre Tendenz zum Individualismus (die antiken tendieren zur Gruppe), ihre Synchronität mit dem modernen rationalen Leben und dem Glauben, dass Spiel auf Freiwilligkeit beruht, gefragter. Antike Rhetoriken weisen eher eine extrinsische Spielmotivation auf, moderne beruhen auf intrinsischer Motivation. (vgl. SUTTON-SMITH 2007, 152) ${ }^{68}$

Fasst man all diese Überlegungen zusammen, dann kann man zu der folgenden (sehr weiten) Spieldefinition gelangen: Demnach ist ein Spiel eine freiwillige, soziale,

\footnotetext{
${ }^{66}$ Sutton-Smith verweist auf die Interdisziplinarität der Game Studies, die letztlich aus der Vielgstaltigkeit des Gegenstandsbereichs resultiert. Derart weit gedacht, lassen sich dann auch vermehrt theoretisch-methodische Zugänge anderer Disziplinen fruchtbar machen. So kann der Rekurs auf Clifford Geertz' Arbeit zum balinesischen Hahnenkampf als ein lohnenswerter Ansatz gesehen werden, um (finanziell) risikoreiche digitale Spiele im Internet mittels ,Teilnehmender Beobachtung ${ }^{6}$ zu untersuchen und somit neue Wege in der Erforschung von digitalen Spielkulturen zu beschreiten. Vgl. dazu GEERTZ (2002a).

${ }^{67}$ Vgl. zur Verwendung der Rhetorik in Computer- und digitaler Spielforschung auch KONZACK (2007).

${ }^{68}$ Vgl. dazu auch FRASCA (2007), 82.
} 
kommunikative und wechselseitige Handlung, die mit Hilfe eines ,Als-ob-Charakters', eines simulativen Modus immersiv in den liminalen Zustand des Zauberkreises als eine raumzeitliche Abgrenzung von der gewöhnlichen Welt einführt und die nicht primär an materiellen Vorteilen in der gewöhnlichen Welt orientiert ist. Das Ergebnis des Spiels wird erst im Spielverlauf bestimmt und am Spielende ermittelt. Dabei können Spiele in mehreren Formen und auf mehrere Arten gespielt werden. Spielerische Handlungen konstituieren immer das Spiel als systemische Entität, die auf Spielregeln, Spielmechaniken und Spielrhetoriken beruht.

\subsubsection{Digitales Spiel}

Eine Differenz zwischen Spiel und digitalem Spiel hat sich bereits im Abschnitt zu Bogosts Konzept der ,prozeduralen Rhetorik' angedeutet. Zwar sind Spiele allgemein rhetorisch aufgebaut und haben einen prozeduralen Charakter, aber erst im digitalen Spiel vereinen sich beide Komponenten zu einer neuen Form. Dass dies möglich ist, hat letztlich mit der besonderen materiellen Gestalt digitaler Spiele zu tun. Dabei nimmt der Begriff digitales Spiel im Unterschied zu Computer- oder Videospiel bewusst ,all kinds of contemporary games utilizing computing technologies within its operation“" in den Fokus. (MÄYRÄ 2010, 12, Anm. 1)

\footnotetext{
This includes, but is not limited to, the video games played with home console systems, arcade video games, computer games played with mainframe or personal computers, mobile games for mobile phones and various new digital devices. In some context and countries, computer games $^{6}$ and ,video games ${ }^{6}$ are used as similar umbrella categories, but ,digital games ${ }^{6}$ is here being adopted into use as the most neutral of the available terms. (ebd.)
}

Die Verwendung des umbrella terms, digitale Spiele‘ ergibt sich daraus, da sich diese nicht nur über ihre mediale Form, also über die spezifische digitale Technologie, auf die sie zurückgreifen, definieren. Der digitale technologische Aspekt ist zweifelsohne von zentraler Wichtigkeit für digitale Spiele, darf dabei aber nicht zur einzig bestimmenden Komponente werden, da auch die mediale Beschaffenheit nur ein Teil des Systems digitales Spiel ist; die im vorangegangenen Teilkapitel dargelegten Aspekte des Spiels gilt es stets mitzudenken. Der Terminus digitales Spiel bietet sich also an, da er eine Engführung auf bestimmte technologische Belange entschiedener als vergleichbare Definitionen ausklammert. (vgl. dazu 1.1.2) Was macht dann aber ein digitales Spiel zum digitalen Spiel? Nach Katie Salen und Eric Zimmerman sind das v.a. vier Eigenschaften: 1) „Immediate but narrow interactivity“, 2) „Manipulation of information“, 3) „Automated complex systems“, 4) „Networked communication“. (SALEN/ZIMMERMAN 2004, 91) 
Derartige Charateristika verdeutlichen die Komplexität der Begriffsbestimmung des digitalen Spiels, da sie oftmals (wie auch in diesem Fall) soweit gefasst sind, dass sie auch auf andere Phänomene anwendbar sind. Salen und Zimmerman räumen ein, dass ihre Merkmalsliste auch auf nicht-digitale Spiele zutrifft und sich somit die Frage nach den heuristischen Vorteilen dieser Kategorisierung stellt. Dies kann man gut am Kartenspiel Black Stories (2004 ff.) aufzeigen. Ausgangslage ist ein in der Regel recht obskures Szenario um eine morbide Geschichte, die kurz lückenhaft beschrieben wird. Die Spieler müssen nun durch Fragen an den Spielleiter, der als einziger die Lösung der Geschichte kennt, versuchen zu erraten, was genau vorgefallen ist. Dabei dürfen nur geschlossene Fragen gestellt werden, die der Spielleiter mit ,ja“ oder „nein“ beantworten kann. Somit ergibt sich im Spielverlauf in der Regel eine Fragestrategie, durch welche sich die Spieler im Idealfall spiralartig der Lösung nähern. Sollten die Spieler nicht fragend zu der Lösung gelangen, dann löst der Spielleiter auf. Da es sich bei Black Stories um ein rundenbasiertes Spiel handelt, erhalten die Spieler jede Runde ein unmittelbares Feedback, indem der Spielleiter ihre Frage beantwortet. Zentrales Spielprinzip ${ }^{69}$ ist die Manipulation von Informationen durch die Spieler, da sich die Spielmechanik des Spiels aus einem Informationsgefälle zwischen Spielleiter und Frager speist. Insofern ist auch ein Spiel wie Black Stories ein komplexes System, das durch den Spielleiter wie die Spielmechaniken eine Automatisierung erhält (wenn auch nicht im technologischen Sinne). Von zentraler Bedeutung für die Lösung des Rätsels ist die verstetigte Kommunikation zwischen den Spielern, ob direkt oder indirekt. Somit treffen zwar alle vier Charakteristika auf Black Stories zu, allerdings würde wahrscheinlich niemand Black Stories als digitales Spiel bezeichnen. Ähnliches gilt z.B. für Cluedo (1948 ff.).

Der entscheidende Unterschied zwischen digitalen und nicht-digitalen Spielen liegt demzufolge doch zu einem nicht unerheblichen Anteil auf der medialen und technologischen Ebene, auch wenn man digitale Spiele nicht hierauf reduzieren sollte, sondern die sich hieraus ergebenden ontologischen Veränderungen und neuen ästhetischen Potenziale vornehmlich in den Blick nehmen sollte. Digitale Spiele sind weitaus stärker medial gebunden als ein Spiel wie Monopoly, das zwar auch physisch fassbare Elemente wie ein Brett, Würfel, Karten und Spielfiguren hat, die aber als Spielgeräte einen anderen Status einnehmen als systeminterne (nicht physisch fassbare) Spielgeräte (z.B. das Menü) bei einem digitalen Spiel wie Beyond: Two Souls (2013). Bei den Spielgeräten von Monopoly handelt es sich um die physische Manifestation von semiotischen Spielartefakten als Schnittstelle zwischen Spielgeschehen

\footnotetext{
${ }^{69}$ Zur Definition dieses Begriffs vgl. 4.2.2.1.
} 
und Spieler. Bei Beyond: Two Souls hingegen treten Spielgerät und Schnittstelle partiell auseinander. Das physisch fassbare Interface, in unserem Fall ein Play Station 3-Controller, ist zwar gleichermaßen Spielgerät und Schnittstelle, jenseits der Eingabe und der Systemoberfläche gibt es aber bei digitalen Spielen wie Beyond: Two Souls weitere physische Manifestationen des Spielsystems. Im Rahmen der Verarbeitung von Eingaben, im Bereich des Programmcodes ist das digitale Spiel immer auf einen Datenträger bzw. elektronischen Medienträger angewiesen, ohne welchen es nicht existieren kann. Die Spieler einer Partie Monopoly führen nach dem Würfelwurf gemäß der Spielregeln und Spielmechaniken den Spielzug aus, indem sie die Spielfigur verschieben, Papiergeld austauschen etc. Anders gesagt: Die Spieler verarbeiten in ihren Gehirnen die ,Eingaben“ und handeln im Zuge der ,Ausgabe‘ dementsprechend. Die Spieler von Beyond: Two Souls müssen dies nicht, sie warten nach der Eingabe lediglich auf die vom System durchgeführte Ausgabe und richten ihre Folgehandlungen hieran aus. Auf diese Weise wird das Spielsystem gleichermaßen zur operationalen Kraft des Spiels und zum Spielleiter. Das digitale Spiel ist somit die erste vollständige mediale Manifestation des (ephemeren) Phänomens Spiel. ${ }^{70}$ Hieraus ergeben sich signifikante Auswirkungen auf die raumzeitliche Dimension digitaler Spiele.

Digitale Spiele sind nur durch ihre Bindung an ein spezifisches Medium existent, im Gegensatz zu den meisten nicht-digitalen Spielen, deren Spielwelt durch Interaktionen zwischen Spielern wie zwischen Spielern und Spielsystem erzeugt wird und oft dabei nicht einmal an Spielgeräte gebunden ist. Ein Spiel wie Fangen kann von Spielern an nahezu jedem beliebigen Ort realisiert werden, die Spielwelt eines digitalen Spiels hingegen ist nur im virtuellen Raum auf Grundlage digitaler Technologien erzeugbar. Hierdurch zeigt sich ein wesentlicher Unterschied zwischen Spiel und digitalem Spiel in Bezug auf die Raumsemantik - beim Spiel können sehr viele reale Räume wie ein Park oder eine Straße in ,Spielraum،71 konvertiert werden, beim digitalen Spiel ist diese Konvertierung immer auf das

${ }^{70}$ Vor dem Hintergrund jenes Medienverständnisses, das dieser Arbeit zugrunde liegt, kann man manche Spielgeräte wie ein Spielbrett bspw. als Medium auffassen, da es beide oben genannten Bedingungen erfüllt, allerdings bilden solche Exempel eher die Ausnahme denn die Regel. Vgl. dazu 1. Im Unterschied zu einem Medium wird ein Spielgerät weniger durch eine produzierende Instanz bzw. die damit verbundene Intention bestimmt, sondern eher durch intersubjektive Aushandlung zwischen Spielern, die z.B. einer Cola-Dose den Status eines Balls als Spielgerät zuschreiben können. Dass dies funktioniert, liegt an der semiotischen Polyvalenz von Spielgeräten, die im Allgemeinen höher ist als bei Medien.

${ }^{71}$ Durch die semiotische Polyvalenz nicht-digitaler Spiele ist eine Raumsemantisierung möglich, die reale Räume multifunktionalisiert. So muss ein dörflicher Fußballplatz keineswegs nur zum Fußballspielen genutzt werden, sondern kann auch im Zusammenhang anderer gemeinschaftlicher Aktivitäten wie Festen eingesetzt werden. Der Spielraum digitaler Spiele bzw. in diesem Fall die Spielwelt ist weniger wandelbar, da sie semiotisch nicht derart polyvalent ist. Spieler eines nicht-digitalen Spiels haben im Regelfall einen erheblichen Einfluss auf den Spielraum, Spieler digitaler Spiele hingegen nicht, es sei denn, dass man den Sonderfall des ,Modding' ansetzt. 
Vorhandensein eines Abspielgerätes beschränkt, was die situative Limitierung digitaler Spiele gegenüber nicht-digitalen Spielen verdeutlicht, auch wenn portable Geräte wie Smartphone und Tablet zur Ausdehnung des Spielraums digitaler Spiele beitragen. ${ }^{72}$ Man kann also sagen, dass Spielmechaniken und Spielregeln für nicht-digitale Spiele eine größere Prägekraft als für digitale Spiele haben, da sie die Spielwelt erst erschaffen. Beim digitalen Spiel kann dies durch den spezifischen medialen Charakter zu einem großen Teil kompensiert werden. ${ }^{73}$

Zu Beginn der 1970er Jahre kam das digitale Spiel mit recht simplen Spielen auf, die in den meisten Fällen Abstraktionen nicht-digitaler Spiele waren wie Pong oder Space Invaders, die Tischtennis bzw. Schießspiele in den digitalen Raum transferierten. In den 1980er Jahren verlagerte sich das digitale Spiel durch Heimcomputer und stationäre Konsolen vom öffentlichen Raum der Spielhallen und Bars in den privaten Bereich. In den eigenen vier Wänden hatten digitale Spiele aber andere Anforderungen zu erfüllen als in der Spielhalle, wo es entscheidend war, dass die Spieler für einen Quarter ${ }^{74}$ nicht allzu lange spielten, damit es nicht unrentabel für Spielhallenbetreiber wie Spielfirmen wurde. Daheim wollten die Spieler aber nicht bloß kurzweilige digitale Spiele mit High Score- und Perma-Death-Prinzip ${ }^{75}$ spielen, sondern sie wollten lange ,Ausflüge' in immersive Welten unternehmen. Dies führte einerseits zu einer Vermehrung und andererseits auch zu einer Ausdifferenzierung der Genres. ${ }^{76}$ Manche Genres (wie das Adventure) erfanden sich regelrecht neu, indem aus dem Textadventure der 1970er Jahre das Grafikadventure wurde, das wir heute u.a. in seiner hybriden Weiterentwicklung des Action-Adventures noch kennen. Mit der Zunahme an Komplexität wie Vielfalt stieg auch die (Durch-)Spielzeit erheblich an; ein Trend, der sich ab den 1990er Jahren noch weiter verstärkte. ${ }^{77}$ Das bedeutet im Unterschied zur Spielzeit in nicht-digitalen Spielen aber nicht nur, dass die Spieldauer in digitalen Spielen häufig

\footnotetext{
${ }^{72}$ Der deutlichste Trend in diese Richtung sind wohl die zahlreichen Augmented Reality-Spiele (AR) wie Pokémon Go (2016 ff.), die den realen Raum um digitale Elemente wie Figuren erweitern oder anreichern.

73 Gerade die steigende Popularität virtueller Spielräume unterstreicht diese Fähigkeit digitaler Spielumgebungen. Die ,Magie' des Zauberkreises, die Spieler immersiv in ihren Bann zieht, wird nicht nur durch die Spielregeln und -mechaniken erzeugt, sie dringt im virtuellen Raum auch in Form des audiovisuell Durchdringenden auf den Spieler ein, versucht diesen mit einem kognitiven Bombast zu überwältigen. Das Gameplay speist sich in solchen Fällen nicht nur aus der Qualität des Spielsystems an sich, sie kann z.T. massiv durch kognitive Immersionsstrategien überformt werden. Zur Kritik am übertriebenen Visualismus digitaler Spiele vgl. NEWMAN (2002).

${ }^{74}$ Gerade die frühen Spielhallenspiele sollten möglichst günstig sein, kosteten in den USA oft nur einen Vierteldollar oder in Japan 100 Yen.

${ }^{75}$ Der Begriff bezeichnet erstens das (permanente) Verschwinden einer Spielerfigur aus einem digitalen Spiel. In der Regel wird der Terminus in dieser Verwendung in RPGs eingesetzt. Des Weiteren wird Perma-Death zunehmend verwandt, um digitale Spiele zu bezeichnen, in denen das Sterben des Avatars bedeutet, dass man das Spiel ganz von vorne beginnen muss.

${ }^{76}$ Vgl. zum Wandel digitaler Spiele in den 1980er Jahren MÄYRÄ (2010), 68-89.

${ }^{77}$ Zur Spielzeit vgl. JuUL (2004).
} 
wesentlich länger ist als in den nicht-digitalen Spielen, sondern v.a., dass dem Spieler digitaler Spiele zu einem großen Teil die Kontrolle über die Spielzeit entzogen wird. In vielen Ludus-Spielen ist dies im analogen Raum zwar auch der Fall, aber das betrifft in erster Linie Sportspiele, bei Gesellschafts- oder Kartenspielen kann dies (abhängig von den Spielern) vollkommen anders sein, da die Spieler leichter selbst entscheiden können, wie lange sie spielen möchten. Durch seinen medialen Charakter, so kann man pointierend festhalten, entzieht das digitale Spiel dem Spieler stärker die Kontrolle über Raum und Zeit als nichtdigitale Spiele. ${ }^{78}$

Diese raumzeitlichen Veränderungen machen aber u.a. die Integration narrativer Elemente in das digitale Spiel überhaupt erst möglich. Wenn man die (medienwissenschaftliche) Narratologie ernstnimmt und eine terminologische Erosion ihrer begrifflichen Instrumentarien wie uferlose (,narrativistische`) Ausweitung ihres Gegenstandsbereichs vermeiden will, dann kommt man nicht umhin, zu konstatieren, dass Spiele im Allgemeinen nicht-narrativ sind, d.h. dass die Narration weder ihr genuiner Vermittlungsmodus ist, noch dass sie (vorrangig) aus Komponenten bestehen, die Erzählungen zu Erzählungen machen. Zwar gibt es strukturelle Äquivalenzen zwischen Spiel und Erzählung, dies bedeutet aber nicht, dass es sich hierbei um identische Phänomene handelt, sondern allenfalls um ähnliche. Diese Besonderheit digitaler Spiele deutet sich bereits in Pen-\&Paper-Rollenspielen wie Dungeons \& Dragons (1974) an, die eine stärkere mediale Manifestation (bedingt durch die textuell fixierten Informationen) aufweisen als andere nicht-digitale Spiele. Möglich wird diese Verbindung aus Spiel und Erzählung im digitalen Spiel, da sich neben den Spielgeräten auch der Zauberkreis medial manifestiert und somit die Spielwelt, welche eine konkrete virtuelle Gestalt annimmt. ${ }^{79}$

Die Gebundenheit des Spiels an ein Medium beim digitalen Spiel erkennt man auch an der Neuverteilung der narrativen Kompetenz. Es wurde viel darüber geschrieben und diskutiert, dass das Neue an digitalen Spielen (und ähnlichen Neuen Medien) darin liege, dass es nicht mehr den traditionellen Rezipienten als passiven Konsumenten des medialen Angebots gebe,

\footnotetext{
${ }^{78}$ Digitale Spiele entziehen dem Spieler als Ludus bspw. die Kontrolle über die Spielzeit, wenn nicht jederzeit (vom Spieler bestimmt) gespeichert werden kann, der Spieler somit auf das Erreichen von Speicherpunkten angewiesen ist, um seines Spielfortschrittes nicht verlustig zu gehen. Bei solchen digitalen Spielen kann der Spieler schnell den Eindruck gewinnen, das Ende der Spielzeit nicht selbst festlegen zu können. Ein rundenbasiertes nicht-digitales Spiel wie Schach ist an solche Konventionen nicht gebunden und die jahrelange Dauer mancher Fernschachpartien zeigt, dass die Spielzeit bei nicht-digitalen Spielen stärker durch den Spieler individualisiert werden kann als bei digitalen Spielen.

${ }^{79}$ Am deutlichsten sind diese Diegesen digitaler Spiele in den letzten Jahren wahrscheinlich im Kontext der Debatten um die sog. ,Storyworlds“ geworden, die insbes. transmediale Welten prägen. Diese sind ,Mischwelten‘, die medial erzeugt und intersubjektiv geteilt werden. Vgl. dazu RYAN/THON (2014).
} 
sondern dass stattdessen der ,Prosument` als Gestalter seines eigenen Angebots auf den Plan trete oder anders gesagt: Der Spieler wird zum Erzähler seiner eigenen Geschichte. Dabei wird aber häufig übersehen, dass neben dem Spieler noch eine weitere Entität zum Produzenten der Narration aufgewertet wird - das Medium selbst. Digitale Technologien verfügen aufgrund ihrer medialen Rahmenbedingungen (z.B. ihres Programmcodes bzw. der implementierten Algorithmen) über eine relative Autonomie, da sie im Ablauf des Spiels aufgrund ihrer Prozeduralität und in Interaktion mit dem Spieler bestimmen können, was, wie, wann oder ob überhaupt erzählt wird. Insofern unterscheiden sich digitale Spiele als prozedurale Systeme signifikant in Bezug auf die narrative Kompetenz von anderen narrativen Medien wie dem Roman, dem Film oder dem Comic. Ermöglicht wird dies durch die Eigenschaften des Medienträgers, die dem Medium erstmals eine operative Autonomie zugestehen.

In Anbetracht dessen kann man digitale Spiele wie folgt definieren: Demnach ist ein digitales Spiel eine freiwillige, soziale, kommunikative und wechselseitige Handlung innerhalb eines prozedural automatisierten Systems, die durch eine Schnittstelle ausgeführt wird. Als System ist ein digitales Spiel immer an ein Medium bzw. einen digitalen Medienträger gebunden. Der ,Als-ob-Charakters‘ des (interaktiv-narrativen) digitalen Spiels kann sich über den simulativen und den narrativen Modus vermitteln und so neue immersive Erlebnisse ermöglichen. Die Spielwelt bzw. der Zauberkreis ist durch ihre mediale Gebundenheit somit weitaus hybrider mit Blick auf die vermittelnden Modi und die Welthaftigkeit als beim Spiel im Allgemeinen. Das Ergebnis des Spiels wird aber weiterhin erst im Spielverlauf bestimmt und am Spielende ermittelt, was die Geschlossenheit der Geschichte im aristotelischen Sinne vor neue Herausforderungen stellt. ${ }^{80}$ Dabei können Spiele in mehreren Formen und auf mehrere Arten gespielt werden, die sich in verschiedenen digitalen Spielgenres niederschlagen. Spielerische interaktive Handlungen zwischen Spieler und System sowie zwischen Spielern (in Mehrspielerspielen) konstituieren das Spiel als systemische Entität, die auf Spielregeln, Spielmechaniken und Spielrhetoriken beruht, auch wenn diese stärker als beim Spiel im Allgemeinen prozedural organisiert sind.

\footnotetext{
${ }^{80} \mathrm{Zu}$ den konfligierenden Potenzialen zwischen narrativen und ludischen Spielenden vgl. HERTE (2016).
} 


\section{Das Kontinuumsmodell zur Analyse interaktiv-narrativer digitaler Spiele}

Dieses Kapitel widmet sich der Profilierung des Kontinuumsmodells und folgt dabei argumentativ gewissermaßen einem Ableitungsverfahren, da das vorgeschlagene Modell eine Synthese diverser bestehender Ansätze, Theorien und Modelle aus verschiedenen Disziplinen und Forschungsfeldern wie den (Digital) Game Studies, der Soziologie, der Narratologie und der Medien- und Kommunikationswissenschaft darstellt. Deshalb ist es unabdingbar, die unterschiedlichen Forschungsstände zu skizzieren und $\mathrm{zu}$ diskutieren, um eine operationale Basis für die Modellbildung zu schaffen.

Von zentraler Bedeutung ist diesbezüglich die Narratologen-Ludologen-Debatte, welche aus mehreren Gründen immer noch (implizit oder explizit) eine signifikante Rolle für jene Studien in den Digital Game Studies spielt, die sich mit dem Verhältnis von Spiel und Erzählung im weitesten Sinne auseinandersetzen. Es scheint allerdings nicht ratsam, in der Narratologen-Ludologen-Debatte lediglich einen abgeschlossenen Diskurs zu sehen, der allenfalls für die Wissenschaftsgeschichte der Digital Game Studies von Relevanz ist. Vielmehr prägt die Debatte zwischen (bis heute) einflussreichen Medien- und Kulturwissenschaftlern das Fach immer noch maßgeblich und kann deshalb im Kontext einer Hybridtheoriebildung nicht außer Acht gelassen werden. So nehmen die Texte, welche zu den bekanntesten jener Diskussion gehören, bis heute einen ,kanonischen' Status innerhalb der Forschung ein, sodass es wenig Studien gibt, die auf sie verzichten. Darüber hinaus bestimmt die Debatte nicht nur die Wahrnehmung der Digital Game Studies in angrenzenden Disziplinen wie den Digital Humanities oder der transmedialen Narratologie, sondern ist auch innerhalb der Digital Game Studies überaus bedeutsam.

Wahrnehmungs- und Deutungsdispositive, mit denen digitale Spiele gegenwärtig von der Forschung betrachtet werden, zeigen auf die eine oder andere Weise Bezüge zu der Debatte auf sowie sie sich andererseits (implizit oder explizit) einer der beiden ,Schulen` zuordnen. Insofern deutet sich an, dass die Debatte auch aktuell immer noch für neue Studien interessant ist bzw. auch immer noch existiert, wenn auch freilich nicht mehr in jener Form aus den Jahren 1999 bis 2005. Überspitzt könnte man sagen, dass, solange zum Verhältnis von Spiel und Erzählung geforscht wird, es immer zu (kontroversen) Diskussionen zwischen 
,Narratologen' und ,Ludologen“ kommen wird. ${ }^{81}$ Aus diesem Grund, und aufgrund der Tatsache, dass die anvisierte Modellbildung nur vor dem Hintergrund der NarratologenLudologen-Debatte gelingen kann, wird dieser Diskurs einerseits im Folgenden anhand der bekanntesten Vertreter der beiden ,konkurrierenden' Schulen nachgezeichnet. Andererseits wird aber auch eine Neubewertung des Diskurses vorgenommen, die die Folgen der Debatte für die gegenwärtigen Digital Game Studies herausstellt. (2.1)

Diesem Teilkapitel schließen sich einige ausgewählte Hybridtheorien an, (2.2) um zu illustrieren, in welchem konkreten Forschungskontext die vorliegende Arbeit steht. Berücksichtigt werden vornehmlich jene Arbeiten, die sich dezidiert als Hybridtheorien verstehen. Diese Einschränkung ist notwendig, da andernfalls und weiter gefasst prinzipiell jede Arbeit in diesem Forschungszweig hybrid zu nennen ist, welche digitale Spiele als Hybride betrachtet und dies in ihren Überlegungen ausdrückt. In diesem Abschnitt gilt es aber auch zu klären, was die Hybridität digitaler Spiele bedeutet bzw. bedeuten kann und, zentraler, wie sie sich manifestiert. Viele Überlegungen der dargelegten Hybridtheorien fließen direkt oder indirekt in die Konzeption des Kontinuumsmodells ein.

Daran schließen sich die Ausführungen zu Interaktivität und Interaktion als einer der beiden Pole des interaktiven-narrativen Kontinuums an. (2.3) Hier spielen neben dem (medien-)soziologischen Interaktivitätsverständnis auch die Auffassungen der Digital Game Studies wie der Theorien ,Neuer Medien“ eine entscheidende Rolle. Im Abschnitt zu Narrativität, Narration und zum Narrativ ${ }^{82}$ gehen die Überlegungen von der literaturwissenschaftlichen Narratologie klassischer Prägung aus, integrieren aber ebenso postklassische Erzähltheorien wie die Arbeiten in den Digital Game Studies zu den Erkenntnispotenzialen der Narratologie bei der Analyse digitaler Spiele. (2.4)

Abgeschlossen wird dieses Kapitel mit dem Kontinuumsmodell, das sich in drei Kontinuen bzw. Ebenen aufteilt - Interaktivität-Narrativität (Attributebene), Interaktiv-Narrativ

\footnotetext{
${ }^{81}$ Dabei sollte nicht vergessen werden, dass die Narratologen-Ludologen-Debatte zwar sehr schnell und auch sehr richtig einige der grundlegendsten Fragen des Forschungsgebietes aufgeworfen hat, dass die Beantwortung dieser Fragen aber zugleich weitestgehend ausgeblieben ist, sodass sich die Virulenz dieser Debatte auch immer noch dadurch erklären lässt, dass die Suche nach möglichen Antworten immer noch nicht beendet ist.

${ }^{82}$ Bei den ausgewählten Beispielen zum Narrativ in interaktiv-narrativen digitalen Spielen konzentriert sich diese Arbeit primär (bedingt durch die Schwerpunktsetzung) auf jene Spiele, die auf das mythologische Narrativ oder seine modernen Derivate wie das Detektiv- oder Abenteuer-Narrativ zurückgreifen. Als Derivat des mythologischen Narrativs werden dabei alle modernen Narrative betrachtet, die (strukturell gesehen) ebenfalls dem Reisemodell des Helden im Sinne Joseph Campbells oder Christopher Voglers folgen, inhaltlich und thematisch aber keine oder kaum Bezüge zu mythologischen Stoffen aufbauen. Zum mythologischen Narrativ vgl. Kapitel 3.2.
} 
(Strukturebene) und Interaktion-Narration (Realisierungsebene). Diese werden durch Analogiebildungen aus den beiden vorangegangenen Begriffsfeldern entwickelt. (2.5) Ziel dieses Modells ist es, interaktiv-narrative digitale Spiele auf mehreren Ebenen mit unterschiedlichen Schwerpunktsetzungen wie Produktion und Rezeption, aber auch ontologisch und ästhetisch differenziert analysieren zu können. ${ }^{83}$

\subsection{Die Narratologen-Ludologen-Debatte}

Nahezu alle Arbeiten, die sich mit narrativen Aspekten digitaler Spiele befassen, haben einen mehr oder weniger intensiven Bezug zu diesem Forschungsdiskurs, wenn sie ihm nicht gar unmittelbar entstammen. Die Frage, was diese Debatte eigentlich war, wer debattierte und worüber, wurde lange mehrheitlich wie folgt beantwortet: Bei der Narratologen-LudologenDebatte handelt es sich um eine (reichlich polemische) ${ }^{84}$ Auseinandersetzung zwischen zwei Schulen im Bereich der Digital Game Studies, die diese ontologisch unterschiedlich definieren und dementsprechend verschiedene Theorien und Methoden anwenden, um digitale Spiele zu untersuchen. So betrachten Narratologen digitale Spiele als eine neue Form von Erzählungen, von Texten, die sich mit erzähltheoretischen Ansätzen untersuchen lassen, wohingegen Ludologen hierin einen Okkupationsversuch ${ }^{85}$ der Narratologen sehen, der die mediale Realität digitaler Spiele vollkommen verkenne. Digitale Spiele seien nichts anderes, so die ludologische Lesart, als Spiele, basieren dementsprechend auf Spielmechaniken und Spielregeln und unterscheiden sich damit fundamental von traditionellen narrativen Medien, weshalb sie auch nicht als solche betrachtet werden können und narratologische Ansätze hier überflüssig seien. So die langläufig tradierte Interpretation der Narratologen-LudologenDebatte als Konflikt um die Deutungshoheit über digitale Spiele.

Allerdings wurde hiergegen in den letzten Jahren eingewandt, dass diese Sichtweise eine sehr starke Verkürzung sei und dass man keinesfalls die Grenze zwischen den beiden Lagern so klar ziehen könne, zumal die Gruppen in sich so heterogen seien, dass man kaum von

\footnotetext{
${ }^{83}$ Die Begriffe ,Ontologie‘ und ,ontologisch` werden in dieser Arbeit im Sinne einer ,existenziellen Ontologie‘ verwandt, die danach fragt, ,what are games and what kind of existence does a game have“. AARSETH (2014b), 484; Herv.i.O. Die Termini ,Ästhetik“ und ,ästhetisch“ werden im Folgenden im Sinne der philosophischen Kunsttheorie gebraucht und meinen damit „die Eigenart solcher Gegenstände, die Kunstwerke sind.“ FEIGE (2015), 15.

${ }^{84}$ Die durchaus vorhandene Polemik lässt sich auch dadurch erklären, dass die Narratologen-Ludologen-Debatte auch eine Emanzipationsbewegung war, die die Erforschung digitaler Spiele als eigenständiges Forschungsfeld etablieren und dieses von anderen Bereichen der Medienwissenschaft abzugrenzen versuchte.

${ }^{85}$ Vgl. dazu AARSETH (2001).
} 
einheitlichen Gruppierungen sprechen könne. ${ }^{86}$ Eine traditionelle Lesart der NarratologenLudologen-Debatte findet sich bspw. bei EsKELINEN (2012), der die Debatte in Person ihrer bedeutendsten Vertreter nachzeichnet, wobei er vornehmlich auf die Narratologen bzw. ,Narrativisten ${ }^{87}$ sowie deren Fehlschlüsse eingeht und die ludologische Position (lediglich implizit) als positives Gegenbeispiel hervorhebt. Eskelinen bekennt sich in diesem Text radikal zur ludologischen Position: „In short, there are no compelling reasons to believe that a revised narrative theory is what (video and computer) game studies need either in the first place or later on.“ (ebd., 232) Bemerkenswert ist dies, da seit fast zehn Jahren von der Narratologen-Ludologen-Debatte vornehmlich als einem historischen Forschungsdiskurs gesprochen wird, der beendet sei.

Aktuelle Arbeiten neigen zuweilen dazu, die Narratologen-Ludologen-Debatte herabzuspielen, indem man sie bspw. als „Gründungsmythos“ bezeichnet. (BEIL et al. 2015b, 7) Dabei sollte man sich aber davor hüten, in ihr eine verkappte origo gentis-Erzählung der Digital Game Studies zu sehen, so wie man sie grundsätzlich nicht als ,erfundenen` Diskurs betrachten sollte. In besonderem Maße hat sich Espen Aarseth in den letzten Jahren dafür stark gemacht, in der Narratologen-Ludologen-Debatte eine Erfindung Henry Jenkins' zu sehen, der die vier bekannten ,Ludologen“ als solche ,otherte', obwohl sie doch auch einen narratologischen Hintergrund haben. (vgl. AARSETH 2012, 130) Diese These, dass die Narratologen-Ludologen-Debatte nie wirklich stattgefunden habe, lässt sich bereits 2003 bei Gonzalo Frasca nachweisen, wenn er feststellt, dass „the so-called ludology versus narratology debate never really took place“. ${ }^{88}$ (FRASCA 2003a) Derartige Äußerungen muten jedoch ähnlich absurd an wie einst Jean Baudrillards Aussagen über die Nichtexistenz des

\footnotetext{
${ }^{86}$ So kommt man nicht umhin, festzustellen, dass unter dem Begriff, Narratologe' im Rahmen der NarratologenLudologen-Debatte nicht unbedingt Erzählwissenschaftler im herkömmlichen Sinn zu verstehen sind. So gibt es zwar zahlreiche literatur- und filmwissenschaftliche Narratologen, allerdings werden auch Bild- oder Dramentheoretiker zu dieser Gruppe gerechnet, was aber daran liegt, dass Narratologen nicht als solche im Kontext der Narratologen-Ludologen-Debatte bezeichnet werden, weil sie erzähltheoretische Instrumentarien verwenden, sondern weil sie digitale Spiele als narrative Medien betrachten.

${ }^{87}$ Populär wurde der Begriff Narrativismus in den Digital Game Studies durch Espen Aarseth, der hierunter jene Tendenz der (narratologisch inspirierten) Kulturwissenschaften versteht, alles als Geschichte zu betrachten, d.h. auch nicht-narrative Entitäten narrativ zu interpretieren. Vgl. AARSETH (2004a). Im Unterschied zum Narratologen, der narrative Phänomene mithilfe seines narratologischen Instrumentariums adäquat untersuche, tue der Narrativist sowohl dem Gegenstand als auch der Methode Gewalt an, indem er narratologische Instrumentarien zu undifferenziert verwende. Eskelinen geht gar so weit, Narrativisten einen wissenschaftlichen Anspruch abzusprechen. So bemerkt er mit Blick auf Janet Murrays berühmte Keynote aus dem Jahr 2005, die vielen als Ende der Narratologen-Ludologen-Debatte gilt: „Hence her keynote is a purely rhetorical plea for peace without any scholarly merit.“ ESKELINEN (2012), 217.

${ }^{88}$ Dass es sich bei der Narratologen-Ludologen-Debatte jedoch nicht, wie von Aarseth und Frasca behauptet, um ein reines ,Othering' durch die, Narratologen' handelt, zeigen Beispiele aus ludologischen Texten, die selbst mit einer Grabenkampfrhetorik arbeiten wie bspw. erneut Eskelinen. Dies wird deutlich, wenn er von den „opponents of ludology“ spricht. ESKELINEN (2012), 210.
} 
Golfkriegs. (vgl. BAUDRILlARD 1996) Denn es ist zweifellos (und zahlreiche wissenschaftliche Texte zeugen hiervon), dass die Narratologen-Ludologen-Debatte existiert hat bzw. noch heute existiert. Genau genommen bietet es sich sogar an, in Bezug auf die Narratologen-Ludologen-Debatte von zwei Narratologen-Ludologen-Debatten zu sprechen. Einerseits kann man die Narratologen-Ludologen-Debatte (und so wurde es bisher mehrheitlich auch getan) als Konflikt zwischen prominenten Vertretern beider Schulen im Besonderen und andererseits als Auseinandersetzung zwischen Forschern beider Ansätze innerhalb eines Forschungsbereichs im Allgemeinen verstehen. Die erste Diskussion wird im Folgenden NLD I und die zweite NLD II genannt. Handelt es sich bei NLD II um einen klassischen kontroversen Forschungsdiskurs, so ist NLD I nicht nur ein Streit über methodische und epistemologische Problemstellungen, sondern eine Inszenierungsstrategie mit verschiedenen erheblichen taktischen Einschlägen, die v.a. von den Ludologen betrieben wurde.

Nicht Narratologen wie Jenkins haben die NLD I erfunden, sondern Ludologen wie Aarseth und Frasca. Eine These, die sich vor dem beruflichen Hintergrund der Beteiligten trefflich untermauern lässt, wenn man bedenkt, dass es sich bei den prominenten Narratologen um etablierte Wissenschaftler handelt, wohingegen die Ludologen vor dieser Debatte eher unbekannt waren. Espen Aarseths und Jesper Juuls universitäre Karrieren fußen z.B. zu einem wesentlichen Bestandteil auf der Bekanntheit, die sie im Zuge der NLD I erwarben. Was aber in den Bereich des ,Mythos' gehört, ist die ritualisierte Beschwörung, dass die NarratologenLudologen-Debatte beendet sei - weder im Sinne von NLD I noch im Sinne noch NLD II. Denn noch immer sind viele der richtigerweise in der NLD I identifizierten Probleme nicht zufriedenstellend gelöst, sodass eine NLD II weiterhin stattfindet, aber nicht mehr unbedingt mit dualistischer Lagerbildung, sondern zunehmend mit dem Bestreben, zwischen beiden Ansätzen zu vermitteln, um der Hybridität digitaler Spiele Rechnung zu tragen. ${ }^{89}$ Und auch die NLD I schreitet weiter voran, wenn auch die Intensität der Auseinandersetzungen deutlich abgenommen hat und sich die Rhetorik der Debatte subtiler darstellt. ${ }^{90}$

\footnotetext{
${ }^{89}$ Freilich kann eine Debatte beendet werden, auch wenn noch die debattierten Probleme bestehen, jedoch muss man dabei betrachten, ob diese Probleme nach dem deklarativen Akt der Beendigung noch weiter in vergleichbaren Kontexten von bestimmten Akteuren diskutiert werden oder nicht. Findet diese Diskussion immer noch statt, so ist durchaus davon auszugehen, dass der vermeintliche Debattenabschluss eben doch nicht das Ende jener Konstroversen war. Dies ist bei der NLD I der Fall.

${ }^{90}$ Bereits in den Jahren der Hochphase der NLD I (1999-2005) waren Konferenzen ein zentraler Ort von Auseinandersetzungen zwischen beiden Lagern. Und so kann man auch auf aktuellen Konferenzen immer noch diese Konfrontationen beobachten, die z.T. von Schülern der Teilnehmer der NLD I (weiter-)geführt werden. Streitpunkte sind dabei u.a. das Verhältnis von Ludizität und Narrativität sowie von Realität und Fiktionalität.
} 
Hierdurch wird deutlich, dass auch nach ihrem proklamierten Ende die NarratologenLudologen-Debatte im zweifachen Sinn auftritt - als Inszenierungspraxis und als kontrovers geführter Forschungsdiskurs. Allerdings bietet es sich aufgrund der negativen Konnotation des Begriffs an, diesen im Folgenden nur dann zu verwenden, wenn von der NLD I die Rede sein wird. Den gegenwärtigen reichen Forschungsdiskurs über digitale Spiele an der Schnittstelle zwischen narratologischer und ludologischer Wissenschaft als NLD II zu bezeichnen, hieße, seine Vielfältigkeit zu ignorieren. Es ist zwar nur bedingt korrekt, dass die Narratologen-Ludologen-Debatte von einer vermittelnden, moderat ludologischen Position ${ }^{91}$ abgelöst wurde, da sowohl die NLD I als auch die NLD II noch fortbestehen, es trifft aber vollkommen zu, dass ein Wandel der Auffassungen stattfand, der digitalen Spielen in ihrer Ambivalenz, Ambiguität und Hybridität gerechter wird, als die Narratologen-LudologenDebatte dies jemals konnte. Dennoch trug die Narratologen-Ludologen-Debatte zur Bekanntheit der Diskutierenden wie zur Kanonisierung ihrer Texte bei, die auch heute noch von großer Bedeutung für neue Studien im Bereich der Digital Game Studies sind.

Im folgenden Abschnitt wird zuerst die ludologische und danach die narratologische Schule vorgestellt, wobei die einzelnen Vertreter separat behandelt wie auch in Kontext zu Mitstreitern und ,Gegenspielern“ gesetzt werden, um Kontinuitäten wie Diskontinuitäten beider diskursiv herauszustellen. Da die NLD I als ein Forschungsdiskurs betrachtet wird, der sich zwischen Ende der 1990er Jahre sowie der Mitte der ersten Dekade des neuen Jahrtausends ereignete, werden im Folgenden ausschließlich Texte aus dieser Zeit berïcksichtigt.

\subsubsection{Die Narratologen-Ludologen-Debatte (NLD I)}

Den Ausgangspunkt der Narratologen-Ludologen-Debatte markieren zwei zeitgleich erschienene Studien, deren Verfasser zu den Prototypen des jeweiligen Lagers wurden - die Rede ist von Espen AARSETHs Cybertext. Perspectives on Ergodic Literature (1997) und Janet MuRRAYs Hamlet on the Holodeck. The Future of Narrative in Cyberspace (1997). Die Außenwahrnehmung dieser Debatte lässt sich in Person dieser beiden prominenten Vertreter anschaulich anhand eines schönen (Bild-)Beispiels illustrieren. Janet Murray verwendet in der Einleitung ihres Vortrages auf der DIGRA 2005, in welchem sie die Narratologen-Ludologen-

\footnotetext{
91 Jene moderat ludologische Position ist (in dieser Lesart der NLD I) das Resultat eines Kompromisses zwischen Ludologen und Narratologen, dessen Zielsetzung sich in etwa so fassen lässt: „Only then [nach der Überwindung des Narrativismus] can we begin to see clearly how games relate to stories, how stories sometimes are used in games and integrate or conflict with the games' action in a simulated world, and maybe learn something new about both discursive models." AARSETH (2004b), 362.
} 
Debatte für beendet erklärt, nämlich ein Bild, das sie und Espen Aarseth als Kontrahenten eines groß aufgezogenen Boxkampfes zeigt. (vgl. MURRAY 2005) Einerseits zeigt diese Fotomontage, dass der Diskurs von außen als antagonistisch wahrgenommen wurde, andererseits unterstreicht die übertriebene Inszenierung der Auseinandersetzung als Boxkampf im pompösen Las Vegas-Stil die ironisch-zynische Distanz, mit welcher das Geschehen betrachtet wurde. Dass die Debatte aber selten derart hitzig war, wie hier suggeriert, illustriert die rasche Veränderung der Argumentationen, die die Beteiligten in wenigen Jahren durchliefen und die im Folgenden nur sehr skizzenhaft nachgezeichnet wird.

\subsubsection{Die ludologische Position}

\subsection{Espen Aarseth}

Mit Rückgriff auf Norbert Wieners Kybernetik (1992) profiliert Aarseth das Konzept des Cybertextes, welchen er keineswegs nur als Phänomen elektronischer Medien ansieht, sondern als ,the mechanical organization of the text, by positing the intricacies of the medium as an integral part of the literary exchange." (AARSETH 1997, 1) So fasst er bspw. auch das I Ching als Cybertext auf. (vgl. ebd., 9) Dem Cybertext schließt er zugleich die Ergodizität ${ }^{92}$ an. Ergodische Literatur definiert er dabei wie folgt: „In ergodic literature, nontrivial effort is required to allow the reader to traverse the text." (ebd., 1) Cybertexte bzw. ergodische Literatur im elektronischen Bereich findet man, nach Aarseth, in Form von Hypertexten, Text-Adventures oder Text-Multi User Dungeons (MUD). Bekanntlich konnten sich beide Konzepte nie wirklich durchsetzen, sodass sie im wissenschaftlichen Diskurs selbst nur eine sehr kurze Halbwertzeit hatten. ${ }^{93}$

Was Aarseths Buch aber dennoch eine nachhaltige Beachtung schenkte, war die Entschiedenheit und Klarheit, mit der er zwischen Narrativen (hier in einem sehr weiten Sinn) und Spielen unterschied. „To claim that there is no difference between games and narratives is to ignore essential qualities of both categories.“ (ebd., 5) Aarseth verfolgt hiermit aber keine radikale Absage an etablierte Literaturtheorien; es geht ihm eher um eine Revision des Status

\footnotetext{
${ }^{92}$ Einen kritischen aber interessanten Beitrag zur Ergodizität von digitalen Spielen liefert Newman (2002). James Newman betont hierin, dass Ergodizität weniger eine Eigenschaft von Medien sei, als vielmehr eine Art und Weise, wie Medien konkret genutzt werden. Weniger das Medium an sich sei ergodisch, sondern seine Nutzung. Vgl. ebd. Es gebe ein ,ergodic continuum“, das sich zwischen einem ergodischen und einem nichtergodischen Pol erstrecke und sich in verschiedenen Phasen unterschiedliche umsetze. Ebd. Es ist zwar eine Art „ergodic potential“ im Medium selbst vorhanden, das den konkreten Grad der Ergodizität bestimme, wie diese realisierte werde, hänge letztlich aber vom Nutzer ab. Ebd.; Herv.i.O.

${ }^{93}$ Ursächlich könnte hierfür die geringe extensionale und intensionale Bestimmung beider Konzepte sein, die v.a. die Ergodizität betrifft. Was diese ,nicht-triviale Anstrengung' ist, die der Nutzer aufbringen muss, um den Text zu ,durchqueren', bleibt leider in Aarseths Buch unklar.
} 
quo: „My main effort is, therefore, to show what the functional differences and similarities among the various textual media imply about the theories and practices of literature. [...] I argue that existing literary theory is incomplete (but not irrelevant) when it comes to describing some of the phenomena studied here, and I try to show why and where new theoretical approach is needed.“ (ebd., 17) Aarseths Buch, und das kann zuweilen vergessen werden, war eine Arbeit in der Literaturwissenschaft, die sich mit neuen (elektronischen) Formen literarischer Texte beschäftigt, es war also nicht als ,revolutionäre' Studie intendiert, zu der es in der Folge stilisiert wurde.

Dies erkennt man auch daran, dass Aarseth eine recht konventionelle Textdefinition vertritt: „A text, then, is any object with the primary function to relay verbal information.“ (ebd., 62) Dass Aarseth sich aber dennoch bereits in diesem Buch von der narratologischen Seite verabschiedet, wird ersichtlich, wenn man berücksichtigt, dass ,[t] $]$ he actions within the game are not narrative actions.“ (ebd., 94) Vielmehr sei Spielen ein ergodischer Prozess im vollumfänglichen Verständnis. Dementsprechend arbeitet er detailliert Unterschiede zwischen Spielen und narrativen Medien heraus.

Narratives have two levels, description and narration. A game such as football has one level, the ergodic. A video game (e.g., Atari's $\mathrm{Pac}-\mathrm{Man}^{94}$ ) has description (the screen icons) and ergodics (the forced succession of events) but not narration (the game may be narrated in a number of ways, but like football, narration is not part of the game). (ebd., 95)

Wenn Aarseth dann in der Folge genauer auf das Text-Adventure eingeht und konstatiert, dass es sich hierbei um eine neue Textform handele, so kann es nicht verwundern, dass er zu der berechtigten Aussage gelangt, dass ,the standard concepts of narratology are not sufficient to explain the literary phenomena of adventure games“. (ebd., 111) Dies ist aber nicht als Absage an die Tauglichkeit von narratologischen Theorien und Modellen zur Analyse von Adventures im Allgemeinen zu verstehen, sondern nur in ihrer damaligen Form, die sich an Medien ausgebildet hatte, die über ganz andere Qualitäten verfügten als jene elektronischen Medien. Es geht Aarseth, so kann man die Quintessenz seines Buches zusammenfassen, darum, was die Narratologie aus diesen neuen Phänomenen lernen kann. (vgl. ebd., 128)

In den folgenden Jahren und als Reaktion auf die (kritischen) Bezugnahmen auf sein Buch, verschärft Aarseth den Ton gegenüber der Narratologie. Er plädiert für eine konsequente Trennung zwischen Film und digitalem Spiel und erhebt die Simulation zu einer Kerneigenschaft digitaler Spiele, die diese von narrativen Medien trenne.

\footnotetext{
${ }^{94}$ Pac-Man (1980) wurde von Namco entwickelt.
} 
The simulation aspect is crucial: it is radically different alternative to narratives as a cognitive and communicative structure. Simulations are bottom up; they are complex systems based on logical rules. Games are both object and process; they can't be read as texts or listened to as music, they must be played. Playing is integral, not coincidental like the appreciative reader or listener. The creative involvement is a necessary ingredient in the uses of games. (AARSETH 2001)

Der Unterschied zwischen einer Geschichte und einem Spiel lasse sich an einem ganz einfachen Beispiel illustrieren, das sehr stark an Huizingas Begründung der Präkulturalität des Spiels erinnert. (vgl. HuIZINGA 1991, 9) Aarseth betont, dass man zwar mit einem Hund spielen, auf diese Weise mit ihm kommunizieren könne, es aber unmöglich sei, ihm eine Geschichte zu erzählen, die er verstehen könne. (vgl. AARSETH 2004a, 46) Aarseth gelangt zu dem Schluss, dass Spiele Spiele seien und nichts mehr und dass eine Gleichsetzung von Spiel und Text verfehlt sei. (vgl. ebd., 46 f.) Indem Aarseth die Fixierung auf den Textbegriff aufgibt, eröffnet er den Blick auf das Spiel im Allgemeinen. Statt traditioneller narratologischer Konzepte und den damit verbundenen Forschungsinteressen kapriziert sich Aarseth auf die folgenden Aspekte als Kerneigenschaften von Spielen. „Any game consists of three aspects: (1) rules, (2) a material/semiotic system (a gameworld), and (3) gameplay (the events resulting from application of the rules of the gameworld).“ (ebd., $47 \mathrm{f}$.) Die sich daraus ergebende Ambiguität des Spiels (und hier schließt er an Brian Sutton-Smith an) trennt dieses nachhaltig von Geschichten. (vgl. ebd., 48) Das Bedürfnis, alles mit Narrativen auszustatten bzw. anzureichern, sei die Folge eines umgreifenden ,Narrativismus', der zu einer „overgeneralization“ verführe. (ebd., 49) „Storytelling has been, and still is, the dominant form of cultural expression. But it is not the only game in town, the only mode of discourse. It is quite possible, not to mention necessary, to identify other modes, games among them, as alternatives to storytelling.“ (ebd., 50) Aarseth bestreitet also nicht die Rolle des Erzählens als Form kulturellen Ausdrucks, sondern die hegemoniale Stellung, die dieser zugeschrieben wird, indem man andere Formen reduziert, abwertet oder ignoriert. Er betont die Unterschiede zwischen beiden kulturellen Phänomenen, die v.a. deshalb in diesem Kontext so bedeutend sind, da der genuine Modus eines digitalen Spiels, und das gilt auch für solche, die narrative Komponenten beinhalten, nicht die Narration, sondern die Simulation sei.

\subsection{Gonzalo Frasca}

In Bezug auf ihr Anliegen, zwischen Spielen und Geschichten zu differenzieren sowie die Simulation als zentralen Modus von Spielen hervorzuheben, stehen sich Frasca und Aarseth sehr nahe, auch wenn, und das ist Frascas großes Verdienst, der Simulationsbegriff durch kaum einen Forscher in den Digital Game Studies so geprägt wurde wie durch Gonzalo 
Frasca. Wie Aarseth erkennt Frasca den Nutzen narratologischer Ansätze für die Analyse digitaler Spiele an, weist aber auch ebenso entschieden auf deren Grenzen sowie darauf hin, dass diese nicht immer konsequent von den Forschern angewandt würden, was primär an einer Fehleinschätzung bezüglich des ontologischen Charakters digitaler Spiele liege.

Some authors see cybertexts and videogames as a new form of or as an expansion of traditional narrative or drama. The fact is that these computer programs share many elements with stories: characters, chained actions, endings, settings. However, there is another dimension that has been usually almost ignored when studying this kind of computer software: to analyze them as games. (FRASCA 1999)

Unter Berücksichtigung der Tatsache, dass die Game Studies weltweit an Universitäten im 20. Jahrhundert einen schweren Stand hatten und sich dies auch auf die Anfänge der wissenschaftlichen Auseinandersetzung mit digitalen Spielen nachhaltig auswirkt, ist Frasca nicht daran gelegen, den narratologischen Ansatz $\mathrm{zu}$ verdrängen, sondern ihn zu komplementieren, indem er Gemeinsamkeiten und Differenzen zwischen beiden Phänomenen aufzeigt und hieraus Rückschlüsse auf die Theoriebildung zieht. In diesem Zusammenhang verwendet er den Begriff ,Ludologie', um damit die systematische Erforschung digitaler Spiele und anderer Cybertextformen zu bezeichnen. Dabei ist ihm die strikte Unterscheidung zwischen Spiel und Geschichte (die Begriffe variieren in der Narratologen-LudologenDebatte sehr stark, obwohl ihre Referenzobjekte identisch sind) ebenso wichtig wie Aarseth. „Thus, we cannot claim that ludus and narrative are equivalent, because the first is a set of possibilities, while the second is a set of chained actions.“ (ebd.) Für einen Beobachter kann ein digitales Spiel zwar wie eine Narration wirken, allerdings ist es dies nicht für den Spieler, welcher, im Gegensatz zum Beobachter, aktiv ist. Wenn der Spieler nicht agiert, dann gibt es kein Spiel. Das Sehen und das Spielen eines Spiels sind zwei verschiedene Dinge. Frasca identifiziert hier auch die narratologische Filmwissenschaft als einen Problemfall, da gerade sie dazu neige, v.a. wenn sie die Prozesshaftigkeit des Spiels ignoriert und sich nur auf die audiovisuelle Repräsentation fokussiert, verkürzte Betrachtungen digitaler Spiele vorzunehmen.

...for an external observer, the outcome of a simulation is a narration. But the simulation itself is something bigger than narrative. It is a dynamic system that yes, contains thousands of potential »stories«, but it is larger than the sum of its parts. The simulation itself is not a narrative, it is something different, in the same way that a kaleidoscope should not be understood as a collection of possible images but instead as a device that produces images according to certain mechanics. (FRASCA 2001, 2; Herv.i.O.)

Frasca unterscheidet Simulation und Narration anhand der Partizipation des aktiven Rezipienten voneinander; dem Spieler eines digitalen Spiels kommt es nicht so vor, als würde 
man ihm eine Geschichte erzählen, er fühlt sich als Teil der Geschichte, als Gestalter der Geschichte, da ihm nicht eine Geschichte vorgegeben wird, sondern er in einem System situiert ist, das ihm im hohen Maße die Möglichkeit gibt, auf sehr verschiedene Arten zu handeln, d.h. nicht nur Geschichten zu erleben und nicht nur eine, sondern viele erleben zu können. In diesem Sinne ist der simulative Modus eine Alternative zum darstellenden und narrativen, weshalb ,videogames should not be viewed as an extension of narrative, literature, theater or cinema“. (ebd., 1) Ontologisch sieht Frasca erhebliche Unterschiede zwischen Spiel und Geschichte, da der darstellende Modus nicht der genuine Modus von Spielen sei. (vgl. ebd.) Eine Überstrapazierung narratologischer Termini verkenne nicht nur die medialen Potenziale digitaler Spiele, sondern laufe zudem Gefahr, zu einer Erosion der Erzähltheorie zu führen, da die Betrachtung eines jeden Syntagmas als Narrativ bedeuten würde, dass nahezu alles ein Narrativ und der epistemologische Wert dieser Kategorie dann mehr als fraglich wäre. (vgl. ebd., 2)

Demzufolge hebt er die Simulation als neues Untersuchungsparadigma hervor und versteht hierunter: „Simulation is act of modeling a system A by a less complex system B, which retains some of A's original behavior“. ${ }^{95}$ (ebd., 3) Das Schlüsselprinzip in Simulationen sind „behavioral rules“. (ebd.; Herv.i.O.) Simulationen verhalten sich wie das Original, das sie simulieren, sie bilden es nicht bloß ab wie Repräsentationen. ${ }^{96}$ Die Simulation hebt sich auch dadurch von der Repräsentation ab, da sie als System an sich komplexer ist, auch wenn Frasca selbst einräumt, dass es zuweilen sehr schwer sei, die Grenzen zwischen beiden auszumachen. (vgl. ebd., 4) Wie Aarseth möchte Frasca nicht die Berechtigung der Repräsentation/des Erzählens als bedeutende kulturelle Form bestreiten. Was er aber kritisiert, ist die Alleinstellung, die ihr in Kultur wie Wissenschaft zukommt. „As I previously said, simulation and representation are two ways of dealing with reality. Until now, both have coexisted in our culture, but representation, along with narrative, have been dominant, mainly because complex simulations require a level of technical sophistication that is impossible without a computer.“"(ebd.)

Entscheidend ist an Simulationen im Vergleich zu Repräsentationen, dass es sich hierbei um Systeme handelt, die für die Manipulation durch den Nutzer nicht nur offen, sondern regelrecht darauf angewiesen sind. (vgl. FRASCA 2003b, 223 f.) Dadurch tragen Simulationen zur Ausbildung von Denkstrukturen bei, die Narrationen nicht evozieren können. (vgl. ebd.,

\footnotetext{
${ }^{95}$ Vgl. dazu auch FRASCA (2003b), 223.

${ }^{96}$ Vgl. hierzu den Begriff des ,Simulacrum‘ bei BAUdRILLARD (2010).
} 
224) Durch ihre experimentelle Prozeduralität können Simulationen den Nutzer interaktiv in einer Weise einbeziehen, wie es Narrationen nicht möglich ist. Hiermit unterstreicht Frasca nicht die Superiorität von Simulationen, sondern ihre Alterität und die damit einhergehenden Veränderungen in der Kultur. Frasca stellt zum einen stets die Grenzen von Simulationen heraus und zum anderen verweist er darauf, dass sich Simulationen erst noch weiterentwickeln müssen, und dass Entwicklungen deshalb noch nicht vorhersehbar seien. (vgl. ebd., 233)

\subsection{Jesper Juul}

Auch Jesper Juuls Arbeiten zeichnen sich durch das Bestreben aus, Spiel und Geschichte voneinander zu trennen, im Unterschied zu Aarseth und Frasca betont er aber bereits früh und vehement eine strikte ludologische Position, wenn er behauptet, dass „the computer game is simply not a narrative medium.“ (JUUL 1999, 1) Zwar erkennt er auch an, dass Spiele und Geschichten zentrale Gemeinsamkeiten haben würden, das dürfe aber keineswegs zu einer Gleichsetzung beider führen, denn abgesehen davon weisen beide auch markante Unterschiede auf. (vgl. ebd.) Ein wichtiges Indiz für diese Verschiedenheit ist, dass Geschichten aus Verkettungen vergangener Geschehnisse bestehen, wohingegen Geschehnisse in Spielen erst im Spielverlauf durch die Handlungen des Spielers entstehen und verkettet würden. Der signifikanteste Unterschied zwischen Spiel und Geschichte liegt demnach auf der Ebene der raumzeitlichen Strukturierung.

There seems to be a conflict between the temporalities of the game and the narrative: When something is interactive - like a game - the interactivity has to be now, when the player makes a choice. But the narrative has a basic trait of being about something past. Similarly, space is treated differently: Computer games always create space, where the player can move around, but narratives are very focused on skipping uninteresting spaces; a journey is only described when something actually happens. It is essential for the narrative that narration does not happen with constant speed, but that we shift between resume, cuts, and scene. The computer action game is based on real time, on the constant control of the player. ${ }^{97}$ (ebd., 3; Herv.i.O.)

Erzählzeit, erzählte Zeit und ,Lesezeit' fallen im digitalen Spiel in einer einzigen Zeit zusammen. Dies führe letztlich auch dazu, dass Narrativität und Interaktivität nie zeitgleich existieren können. Interaktivität im Juul'schen Sinne setzt nämlich Echtzeit-(Inter-)Aktionen als fundamentalen begriffsbestimmenden Maßstab. Das bedeutet aber auch, dass der Spieler in seinen interaktiven Handlungsoptionen kaum limitiert werden sollte. (vgl. ebd., 16) Diese Vorrangstellung der Interaktivität führt Juul letztlich dahin, jede Form von möglichen Hybridisierungen zwischen Spiel und Geschichte kategorisch abzulehnen.

\footnotetext{
${ }^{97} \mathrm{Zu}$ Raum und Zeit in digitalen Spielen vgl. auch Mark J.P. WOLF (2003a sowie 2003b).
} 
Narratives, linear and fixed sequences, a chain of events that are claimed to necessarily follow each other; variable speed, skips, and a distance between the time narrated and the time of the reading. The computer game, interactive and non-linear, with smaller elements that can be combined again and again, an interactivity that presupposes a now where the user has influence, and where the time narrated and the time of the reading are identical. These two are too different to be simply combined. The interactive narrative is not impossible, that is, works can be created that are alternating narrative and interactive. But it does not create something new, something just equal to the sum of its parts. Which means that the critics are partially right: The computer game cannot create the experiences that a good book or movie can create. And they do seem to lack something based more on traditional story themes and less on motor skills and reaction time. (ebd., 76)

Interessant ist an Juuls Ansatz, dass er sehr intensiv auf narratologische Konzepte zurückgreift, diese aber nutzt, um die Grenzen zwischen beiden Phänomenen deutlich aufzuzeigen und darüber hinausgehend bestimmter als Aarseth und Frasca Einspruch gegen die Betrachtung von Spielen als narrativen Phänomenen erhebt sowie eine damit verbundene Überbeanspruchung des Narrativs als erklärendes Muster für kulturelle Prozesse im Allgemeinen vehement ablehnt. In der Folgezeit werden seine Unterscheidungen immer differenzierter:

The article then explores three important reasons for describing games as being non-narrative: 1) Games are not part of the narrative media ecology formed by movies, novels, and theatre. 2) Time in games works differently than in narratives. 3) The relation between the reader/viewer and the story world is different than the relation between the player and the game world. (JUUL 2001)

Neu an dieser Auflistung ist, dass Spiele kein Teil einer ,narrativen Medienökologie‘ sind bzw. über Merkmale verfügen, die für genuin narrative Medien untypisch sind. Juul geht aber hierüber hinaus und betrachtet einen Aspekt, der heute noch zu erheblicher Konfusion führt. „Narratives may be fundamental to human thought, but this does not mean that everything should be described in narrative terms. And that something can be presented in narrative form does not mean that it is narrative." (ebd.; Herv.i.O.) Man muss dazwischen unterscheiden, ob die dargebotene Narration ein Aspekt der medialen Darstellung ist, oder ob es sich hierbei um eine Leistung des Rezipienten handelt, der ein Erlebnis narrativiert. ${ }^{98}$ Problematisch wird die Narrativierung eines Ereignisses, wenn vom Betrachter nicht erkannt wird, dass die Narration seine eigene ist und nicht vom Medium ausgeht. Diese Fehlleistung kann schnell dazu führen, dass Phänomene, die nicht narrativ sind, als narrativ wahrgenommen werden. Jene Fehlleistungen sind auch die Ursache für den von Aarseth kritisierten ,Narrativismus' und die damit zusammenhängende ,Übergeneralisierung‘, die dazu tendiert, kategoriale Unterschiede auszublenden.

\footnotetext{
${ }^{98}$ Vgl. dazu Kapitel 2.4.4.
} 
Im Vergleich zu Aarseth und Frasca ist Juul auch später kaum auf die narratologische Seite zugegangen, auch wenn er in der Folge nicht mehr derart vehement gegen eine Betrachtung von Spielen als Narrativen gesprochen hat. Dies liegt meines Erachtens aber auch daran, dass es für Juul sehr eindeutig ist, dass Spiele nichts mit Narrativität zu tun haben, außer mit einer vom Rezipienten zugeschriebenen. Dennoch blieb er literaturwissenschaftlichen Konzepten verpflichtet. Bereits in seinen frühen Arbeiten spielt Wolfgang Isers ${ }^{99}$ Rezeptionsästhetik eine wichtige Rolle, in Half-Real. Video Games between Real Rules and Fictional Worlds (2005) wird sie zum zentralen Stützpfeiler.

In the title, Half-Real refers to the fact that video games are two different things at the same time: video games are real in that they consist of real rules with which players actually interact, and in that winning or losing a game is a real event. However, when winning a game by slaying a dragon, the dragon is not a real dragon but a fictional one. To play a video game is therefore to interact with real rules while imagining a fictional world and a video game is a set of rules as well as a fictional world. (JUUL 2005, 1)

Was bei Iser das Vorkommen der Realität in der Literatur in verzerrter Form ist, gestaltet sich bei Juul als real-fiktionaler Hybridzustand, der sich aus der Realität der Regeln wie auch der spielerischen Handlungen manifestiert, die aber wiederum in einem fiktionalen Kontext angesiedelt sind, der deutlich mit der lebensweltlichen Realität der Spieler bricht. Fiktionalität ist hier aber nicht im Sinne einer Fiktionalität narrativer Medien zu verstehen, wie es meistens in den Literatur- und Medienwissenschaften und der gegenwärtigen Medienkultur begriffen wird, ${ }^{100}$ sondern in einem allgemeineren Verständnis, das sich bspw. bei Roger Caillois finden lässt. ${ }^{101}$ Diesem Fiktionalitätsverständnis folgend ist die Fiktion in einem narrativen Sinne für Spiele nach Juul unerheblich; hierfür führt er fünf Gründe in Form einer Ableitung an: 1. Regeln machen das Spiel zum Spiel. 2. Fiktion ist für Spiele nebensächlich. 3. Ein Spiel kann ohne Fiktion interessant sein. 4. Ein Spiel mit einer interessanten fiktionalen Welt kann ein schreckliches Spiel sein. 5. Deshalb ist Fiktion in Spielen unerheblich. (vgl. ebd., 13)

\footnotetext{
${ }^{99}$ Wolfgang Isers Entwurf einer Fiktionstheorie vertraut nicht auf eine dichotomische Einteilung zwischen Fiktion und Realem (wie die meisten anderen Fiktionstheorien), sondern schlägt stattdessen eine Trias aus dem Fiktiven, dem Imaginären und dem Realen vor. Vgl. ISER (2009).

${ }^{100}$ So betrachtet die Literaturwissenschaft vornehmlich epische Werke, wenn von fiktionalen Texten die Rede ist. Ähnlich sieht dies in der Filmwissenschaft aus, wo (fiktionaler) Film oft synonym mit Spielfilm verwendet wird. Diese Praxis der Medien- und Kulturwissenschaften speist sich letztlich aber aus der konkreten Medienpraxis an sich, die sich in Produktion, Distribution/Mediation wie Rezeption zunehmend auf narrative Medienobjekte beschränkt.

${ }^{101}$ Fiktionalität in diesem Sinne bezieht sich im Allgemeinen auf die Darstellung von etwas. Das Fiktive ist, nach Frank Zipfel, als ,frei erfunden“ zu beschreiben „und bezieht sich auf die Nicht-Wirklichkeit des Dargestellten.“ ZIPFEL (2001), 19; Herv.i.O. Im Unterschied dazu beruht das Fiktionale auf einer Fiktion, betrifft also nicht das Nicht-Wirklich-Sein an sich, sondern die Darstellung von Entitäten, die nicht wirklich sind. Vgl. ebd. So soll auch in dieser Arbeit Fiktionalität verstanden werden. Zum Fiktionalen in digitalen Spielen vgl. ATKINS (2003) sowie DEGLER (2009).
} 
Wichtig kann Fiktion (wiederum in dem allgemeineren Sinn) aber dann für Spiele sein, wenn sie bestimmte Aspekte des Spiels unterstützt und zwar im Besonderen die Regeln. So kann die Fiktion einerseits dazu beitragen, dass die Regeln besser verstanden werden und andererseits führen beide zu einer Abgrenzung des Spielers von der gewöhnlichen Welt. Insofern teilen sich fiktionaler Raum und Johan Huizingas Zauberkreis eine Eigenschaft, die dazu prädestiniert ist, den liminalen Zustand (nach Victor Turner) zu erlangen. (vgl. ebd., 163

f.) So kommt Juul dann auch zu dem Schluss.

That the rules of a game are real and formally defined does not mean that the player's experience is also formally defined. However, the rules help create the player's informal experience. Though the fictional worlds of games are optional, subjective, and not real, they play a key role in video games. The player navigates these two levels, playing video games in the half-real zone between the fiction and the rules. (ebd., 202)

\subsection{Markku Eskelinen}

Auf die Besonderheiten der Spielsituation geht auch Markku Eskelinen ein, um die Ludologie von der Literatur-, Theater- und Filmwissenschaft abzugrenzen. Um zu verhindern, dass Spiele lediglich auf narrative Deutungsmuster reduziert werden, etabliert er die ,gaming situation“. (ESKELINEN 2001) Diese sei von der narrativen oder der dramatischen Situation separat $\mathrm{zu}$ betrachten. Dabei zeichne ,the manipulation or the configuration of temporal, spatial, causal and functional relations and properties in different registers" die ,gaming situation' aus. (ebd.) In diesem Sinne ist Spielen eine konfigurative Praxis, die im Rahmen des Spiels stattfindet und dabei unter besonderen situativen Rahmenbedingungen abläuft. In der Spielsituation ist die Rolle des Spielers dementsprechend aktiver als im rezeptiven narrativen Modus, in dem die Interpretation schon die höchste Form der Rezipientenaktivität ist, welche aber hinter dem Partizipationsgrad während der Spielsituation zurückbleibt.

Wie Juul plädiert Eskelinen auch gegen Ende der Narratologen-Ludologen-Debatte noch energisch für eine konsequente ludologische Herangehensweise, hebt sich aber dadurch von Juul ab, dass Eskelinen die narratologische Seite offen attackiert. Narratologische, dramentheoretische und filmwissenschaftliche Ansätze seien schlichtweg nicht auf Spiele übertragbar und außerhalb der Wissenschaft habe auch niemand ein Problem mit dieser Unterscheidung. Diese Spitze pointiert er in seinem berühmten Satz: „if I throw a ball at you, I don't expect you to drop it and wait until it starts telling stories." (ESKELINEN 2004, 36) Dieser Satz ist viel zitiert und diskutiert worden; einerseits hat er etwas sehr Treffendes, da er einen Unterschied zwischen zwei Phänomenen markiert, der erfahrenen Spielern nicht schwer fällt, manchen Kulturwissenschaftlern aber offensichtlich schon. Andererseits ist ein Ball aber 
ein schlichtes Spielgerät, das nicht annähernd über die medialen Möglichkeiten eines digitalen Spiels verfügt.

Vor diesem Hintergrund kommt auch Eskelinen nicht umhin, trotz der Grenzziehung zwischen dynamischen Spielen und statischen Geschichten, einzuräumen, dass die Narratologie sehr wohl produktive Beiträge zur Erforschung von Spielen leisten könne, allerdings nur dann, und hier hat er Recht, wenn diese ihre Instrumente an den Gegenstand anpasst und nicht den Gegenstand an die Instrumente. (vgl. ebd., 38) In diesem Kontext macht er dann auch die Genette'schen Kategorien der Ordnung, Dauer und Frequenz für die Erforschung der Zeit in digitalen Spielen fruchtbar. (vgl. ebd., 39 ff.)

Vergleicht man die Positionen der vier Ludologen miteinander, so stellt man fest, dass es innerhalb dieser zwei Lager gibt - auf der einen Seite Espen Aarseth und Gonzalo Frasca sowie auf der anderen Seite Jesper Juul und Markku Eskelinen. Allen gemein ist das Anliegen, das Bewusstsein der Forschung für die Unterschiede zwischen Spielen und Geschichten zu schärfen und alle greifen hierzu mehr oder weniger auf narratologische Konzepte zurück (Frasca am wenigsten). Aarseth und Frasca nähern sich aber im Laufe der Zeit stärker der narratologischen Seite an als Juul und Eskelinen. Der Grund hierfür liegt meines Erachtens in der Tatsache begründet, dass Juul und Eskelinen entschiedener die Hybridität von Spiel und Geschichte, von Interaktivität und Narrativität verneinen, als Aarseth und Frasca dies tun. Ebenso verschieden sind die einzelnen Forschungsschwerpunkte der Beteiligten - Aarseth versucht die Literaturtheorie für die Erforschung digitaler Spiele zu modifizieren, Frasca betrachtet vornehmlich die simulativen Aspekte von Spielen, Juul die raumzeitlichen und Eskelinen die Spezifika der Spielsituation im Unterschied zu anderen Modi.

\subsubsection{Die narratologische Position}

\subsection{Janet Murray}

Janet Murrays Überlegungen stehen vor dem Hintergrund einer Veränderung des Erzählens bzw. der Ausbildung neuer Erzählformate in und durch elektronische Medien. Insgesamt, und das zeigt eigentlich, dass die Bezeichnung, Narratologen“ für dieses Lager nicht unproblematisch ist, wird bei Murray bereits deutlich, dass weniger narratologische Methoden bzw. deren Verwendung bezeichnend für diese Gruppe sind, sondern deren primäre Fokussierung auf digitale Spiele als (neue) erzählende Medien. Murray selbst folgt dramentheoretischen Arbeiten, die im Zusammenhang mit elektronischen Medien im 
Allgemeinen wie dem Personal Computer im Besonderen eng mit Brenda LAURELs Computers as Theatre (1993) verbunden sind.

Murray profiliert, mit Rückgriff auf das u.a. aus Star Trek: Raumschiff Voyager (19952001) bekannte Holodeck als Metapher, ihr Modell „of the computer as a kind of storytelling genie in the lamp“. (MURRAY 1997, 15) Der Computer selbst wird bei Murray zum erzählenden Subjekt, was ihrem Ansatz auch heute noch einen innovativen Status sichert, da die meisten Arbeiten die Verlagerung der Erzählinstanz vom Autoren zum Leser und nicht vom Menschen zur Maschine fokussieren. Da ein Holodeck technologisch (bisher) unmöglich ist, muss sich Murray bei ihren Beispielen auf Episoden aus der genannten TV-Serie konzentrieren, die fast ausschließlich klassische (kanonische) englische Literatur des 19. Jahrhunderts simulieren. Murrays Ansatz fokussiert hybride Medien, die Narration und Simulation zusammenführen, allerdings zieht Murray hier keine derart trennscharfen Linien wie Gonzalo Frasca. Überhaupt muss man sich fragen, warum Murray das Erzählen als dominanten Modus so stark macht, wenn doch an ihren Beispielen ersichtlich wird, dass es ihr v.a. um die simulativen Potenziale elektronischer Medien geht? ${ }^{102}$

Jene Vermengung hält auch weiter an, wenn sie auf andere literarische Beispiele wie Aldous HuXLEYs Schöne neue Welt (2006) eingeht. Diffizil ist, dass es sich hierbei nicht um Literatur handelt, die über simulative Modi wirkt, sondern lediglich davon erzählt. (vgl. MURRAY 1997, 18 f.) Darum geht es Murray aber eigentlich nicht, ihr ist daran gelegen, die neuen erzählerisch-simulativen Möglichkeiten von elektronischen Medien aufzuzeigen, die mediales Erleben derart verändern, dass die virtuelle Realität (VR) die eigentliche Realität dergestalt überlagert, dass sie nicht mehr voneinander zu trennen sind. Der Spieler taucht in einen ,halb-realen“ (Juul) Zauberkreis (Huizinga) ein, befindet sich in einem liminalen Zustand (Turner), in dem ihm Hyperrealität im Sinne Baudrillards entgegentritt, sodass sich beide Räume überlagern. Damit rücken die neuen Ausdrucksformen digitaler Medien, digitalen Erzählens in den Mittelpunkt, die nur digitale Technologien offerieren und die auch Ian Bogost (2010) interessieren. ${ }^{103}$

\footnotetext{
${ }^{102}$ In diesem Kontext erscheint es besonders problematisch, dass Murray Erzählen und Theater gleichsetzt, ohne dies dezidiert zu begründen.

${ }^{103}$ Am markantesten lässt sich diese Amalgamierung von Realität und virtueller Realität in der Wahrnehmung des Nutzers bei der Mediennutzung von Medienprodukten des gegenwärtigen digitalen Massenmarktes an den Bestrebungen der digitalen Spielindustrie deutlich machen, VR Hardware im Gaming zu etablieren. Man denke diesbezüglich an Oculus Rift und Vive. Allerdings fokussiert sich das Gamedesign hier eher auf actionlastige Spielgenres und bisher weniger auf neue erzählerische Möglichkeiten.
} 
Überspitzt könnte man sagen, dass Janet Murray eines der frühesten Hybridmodelle entwickelt hat, aber ohne dies dementsprechend zu vertreten, da sie sich fast ausschließlich auf die erzählerischen Komponenten beschränkt. Digitale Spiele sind für Murray deshalb so interessant, da sie zum Zeitpunkt ihrer Studie das Medium waren, das dem Holodeck am nächsten kam und auch sehr populär war. Sie interessiert dabei die „theatrical experience“ des Spiels. (MurRAY 1997, 53) Indem Murray die theatralische Aufführung und das Erzählen gleichsetzt, den dramatischen und den narrativen Modus nicht konsequent voneinander trennt, lässt sich auch die Vermischung von Narration und Simulation erklären. Ihre exemplarische Analyse des Arcade-Shooters Mad Dog McCree (1990) untermauert dies. (vgl. ebd., 54) Murray reflektiert nicht, dass die Immersion ins Spiel, die sie anhand ihrer eigenen Spielerfahrung einer Spielsession beschreibt, sich aus narrativem und simulativem Erleben ergibt. Das macht prinzipiell die Besonderheit elektronischer Medien aus, sie erzählen nicht nur, sondern sie vermitteln sich zudem simulativ und erlauben neue Formen der Partizipation durch den Rezipienten.

Die Ludologen, wenn sie auf Murray reagierten, stießen sich an ihrer Gleichsetzung von Narration und Simulation bzw. der Integration der Simulation in die Narration, für die Murray selbst keine einleuchtende Begründung liefert. Die wahrscheinlichste Ursache hierfür dürfte der von Aarseth kritisierte ,Narrativismus' sein, der andere kulturelle Wahrnehmungsmuster verdränge und somit alles auf narrative Verkettung reduziere. In diesem Kontext sind auch Frascas Arbeiten zum Verhältnis von Simulation und Narration zu sehen. (vgl. zu Simulation und Narration auch THON 2007)

Murray wehrte sich gegen die Vorwürfe der Ludologen und bezeichnete diese als zu abstrakt formalistisch. „This approach, which has been associated with the term »ludology«, which means the rather neutral enterprise of the study of games, functions as both an ideology and a methodology.“ (Murray 2005) Die Ideologie der Ludologie sei ein „game essentialism“, weshalb es angebracht sei, anstatt von Ludologie von ,computer game formalism“ zu sprechen. (ebd.) Janet Murray differenziert deutlich zwischen der ideologischen und methodologischen Seite, wobei zutage tritt, dass Murray nicht an den methodologischen Anliegen der Ludologen Anstoß nimmt, diese vielmehr anerkennt und hervorhebt, sondern sich gegen die ideologischen Einschläge richtet, die in besonderem Maße in den Angriffen gegen die ,Narratologen` zum Ausdruck kommen. 
Niemand würde, nach Murray, bestreiten, dass Spiele und Geschichten Gemeinsamkeiten haben würden, das Problem, gegen welches die Ludologen zu Felde ziehen, existiere gar nicht. (vgl. ebd.) Freilich ist das richtig, wenn man die Narratologen-Ludologen-Debatte (nur) als einen inszenierten Konflikt begreift, der v.a. den Ludologen nutzte und deshalb auch von diesen befeuert wurde, und ferner ist es korrekt, dass Murray selbst nie die Gemeinsamkeiten zwischen Spiel und Geschichte bestritten hat. Jedoch ist dies auch nicht der Hauptkritikpunkt der ludologischen Seite an ihren Ansichten gewesen, sondern vielmehr die Vereinnahmung von digitalen Spielen als erzählerische Medien. Dies mag an Murrays kaum vorhandener Differenzierung zwischen narrativer und dramatischer Situation, zwischen Narration und Simulation liegen. Janet Murray, und ohne dabei ihre zahlreichen Verdienste für die Digital Game Studies zu vergessen, wurde nicht allein Opfer einer ideologischen Hetzkampagne der Ludologen, die sie zum Feindbild stilisierten, sondern auch ihrer eigenen vagen Ausführungen.

\subsection{Marie-Laure Ryan und Henry Jenkins}

Marie-Laure Ryan wendet sich, und hierin steht sie Frasca sehr nahe, der auch eine Öffnung zur ,Gegenseite‘ hin fordert, gegen eine überbordende Ausdehnung von Narrativen und spricht von „narrative myths“. (RYAN 2001a) Einer dieser Mythen sei der „myth of the Holodeck“. (ebd.) Ryan bezieht sich dabei im Besonderen auf Murrays Vorstellung des Holodecks „as model of digital narrative“, welches technologisch noch nicht umsetzbar sei. ${ }^{104}$ (ebd.) Dies scheitere an der Inexistenz dementsprechender immersiver virtueller Realitäten und an Algorithmen, die noch nicht komplex genug gestaltet werden könnten, um den entsprechenden Anforderungen gerecht $\mathrm{zu}$ werden. ${ }^{105}$ Es bleibt aber fraglich, ob dieses Gegenargument so gerechtfertigt ist, da Murray in ihren Überlegungen das Holodeck lediglich als metaphorisches Modell für neue Formen des Erzählens in elektronischen Medien gebraucht. Ryan zielt mit ihrer Kritik wohl eher auf die unrealistischen Erwartungen ab, die derartige Metaphern wecken könnten; in diesem Sinne ist der Mythenbegriff ${ }^{106}$ wohl zu verstehen.

\footnotetext{
${ }^{104}$ Dennoch besitzt das Holodeck als Metapher heute noch eine nicht zu unterschätzende Wirkung und zwar auch auf die Medienwissenschaft. Jens SCHRÖTER (2018) arbeitet bspw. heraus, inwiefern das Holodeck als Leitbild geeignet ist, um virtuelle Räume zu erforschen.

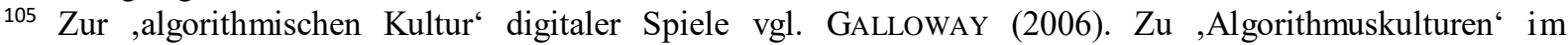
Allgemeinen sowie deren Verhältnis zum Sozialen vgl. SEYFERT/ROBERGE (2017).

${ }^{106}$ Vgl. dazu Kapitel 3.1.
} 
Dennoch erkennt Ryan die veränderte Rolle des Rezipienten an, die diesem auf dem Holodeck zukommt. Die Partizipation, Involviertheit und Immersion des Rezipienten werden signifikant aufgewertet, sodass sich diese Rezeptionssituation erheblich von derjenigen traditioneller narrativer Medien unterscheidet. ${ }^{107}$ (vgl. ebd.) Ryan hebt sich dadurch von Murray ab, dass sie die einzige wirkliche Narratologin unter den ,Narratologen“ ist und dementsprechend umfassend auf narratologische Instrumentarien zurückgreift. Interessanterweise gelangt sie aber nicht zu der Ansicht, dass alle digitalen Spiele narrativ seien, sondern nur manche. (vgl. ebd.)

Henry Jenkins ist von den ,Narratologen“ jener, der eher im filmischen Bereich der Medienwissenschaften zu verorten ist und allgemein den breitesten Gegenstandsbereich im Rahmen seiner Forschung bearbeitet. So befasste sich Jenkins nicht nur mit theoretischmethodischen oder ideologischen Aspekten von digitalen Spielen und deren Erforschung, sondern plädiert bspw. auch für den Einsatz von digitalen Spielen als Lehr- und Lerninstrument in Unterrichtssituationen. (vgl. JENKINS 2002) Ähnlich wie das Militär Simulationen eingesetzt habe, um Soldaten auf gefährliche Kampfeinsätze vorzubereiten, sei es auch denkbar, Lerner in anderen Kontexten mithilfe der simulativen Komponenten digitaler Spiele zu unterrichten. Jenseits der Ausnutzung von Aspekten der Gamification kommen Spiele aber auch als Test infrage und nicht nur als bloßes Lehrmittel.

Würde man eine vollständige Diskursanalyse der Narratologen-Ludologen-Debatte durchführen, so wäre es unabdingbar, auch Jenkins' Blogeinträge und Konferenzvorträge einer eingehenden Betrachtung zu unterziehen, da sich unter diesen interessante Diskussionen mit Ludologen wie Aarseth befinden. Da diese Arbeit aber keinen wissenschaftshistorischen Schwerpunkt hat und der Rahmen nicht über Gebühr strapaziert werden soll, unterbleibt dies im Folgenden. Stattdessen soll exemplarisch ein Aufsatz von Jenkins herangezogen werden, der auch heute noch rege zitiert wird. Henry Jenkins war einer der ersten, der prominent auf die Unterschiede aufmerksam machte, die sich beim Vergleich der narrativen Strukturen von digitalen Spielen und genuin narrativen Medien ergeben. Er stellt dazu heraus, dass Filmwissenschaftler zuweilen dazu neigen würden, die medialen Unterschiede zwischen Filmen und digitalen Spielen zu übersehen, es sei aber aus seiner Sicht unstrittig, dass nicht alle digitalen Spiele Geschichten erzählen. (vgl. dazu auch RYAN 2001a) Jenkins möchte narratologische und ludologische Ansätze zusammenführen, betrachtet digitale Spiele deshalb

\footnotetext{
${ }^{107}$ Zur Immersion des Spielers und deren Messbarkeit im Kontext von Erzählungen in digitalen Spielen vgl. QIN et al. (2007 sowie 2009).
} 
auch nicht als Geschichten, sondern als Räume der „narrative possibility“. (JENKINS 2004, 119) Allerdings betont Jenkins neben der notwendigen Modifikation narratologischer Instrumentarien zur Analyse digitaler Spiele auch Fehleinschätzungen der Ludologen. Diese verkennen die wahre Beziehung zwischen Spiel und Narration, da sie erstens oft ein zu enges Narrationsverständnis haben und sich zweitens zu sehr auf den Erzähler und zu wenig auf „the process of narrative comprehension“ konzentrieren. (ebd., 120 f.) Drittens suchen Ludologen immer nach einem Narrativ, das das ganze Spiel strukturiert und nicht nach partiellen narrativen Elementen. (vgl. dazu auch ENGELNS 2014)

Allerdings sei die Suche nach Strukturen und Narrativen deshalb verkehrt, weil diese für die narrative Ausgestaltung digitaler Spiele nicht entscheidend seien, sondern vielmehr die Räumlichkeit der Spielwelt. Deshalb brauche man auch „narrative architects“ und keine Erzähler als Designer. (JENKINS 2004, 121) Die Spielwelt ist wichtiger als das Narrativ, was aber bedeutet, dass digitale Spiele ,Raummaschinen' sind, die Räume ${ }^{108}$ schaffen. Dies funktioniert über ,räumliches Erzählen‘.

Environmental storytelling creates the preconditions for an immersive narrative experience in at least one of four ways: spatial stories can evoke pre-existing narrative associations; they can provide a staging ground where narrative events are enacted; they may embed narrative information within their mise-en-scene; or they provide resources for emergent narratives. (ebd., 123)

Damit nimmt Jenkins die voneinander abweichende Gestalt der Räume in verschiedenen Medien unter Berücksichtigung der räumlichen Spezifika digitaler Spiele in den Blick und verdeutlicht anschaulich die Auswirkungen auf das narrative (Raum-)Design bzw. die narrative Architektur digitaler Spiele.

Bereits dieser sehr kurze Streifzug durch einige wenige zentrale Texte der narratologischen Position innerhalb der Narratologen-Ludologen-Debatte zeigt, dass die ,Narratologen“ keineswegs derart herrisch Kolonialisierende waren, wie Espen Aarseth dies darstellt. Zugegebenermaßen hat es diese Okkupationsversuche gegeben (v.a. von filmwissenschaftlicher Seite) und freilich beruhen diese Okkupationsversuche auf einer Ignoranz gegenüber den medialen Spezifika digitaler Spiele, aber die wurden eben nicht von den Narratologen begangen. Diese wurden (und MURRAY (2005) macht dies deutlich) von

\footnotetext{
108 Jenkins differenziert zwischen „Evocative“ und „Enacting Spaces“. JenkINS (2004), 123 ff. Gunter Süß merkt an (und geht Jenkins hierdurch gewissermaßen voraus), dass das digitale Spiel die Continuity räumlich und nicht zeitlich herstellt wie der Film. Als Beispiel für die räumliche Organisation des digitalen Spiels dient Süß das ,scripted event ${ }^{\star}$, d.h. bestimmte Handlungen im digitalen Spiel werden nur dann ausgelöst, wenn der Spieler einen bestimmten Raum oder Ort betritt; mit der zeitlichen Achse hat dies nichts zu tun. Vgl. Süß (2003), 42.
} 
Espen Aarseth zu Antagonisten stilisiert, die sie nicht waren. Dafür waren sie von ihrer fachlichen Provenienz und ihren Anliegen her zu heterogen und auch der ludologischen Seite gegenüber weitaus offener, als diese das für die narratologische Position war. ${ }^{109}$

\subsection{Hybridtheorien in den Digital Game Studies}

Das folgende Kapitel widmet sich den Hybridtheorien in den Digital Game Studies. Den Ausgangspunkt bilden dabei Überlegungen dazu, aus welchen Perspektiven die Hybridisierung digitaler Spiele gegenwärtig in den Digital Game Studies verhandelt wird. (2.2.1) Mit der medialen und der attributiven Hybridisierung werden zwei verschiedene Hybridisierungsformen kurz skizziert, die die Hybridität interaktiv-narrativer digitaler Spiele ausmachen. Im Anschluss daran geht es um die Hybridtheorien in den Digital Game Studies an sich und wie sie sich gewissermaßen als Gegenbewegung zur Narratologen-LudologenDebatte entwickelt haben. (2.2.2) Im Unterschied zur narratologischen bzw. ludologischen Ausrichtung argumentieren diese Hybridtheorien weniger dichotomisch, sondern profilieren Modelle, die zwischen den Polen der Spannungsfelder hybrider digitaler Spiele ,vermitteln“ (und somit gewissermaßen auch zwischen den anderen beiden Ausrichtungen des Forschungsdiskurses einen Ausgleich anstreben). Ehe final einige ausgewählte Hybridtheorien aus den Digital Game Studies vorgestellt werden, soll einem gängigen Einwand von Hybriditätskritikern entgegnet werden, die eine Vereinbarkeit von Konzepten wie Interaktivität und Narrativität kategorial ablehnen. Dazu sollen vier Beispiele kurz angerissen werden, die illustrieren, welche Möglichkeiten zur künstlerischen Umsetzung der Hybridisierung von Interaktivität und Narrativität in digitalen Spielen bereits bestehen.

\subsubsection{Hybridität in digitalen Spielen - zwischen medialer und attributiver Hybridisierung}

Ein großes Verdienst der Narratologen-Ludologen-Debatte besteht freilich darin, dass sie zu einer regen Konjunktur von Studien führte, die digitale Spiele als Hybride betrachten oder gar eigene Modelle und Theorien entwickeln, um diese Hybride angemessen analysieren zu können. Hierdurch trat zwischen die ,narratologische' und die ,ludologische“ Ausrichtung der Forschung eine, vermittelnde' Position bzw. Schule. Digitale Spiele, so der weitreichende Konsens dieser vermittelnden Position innerhalb des Forschungsdiskurses, die auf narrative

\footnotetext{
${ }^{109}$ Ein weiteres Beispiel für die tendenzielle Offenheit der Narratologen gegenüber den medialen Besonderheiten digitaler Spiele findet man exemplarisch bei Celia PEARCE (2004). In europäischen Arbeiten zur NarratologenLudologen-Debatte wird sie oft nicht berücksichtigt, dennoch spielte sie aber im Kontext der US-amerikanischen Medienwissenschaft in der Debatte um narrative Anteile digitaler Spiele eine wichtige Rolle.
} 
Elemente zurückgreifen, weisen eine einzigartige Struktur auf, die durch die synergetischsymbiotische Beziehung aus zwei eigentlich verschiedenartigen Entitäten entsteht. Diesem Gedanken folgt auch das Kontinuumsmodell, wenn es Interaktivität und Narrativität als Pole des Kontinuums interaktiv-narrativer digitaler Spiele betrachtet. Synergieeffekte - in diesem Sinne - sind Kräfte, die nur durch das Zusammenwirken mehrerer Entitäten zustande kommen, die mehr sind als die Summe der einzelnen Teile.

Unter Hybridität wird im Folgenden das Zusammengehen bzw. das Zusammengegangensein von mehreren Entitäten begriffen, die sich - wenn auch nur temporär und partiell - in Form einer neuen Entität auflösen, die die Ausgangsentitäten zwar miteinschließt, sie aber nicht mehr in der vorher vorhandenen Reinform aufweist. Durch diese symbiotische Synergie entstehen Formen und Wirkungsweisen, die sich andernorts nicht nachweisen lassen, da sie für diese hybride Entität spezifisch sind. ${ }^{110}$ Wie sich diese Hybridität aber ausdrückt, darüber gibt es z.T. erheblich voneinander abweichende Ansichten in der Forschung. So kann man unter Hybridisierung erstens eine ,mediale Hybridisierung، verstehen, wie sie bspw. von Jay David Bolter und Richard Grusin mit deren populärer These der ,remediation“ vertreten wird. Diese Remedialisierung manifestiere sich in der „double logic of remediation“, worunter die Autoren die „contradictory imperatives for immediacy and hypermediacy“ verstehen. (BOLTER/Grusin 2000, 5; Herv.i.O.) Hiermit sind die ambivalenten Tendenzen von Medien gemeint, zwischen dem ,Sich-Unsichtbar-Machen“ und dem ,Seine-Eigene-Artifizialität-Herausstellen` zu oszillieren. Im Zuge der Immediacy tritt das Medium zurück, wohingegen es im Kontext der Hypermediacy fast schon plakativ hervortritt und seine Gemachtheit ausstellt. (vgl. dazu auch SCHWINGELER 2014) Obwohl diese kulturellen Medienpraktiken sehr verschieden sind, greifen sie beide auf die Integration eines Mediums in ein anderes zurück und dies ist letztlich das, was Bolter und Grusin unter ,remediation“ verstehen. „Again, we call the representation of one medium in another remediation, and we will argue that remediation is a defining characteristic of the new digital media.“111 (BOLTER/GRUSIN 2000, 45; Herv.i.O.)

Grundsätzlich kann man sagen, dass Studien, die sich primär medialen Hybridisierungen zuwenden und zwar unabhängig davon, ob sie der These von Bolter und Grusin oder einer

\footnotetext{
${ }^{110}$ Diese Auffassung der Hybridität ist von Michel Espagnes und Michael Werners Modell des ,Kulturtransfers“ beeinflusst. Vgl. ESPAGNE/WERNER (1988).

${ }^{111}$ Dies gilt im Besonderen - wie auch Britta Neitzel feststellt - für den Computer: „,[T]he computer is a hybrid medium that integrates various forms and other media and in so doing dissolves distinctions between them". NeITZEL (2011), 227.
} 
anderen folgen, dazu neigen, hybride Medien als ,hypermedial` ${ }^{`} \mathrm{zu}$ betrachten. Interaktivnarrative digitale Spiele, um ein konkretes Beispiel zu nehmen, remedialisieren diverse Medien, die entweder genuin narrativ sind oder die die Narration im digitalen Spiel unterstützen wie Roman, Film, Fernsehen, Musik, Fotografie oder Malerei, z.T. aber auch schon, wie das Theater, ${ }^{112}$ performative Angebote an den Spieler machen. Darüber hinaus integrieren interaktiv-narrative digitale Spiele aber auch das Phänomen des Spiels in seinen unzähligen Spielarten und -formen (je nach Genre variierend) in ihre mediale Struktur. Insofern vereinen interaktiv-narrative digitale Spiele im Kontext ihrer Hypermedialität nicht nur verschiedene bestehende Medien, sondern auch Kulturtechniken sowie beide Formen miteinander. ${ }^{113}$ Dementsprechend verweist die Hypermedialität bereits auf die zweite Hybridisierungsform.

Man kann unter Hybridisierung nämlich nicht nur die mediale Hybridisierung durch bspw. die Remedialisierung des Films, des Theaters oder der Literatur in einem hybriden Medium wie dem digitalen Spiel verstehen, sondern zweitens auch eine ,attributive Hybridisierung von Kulturformen oder -techniken wie z.B. Spiel und Erzählung in digitalen Spielen. Benjamin Beil bemerkt dazu: „Computerspiele werden [...] als Hybridkonstruktionen betrachtet, die sich aus ludischen und narrativen Elementen zusammensetzen und durch simulative Aspekte überformt werden“. (BEIL 2010, 53) Derartige Einschätzungen sind weitverbreitet in Arbeiten der Digital Game Studies, die sich auf attributive Hybridisierungen konzentrieren. Dies ist letztlich nicht verwunderlich, wenn man bedenkt, dass es zu den zentralen Fragestellungen der Narratologen-Ludologen-Debatte als dem historisch gesehen nachhaltigsten Forschungsdiskurs der Digital Game Studies gehörte, zu klären, ob digitale Spiele Erzählungen oder Spiele sind. Die vorliegende Arbeit möchte diese Einteilung so jedoch nicht vornehmen, ohne die Berechtigung einer solchen Differenzierung damit ablehnen zu wollen. Warum das Kontinuumsmodell dieser Einordnung nicht folgt, die mehr oder weniger fast alle attributiven Hybridtheorien bestimmt, die sich unter dem ,umbrella term“ ,Ludonarrativität ${ }^{` 114}$ zusammenfassen lassen, bedarf jedoch einer Erläuterung. Betrachtet man

\footnotetext{
112 Theater wird in einem solchen Fall als ein Medium im kulturwissenschaftlichen Sinne verstanden.

${ }^{113}$ Zum Spiel als Kulturtechnik vgl. LILGE/STEIN (2018).

${ }^{114}$ Ferner ist an dieser Form der Begriffsbildung nicht unproblematisch, dass sie eine hegemoniale Stellung der Narrativität gegenüber der Ludizität suggeriert, da ,ludo“ hier lediglich als Präfix fungiert, was es letztlich nicht wenig diffizil erscheinen lässt, diesen Terminus für ein Hybridmodell zu verwenden. Zudem, und bedingt durch ihre Funktion als umbrella term, ist die Ludonarrativität oder der ,Ludonarrativismus ‘ kein homogener Ansatz, sondern vereint eine Vielzahl an verschiedenen Theorien, Methoden und Modellen mit unterschiedlichen Zielsetzungen wie Marie-Laure Ryan 2006 in Avatars of Story betont: „I am not proposing a literary approach that isolates narrative scripts from the rules of a game and studies them for their instrinsic aesthetic merit [...],
} 
digitale Spiele als ludonarrative Erscheinungen, so heißt dies letztlich, dass man Ludizität und Narrativität als die beiden Pole (im Rahmen eines Kontinuumsmodells) setzen müsste. Dazu muss man sich jedoch die Frage stellen, ob beide kategorial auf ein- und derselben Ebene zu verorten sind. Meines Erachtens nach ist dies nicht bzw. nur sehr bedingt der Fall, sodass sie sich nur schwer (kategorial gesehen) miteinander vergleichen lassen. Ludizität, hier grundsätzlich verstanden als die Eigenschaft von Spielen (im Allgemeinen), ludisch zu sein und wirken zu können, ist das Kennzeichen aller Spiele. (vgl. dazu EnSSLIN 2014) Gebunden an ein Medium wie ein digitales Spiel drückt sich die Ludizität eines Spiels wie Cool Spot (1993) allerdings anders aus als die eines analogen Strategiespiels wie Schach. ${ }^{115}$ Verengt man den Fokus und wendet sich lediglich digitalen Spielen zu, so muss man selbst dort feststellen, dass sich Cool Spot als nicht-narrativer Platformer aber wiederum von einem sehr narrativen Adventure wie Myst (1993) in Bezug auf die Ludizität unterscheidet. Erkennt man dies und erkennt es an, dann bedeutet das aber folglich, dass die Narrativität eine (Teil)Eigenschaft der Ludizität digitaler Spiele sein kann, aber nicht muss. Demnach ist Ludizität eine obligatorische Eigenschaft digitaler Spiele, wohingegen (mediale) Narrativität bloß eine optionale ist, die sich lediglich bei hybriden digitalen Spielen nachweisen lässt. Somit kann man zu dem Schluss gelangen, dass die Narrativität in digitalen Spielen der Ludizität untergeordnet ist. Folglich kann sie im Rahmen eines Analysemodells nicht das (kategorial äquivalente) Gegenstück zur Ludizität bilden, da die Narrativität vielmehr einen Teil der Ludizität interaktiv-narrativer digitaler Spiele darstellt. Als ,Gegenpol‘ zur Narrativität bietet sich im Rahmen eines hybriden Theoriemodells eher die Interaktivität an, da sie gemeinsam mit der Narrativität die interaktiv-narrative Ludizität derartiger Spiele ausmacht. ${ }^{116}$ Studien wie bspw. diejenige Roman Sedas haben diese Polarität identifiziert, weshalb dieser auch folgerichtig zwischen ,interaktive[r] Geschichte“ und „narrative[r] Interaktion“ unterscheidet. (SEDA 2008, 13)

Diese Polsetzung hat weitreichende Folgen für hybride digitale Spiele, auf die ich kurz anhand zwei exemplarischer Relationen eingehen möchte, die sich einerseits auf die Welt und

but rather, a functional ludo-narrativism that studies how the fictional world, realm of make-believe, relates to the playfield, space of agency." RYAN (2006), 203. Nicht zuletzt jener weit gefasste Anspruch des Konzeptes könnte ursächlich dafür sein, dass es sich bis heute nicht wirklich in den Digital Game Studies durchsetzen konnte.

115 Durch die Bindung an ein digitales Medium verändern sich einerseits die kognitiv-sensorischen Rahmenbedingungen sowie sich andererseits (und durch die geänderten kognitiv-sensorischen Rahmenbedingungen hervorgerufen) Performativität, Immersion und Involviertheit anders darstellen. Vgl. dazu Kapitel 1.2.2.

${ }^{116} \mathrm{Zu}$ den Gründen für die Auswahl der beiden Pole des Kontinuumsmodells vgl. Kapitel 1. 
andererseits auf den Modus beziehen. Mit Blick auf die Welthaftigkeit interaktiv-narrativer digitaler Spiele lässt sich feststellen, dass diese sowohl virtuell ${ }^{117}$ als auch fiktional sind. Die Virtualität der Spielwelt drückt sich in der Performanz aus, die diese dem Rezipienten im Vergleich zur fiktionalen Diegese einräumt. ${ }^{118}$ Die fiktionale Diegese wiederum ,entlastet` den Spieler und schafft den sprichwörtlichen Raum für die Narration. Ein wesentlicher Unterschied zwischen beiden Welten besteht in der Einflussnahme des Spielers auf diese und darin, wie diese die Raumwahrnehmung des Spielers verändert. ${ }^{119}$ Eine Diegese ist strikt vom Autor bestimmt und bildet gemäß dessen Vorstellungen eine erzählte Welt, in die sich der Rezipient einfügen muss, ohne sie entscheidend beeinflussen zu können. Virtuelle Welten ${ }^{120}$ hingegen erfordern die (Inter-)Aktivität des Spielers, weisen ihm eine hohe Agency ${ }^{121}$ zu und machen ihn somit zum Fixpunkt dieser Welten. Anders gesagt: Fiktionale Welten weisen mit Blick auf die Realisierung eine stärkere Abhängigkeit von ihrem Schöpfer auf als virtuelle Welten, die intensiver durch die Rezipienten (mit-)bestimmt werden. Auf diese Weise wird in das interaktiv-narrative Spielweltdesign durch die Virtualität die Interaktivität und durch die Fiktionalität die mediale Narrativität in die Spielstruktur eingeschrieben. Durch diesen virtuell-fiktionalen Charakter der Spielwelt kommt das Spiel individuellen InteraktionNarrationen entgegen und steigert somit die Immersion des Spielers ins Spiel. (vgl. dazu RYAN 2001a)

117 Nach Söke Dinkla sind digitale Spiele materiell „von einer weitgehenden Dematerialisierung, Immaterialsierung und Virtualisierung geprägt“. DiNKLA (2009), 90. Das Virtuelle ist somit kein konkret Fassbares, aber dafür ein konkret, wenn auch medialisiert, Erlebbares. Marie Laure-Ryan verdeutlicht dies: „[V]irtual reality is an immersive, interactive experience generated by computer". RYAN (2001b), 12. Der Begriff virtuell kann nach Ryan in diesen Zusammenhängen auf dreierlei Weise gebraucht werden: Als ,an optical one (the virtual as illusion), a scholastic one (the virtual as potentiality), and an informal technological one (the virtual as the computer-mediated)“. Ebd., 13.

${ }^{118}$ Die gilt grundsätzlich für virtuelle Räume und zwar unabhängig davon, ob es sich hierbei um virtuelle Hardware von etablierten Unternehmen wie HTC, Lenovo oder Sony handelt, die in Verbindung mit Smart Devices und Spielkonsolen oder unabhängig von diesen virtuelle Räume partiell erfahrbar machen oder ob es um umfangreichere virtuelle Umgebungen geht, die ein vollständiges (auch körperliches) Eintauchen in diese virtuellen Erfahrungsräume ermöglichen. Eines der prominentesten und anschaulichsten Beispiele diesbezüglich dürfte der virtuelle Freizeitpark ,The Void' sein. Derartige virtuelle Umgebungen zielen darauf ab, Handlungsoptionen in virtuellen Räumen zu etablieren, die sich dem Teilnehmer in dessen realer Umgebung sonst entziehen. Das ansprechende an ,The Void“ ist, dass man - um ein Exempel zu nehmen - nicht die Geschichte eines Weltraumheldens wie in Alien (1979) erzählt bekommt, man kann dieser Held selbst werden; man sieht, was er sieht, man hört, was er hört, man fühlt, was er fühlt, man handelt, wie er handelt. Zu ,The Void' im Allgemeinen vgl. GRUBER (2015), zum Alien Level von ,The Void‘ vgl. das folgende Video von TECH INSIDER https://www.youtube.com/watch? $v=0 C X$ thgLTj3Q (30.06.2018), das anhand der Reaktionen des Teilnehmers auch einen ersten Eindruck der performativen Potenziale virtueller Räume vermittelt.

${ }^{119}$ Die Raumwahrnehmung betreffend bemerkt Mark J.P. Wolf, dass digitale Spiele die Wahrnehmung künstlicher Welten durch den Menschen verändert haben, da sie die Welt für den Menschen als Spieler direkt begeh- und erlebbar machen. Wolf meint damit, dass der Spieler eine aktivere Rolle einnimmt als in anderen künstlichen Welten wie der fiktionalen Welt traditioneller Erzählungen. Vgl. WOLF (2003c), 31.

${ }^{120}$ Vgl. zu virtuellen Spielwelten PIETSCHMANN (2009).

${ }^{121}$ Vgl. dazu Kapitel 2.3. 
Modal gesehen wirken digitale Spiele sowohl simulierend als auch repräsentierend (man denke hier erneut an die dichotomische Denkweise der Narratologen-Ludologen-Debatte). Durch die interaktive Struktur digitaler Spiele kann der Spieler in Bezug auf ein System handeln, das ein komplexeres System ${ }^{122}$ simpler abbildet, als dieses eigentlich ist, sich aber dennoch genauso verhält, wie das simulierte System. (vgl. FRASCA 2001, 3) Diese interaktivsimulativen Phasen weisen eine markante Differenz zu den narrativ-repräsentierenden Phasen auf, da die Simulation einen interaktiv handelnden Spieler verlangt, wohingegen es für die Repräsentation notwendig ist, dass der Rezipient im wahrsten Sinne des Wortes nur passiv Aufnehmender ist. Durch die Vereinigung von Simulation und Repräsentation können interaktiv-narrative digitale Spiele einerseits Erfahren und Erleben (virtuell) simulieren und andererseits ikonografisch oder deskriptiv darstellen. Interaktiv-narrative digitale Spiele führen somit zwei bedeutende Modi der menschlichen Wirklichkeitserfassung und Realitätskonstruktion in einem Medium zusammen. Sie simulieren Handeln in einer Spielwelt, repräsentieren aber zugleich ein Abbild der Realität, erzählen genauso, wie sie dem Spieler Raum zur spielerischen Interaktion lassen.

Zusammenfassend lässt sich mit Blick auf die Hybridität digitaler Spiele festhalten: Wenn in dieser Arbeit von der Hybridität digitaler Spiele die Rede ist, so ist damit vornehmlich die attributive Hybridisierung von Interaktivität und Narrativität gemeint. Die mediale Hybridisierung im Sinne einer Remedialisierung spielt demgegenüber eine eher periphere Rolle, auch wenn man sie nicht ausblenden darf, da viele attributive Hybridisierungen aus Interaktivität und Narrativität durch die Remedialisierungen älterer Medien in interaktivnarrativen digitalen Spielen evoziert werden.

\subsubsection{Von der Narratologen-Ludologen-Debatte zu den ,vermittelnden“ Hybridtheorien}

Begriffsverwendungen wie diejenige Roman SEDAs (2008) zeugen von einem weitreichenden Problembewusstsein für die medial-ästhetischen Spezifika digitaler Spiele,

\footnotetext{
${ }^{122}$ Wenn man das Spiel als System ernst nimmt und Niklas Luhmanns Systemtheorie hinzuzieht, dann wird klar, dass die (ludische) Interaktion jene Operation ist, die das Spiel als System erzeugt, erhält und somit von seiner Umwelt sowie von anderen Systemen abgrenzt. Luhmann führt dazu aus: „Eigentlich bietet sich nur die Kommunikation als Typ von Operation an [...]: Ein Sozialsystem entsteht, wenn sich Kommunikation aus Kommunikation entwickelt.“ LUHMANN (2009), 78. Bedenkt man nun, dass Interaktion im soziologischen Sinne immer Kommunikation impliziert bzw. Anschlusskommunikation, dann werden die heuristischen Vorteile der Systemtheorie Luhmanns in Bezug auf derlei Forschungsfragen evident. Vor diesem Hintergrund kann dann auch die Narration als eine Operation begriffen werden, die ein System erzeugt, welches aber kein Spiel ist, sondern das System Erzählung. Auf diese Weise scheinen präzisere Unterscheidungen zwischen Erzählung und Spiel möglich zu sein.
} 
gehen meines Erachtens aber terminologisch wie erkenntnistheoretisch nicht weit genug, da sie in gewisser Weise immer noch einem dichotomischen Denken verpflichtet bleiben, wie es in der Narratologen-Ludologen-Debatte auftrat und welches das Kontinuumsmodell bzw. die Interaktivität-Narrativität (als zentrale Eigenschaft interaktiv-narrativer digitaler Spiele im Rahmen der Attributebene des Kontinuumsmodells) auflösen möchte. Notwendig werden solche hybriden Theoriemodelle v.a. deshalb, da sich interaktive und narrative Spielphasen in digitalen Spielen nicht nur alternierend aneinanderreihen, sondern da sich Interaktivität und Narrativität strukturell derart stark verschränken, verschmelzen, dass sie nicht mehr voneinander zu trennen sind. Die Überwindung dichotomischer Denkmuster soll sich auch auf begrifflicher Ebene zeigen, indem Interaktivität und Narrativität in einem ,BindestrichTerminus‘ aufgelöst werden und die Vereinigung der Konzepte somit auch im Ausdruck selbst sichtbar wird. Zuvor gilt es jedoch, die kurze, aber ereignisreiche Geschichte der Hybridtheorien in den Digital Game Studies skizzenhaft anhand einiger ausgewählter Studien nachzuzeichnen, um einen Brückenschlag zwischen der Narratologen-Ludologen-Debatte und den aktuellen Diskursen um die Hybridität digitaler Spiele zu leisten. Deshalb bietet es sich an, zentrale Positionen, Ansichten und Argumente der Narratologen-Ludologen-Debatte wachzurufen, da viele der folgenden ausgewählten Hybridtheorien sich durch Abgrenzungsbewegungen zu besagter Debatte entwickelt haben.

Die Narratologen-Ludologen-Debatte verschaffte dem jungen Forschungsfeld nicht nur schnell Aufmerksamkeit, sondern identifizierte auch zwei Ebenen, die für die Untersuchung digitaler Spiele immer noch von zentraler Bedeutung sind. Auf der ontologischen Ebene geht es darum, was digitale Spiele sind: Sind es Spiele, Simulationen, Repräsentationen, Erzählungen oder Texte? Auf der rezeptiv-ästhetischen Ebene sind primär die Wirkungsweisen digitaler Spiele von Belang: Wirken digitale Spiele ludisch, narrativ, interaktiv, performativ, repräsentierend oder ergodisch? Irreführend wurden solche Fragestellung in der Regel nur dann, wenn die Ebenen miteinander vermengt wurden, wenn also z.B. danach gefragt wurde, ob digitale Spiele Spiele seien oder ob sie erzählen, also wenn die ontologische und rezeptiv-ästhetische Dimension ohne erkennbaren Grund miteinander verglichen wurden. Zuweilen können induktive Fehlschlüsse auch zu Komplikationen führen. In den meisten Fällen untersuchen Narratologen digitale Spiele mit erheblichen narrativen Anteilen, wohingegen Ludologen eher digitale Spiele in den Blick nehmen, die recht unstrittig keine oder kaum narrative Elemente beinhalten. Dieses methodische Vorgehen ist auch legitim, es ist aber epistemologisch diffizil, hieraus induktiv Aussagen abzuleiten, die 
Charakteristika digitaler Spiele im Allgemeinen beschreiben wollen. So kann kein Forscher, der so verfährt, generelle Aussagen über den Forschungsgegenstand treffen, was aber nicht selten dennoch getan wurde und z.T. noch immer wird.

Vor diesem Hintergrund entstanden hybride Theorien zur Erforschung digitaler Spiele, die, auch wenn sie nicht zwischen beiden Seiten vermitteln wollen, dazu neigen, relativistisch zu argumentieren. Anstatt der Opposition zwischen narrativ-repräsentativem und ludischsimulativem Modus der Narratologen-Ludologen-Debatte verhaftet zu bleiben, rückt eine Art ludonarrativer Modus in den Fokus des Interesses. Jene Hybridtheoriebildungen sahen sich lange (und sehen sich teilweise heute immer noch) Auffassungen gegenüber, die eine ontologische wie ästhetische Hybridität digitaler Spiele verneinen. ${ }^{123}$ So glaubt bspw. der Gamedesigner Ernest Adams, dass sich Narrativität und Interaktivität gegenseitig relativieren. Das bedeutet, umso stärker die eine Komponente ausgeprägt ist, umso schwächer ist die andere.

Interactivity is about freedom, power, self-expression. It's about entering a world and changing that world by your presence. In most games the world is static and dead until the player arrives; the player is the only thing that makes it move. Interactivity is almost the opposite of narrative; narrative flows under the direction of the author, while interactivity depends on the player for motive power. (ADAMS 1999; Herv.i.O.)

Da Interaktivität für Adams die signifikante Eigenschaft digitaler Spiele ist, die diese für den Spieler überhaupt erst interessant macht, dürfen sich v.a. die narrativen Elemente nicht störend $\mathrm{zu}$ den interaktiven verhalten. Dementsprechend bewertet er die Aufgaben von Spieldesignern. „It's not our job to tell stories. It's our job to build worlds in which players can live a story of their own creation“. (ebd.; Herv.i.O.) Neben Adams gibt es aber noch andere Stimmen, Jesper Juul und Markku Eskelinen könnte man hier abermals nennen, die einem Zusammenwirken von Interaktivität und Narrativität nicht skeptisch gegenüber stehen, sondern diese beiden für vollkommen unvereinbar halten. So urteilt z.B. Klaus Walter, dass „die beiden Größen Spiel und Erzählung [...] inkompatibel“ seien. (WALTER 2001, 47) Dass dies aber nur die ontologische und nicht die rezeptiv-ästhetische Dimension betrifft, wird im Folgenden deutlich. „Die Analyse dieser Kombination [gemeint sind Spiel und Erzählung] erfolgt unter der Prämisse, daß beide Kategorien oppositionelle Strukturen und Merkmale aufweisen, d.h. eigentlich nicht kombinierbar sind“. (ebd., 61) Um dies zu untermauern, bedient sich Walter in seiner Analyse eines sehr narrativen digitalen Spielgenres - des Adventures - und kommt zu folgendem Resultat: „Adventure Games sind nicht paradox. Sie

\footnotetext{
${ }^{123}$ Vgl. dazu exemplarisch BÜNGER (2005), 12.
} 
sind entweder SPIEL oder Erzählung, doch niemals beides zugleich.“ (ebd., 301; Herv.i.O.) Hieran wird ein Aspekt erkenntlich, der oft in der Argumentationsführung der Anhänger dieser Auffassung auftaucht und nicht unproblematisch ist - die Gleichsetzung von kategorialer Differenz und Simultanität. Die Vertreter dieser Ansicht gehen davon aus, dass, wenn (Teil-)Entitäten nur alternierend vorkommen bzw. nicht gleichzeitig wirken, dies zugleich bedeutet, dass sie derart verschieden sein müssen, sodass sie niemals Teile einer größeren, beide umfassenden hybriden Entität sein können. Jedoch sollte man bedenken, dass allein die Tatsache, dass zwei Entitäten sich gegenseitig abwechseln können, dies bereits heißt, dass zumindest eine gewisse gemeinsame Basis vorhanden sein muss. Denn, würden beide vollkommen verschieden sein, so wäre eine Alternation nicht möglich, da Alternieren auch impliziert, an das Andere anzuschließen, sich auf es zu beziehen und den erneuten Bezug zu ermöglichen. Somit muss aus einem alternierend-zeitversetzten Ablauf verschiedener Entitäten noch keine kategoriale Verschiedenartigkeit dieser folgen.

\subsubsection{Exkurs: Beispiele für Formen der Interaktivität-Narrativität in gegenwärtigen digitalen Spielen}

Um dies zu verdeutlichen, wird ein kurzer Exkurs eingeschaltet, der vier Formen der Interaktivität-Narrativität bzw. der interaktiv-narrativen Hybridität digitaler Spiele herausstellt, die in den letzten Jahren besonders hervorgetreten sind. Dabei fällt auf, dass diese Formen v.a. die Genres betreffen, die sehr narrativ sind; vornehmlich das ActionAdventure, das Role-Playing Game, den Interaktiven Film sowie all deren Hybridisierungen.

\subsection{Das Quick Time Event}

Im Rahmen interaktiv-narrativer digitaler Spiele ist seit der zweiten Hälfte der ersten Dekade der 2000er Jahre eine Spielmechanik populär geworden, die gewissermaßen ein künstlerisches Gegenargument zur These der Unvereinbarkeit von Interaktion und Narration in digitalen Spielen darstellt - das ,Quick Time Event' (QTE). ${ }^{124}$ Bemerkenswert ist am QTE, dass es die (spielerische) Interaktion und die (mediale) Narration simultan ablaufen lässt und somit eines der populärsten Argumente von Hybriditätskritikern selbstperformativ entkräftet. Die Narration geht beim QTE nur und/oder auf eine bestimmte Art und Weise weiter, wenn die Interaktion zwischen Spieler und System ein (vorher) genau definiertes Ergebnis erbracht hat. Somit finden Interaktion und Narration im Rahmen des QTE nicht nur simultan statt,

124 Eines der ersten digitalen Spiele, das diese Spielmechanik popularisierte, war Star Wars: The Force Unleashed (2008). Das Let's Play von ACERCODE bietet einen Eindruck der QTEs in Star Wars: The Force Unleashed anhand der PlayStation 2-Version https://www.youtube.com/watch?v=RXThm3uP0Gs (30.06.2018). 
sondern sind auch voneinander abhängig, da sie miteinander verschränkt sind. Diese Verschränkung kann dabei derart massiv ausgeprägt sein, dass es zu einer Verschmelzung beider kommt und sie nicht mehr exakt voneinander zu trennen sind. Dies trifft bspw. partiell auf Passagen der Quantic Dream-Spiele Heavy Rain und Beyond: Two Souls zu. ${ }^{125}$ Dass gerade diese Titel die Verschmelzung zwischen Interaktion und Narration in Bezug auf das QTE so weit vorangetrieben haben, liegt wohl nicht zuletzt auch daran, dass Quantic Dream die technologischen Möglichkeiten, die AAA-Hardcore-Spielen ${ }^{126}$ bedingt durch die Hardware zur Verfügung stehen, konsequent genutzt hat. Dass QTEs in dieser ausdifferenzierten Form aber keineswegs nur mithilfe sehr leistungsfähiger Hardware zu realisieren sind, untermauern die Telltale Games-Spiele zu den bekannten transmedialen Welten The Walking Dead (2012 ff.) und Game of Thrones (2014 f.), welche episodenhaft erschienen sind und die Erzählung der jeweiligen Welt ausgebaut haben. Diese (auf diversen Plattformen spielbaren) digitalen Spiele unterstreichen, dass QTEs nicht bloß eine Spielmechanik von Genres des klassischen Hardcore Gamings sind, sondern dass diese auch immer stärker in die Gaming und Media Culture im Gesamten einzieht. Trat das QTE seinen Siegeszug in interaktiv-narrativen digitalen Spielen zu Beginn noch in digitalen Spielen wie dem Action-Adventure Star Wars: The Force Unleashed an, so verlässt es mittlerweile mit Telltales Adventures zunehmend das etablierte Hardcore Gaming des neuen Jahrtausends. ${ }^{127}$ Zudem ist bemerkenswert, dass das QTE nicht bloß eine kulturell sehr limitierte Spielmechanik ist, sondern auch jenseits des, westlichen Kulturkreises' verbreitet ist. Beispielhaft könnte man hier das japanische Spiel Asura's Wrath (2012) nennen, das das Beat 'em up-Genre mittels QTE und Anime-Ästhetik zu einem Interaktiven Film oder, wenn man so will, einem ,Interaktiven Anime‘ verschmilzt.

\footnotetext{
125 Einen kurzen Zusammenschnitt von QTEs aus Heavy Rain bietet das folgende Let's Play von RAJMANGAMING HD, das anschaulich die beschriebenen Charakteristika von QTEs illustriert. Vgl. dazu https://www.youtube.com/watch?v=VY6h8FY1EC0 (30.06.2018).

${ }^{126}$ Mit der Abkürzung ,AAA' werden in der digitalen Spielindustrie jene digitalen Spiele bezeichnet, die mit den höchsten Budgets ausgestatt sind. Ein Analogon zu ,AAA‘ bildet in der Filmbranche der sog. ,Blockbuster`.

${ }^{127}$ Zählte das Adventure in den 1970er und 1980er Jahren, im Gegensatz zu den meisten Arcade Games, die für Hardcore wie Casual Gamer interessant waren, noch zum Core Gaming, so verlor es gegen Ende der ersten Hälfte der 1990er Jahre weitestgehend an Bedeutung und war eher ein randständiges Genre, für das kaum nennenswerte Titel auf dem Massenmarkt produziert wurden. $\mathrm{Ob}$ und inwiefern der gegenwärtige Bedeutungsaufschwung des Adventures mit dem QTE und ähnlichen Spielmechaniken sowie interaktivnarrativen Verschränkungen einhergeht, ist eine noch zu klärende Frage von Forschungsarbeiten mit einer spielhistorischen Perspektivierung.
} 


\subsection{Simultane Verschmelzung zwischen Interaktion und Narration in interaktiv- narrativen digitalen Spielen jenseits des Quick Time Events}

Die interaktiv-narrative Verschmelzung in digitalen Spielen geht, wenn auch bisher größtenteils nur im Bereich von Independent-Produktionen, ${ }^{128}$ jedoch über das QTE hinaus. So erzeugt ein Spiel wie The Stanley Parable (2013) eine Simultanität aus Interaktion und Narration, indem über klassische interaktive Spielphasen ein Voice-over gelegt wird, das zwischen Kommentator, Erzähler und Spielleiter oszilliert. Gerade die Abschnitte, in denen das Voice-over als Erzähler auftritt, führen zu interessanten Interaktionen zwischen der medialen Narration des Systems und den spielerischen Interaktionen. Da The Stanley Parable keinem Ludus im herkömmlichen Sinne verpflichtet ist, fordert es regelrecht zum paidianischen Spielen auf. Dieses führt wiederum dazu, dass Spieler in der Regel schnell entdecken, dass es zum Spielprinzip von The Stanley Parable gehört, die narrativen Einflussnahmen des Voice-over interaktiv zu unterlaufen, um bestimmte Endings zu erreichen. Dabei fungiert The Stanley Parable ähnlich wie das ebenso von Davey Wreden entwickelte The Beginner's Guide (2015) als ein ,Metaspiel', das fortwährend Konventionen gegenwärtiger populärer digitaler Spiele bzw. Spielgenres kritisch reflektiert und hinterfragt. The Stanley Parable wendet sich in diesem Zuge ebenso gegen die semantisch vollkommen entleerte Jagd des Spielers nach Achievements, auf die viele digitale Spiele im Kontext ihrer überbordenden Belohnungssysteme rekurrieren, wie gegen die (mediale) Narrativität digitaler Spiele selbst. Indem The Stanley Parable den ,Voice-over-Erzähler ${ }^{129}$ mit dem Spieler interagieren lässt, müssen beide im Zusammenspiel erkennen, dass sie zunehmend den Plot aus den Augen verlieren, was darin kulminiert, dass der Erzähler seine Rolle als solcher aufgibt, da er sie für absurd hält. ${ }^{130}$ Ludus und mediale Narration treten gleichermaßen zugunsten des Paidia-Spiels und der personalen Narration zurück. Wenn The Stanley Parable mit der medialen Voice-over-Narration eine Möglichkeit vorführt, wie Interaktion und Narration in digitalen Spielen simultan zusammengeführt werden können, so hebt es damit

\footnotetext{
${ }^{128}$ Martin Stobbe und Tristan Weigang haben sich jenem Bereich des Feldes digitaler Spiele kultursoziologisch genähert, der sich als ,Indie ‘ versteht bzw. so bezeichnet wird und hierdurch eine Abgrenzung gegenüber jenen Spielen vornimmt, die als ,bloße‘ Unterhaltung aufgefasst werden. Vgl. dazu StoBbe/Weigang (2016).

${ }^{129}$ Zum Voice-over-Erzählen in digitalen Spielen unter Berücksichtigung von The Stanley Parable vgl. FROSCHAUER (2016).

${ }^{130}$ Vgl. dazu das Let's Play von H0LLYLP https://www.youtube.com/watch?v=wD_q0i00_BI (30.06.2018). Dieses Let's Play illustriert, dass eine wesentliche Funktion von Let's Plays auch in deren unterhaltendem Charakter zu sehen ist. Vgl. dazu KIRSCHNER/EISEWICHT (2017). Die Unterhaltungsfunktion kann noch gesteigert werden, wenn es sich bei den Let's Playern um bekanntere Akteure mit inszenatorischem Talent wie z.B. Gronkh handelt. Zur Bedeutung von Gronkh und anderen populären deutschen Let's Playern vgl. KOHRING/SINDERMANN (2017).
} 
zugleich selbstperformativ die Grenzen der Narrativität interaktiv-narrativer digitaler Spiele hervor.

\subsection{Spielerische Interaktion und ,narrative Rezeptionsangebote' in interaktiv-narrativen digitalen Spielen}

The Stanley Parable plädiert dafür, dass Spieler sich ihre eigenen Geschichten in digitalen Spielen erschaffen, sie personal narrativieren. Allerdings ist es hierbei im Rahmen des Interaktionsdesigns unerlässlich, Angebote $\mathrm{zu}$ kreieren, die dem Spieler narrative Deutungsmöglichkeiten zur Verfügung stellen, anhand derer die personale Narration (gelenkt) erfolgen kann. Markus Engelns hat diesbezüglich den Begriff des ,narrativen Rezeptionsangebots“ ${ }^{131}$ geprägt, worunter er ein ,[s]pielseitiges Angebot, das die Rezeption des Spielers explizit oder implizit auf narrative Teilelemente von Computerspielen fokussiert", versteht. (ENGELNS 2014, 393) Dabei fallen besonders jene interaktiv-narrativen digitalen Spiele ins Auge, die diese narrativen Rezeptionsangebote mit bestimmten Spielweisen verbinden. Dies gilt u.a. für das Role-Playing Game Bloodborne (2015) von From Software, das (ähnlich wie Spiele der Souls-Reihe) ${ }^{132}$ narrative Elemente als narrative Rezeptionsangebote über die gesamte Spielwelt verstreut. Der Spieler muss diese auffinden, ordnen und miteinander kombinieren, um die versteckten (Hintergrund-)Geschichten zu entdecken. ${ }^{133}$ Narrative Rezeptionsangebote können in Bloodborne (wie oft auch in anderen interaktiv-narrativen digitalen Spielen) Texte, Dialoge, visuelle oder akustische Hinweise sein. Dabei fällt auf, dass Spiele wie Bloodborne eine Konvention unterlaufen, die für interaktiv-narrative digitale Spiele seit dem Aufkommen der ersten Text-Adventure in den 1970er und v.a. ab den 1980er Jahren charakteristisch war - die Verbindung zwischen Narrativ und Ludus. ${ }^{134}$ (vgl. dazu 1.2.1 sowie 2.4) Die Zusammenfügung aus ludischer und narrativer Struktur war lange eine Art ,Schablone‘, wenn es um das Design interaktivnarrativer digitaler Spiele ging. In den meisten Fällen ist sie dies auch immer noch (und berechtigterweise), allerdings lassen Spiele wie Bloodborne diese Option nicht mehr singulär

\footnotetext{
${ }^{131}$ Zum ,narrativen Verstehen' im Allgemeinen vgl. RATH (2011).

${ }^{132}$ Zur Souls-Reihe, die in Hardcore Gaming-Kreisen v.a. aufgrund ihres hohen Schwierigkeitsgrades, der sich merklich von demjenigen anderer digitaler Spiele des Role-Playing Games-Genres abhebt, geschätzt wird, gehören Demon's Souls (2009), Dark Souls (2011), Dark Souls 2 (2014) sowie Dark Souls III (2016).

133 Vgl. dazu das Video von VAATIVIDYA, das die Hintergrundgeschichte von Bloodborne beschreibt https://www.youtube.com/watch?v=yvB1Vo87uK0 (30.06.2018). Wie nebensächlich diese Hintergrundgeschichten zuweilen sein können, auch wenn die Lore innerhalb der Fankultur transmedialer Welten einen immer größeren Stellenwert einnimmt, illustriert das Video von LORE, das die Hintergrundgeschichte in einer Minute präsentiert und zugleich das Gesagte durch die Darstellung des ComicStils konterkariert https://www.youtube.com/watch?v=RmvYgwbTHOo (30.06.2018).

${ }^{134}$ Bezeichnenderweise heißt die Storyline, die Spieler und Voice-over-Erzähler in The Stanley Parable gemeinsam verlieren, „Adventure Line“.
} 
stehen. Stattdessen rücken die narrativen Potenziale des paidianischen Spielens zunehmend in den Vordergrund und zeigen somit neue Formen der simultanen Verschränkung zwischen Interaktion und Narration. Die klassische Verbindung aus Ludus und Narrativ vertraut weitestgehend auf die geläufige Alternation von interaktiven und narrativen Phasen, die zu der Annahme führte, dass beide Phänomene inkompatibel seien. Beim paidianischen Spielen in Bloodborne entschlüsselt der Spieler aber nicht nur (interagierend mit dem System) mehr und mehr die Spielregeln und Spielmechaniken, das Spiel selbst, sondern findet hierdurch zugleich immer mehr narrative Rezeptionsangebote, welche er dann wiederum zu Geschichten zusammenfügen kann, um bspw. herauszufinden, was ursächlich für die Seuche ist, von der die Spielwelt von Bloodborne befallen ist. Dementsprechend kann auch das Auffinden, Systematisieren, Kontextualisieren und Verbinden von narrativen Rezeptionsangeboten durch Interaktionen zwischen Spieler und System als eine beachtenswerte Form der Interaktivität-Narrativität digitaler Spiele gelten.

\subsection{Fließende Übergänge zwischen interaktiven und narrativen Phasen}

Ein Punkt, der bereits im Abschnitt zum QTE angeschnitten wurde, ist die Verschmelzung zwischen Interaktion und Narration, die sich auch in fließenden Übergängen zwischen diesen beiden Phasen ausdrückt. Im etablierten interaktiv-narrativen Grundmodell digitaler Spiele, das aus einer Alternation zwischen Interaktion und Narration besteht, existieren deutliche Marker, die unmissverständlich herausstellen, in welcher Phase sich der Spieler aktuell befindet. Damit ist aber nicht nur die schlichte Tatsache gemeint, dass ein Spieler entweder aktiver Gestalter des Geschehens (interaktive Phase) oder passiver Rezipient einer dargebotenen Darstellung (narrative Phase) ist, sondern dass die jeweilige Phase auch unabhängig von den Handlungsoptionen visuell gesondert markiert wird. Technologisch war es lange bspw. so, dass die In-Game-Grafik qualitativ schlechter war als diejenige der narrativen Cutscenes, weshalb der Spieler in der Regel aufgrund dieser technologischen Rahmensetzung stets wusste, in welcher Phase er sich befindet. ${ }^{135}$ Durch die technologische Entwicklung der Hardware in den letzten Jahren wurde es aber möglich, beide einander anzugleichen, um neue Hybridisierungen von Interaktivität und Narrativität in digitalen Spielen zu schaffen und mit anderen, bereits bestehenden, zu verbinden. Gute Beispiele, um diese Entwicklung zu illustrieren, sind die bereits genannten digitalen Spiele von Quantic

\footnotetext{
${ }^{135}$ Wie stark die grafische Darstellungsqualität zwischen narrativen Cutscenes und interaktiven Spielphasen in früheren digitalen Spielen voneinander abweichen konnte, verdeutlichen Spiele wie Syndicate (1993), wo die Darstellungsqualität der narrativen Exposition deutlich von der eigentlichen Spielgrafik abweicht. Vgl. dazu exemplarisch das Let's Play von GERUGON https://www.youtube.com/watch?v=bUED9SD3Zdo (30.06.2018).
} 
Dream oder Telltale Games. Diese Exempel unterstreichen aber auch zwei weitere Aspekte: Erstens, dass es eine große Affinität dieser Tendenz zu interaktiv-narrativen digitalen Spielen zu geben scheint, die massiv auf das QTE als Spielmechanik setzen. Zweitens, dass Bild- und Wiedergabequalität nicht allein ausschlaggebend sind, um die Übergänge zwischen interaktiven und narrativen Phasen fließend zu gestalten. Neben technologischen sind ästhetische Innovationen ebenso bedeutend. Nicht allein (wie fast immer in der Mediengeschichte) das Aufkommen von neuen technologischen Rahmenbedingungen verändert die Medienkultur, sondern es müssen Produzenten wie Rezipienten gegeben sein, die diese neuen Möglichkeiten erkennen und nutzen. Ein sehr anschauliches Beispiel hierfür ist der Anfang des Action-Adventures Uncharted 4 (2016). ${ }^{136}$ Hieran lässt sich nicht nur zeigen, dass sich In-Game- und Cutscene-Grafik qualitativ kaum mehr unterscheiden lassen, sondern dass diese neuen technologischen Möglichkeiten auch ästhetisch genutzt werden. So sind fast alle Marker, die betonen, in welcher Phase sich der Spieler befindet (bis auf den Untertitel in der narrativen und die Steuerungshinweise in der interaktiven Phase), vollkommen verschwunden. Am deutlichsten wird das Verschwimmen der Übergänge aber daran, dass der Schnitt fehlt. Stattdessen zoomt die ,Kamera“ lediglich in die Halbtotale heraus, sodass die filmsprachlichen Marker, die typisch für narrative Spielfilme sind, auf ein Minimum reduziert werden. ${ }^{137}$

Diese vier ausgewählten Beispiele, die keineswegs vollständig sind, illustrieren, dass die digitale Spielindustrie allmählich beginnt, die neuen ästhetischen Möglichkeiten, die sich aus der technologischen Entwicklung v.a. der Hardware ergeben haben, zu nutzen. Dass bisher eher weniger Beispiele vorliegen, die eindeutig die hybriden Aspekte interaktiv-narrativer digitaler Spiele herausstellen, liegt weniger daran, dass diese beiden nicht vereinbar sind, sondern daran, dass die Industrie wie auch die Spielerschaft mit Blick auf ästhetische Innovationen eher konservativ sind. So bemerkt u.a. der Journalist Christian Huberts vollkommen zu Recht: „[Künstlerisch-ästhetische] Experimente sind auf dem Vormarsch, aber der Kern der Computerspielkultur ist noch geprägt von beinhartem Konservatismus.“ (Huberts 2014, 37) Dennoch gilt es, besonders in Kapitel 2.5, diesen ,Experimenten“

\footnotetext{
${ }^{136}$ Vgl. exemplarisch dieses Let's Play von DeRSORBus https://www.youtube.com/watch?v=T7pq8HHAzXE (30.06.2018).

${ }^{137}$ Vergleicht man dies mit dem ersten Teil der Uncharted-Serie (2007), so werden nicht nur die grafischen Unterschiede deutlich, sondern auch der Schnitt trennt die narrative Exposition via Cutscene deutlich von der folgenden interaktiven Phase. Vgl. dazu exemplarisch dieses Let's Play von KeYsJore https://www.youtube.com/watch?v=ZeDVsNFivkU\&list=PLT5cw0HwssyrsLPmoPBCNwCDUE9j4XQjf (30.06.2018).
} 
nachzuspüren, um die strukturellen Verbindungen zwischen Interaktivität und Narrativität in interaktiv-narrativen digitalen Spielen herauszuarbeiten, die evident machen, dass es sich bei interaktiv-narrativen digitalen Spielen um neue hybride Erscheinungen handelt. Wie stark der Gegenstandsbereich das Denken der Forschung bestimmt, wird auch mit Blick auf die folgende Skizze der, vermittelnden` Hybridtheorien klar.

\subsubsection{Die ,vermittelnden' Hybridtheorien}

\subsection{Von den dichotomischen zu den Hybridansätzen}

Ähnlich wie Klaus Walter, der die kategoriale Vergleichbarkeit von Spiel und Erzählung, von Interaktion und Narration vehement negiert, argumentiert Uwe Mattusch. „Erzählen als sequentiell und linear organisierte Präsentation von Inhalten steht auf den ersten Blick gerade diametral der Interaktion, d.h. dem externen Eingriff in die Bildschirmhandlung durch den Spieler entgegen“. (MATTUSCH 2000, 322) Auch er betrachtet die passive Darbietung von erzählerischen Handlungssträngen und die aktive Handlungskompetenz des Spielers als einander widerstrebende Phänomene, die sich nur insofern verbinden lassen, als sie alternierend in digitalen Spielen vorkommen, d.h. es findet entweder narrative Vermittlung oder interaktive Aushandlung statt. „Wo erzählt wird, wird nicht gespielt, und wo gespielt wird, wird nicht erzählt, oder anders gesagt: Eine Erzählung erzählt von Handlungen, im Spiel jedoch werden Handlungen ausgeführt. Erst wenn das Spiel zu Ende ist, kann von ihm erzählt werden“. (Neitzel 2000, 9) Auch Britta Neitzel leitet aus dieser Sukzession bzw. der Alternation zwischen den interaktiven und den narrativen Phasen eine kategoriale Differenz ab, sodass Spiel und Erzählung „nie auf derselben Ebene“ liegen können. (ebd., 10)

Auffällig ist bei Studien dieser dichotomischen Argumentationsführung, dass die meisten dieser Arbeiten um die Jahrtausendwende publiziert wurden, d.h. in den späten 1990er Jahren entstanden sind, als die technologischen Möglichkeiten und deren ästhetische Umsetzung in Bezug auf interaktiv-narrative digitale Spiele noch deutlich andere waren, als dies ab den frühen 2000er Jahren der Fall ist. Somit liegt die Vermutung nahe, dass dieses ,Entwederoder-Denken', das auch für viele Arbeiten der Narratologen-Ludologen-Debatte kennzeichnend war, maßgeblich mit der Beschaffenheit der damals gewählten Untersuchungsgegenstände zusammenhängt. So bezogen sich fast alle dieser Arbeiten zum Verhältnis von Interaktivität und Narrativität in interaktiv-narrativen digitalen Spielen ausschließlich auf das Adventure-Genre. Dabei fungierten aber seltener innovative ,Point and Click'-Adventure wie Day of the Tentacle oder Meilensteine des Grafik-Adventures wie die 
Monkey Island-Reihe (1990 ff.) als Untersuchungsgegenstände, sondern vielmehr Klassiker des Text-Adventures wie die Zork-Reihe (1980-1997). Hierdurch ergibt sich jedoch das Problem, dass sich die Aussagen über das Verhältnis von Interaktivität und Narrativität, die in Arbeiten um die letzte Jahrtausendwende getätigt wurden, dementsprechend weniger auf Form und Wirkungsweise zu dieser Zeit aktueller interaktiv-narrativer digitaler Spiele bezogen, sondern auf Spiele aus den 1980er Jahren, ohne dass dies angemessen kontextualisiert wurde. Die fehlende Reflexion der Gegenstandsbedingtheit der eigenen Theorien milderte sich in den Folgejahren ab und führte schließlich zu der aktuellen Wissenschaftspraxis der Digital Game Studies, die größtenteils von Arbeiten dominiert wird, die digitale Spiele als hybride Medien betrachten, deshalb kaum mehr, historische“ digitale Spiele analysieren, in denen Formen von Interaktivität-Narrativität eher schwach ausgeprägt sind, sondern fast nur gegenwärtige digitale Spielproduktionen untersuchen. So kann man resümierend festhalten, dass sich Hybridtheorien in den Digital Game Studies von den dichotomisch vorgehenden Ansätzen dadurch abgrenzen, dass sie andere (aktuellere) Forschungsgegenstände wählen und nicht zuletzt auch hierdurch $\mathrm{zu}$ anderen Ergebnissen gelangen. Pointiert formuliert heißt dies, dass die dichotomischen Theoriebildungen tendenziell zu Perspektivierungen auf, historische“ Beispiele neigen, wohingegen die hybriden Theoriebildungen primär , aktuellere‘ Exempel verwenden.

\subsection{Hybridtheoriebildungen in den Digital Game Studies}

Julian Kücklich ist einer der ersten prominenten digitalen Spielforscher, der sich stärker der Hybridität digitaler Spiele zuwendet und dies auch in seinen Modellen abbildet. So urteilt er z.B. bereits verhaltener als andere Forscher wenige Jahre zuvor, wenn er Spannungen zwischen dem Narrativ und der Interaktivität in digitalen Spielen konstatiert. Kücklich betont nämlich, dass der Spieler z.B. aufgrund seiner selektiven Eingriffe entscheiden kann, wie der Plot verläuft. Das Problem besteht für ihn v.a. in dem Konflikt zwischen der Interaktivität zwischen Spieler und System und dem Fortschritt bzw. dem ggf. nicht vorhandenen Fortschritt des Narrativs. (vgl. KÜCKLICH 2007, 121) Kücklich nimmt dieses Spannungsverhältnis als produktiv wahr und deutet es nicht exkludierend, sondern inkludierend, weshalb er von der ,hybride nature“ digitaler Spiele spricht. (KÜCKLICH 2003) „Narrative and interaction must then be seen as mutually dependent, rather than concepts that cannot be reconciled.“ (ebd.) Konsequenterweise präsentiert Julian Kücklich deswegen auch eines der ersten Hybridmodelle zur Erforschung digitaler Spiele in Form einer Dreiecksmatrix. 
Die einzelnen Computerspielgenres zeichnen sich also einerseits durch verschiedene Grade der >Narrativität` aus - wodurch sich das einseitige Interesse literaturwissenschaftlicher Betrachtungsweisen am Genre der Abenteuerspiele erklärt -, andererseits lassen sich Computerspiele anhand der Kriterien 〉Offenheit` und >Interaktivität` unterscheiden. Innerhalb einer Dreiecksmatrix, die durch diese drei Kriterien definiert ist (siehe Figur 1), nehmen Abenteuerspiele (ADV), Strategiespiele (STR) und Actionspiele (ACT) also Extrempositionen ein, während Rollenspiele (ROL) und Simulationen (SIM) einen Kompromiss aus Narrativität und Offenheit bzw. Offenheit und Interaktivität darstellen. (KÜCKLICH 2001, 31)

Neben der Interaktivität als wechselseitiger Kommunikation zwischen Spieler und System ist die Offenheit ein zentrales Element von Spielen (nicht nur digitalen), da sie erst garantiert, dass das Ende des Spiels nicht von Beginn an feststeht, was dem Reiz eines Spiels diametral entgegenstehen würde. ${ }^{138}$

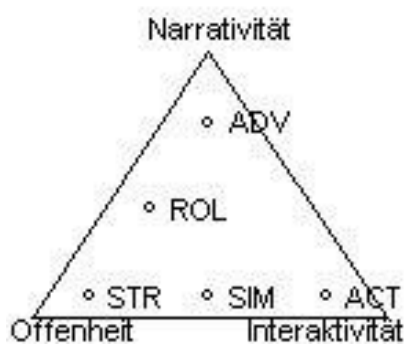

Abb. 1: Kücklichs Dreiecksmatrix ${ }^{139}$

Kücklichs Modell erlaubt somit recht präzise Einordnungen von digitalen Spielen nach Genre $^{140}$ in Abhängigkeit von den genreprägenden Faktoren. ${ }^{141} \mathrm{Im}$ Unterschied zu vielen anderen Modellen gestattet es sogar eine Einordnung von Hybridgenres, die im Zuge einer zunehmenden Hybridisierung populärer digitaler Spielgenres in der digitalen Spielkultur

\footnotetext{
${ }^{138}$ Zuweilen wird diese Offenheit von Spielen von Skeptikern aber als Grund dafür angesehen, dass Spiele und Erzählungen unvereinbar seien, da dies die Geschlossenheit der Geschichte im Sinne Aristoteles' unterminiere.

${ }^{139}$ KüCKLICH (2001), 31.

${ }^{140}$ Ohnehin ist die Bestimmung dessen, was ein Genre zum Genre macht in den Kulturwissenschaften seit jeher schwierig, bei digitalen Spielen kommt aber noch eine Besonderheit hinzu, die im Kontext traditioneller Medien bisher kaum eine Rolle gespielt hat. Neben den ikonografischen oder thematischen Gesichtspunkten, die bspw. einen Westernfilm als solchen klassifizieren, sind im digitalen Spiel auch bestimmte Interaktionsmuster bzw. typen von zentraler Wichtigkeit. Vgl. Wolf (2003d), 114 f. sowie Arsenault (2009). Somit tritt neben die Gegenständlichkeit als Definitionskriterium auch noch die Interaktivität. Vgl. APPERLEY (2006), 7. Demnach plädiert Thomas Apperley für „genres of interactivity“. Ebd., 21. Was ein Shooter demzufolge zum Shooter macht, ist, dass das vorherrschende Interaktionsmuster ,Schießen' heißt und was ein digitales Rennspiel zum Rennspiel macht, ist die Tatsache, dass der Spieler im virtuellen Raum Rennen fährt etc. Einen sehr umfassenden Literaturbericht zum Genre in digitalen Spielen, der darüber hinaus Systematisierungsversuche vornimmt, findet man bei STERBENZ (2011). Eine überaus gelungene Kurzdarstellung zur Genretheorie in den Digital Game Studies stellt Benjamin BeIL (2015) dar. Zu digitalen Spielgenres unter transmedialer Perspektive vgl. RAUSCHER (2012).

${ }_{141} \mathrm{Im}$ Unterschied zu den meisten dichotomischen Ansätzen beziehen die hybriden oft mehr und verschiedenartige Genres digitaler Spiele in ihre Untersuchungen mit ein, sodass ihre Modelle potenziell weitreichende Erkenntnisse versprechen.
} 
immer wichtiger wird und somit auch in Theoriemodelle integrierbar sein muss. ${ }^{142}$ Kücklich erweitert sein Modell um die MURRAY’schen (1997) Kategorien „,immersion“, ,,agency“ und „rapture“ und gelangt anschließend zu der folgenden Erweiterung seines Modells:

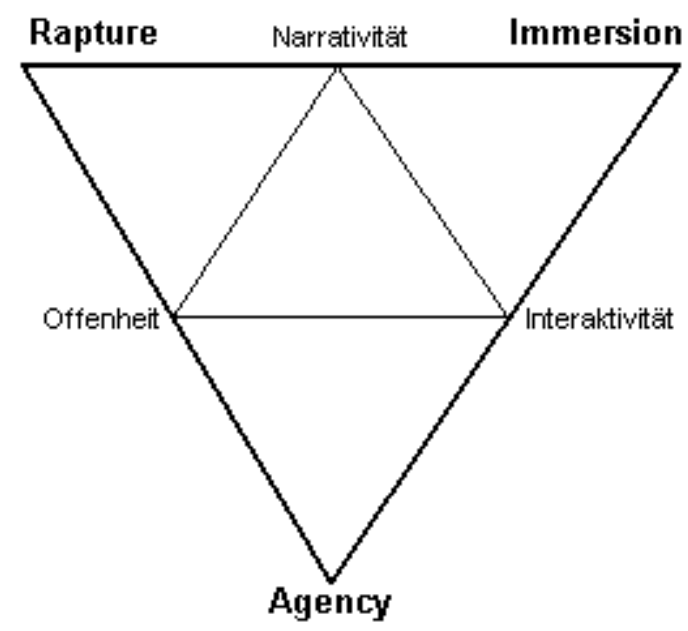

Abb. 2: Modifizierte Dreiecksmatrix ${ }^{143}$

So stellt sich rapture als Ergebnis aus Narrativität und Offenheit dar, während immersion aus der Verbindung von Interaktivität und Narrativität resultiert. Agency ergibt sich dann aus der Verbindung von Interaktivität und Offenheit. Einander gegenüber stehen sich Narrativität und agency, da eine weitgehende Einflussnahme des Spielers einen geregelten Handlungsablauf erschwert, wenn nicht sogar verunmöglicht; Immersion und Offenheit, da größtmögliche Handlungsfreiheit meist zu einer abstrahierenden und damit anti-immersiven Spielweise führt; sowie rapture und Interaktivität, da eine hohe Interaktionsfrequenz »the entranced attachment to objects in that reality« entgegenwirkt. Die Beziehung von Narrativität zu Offenheit und Interaktivität stellt sich also als Funktion dar, aus der >Ergriffenheit< bzw. >Immersion` resultiert. (KÜCKLICH 2001, 34)

Auch wenn Kücklichs Modell bzw. dessen Anwendung zu einigen sehr beeindruckenden Erkenntnissen führt, kann es dennoch nicht darüber hinwegtäuschen, dass die vorgegebene Statik bisweilen nicht der medialen Realität digitaler Spiele als dynamischen Systemen entspricht. So kann der Spieler bspw. von den Interaktionen zwischen sich und dem System ergriffen sein, obwohl sie sich in Kücklichs Modell diametral entgegenstehen und einander, wie er behauptet, ,entgegenwirken‘. Was Kücklich weniger zu bedenken scheint (und dies gilt auch für die Immersion), ist, dass Ergriffenheit und Immersion des Rezipienten nicht nur

\footnotetext{
${ }^{142}$ Randi Gunzenhäuser merkt zur Genrehybridität in digitalen Spielen an: „Zudem sind Computerspiele explizit hybride und damit schwer einzugrenzende Medien. [...] Hinzu kommt, dass kaum ein älteres Genre - zum Beispiel adventures oder Rollenspiele - mehr in einer »reinen «, [»] ursprünglichen « Form existiert. Vielmehr haben sich die frühen Genres schnell vermischt und sich zum Beispiel als Action-Rollenspiel (wie Diablo) oder Action-adventure (wie Blade Runner. The Computer Game) auf dem Markt etabliert“. GUNZENHÄUSER (2003), 111; Herv.i.O. Vgl. hierzu auch BeIL (2015), 46 ff., der mit der ,Genrekombination', der ,Genreverschmelzung“ und der ,Genreakkumulation` drei gegenwärtige Strategien der Genrehybridisierung digitaler Spiele herausarbeitet.

${ }^{143}$ KÜCKLICH (2001), 34.
} 
durch darstellende Medien, sondern auch durch Spielen (in einem sehr allgemeinen Sinn) evoziert werden können. Man merkt dem Modell bei all seinen Verdiensten an, dass es aus Sicht der Literaturwissenschaften konstruiert wurde und deshalb in eher geringerem Maße die ludischen Aspekte hybrider digitaler Spiele berücksichtigt.

Jene Problematik kann auch mit Blick auf andere Modelle festgestellt werden, die versuchen, digitale Spiele per Genreeinordnung graduell zu verorten wie Mela Kochers ,ludoliterarischer Typenkreis/Zirkel ${ }^{‘} .{ }^{144}$ Kocher versteht ihr Modell bewusst als Hybride, der versucht, narratologische und ludologische Ansätze miteinander zu verbinden. (vgl. KocHER 2007, 108) Der Zirkel wird aus den drei Achsen Perspektive, narrativer Modus und Interaktivität gebildet, die sich zwischen den Polen intern/extern (Perspektive), mimetisch/diegetisch (Modus) sowie dynamisch/statisch (Interaktivität) erstrecken. (vgl. ebd., 109) Das Modell ${ }^{145}$ funktioniert in der Analyse dabei folgendermaßen: Man kann ein digitales Spiel auf der Kreislinie des ludoliterarischen Zirkels in der Nähe eines Pols verorten. Tut man dies, dann kann man das Spiel im Kontext der beiden angrenzenden Parameter/Pole untersuchen. Ist ein Spiel z.B. dynamisch, dann kann man es im Kontext einer internen Perspektive und eines mimetischen Modus betrachten usw. Genau wie Kücklich konzentriert sich Kocher dabei primär auf die Einordnung von digitalen Spielgenres in das Modell. (vgl. ebd., 111-116) Diffizil an Kochers Modell ist, dass die Achsen ,Perspektive“ und ,Modus“ mit den vorgenommen Polsetzungen wenig Aussagewert für hybride digitale Spiele besitzen. So verdeutlicht bspw. Benjamin Beils exzellente Dissertation zur Perspektive in digitalen Spielen und Filmen aus formästhetischer Sicht und mit besonderer Betrachtung der Subjektivität und der Subjektivierungsstrategien, wie komplex Perspektive und Point of View in digitalen Spielen sind, sodass eine Unterscheidung zwischen interner und externer Perspektive wenig Mehrwert verspricht. (vgl. BEIL 2010) In Bezug auf den Modus bleibt festzustellen, dass es nicht unverfänglich erscheint, hybride digitale Spiele nur dadurch modal bestimmen zu wollen, ob sie diegetisch oder mimetisch wirken. ${ }^{146}$ Dies ignoriert einerseits andere Modi wie den simulativen oder den ludischen (vgl. dazu EsKELINEN 2001) und andererseits führt das Modell hierbei zu paradoxen Einordnungen. So ordnet Kocher das Role Playing Game (RPG) bspw. nicht dem mimetischen Pol zu, obwohl gerade dieses Genre durch seine mannigfaltigen Möglichkeiten der Manipulation des Player Characters wie kaum

\footnotetext{
${ }^{144}$ Dieser erinnert von seinem Aufbau her stark an F. K. Stanzels Typenkreis. Vgl. dazu StanzEL (1987); zur Kritik am Typenkreis vgl. MARTINEZ/SCHEFFEL (2005), 89 ff.

${ }^{145}$ Für Schaubilder des Modells vgl. KocHER (2007), 108 sowie 111.

${ }^{146}$ Diese Problematik intensiviert sich in transmedialen Kontexten, in denen immer häufiger Fragen nach der ,Mulitmodalität‘ laut werden. Vgl. dazu GiBBOns (2012).
} 
ein anderes durch nachahmende Charakteristika bestimmt wird. (vgl. KocHER 2007, 111; vgl. zur ,Mimicry‘ CAILlois 1960, 19)

Gesamt betrachtet ergeben sich für Kochers Modell ähnliche Schwierigkeiten, die auch schon Kücklichs Modell aufweist, die u.U. dazu geführt haben mögen, dass beide Modelle bis heute kaum Anwendung in den Digital Game Studies gefunden haben. Beide, trotz (und das sei nochmals herausgestrichen) der analytischen Möglichkeiten, die sie offerieren, sind zu statisch $^{147}$ und bleiben bei der Genreeinordnung digitaler Spielgenres stehen, was ihren Aussagewert für Studien limitiert, die sich z.B. innerhalb eines digitalen Spielgenres bewegen oder gar ein ,close playing، ${ }^{148}$ eines bestimmten Abschnittes eines einzigen digitalen Spiels anstreben. Dies mag ursächlich dafür sein, dass Hybridtheorien der Digital Game Studies in der Folgezeit eher dazu neigen, das Verhältnis zwischen den hybriden Kräften digitaler Spiele $\mathrm{zu}$ beschreiben, als diese fixieren zu wollen. So fokussiert Martin Sallge bspw. auch das Spannungsverhältnis zwischen Interaktivität und Narrativität, steuert dabei aber nicht auf eine konkrete Modellbildung zu, sondern untersucht mediensoziologisch die „scheinbare“ Paradoxie zwischen Interaktivität und Narrativität. (SALLGE 2010, 79) Er wertet eine OnlineUmfrage auf der Basis von 517 Befragten aus, die ergibt, dass Interaktion und Narration die beiden wichtigsten Komponenten (interaktiv-narrativer) digitaler Spiele für die Spieler sind, wobei die Interaktion von den Spielern als zentraler erachtet wird. (vgl. ebd., 86) In Anbetracht dieser Ergebnisse resümiert Sallge: „Zusammenfassend lassen sich alle diejenigen Methoden als zukunftsweisend deklarieren, die geschickt das Storytelling [Narration] in das Gameplay [Interaktion] inkorporieren, ohne die Rechte des Spielers und den Spielfluss mehr als nötig einzuschränken oder zu unterbrechen.“ (ebd., 92) Ferner beschreibt Sallge auch die Synergien hybrider digitaler Spiele:

Die Wirkung der Story wird verstärkt, weil der Spieler in den gameplaybetonten Abschnitten des Spiels ein Gefühl der Immersion und der Bindung an die Charaktere erfährt, die in klassischen Geschichten nicht erreicht werden kann. Und die Wirkung des Spiels wird verstärkt, weil das Lösen von Rätseln und das Überkommen von Hindernissen vor einem narrativen Hintergrund nicht (mehr) nur Selbstzweck ist, sondern motiviert und rhythmisiert wird. (ebd., 96)

\footnotetext{
${ }^{147}$ Die Statik der beiden Modelle resultiert dabei nicht aus den graduellen Verortungsmöglichkeiten zwischen den Polen. Im Gegenteil - diese sind Garanten für die Variabilität beider Modelle. Was ihre Dynamik reduziert, sind die Beziehungen bzw. Kontexte, in die sie gesetzt werden, ergo die anderen Achsen und Konzepte, mit denen sie in Beziehung stehen. Hierdurch werden die Kombinationsmöglichkeiten von einzelnen Größen der Modelle, mathematisch gesehen, sogleich wieder verringert. Somit schließen diese Modelle Kombinationen aus, die für viele digitalen Spiele bzw. deren Analyse, v.a. unter dem Aspekt der Genrehybridisierung, von zentraler Bedeutung sind.

${ }^{148}$ Zum ,close playing 'vgl. u.a. CHANG (2008).
} 
So motiviert, orientiert, instruiert und rhythmisiert die Story das Gameplay und so verstärkt das Spiel die Suspense, die Immersion und die Moralisierung der Narration. Das Gesamtprodukt Computerspiel kann auf diese Weise mehr sein als eine fesselnde Geschichte und eine spannende interaktive Erfahrung, mehr als die Summe seiner Teile. (ebd., 102)

Umso erstaunlicher ist es aber, dass Sallges Aufsatz dennoch den Titel Interaktive Narration im Computerspiel trägt, ${ }^{149}$ somit also nicht jenen hybrid-theoretischen Anspruch, den er richtigerweise mediensoziologisch herausarbeitet, auch terminologisch einlöst, sondern eine Vorrangstellung der Narration über die Interaktion suggeriert. Diesen Schritt geht Roman Seda, wenn er zwischen „interaktiver Geschichte[]“ und „narrativer Interaktion[]“ differenziert und sich hierdurch bewusst gegen jene terminologische Schieflage wendet, die Begriffe wie ,Interactive Storytelling، ${ }^{150}$ bedeuten. (SEDA 2008, 13) Am Beispiel des Adventures, welches er als „komplexes Hybridphänomen unterschiedlicher Medien, Formen und Strukturen" versteht, (ebd., 16) untersucht er die Hybridisierung von Interaktion und Narration, von Spiel und Erzählung. Seine Ausführungen sind für hybride Theoriebildungen

${ }^{149}$ Im Zusammenhang interaktiver Narrationen bzw. interaktiven digitalen Erzählens in digitalen Spielen sind die Studien von PERLIN (2005) sowie NITSCHE (2006) sehr lesenswert. Das ,interactive narrative' gilt vielerorts immer noch als ,[h]oly Grail of digital entertainment“. RYAN (2014a), 292. Die Möglichkeiten, ,interaktive Narrative' umzusetzen, sind zahlreich. So rechnet Marie-Laure Ryan hierzu bspw. den Graphen, das Netzwerk, den Baum oder das Labyrinth. Vgl. RYAn (2001b), 246 ff. Ein Problem digitaler Spiele, die versuchen, ein ,interactive narrative' zu sein, besteht aber laut Ryan darin, dass die Basisaktionen von digitalen Spielen (laufen, werfen, kämpfen etc.) zu oberflächlich für eine komplexe Geschichte seien und deshalb mit komplexeren Tätigkeiten wie intrigieren, betrügen, versprechen oder rächen kombiniert werden müssen, um die Geschichte anzureichern. Problematisch ist in diesem Zusammenhang auch das Fehlen von ansprechenden Dialogen, die bisher technologisch nicht möglich waren, sodass diese Spiele oft aus einer bloßen Alternation ludischer und narrativer Phasen bestehen. Vgl. RYAN (2014a), 295. Diese Einsicht teilt Jesse Schell, wenn er konstatiert, dass „Computerspiel-Verben“ wie „rennen, schießen, springen, klettern, werfen und schlagen“ im Unterschied zu „Film-Verben“ wie „reden, verhandeln, argumentieren, flehen und klagen“ nicht ausreichend seien, um ansprechende Geschichten zu erzählen. ScHELL (2015), 358. Sowohl Ryan als auch Schell machen damit eine Dichotomie zwischen physischen und psychischen Aktionen auf, wobei letztere erstens notwendig seien, um komplexe Geschichten zu erzählen und zweitens (noch) nicht zur ,Sprache' digitaler Spiele gehören. Wie Ryan glaubt Schell, dass in der technologischen Entwicklung zu einer immer größeren Realitätstreue der interaktiven Kommunikationsfähigkeit der Avatare eine fantastische Möglichkeit liege, zukünftig bessere Geschichten in digitalen Spielen zu erzählen als bisher. Vgl. ebd., 363 ff. Dementsprechend ist er davon überzeugt, dass es einen „Shakespeare des Computerspiels“ geben werde, welcher aber „weniger ein Geschichtenerzähler [...] und mehr ein Schöpfer von Figuren“ sein werde. Ebd., 371. Einen sehr empfehlenswerten Überblick zum gegenwärtigen Stand der Forschung zu interaktiven digitalen Erzählungen bieten KoENITZ et al. (2015).

${ }_{150}$ Alternativ werden in solchen Kontexten auch Begriffe wie Interactive Fiction, Hyperfiction, interaktive Narration oder digitales Erzählen verwendet. Dabei fokussieren sich alle Konzepte prinzipiell auf dieselben Untersuchungsgegenstände, vornehmlich digitale Spiele, Hypertexte oder MUDs und betonen Merkmale derartig ,neuer` Erzählungen wie die Non-Linearität. Am nachhaltigsten wurde der Begriff der Hyperfiktion im deutschsprachigen Raum von Beat Suter geprägt. Eine zentrale Leistung seiner Arbeit besteht für die Digital Game Studies bis heute darin, dass er zwischen Hyperfiktionen und interaktiven Fiktionen unterscheidet und somit die Unterschiede zwischen Hypertexten und digitalen Spielen markiert. „Auf der einen Seite haben wir Hypertext-Geschichten oder Hyperfiktionen mit starker Neigung zum Narrativen; bei Ihnen ist es der Leserin möglich, sich mit einfachen Mitteln durch die fragmentarisch angeordneten Erzählsegmente zu navigieren, indem sie entweder bestimmten Figuren oder unterschiedlichen thematischen Anknüpfungen mittels der vorhandenen Hyperlinks folgt. Auf der andern Seite haben wir Simulationen und interaktive Spiele, die der Leserin - hier eher Rezipientin oder Spielerin - erlauben, eine immersive Perspektive einzunehmen und Situationen mehrmals zu wiederholen, bzw. durchzuspielen und den Text jeweils nach alternativen Möglichkeiten abzusuchen."SUTER (2000), 45. 
in den Digital Game Studies im Allgemeinen sehr interessant, allerdings, auch wenn er hier weitergeht als z.B. Martin Sallge, folgt auch aus Sedas überaus überzeugenden Ausführungen zur Hybridität digitaler Spiele keine vollständige terminologische (wie konzeptuelle) Hybridisierung, obwohl er dieser freilich sehr nahe ist.

Studien wie diejenige Sebastian Domschs versuchen, dies zu leisten: „Some things are played as games, and some things are read as narrative, and sometimes, a thing is both. The latter is what is called storyplaying. " (DOMSCH 2013, 3) Diese Arbeit kommt im Folgenden jedoch derart konventionell daher, dass auch hier schwerlich von einem Hybridmodell zu sprechen ist. Dies mag einerseits daran liegen, dass er, obwohl er ein Hybridmodell anstrebt, sehr stark narratologisch argumentiert und hierbei zudem kaum neuere Literatur aus diesem überaus vitalen Bereich des Forschungsfeldes verwendet und andererseits in seinen Ausführungen zum Storyplaying im Fortgang der Argumentation nicht deutlicher wird, sodass das Konzept des Storyplayings intensional wie extensional wenig konturiert bleibt.

Aus diskursiver Perspektive lässt sich somit feststellen, dass es zwar viele Arbeiten zur interaktiv-narrativen Hybridität digitaler Spiele gibt und dass diese zu interessanten und wichtigen Einsichten und Überlegungen gelangt sind, dass es aber bis dato noch kein Hybridmodell gibt, das es erlaubt, die Hybridität digitaler Spiele detailliert sowie umfassend bzw. ganzheitlich zu untersuchen. Aus diesem Grund möchte das Kontinuumsmodell versuchen, einen weiteren Schritt in diese Richtung zu gehen. Die Arbeiten von Kücklich, Kocher, Sallge, Seda und Domsch dienen dabei als Vorbilder, deren Gedankengänge in das Kontinuumsmodell mit einfließen. Es bietet sich an dieser Stelle - um den Blick heuristisch sinnvoll zu schärfen - an, das Augenmerk auch auf Arbeiten zu richten, die sich nicht explizit als Hybridtheorien verstehen. Denn vielmehr sind (in einem weiteren Sinne) all jene Arbeiten der Digital Game Studies als Beitrag zur Erforschung der Hybridität digitaler Spiele zu verstehen, die digitale Spiele als Hybridphänomene ansehen. So gefasst folgen gegenwärtig die meisten Studien einer hybriden (,vermittelnden') Perspektive, was an einigen ausgewählten Beispielen verdeutlicht werden soll.

Benjamin Beil betrachtet in seiner bereits erwähnten und zitierten Dissertation digitale Spiele „als Hybridkonstruktionen“. (BEIL 2010, 53) „Immersion ist ein Effekt, der sich durch Wechselwirkungen innerhalb der Hybridstruktur generiert und somit an die Verknüpfung von 
Spiel und Erzählung gebunden ist.“151 (ebd., 53 f.) Digitale Spiele sind (und hierin ist er Roman Seda sehr nahe) „keine interaktiven Erzählungen“, da sie „dem Ideal der Interactive Fiction, der Verschmelzung von Interaktion und Storytelling“ widersprechen. (ebd., 56) Beil vertritt hiermit deutlich eine ontologische Hybridität digitaler Spiele aus Spiel und Erzählung, negiert aber zugleich eine rezeptiv-ästhetische Hybridität aus Interaktion und Narration.

Einen interessanten Hybridansatz, jedoch unter einer hegemonialen Perspektive des Narrativen, vertritt Hans-Joachim Backe:

Literatur, die mit dem Leser spielt und ihn zur Partizipation nötigt, bleibt in erster Linie Literatur. Architektur, die mit der Kombination von Stilelementen spielt und zum Entschlüsseln der Prinzipien hinter dem scheinbaren Eklektizismus einlädt, bleibt Architektur. Ein Spiel jedoch, das auch eine Geschichte erzählt, ist ein neues Paradigma, zu dem es zwar Parallelen gibt, das aber in dieser Form noch nicht dagewesen ist. (BACKE 2008, 103)

Die Hybridität digitaler Spiel erscheint somit als kategorial Neues, wenn auch vor dem Hintergrund, dass Backe narratologische Ansätze zur Analyse digitaler Spiele gegenüber ludologischen Vorbehalten zu verteidigen sucht. Backes Intention ist dabei aber nicht die Rehabilitation der narratologischen bzw. narrativistischen Schule der NarratologenLudologen-Debatte, sondern die Betonung der unabdingbaren Notwendigkeit zur Zusammenführung von narratologischen und ludologischen Ansätzen. Von zentraler Bedeutung für seine Argumentation sind dabei die sechs Verknüpfungsstrategien zwischen narrativen und ludischen Phasen digitaler Spiele, ${ }^{152}$ mit denen er so deutlich wie keiner seiner Vorgänger die konkreten Ausgestaltungsmöglichkeiten dieser Alternation fokussiert. So kann das Verhältnis zwischen narrativen und ludischen Phasen linear mit Einflussnahme des Spielers (1) bzw. ohne Einflussnahme des Spielers (2) gestaltet sein. In beiden Fällen wechselt eine ludische eine narrative Phase ab und umgekehrt. Allerdings können Spieler im zweiten im Vergleich zum ersten Fall die Reihenfolge der Alternation bestimmen. Des Weiteren gibt es die Möglichkeit der hypertextuellen Verknüpfung mit multioptionalen Spielverläufen, wobei zwischen hypertextuellen digitalen Spielen zu differenzieren ist, die in ihrem Fortlauf nur auf den Entscheidungen des Spielers (3) sowie auf dem Ausgang einer bestimmten ludischen Phase basieren (4). (5) Liegt ein Sonderfall von (4) vor, wenn dem Spieler erst retrospektiv bewusst wird, dass der Ausgang einer ludischen Phase für den Fortlauf des Spiels verantwortlich war. Die letzte Verknüpfungsform stellt die Quest-Struktur

\footnotetext{
${ }^{151}$ Hierdurch hebt Beil sich bereits deutlich von Julian KüCKLICH (2001) ab, der die Immersion primär auf die darstellenden Aspekte digitaler Spiele bezieht.

${ }^{152}$ Dieser Wechsel zwischen narrativen und ludischen Phasen wird zuweilen auch als „Perlenkettenmodell“ bezeichnet, für das eine Oszillation zwischen „Selbst- und Fremdbestimmung“ kennzeichnend ist. EICK (2014), 109.
} 
(6) dar, wie im Kapitel zum Mythos ${ }^{153}$ als Interaktiv-Narrativ detailliert zu erörtern sein wird. (vgl. ebd., 149 ff.)

Daß sich Spiel und Geschichte weitgehend problemlos in einer Einzelspielerkampagne kombinieren lassen, liegt in strukturellen Gemeinsamkeiten begründet. Beide sind deutlich segmentierte Gebilde, die nicht bruchlos von ihrem Anfang dem Ende zustreben, sondern diesen Weg in Etappen mit zahlreichen Zwischenzielen einteilen. (ebd., 206)

Diese strukturellen Gemeinsamkeiten von Spiel und Geschichte führen letztlich dazu, dass jene beschriebene Verkettung von ludischen und narrativen Phasen in digitalen Spielen erst möglich wird. Ihren konkreten Ausdruck im digitalen Spiel finden jene strukturellen Gemeinsamkeiten auf drei verschiedenen Strukturebenen, nämlich sub-, mikro- und makrostrukturell.

Die Substruktur besteht aus den Möglichkeiten des Avatars in der Spielwelt. In ihr finden paidiische Handlungen statt, die nur von den Weltregeln der Simulationsumgebung eingegrenzt werden, und deren Ziel völlig intrinsisch im Genuß des Spielens selbst liegt. Die Mikrostruktur besteht aus der Vorgabe von Zielen, die mit Hilfe der Substrukturelemente zu erreichen sind. Das Erreichen dieser Ziele ist eine ludisch motivierte Handlung, deren Parameter von den Spielzielen vorgegeben sind. Ziel ist es, möglichst erfolgreich zu spielen, was taktisches Vorgehen gegenüber unmittelbarem Spielspaß aufwertet. Die Makrostruktur besteht aus Motivationen oder Erklärungen für die Ziele, die auf der Mikrostrukturebene formuliert werden. Die Handlungen dieser Ebene stellen ein Spiel zweiter Ordnung dar und können beliebig motiviert sein und nach unterschiedlichen Zielen streben, die aber strenggenommen alle (auf das eigentliche Spiel erster Ordnung bezogen) spielextrinsisch sind. Noch kürzer gefaßt läßt sich die Bedeutung jeder Ebene mit einer Spielfrage identifizieren: »Was kann ich tun?« - Was soll ich tun?« - »Warum soll ich es tun?« (ebd., 375)

Unabhängig davon, für wie heuristisch wertvoll man Backes Modell für konkrete Analysen digitaler Spiel hält, verdeutlicht es dennoch, wie fundamental wichtig hybride Theoriebildungen für hybride digitale Spiele sind. ${ }^{154}$ Zudem illustrieren die drei Fragen Backes, dass es für hybride Theorien einerseits zentral ist, welche strukturellen Gegebenheiten vorherrschen, dass es darüber hinaus aber genauso bedeutend ist, zu fragen, was Spieler damit machen (können). So hebt z.B. Gordon Calleja mit seinem Konzept der „alterbiography“ hervor, (CALLEJA 2009, 1) dass es im Kontext von Erzählungen und digitalen Spielen weniger entscheidend sei, dass digitale Spiele diese beinhalten (können), sondern dass sie es dem Spieler ermöglichen, seine eigenen Geschichten spielend zu

\footnotetext{
${ }^{153}$ Zum Mythos und zum mythologischen Narrativ vgl. Kapitel 3.

${ }^{154}$ Konkrete analytische Zugänge zu digitalen Spielen bietet bspw. KRINGIEL (2009), der Methoden vorgestellt und deren Funktionalität exemplarisch vorführt. Vgl. dazu auch NEITZEL et al. (2010).
} 
erzeugen. ${ }^{155}$ Dementsprechend müsse der Forscher nicht das Storytelling in digitalen Spielen, sondern die „story generation“"156 durch digitale Spiele in den Blick nehmen. (ebd.)

Das ist das Besondere bei Hybridansätzen (ob sie sich explizit als solche verstehen oder nicht) - sie betrachten nicht vornehmlich, welche anderen Medien und Kulturtechniken in hybriden Erscheinungen vorkommen, sie untersuchen, inwiefern diese medialen und attributiven Hybridisierungen neue hybride Formen erschaffen.

Computerspiele sind in erster Linie Bilderscheinungen und als solche deutlich von Literatur, Film und auch von anderen Spielen unterschieden. Daher liegt die Besonderheit auch nicht allein in der Interaktivität, da es diese ja bereits auch zwischen spielenden oder kommunizierenden Menschen gibt, sondern sie liegt in der Manipulationsmöglichkeit des interaktiven Bildes selbst. (GÜNZEL 2013, 382 f.)

Durch seinen bildwissenschaftlichen Zugang arbeitet Stephan Günzel heraus, dass das Spezifikum digitaler Spiele nicht in ihrer Interaktivität per se, sondern vielmehr in ihrer besonderen Form der Interaktivität liege. ${ }^{157}$ Denn Spieler können in digitalen Spielen das virtuelle Geschehen direkt manipulieren, dies macht digitale Spiele besonders, da es Ausdruck ihrer Hybridität ist. ${ }^{158}$

Das Kontinuumsmodell versucht dieser Hybridität interaktiv-narrativer digitaler Spiele auf ontologischer wie rezeptiv-ästhetischer Ebene gerecht zu werden. Es nimmt zwar primär die Hybridität aus Interaktivität und Narrativität in den Blick, versucht aber auch, die sich hieraus ergebenden Synergien und Verschmelzungen zwischen Spiel und Erzählung zu bedenken.

\subsection{Interaktivität, Interaktion, Interaktiv - Ausführungen zum ,interaktiven' Begriffsfeld}

Interaktivität ist zugegebenermaßen kein Phänomen, das erst mit elektronischen Technologien und digitalen Medien auftaucht, es ist allerdings ein Begriff, der im

\footnotetext{
${ }^{155}$ Einen ähnlichen Ansatz verfolgt Mia Consalvo, die Walkthroughs von The Legend of Zelda: Majora's Mask (2000) untersucht und als ,erlebte Narrative' der Spieler betrachtet, welche wiederum die Spielerfahrungen anderer beeinflussen (können), die diese lesen. Vgl. Consalvo (2003). Solche Überlegungen werden im Rahmen des Kontinuumsmodells weiter verfolgt, allerdings wird hierbei strikt zwischen medialen und personalen Narrationen unterschieden. Dies ist zum einen notwendig, um die spezifischen Besonderheiten personaler Narrationen digitaler Spiele herausstellen zu können, wie sie z.B. CALLEJA (2009) betont und zum anderen um im Rahmen attributiver Hybridisierungen analysieren zu können, welche Rolle Medium und Rezipient hierbei jeweils einnehmen.

${ }^{156}$ In diesem Sinne ist ein (interaktiv-narratives) digitales Spiel ein „Geschichtenautomat“. EICK (2014), 110.

${ }^{157}$ Vgl. dazu ausführlicher auch Stephan Günzels Habilitationsschrift Egoshooter. Das Raumbild des Computerspiels (2012).

${ }^{158}$ Ein anderes Beispiel für eine hybride Theorie, die sich nicht primär als solche versteht, aber dennoch selbstverständlich von der Hybridität digitaler Spiele ausgeht, findet man bspw. bei Schröter und Thon, die ihr Modell von Charakteren im digitalen Spiel unter Berücksichtigung narrativer, ludischer, simulativer und sozialer Parameter entwickeln. Vgl. SCHRÖTER/THON (2014).
} 
Zusammenhang mit dem kulturellen Wandel durch Neue Medien ${ }^{159}$ eine vorher ungeahnte Konjunktur erlebt. ,Interaktiv` scheint eine Art Qualitätskriterium zu sein, wie es im Fernsehen ,live‘ geworden ist. Die ubiquitäre Verwendung des Ausdrucks, interaktiv' im alläglichen Gebrauch hat ihn schnell zu einem Terminus gemacht, den sich diverse wissenschaftliche Disziplinen angeeignet haben, besonders jene in den Kultur-, Medien- und Kommunikationswissenschaften, der aber im Allgemeinen ein geteiltes Echo hervorruft viele verwenden ihn, viele kritisieren ihn. Mit Blick auf die Kritiker des Interaktivitätskonzeptes wird ersichtlich, dass die Evaluation seiner Unangemessenheit v.a. aus seinen Unterschieden zur sozialen Anwesenheitskommunikation resultiert. Jene Interaktion via Medien, via Technologien wird somit entweder als Schwundstufe sozialen Austausches begriffen oder ihr wird gar jedwede Vergleichbarkeit abgesprochen. Beides führt zu einer Verwerfung des Konzeptes bzw. teilweise zur Substitution durch vermeintlich alternative Begriffe wie ,Agency ${ }^{6}$.

In den Digital Game Studies hängt der Begriff der Agency eng mit dem Namen Janet Murray zusammen, die ihn als Alternative für Interaktivität vorschlägt. (vgl. MURRAY 1997, 126-153) Studien der Digital Game Studies, die sich an Murrays Konzept anschließen, findet man z.B. bei DoMsch (2013) sowie GoMes (2005). Die Strategie, das Interaktivitätskonzept durch das der Agency ersetzen zu wollen, ist immer noch populär, obwohl beide Konzepte in der Soziologie zwei verschiedene Handlungstheorien sind, die intensional andere Handlungen bezeichnen und extensional unterschiedlich weit ausgreifen. So bezieht sich das AgencyKonzept, wie Murray richtig herausarbeitet, auf die Handlungsmacht des Subjektes, wohingegen Interaktivität Handeln in intersubjektiven Kontexten meint. „Agency is the satisfying power to take meaningful action and see the results of our decisions and choices." (MurRAY 1997, 126; vgl. dazu auch Domsch 2012, 197) Somit ist die Agency allgemein die „,condition of activity“, wie Martin Hewson es ausdrückt, und bezeichnet deshalb die Fähigkeiten und Möglichkeiten eines Subjektes, zu handeln. (HEwson 2010, 12) Interaktionen sind aber ein bestimmter Typ von Handlungen, die nicht allein von der Handlungsmacht des einzelnen Subjektes bestimmt werden, sondern sich eher an den Strukturen und Kontexten orientieren, die interaktives Handeln determinieren. Somit wird zweierlei deutlich: Erstens scheint es mit Blick auf Agency und Interaktivität kaum möglich, das eine durch das andere handlungstheoretische Konzept zu ersetzen, ohne dabei Gefahr zu

\footnotetext{
${ }^{159}$ Im Kontext der Theorien Neuer Medien ist der Sammelband The New Media Reader von WARDRIPFrUin/MONTFORT (2003) empfehlenswert, der Texte von Klassikern bzw. kanonischen Autoren des Forschungsfeldes wie Vannevar Bush, Theodor Nelson, Jorge Luis Borges oder Marshall McLuhan versammelt.
} 
laufen, Handeln zu missinterpretieren. Zweitens, und durch den vorhergehenden Punkt beeinflusst, erscheint es sinnvoller, wenn man Handeln umfassend erfassen, beschreiben und analysieren möchte, beide handlungstheoretischen Konzepte miteinander zu verbinden. In der Soziologie wird diese Tendenz prominent durch Anthony Giddens und den auf ihm aufbauenden Uwe Schimank vertreten. Beide untersuchen die Zusammenhänge zwischen Handlungen bzw. den Handlungsoptionen des sozialen Akteurs und den Strukturen, die den Handlungsrahmen für die Handlungsmöglichkeiten der sozialen Akteure abstecken sowie sie aber wiederum selbst durch die Handlungsfolgen der Handlungen der sozialen Akteure, die aus deren Agency folgen, verändert werden können. (vgl. GIDDENs 1997 sowie SCHIMANK 2010) Somit stehen Agency und Interaktivität stets in einem nicht auflösbaren reziproken Zusammenhang. Diesem Gedanken folgt auch die vorliegende Studie, selbst dann, wenn sie sich in ihren Ausführungen primär mit der Interaktivität auseinandersetzt. Ursächlich hierfür ist schlichtweg die Orientierung des Forschungssettings, die mehr das Verhältnis zwischen Spieler und System betrachtet und weniger die Fähigkeit, Möglichkeit und Kompetenz des Subjekts, zu handeln. ${ }^{160}$

Dieser kurze Exkurs zum Zusammenhang zwischen Agency und Interaktivität unterstreicht bereits, dass die Eliminierung eines Ausdrucks nicht automatisch heißt, dass man auch die epistemologischen oder methodischen Probleme beseitigt. Überspitzt gesprochen führen alternative Begriffsverwendungen oft $\mathrm{zu}$ den alten Problemen mit neuen Termini, der angestrebte Paradigmenwechsel ${ }^{161}$ ist somit von fragwürdiger Gestalt, da auch das neue Paradigma mit denselben Unvereinbarkeiten zwischen Terminologie und Gegenstand konfrontiert ist wie der vorherige Begriff. Aus diesem Grund möchte die vorliegende Arbeit dennoch das Konzept der Interaktivität verwenden, auch wenn sie um seine Schwächen weiß. Diese Schwächen sind aber häufig nicht unbedingt Defizite des Konzeptes an sich, sondern eher seiner Anwendung. Die Interaktivität digitaler Spiele wie digitaler Medien im Allgemeinen und die Interaktivität zwischen Akteuren der sozialen Realität darf nicht in eins gesetzt werden, da hier keineswegs kongruente Erscheinungen vorliegen. Die Applikation von

\footnotetext{
${ }^{160}$ Zum Zusammenhang zwischen Agency und Interaktivität in digitalen Spielen vgl. MATUSZKIEwICZ (2016); zu Game Studies und Agency vgl. SchumACHER/Korbel (2009).

${ }^{161}$ Vgl. hierzu die wegweisende Studie von Thomas S. KUHN (2012). Freilich ist jener hier beschriebene Paradigmenwechsel nicht mit der ,Kopernikanischen Wende“ vergleichbar, da dessen soziokulturelle Auswirkungen bei weitem nicht die Tragweite haben, wie es Kopernikus Entdeckungen hatten. Jedoch funktioniert der Paradigmenwechsel (von seinem Ablauf her) hier ebenso wie von Kuhn dargelegt, weshalb der Begriff an dieser Stelle Verwendung findet.
} 
,interaktiv` vom realen sozialen in den digitalen Raum soll somit keine vollständige, sondern lediglich eine partielle Ähnlichkeit andeuten.

Da Interaktivität in digitalen Medien stets (im Positiven wie im Negativen) mit der Interaktivität sozialer Gemeinschaften verbunden wird, ist es ratsam, dem soziologischen Interaktionsbegriff Aufmerksamkeit $\mathrm{zu}$ schenken, da eine Profilierung des Interaktivitätskonzeptes aus dieser Richtung heuristisch lohnenswert erscheint und v.a. mit Blick auf die Mediensoziologie hilft, viele Potenziale des Missverstehens auszuräumen. (2.3.1) Dennoch ist es unerlässlich, auch kritische Stimmen aus den Digital Game Studies, den Medien- und Kommunikationswissenschaften, der Informatik oder den Digital Humanities anzuführen, die dazu beitragen, die Begriffsbestimmung des interaktiven Begriffsfeldes zu konturieren. (2.3.2) Im Anschluss daran wird der Blick darauf gelenkt, was Interaktivität und Interaktion in digitalen Spielen konkret ausmacht. (2.3.3) Dem Folgen zwei Kapitel, die einerseits mit dem Interaktiv ein neues Konzept in die Digital Game Studies einführen (2.3.4) sowie andererseits mit der realen und der virtuellen Interaktion versuchen, die Interaktionen in digitalen Spielen differenzierter beschreibbar zu machen. (2.3.5)

\subsubsection{Interaktivität und Interaktion - eine erste Annäherung}

Wenn es um die Definition der Interaktivität geht, dann hat es ein Zitat Sheizaf Rafaelis zu immenser Popularität gebracht. ${ }^{162}$

Interactivity is a widely used term with an intuitive appeal, but it is an underdefined concept. As a way of thinking about communication, it has high face validity, but only narrowly based explication, little consensus on meaning, and only recently emerging empirical verification of actual role. (RAFAELI 1988, 110)

Rafaeli konstatiert bereits Ende der 1980er Jahre die Diskrepanz zwischen der ubiquitären Verwendung des Begriffs aufgrund seiner (vermeintlichen) intuitiven und daher intersubjektiven Nachvollziehbarkeit und seiner gering ausgeprägten Fundierung als theoretisches Konzept. Dass Rafaeli zu einem Klassiker der Interaktivitätsforschung wurde, hat aber nicht nur mit seiner Feststellung zu tun, sondern auch mit einer Festsetzung. Nach Rafaeli gibt es nämlich drei Level der Interaktivität: Die Zwei-Weg-Kommunikation (1), die „reactive“ also quasi-interaktive Kommunikation (2) und die „full interactivity“ oder „responsiveness“ (3). (ebd., 119) Er unterscheidet also die bidirektionale Kommunikation zwischen gleichberechtigten Interaktionspartnern von der reaktiven Interaktivität, bei der ein

\footnotetext{
${ }^{162}$ Zur Problematik der Definition von Interaktivität bzw. Interaktion vgl. auch DownEs/MCMillan (2000)
} SOWie MAGENHEIM (2008). 
gewisses Gefälle zwischen den Interagierenden vorherrscht. Zudem gibt es mit der „responsiveness“ ein Konzept vollkommenerer Interaktivität. Jedoch muss man zwei Dinge einwenden, trotz des Mehrwertes der dargebotenen Unterscheidungen. Denn erstens sind die drei Level der Interaktivität nicht detailliert ausgearbeitet, sondern eher angedeutet und zweitens verschwimmen bei Rafaeli die Grenzen zwischen Interaktivität und Interaktion, wenn er Interaktivität als Kommunikation betrachtet.

Christoph Neuberger führt hierzu an: „Ausgeblendet wird dabei die Unterscheidung zwischen dem technischen Potenzial eines Mediums und seinem tatsächlichen Gebrauch, d.h. zwischen Interaktivität (=Potenzial) und Interaktion (=Prozess).“ (NEUBERGER 2007, 35 f.) Noch klarer wird dies im Fortgang seiner Ausführungen: „»Interaktivität« ist das Potenzial eines technischen Einzelmediums oder einer Kommunikationssituation, das interaktive Kommunikation begünstigt, also den Prozess der Interaktion“. (ebd., 43 f.) Jene Unterscheidung zwischen Interaktivität und Interaktion findet sich auch bei Lori Landay wieder: „Interactivity is the potential for, or phenomenon of, interaction; interactivity can be a property of an artifact, a perception, or an experience. Interaction is an action that occurs as two or more participants exchange information (people, artifacts, materials, or machines) that has a reciprocal effect on each other.“ (LANDAY 2014, 173; Herv.i.O.) Es bietet sich also mit Bezug auf Neuberger und Landay an, zwischen der Eigenschaft von Medien und Phänomenen interaktiv zu sein (Interaktivität) und der konkreten Nutzung dieser potenziellen Eigenschaft (Interaktion) zu differenzieren. ${ }^{163}$ Dies bedeutet aber auch, dass der Interaktivitätsbegriff über den Interaktionsbegriff bestimmt wird und es somit von signifikanter Bedeutung ist, diesen zu klären.

In diesem Kontext haben es v.a. zwei Aufsätze zu erheblichem Einfluss gebracht, sind sogar international rezipiert worden - die Rede ist von Lutz Goertz und Michael Jäckels Aufsätzen in Rundfunk und Fernsehen von 1995. Beiden geht es darum, Interaktion und Interaktivität als Konzepte, die in der Kommunikationswissenschaft applizierbar sind, zu konkretisieren, wobei sich beide auf das soziologische Verständnis des ,interaktiven“ Begriffsfeldes stützen. So hebt Goertz hervor, dass es sich bei einer Interaktion um eine „Wechselbeziehung“ bzw. um „Beziehungen zwischen zwei oder mehreren Menschen“

\footnotetext{
${ }^{163}$ Einen Vorschlag, der diese Unterscheidung bewusst unterlässt, unterbreiten QUIRING/SCHWEIGER (2006), wenn sie, um sich deutlich vom soziologischen Interaktionsbegriff abzugrenzen, den Interaktivitätsbegriff dazu verwenden, um interaktive Beziehungen zwischen Nutzern und System bzw. zwischen Nutzern mit Unterstützung elektronischer Systeme zu bezeichnen. Somit betrachten sie Interaktivität nicht als Eigenschaft, sondern als den Austauschprozess an sich. Vgl. dazu auch BraUn-ThÜRMANn (2002), 117.
} 
handele. (Goertz 1995, 477 sowie 478; Herv.i.O.) Demzufolge ist Face-to-Face- oder Anwesenheitskommunikation das „Ideal der interaktiven Medien“. Das „interaktivste“ Medium ist demnach das, welches die „natürlichste Kommunikation“ ermöglicht. (ebd., 479)

Das heutige Verständnis der »interaktiven Medien« enthält demnach sowohl das Interaktionskonzept der Soziologie (wechselseitig aufeinander bezogene menschliche Handlungen) als auch das der Informatik (Handlungen zwischen Mensch und Computer, die Handlungen zwischen Menschen ähneln). (ebd.)

Damit präzisiert Goertz die Interaktion auf zweierlei Weise: einerseits, indem er mit der Interaktion als Handlung eine zweite Kernkomponente der Interaktion im soziologischen Sinne anführt und indem er zweitens (wie fast alle kommunikationswissenschaftlichen Arbeiten der jüngeren Vergangenheit), die Interaktion aus informatischer Sicht mit in den Blick nimmt. Der Übertrag des soziologischen Terminus in den Bereich der Informatik beruht auf der beschriebenen Ähnlichkeitsbeziehung zwischen der Interaktion zwischen Menschen zum einen sowie zwischen Mensch und Maschine zum anderen. Die Maschine ist hierbei zugleich Interaktionspartner und die Interaktion ermöglichendes Medium. (vgl. ebd.) Goertz plädiert dafür, dass man zur Beurteilung der Interaktivität, welche er als graduelle $\mathrm{e}^{164}$ Eigenschaft betrachtet, eines Mediums nicht die „tatsächliche[] Nutzung“ ansehen sollte, sondern die „technischen Gegebenheiten“. (ebd., 485) Hiermit rekurriert er avant la lettre auf Neubergers Unterscheidung zwischen Interaktion als konkreter Nutzung und der Interaktivität als potenzieller Möglichkeit.

Das Grundmodell, an dem sich der soziologische Interaktionsbegriff orientiert, ist die Beziehung zwischen zwei oder mehr Personen, die sich in ihrem Verhalten aneinander orientieren und sich gegenseitig wahrnehmen können.

Erst der Symbolische Interaktionismus [...] legte Wert auf die Feststellung, daß Interaktionen aus den wechselseitigen Orientierungen der Interaktionspartner resultieren.

Wenn Interaktion stattfindet, findet immer auch Kommunikation statt. Kommunikation kann auch ohne Interaktion stattfinden. (JÄCKEL 1995, 463; 464 sowie 467)

Michael Jäckel betont damit, dass Interaktionen Beziehungen zwischen mehreren Akteuren sind, die sich gegenseitig wahrnehmen können, d.h., die sich gleichzeitig an einem Ort befinden, die sich von Angesicht zu Angesicht gegenüberstehen, also Anwesenheitskommunikation im engsten Sinne des Wortes betreiben. Dies erinnert unmittelbar an Max Webers Definition des ,sozialen Handelns“ .,»Soziales« Handeln aber

\footnotetext{
${ }^{164}$ Man kann, nach Goertz, den Interaktivitätsgrad von Medien demnach auf einer Skala (kaum interaktiv bis sehr interaktiv) verorten. Gering interaktive Medien sind Bücher oder Filme, sehr interaktive Medien sind digitale Spiele oder Neue Medien im Allgemeinen. Vgl. dazu GoERTZ (1995), 481 sowie QuiRING/SCHWEIGER (2006), 21.
} 
soll ein solches Handeln heißen, welches seinem von dem oder den Handelnden gemeinten Sinn nach auf das Verhalten anderer bezogen wird und daran in seinem Ablauf orientiert ist.“ (WEBER 1984, 19; Herv.i.O.) Dementsprechend klärt sich die Art der Beziehungen zwischen Akteuren, die Interaktionen erzeugen; es sind wechselseitige Handlungen, die sich mit Blick auf die Gemeinschaft, in deren Kontext interagiert wird, konstituieren. Erweitert man dies um Jürgen Habermas Konzept des ,kommunikativen Handelns', dann gelangt man zu einer abschließenden Profilierung der Interaktion in der Soziologie. „Der Begriff des kommunikativen Handelns schließlich bezieht sich auf die Interaktion von mindestens zwei sprach- und handlungsfähigen Subjekten, die (sei es mit verbalen oder extraverbalen Mitteln) eine interpersonale Beziehung eingehen.“ (Habermas 1981, 128) Damit kommt der Sprache eine fundamentale Bedeutung für Interaktionen zu. „Der Begriff des kommunikativen Handelns setzt Sprache als Medium einer Art von Verständigungsprozessen voraus“. (ebd., 148) Dabei darf man das Sprechen aber nicht als die Handlung selbst betrachten, denn „kommunikatives Handeln bezeichnet einen Typus von Interaktionen, die durch Sprechhandlungen koordiniert werden, nicht mit ihnen zusammenfallen.“ (ebd., 151) Somit bildet die Sprache auch im Fall der Anwesenheitskommunikation das Medium, über das Interaktionen erst ablaufen können. Vor dem Hintergrund eines derart offenen Medienverständnisses ist also letztlich jede Interaktion medial vermittelt.

Zusammenfassend lassen sich Interaktion und Interaktivität wie folgt definieren: Interaktionen sind wechselseitige, kommunikative (via Medien vermittelte) Handlungen zwischen ,anwesenden" Akteuren. Entscheidend ist hierbei die kognitive wie handlungsautonome Gleichberechtigung zwischen den Interaktionspartnern. Die Interaktivität bezeichnet das (graduationsfähige) Potenzial von Medien und Phänomenen, diese Interaktionen zu gewährleisten.

\subsubsection{Interaktivität und Interaktion in Medien - zwischen Kritik und Zuspruch}

Einer der prominentesten Kritiker der Übertragung des (soziologischen) Interaktionsbegriffs auf die Mediennutzung ist Niklas Luhmann. Bei der Kommunikation via Massenmedien findet, so Luhmann, „keine Interaktion unter Anwesenden zwischen Sender und Empfänger“ statt. „Interaktion wird durch Zwischenschaltung von Technik ausgeschlossen, und das hat weitreichende Konsequenzen, die uns den Begriff der Massenmedien definieren.“ (LUHMANN 1996, 11) Wenn keine Interaktion unter Anwesenden gegeben ist, dann liegt nach Luhmann eine „Unterbrechung des unmittelbaren Kontaktes“ vor. 
(ebd.) Eine technisch vermittelte Kommunikation zwischen Akteuren kommt für Luhmann als Interaktion somit nicht in Betracht, da sie eine Kommunikation unter Anwesenden erübrigt. Insofern sind aber nicht bloß Neue Medien ,anti-interaktiv', sondern alle Medien, die (unmittelbare) Kommunikation unter Anwesenden ersetzen (was per definitionem für alle Medien gilt). Der „Buchdruck multipliziert das Schriftgut so stark, daß eine mündliche Interaktion aller an Kommunikation Beteiligten wirksam und sichtbar ausgeschlossen wird.“ (ebd., 33 f.) Das Medium als ein Informationen kommunizierend Vermittelndes unterbindet somit immer soziale Interaktion im Luhmann'schen Sinne. Niklas Luhmann konstatiert mit Blick auf die Massenmedien aus einer medienhistorischen Perspektive heraus eine zunehmende Substitution der sozialen Interaktion durch massenmediale Kommunikation. Die Massenmedien können „ein autopoietisches, sich selbst reproduzierendes System entstehen [lassen], das auf Vermittlung durch Interaktionen unter Anwesenden nicht" angewiesen ist. ${ }^{165}$ (ebd., 34)

Luhmann redet damit keineswegs einem medienkritischen Kulturpessimismus Wort, da seine Argumente einerseits wohlbegründet sind und sich seine Einschätzungen andererseits durch seine sehr traditionelle Sichtweise des soziologischen Interaktionsbegriffs erklären lassen. Im Unterschied zu medienkritisch-kulturpessimistischen Strömungen, die alte Medien stets nutzen, um die vermeintlich ,degenerativen“ Potenziale der Neuen Medien herauszustellen, die einen vergangenen Zustand verklären und demgegenüber den jetzigen verdammen, sind für Luhmann alle Medien sozial desintegrierend. Das Buch als Leitmedium konservativ-elitärer Gesellschaftsschichten ist demnach genauso wenig interaktiv wie das Fernsehen als alltagsfüllende Praxis einkommens- und sozialschwacher Mediennutzer. Man kann Luhmann dementsprechend nicht die Vorhaltung machen, dass er (ein ideologisch motivierter) Medienkritiker ${ }^{166}$ oder Kulturpessimist sei. Aber dennoch muss man, zumindest wenn die Medienwissenschaften nicht das Interaktivitätsparadigma aufgeben wollen, Luhmanns Einwand gegen den Transfer des Interaktionsbegriffs in Bezug auf Neue Medien zurückweisen. Luhmann betrachtet, bedingt dadurch, dass der digitale Medienwandel im Wesentlichen erst nach der Veröffentlichung seiner Studie erfolgte, traditionelle Massenmedien wie Printmedien oder Rundfunk, die grundlegend andere mediale Eigenschaften aufweisen als die neuen digitalen Medien, wie ein Seitenblick auf Gerhard

\footnotetext{
${ }^{165}$ Zum Verhältnis von Massenkommunikation und Interaktion vgl. auch Tilmann SUTTER (1999 sowie 2010).

${ }^{166}$ Luhmann betrachtet massenkommunikative Medien zwar grundsätzlich kritisch, er bezieht seine Medienkritik aber im Unterschied zu anderen, die hierdurch ihre Weltsicht untermauern wollen, nicht nur auf bestimmte Medien, die aus ideologischen Gründen zu Zielscheiben werden, sondern auf Medien im Gesamten. Insofern ist Luhmann durchaus ,medienkritisch“ ohne aber ein kulturpessimistischer Medienkritiker zu sein.
} 
Maletzkes Definition der Massenkommunikation verdeutlicht. So ist die Interaktion als Kommunikation in Neuen Medien zwar technisch vermittelt (1), indirekt (2) und an ein disperses Publikum (3) adressiert, sie ist aber nicht zwingend öffentlich (4) und keineswegs einseitig (5). (vgl. dazu MALETZKE 1963, 32) Diese fünf Kennzeichen weisen aber alle traditionellen Massenmedien auf, auf denen Luhmanns Überlegungen basieren. Was Neue Medien von herkömmlichen Massenmedien abhebt, ist aber ihre Fähigkeit, medienintern Rückkopplungskanäle zu bieten. Diese Eigenschaft weisen Massenmedien nicht auf, da Feedback hier immer nur gegeben werden kann, wenn das Medium gewechselt wird. Wenn eine Fernsehsendung mein Missfallen erregt, dann kann ich die Sendeanstalt nur kontaktieren, indem ich einen Brief oder eine E-Mail schreibe oder anrufe, ich kann mich aber nicht vor den Fernseher setzen und ihm meine Beschwerde mitteilen, zumindest dann nicht, wenn ich erwarte, dass meine Handlung als Interaktion wahrgenommen werden soll. ${ }^{167}$ Das unterscheidet beide Medienarten voneinander - digitale Medien bieten Spielraum für reziproke Handlungen und traditionelle Massenmedien eben nicht.

Unter Berücksichtigung dieser Faktoren wiegt bspw. die Kritik von Lev Manovich schwerer. Es geht Manovich im Vergleich zu Luhmann nicht darum, die Vergleichbarkeit zwischen sozialen Interaktionen und Interaktionen mit Computersystemen zu bestreiten, vielmehr findet er ,the concept [gemeint ist die Interaktivität] to be too broad to be truely useful““. (MANOVICH 2001, 55) Die Verwendung des Begriffs Interaktivität sei im Kontext Neuer Medien tautologisch, denn „,[m]odern HCI [Human Computer Interaction] is by definition interactive $[\ldots]$, to call computer media »interactive « is meaningless - it simply means stating the most basic fact about computers“. (ebd.) Stattdessen sei es sinnvoller, spezifische Konzepte der Interaktivität zu verwenden und so z.B. zwischen „menu-based interactivity, scalability, simulation, image-interface, and image-instrument" $\mathrm{zu}$ unterscheiden. (ebd., 56) Aus Sicht der Digital Humanities macht Manovich somit einen methodisch bedenkenswerten Vorschlag - es sollte nicht primär darum gehen, die Interaktivität digitaler Medien zu bestreiten oder diese mit der sozialen Realität zu vergleichen. Stattdessen ist es vorrangig, die konkreten Formen des Interaktiven in digitalen Medien zu untersuchen. Was ist besonders an der Interaktivität digitaler Medien? Was ist kennzeichnend für Interaktionen in, mit und durch digitale Medien?

\footnotetext{
${ }^{167}$ Angesichts der Zunahme an Smart Devices in Haushalten, die per Sprachsteuerung bedienbar sind, kann diese Feststellung bereits in wenigen Jahren vielleicht als antiquiert angesehen werden. Sollte dies so sein, so würde dies aber auch bedeuten, dass die traditionellen Massenmedien - zumindest wie Luhmann sie verstanden hat nicht oder kaum mehr existieren.
} 
Manovich verweist auf die HCI, also auf jene Teildisziplin der Informatik, die das interaktive Verhältnis zwischen dem Menschen und dem Computer betrachtet. Von zentraler Bedeutung ist für die $\mathrm{HCI}^{168}$ der „Dialogbetrieb (interactive processing)“. (HEINECKE 2012, 3; Herv.i.O.)

Dialogbetrieb zeichnet sich dadurch aus, dass ein ständiger Wechsel der Aktivität zwischen Mensch und Rechnersystem vorhanden ist. Auf Eingaben reagiert das Rechnersystem unmittelbar durch eine Rückmeldung. Wenn die Verarbeitung damit bereits abgeschlossen ist, kann sofort wieder der Mensch aktiv werden. Falls die Verarbeitung der Eingabe länger dauert, erfolgt an deren Ende eine Ausgabeaktivität des Rechners, die dann die Initiative wieder dem Menschen überlässt. Diese wechselnde Aktivität wird als Dialog bezeichnet, obwohl dieser Begriff nicht ganz angemessen ist, da er eigentlich bewusste und gleichberechtigte Partner voraussetzt. Rechnersysteme im Dialogbetrieb sind ein Beispiel für interaktive Systeme. [...] Als interaktiv wird ein System bezeichnet, bei dem der Benutzer durch Bedienhandlungen den Arbeitsablauf des Systems beeinflussen kann. (ebd.; Herv.i.O.)

Andreas Heinecke steht dem Interaktivitätsbegriff im Zusammenhang der Interaktion zwischen Mensch und Maschine kritisch gegenüber, da er im Vergleich zum sozialen Interaktionsbegriff keine Wechselseitigkeit unter gleichberechtigten Interaktionspartnern voraussetzt, sondern einseitig sei. Diese Gleichberechtigung zwischen Mensch und Maschine scheitert letztlich an der fehlenden KI aktueller Computerprogramme, die die menschlichen Aktionen nicht in der notwendigen Komplexität wahrnehmen und verarbeiten können. (vgl. dazu auch GoERTz 1995, 480) Diese Position vertritt aus Sicht der Digital Game Studies auch Mathias Mertens. Da Handlungsoptionen in digitalen Spielen vordefiniert seien, darauf warten, von dem Spieler in die ,richtige Abfolge“ gestellt $\mathrm{zu}$ werden, ,ist der Begriff Interaktivität, das Reden von der Entscheidungs- und Bewegungsfreiheit, die man bei Computerspielen im Gegensatz zu anderen Medien hätte, falsch“. ${ }^{169}$ (MERTENS 2004, 283) Daraus schließt Mertens: „Computerspiele sind nicht interaktiv. Sie bieten nur endlos emergierende Reaktionsmuster von Spieler und Programm.“” (ebd., 287)

Was derartige Argumentationsführungen aber oft ausblenden, ist die Wahrnehmung des Rezipienten. Sowohl Heinecke als auch Mertens bestreiten die Interaktivität des Computers bzw. des digitalen Spiels mit Rückgriff auf die geringen dialogischen Fähigkeiten von Computersystemen, die unmittelbar aus den gegebenen technologischen Rahmenbedingungen resultieren. In der Interaktivitätsforschung lassen sich jedoch prinzipiell drei Perspektiven

\footnotetext{
${ }^{168}$ Eine interessante Arbeit in diesem Zusammenhang ist der Aufsatz von Camille UTTERBACK (2004). Sie geht dabei der Frage nach, welche Rolle der Körper in solchen Konstellationen einnimmt bzw. wie sich das Verhältnis zwischen dem Physischen und dem Symbolischen gestaltet.

${ }^{169}$ Die Frage nach der „Entscheidungs- und Bewegungsfreiheit“ ist aber weniger eine nach der Interaktivität des kommunikativen Kontextes zwischen Mensch und Maschine, es ist eher eine Frage nach der Agency des Subjekts.
} 
unterscheiden, die Interaktivität entweder als ,a formal property of a media technology“ (1) oder als ,a type of communication“ (2) oder als ,a cognitive process“ (3) begreifen. (vgl. Mechant/Looy 2014, 303) Bedenkt man dies, so ist es interessant, festzustellen, dass Kritiker des Interaktivitätskonzeptes oft einem Verständnis von Interaktivität im Sinne von (1) anhängen und nur die formalen technologischen Eigenschaften mit in den Blick nehmen. Dabei geraten kognitive Aspekte (3) leicht aus dem Blickfeld.

Jedoch ist es für die Beurteilung der Interaktion mit einem Computersystem durch einen Nutzer nicht unbedingt entscheidend, wie diese Interaktion tatsächlich (determiniert durch die technologischen Bedingungen des Mediums) ist, sondern wie sie vom Mediennutzer wahrgenommen wird. ${ }^{170}$ Nehmen wir bspw. Alan Turings berühmtes ,Imitationsspiel` oder auch ,Turing-Test“ genannt. Turing erläutert ein „Imitationsspiel“, bei dem ein Fragesteller (egal welchen Geschlechts) einen Mann und eine Frau abwechselnd befragt, die er beide aber weder sehen kann, noch kennt er sie (er kennt sie nur unter den Abkürzungen X und Y). Am Ende muss er benennen können, wer der Mann und wer die Frau ist. Mann und Frau müssen ihre Antworten so wählen, dass sie dem Fragesteller die Identifizierung erschweren. (vgl. TURING 1988, 59) Es gilt allerdings einige Faktoren auszuschalten, die dem Frager einen simplen Rückschluss auf die Identität der Befragten liefern würden. „Damit die Tonqualität der Stimme dem Fragesteller nichts verraten kann, sollten die Antworten geschrieben oder, besser noch, getippt werden. Die ideale Anordnung wäre, eine Fernschreiberverbindung zwischen den beiden Räumen zu haben.“(ebd., 60) In Bezug auf die Frage der Interaktivität zwischen Mensch und Maschine ist eine finale Modifikation Turings interessant. „Was geschieht, wenn eine Maschine die Rolle von A [dem Mann] in diesem Spiel übernimmt? Wird dann der Fragesteller genausooft zu einem falschen Ergebnis kommen, wie wenn das Spiel zwischen einem Mann und einer Frau gespielt wird?“( (ebd.)

Turings bekanntes Gedankenexperiment verdeutlicht aber meines Erachtens weniger die kommunikativen Fähigkeiten, die Computersysteme haben oder eines Tages haben könnten, es illustriert vielmehr, wie simpel soziale Interaktion als Kommunikation eigentlich ist und wie einfach sie dementsprechend von Maschinen imitiert werden kann, sodass der Mediennutzer sie als überaus zufriedenstellend wahrnimmt. ${ }^{171}$ Damit lässt sich ein

\footnotetext{
170 Die Interaktion zwischen Mensch und Maschine gelingt letztlich auch deshalb, weil Menschen ,abwärtskompatibel‘ sind, d.h. sie besitzen die Fähigkeit, sich auf die geringeren interaktiven Möglichkeiten von Maschinen einstellen zu können, auch wenn sich diese erheblich von ihren eigenen unterscheiden sollten.

${ }^{171}$ Eine sehr frühe Realisierung des Turing-Tests ist das Programm ELIZA, das Joseph Weizenbaum 1966 vorstellte. ELIZA simuliert dem menschlichen Nutzer ein ,reales' Gespräch aufgrund von simplen syntaktischen
} 
bedeutender Kritikpunkt an den Kritikern des Interaktivitätskonzeptes herausstellen. Sie vertreten (neben einem formalen Technozentrismus) emphatische Interaktionsbegriffe im sozialen Raum, die interaktive Beziehungen zwischen menschlichen Akteuren nicht erklären, sondern verklären.

,Freie Interaktivität‘ existiert weder im sozialen Raum noch in der Interaktion mit Computersystemen. Ursächlich hierfür ist die Agency. Es ist freilich korrekt, wenn man konstatiert, dass die Fähigkeiten von Computersystemen, mit dem Mediennutzer zu interagieren, gegenwärtig (aus technologischer Sicht) noch recht limitiert sind. Dies hat unmittelbare Auswirkungen auf die ,individuelle Agency“ des Mediennutzers. (vgl. HewsON 2010, 12 f.) Man kommt aber auch nicht umhin, zu bemerken, dass die Handlungsmöglichkeiten des sozialen Akteurs im sozialen Raum ebenfalls nicht endlos sind. Werte und Normen, diskursive Sagbarkeitsregeln, soziale Konventionen sowie die physische oder psychische Leistungsfähigkeit bestimmen neben den ökonomischen Faktoren maßgeblich die individuelle Agency eines jeden sozialen Akteurs. Dies ist das von Uwe SCHIMANK (2010) untersuchte Wechselspiel zwischen Handeln und Struktur. So kann sich das Ausleben der Sexualität eines Subjektes S deutlich unterscheiden, je nachdem, in welcher Gesellschaft es lebt. Nehmen wir an, es gäbe zwei Gesellschaften $-G_{1}$ und $G_{2}-$ wobei $G_{1}$ tolerant gegenüber den sexuellen Präferenzen von $S$ ist und $G_{2}$ diese entschieden ablehnt. ${ }^{172}$ Lebt $S$ in $G_{1}$, dann wird einem aktiven Ausleben und offenen Bekennen seiner sexuellen Ausprägung, zumindest von Seite der sozialen Struktur aus, wenig im Wege stehen. Somit ist die individuelle Agency von $S$ in Bezug auf das Ausleben seiner Sexualität in $G_{1}$ sehr hoch. Lebt $S$ hingegen in $G_{2}$, so wird ein Ausleben der sexuellen Präferenzen im öffentlichen Raum nahezu unmöglich sein oder nach eventueller Ausübung sanktioniert werden. Im Vergleich zu $\mathrm{G}_{1}$ hat $\mathrm{S}$ in $\mathrm{G}_{2}$ weniger Handlungsoptionen das Ausleben seiner Sexualität betreffend und demzufolge eine weitaus geringere individuelle Agency. Man kann dieses Beispiel aber auch

\footnotetext{
Verknüpfungen sowie einer sehr allgemeinen Fragetechnik. Bemerkenswert ist an diesem Programm, und das hat seinen eigenen Schöpfer letztlich entsetzt, dass viele Versuchspersonen, die Weizenbaum mit dem Programm konfrontierte, ELIZA für ein Programm hielten, dass ,menschlich` denke und kommuniziere. Mit anderen Worten, obwohl ELIZA den Turing-Test (technologisch) nicht bestand, wurde es dennoch für menschlich gehalten. Ein Grund dafür, dass es selbst einem derart simplen Programm wie ELIZA gelang, menschliche Kommunikation zu imitieren, dürfte letztlich darin liegen, dass unsere Interaktionen und Kommunikationen zu einem Großteil viel einfacher und oberflächlicher ablaufen, als wir dies oft wahrhaben wollen.

${ }^{172}$ Gedankenexperimente werden in der vorliegenden Arbeit häufiger eingesetzt, um bestimmte Phänomene zu veranschaulichen. Im Unterschied zu Gedankenexperimenten in der Theoretischen Physik wird aber nicht etwas gedanklich simuliert, das so real nicht durchführbar ist. Die Gedankenexperimente fungieren hier eher als konszise Darstellung von real so denk- und durchführbaren Handlungen, die aber aus Gründen der Einfachheit und Kürze in dieser Form präsentiert werden. So gesehen ersetzen diese Gedankenexperimente keinesfalls empirische Erhebungen, sie behandeln aber sehr wohl Fälle, die sich empirisch so auch finden lassen.
} 
auf digitale Medien übertragen. Dann wird aus S der Spieler, aus der Ausübung der Sexualität die Interaktion mit dem strukturellen Kontext, aus $\mathrm{G}_{1}$ die Interaktion im sozialen und aus $\mathrm{G}_{2}$ die Interaktion im digitalen Raum. So lässt sich die Basisargumentationsfigur vieler Interaktivitätskritiker beschreiben. Drei Dinge sind daran aber nicht unproblematisch: Erstens hat das Gedankenexperiment gezeigt, dass man technologische Rahmensetzungen nicht pauschal als zu limitiert betrachten sollte, sondern dass viele soziale Strukturen uns stärker limitieren, als wir dies glauben. Zweitens betrachten Interaktivitätskritiker paradoxerweise oft nicht die Interaktivität direkt, sondern die Agency des Subjektes und ziehen hieraus indirekte Rückschlüsse auf die Interaktivität. Drittens hängt die Interaktivität zwischen einem Subjekt und einer Struktur maßgeblich davon ab, wie das Subjekt diese wahrnimmt und realisiert. Wenn das Subjekt bspw. nur sehr wenige oder eventuell gar keine Handlungsoptionen wahrnimmt, dann kann es diese auch nicht alle performativ umsetzen, d.h. es bestehen zwar Handlungsmöglichkeiten, diese werden aber nicht genutzt, sodass sich das Subjekt letztlich selbst limitiert.

Die sozial-reale Limitierung unseres Handelns hat bereits George Herbert Mead untersucht, auf den Michael Jäckel durch seinen Rekurs auf den ,Symbolischen Interaktionismus' indirekt verweist. Eine Kernthese von Meads Schaffen ist der ,verallgemeinerte Andere‘. Hierunter versteht Mead die „organisierte Gemeinschaft der gesellschaftlichen Gruppe, die dem Einzelnen seine einheitliche Identität gibt“. (MEAD 1995, 196)

In der Form des verallgemeinerten Anderen beeinflußt der gesellschaftliche Prozeß das Verhalten der ihn abwickelnden Individuen, das heißt, die Gemeinschaft übt die Kontrolle über das Verhalten der einzelnen Mitglieder aus. (ebd., 198)

Bemerkenswert am ,verallgemeinerten Anderen' ist, dass für die Verhaltenskontrolle des Individuums durch die Gesellschaft nicht primär die tatsächlich offenbarten Haltungen der Gesellschaft gegenüber dem Einzelnen entscheidend sind, sondern die vom Individuum angenommenen Haltungen. Das Individuum konstruiert so Haltungen, von denen es meint, dass sie ihm gegenüber vertreten werden, und verhält sich diesen Annahmen gegenüber konform. Man könnte auch sagen, dass sich das Individuum selbst reguliert. Dies ist auch bei der interaktiven Mediennutzung so. Oft ist es für die qualitative Evaluation der Interaktion durch den Mediennutzer nicht wichtig, wie diese war, sondern wie der Nutzer diese wahrgenommen hat (Turing), und zwar aufgrund der von ihm angenommen Erwartungen, die 
das System an seine Interaktionen haben wird (Mead). ${ }^{173}$ So kann sich der Rezipient auf die geringeren interaktiven Potenziale digitaler Medien einstellen, ohne dies bewusst wahrzunehmen. Dies gilt aber auch für Interaktionen jenseits des digitalen Raums; kehren wir dafür nochmals kurz zu unserem Gedankenexperiment zurück. Es kann sein, dass S die Limitierung seines sexuellen Auslebens in $\mathrm{G}_{2}$ nicht als derart unterdrückend und einengend wahrnimmt, wenn S z.B. Erfüllung in einem Ausleben im Verborgenen erfährt. In diesem Fall genügt die Realisierung einer einzigen Handlungsoption, um S' Bedürfnisse zu befriedigen. Die Tatsache, dass dies vielleicht wirklich die einzige Handlungsoption ist, die S (straffrei) in $\mathrm{G}_{2}$ ausführen kann, bleibt dann für die Evaluation seiner sozialen Situation aus der subjektiven Perspektive von $S$ heraus unerheblich. Nehmen wir demgegenüber ein $S$ in $G_{1}$ an, das (aus welchen Gründen auch immer) seine sexuelle Präferenz nicht auslebt, da es befürchtet, sozial ausgegrenzt oder sanktioniert zu werden, obwohl $G_{1}$ dies nicht tun wird. In diesem Szenario hat $S$ im Vergleich zu dem $S$ in $G_{2}$ viele Handlungsoptionen, eine hohe individuelle Agency, setzt diese aber nicht tatsächlich um, sondern reguliert sich durch den , verallgemeinerten Anderen“ selbst. Hierdurch wird deutlich, wie wichtig das Wahrnehmungsvermögen eines Subjektes in einem Kontext ist, um zu eruieren, welche Handlungsoptionen für dieses Subjekt bestehen. Es wird darüber hinaus aber klar, dass man nicht die potenziellen Gegebenheiten eines Kontextes als alleinigen Maßstab ansetzen kann. Interaktivität und Agency sagen lediglich etwas über die Handlungsmöglichkeiten eines Subjektes aus, aber erst Interaktion und Handlung zeigen, was ein Subjekt wirklich tut. Dabei ist es wichtig, zu erkennen, dass eine signifikante Diskrepanz in Bezug auf die Handlungsoptionen besteht, dies muss aber nicht bedeuten, dass die Interaktivität oder Agency nicht vorhanden oder nur von geringer Qualität sei, da es neben der Bandbreite an Handlungsoptionen (wie weiter unten expliziert wird) noch andere Faktoren gibt, anhand derer man Handeln analysieren und beurteilen kann.

\footnotetext{
${ }^{173}$ Hans-Jürgen Bucher hat diesbezüglich den Begriff der ,unterstellten Interaktivität ‘ geprägt: „Unterstellte Interaktivität ist das konstitutive Merkmal dieser Form nichtlinearer Medienkommunikation. Diese Unterstellung zeigt sich nicht nur darin, daß Online-Nutzer so tun, als ob sie mit dem Angebot interagieren, sondern auch darin, dass sie das Angebot darauf festlegen, dass es ihnen in entsprechender Weise antwortet." BUCHER (2001), 167. Selbst wenn Interaktivität primär als „Eigenschaft des Mediums“ vorliegt, ist dennoch bedeutend, wie Mediennutzer diese wahrnehmen. Neuberger (2007), 44. Auch Oliver Quiring und Wolfgang Schweiger betonen, dass bei der Nutzung eines Systems die „Situationsevaluation der Nutzer“ wichtig sei, welche die „subjektive Wahrnehmung des interaktiven Systems und der Kommunikationssituation“ beinhalte. QUIRING/SCHWEIGER (2006), 11 f. Diese Situationsevaluation beeinflusst maßgeblich die Aktionen des Nutzers, also sein beobachtbares Verhalten.
} 
Vor diesem Hintergrund kann man sich einer fruchtbaren Verwendung des ,interaktiven Begriffsfeldes' in der Medienwissenschaft stellen und jenen Pfad weitergehen, den Lev Manovich andeutet. So merkt etwa Holger Braun-Thürmann an:

Künstliche Interaktion steht für diejenigen Bemühungen der Technowissenschaften, soziale oder sozialähnliche Interaktionen mit Computertechnik zu erzeugen. Künstliche Interaktionen können sich zwischen zwei technischen Artefakten ereignen, oder in hybrider Form zwischen einem menschlichen Individuum und einem technischen Artefakt. (BRAUN-THÜRMANN 2002, 14)

Nach Braun-Thürmann sind künstliche Interaktion keine „natürliche Form der sozialen Interaktion“, allerdings sind soziale Interaktionen an sich aber ebenfalls nicht natürlich, da sie nicht auf „natürlichen Mechanismen“ beruhen wie „Instinkten“ oder „ReizReaktionsmustern“, sondern soziale Interaktionen sind selbst ,artifiziell im Sinne von sozialisiert, eingeübt, konventionalisiert, ja sogar mechanisiert“. (ebd., 14 f.) In Differenz zu den Kritikern des Interaktivitätskonzepts erkennt Braun-Thürmann die Diskrepanz zwischen sozialer Interaktion und technisch vermittelter Interaktion, betrachtet letztere aber nicht als Schwundstufe, schließt eher an Überlegungen wie diejenigen von Turing oder Mead an, wenn er unter künstlichen Interaktionen ,jene Interaktionen, an denen technische Dinge in einer Weise teilnehmen, dass sie von menschlichen BeobachterInnen als Subjekte einer sozialen Interaktion wahrgenommen werden können“, subsumiert. (ebd., 15)

\subsubsection{Interaktivität und Interaktion in digitalen Spielen}

Wenn man also akzeptiert, dass die Interaktionen von Nutzern in und durch digitale Mediensysteme eine verwandte Form der Interaktion unter unmittelbar Anwesenden in der sozialen Realität sind, die aber dennoch erhebliche Unterschiede aufweisen, dann kann man die Interaktivität zur Analyse digitaler Spiele fruchtbar machen und mehr noch, man kann ihre Besonderheiten würdigen und untersuchen. Das bedeutet letztlich, dass man sich der ,ludischen Interaktivität‘ digitaler Spiele, die sich in ,ludischen Interaktionen“ konkretisiert, zuwenden kann. Es ist aber wichtig, die Interaktivität anhand der beteiligten Interaktionspartner zu unterscheiden. Oben wurden bereits die Nutzer-Nutzer-Interaktivität sowie die Nutzer-System-Interaktivität erwähnt. Erstere ist eine Interaktion zwischen Menschen via Medien und letztere ist eine Interaktion zwischen Mensch und Maschine. Daneben gibt es aber noch ein drittes Interaktivitätsverständnis, das z.B. in der Literaturwissenschaft dann zutage tritt, wenn von der Interaktion zwischen Leser und Text gesprochen wird. (vgl. hierzu MECHANT/LOOY 2014, 304) Insofern, wenn man ein digitales Spiel als Text versteht, kann man die Interaktivität zwischen Spieler und digitalem Spiel auch 
als eine zwischen Mensch und Dokument verstehen. (vgl. dazu auch ISER 1970) Hiervon distanziert sich die vorliegende Arbeit aber, da ein textliches Artefakt (im engen Sinne) über keine medieninternen Rückkopplungskanäle verfügt und somit keine „responsiveness“ erzeugt oder wenigstens suggeriert werden kann. ${ }^{174}$ Das Kontinuumsmodell orientiert sich deshalb an den ersten beiden Typen, macht aber auch hier eine Einschränkung. Aus heuristischen Gründen werden keine Mehrspielerspiele analysiert, was bedeutet, dass NutzerNutzer-Interaktionen somit nicht im Fokus liegen. Freilich kann das Modell auch auf solche angewendet werden, allerdings bedarf es hierzu einer Modifikation, die bspw. die verschiedenen korrespondierenden und konkurrierenden personalen Narrationen der menschlichen Interaktionspartner berücksichtigt. ${ }^{175}$ Dies kann aufgrund des begrenzten Rahmens leider nicht erfolgen. Stattdessen konzentriert sich das Modell primär auf die Nutzer-System-Interaktionen in interaktiv-narrativen digitalen Spielen.

Innerhalb der Ludizität von digitalen Spielen ist die Interaktivität das bedeutendste Element: „Interaktivität [...] ist zunächst also unbestritten das konstitutive Prinzip des Computerspiels - so sollte es zumindest sein.“ (FURTWÄNGLER 2001, 372) Im wahrsten Sinne des Wortes kann man die Interaktivität damit als das begreifen, was digitale Spiele zu digitalen Spielen macht. Nach Söke Dinkla liegt das Besondere eines „Meta Games“ (eines Spieles) nämlich darin, dass das Werk erst durch das „,wechselseitige[] Verhalten der Besucher und der programmierten Regeln“ konstituiert wird. (DINKLA 2009, 89) Konstruktivistisch betrachtet wird das digitale Spiel also erst zum digitalen Spiel, wenn jene interaktive Beziehung zwischen Spieler und System beginnt. Dies resultiert letztlich aus der engen Verbindung zwischen Ludizität und Interaktivität, wie Daniel Cermak-Sassenrath herausstellt.

Man kann, so Cermak-Sassenrath, „vom Spiel des users im alltäglichen Umgang mit dem Rechner“ sprechen. In diesem Zusammenhang ist das Spiel „eine willentlich eingenommene Perspektive“, durch welche der Mediennutzer „sein eigenes Handeln als Spiel ansieht“.

\footnotetext{
${ }^{174}$ Frank Furtwängler betont den entscheidenden Unterschied zwischen Nutzer-System- und Nutzer-TextInteraktionen, indem er darauf verweist, dass Interaktivität als Konzept nur für dynamische Systeme wie ein digitales Spiel, nicht aber für statische wie einen Text infrage komme. In statischen Medien wie Film oder literarischem Text ist der Rezipient schlicht zu passiv. Vgl. FURTWÄNGLER (2001), 375.

${ }^{175}$ Diesbezüglich sind bspw. digitale Spiele interessant, die die Entscheidungen und Handlungen von Spielern simultan zueinander in Bezug setzen wie Hidden Agenda (2017). Dieses ist als PlayLink-Spiel von bis zu sechs Spielern spielbar, wobei Smartphone oder Tablet zur Eingabe genutzt werden. Zentral ist hierbei die konsensuale Entscheidungsfindung, wobei (moralisch schwierige) Entscheidungen einstimmig oder mehrheitlich gefällt werden müssen. Unter bestimmten Bedingungen besteht aber auch die spielmechanische Möglichkeit, die Gruppe zu überstimmen und dementsprechend den eigenen Wellen durchzusetzen. Vgl. dazu exemplarisch das Let's Play von SHOTANA STUDIOS https://www.youtube.com/watch?v=VhFB-6b3tu8 (30.06.2018).
} 
(CERMaK-SASSEnRath 2010, 321) „Das Spiel im alltäglichen Umgang mit dem Computer scheint sich im Ausprobieren, Probehandeln und explorativen Lernen zu zeigen“". (ebd., 322) Daniel Cermak-Sassenrath erweitert hierdurch den Wirkungskreis von Ludizität und Interaktivität, sieht nicht nur das Spielen digitaler Spiele als Spiel an, sondern den Umgang mit dem Computer grundsätzlich. Die technologischen Rahmenbedingungen des Computers befördern einen interaktiven Umgang mit diesem und führen somit letztlich auch zu einer spielerischen Verwendung dieses Medienträgers. Ludizität in und mit digitalen Medien ist somit immer interaktiv. Das bedeutet aber auch, dass designerische Aspekte in den Blick genommen werden müssen. Denn, wenn man ein bestimmtes Spielerlebnis evozieren will, dann muss man Interaktionen ,designen', die diese Art des Spielens dem Spieler nahelegen. Dabei gilt:

Problematisch ist es, wenn der Gamer zu wenig Handlungsfreiheit hat - dann wird er sich schnell bevormundet fühlen. Oder wenn er zu viele Freiheiten hat - dann wird er unter Umständen orientierungs- und hilflos sein. Vor allem geht es in Games vornehmlich darum, das »Gefühl von Handlungsfreiheit« zu entwickeln - auch wenn der Spieler vielleicht in einem engen festgesteckten Rahmen agieren muss. (EICK 2014, 103)

Die Frage mit Bezug auf das Interaktionsdesign ${ }^{176}$ muss also lauten: Wie designt man Interaktionen, ohne das Spieler die handlungsbezogenen Limitierungen erkennen? Wie gehen Spieler bspw. mit interaktiven Phasen in digitalen Spielen um, in denen ihre Interaktionsmöglichkeiten eingeschränkt werden? Spiele wie Uncharted 2: Among Thieves (2009) entziehen Spielern temporär die Option, bestimmte Knöpfe des Interfaces zu bedienen, sodass es in diesen Fällen oft nur möglich ist, Eingaben über den Joystick zu tätigen. Man hat es hier mit Fällen von „reduced interactivity“ zu tun. (SCHRÖTER/THON 2014, 56) Kritiker nehmen solche Befunde als Anlass und gehen teilweise sogar so weit, dass sie behaupten, dass Spieler in digitalen Spielen weder Agency besitzen würden noch Interaktionen ausführen könnten. Stattdessen erzeugen digitale Spiele, so u.a. Alec Charles, lediglich Illusionen von Agency und Interaktivität, die dem Spiel dazu dienen, dem Subjekt eine Subjektivität aufzudrängen, die nicht seine eigene ist. (vgl. CHARLES 2009) Versucht man derartige Thesen zu verifizieren und beobachtet die Handlungsoptionen, die Spielern in digitalen Spielen z.B. in Bezug auf die Raumbemächtigung zur Verfügung stehen, so bemerkt man recht schnell eine Differenz zwischen der Wahrnehmung von Handlungsoptionen durch den Spieler und den tatsächlich vom System gegebenen Möglichkeiten. Designmethoden wie die ,Skybox“

\footnotetext{
${ }^{176}$ Zum Interaktionsdesign bietet Gerhard M. BUURMANs (2005) Sammelband einen umfassenden Überblick aus Designersicht. Die Beiträge setzen sich vornehmlich mit dem Verhältnis von Mensch und Maschine im technologisch-designerischen Kontext auseinander.
} 
lassen sich einsetzen, um die Spielwelt größer erscheinen zu lassen, als diese eigentlich ist. Dabei werden Hintergrundelemente wie Himmel, Berge oder Gebäude eingeblendet, die einen Horizont bilden und dem Spieler das Gefühl geben, in einer immensen Welt situiert zu sein, in der er sich räumlich frei und ausgreifend bewegen kann. Versucht der Spieler aber, an diese in der Ferne liegenden Orte zu gelangen, dann realisiert er, dass diese sprichwörtlich unerreichbar sind. Der Skybox-Effekt unterstützt also die Illusion, die räumlichen Grenzen der Spielwelt in der visuellen Wahrnehmung des Spielers weiter wirken zu lassen, als dies de facto der Fall ist. Wie eng die tatsächlichen, geografischen“ Grenzen der Spielwelt im Kontrast zu den vom Spieler wahrgenommenen zuweilen sind, illustriert der deutsche Filmschaffende Harun Farocki in seiner neunminütigen Videoinstallation Parallele II (2014). Dort werden in einer Sequenz rote Wände in die Spielwelt eingefügt, welche den tatsächlich vom Avatar begehbaren Raum von dem durch die Skybox erschaffenen abtrennen. Gerade in dem Moment, in dem die ,Kamera' herauszoomt, wird evident, wie klein der tatsächliche Spielraum dieser Spielwelt eigentlich ist und wie viel Raum lediglich eine bloße Wahrnehmungstäuschung ist. Die relativ engen räumlichen Grenzen der Spielwelt unterstreichen, wie gering der Handlungsraum in digitalen Spielen für den Spieler oft wirklich ist. Ein weiteres sehr anschauliches Beispiel, das diese Differenz künstlerisch herausstellt, stammt von Thomas Hawranke.

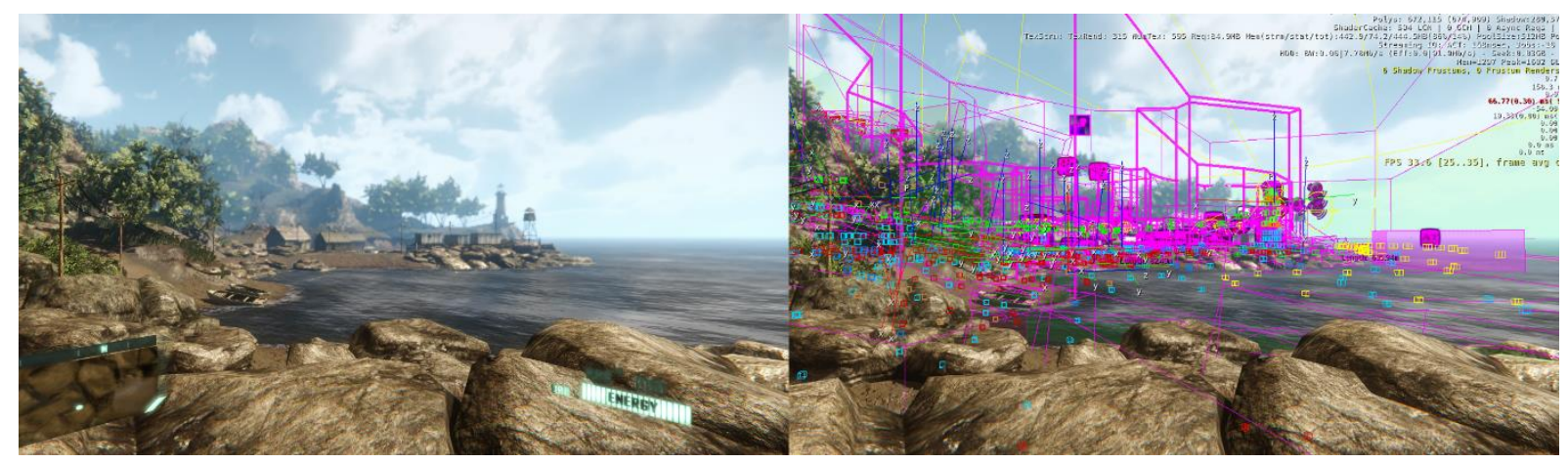

Abb. 3: In-Game/In-Engine, Thomas Hawranke, $2013^{177}$

Auf der linken Seite von Abbildung 3 sieht man die In-Game-Sicht der CryEngine, eine der global populärsten Spiel-Engines, des deutschen digitalen Spielentwicklers Crytek. Auf der rechten Seite hingegen befindet sich die In-Editor-Sicht aus derselben Perspektive, die die (räumlichen) Grenzen der CryEngine aufzeigt. Beide Exempel heben hervor, dass in der

177 Ich bin Thomas Hawranke für die Erlaubnis, diese Abbildung verwenden zu dürfen, zu tiefem Dank verpflichtet. 
Regel eine Differenz zwischen den vom Spieler wahrgenommenen und den tatsächlich realisierbaren Handlungsoptionen besteht. Diese Feststellung sollte aber keineswegs so weit geführt werden, dass man Spielern in digitalen Spielen jedwede Handlungsfreiheit abspricht, Agency und Interaktivität zu bloßen Illusionen deklariert. Dennoch weisen die künstlerischen Experimente von Farocki und Hawranke darauf hin, dass es von fundamentaler Wichtigkeit für die Digital Game Studies aber v.a. auch das Gamedesign ist, Kategorien zu haben, um die Qualität der Interaktivität beurteilen zu können. Zur Beurteilung der Interaktivität in digitalen Spielen bietet sich (aus Sicht der Digital Game Studies wie des Gamedesigns) eine Distinktion von Brenda Laurel an.

I posited that interactivity exists on a continuum that could be characterized by three variables: frequency (how often you could interact), range (how many choices were available), and significance (how much the choices really affected matters). (LAUREL 1993, 20)

Im Fall einer reduzierten Interaktivität wird meistens die Reichweite (range) der Interaktionsmöglichkeiten des Spielers eingeschränkt, wohingegen die Signifikanz und die Frequenz eher weniger berührt werden. Tendenziell lässt sich sagen, dass digitale Spiele gegenwärtig oft eine recht hohe Frequenz in Bezug auf ihre Interaktivität aufweisen und auch die Reichweite hat in den vergangenen Jahren zugenommen, allerdings ist die Signifikanz der Interaktionen des Spielers nach wie vor relativ gering. Selbst komplexe digitale Spiele wie Beyond: Two Souls mit ihren multilinearen Spielverläufen und der damit verbundenen Multioptionalität führen die diversen Spielverläufe immer wieder an bestimmten Knoten zusammen, sodass es, retrospektiv betrachtet, (nahezu) unerheblich ist, wie man sich vorher entschieden hat, man ist doch an demselben Punkt angelangt wie derjenige, der sich zuvor ganz anders entschieden und dementsprechend einen anderen Pfad eingeschlagen hat. ${ }^{178}$ Hypertextuell betrachtet sind selbst digitale Spiele wie Beyond: Two Souls sehr simpel gebaut und kaschieren ihre Einfachheit bspw. durch die Ausdehnung der erzählerischen Elemente, die zusätzliche immersive Effekte erzeugen und den Rezipienten somit ,ablenken“ sollen. (vgl. dazu RYAN 2001b, 258 ff.)

Was sich hieraus grundsätzlich für das Interaktionsdesign digitaler Spiele sagen lässt, ist, dass diese Spiele die Diskrepanz zwischen hoher Frequenz und Reichweite der Interaktionsmöglichkeiten auf der einen und niedriger Signifikanz auf der anderen Seite verdecken müssen. Eine hohe Signifikanz ist bisher aus finanziellen Gründen nicht realisierbar, da die Multioptionalität eines Knotens - selbst dann, wenn sie nur zweiwertig ist

\footnotetext{
${ }^{178}$ In extremer Form gilt dies für die digitalen Spiele von Telltale Games.
} 
- zu einer immensen Ausdifferenzierung der hypertextuellen Struktur führen würde. Aus einem Knoten werden zwei, aus zwei vier, aus vier acht, aus acht sechzehn usw. Der Programmieraufwand für die grafische Wiedergabe dieser Knoten und ihrer Handlungsfolgen wäre zu groß. Man muss sich aus technologischen und ökonomischen Gründen von der Idee verabschieden, dass digitale Spiele als simulative Systeme in der Lage sind, die Komplexität der Realität ohne Verluste wiederzugeben (was Simulationen, man denke an Frasca, aber grundsätzlich nicht tun, da das simulierende System immer kleiner ist als das simulierte). (vgl. FRASCA 2001) In Anbetracht dessen, ist das Design von Interaktionen unerlässlich, aber was heißt das genau?

Nach Salen und Zimmerman ist es bei der Beurteilung einer Interaktion wichtig, festzustellen, ob es sich hierbei um eine Interaktion handelt, die designt wurde oder nicht. Designte Interaktionen erkennt man an drei Merkmalen: Sie sind Teil eines Systems bzw. in einen definierten Kontext eingebettet wie ein Spiel (1), „meaningful by a set of rules describing their relationship“ (2) und es besteht eine Verbindung zwischen der (Inter-)Aktion und dem Ergebnis (3). (SAlen/Zimmerman 2004, 60 f.) Das System, in dem designte Interaktionen situiert sind, entsteht autopoietisch durch diese und macht das Spiel damit erst zum Spiel. Designte Interaktionen produzieren somit durch den menschlichen Interagierenden manipulierbare Spielsysteme. Für das Interaktionsdesign bedeutet dies, dass bei der Entwicklung jeder designten Interaktion ihr systemischer Kontext mitgedacht werden muss. Jede Interaktion muss sich bspw. konform zum Genre, dem Narrativ oder anderen designten Interaktionen verhalten, denn andernfalls droht ein Bedeutungsverlust, der im schlimmsten Fall zum Scheitern des Spiels führen kann.

Zur Illustration einige kurze Beispiele: In einem Shooter wie Space Invaders ergibt es wenig Sinn, Interaktionen zu designen, die nicht zum Shooter-Genre passen. Designte Interaktionen wie Fußballspielen sind für Fußballadaptionen innerhalb des Sportsimulationsgenres à la FIFA konstitutiv, wirken aber in einem Shooter wie Space Invaders kontraproduktiv. Hier beziehen sich die meisten designten Interaktionen auf die Spielmechanik des Schießens. So kann sich der Spieler verstecken oder ausweichen, ist hierin aber auch (räumlich) limitiert, da Space Invaders dem Subgenre des Fixed Shooters angehört und somit - im Vergleich zu den meisten aktuellen Shootern wie Destiny (2014 ff.) - dem Spieler nur in sehr geringem Maße eine Raumbemächtigung via Avatar gestattet. Designte Interaktionen im Fixed Shooter müssen sich an dieser Reduktion der räumlichen Bewegungsmöglichkeiten des Avatars orientieren, um als Fixed Shooter spielbar zu sein. Ein 
Fixed Shooter, in dem sich der Avatar frei bewegen kann, ermöglicht dem Spieler zwar eine größere Vielfalt an möglichen Taktiken, untergräbt aber zugleich das Spielprinzip des Fixed Shooters.

Komplexer wird dies, wenn man digitale Spiele hinzuzieht, die narrative Elemente beinhalten wie Heavy Rain. Die designten Interaktionen müssen sich einerseits an den Spielmechaniken orientieren, die Spieler mit einem Interaktiven Film mit AdventureAnleihen verbinden, andererseits müssen die Interaktionen aber auch die (medialen) Narrationen plausibilisieren und umgekehrt. Interaktionen, die der Narration zuwiderlaufen, müssen vermieden werden, da sie die Immersion des Spielers nachhaltig beschädigen könnten. Im Sinne des Spielprinzips von Heavy Rain wird der Spieler in die Rolle von vier Avataren versetzt, die von den Handlungen des Origami-Killers getrieben werden, die stets passiv auf die Handlungen des aktiven Mörders reagieren müssen. Diese Passivität der Avatare schließt aber eine Vielzahl an aktiven Interaktionstypen wie Schießen (weitestgehend) aus. Im Unterschied $\mathrm{zu}$ digitalen Spielen wie Grand Theft Auto: ${ }^{179}$ San Andreas (2004), wo der Spieler zwar auch von äußeren Umständen zu seinen Taten getrieben wird, aber dennoch stets als den Spielverlauf voranbringende Figur auftritt, sind die Avatare in Heavy Rain in ihrer Agency deutlich eingeschränkter, verfügen über weitaus geringere Interaktionsmöglichkeiten als der Protagonist CJ in San Andreas. Die größere Anzahl an Handlungsoptionen in San Andreas hängt aber auch mit dem Open-World-Prinzip zusammen, das eine Vielzahl an Möglichkeiten bzw. einen Möglichkeitsraum mit derart hoher Frequenz, Reichweite und Signifikanz der Interaktionen begünstigt.

But game designers do not directly design play. They only design the structures and contexts in which play takes place, indirectly shaping the actions of the players. We call the space of future action implied by a game design the space of possibility. It is the place of all possible actions that might take place in a game, the space of all possible meanings which can emerge from a game design. (SALEN/ZIMMERMAN 2004, 67; Herv.i.O.)

Designer sollten, nach Salen und Zimmerman, dem Spieler keine Interaktionen aufoktroyieren, sondern einen Möglichkeitsraum entwerfen, der dann letztlich neben dem Ludus auch Paidia-Spiele befördert. Idealerweise entsteht hierdurch ein Spielraum, der Spielern ein Höchstmaß an ludischer Agency garantiert und eine dementsprechend hohe Bandbreite an Interaktionen bereitstellt. Kaum ein digitales Spiel zeigt klarer, was im Gamedesign unter einem Möglichkeitsraum zu verstehen ist als Minecraft (2009 ff.). Im sog. „Kreativ-Modus‘ des Spiels stehen dem Spieler unbegrenzte Ressourcen zur Verfügung, die er

\footnotetext{
${ }^{179}$ Im Folgenden mit GTA abgekürzt.
} 
verwenden kann, um aus den 3D-Blöcken den Spielraum ganz nach seinem Belieben zu formen. ${ }^{180}$ Dabei fokussiert er sich neben dem Erkunden der immens großen Welt (in manchen Versionen sogar nahezu unendlich groß) ${ }^{181}$ auf das Bauen diverser Bauwerke. Er kann, wie für Minecraft grundsätzlich charakteristisch, Objekte abbauen und in vielen möglichen Variationen kombinieren. Im Unterschied $\mathrm{zu}$ anderen Modi des Spiels sind im Kreativmodus die physikalischen Kräfte noch weitgehender aufgehoben, als dies ohnehin schon der Fall ist, was aber dazu dienen soll, die freie Konfiguration des Spielraums durch den Spieler noch weiter zu erleichtern. Das Spiel hat dabei kein Spielziel, dementsprechend kein Ludus, unterstützt hingegen vollständig das paidianische Spielen des Spielers. Dies wird möglich, da die designerischen Rahmensetzungen einen sehr großen Möglichkeitsraum generieren, der eine Vielzahl an Interaktionen zwischen Spieler und System gestattet sowie die individuelle Agency des Spielers dermaßen erhöht, dass es kaum ein anderes digitales Spiel gibt, in dem der Spieler mehr Handlungsmacht und Handlungsoptionen hat. Jedoch sollte man nicht vergessen, dass Minecraft hier ein Extrembeispiel ist, und dass viele andere digitale Spiele entweder aus pragmatischen technologischen bzw. ökonomischen Ursachen oder weil sie eine bestimmte Geschichte erzählen wollen, nicht einen derartigen Möglichkeitsraum wie Minecraft anbieten können. Hier gilt es nun, Interaktivität und Agency $\mathrm{zu}$ reduzieren, ohne dass der Spieler umgehend realisiert, wie limitiert er in seinen Handlungen ist. Dies funktioniert letztlich auch durch die Manipulation der Entscheidungsfindung ${ }^{182}$ des Spielers, die diesem in der Regel nicht bewusst ist. Um z.B. die Kohärenz der Interaktionen in interaktiv-narrativen digitalen Spielen zu gewährleisten, wird häufig die vom Gamedesign intendierte Handlungsoption ${ }^{183}$ indirekt herausgestellt, indem eine Handlungsoption mit Blick auf das Narrativ (eindeutig) plausibler bzw. naheliegender ist

\footnotetext{
${ }^{180}$ Vgl. dazu exemplarisch das Let's Play von VinYLTox https://www.youtube.com/watch?v=XIVwLEvoj20 (30.06.2018).

${ }^{181}$ Dies funktioniert, da die Spielwelt prozedural generiert wird wie bspw. in The Elder Scrolls II: Daggerfall (1996).

${ }^{182}$ Im designerischen Kontext machen Salen und Zimmerman auf die „Anatomy of a choice“ aufmerksam. Diese besteht aus fünf Schritten der Entscheidungsfindung als interaktivem Prozess zwischen Spieler und System. Dem Kontext (1), der Übermittlung der Entscheidungsoptionen des Systems an den Spieler (2), der konkreten Entscheidung des Spielers (3), dem Ergebnis und den Folgen (4) sowie der Übermittlung des Entscheidungsergebnisses des Systems an den Spieler (5). Vgl. Salen/Zimmerman (2004), $63 \mathrm{f}$.

${ }^{183}$ Markus Engelns führt hierzu aus: „Der Trick solchen Spieldesigns liegt somit weniger darin, dem Spieler die Möglichkeit zur Bildung eines spielerischen Selbst zu geben und ihn tatsächlich moralisch entscheiden zu lassen. Vielmehr steht im Zentrum die Suggestion, das Spiel biete so differenzierte Entscheidungsmöglichkeiten an, dass der Spieler als komplexes gesellschaftliches Wesen etwas über sich selbst erfährt. Dass dabei viele Entscheidungen hochgradig verknappt sind, und zwar sowohl was die Vorgeschichte, als auch was die tatsächlichen Entscheidungsmöglichkeiten angeht, fällt dabei zumeist erst bei einem zweiten Spieldurchgang auf, wenn nämlich die wenigen Differenzen zwischen den verschiedenen Spielabläufen offenbar werden." ENGELNS (2015); Herv. KM.
} 
als die anderen oder indem die Moralität ${ }^{184}$ des Handelns hinzugezogen wird. ${ }^{185}$,Moralität ${ }^{\text {‘ }}$ ist in diesem Kontext in einem sehr allgemeinen Sinne zu begreifen, wie der Philosoph Ronald Dworkin herausstellt, wenn er den Unterschied zwischen Ethik und Moralität bzw. Moral betont. „I emphasize here and throughout the book the distinction between ethics, which is the study of how to live well, and morality, which is the study how we must treat other people." (DWORKIN 2013, 13) Wie wir unsere Mitmenschen behandeln, wie wir moralisch urteilen, richtet sich dabei nach „basic moral concepts“, (ebd., 12) die sich, wenn man so will, als anthropologische Grundkonstanten historisch, sozial und kulturell unverändert zeigen. Beispiele für Handlungen, die als unmoralisch deklariert und bei Ausübung sanktioniert werden, findet man in den meisten, wenn vorhanden, kodifizierten Schriften der diversen

${ }^{184} \mathrm{Zu} \mathrm{Moral/Ethik} \mathrm{in} \mathrm{digitalen} \mathrm{Spielen} \mathrm{vgl.} \mathrm{Miguel} \mathrm{SICARTs} \mathrm{(2009)} \mathrm{wegweisende} \mathrm{Studie} \mathrm{The} \mathrm{Ethics} \mathrm{of} \mathrm{Computer}$ Games. Beim Blick auf die Darstellung von und die Anleitung zu moralischem Verhalten in digitalen Spielen muss man konstatieren, dass diese bisher weniger durch sehr feine Schattierungen moralischer und ethischer Kodizes hervorgetreten sind. Zwar gibt es digitale Spiele wie Life Is Strange (2015) oder This War of Mine (2014), die das moralische Handeln einzelner Subjekte im kleinstädtischen Milieu oder gar das Überleben Unbeteiligter im Krieg thematisieren und dabei durchaus einiges an reflektierendem Potenzial offenbaren, dem stehen aber häufig digitale Spiele gegenüber, für die Moral nur eine binäre Entscheidungsoption zwischen Schwarz und Weiß ist. Exemplarisch seien hier zwei Memes angeführt, die sich moralisch mit der Entscheidung befassen, ob man den Drachen Paarthurnax in The Elder Scrolls V: Skyrim (2011) töten sollte oder eben nicht. Vgl. hierzu https://me.me/i/if-you-killed-paarthurnax-wecantbe-friends-credit-hundi-the-dovakiin\%E2\%80\%A2-elderscrolls-1662084 sowie https://me.me/i/8799370 (30.06.2018). Beide Memes zeugen von einer immensen Emotionalität und stehen stellvertretend für die große Mehrheit an Fanartefakten, die für Paarthurnax Partei ergreifen. Dabei kündigen sie der Gegenseite nicht nur die Freundschaft auf, sondern teilen die Fanwelt in zwei Lager - die ,Goldenen' (pro Paarthurnax) und die ,bösen Bastarde' (contra Paarthurnax). Die Verschonung von Paarthurnax durch den Spieler wird durch die Positionierung des Drachen sowie der Gegenpartei (der sog. ,Klingen') in der narrativen Figurenkonstellation von Skyrim als intendierte Handlungsoption profiliert. Zwar war Paarthurnax einst Stellvertreter des Antagonisten Alduin, dieser konnte lange vor Handlungsbeginn von Sykrim letztlich aber nur besiegt werden, da Paarthurnax diesen verriet. Anschließend gründete Paarthurnax die Organisation der ,Graubärte', um die magisch-militärisch überlegenen Fähigkeiten der Drachen mit den Menschen zu teilen. Paarthurnax wird somit als eine ,Vom-Saulus-zumPaulus'-Figur dargestellt, die in einer Rede über Vertrauen die moralisch bedeutende Frage stellt, ob es besser sei, gut geboren zu werden oder seine böse Natur zu überwinden. Vgl. hierzu das Let's Play von DFD_FrEESPEECH https://www.youtube.com/watch? v=XpgLDjLwego (30.06.2018). Die Klingen erscheinen demgegenüber als eine ideologisch verbrämte und reaktionäre Militärsekte, die sich nicht von alten Verhältnissen zu lösen vermag und im Prozess ihres endgültigen Untergangs versucht, möglichst viel Schaden anzurichten. Paarthurnax auf der einen und Delphine und Esbern (Klingen) auf der anderen Seite spiegeln in ihrer Frontstellung auch dynamische gegen statische Figurenentwürfe, wobei anscheinend jene eher auf die Zustimmung der Nutzenden treffen, die sich läutern können, die hierdurch reflektierter und versöhnlicher sind, als jene, die nur Hass und Rache kennen. Interessanterweise wenden sich gerade jene Eigenschaften in Person der Fans innerhalb der Fankultur wiederum gegen die Klingen selbst, die in der Fankunst brutal ermordet und zu pädagogischen Zwecken ausgestellt werden. Vgl. https://www.nexusmods.com/skyrim/images/67708 (30.06.2018). Derartige Fanartefakte sind als eine ,Strafe' der Fans zu verstehen, die sich nicht von den Klingen instrumentalisieren lassen wollten, um den Auftragsmord an Paarthurnax zu begehen. Diese Entscheidung wird zudem spielstrategisch unterstrichen, da die Ermordung des Drachen den Kontaktabbruch zu den Graubärten zur Folge hat, was bedeutet, dass der Spieler nicht mehr in den Besitz neuer drachenmagischer Fähigkeiten gelangt, die für den Spielerfolg aber sehr wichtig sind.

${ }^{185}$ Zum ,wertebewussten' Design digitaler Spiele unter politischen, sozialen und moralischen Gesichtspunkten vgl. BeLMAN/FLANAGAN (2010). 
historischen Religionen. ${ }^{186}$ Ein jüdisch-christliches Exempel hierfür sind die zehn Gebote des Alten Testaments, die bspw. Mord, Diebstahl oder Verleumdung untersagen. Ein moralisches Handeln ist in diesem Sinne immer eines, das sich unter Berücksichtigung der unstrittig geltenden ,moralischen Basiskonzepte، an anderen und deren Integrität orientiert. Digitale Spiele arbeiten mit diesen moralischen Basiskonzepten, sodass dem Spieler letztlich eine bestimmte Handlungsoption zweifellos als ,moralischer ${ }^{6}$ als die anderen erscheint. Dies impliziert eine Fokussierung, und das ist für diese Arbeit insgesamt zentral, auf digitale Spiele als ,geschlossene ethische Systeme‘. Miguel Sicart unterscheidet diese von ,offenen ethischen Systemen', welche sich dadurch auszeichnen, dass sie einen Spieler verlangen, der eigene ethische und moralische Entscheidungen trifft und dementsprechend handelt. ,Geschlossene ethische Systeme' hingegen konfrontieren den Spieler mit einem vordefinierten Set an ethischen und moralischen Werten, zu denen sich der Spieler verhalten muss. (vgl. SICART 2009,214 ff.)

Ein Beispiel verdeutlicht die Funktion von digitalen Spielen als ,geschlossenen ethischen Systemen': Es existiert eine Situation in einem digitalen Spiel, in welcher der Spieler in den Besitz eines beliebigen Objektes gelangen muss. Hierzu werden ihm zwei Handlungsmöglichkeiten vom Spiel angeboten. Er kann entweder den Non-Player Character (NPC), der besagtes Objekt gegenwärtig sein Eigentum nennt, töten oder ihm dies abkaufen. Dabei ist der käufliche Erwerb des Objektes die vom Gamedesign intendierte Handlungsoption. Die meisten Spieler dürften bereits in diesem Szenario die zweite Option wählen, jedoch kann man dies von Seiten des Gamedesigns noch eindeutiger gestalten, indem man bspw. den Eigentümer des Objektes dem Avatar gegenüber sehr freundlich auftreten lässt, den Kaufpreis sehr gering ansetzt etc. Hierdurch wird die intendierte Handlungsoption herausgearbeitet und zugleich als solche kaschiert (da immerhin zwei Handlungsmöglichkeiten vorliegen, die potenziell gleichwertig erscheinen), sodass sie dem Spieler, und besonders wenn seine Immersion sehr intensiv ist, nicht unbedingt als intendierte Handlungsoption bewusst werden muss, obwohl er sie dennoch realisiert. Häufig korrespondiert dies mit dem Narrativ bzw. mit der (durch das Narrativ bedingten) narrativen Figurenkonzeption des Avatars oder der NPCs. Andreas Rauscher merkt hierzu an:

\footnotetext{
${ }^{186} \mathrm{Zu}$ der sich daraus ergebenden Einteilung in ,gut‘ und ,böse‘ der Theologe D.M. Burke: „So, the Christian Worldview provides a logical foundation by which we are able to apprehend what is good, (whatever provides value to human beings, both individually and corporately, and fosters loving relationship between God and human beings and among humanity) and what is evil, (whatever devalues human beings, both individually and corporately, and hinders loving relationship between God and human beings and among humanity).“ BURKE (2011), 169 .
} 
Dieses Vorgehen [gemeint ist das Acting] ${ }^{187}$ konzentriert sich auf das Ausagieren der narrativen Rolle; die Schauspieler versuchen in ihrem Spiel ganz dem Charakter der vorgegebenen Figur $\mathrm{zu}$ entsprechen. Der weiter gefasste Begriff der Performance integriert hingegen auch Eigenheiten, die ein Schauspieler durch seine oder ihre Persönlichkeit in die Rolle einbringt, diese können von einer unbewussten spontanen Reaktion bis hin zu idiosynkratischen Einfühlung des Method Acting reichen. (RAUSCHER 2015, 99)

In diesem Zusammenhang ist besonders das Acting von Interesse, wenn man es auf den Spieler überträgt. Dann kann nämlich der Spieler beim Spielen eines interaktiv-narrativen digitalen Spiels die vorgegebene Figurenkonzeption ausagieren, indem er diese übernimmt und auf seine Realisierung des Avatars überträgt. ${ }^{188}$ Ein Beispiel: Wenn Ethan Mars in Heavy Rain vom Origami-Killer vor die ,Aufgabe‘ gestellt wird, einen anderen Menschen (NPC) zu töten, um der Rettung des Lebens seines Sohnes Shaun näherzukommen, so verstößt dies eindeutig gegen moralische Basiskonzepte. Die Tötung des besagten NPCs ist aber dennoch die intendierte Handlungsoption, sodass sie plausibilisiert werden muss. ${ }^{189}$ Moralisch wird dies einerseits dadurch ,erleichtert ${ }^{\star}$, dass der zu Tötende ein Drogenhändler ist. ${ }^{190}$ Auf perfide Art wird hierdurch der ,Tausch' des Lebens des unschuldigen Shauns mit dem des schuldbeladenen Kriminellen suggeriert. Andererseits, und damit verbunden, legt das Acting des Spielers diese Handlungsoption zudem nahe, wenn man die narrative Figurenkonzeption Ethan Mars' betrachtet. Dieser wird als vollkommen verzweifelter Vater dargestellt, dessen moralische Standards im Fortlauf der Handlung zunehmend erodieren (können), was dieser (und damit der Spieler) aber oft bereit sein wird, in Kauf zu nehmen, da die Rettung des Sohnes zum immer dominierenderen Handlungsmovens und zur Legitimationsgrundlage sämtlicher Handlungen wird. Die Situation der Figur Ethan Mars' als Opfer des OrigamiKillers im erweiterten Sinn, die im Spielverlauf immer prekärer wird, bietet immersive Potenziale an, die den Spieler via Emotionalisierung für die Figur einnehmen und diese dazu anleiten sollen, gemäß der Anlage der narrativen Figurenkonzeption zu handeln. (vgl. RYAN

\footnotetext{
${ }^{187}$ Rauscher bezieht sich hier auf die Unterscheidung zwischen Acting und Performance nach James NAREMORE (1990).

${ }^{188}$ Kathrin Fahlenbrach und Felix Schröter merken zum Einfluss der narrativen Anlagen eines digitalen Spiels auf das Spielerhandeln in ihrem Aufsatz zu rezeptionsästhetischen Perspektiven in den Digital Game Studies an: „Auf einer weniger basalen Ebene sind für das perzeptive Erfassen von narrativen Strukturen (wie etablierten Konflikten und Figurenkonstellationen) auch archetypische Handlungsskripts charakteristisch, die von Spielern aufgrund angeborener Mustererkennung rasch erfasst werden und entsprechend einfache Handlungsreflexe auslösen können. [...] Wie Grodal aus einer evolutionspsychologischen Perspektive argumentiert, handelt es sich bei derartigen Mikroskripts um biologisch und damit in der sinnesbasierten Wahrnehmung verankerte Muster, die das perzeptive Erfassen und Erleben von Geschichten grundlegend strukturieren können“". FAHLENBRACH/SCHRÖTER (2015), 184. Vgl. dazu auch GrODAL (2003).

${ }^{189}$ Als intendierte Handlungsoption wird sie dadurch erkennbar, dass ihre Realisierung die Chancen, Shaun zu retten, (spielmechanisch betrachtet) signifikant erhöht, da Ethan für jede vom Origami-Killer gestellte Aufgabe einen Hinweis auf den Aufenthaltsort seines Sohnes erhält.

190 Vgl. dazu das Let's Play von THE GAMEDePOT https://www.youtube.com/watch?v=ZAv7dIKVqBw (30.06.2018).
} 
2001b, 263 f.) Was dieses Beispiel damit unterstreicht, ist, dass innerhalb des Sets der designten Interaktionen eine bestimmte Interaktion (in seltenen Fällen auch eine Gruppe von Interaktionen) vom Design präferiert werden kann und in der Regel auch wird (zumindest in Ludus-Spielen).

Damit ist ein entscheidender Aspekt angesprochen - Interaktionen und Handlungsoptionen stehen in digitalen Spielen nicht für sich allein, sondern sind in einen Kontext eingebettet, sie sind Teil eines Sets, das alle möglichen Interaktionen bündelt und miteinander synchronisiert. Dieses Set nenne ich das Interaktiv und führe es im folgenden Kapitel aus. Zuvor soll jedoch in aller Kürze zusammengefasst werden, was explizit und implizit über die Interaktivität digitaler Spiele gesagt wurde. Für die Interaktivität Neuer Medien ist grundsätzlich kennzeichnend, dass sie sich (bedingt durch hypertextuelle, non-lineare ${ }^{191}$ oder netzwerkartige Strukturen der Medienträger) explorativ-testend manifestiert. Der Mediennutzer verfährt kursorisch im Trial and Error-Verfahren, um den Möglichkeitsraum zu erkunden. Die Interaktivität digitaler Spiele hebt sich aber auch dadurch von derjenigen anderer Neuer Medien ab - worauf Daniel Cermak-Sassenrath zu Recht hingewiesen hat -, dass sie nicht nur ludisch wirkt, sondern auch Formen und Arten des Spiels viel stärker mit umfasst. So bezieht sich die Interaktivität digitaler Spiele vornehmlich auf Ludus und Paidia.

Die ,Ludus-Interaktivität ${ }^{6}$ ist strikt (vor-)definiert, da der Spieler versucht, die Konventionen dieser möglichst schnell zu erfahren, um sich im Anschluss daran gemäß diesen zu verhalten, um das Spielziel somit zu erreichen. Spieler tendieren im Rahmen der Ludus-Interaktivität nicht dazu, Agency und Interaktivität vollkommen zu erkunden, sondern identifizieren lediglich die intendierte Handlungsoption und realisieren diese, um im Spielverlauf voranzuschreiten. Die ,Paidia-Interaktivität‘ setzt demgegenüber darauf, gerade Agency und Interaktivität vollends zu erkunden, möglichst viele Handlungsoptionen zu realisieren, um einen maximalen Möglichkeitsraum zu erhalten. Grundsätzlich kann man diese beiden ludischen Interaktivitätsformen auch in Neuen Medien generell beobachten, jedoch nicht, wenn man andere Formen zu spielen mit einbezieht. So findet man z.B. beim Surfverhalten von Mediennutzern im Internet Interaktionen, die einer Ludus-Interaktivität nicht unähnlich sind, da diese streng zielorientiert vorgehen. Im Kontrast zur LudusInteraktivität in digitalen Spielen spielt Agonalität dabei aber eher eine untergeordnete Rolle, welche sehr oft eine Wettkampfatmosphäre zwischen Spieler und System bzw. dessen

${ }^{191}$ Vgl. zur Non-Linearität und Literaturtheorie AARSETH (2003). 
Repräsentanten aufbaut. ${ }^{192}$ Digitale Spielgenres wie Adventure, Action-Adventure, Hack \& Slay, Jump'n'Run, Shooter, Sportsimulation, Aufbausimulation und Strategiespiel zeugen davon. Beim Surfen im Internet kann man zudem Mediennutzer beobachten, die sehr kursorisch-paidianisch interagieren, jedoch kommt dem Mimicry dabei kaum eine Bedeutung zu, wohingegen dies für Paidia-Interaktivität in digitalen Spielen zentral ist. Hier nimmt der Spieler immer wieder neue Rollen ein, maskiert sich, um verschiedene Aspekte seiner Persönlichkeit auszuprobieren. Exemplarisch zu nennende digitale Spielgenres hierfür sind nahezu alle Subgenres des RPGs. Betrachtet man mit dem Alea-Spiel eine weitere Hauptrubrik von Spielen nach Caillois, so treten noch mehr Differenzen zutage. (vgl. 1.2.1) Die zufallsbasierte Interaktion ist nämlich bei kaum einem Neuen Medium derart stark vertreten wie bei digitalen Spielen. Dies liegt grundsätzlich daran, dass der Ausgang von Interaktionen im (digitalen) Spiel immer offen ist, wohingegen dieser bei der Interaktion im sozialen Raum oder der Interaktion mit Neuen Medien oder zwischen Nutzern vermittelt durch Neue Medien in der Regel schon vorher feststeht. Die Interaktivität digitaler Spiele ist dadurch letztlich simulativer als die anderer Medien, weist stets einen spieltypischen Als-ObCharakter auf.

\subsubsection{Das Interaktiv in digitalen Spielen}

Das Interaktiv ist das Pendant zum Narrativ und legt die interaktiven Optionen und Handlungsmöglichkeiten fest. Insofern ist das Interaktiv ein Set ${ }^{193}$ aus (vom Designer) definierten Handlungsoptionen und designten Interaktionen, die an einem dominanten Spielprinzip orientiert sind. Dieses Spielprinzip wird durch die Interaktionstypen und Spielmechaniken bestimmt, die konstitutiv für das Genre des jeweiligen digitalen Spiels sind. Bei einem Action-Adventure wie The Legend of Zelda: Twilight Princess (2006) sind dies das Erkunden der offenen Spielwelt, das Lösen von Rätseln und der Kampf mit diversen Gegnern unterschiedlicher Stärke. Durch diese drei Maximen ergeben sich weitreichende Konsequenzen für den Möglichkeitsraum, den das Interaktiv anbieten muss. So sind die designten Interaktionen an der erheblichen räumlichen Offenheit ebenso orientiert wie an der agonalen Ausgestaltung des Spiels durch die zahlreichen Kämpfe. Die designten Interaktionen

\footnotetext{
192 Wie aus dem Surfen auf Websiten wie Wikipedia aber ein agonales Spiel mit einer Ludus-Interaktivität werden kann, verdeutlichen digitale Spiele wie das The Wiki Game (2017). Hier wird ein Startbegriff gegeben und der Spieler muss innerhalb der vorgegebenen Zeit zu einem Zielbegriff gelangen. Durch den Einbezug von Highscore-Elemente wird die Ludus-Interaktivität erheblich agonalisiert, da man gegen andere Spieler antritt. Dabei gewinnt jener Spieler, der am schnellsten und mit den wenigsten Klicks das Spielziel erreicht.

${ }^{193}$ Hier im Sinne einer (intentionalen) Zusammenstellung begriffen, die mehrere Elemente strukturell und systemisch miteinander verbindet.
} 
richten sich hierbei aber nicht nur nach diesen Maximen und den anderen designten Interaktionen, mit denen sie in einem steten systemischen Kontext stehen, sondern auch nach dem Narrativ und den hiermit verbundenen Figurenkonzeptionen. Der Mythos als Narrativ und seine Figuren erfordern vom Interaktiv designte Interaktionen, die für den Spieler in Bezug auf den Mythos plausibel erscheinen, sodass eine Kohärenz zwischen interaktiven und narrativen Elementen gegeben ist.

Das bedeutet aber auch, dass das Interaktiv zum einen festlegt, was Spieler machen können, wie es zum anderen bestimmt, was Spieler (nicht) machen dürfen. Das Interaktiv ist die Sanktionsinstanz des digitalen Spiels, die präventiv , falsche“ Interaktionen ausschließt bzw. die ,richtige‘ Interaktion markiert, indem sie besonders plausibel im Zusammenhang des Narrativs und der Figurenkonzeption erscheint oder andere Interaktionsmöglichkeiten als moralisch fragwürdig oder amoralisch kennzeichnet. (vgl. 2.3.3) Anders gesagt definiert das Interaktiv die sozialen Konventionen und diskursiven Sagbarkeitsregeln der digitalen Spielwelt, ist (zusammen mit dem Narrativ) die regulative Einheit interaktiv-narrativer digitaler Spiele und dient hiermit letztlich der Ordnungsstiftung im System.

Interessant ist am Interaktiv, dass es als Teil des Interaktiv-Narrativs vom Produzenten bestimmt wird, indem dieser die potenziellen Möglichkeiten der Interaktivität digitaler Spiele konkret für sein Interaktionsdesign nutzt, dass seine wesentliche Funktion aber nicht nur in der Anleitung der Spieler, sondern auch in seiner sukzessiven Aufdeckung besteht. Dies liegt daran, dass das Interaktiv neben dem Interaktionsdesign einen weiteren fundamentalen Aspekt digitaler Spiele koordiniert - die Spielregeln. Diese Regeln und die Interaktionen sind eng miteinander verbunden, da Interaktionen als Operationen des Systems Spiel immer regelgeleitet sein müssen, Spielregeln aber andererseits kompatibel mit den designten Interaktionen sein müssen und letztlich, wenn sie nicht direkt vom System artikuliert werden, indirekt durch die Interaktionen erlernt werden. In diesem Sinne ist das Interaktiv zu Spielbeginn für den Spieler enigmatisch, wird aber im Spielverlauf von diesem mehr und mehr erschlossen, bis dieser die Spielegeln und möglichen Interaktionen kennt bzw. mehr noch, darüber hinausgehend, diese derart internalisiert hat, dass eine Manipulation des Systems durch den Spieler in einem höheren Maße möglich wird. Versierte Spieler können dann das Regelsystem und das Interaktionsdesign gegen das System selbst einsetzen, um es 
$\mathrm{zu}$,besiegen'. Speedruns ${ }^{194}$ bspw. beruhen in der Regel auf der vollkommenen Entschlüsselung des Interaktivs durch den Spieler, der die Oberfläche digitaler Spiele durchbricht und die im Programmcode angelegten Strukturen des Interaktivs ausnutzt. (vgl. dazu auch 4.2.2.4.1.1)

Dies bedeutet letztlich aber auch, dass der Spieler die Spielmechaniken ebenfalls aufdecken, internalisieren und beherrschen lernen muss. Im Unterschied zu den Spielregeln, die gewissermaßen die Grenzen der interaktiven Handlungsräume setzen, sind die Spielmechaniken aber jenem Bereich des Interaktivs zuzuordnen, der Richtungs- oder Zielvorgaben für die interaktiven Handlungen des Spielers macht, die dieser aber nicht einhalten muss. Insofern sind für die Analyse der Spielmechaniken eines Spiels die Interaktionen bzw. das Interaktionsdesign von zentralem Interesse. Im Kontext designter Interaktionen bietet es sich an, die Interaktion in digitalen Spielen aufzuspalten und zwischen realen und virtuellen Interaktionen zu unterscheiden.

\subsubsection{Reale und virtuelle Interaktionen in digitalen Spielen}

Ein derartiger Interaktionsbegriff betrachtet im Interaktionsprozess zwischen Spieler und System primär die Rolle des menschlichen Interagierenden bzw. dessen Handlungen im Rahmen der Interaktionen. Unter ,realen Interaktionen“ verstehe ich alle Handlungen des Spielers, die zwar mit Bezug auf das digitale Spiel ausgeführt werden, die aber im ,realanalogen' Raum stattfinden, also als tatsächliche physische Handlung oder Reaktion ausgeführt werden. Ein Beispiel hierfür sind u.a. die Eingaben/Aktionen des Spielers in die Schnittstelle. Mit dem Begriff der, virtuellen Interaktion' fasse ich alle Handlungen des Spielers sowie Reaktionen des Systems, die im virtuellen Raum situiert sind oder hier ihren Ursprung haben. Bei der virtuellen Interaktion ist weniger die physische Aktivität des Spielers entscheidend als vielmehr die psychische bzw. die kognitive. Ein Beispiel hierfür ist u.a. die Kommunikation des Spielers via Avatar mit den NPCs. Somit stellt sich die Nutzer-SystemInteraktion in digitalen Spiel als Zirkel aus realen und virtuellen Interaktionen dar, die sich permanent gegenseitig bedingen und hierdurch zur Autopoiesis des Systems beitragen.

Reale und virtuelle Interaktion bilden dabei einen Zirkel, da die realen Aktionen des Spielers als Eingaben in die Schnittstelle im realen Raum stattfinden, aber als Ausgabe nur virtuell erfolgen. Die kognitive Wahrnehmung des Spielers und sein tatsächliches Handeln lassen sich analytisch also differenzieren, auch wenn dabei nicht vergessen werden darf, dass reale und virtuelle

\footnotetext{
${ }^{194}$ Unter einem Speedrun versteht man das schnellstmöglich Durchspielen eines digitalen Spiels. Dies ist oft mit dem Vorsatz verbunden, den derart entstandenen Spieldurchlauf aufzuzeichnen und anschließend der Community im Internet zugänglich zu machen. Zum Speedrun als Praktik vgl. SCULLY-BLAKER (2014).
} 
Interaktion nur gemeinsam zum Gelingen der Interaktion zwischen Spieler und System beitragen können. (MATUSZKIEWICZ 2014, 5 f.)

Neben der Handlung wird hierdurch ein zweites Kernelement des soziologischen Interaktionsverständnisses deutlich - die Kommunikation. Als Nutzer mit einem Computersystem $\mathrm{zu}$ interagieren - Turings Gedankenexperiment fußt z.B. auf dieser Annahme -, heißt, mit ihm zu kommunizieren. Das Prinzip dieser Kommunikation beruht auf dem wechselseitigen Charakter interaktiver Prozesse, der sich metaphorisch am signifikantesten in der ,Feedbackschleife ${ }^{6}$ manifestiert. ${ }^{195}$ Maren Conrad macht diese, mit Rekurs auf Konzepte wie Douglas Hofstadters ,seltsame Schleife‘ oder die mathematischen Modelle der Lemniskate und des Möbiusbandes, für die Beschreibung der Interaktivität digitaler Spiele fruchtbar. (vgl. HOFSTADTER 1988) Diese Schleife zeichnet sich, nach Conrad, durch drei Merkmale aus: Sie ist potenziell, bedingt durch ihre Zirkularität, unendlich (1), drückt durch ihre Form bzw. die Überschneidung und die damit verbundene Rückkehr „ein Moment der Selbsterkenntnis“ aus (2) und ist in ihrer Schleifenform ein Paradox, da sie „die Einheit einer Vielfalt" visualisiert (3). (CONRAD 2015, 81)

Die Feedbackschleife verdeutlicht in ihrer visuellen Gestalt (als Metapher) die Autopoiesis des Systems, die bei jeder Interaktion die Selbstreflexion mitdenkt und ein einheitliches Interagieren zwischen unterschiedlichen Interaktionspartner voraussetzt und sich hierdurch von Ansätzen abgrenzt, die Interaktion zwischen Mensch und Maschine nicht als Interaktion betrachten. Somit dient die Feedbackschleife ,als Ausformung eines selbstreferentiellen Systems“. (ebd., 82) Entscheidend an dieser Überlegung ist, dass sie Interaktionen in digitalen Spielen nicht als temporäre, ephemere, sondern als permanente kommunikative systemische Operation digitaler Spiele herausstellt. Hierdurch wird die konstitutive Bedeutung, die Interaktivität für digitale Spiele hat, deutlich, denn ohne Interaktion gibt es kein digitales Spiel, da seine systemerzeugende und -erhaltene Operation fehlt.

Solche Beurteilungen erscheinen im ersten Moment als radikale Absage an den narrativen Gehalt digitaler Spiele, unter der Prämisse, dass man von einer Unvereinbarkeit von

\footnotetext{
${ }^{195}$ Auch das Verhältnis zwischen realen und virtuellen Interaktionen lässt sich (aufgrund der zwei Seiten der Schleife) metaphorisch als Feedbackschleife auffassen. Der mittlere Punkt, an dem sich beide Seiten überschneiden, stellt dann jene Schnittstelle zwischen beiden Bereichen der Mensch-Maschine-Interaktion dar, der für zukünftige Studien ein wichtiger Ansatzpunkt sein kann. Wie geht das System mit den (real interagierend) ausgeführten Eingaben des Nutzers um, wie verarbeitet es diese und wie gibt es das Ergebnis aus? Wie reagiert der menschliche Nutzer hierauf? Daraus lassen sich dann für das Interaktionsdesign interessante Fragen formulieren, die sich danach ausrichten, wie Systeme beschaffen sein müssen, um potenziell unendliche Interaktionsprozesse wie die beschriebenen so zu konstruieren, dass diese den Präferenzen des Mediennutzers entsprechen.
} 
Interaktion und Narration ausgeht, da beide, demgemäß, nicht simultan stattfinden können. Es wird im folgenden Abschnitt aber deutlich werden, dass Interaktion und Narration zwar keine deckungsgleichen, sondern sehr verschiedene Phänomene sind, dass sie aber über Gemeinsamkeiten verfügen, die Hybridisierungen ermöglichen.

\subsection{Narrativität, Narration, Narrativ - Ausführungen zum ,narrativen Begriffsfeld“}

Für das ,narrative“ Begriffsfeld gilt unter dem Gesichtspunkt der Verwendung der dazugehörigen Termini interessanterweise dasselbe wie für das ,interaktive' Begriffsfeld. Die Ausdrücke erfreuen sich aktuell einer regen Konjunktur, was allerdings auch zu ihrer terminologischen Erosion beiträgt. Nicht nur in den Kultur- und Sozialwissenschaften gehören Narrative zum Standardrepertoire vieler Forschungssettings, auch im Kulturjournalismus und den diversen Tätigkeitsfeldern des Kulturmanagements sind sie nicht mehr wegzudenken. Bemerkenswert ist diese Entwicklung v.a. vor dem Hintergrund, dass Narrativität und Narrativ vornehmlich Begrifflichkeiten sind, die im Kontext der postklassischen Narratologie entstanden bzw. hier ihren Aufstieg erlebten.

Problematisch erscheint bei der Definition des ,narrativen“ Begriffsfeldes insbes. der Narrativbegriff $\mathrm{zu}$ sein. ${ }^{196}$ In der Forschung schwanken seine Relationen $\mathrm{zu}$ anderen erzähltheoretischen Termini wie Story, Plot, fabula, sujet, histoire oder discours z.T. ganz massiv. Dabei variiert das Verhältnis zwischen Story/histoire/Plot und Narrativ besonders stark. Von signifikantem Interesse ist in diesem Zusammenhang die Frage, ob die Story ein Produkt des Narrativs ist oder umgekehrt. Es geht darum, zu klären, was woraus hervorgeht.

We have defined a story as a narrative of events arranged in their time-sequence. A plot is also a narrative of events, the emphasis falling on causality. »The king died and then the queen died «, is a story. »The king died, and then the queen died of grief «, is a plot. The time-sequence is preserved, but the sense of causality overshadows it. (FORSTER 1974, 93 f.)

Edward Morgan Forsters berühmte Unterscheidung zwischen Story und Plot, die die kausale Verknüpfung, welche die chronologisch-sequentielle im Fall des Plots ergänzt, als Differenzkriterium zwischen beiden herausstellt, ist zugleich erhellend wie verwirrend. Ergibt es Sinn, Story und Plot gleichermaßen als Narrative zu bezeichnen? ${ }^{197}$ Worin liegt dann der epistemologische Wert des Narrativbegriffs? Das Problem liegt darin, dass der Terminus Narrativ oft dann verwendet wird, wenn es darum geht, eine sequentielle Verkettung zu

\footnotetext{
196 Im (alltäglichen wie fachsprachlichen) englischen Sprachgebrauch bezieht sich das Substantiv ,narrative“ sowohl auf den Prozess der Hervorbringung einer Erzählung als auch auf das Produkt dieses Prozesses.

197 Jannidis bemerkt hierzu: „The narrative is theoretically independent of the story.“ JANNIDIS (2003), $46 \mathrm{f}$.
} 
bezeichnen. Dies spiegelt sich ebenfalls in der bekanntesten bzw. prägendsten Definition des Narrativs durch Gerald Prince wider. Dieser versteht unter einem Narrativ: „,[a] narrative is the representation of at least two real or fictive events or situations in a time sequence, neither of which presupposes or entails the other." (PRINCE 1982,4) Narrative ergeben sich demnach stets aus chronologischen Aneinanderreihungen von Geschehnissen oder Situationen, unabhängig davon, ob sie faktischen oder fiktiven Ursprungs sind.

Dies erklärt dann auch die überbordende Verwendung, die der Narrativbegriff in den vergangenen Jahren - im Besonderen unter dem Einfluss der Cultural Turns - erfahren hat. Die Frage, die sich in Anbetracht dieser Umstände ergibt, ist, ob es nicht notwendig ist, den Begriff terminologisch stärker zu konturieren, um seinen analytischen Gehalt zu erhöhen. Dabei ist aus meiner Sicht v.a. der Aspekt der Chronologie bzw. der Zeitlichkeit nicht unproblematisch als ein Hauptkriterium des Narrativbegriffs. Einerseits wirft dieser Fragen auf, die das komplexe Verhältnis zwischen der Zeitlichkeit von Fiktionen auf der einen und der Realität auf der anderen Seite betreffen. Andererseits setzt dieses Kriterium aber auch (implizit) voraus, dass Narrative immer realisiert werden müssen, da sie nur dann eine ,reale، zeitliche Dimension (im Sinne einer Erzählzeit) erhalten. ${ }^{198}$ Um Missverständnissen vorzubeugen; es sollen hier weder Erzählzeit oder erzählte Zeit als gängige narratologische Konzepte bestritten werden. Es soll lediglich darauf aufmerksam gemacht werden, dass Zeitlichkeit nicht das beste Definitionskriterium für Narrative in Bezug auf deren Sequentialität ist. Denn die meisten narratologischen Arbeiten, die sich auf den sequentiellen Charakter von Narrativen beziehen, untersuchen nicht die chronologische Dimension der Sequentialität, sondern den syntagmatischen Aufbau von Narrativen in seiner Verfahrensmäßigkeit. ${ }^{199}$ Deshalb bietet es sich an, sich vom zeitlich-chronologischen

\footnotetext{
${ }^{198}$ Die Begriffe ,Zeitlichkeit‘ oder ,Chronologie‘ sind aus zwei Gründen im Kontext von Narrativen als diffizil zu betrachten. Zum einen impliziert Zeit, dass etwas realisiert werden muss, damit es sich tatsächlich zeitlich entfalten kann. Der Plot eines Narrativs eines Romans von Christian KRACHT wie 1979 (2001) realisiert sich demnach nur dann konkret, wenn er (vor-)gelesen wird. Zudem ist Zeitlichkeit in solchen narrativen Werken, auch dann, wenn sie wie 1979 auf realen Vorbildern basieren, nur ein fiktives Konstrukt, das keine reale faktische Dimension hat wie bspw. der wöchentliche Einkauf. Insofern ist etwas konkret physikalisch Messbares wie Zeit wahrscheinlich nicht das geeignetste Mittel, um den hier verhandelten Sachverhalt zu beschreiben. Denn zum anderen soll mit dem Terminus ,Zeitlichkeit` oft etwas anderes ausgesagt werden. Primär geht es nämlich darum, nach welchen Regelhaftigkeiten sich die Elemente eines Narrativs syntagmatisch zusammenfügen, wie im Folgenden thematisiert wird.

${ }^{199}$ Dies gilt i.d.R. für die Arbeiten, die strukturalistisch oder formalistisch verfahren. Exemplarisch könnte man u.a. Vladimir PROPP (1972), Joseph CAMPBELL (2011) oder Christopher VogLER (2010) nennen.
} 
Definitionskriterium zu verabschieden und die Sequentialität von Narrativen stattdessen als eine prozessual-prozedurale ${ }^{200} \mathrm{zu}$ begreifen.

Insofern verstehe ich Narrative nicht als chronologische Verkettungen, sondern als erzähllogische. Unter Erzähllogik wird ein bestimmter prozessual-prozeduraler Aufbau eines Narrativs oder einer Gruppe von zusammenhängenden Narrativen verstanden, der für diese typisch ist. ${ }^{201}$ Die Erzähllogik bedingt dabei ein bestimmtes syntagmatisches Muster der essentiellen narrativen Funktionen eines Narrativs, die Roland Barthes ,Kardinalfunktionen“ nennt. ${ }^{202}$ Dieses Syntagma wiederholt sich in Narrativen immer wieder. Bedenkt man Seymour Chatmans Modifikation der narrativen Funktionen Roland Barthes', welcher anstelle des Ausdrucks Kardinalfunktion ,kernel' und anstelle des Begriffs Katalyse ,satellite gebraucht, (vgl. CHATMAn 1993, 53-56) so liegt ein wesentlicher Unterschied zwischen Chatmans und Barthes' Konzept darin, dass ersterer in Bezug auf die ,kernels‘ die Selektivität und Multioptionalität von Handlungsmöglichkeiten der narrativen Figur und deren Konsequenzen in den Fokus rückt. (vgl. ebd.) Als zentrale handlungstreibende Funktion an sich verketten ,kernels‘ sich zwar syntagmatisch, sodass sie monooptional erscheinen, allerdings ist dies nur in einer retrospektiven Betrachtung der Fall. In dem Moment, in dem sich das zentrale Ereignis vollzieht, das als Handlung ein kernel ausmacht, bestehen für die handlungsfähige Figur (zumindest theoretisch) mehrere Optionen, von denen aber letztlich

\footnotetext{
${ }^{200}$ Unter prozessual werden im Folgenden alle jene Aspekte verstanden, die sich auf den Prozess der Verkettung narrativer Elemente eines Narrativs beziehen. Prozedural bezeichnet dabei die Verfahrensmäßigkeiten, nach denen diese Verkettung abläuft. Im Zuge des Prozessualen gerät somit in den Blick, wie narrative Elemente ausgewählt, arrangiert und kombiniert werden, wohingegen - und ergänzend - das Prozedurale das Augenmerk auf bestimmte Strukturen und Regelhaftigkeiten lenkt, die diesen Prozess determinieren.

${ }^{201}$ Dabei ist es auch möglich, so die Entstehung neuer Narrative als Ergebnis von zwei oder mehr Narrativen zu verstehen, die aber erzähllogisch kompatibel sind. Im Spielfilm Freaky Friday (2003) - mit Jamie Lee Curtis und Lindsay Lohan in den Hauptrollen - tauschen Mutter und Tochter auf magische Art und Weise ihre Körper und müssen dies solange erdulden, bis sie sich in die Probleme der anderen durch Perspektivübernahme versetzen und sich somit versöhnen können. Im Drama Das Haus am See (2006) schreiben sich Kate (Sandra Bullock) und Alex (Keanu Reaves) über den Briefkasten des Seehauses Briefe, ehe sie feststellen, dass diese offensichtlich durch die Zeit versendet werden, da Alex zwei Jahre ,vor' Kate lebt. Zu einem verabredeten Treffen erscheint Alex nicht, wobei sich später herausstellt, dass Alex zu diesem Zeitpunkt tot ist, da er kurz zuvor bei einem Autounfall ums Leben kommt. Kate kann Alex jedoch noch rechtzeitig über den Briefkasten warnen, sodass sich beide zwei Jahre später treffen können. Beide Narrative handeln von zwei Figuren, die sich selbst bzw. jemanden suchen, dem sie vertrauen, den sie lieben können. Der Handlungsverlauf gestaltet sich bei beiden als eine Reise voller Prüfungen und Gefahren dar, die nur zu bewältigen sind, wenn sich beide Figuren helfen bzw. gar wortwörtlich in den anderen hineinversetzen. Als ,Lohn“ hierfür winkt letztlich die Versöhnung bzw. das erste Treffen. Auch wenn beide Narrative auf den ersten Blick thematische Unterschiede aufweisen, so sind ihr prozessual-prozduraler Aufbau identisch und sie folgen beide derselben Erzähllogik. Diese Kompatibilität führt letztlich dazu, dass sich beide kombinieren lassen, wie es Makoto Shinkai im international gefeierten Anime Your Name (2016) getan hat, der die Narrative beider Filme amalgamiert.

${ }^{202}$ Unter den Kardinalfunktionen subsummiert Barthes all jene narrativen Funktionen, die das elementare Grundgerüst eines Narrativs bilden, die zwingend notwendig für die Existenz von Narrativen sind. Katalysen hingegen sind optional, da sie die Kardinalfunktionen des Narrativs lediglich katalysieren, indem sie diese näher beschreiben und hierdurch das Narrativ ausbauen. Vgl. BARTHES (1988).
} 
nur eine realisiert wird. Damit verweist Chatman darauf, dass die Figur hypothetisch andere Handlungsmöglichkeiten gehabt hätte, als diejenige, die sie letztlich im Rahmen des Narrativs ,wählt' ${ }^{203}$ So hätte Effi in Theodor FonTANEs Effi Briest (2004) keinen Ehebruch mit Major von Crampas begehen müssen, sondern hätte (theoretisch) viele andere (unverfängliche) Möglichkeiten gehabt, um sich mit der langweiligen Ehe mit Baron von Innstetten zu arrangieren. Dass Effi aber dennoch die Affäre eingehen muss, liegt in der Erzähllogik des Narrativs begründet, auf dem Romane wie Effi Briest, Madame Bovary (2014) oder Anna Karenina (2009) beruhen. ${ }^{204}$ Bereits dieses kurze Beispiel untermalt, dass Narrative Erzähllogiken etablieren, die zeitlich wie räumlich ausgesprochen konstant sind und eine Art Grundmuster für Erzählungen bilden. Das bedeutet, dass Story und Plot keine Narrative sind, sondern konkrete Umsetzungen eines bestimmten Narrativs wie z.B. des mythologischen Narrativs.

Bevor es gilt, dieses Narrativverständnis weiter zu erörtern, wird auf Narrativität und Narration eingegangen, dabei wird das Begriffsfeld einerseits aus Richtung der literaturwissenschaftlichen Narratologie und andererseits von Arbeiten in den Digital Game Studies erschlossen. Die Argumentation folgt weder eindeutig klassischen noch postklassischen Ansätzen der Erzähltheorie, sondern verbindet Überlegungen beider Ausrichtungen.

\subsubsection{Narrativität und Narration in der literaturwissenschaftlichen Narratologie}

Narrativität wird, nach H. Porter Abbott, in zwei Weisen verwendet: ,in a fixed sense as the »narrativeness « of narrative and in a scalar sense as the »narrativeness « of a narrative". (Аввотт 2011; Herv.i.O.) Somit kann sich Narrativität grundsätzlich auf Narrative im

\footnotetext{
${ }^{203}$ Im Folgenden wird aber dennoch, zumindest terminologisch, weiterhin auf Barthes' Begriffe zurückgegriffen, da sie gemeinhin bekannter sind. Heuristisch wertvoll kann Chatmans Modifikation des Konzeptes Roland Barthes' v.a. mit Blick auf personale Narrationen sein, da bei diesen die Multioptionalität eine größere Rolle spielt als bei medialen Narrationen. Selbst in hypertextuell aufgebauten digitalen Spielen sind bestimmte Entscheidungen, die Spieler treffen, retrospektiv betrachtet von geringer Bedeutung, da, aus ökonomischen wie technologischen Gründen, verschiedene Zweige recht schnell wieder zusammengeführt werden. Somit hat man es hier weniger mit einer wirklichen als vielmehr mit einer inszenierten Multioptionalität zu tun. Das folgende, wenn auch etwas polemische, Bild aus einem Fan-Forum verdeutlicht dies mit Bezug auf die The Walking DeadSpiele von Telltale Games. Vgl. http://i.imgur.com/4S2ki.png (30.06.2018).

${ }^{204}$ Verkürzt ausgedrückt besteht die Erzähllogik des Narrativs, das diesen Romanen zugrunde liegt, aus einer Verkettung der folgenden Kardinalfunktionen: Eine junge, leidenschaftliche Frau lebt in einem idyllischen Mikrokosmos, heiratet einen sozial exponierten Herren und zieht an einen Ort, der ihren Präferenzen zutiefst widerspricht und versucht der hierdurch hervorgerufenen Langeweile durch (außereheliche) Eskapaden zu entfliehen. Der Enttarnung dieser Eskapaden folgen die soziale Ächtung und schließlich der (Frei-)Tod. Die Erzähllogik zeichnet sich dadurch besonders aus, dass sie Handlungsbeginn und Handlungsende immer durch eine nahezu identische prozessual-prozedurale Abfolge von Kardinalfunktionen miteinander verbindet.
} 
Allgemeinen beziehen wie auf ein bestimmtes. Verkompliziert wird die Bestimmung der Narrativität durch die zahlreichen narratologischen Konzepte, die ihr ähnlich sind. Abbott nennt hier exemplarisch: „»narrativeness« (used colloquially above), »narrativehood,« »narratibility, « »tellability,« »eventfulness, « »emplotment, « and »narrative«“". (ebd.) Gemein ist den meisten dieser Begriffe, und hierdurch kommt man dem Kern der Sache näher, dass sie Eigenschaften bezeichnen. ${ }^{205}$ So stellt auch Abbott fest, dass Narrativität eine „variable quality“ sei. (ebd.) Narrativität ist aber nicht nur eine Qualität, eine Eigenschaft, sondern ist in ihrer Gestalt variabel oder graduell, d.h. etwas (bspw. ein Medium) kann mehr oder weniger narrativ sein. ${ }^{206}$ (vgl. dazu auch WOLF 2002 sowie RYAN 2001a) Wenn Narrativität aber eine „graduationsfähige Eigenschaft“ von Objekten ist, dann stellt sich die Frage, was die Narrativität ausmacht. (MÜLLER 2014, 26)

Eine entscheidende Begriffsschärfung hat diesbezüglich Gerald Prince geleistet, indem er die Narrativität in zwei Bereiche aufteilt: „,narrativehood“ und „,narrativeness“. (PRINCE 2008, 20; Herv.i.O.) Unter narrativehood versteht er alle Entitäten, „which [...] constitute narratives“, wohingegen narrativeness keine Objekte bezeichnet, sondern qualitative Eigenschaften von Narrativen. (ebd.) Prince spaltet damit die Narrativität extensional (narrativehood) und intensional (narrativeness) auf. Dies geschieht vor dem Hintergrund der Modifikation seiner eingangs zitierten Narrativdefinition: „, $[\mathrm{A}] \mathrm{n}$ object is a narrative if it is taken to be the logically consistent representation of at least two asynchronous events that do not presuppose or imply each other“". (ebd., 19) Die zeitliche Sequenzialität ist einer (erzähl)logischen Konsistenz der Darstellung gewichen. Hierdurch hebt Prince das dominante Paradigma der syntagmatischen Gestaltung von Narrativen hervor - die Erzähllogik. Nicht anhand einer zeitlichen Abfolge werden Narrative konstruiert, sondern anhand einer erzähllogischen Aneinanderreihung. Die Narrativbestimmung, als eine Art Minimaldefinition, dient dabei der graduellen Bestimmung von Narrativität (narrativeness). Je nachdem wie viele Kriterien der gegebenen Narrativdefinition bei einem Objekt erfüllt werden und je nachdem wie diese gewichtet sind, unterscheidet sich der Grad an Narrativität zwischen diesen

\footnotetext{
${ }^{205}$ Anders wird die Narrativität u.a. bei Shlomith Rimmon-Kenan definiert, die hiermit „,an immanent story structure“ meint. RIMMON-KENAN (1983), 7.

${ }^{206}$ Diese graduellen Abweichungen der Narrativität lassen sich an verschiedenen Faktoren festmachen, die die Figuren, die Welt und die Struktur betreffen. Bei einer geringen narrativen Ausprägung eines Mediums kann bspw. eine dominante erzählende Instanz fehlen, die Figuren sowie die Welt sind kaum oder gar nicht narrativ aufgeladen bzw. funktionalisiert und es existiert auch kein Narrativ, zumindest kein umfassendes, das die Grundstruktur des Mediums (mit-)organisiert. Unter Berücksichtigung der genannten Faktoren ist Pokémon (1996 ff.) ein digitales Spiel mit sehr schwacher narrativer Ausprägung, da narrative Elemente hier lediglich eine Art Rahmung bieten, wohingegen ein digitales Spiel wie The Walking Dead weder ästhetisch noch ontologisch ohne Narrativität denkbar ist.
} 
Objekten. In diesem Sinne ist es möglich, zwischen Narrativen, Fast-Narrativen oder NichtNarrativen zu unterscheiden und auch innerhalb dieser zwischen Objekten unterschiedliche Grade an Narrativität bestimmen zu können. ${ }^{207}$ (vgl. ebd., 21 f.)

Die vorliegende Arbeit verwendet den Narrativitätsbegriff im Folgenden (vornehmlich) als narrativeness nach Gerald Prince, auch wenn sich - wie weiter unten ersichtlich wird - die Narrativdefinitionen unterscheiden sowie sich die extensionalen Aspekte der Narrativität nicht immer ausblenden lassen. Von zentraler Wichtigkeit für die Bestimmung der Narrativität eines Objektes ist allerdings nicht nur das Narrativ, sondern, und hierin gleichen sich das ,interaktive ${ }^{6}$ und das ,narrative ${ }^{6}$ Begriffsfeld, auch die Narration. Versteht man die Narrativität (wie die Interaktivität) als Eigenschaft, Qualität oder Potenzial, dann kann man die Narration (analog zur Interaktion) als einen Prozess bezeichnen. So versteht Gerald Prince unter der Narration den ,act of [...] narrating“, Shlomith Rimmon-Kenan den ,act or process of production“ und Gérard Genette den ,produzierenden narrativen Akt“. (PRINCE 1982, 7; RIMMON-KENAN 1983, 3 sowie GENETTE 1994, 16) Die Narration ist dementsprechend gefasst der Prozess der Hervorbringung, oder genauer, der Realisierung eines Narrativs als Plot oder Story. Im Akt der Narration wird also eine Vermittlungsleistung erbracht, bei welcher die angelegte Struktur des Narrativs spezifisch konkretisiert wird. Dies kann nur gelingen, weil auch die Narration ein kommunikativer Akt ist, der die Kommunikation zwischen Sender und Empfänger ermöglicht. (vgl. dazu BARTHES 1988, 125 ff.) Allerdings ist die Wechselseitigkeit dieser Kommunikation deutlich schwächer als bei der Interaktion und auch der Handlungscharakter, in einem performativen Sinne, ist qualitativ nicht vergleichbar.

Fassen wir die bisherigen Ausführungen kurz zusammen: Narrativität ist eine intensionale Eigenschaft, die sich einerseits auf Objekte oder Phänomene im Allgemeinen und andererseits im Besonderen beziehen kann. Im letzteren Fall sind graduelle Einordnungen der Narrativität (durch vergleichende Betrachtungen) möglich. Bestimmt werden kann der Grad der Narrativität einer betreffenden Entität durch das ihr zugrundeliegende Narrativ und die Narrationen, die es erzeugen kann. Die Narration ist der Prozess der Realisierung eines Narrativs als potenziellem Objekt in einer konkreten Gestalt als Plot oder Story. ${ }^{208}$

\footnotetext{
${ }^{207}$ So unterscheidet z.B. Werner Wolf zwischen ,genuin narrativ verwendbaren', ,narrationsinduzierenden " und ,quasi-narrativ verwendbaren Medien‘. Vgl. WoLF (2002), 96 sowie WoLF (2003f).

${ }^{208}$ Wenn man Story und Plot als Realisierung eines Narrativs durch eine Narration betrachtet, dann ist es möglich, zu erklären, warum ein Narrativ wie die Detektivgeschichte auf unzählige verschiedene Weisen realisiert werden kann. Man denke bspw. an die diversen Sherlock Holmes-Fernsehadaptionen in den letzten Jahren wie Sherlock (2010 ff.), Elementary (2012 ff.), Dr. House (2004-2012) oder Forever (2014-2015), die
} 


\subsubsection{Narrativität und Narration in den Digital Game Studies ${ }^{209}$}

Die Bestimmung der Narrativität digitaler Spiele war ein zentrales Anliegen der Narratologen-Ludologen-Debatte, aber darüber hinaus gibt es auch unzählige Herangehensweisen, unabhängig von ihrer Positionierung im Forschungsfeld und ihrer wissenschaftlichen Provenienz, die sich hiermit befassen. Charakteristisch für solche Arbeiten ist es, dass sie Begriffe wie Narrativität oder Narration häufig nicht oder nur indirekt definieren. ${ }^{210}$ So sieht Scott Brendan Cassidy die Narrativität digitaler Spiele durch die folgenden Aspekte bedingt: ,film-like cut-scenes, characters, settings, and events.“ (CASSIDY 2011, 294 f.) Ausgehend von solchen narratologischen Kategorien werden Besonderheiten digitaler Spiele fokussiert wie die Hypertextstruktur, die veränderte Rezipientenrolle und die sich daraus ergebenden medial-spezifischen Merkmale von Narrativität in digitalen Spielen. Dies kann dann zu Positionen führen, die der narratologischen Schule in der NarratologenLudologen-Debatte nicht fremd waren.

This means that interacting with a videogame text is in fact an act of narration, in »real-time«, in the present. This means that a videogame is a narrative, one that is collaboratively created by the player's interaction. (ebd., 297; Herv.i.O.)

Narration erscheint auch hier als ein Akt, aber als einer, der die Interaktion überlagert und hierdurch neue Formen des Erzählens erschafft, wobei sich die Frage stellt, ob es sich hierbei noch um Erzählen handelt. Solche Argumentationsweisen führen letztlich zu sehr weiten Begriffsverwendungen, deren Validität spätestens in dem Moment ins Wanken gerät, in dem sich der Fokus weg von AAA- und hin zu Indie-Produktionen bzw. vom Hardcore zum Casual Game verlagert. Zwar ist es richtig, dass jedes Medium, das erzählen oder in dessen Rahmen erzählt werden kann, charakteristische Formen des Erzählens ausbildet, allerdings sind diese nicht fundamental anders im Vergleich zu anderen Medien. Zu weit ausgreifende Begriffsverwendungen laufen Gefahr, verschiedene Komponenten digitaler Spiele zu vermengen und somit ihre eigenen heuristischen Vorteile selbst wieder zu relativieren.

The heuristic value of a prototypical definition of narrative and a gradual conception of narrativity becomes particularly apparent in the case of interactive digital media such as computer games. (THON 2014, 353)

alle demselben Narrativ folgen, das dieselbe Figurenkonstellation (zumindest im Kern) bedingt, die als Plots aber doch sehr unterschiedlich umgesetzt sind.

${ }^{209}$ Einen kurzen und sehr gelungenen Überblick über die Rolle der Narratologie in den Digital Game Studies bieten Dominic Arsenault (2014) sowie Jan-Noël THON (2015). Zur Narratologie im Allgemeinen vgl. JANNIDIS (2003).

${ }^{210}$ Mark J.P. Wolf definiert bspw. das titelgebende „Narrative“ in seinem Aufsatz nicht. Vgl. WoLf (2003e). 
Jan-Noël Thon, der aus der Perspektive der transmedialen Narratologie ${ }^{211}$ argumentiert, stellt die Notwendigkeit für derartige Weiterentwicklungen der narratologischen Ausdrücke heraus, die dabei aber nicht die Spezifika anderer Medien auf digitale Spiele übertragen, sondern die markanten Merkmale der Narrativität in digitalen Spielen herausarbeiten sollen. Auch wenn die Narratologen-Ludologen-Debatte mittlerweile abgekühlt sei, so lasse sich dennoch konstatieren, dass, so Thon, „the specific mode of narrativity of computer games remains an interesting problem“. (ebd.) Entscheidend ist heute nicht mehr so sehr die Frage, ob digitale Spiele narrativ sind, sondern wie diese Narrativität aussieht und wie sie sich von anderen Medien unterscheidet. Vor diesem Hintergrund sei nicht primär interessant, welche neuen Formen der Narrativität entstehen, sondern wie sich diese zur Interaktivität verhalten. Wie sehr begriffliche Modifikationen benötigt werden, hat Fotis Jannidis exemplarisch anhand einer terminologischen Doppeldeutigkeit im Forschungsdiskurs identifiziert, die in der Narratologen-Ludologen-Debatte ebenso zu Missverständnissen führte wie auch heute noch.

A problem in the discussions [zwischen Ludologen und Narratologen] seems to be the double meaning of the term narration [...]. On the one hand narration signifies the medial representation of a self-contained storyline; on the other hand it means a sequence of chronologically ordered and causally linked events. (JANNIDIS 2007, 283)

Nur im ersten Fall sieht Jannidis den Ausdruck Narration als angebracht an, im zweiten hingegen schlägt er vor, den Begriff Narration durch Plot zu ersetzen. Damit verweist Jannidis darauf, dass man Narration zwar (analog zur Narratologie jenseits digitaler Spiele) verwenden kann, um den Prozess des Erzählens oder die ,representation` zu bezeichnen, dass man aber vorsichtig sein müsse, bei jeder chronologischen wie kausalen Verkettung von Ereignissen von einer Narration zu sprechen (zumal sich hieraus auch Vermischungen mit Narrativbestimmungen ergeben können, die an Gerald Prince anschließen). Neben der Narration wird aber auch der Narrativbegriff mit sehr verschiedenen Bestimmungsversuchen angewandt, die zumindest aus narratologischer Sicht noch weiter profiliert werden könnten. So bestimmt Tomas Rawlings das Narrativ wie folgt: „Narrative (Noun): A narrated account; a story. The art, technique, or process of narrating.“ (RAWLINGS 2006) In dieser Definition verschwimmen verschiedene narratologische Konzepte wie Narrativ, Story und Narration unter einem Begriff und zwar mit weitreichenden Folgen für die Narrativität digitaler Spiele, welche (zu einem großen Teil) über Narration und Narrativ definiert wird. In diesen Zusammenhängen, wenn auch nur streiflichtartig angedeutet, scheint eine Profilierung der

\footnotetext{
${ }^{211}$ Vgl. dazu ThON (2016); MAHNE (2007) sowie AlBER/HANSEN (2014).
} 
narratologischen Termini durch die literatur- und filmwissenschaftliche Erzähltheorie als adäquates Mittel, um zu trennscharfen Analyseinstrumenten zu gelangen. ${ }^{212}$

Im Folgenden möchte ich zwei Präzisierungen vorschlagen, die einen Schritt in diese Richtung gehen sollen. Zum einen möchte ich den Narrativbegriff ,umwerten“ und zum anderen möchte ich eine Modifikation des Narrationsbegriffs stark machen, die besonders zur Analyse digitaler Spiele beitragen kann.

\subsubsection{Narrative als Ordnungsprinzip und Grundmuster}

Ausgehend von Princes Modifikation seiner eigenen Definition des Narrativs ${ }^{213}$ kann man Narrative nicht bloß als strukturelle Verkettungen begreifen, sondern als Systeme, die sich zwar primär auf das zugrundeliegende Syntagma beziehen, darüber hinaus aber Elemente umfassen, die über eine Aneinanderreihung von narrativen Ereignissen hinausgehen. So betrachtet H. Porter Abbott ein Narrativ als ,a necessary component or set of components“. (Аввотт 2011) Dadurch bekommt das Narrativ eine Reichweite, die deutlich über vorherige Definitionen hinausgeht. ${ }^{214}$ Die Bezeichnung ,set“ suggeriert, dass ein Narrativ mehrere Komponenten bzw. narrative Elemente verbindet. Nach J. Hillis Miller enthalten alle Narrative:

[A]n initial situation, a sequence leading to a change or reversal of that situation, and a revelation made possible by the reversal of situation. Second, there must be some use of personification whereby character is created out of signs - for example, the words on the page in a written narrative, the modulated sounds in the air in an oral narrative. However important plot may be, without personification there can be no storytelling. The minimal personages necessary for a narrative are three: a protagonist, an antagonist, and a witness who learns. [...] Third, there must be some pattering or repetition of key elements, for example, a trope or system of tropes, or a complex word. [...] Any narrative, then, to be a narrative, I claim, must have some version of these elements: beginning, sequence, reversal; personification, or, more accurately and technically stated, prosopopoeia, bringing protagonist, antagonist, and witness

\footnotetext{
${ }^{212}$ Wenngleich man freilich einräumen muss, dass sich die Diffusion des Narrativbegriffs, wie sie bei Rawlings zutage tritt, nie gänzlich wird auflösen lassen, da sie, wie weiter oben ausgeführt, tief in der englischen Sprache verwurzelt ist. Besonders folgenreich erweist sich diese doppeldeutige Verwendung durch die Funktion der englischen Sprache als ,lingua franca' in den modernen Kultur- und Medienwissenschaften.

${ }^{213},[\mathrm{~A}] \mathrm{n}$ object is a narrative if it is taken to be the logically consistent representation of at least two asynchronous events that do not presuppose or imply each other“. PRINCE (2008), 19.

${ }^{214}$ Fotis Jannidis fasst den Diskurs um die Begriffsbestimmung des Narrativs zusammen: „It is generally agreed, then, (1) that a narrative is a representation and (2) that the object of this representation exhibits a certain set of properties; namely, chronological and causal arrangement.“ JANNIDIS (2003), 36. So gefasst beschränkt sich ein Narrativ auf die Darstellung eines Objektes, das bestimmte Eigenschaften aufweist, die die Darstellung via Syntagma ermöglichen. Eine Darstellung ist aber mehr ein Prozess, ein Akt als ein festes Produkt, sodass sich die Frage ergibt, wie man Narrativ und Narration voneinander abgrenzt, wenn beide mit der Prozesshaftigkeit des narrativen Modus in Verbindung stehen. Aus diesem Grund wird in dieser Arbeit die Unterscheidung zwischen Grundstruktur (Narrativ) und Prozess (Narration) verwendet. In Jannidis Terminologie ergibt sich dieses Problem dadurch nicht, dass er als „meaningful structure“ die „story“ betrachtet und nicht das Narrativ, somit andere Gewichtungen vornimmt. Ebd., 43.
} 
»to life«; some pattering or repetition of elements surrounding a nuclear figure or complex word. (MILLER 2006, 75)

Neben der Sequentialität erweitert Miller den Narrativbegriff um das Vorhandensein bestimmter Figuren sowie eine motivationale Verwendung von rhetorischen Schlüsselelementen. Ein derartiges Narrativverständnis berührt letztlich auch die Sequentialität, wenn auch nicht in der Weise, dass es sie infrage stellt. Anstelle der Fixierung auf die sequentielle Abfolge von Ereignissen scheint es ratsam, Narrative eher als Verkettung von narrativen Funktionen zu verstehen. Dabei sind im Besonderen die Kardinalfunktionen maßgeblich für ein Narrativ, da sie ihm seine spezifische Form verleihen. Katalysen kommen dann zum Tragen, wenn in Adaptionen oder konkreten Rezeptionen zusätzliche Funktionen ergänzt werden, die den Ausgang des Plots aber nicht signifikant verändern oder - anders gesagt - die Struktur des Narrativs an sich nicht tangiert wird.

Die spezifische Struktur eines Narrativs, die bspw. ein Verfallsnarrativ von einem Abenteuernarrativ unterscheidet, die durch die bestimmte Verkettung von Kardinalfunktionen entsteht, bedingt aber nicht nur eine schematische Figurenkonstellation, wie Miller sie beschreibt, sondern eine ganz bestimmte, die zu diesem passt, sowie des Weiteren auch die Figurenkonzeptionen vom Narrativ bestimmt werden. So folgen Realisierungen des Abenteuernarrativs wie die Indiana Jones- (1981 ff.) oder die Mumien-Filmreihe (1999 ff.) oder digitale Spielreihen wie Tomb Raider (1996 ff.) oder Uncharted (2007 ff.) nicht nur derselben Erzählstruktur, sie weisen auch dieselben Figurenkonstellationen und Figurenkonzeptionen auf. ${ }^{215}$ Daneben bedingt dieses Narrativ aber auch eine bestimmte Diegese. Die Spezifik drückt sich dabei einerseits motivisch aus, sodass diese fiktionalen Welten in ihrer optischen Erscheinung wie ihrem topografischen Aufbau frappierende Ähnlichkeiten aufweisen, und andererseits darin, dass die Figuren innerhalb dieser Welt eine bestimmte Position einnehmen, was sich wiederum unmittelbar auf ihre Handlungsräume auswirkt.

Dies kann man auch auf alle anderen Narrative übertragen; als Beispiel dient im Folgenden der Vergleich von Abenteuer- und Detektivnarrativ. In diesem besteht eine antagonistische

\footnotetext{
${ }^{215}$ Die Untersuchung derartiger Narrative, auch wenn es sich bei diesen genannten Beispielen ausschließlich um Serien oder Reihen handelt, ist auch jenseits serieller Narrationen möglich. Diese bieten jedoch den Vorteil, dass Vergleiche innerhalb eines größeren ,Werkzusammenhangs' durchführbar sind. Zudem - und vor dem Hintergrund der zunehmenden Verbreitung transmedialer Welten - entstehen immer mehr narrative Werke als transmediale Artefakte, deren transmediale (narrative) Zusammenhänge sich letztlich sehr zuverlässig durch serielle Narration kreieren lassen. Deshalb erscheinen narrative Werke als Teile transmedialer Welten und Objekte unserer digitalen Medienkultur ein interessanter Untersuchungsgegenstand zu sein, auf den auch diese Arbeit deshalb immer wieder zurückgreift.
} 
Beziehung zwischen dem Protagonisten und dem Antagonisten. Wie im Abenteuernarrativ geht es darum, einen enigmatischen Zeitpunkt in der Vergangenheit aufzuklären bzw. ein bestimmtes Artefakt zu finden, wozu der Protagonist besondere Fähigkeiten und Fertigkeiten benötigt. Als Archäologe oder forensischer Ermittler verfügen die Protagonisten meistens über ein sehr spezifisches Fachwissen, das an ein erstaunlich breit gefasstes Allgemeinwissen gekoppelt ist, was am eindrücklichsten die Figur des Sherlock Holmes' verdeutlicht. Zudem wird die Figurenkonzeption des Protagonisten moralisch als überaus positiv gezeichnet, was zu einer Aufladung der Figurenkonstellation führt, wie man sie besonders in der Gut-BöseDichotomie des Mythos findet. Worin sich beide Narrative aber unterscheiden, obwohl Motivation, Figurenkonzeption und -konstellation sehr ähnlich sind, ist die Raumbemächtigung der Figuren in der Diegese. Die Diegese eines Abenteuernarrativs wird im Wesentlichen durch das Reisen bestimmt, da es diverse Handlungsorte auf verschiedenen Kontinenten gibt, ${ }^{216}$ wobei sich der Held sukzessive dem geheimsten Ort nähert, wo es zum Höhepunkt der Handlung kommt. Die Ähnlichkeiten zum Reisemodell Joseph CAMPBELLs (2011), das die Grundstruktur des mythologischen Narrativs beschreibt, zeigen, dass das Abenteuernarrativ eine Abwandlung des mythologischen Narrativs ist, die sich aber dadurch voneinander unterscheiden, dass der Held im Abenteuernarrativ seine mythisch-religiöse Funktion als Weltenretter weitestgehend eingebüßt hat.

In der Differenz zum Abenteuer- und mythologischen Narrativ verfügt das Detektivnarrativ über eine sehr starre Räumlichkeit. Handlungsräume sind meistens urbane Ballungsräume der Moderne, Wechsel zwischen Handlungsorten innerhalb dieser dementsprechend geografisch weniger weit ausgreifend und in ihrer Darstellung weitaus homogener. Was alle drei Narrative aber eint, ist die hohe Statik der Figurenkonzeptionen und -konstellationen. Batman ändert (bis auf wenige Ausnahmen) ${ }^{217}$ nie seine Einstellung, den Joker mithilfe tödlicher Gewalt aufzuhalten, und auch dieser ändert nie seine Einstellung zu Batman, sodass jedes Aufeinandertreffen beider stets die Wiederholung des alten Schemas in neuem Gewand ist. Dass sich Figurenkonzeptionen aber auch anders darstellen können, zeigt der Blick auf das in den letzten Jahren durch Fernsehserien wie The Walking Dead (2010 ff.) bekannt gewordene Narrativ der Zombieapokalypse. Zentrales Motiv ist das Überleben einer

\footnotetext{
${ }^{216}$ Die eindrücklichste Versinnbildlichung dessen dürfte wohl in den Indiana Jones-Filmen zu finden sein. Der raumgreifende Wechsel von Handlungsorten wird hier bildlich untermalt, indem der Zuschauer sieht, wie ein Flugzeug auf einer roten Linie über die Weltkarte fliegt.

${ }^{217}$ Eine dieser Ausnahmen in der transmedialen Welt Batmans stellt Frank MiLlers Batman. Die Rückkehr des dunklen Ritters (1989) dar.
} 
kleinen Gruppe von Menschen, während die Zivilisation sowie ihre Werte und Normen immer mehr zerfallen. Dieser zivilisatorische Schwund offenbart sich in einer dynamischen Figurenentwicklung, die primär durch einen Wandel der moralischen Dispositionen der Figuren bedingt ist.

Daneben spielt aber auch die zeitliche Ausdehnung (erzählte Zeit) des im Narrativ angelegten Plots eine Rolle, da sich diese auch von Narrativ zu Narrativ erheblich unterscheiden kann. Detektivnarrative spannen meistens einen Bogen, der wenige Tage umfasst, wohingegen Narrative mit großen räumlichen Freiheiten, die sich in ausgedehnten Reisen der Figuren niederschlagen, oft mehrere Monate oder gar Jahre umfassen können. In ihrer Extremform können Narrative mehrere Jahrtausende als Handlungszeitraum haben. Dies trifft v.a. auf Metanarrative ${ }^{218}$ zu. Schon die Mythen der nordischen Kulturen Europas umfassen Mythen auf zwei Ebenen. Für sich genommen beruht jede dieser Geschichten auf einem Narrativ, das dieser Erzählung zugrunde liegt. Gesteuert werden diese Narrative aber von einem übergeordneten Narrativ, das prinzipiell denselben Aufbau hat wie die ,kleineren“ Narrative. ${ }^{219}$ Es beginnt bei einem positiven Anfangszustand, der von einer Krise überschattet wird, die die gesamte Welt bedroht und die es zu verwinden gilt. Was im mythologischen Narrativ im Kleinen der Kampf gegen ein mythisches Wesen wie einen Drachen ist, gestaltet sich auf der Ebene des mythologischen Metanarrativs als Bogen, der von der Kosmologie bis zur Eschatologie reicht.

Dies kann man auch auf den Untersuchungsgegenstand dieser Arbeit übertragen - The Legend of Zelda. Jeder Einzeltitel der Hauptserie folgt demselben mythologischen Narrativ, das auch auf der Metanarrativebene die gesamte Serie organisiert. Ganon als Links Antagonist ist durch seine Unsterblichkeit eine Bedrohung, die Hyrule immer wieder heimsucht und die Links Reinkarnationen stets bekämpfen müssen. Auf der Makro- wie der Mikroebene herrschen dieselben Figurenkonzeptionen und -konstellationen vor, sind dieselben räumlichen

\footnotetext{
${ }^{218}$ Als Metanarrative werden hier jene Narrative angesehen, die einer bestimmten Gruppe von Narrativen übergeordnet sind und diese gewissermaßen steuern. Dabei geben die Metanarrative oft jene Erzählstruktur vor, die die untergeordneten Narrative aufweisen. So kann die Offenbarung des Johannes als Exempel für ein Metanarrativ angesehen werden, das bis heute die Erzählstruktur, die Figuren sowie die Ikonografie und Thematik apokalyptischer Narrative nachhaltig beeinflusst. Zugleich illustriert es aber auch, dass Metanarrative in Konkurrenz zu anderen Metanarrativen stehen können, da moderne apokalyptische Narrative nicht nur maßgeblich von der Offenbarung des Johannes beeinflusst werden, sondern bspw. auch vom Ragnarök.

${ }^{219}$ Insofern spielen hier aber gewissermaßen auch serielle Elemente eine Rolle wie die von Knut Hickethier geprägte ,doppelte Formstruktur'. „Diese doppelte Formstruktur der Serie, einerseits zeitlich und inhaltlich begrenzte Einheit zu bieten, andererseits sich auf einen größeren, häufig auch vom Zuschauer gekannten Gesamtszusammenhang zu beziehen, stellt einen der vielen Attraktionsmomente der Serie dar.“ HICKETHIER (1991), 10.
} 
Determinanten zu finden, liegt dieselbe Struktur der Verkettung der Kardinalfunktionen vor. Das einzige, was die Ebenen unterscheidet, ist die zeitliche Ausdehnung des Narrativs, die beim Metanarrativ wesentlich weiter ausgreift. ${ }^{220}$

Man kann Narrative mit Umberto Eco, selbst wenn er den Begriff an sich nicht verwendet, als „konstante[] narrative[] Schema[ta]“ verstehen. ${ }^{221}$ (ECO 1993, 160) Ein Narrativ ist demgemäß eine kulturell verfestigte Erzählstruktur, die auf einer spezifischen Verkettung von Kardinalfunktionen beruht und die auf ein bestimmtes Figurenpersonal sowie Raum-ZeitGefüge zurückgreift. Narrative können somit als ordnende Instanzen gesehen werden. ${ }^{222} \mathrm{Sie}$ können als Metanarrative oder ,große Erzählungen‘, wie Jean-François LYOTARD (1986) sie fasst, eine legitimierende und ordnende Wirkung für das soziokulturelle Leben haben, die sich bspw. in philosophischen Diskursen manifestieren, sie können aber auch die ordnende Instanz von Phänomenen wie Neuen Medien sein, die die Hierarchie traditioneller narrativer Medien und Gattungen infrage stellen. Wie Rezipienten mit ihrem höheren Freiheits- und Partizipationsgrad in Neuen Medien wie dem digitalen Spiel umgehen, hängt damit zusammen, wie sie im rezeptiven Prozess mit dem Narrativ interagieren.

So können Narrative durch ihre implementierten Figurenkonzeptionen und -konstellationen den Rezipienten zu einem Handeln verleiten, das mit dem Narrativ konform geht. (vgl. dazu erneut RAUSCHER 2015) Die Spielersteuerung bzw. die Limitierung von Handlungsoptionen der Spieler kann aktiv und direkt durch das Interaktiv erfolgen, sie kann aber auch passiv und indirekt durch das Narrativ ablaufen. Das Narrativ fungiert in solchen Fällen als ,verallgemeinerter Anderer ${ }^{\star}$ des Spielers, veranlasst Spieler in der Regel dazu, sich den Erwartungen/Haltungen des Narrativs anzupassen, die sie mit ihm verbinden. Aus diesem Grund, oder vielleicht auch, weil es so wenige grundlegende Narrative gibt, greifen interaktivnarrative digitale Spiele auch so oft auf bekannte Narrative wie das mythologische zurück. Damit das Narrativ diese Funktion übernehmen kann, muss es vom Spieler intuitiv erkannt

\footnotetext{
${ }^{220}$ Wenn man den neuesten Teil der Hauptserie - The Legend of Zelda: Breath of the Wild (2017) - in die gesamte serielle und transmediale Erzählstruktur von The Legend of Zelda einbeziehen möchte, dann umfasst der Zeitraum des Metanarrativs mehrere zehntausend Jahre.

${ }^{221}$ Dazu auch Werner Wolf: „Narrative in its most basic sense [...] is an acquired (macro-)frame of relative historical constancy which is derived mostly from (fictional) verbal prototypes.“ WoLf (2003f), 188. Manfred Pirner führt zur überkulturellen Bedeutung von Narrativen aus: „Es gibt bestimmte erzählerische Strukturschemata und Standardmotive, die überindividuelle und teilweise sogar kulturübergreifende Tiefenbedeutung für die Menschen haben." PIRNER (2001), 260.

${ }^{222}$ Häufig lassen sich Narrative in digitalen Spielen mit langer Gesamtspielzeit finden, die sich nur in mehreren Spielsitzungen durchspielen lassen, die teilweise, bedingt durch die alltäglichen Verpflichtungen des Spielers, zeitlich weit auseinanderliegen können. Das Narrativ ordnet hier das Geschehen und bietet dem Spieler Unterstützung, indem es ihm hilft, die wichtigen Ereignisse/Funktionen zu erinnern, sich besser in diesen Spielen orientieren zu können.
} 
werden können, auch wenn ihm dies nicht unmittelbar bewusst ist. ${ }^{223}$ Zudem darf aber auch die Illusion des Spielers dabei nicht durchbrochen werden. Ein Aspekt, der hierzu beiträgt und der maßgeblich vom Narrativ abhängt, ist die emotionale Involvierung des Spielers, die immersionssteigernd wirken soll. (vgl. dazu RYAN 2001b, 263 f.) Dazu kann der Designer, neben dem, was das betreffende Narrativ ohnehin vorgibt, weitere Katalysen oder neue Figuren ins Narrativ einfügen, um die emotionale Bindung des Spielers ans Spiel weiter zu erhöhen.

Es lässt sich, bedingt durch die Beschaffenheit Neuer Medien, konstatieren, dass Narrative nicht mehr derart sakrosankt wie früher sind, vielmehr haben sie sich gegenüber dem Rezipienten geöffnet, sind durch diesen konfigurierbar geworden. Das wird erforderlich, damit sie u.a. für die interaktive Natur digitaler Spiele geöffnet werden können. Nimmt man die veränderte Rolle des Rezipienten in digitalen Spielen in Bezug auf das Narrativ ernst, und besonders das Gamedesign hat dies getan, dann kann man zwei Arten von Narrativen unterscheiden, die zwei verschiedene Formen der Narration bedingen.

\subsubsection{Mediale und personale Narrationen ${ }^{224}$}

Der Designer Marc LeBlanc hat auf der Game Developers Conference 1999 zwischen „embedded“ und „emergent narratives“ differenziert. Unter ,eingebetteten“ Narrativen sind all diejenigen zu fassen, die in die Struktur des Spiels integriert, die ein fester Bestandteil des Programmcodes sind, die also vom Designer angelegt wurden. ,Emergente ${ }^{6}$ Narrative hingegen bezeichnen alle Narrative, die vom Spieler beim Spielen erzeugt werden bzw. die dieser Erzeugung zugrundeliegen. Richard Rouse macht diese Unterscheidung ebenso auf, spricht aber stattdessen von den Geschichten des Designers (,eingebettete Narrative`) und den Geschichten der Spieler (,emergente Narrative'). (vgl. RouSE 2005, 203 ff.) Etabliert hat sich aber die Terminologie LeBlancs, die sich in zahlreichen Arbeiten der Digital Game Studies wiederfinden lässt. (vgl. Jenkins 2004; PEARCE 2004 sowie SALEN/ZimMERMan 2004) Besondere Aufmerksamkeit wird dabei dem ,emergenten' Narrativ geschenkt, da viele Forscher hierin ein Spezifikum digitaler Spiele erkennen. ,Emergente“ Narrative sind

\footnotetext{
${ }^{223}$ Das mythologische Narrativ (mit all seinen Derivaten) ist besonders geeignet, um diese Funktion zu erfüllen, da es nicht nur ein Narrativ ist, dass die Medien- und Kunstgeschichte der westlichen Kultur über zweitausend Jahre lang massiv bestimmte und Vorbild für viele moderne Narrative ist, sondern auch weil es mehr oder weniger immer noch in seiner, reinen " Form auftritt und die populäre Medienkultur mitprägt. Filmreihen wie der Herr der Ringe (2001-2003) oder Der Hobbit (2012-2014), Romanreihen wie Andrzej Sapkowskis Geralt von Riva-Saga (2008-2011) oder digitale Spielserien wie God of War (2005-2010) zeugen von der Popularität und Virulenz des Mythos in der Mainstream-Populärkultur, sodass man von einer breiten Akzeptanz und tiefen Vertrautheit der Rezipienten mit diesem Narrativ ausgehen darf.

${ }^{224}$ Vgl. zur medialen und personalen Narration in digitalen Spielen auch MATUSZKIEWICZ (2017).
} 
Narrative, bei denen die Erfahrung durch den Spieler von zentraler Bedeutung ist. Gordon Calleja greift dieses Konzept auf und entwickelt es weiter. Er verwendet die Bezeichnung

alterbiography $[\ldots]$ to refer to the here and now interactions with the game environment that generate story through the player's interpretation of events occurring within the game environment, their interaction with the game rules, human and AI entities and objects. (CALleJA 2009, 1)

Damit macht er deutlich, dass es sich bei ,emergenten' Narrativen um Narrative handelt, die nicht in der Spielstruktur des digitalen Spiels an sich enthalten sind. Im Gegenteil - sie werden vom Spieler eingesetzt, um sein nicht-narratives Spielerlebnis zu narrativieren. Der Ursprung der Narration ist in diesem Fall also der Spieler, wohingegen die Narration im Fall des ,eingebetteten' Narrativs eindeutig vom Spiel ausgeht. Einerseits hat man es mit einer Narration zu tun, die vom Spieler erzeugt wird und andererseits mit einer Narration, die im System ihren Ursprung hat. Erstere nenne ich eine ,personale Narration', letztere eine ,mediale Narration‘. ${ }^{225}$ Ausschlaggebend hierfür ist jene Instanz, von der die Narration ausgeht - im einen Fall die Person, im anderen das Medium. Eine solche Unterscheidung schließt an narratologische Konzepte der jüngeren Vergangenheit an, die sich von der Idee eines Erzählers lösen. ${ }^{226}$ Fotis Jannidis hält hierzu fest:

Here we are faced once more with the question of what the important, ultimately even decisive features of the prototype are. In particular, the question of whether every form of a narrative must have a narrator - a source behind the utterance, behind the discourse - is not exactly trivial when it comes to defining what narratologists study. Reviewing contemporary approaches to this question, we find that there is an overwhelming consensus that the narratorial instance should be dispensed with. (JANNIDIS 2003, 48)

Jene Überlegungen ergeben umso mehr Sinn, wenn man bedenkt, wie Erzählen in einem Medium wie dem digitalen Spiel funktioniert. Nehmen wir ein Spiel wie L.A. Noire (2011) und stellen uns die Frage, wer oder was hier erzählt? Erzählende Rollen übernehmen die Player Characters wie NPCs oder die Bildlichkeit, über die digitale Spiele als Videospiele wirken. Diese Erzählinstanzen können bspw. durch ein Voice-over ergänzt werden, das als

\footnotetext{
${ }^{225}$ Dabei kann ein und dasselbe Narrativ sowohl als eingebettetes als auch als emergentes Narrativ eingesetzt werden. Das mythologische Narrativ der Heldenreise fungiert in Darksiders (2010) als eingebettetes Narrativ, das im Zuge der medialen Narration des Spiels einen (vorgegebenen) apokalyptischen Plot an den Rezipienten vermittelt. Es kann aber auch als emergentes Narrativ benutzt werden, damit Spieler ihr Spielerlebnis eines digitalen Spiels wie Driver (2000), dessen Narrativität eher schwach ausgeprägt ist, zusätzlich im Zuge der personalen Narration narrativieren können, um so einen eigenen Plot zu generieren bzw. den vorhandenen zu verstärken. Hierdurch kann z.B. der Protagonist und Undercover-Polizist Tanner noch deutlicher als Held herausgearbeitet werden, der gegen dunkle Machenschaften kämpft.

${ }^{226}$ Tilmann Köppe und Tom Kindt zeigen die Gründe hierfür an einigen Beispielen treffend auf, ohne sich von der Idee des fiktiven Erzählers an sich zu verabschieden. Vielmehr geht es ihnen darum, genau zu prüfen, ob hinreichende Anhaltspunkte gegeben seien, die es rechtfertigen, bei einer Erzählung davon auszugehen, dass es einen solchen Erzähler gebe. Sie zeigen dadurch, dass ein fiktiver Erzähler kein zwingendes Kriterium einer fiktionalen Erzählung sein muss. Vgl. KöPPE/KINDT (2014), 88 ff.
} 
eine Art auktorialer Erzähler berichtet. Zudem, und dies kann leicht übersehen werden, übernehmen der Programmcode bzw. die Operationen, in denen das System seinen Dialogbetrieb ausführt, erzählerische Funktionen, indem sie bedingen, was, wie, wann oder ob überhaupt erzählt wird. ${ }^{227}$ Diese technologische Perspektive gewinnt permanent an Bedeutung, v.a. mit Blick auf die steigende KI von Computersystemen. ${ }^{228}$ Spätestens ab dem Zeitpunkt, ab dem komplexe Formen non-linearen Erzählens im Dialogbetrieb umgesetzt werden können, die den Computer eindeutig als (autonome) erzählende Instanz markieren, dürften die Zweifel an einem Konzept wie dem des Erzählers evident werden. Aber lässt sich nicht bereits jetzt die Frage stellen, ob es Sinn ergibt, diese Gemengelage aus Charakteren, Visual Storytelling, Voice-over-Erzählung und Programmcode einen Erzähler zu nennen? Ist die Heterogenität eines solchen narrativen Modus nicht zu groß, um von einer Kategorie wie dem Erzähler gefasst werden zu können? Und ist ein Erzähler an sich nicht in solchen Fällen ein bloßes analytisches Konstrukt, das durch seine Abstinenz in manchen postmodernen Kunstwerken nur umso deutlicher seine Artifizialität herausstellt?

Dieser Frage soll an dieser Stelle nicht weiter nachgegangen werden, die Bedenken sollen aber zum Anlass genommen werden, im Zusammenhang mit einem Narrationsbegriff, der den Prozess des Hervorbringens/Realisierens betont, im Folgenden nicht von einem Erzähler zu sprechen, sondern nach derjenigen Entität zu suchen, die für die Produktion einer konkreten Narration die maßgebliche Produktionsinstanz ist. So gefasst kommen in der Regel (in Bezug auf digitale Spiele) zwei fassbare Akteure in Betracht - das Medium und die Person. Mediale Narrationen kommen in der Literatur, im Film, im Fernsehen oder in einem digitalen Spiel vor, bei ihnen handelt es sich um eine eingeschriebene Narrativität, da sie nachweislich Teil

227 Dies verdeutlichen insbes. digitale Spiele wie Hidden Agenda, in denen bestimmte Abschnitte des eingebetteten Narrativs nur dann realisiert werden, wenn der/die Spieler bestimmte Entscheidungen im vorherigen Spielverlauf getroffen hat.

${ }^{228}$ Diese technologisch-informatische Perspektive findet bisher in den narratologischen Diskursen der Digital Game Studies weniger Beachtung. Exempel wie der deutliche Sieg des Programms AlphaGo über den südkoreanischen Weltklasse-Go-Spieler Lee Sedol im März 2016 zeigen jedoch, dass Computerprogramme als lernfähige >künstliche neuronale Netzwerkeく (KNN) nicht nur in der Lage sind, komplexe menschliche Denkvorgänge zu imitieren - sie können vielmehr sogar Syntagmen herstellen, die Menschen offensichtlich nicht generieren. So entwickelte AlphaGo, nachdem eine immense Menge von Daten historischer Go-Partien in es eingespeist wurde, im Laufe seines Trainings Spielzüge und Taktiken, die menschlichen Go-Spielern unbekannt waren und die Sedol in mehreren Partien überforderten. Dieses Beispiel demonstriert, dass Computerprogramme als lernfähige Netze künstlicher Intelligenz sehr wohl, entgegen vieler Annahmen, autonom handeln können. Spätestens, wenn KNNs mit Narrativen oder anderen erzählsyntaktischen Mustern gespeist werden, und hieraus neue Syntagmen entwickeln, die sich unter Umständen (ähnlich wie die GoSpielzüge) deutlich von menschlich produzierten und erzeugten Narrativen abheben, stellt sich der Narratologie die Herausforderung, Formen des Erzählens erklären zu müssen, die sich von den bisherigen unterscheiden. Ab diesem Zeitpunkt kommt die Forschung nicht mehr umhin, das Computersystem als narrative Instanz zu berücksichtigen. Zum ,maschinellen Lernen` bieten ENGEMANN/SUDMANN (2018) einen aktuellen Überblick. 
der medialen Struktur ist. Bei einer personalen Narration ist dies anders. Personale Narrationen entstehen, wenn Prozesse, die sich prozessual-prozedural beschreiben lassen, auf ihre Grundelemente heruntergebrochen und dann narrativiert werden. Hierzu werden zentrale Ereignisse des narrativierten Prozesses in Kardinalfunktionen überführt, ebenso das Figurenpersonal. Die Person, die eine personale Narration erzeugt, nimmt ein ,emergentes ${ }^{6}$ Narrativ hinzu, das über die erforderliche Verkettung der narrativen Funktionen, das passende Figurenpersonal sowie den dazugehörigen Chronotopos verfügt und narrativiert somit sein reales Erleben. Ein Beispiel: Nehmen wir an, ein Mensch verliert unmittelbar nacheinander seine Anstellung, seinen Partner und auch die Beziehungen $\mathrm{zu}$ seinen anderen nächsten Mitmenschen verschlechtern sich rapide. Die Beobachtung des Betroffenen ist in so einem Fall eindeutig - er nimmt sein Leben als eine permanente Abwärtsspirale wahr.

Unter Hinzunahme eines Verfallsnarrativs kann diese Entwicklung narrativiert werden, wodurch sich ein Muster ergibt, aus dem wiederum eine zwingende Logik folgt, nämlich die des unausweichlichen Niedergangs. Dieser Prozess kann auf sämtliche Prozesse unseres Lebens, unserer Kultur, unserer Gesellschaft übertragen werden. Eine der prominentesten Beschreibungen von personalen Narrationen stellt Hayden WHITEs Werk Metahistory (2008) dar. Hierin beschreibt White die Rolle, die narrative Grundmuster bei der Historiografie spielen. Er zeigt auf, dass historische Tatsachen durch Erzählweisen wie die Satire, die Tragödie oder die Komödie zusammengefügt werden, d.h., dass historische Zusammenhänge narrativ konstruiert werden und somit keinesfalls unmittelbar vorliegen. Geschichte, so könnte man sagen, wird immer geschrieben, ist eine Konstruktionsleistung, die (inter)subjektiv erbracht wird. Was White damit deutlich markiert, ist, dass man für die Konstruiertheit von Objekten, Artefakten und Phänomenen aufmerksam sein muss. Es handelt sich bei personalen Narrationen nämlich nicht um solche, die aus dem Zugrundeliegenden hervorgehen, sondern sie werden ihm zugeschrieben. Die Narrativität, die personale Narrationen erzeugt, ist somit immer eine zugeschriebene Narrativität, die dem narrativierten Prozess nicht genuin zu eigen sein muss. Marie-Laure Ryan bemerkt hierzu:

I propose to make a distinction between ,being a narrative' and ,possessing narrativity". The property of ,being' a narrative can be predicated on any semiotic object produced with the intent of evoking a narrative script in the mind of the audience. ,Having narrativity', on the other hand, means being able to evoke such a script. In addition to life itself, pictures, music, or dance can have narrativity without being narratives in a literal sense. (RYAN 2004, 9)

Übertragen auf digitale Spiele bedeutet dies, dass Spielen kein narratives Phänomen sein muss, nur weil der Spieler es (retrospektiv) personal narrativieren kann. Alltägliche Vorgänge 
wie der Einkauf im Supermarkt, der Spaziergang im Park oder das neue Projekt im Büro lassen sich problemlos narrativieren, aber sind sie deshalb narrative Phänomene? - wohl kaum. Personale Narrationen sind Konstruktionsleistungen, die die Person hervorbringt, um ihre Umwelt zu ordnen oder ihrem Leben einen Sinn zu verleihen, sie können zuweilen recht wenig mit der Realität der narrativierten Phänomene zu tun haben. Dadurch, dass Narrationen im Allgemeinen die Komplexität einer Erscheinung oder eines Vorgangs reduzieren und mithilfe eines Musters in einen Prozess überführen können, der diese umdeutet, können Narrationen alles narrativ beschreiben. Die Folge wäre, würde man dieser Logik folgen, dass alles und somit zugleich nichts mehr Narration ist, da das Konzept am Punkt seiner maximalen Ausdehnung unweigerlich ineinander zusammenfällt. Shlomith Rimmon-Kenan zielt mit ihrer Kritik am ,narrative turn' genau auf diesen Umstand ab.

What do I gain by such a move? By narrowing the scope of ,narrative', I am trying to defend the term against being emptied of all semantic content: if everything is narrative, nothing is. (RIMMON-KENAN 2006, 17)

Vor diesem Hintergrund scheint es ratsam, die vorgeschlagene Unterscheidung zu verwenden, wodurch sich auch bestimmte Interpretationen in den Digital Game Studies (v.a. der frühen Jahre) erklären lassen, die allzu weite Auffassung der Narrativität digitaler Spiele vertreten haben. Oft fällt hier auf, dass die Einschätzungen der Forscher auf personalen Narrationen digitaler Spielerlebnisse ihrerseits beruhen, die von diesen aber nicht als persönliche Konstrukte, sondern als mediale Eigenschaft digitaler Spiele eingestuft wurden, wodurch sich erklären lässt, warum digitale Spiele wie Tetris (1984) als (medial) narrativ betrachtet werden. 229 Es liegt eine induktive Fehlleistung vor. Ein digitales Spiel wie Asteroids (1979) oder die meisten aktuellen Mobile Games sind keine narrativen Spiele in dem Sinne, dass die Narration vom Medium ausgeht. Sie können personal narrativiert werden, aber dies sagt nichts über ihren narrativen Gehalt, über ihre Narrativität an sich aus.

Diesbezüglich bietet es sich an, zwischen medialer und personaler Narrativität zu unterscheiden. Bei der medialen Narrativität schreibt der Designer ein ,eingebettetes ‘ Narrativ in das Programm ein und bei der personalen Narrativität schreibt die Person mithilfe eines ,emergenten` Narrativs einem Prozess Narrativität zu. Es sollte aber keineswegs der Eindruck entstehen, dass personale Narrationen in digitalen Spielen zu vernachlässigen sind; das Gegenteil ist der Fall. Nicht nur Genres werden in digitalen Spielen hybridisiert, auch medial narrative Spiele tendieren dazu, zusätzlich Raum für zahlreiche Möglichkeiten zu geben, ein

\footnotetext{
${ }^{229}$ Espen Aarseth merkt hierzu an: „Discussions about »the narrative in Tetris« or »the function of the back story
} in Space Invaders« are, quite frankly, an intellectual waste of time.“ AARSETH (2004b), 365. 
Spiel personal zu narrativieren. ${ }^{230}$ Und Raum ist hier wörtlich zu nehmen, denn digitale Spiele mit Open-World-Prinzip neigen dazu, viel Spielraum für Paidia-Spiele zu offerieren, die oft mit personalen Narrationen einhergehen (können). In medial narrativen digitalen Spielen intensivieren personale Narrationen die Narrativität dieser Spiele und sind somit ein wesentlicher Aspekt der Ludizität solcher digitalen Spiele. Die Analysen zu Ocarina of Time werden dies zeigen. (vgl. 4.2) Eine konkrete Narration im digitalen Spiel, ob medial oder personal, ist stets die Auseinandersetzung eines Rezipienten mit dem Narrativ, wodurch dem Übergang zwischen beiden in der Analyse besondere Aufmerksamkeit geschenkt werden wird.

Dennoch ist die Differenzierung zwischen medialer und personaler Narration heuristisch notwendig, um irreführenden Analysen vorzubeugen, wie sie bereits in der NarratologenLudologen-Debatte zu finden waren und auch heute noch z.T. Arbeiten zum Verhältnis von Spiel und Erzählung in den Digital Game Studies bestimmen. (vgl. 2.1-2) Dabei fällt besonders auf, dass es narrativistische Arbeiten sind, die personale Narrationen nutzen, um eine Legitimationsgrundlage für ihre Forschung zu schaffen. Die Frage ist jedoch, ob es wirklich dieser unendlichen Legitimations- und Nobilitierungsversuche in den Digital Game Studies bedarf, oder ob es nicht sinnvoller wäre, die Grenzen von narratologischen Instrumentarien zu erkennen und sich gegenstandsgerecht zu verhalten, d.h., dass nur digitale Spiele als narrativ betrachtet werden sollten, die auch medial narrativ sind. Selbst wenn man so verfährt, spricht nichts dagegen, personale Narrationen digitaler Spiele zu untersuchen. Dies sollte aber vor dem Hintergrund geschehen, dass man bewusst reflektiert, dass es sich hierbei um personale Narrationen, also um subjektive Konstrukte handelt. Abschließend, bevor die Vorstellung des Kontinuumsmodell beginnt, sollen die Ausführungen zur medialen und personalen Narrativität nochmals zusammengefasst sowie um einige bisher nicht genannte Punkte erweitert werden.

Mediale Narrativität liegt dann vor, wenn ein Designer ein Narrativ in das Programm einbettet, wodurch das System im Dialogbetrieb auf den narrativen Modus zur Vermittlung zurückgreifen kann. Da es sich hierbei um eine Narrativität handelt, die von der Produzentenseite aus intendiert ist, sind mediale Narrationen in der Regel intersubjektiv ähnlich erfahr- und wahrnehmbar. Der Spieler ist bei medialen Narrationen eher passiv sowie

\footnotetext{
${ }^{230}$ Derartig generierte Plots werden von Spielern zudem zuweilen mit anderen Spielern durch Share-Plattformen im Internet geteilt und sind in Form von z.B. Fanfictions der Forschung zugänglich. Vgl. dazu auch Kapitel 4.2.3.3.
} 
man diese auch meistens in digitalen Spielen findet, die stark auf den Ludus hin ausgelegt sind. Was mediale deutlich von personalen Narrationen trennt, ist, dass bei ersteren Rezeption und Narration immer simultan verlaufen.

Personale Narrativität ist dann gegeben, wenn ein Spieler sein Spielerlebnis unter Hinzunahme eines ,emergenten“ Narrativs narrativiert. Diese Narration kann retrospektiv, aber auch simultan zum Spielen erfolgen. Letzteres ist aber nur dann möglich, wenn intuitiv vom Spieler ein Narrativ gefunden wird, das zum Spielverlauf passt. Im Unterschied zur medialen Narration sind personale Narrationen in digitalen Spielen oft nur für das erzeugende Subjekt erfahr- und wahrnehmbar, sind dementsprechend deutlich ephemerer als mediale Narrationen. Dadurch ist die Rolle des Rezipienten im Allgemeinen aber auch wesentlich aktiver, v.a. deshalb, weil personale Narrationen in einer engen Verbindung zu Paidia-Spielen stehen.

\subsection{Profilierung des Kontinuumsmodells}

In den beiden vorangegangenen Kapiteln zum interaktiven und zum narrativen Begriffsfeld wurde zwischen Interaktivität, Interaktion und Interaktiv auf der einen Seite sowie Narrativität, Narration und Narrativ auf der anderen Seite unterschieden. Interaktivität und Narrativität wurden dabei als Eigenschaften bzw. Potenziale begriffen, die Medien oder Phänomene aufweisen und die sich graduell abweichend ausprägen können. Es geht also um die attributive Dimension einer Entität. Im Unterschied dazu markieren die Interaktion und die Narration Prozesse, die die potenziellen Eigenschaften konkret nutzen, die - anders gesagt - diese realisieren. Es ergibt sich somit einerseits eine attributive Ebene, die die Potenzialität umfasst, und andererseits eine Realisierungsebene, auf welcher der Spieler diese Möglichkeiten handelnd umsetzt. Ergänzt werden diese zwei Ebenen um eine dritte, die zwischen beiden vermittelt. Interaktiv und Narrativ wurden als strukturgebende Instanzen beschrieben, die die Ordnung eines interaktiv-narrativen digitalen Spiels herstellen, indem sie Handlungsoptionen definieren sowie bestimmte Narrative samt Figurenpersonal und chronotopischen Eigenschaften integrieren. Diese Ebene kann deshalb als Ordnungs- bzw. Strukturebene klassifiziert werden. Hieraus ergibt sich dann die folgende Abfolge der Ebenen: Attribut-, Struktur- und Realisierungsebene.

Diese Ebenen stellen sich als Kontinuen dar, die sich zwischen dem interaktiven und dem narrativen Pol bilden und denen man dementsprechend Interaktivität-Narrativität, InteraktivNarrativ und Interaktion-Narration zuordnen kann. Die Interaktivität-Narrativität ist auf der 
Attributebene anzusiedeln, da sie durch das Zusammenspiel aus Interaktivität und Narrativität entsteht. Sie ermöglicht, im Sinne der skizzierten Graduationsfähigkeit, im Allgemeinen graduelle Einordnungen von Medien oder Phänomenen, die diese relational zu anderen verorten. So kann man einerseits einen Roman im narrativen, ein Brettspiel wie Mensch ärgere Dich nicht (1910) im interaktiven oder ein digitales Spiel wie The Legend of Zelda im interaktiv-narrativen Bereich verorten und andererseits kann man innerhalb der einzelnen Bereiche graduelle Abstufungen herausstellen. Ein Beispiel: Sowohl Beyond: Two Souls als auch Uncharted sind im interaktiv-narrativen Bereich zu verorten, unterscheiden sich aber dahingehend, dass ihre Interaktivität-Narrativität unterschiedlich ausgeprägt ist. Beyond: Two Souls hat sehr viele narrative Phasen, die auch sehr viel Spielzeit in Anspruch nehmen, wohingegen sich bei Uncharted interaktive und narrative Spielphasen in einem stärkeren Gleichgewicht befinden. ${ }^{231}$ Zusätzlich kann man festhalten, dass die Interaktivität unter dem Gesichtspunkt der Signifikanz und der Frequenz der Interaktionen in beiden Spielen zwar annähernd vergleichbar ist, dass sie sich aber in Bezug auf die Bandbreite an Interaktionsmöglichkeiten erheblich unterscheiden. Beyond: Two Souls gestattet dem Spieler fast nur Interaktionen, die es ihm unmittelbar vorgibt, ist somit sehr stark als Ludus konzipiert, Uncharted hingegen bietet zahlreiche Möglichkeiten für Paidia-Spiele an, indem eine Vielzahl von Strategien zur Überwindung der gegnerischen NPCs in den interaktiven Kampfphasen möglich ist, die Beyond: Two Souls nicht offeriert. Uncharteds InteraktivitätNarrativität (als Action-Adventure) ist somit deutlich interaktiver angelegt als die eines Interaktiven Films wie Beyond: Two Souls. ${ }^{232}$

Hieran wird ersichtlich, dass man auf der Attributebene einerseits makroperspektivisch verschiedene Medien/Phänomene miteinander vergleichen kann, dass man aber auch mesoperspektivisch Genres eines Mediums zueinander in Bezug setzen kann, sowie es die Attributebene mikroperspektivisch gestattet, diverse Genrevertreter eines bestimmten Genres graduell einzuordnen. ${ }^{233}$ So ist es denkbar, zu fragen, wie unterschiedlich sich die

\footnotetext{
${ }^{231}$ Da sich derartige Beobachtungen nur aus einer diskursiven Betrachtung heraus vornehmen lassen, ist es notwendig, die betreffenden Spiele in Gänze zu untersuchen. Vgl. deshalb zu Beyond: Two Souls exemplarisch den Walkthrough von XCV https://www.youtube.com/watch?v=9qolJTsmmWA (30.06.2018) sowie zu Uncharted am Beispiel von Uncharted: The Lost Legacy (2017) den Walkthrough von RABIDRETROSPECTGAMES https://www.youtube.com/watch? v=h_jnaqSN-MU (30.06.2018).

232 Vgl. dazu exemplarisch das Let's Play von XCV zu Beyond: Two Souls https://www.youtube.com/watch?v=Kx57Hy_GUs0 (30.06.2018) sowie das Let's Play von TMARTN2 zu Uncharted: The Lost Legacy https://www.youtube.com/watch?v=HpsZkShCXpM (30.06.2018).

${ }^{233}$ Prinzipiell ist es möglich, die Perspektive aber auch hier weiter zu verkleinern, indem man sich von der diskursiven Betrachtung von Spielreihen und -serien löst und stattdessen die Einzeltitel (relational oder nicht) auf dem Kontinuum verortet. Ebenfalls ist es denkbar, zu betrachten, inwiefern sich einzelne Abschnitte eines
} 
Interaktivität-Narrativität in einem Genre wie dem Action-Adventure darstellen kann, indem man betrachtet, inwiefern sich die Interaktivität-Narrativität von The Legend of Zelda, Tomb Raider, Uncharted oder Assassin's Creed voneinander abheben.

Das Interaktiv-Narrativ stellt die Strukturebene (man könnte auch vom Ordnungsprinzip sprechen) eines interaktiv-narrativen digitalen Spiels dar, die sich zwischen dem Interaktiv und dem Narrativ erstreckt. Als strukturgebende Instanz ist es vom Designer angelegt, der im Interaktiv Handlungsoptionen, Spielregeln und Spielmechaniken anlegt. So gefasst hat jedes digitale Spiel ein Interaktiv, was es aber nicht immer hat, ist ein Narrativ. Hieraus ergeben sich die Besonderheiten hybrider interaktiv-narrativer digitaler Spiele, die oft jene Frage umkreisen, wie eine Zusammenführung von interaktiven und narrativen Elementen möglich wird. Bei der Betrachtung des Interaktiv-Narrativs geht es um die Anlage der InteraktivitätNarrativität eines digitalen Spiels durch den Produzenten. Dass bzw. wie InteraktivitätNarrativität realisierbar ist, wird mit Blick auf das Interaktiv-Narrativ deutlich. Es gibt Elemente, die ,interaktiv-narrativ polyvalent' sind, d.h. die sich innerhalb des Kontinuums in jedem der drei Bereiche umsetzen lassen. Diese Elemente können demzufolge narrativ, interaktiv und interaktiv-narrativ eingesetzt werden. Im Kontext der interaktiv-narrativen Polyvalenz sollen besonders drei Aspekte betrachtet werden: die Figuren, die Welt und die Struktur.

Eine Figur kann als Charakter in einer Erzählung (narrativ), als Spielfigur eines Spiels (interaktiv) und als Avatar realisiert werden, der sowohl erzählerische als auch interaktive Komponenten umfasst (interaktiv-narrativ). Dasselbe gilt für eine Welt, die als Diegese (narrativ), als simulativer Spielraum (interaktiv) oder als interaktiv-narrative Spielwelt (interaktiv-narrativ) umgesetzt werden kann ebenso wie für die Struktur, welche narrativer (Erzählstruktur), ${ }^{234}$ interaktiv-ludischer (Queststruktur) oder interaktiv-narrativer Art (interaktiv-narrative Spielstruktur) sein kann. Auch auf der Strukturebene ist eine graduelle Verortung auf dem Interaktiv-Narrativ möglich, welche sich in der Regel mit der Frage befasst, wie ein Designer die Interaktivität-Narrativität seines Spiels ausgestaltet. Wird die Interaktivität-Narrativität interaktiv, narrativ oder interaktiv-narrativ angelegt? Zeigen sich hier signifikante Veränderungen im Spielverlauf? Dies berührt Fragen der Interaktivität-

bestimmten Spiels zueinander verhalten, d.h. ob sie bspw. signifikante Abweichungen aufweisen. Insofern funktioniert die Verortung auf der Attributebene ähnlich wie die Ebenen ,hypodiegetischen Erzählens‘. Vgl. dazu BAL (1981). Da die Funktionsweise der Attributebene aber anhand der drei dargebotenen Perspektiven deutlich werden sollte, wird im Folgenden auf weitere Perspektiven verzichtet.

${ }^{234}$ Zum Schreiben von digitalen Spielen bzw. deren Geschichten vgl. CHANDLER (2007). 
Narrativität digitaler Spiele auf der Attributebene, wie sie sich v.a. in der Mikroperspektive ergeben und kann nur gemeinsam mit diesen betrachtet werden. Die Strukturebene untersucht - anders gesagt - wie die attributiven Potenziale der Interaktivität-Narrativität (bspw. die interaktiv-narrativ polyvalenten Elemente) im Gamedesign angewendet werden. Hierdurch wird deutlich, wie eng die einzelnen Ebenen miteinander verbunden sind.

Interaktion und Narration wirken auf der Realisierungsebene in Gestalt der InteraktionNarration zusammen. Hierzu interagiert der Spieler mit den Anlagen des Interaktiv-Narrativs, die er im Rahmen seiner Interaktion-Narration subjektiv umsetzt. Interaktiv-Narrativ und Interaktion-Narration bzw. Struktur- und Realisierungsebene trennen Produzenten- und Rezipientenseite voneinander, fokussieren aber auch die Wechselwirkungen, die zwischen diesen stattfinden, wenn der Spieler in der Interaktion-Narration Angebote des InteraktivNarrativs realisiert. Ferner wird ersichtlich, dass das Kontinuumsmodell von oben nach unten (also von der Attribut- über die Struktur- hin zur Realisierungsebene) zunehmend konkreter wird. Beziehen sich Aussagen, die man auf der Attributebene treffen kann, sehr allgemein auf potenzielle Eigenschaften, so stellt die Strukturebene eine Konkretisierung erster Ordnung dar, indem der Designer aus der Gesamtheit interaktiv-narrativer Elemente bestimmte auswählt, um das Interaktiv-Narrativ des jeweiligen Spiels zu erschaffen. Er kann bspw. ein (interaktiv-narratives) Narrativ auswählen, dessen Struktur, Figuren und Welt interaktivnarrativ polyvalent sind und dessen Erzähllogik sich performativ in digitalen Spielgenres umsetzen lässt. Zudem kann er auf Spielmechaniken wie das QTE zurückgreifen, die Interaktion und Narration in digitalen Spielen simultan ablaufen lassen und hierdurch die interaktiv-narrative Hybridisierung digitaler Spiele auch mit Blick auf die Spielzeit herausstellen.

Eine Konkretisierung zweiter Ordnung tritt beim Übergang vom Interaktiv-Narrativ zur Interaktion-Narration zutage. Das Interaktiv-Narrativ ist zwar konkreter als die Potenzialität der Interaktivität-Narrativität, im Vergleich mit der/den Interaktion-Narration(en) weist das Interaktiv-Narrativ aber einen potenziellen Charakter auf. Es gibt dem Spiel zwar eine Struktur, aber ohne den Spielern eine bestimmte Ordnung aufzuzwingen. Vielmehr sollten die Spielstrukturgebungen durch das Interaktiv-Narrativ nicht als strikte Vorgaben, sondern als Angebote, die den ,Möglichkeitsraum“ etablieren, verstanden werden, die viele verschiedene Möglichkeiten der Realisierung zulassen. Das bedeutet letztlich, dass es nicht eine Realisierung, sondern einen Pluralismus an Realisierungen gibt, die sich in diversen abweichenden Realisierungen niederschlagen (können). Interaktion-Narrationen sind als 
konkreter Prozess des Spielens eines interaktiv-narrativen digitalen Spiels ein Aspekt, der v.a. mediensoziologisch interessant ist, da es sich bei Interaktion-Narrationen um konkrete Mediennutzungen handelt, die verschiedene Studien zum Mediennutzungsverhalten von Spielern erlauben. Dadurch erhalten sie eine Janusköpfigkeit, die diese Arbeit nur bedingt abbilden kann. Stattdessen soll es darum gehen, kennzeichnende Merkmale von InteraktionNarrationen hervorzuheben, die bei der Analyse dieser von primärem Interesse sind. Die Realisierungsebene gestattet auch wie die anderen höheren Ebenen eine graduelle Verortung innerhalb des Kontinuums, welche tendenzielle Aussagen über drei verschiedene Spielertypen interaktiv-narrativer digitaler Spiele zulässt.

Abbildung 4 visualisiert das bisher Ausgeführte. Von besonderer Relevanz ist der ,mittlere‘ Bereich der Kontinuen, jener Bereich, indem sich im Besonderen die interaktivnarrative Hybridität manifestiert. Das Modell betont hiermit bewusst einen ,dritten Raum‘, womit aber keinesfalls Anschluss an die postkoloniale Hybriditätstheorie Homi Bhabhas gesucht werden soll. ${ }^{235}$ Es ist eher dem zentralen Anliegen dieser Studie geschuldet, die Hybridität digitaler Spiele auch auf theoretisch-methodischer Ebene konsequent abbilden zu wollen, indem man diese räumlich verortet und die (ontologische wie rezeptiv-ästhetische) Hybridität interaktiv-narrativer digitaler Spiele so für Untersuchungen zugänglich macht.

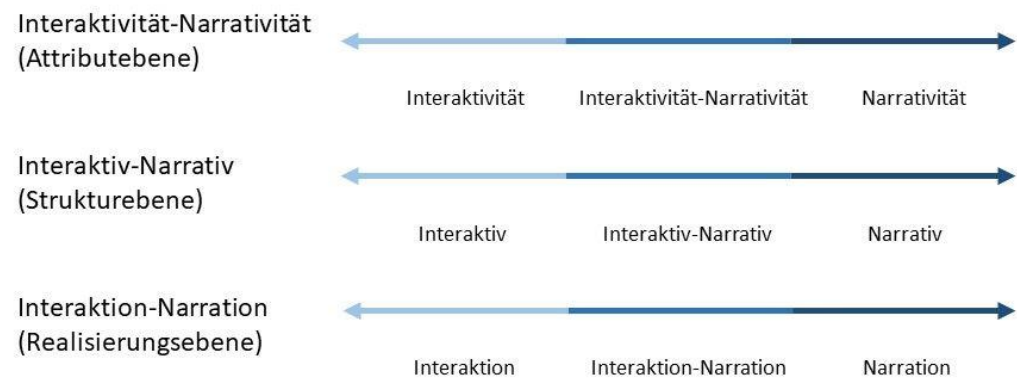

Abb. 4: Kontinuumsmodell

${ }^{235}$ Zum Hybriditäts verständnis Bhabhas vgl. BнABHA (2012). 
Diese Abbildung des Modells kann auf den ersten Blick etwas verwirren, da einerseits das gesamte Kontinuum (z.B. der Attributebene) als Interaktivität-Narrativität bezeichnet wird, andererseits der Übergangsbereich zwischen dem interaktiven und dem narrativen Bereich auch mit dem Begriff Interaktivität-Narrativität ausgestattet wird. Aus dieser Beobachtung ergibt sich dann die Frage, wie sich dieser Widerspruch auflösen lässt. Genau genommen, liegt aber kein Widerspruch vor, denn Interaktivität-Narrativität, wenn man die Hybridität ernst nimmt, kann nur dann vorliegen, wenn beide Ausgangsentitäten (Interaktivität und Narrativität) gegeben sind und im Rahmen der Modellbildung berücksichtigt werden. Somit bezeichnen die Begriffe Interaktivität-Narrativität, Interaktiv-Narrativ und InteraktionNarration stets die gesamte Ausdehnung der Kontinuen. Der mittlere Bereich hingegen ist der Raum der größten hybriden Ausprägung, also jenes Areal, in dem der Ausgleich zwischen beiden Polen am stärksten ist, wobei die maximale Balance in der Mitte des Kontinuums zu finden ist. Hieraus ergeben sich aber auch die Grenzen des Modells, da es dort endet, wo der Gegenpol nicht mehr vorhanden ist. Sobald ein Phänomen nur direkt an einem der Pole verortet werden kann, ist es nicht mehr interaktiv-narrativ. Ein Spiel wie Fangen ist ein rein interaktives Phänomen und ein Roman (als Kodex) ein rein narratives Medium. Sie schließen (in ihren traditionellen Formen) das Andere aus und negieren somit die InteraktivitätNarrativität. Zwar kann man das Spielerlebnis eines Spieles wie Fangen personal narrativieren, an sich besitzt das Phänomen aber keine narrativen Eigenschaften, die ihm inhärent sind. Das bedeutet aber auch, dass das Modell über Phänomene und Medien, die sich nur an den Polen verorten lassen, lediglich die Aussage treffen kann, dass sie nicht interaktivnarrativ sind.

Im Fortlauf dieses Kapitels wird das Modell anhand der drei Ebenen detailliert vorgestellt und seine analytischen Funktionen werden in diesem Zusammenhang mit Bezug auf einige Beispiele erläutert. Anschaulich und konkreter wird dies freilich erst in Kapitel 4 werden, wenn Ocarina of Time mithilfe des Kontinuumsmodells analysiert wird.

\subsubsection{Die Attributebene}

Begreift man Interaktivität und Narrativität als Kernkomponenten digitaler Spiele, dann folgt daraus zwangsläufig deren Hybridität. Untermauern lässt sich dies mit Beobachtungen des zunehmenden Verschwimmens zwischen Interaktivität und Narrativität. (vgl. dazu 2.2.2.1) Dabei vermischen sich nicht nur interaktive und narrative Spielphasen, sondern auch die Figuren oder verschiedene Konzepte der Welthaftigkeit. So ist es für einen Spieler in 
aktuellen interaktiv-narrativen digitalen Spielen z.B. nicht immer ersichtlich, ob er sich noch in einer narrativen Sequenz oder schon wieder in einer interaktiven Spielphase befindet (und umgekehrt), da interaktiv-narrative digitale Spiele auch eine Hybridisierung von medialen Rezeptionsbedingungen mit sich bringen. Dies wirkt sich dann auch auf die Figuren aus, wenn sich der Spieler die Frage stellt, ob sein Avatar gerade als narrativer Charakter oder als Spielfigur fungiert und ob (damit zusammenhängend) die Welt aktuell diegetisch und hierdurch seinem aktiven Eingriff entzogen ist oder als simulative Welt nur auf sein Eingreifen in diese im Kontext des Dialogbetriebs wartet. Diese Oszillation zwischen den Wirkmächten interaktiv-narrativer digitaler Spiele gilt es auch zu bedenken, wenn Kategorisierungen im Folgenden präsentiert werden, welche nicht absolut, sondern eher tendenziell verstanden werden sollten. Die Attributebene dient dazu, um dies prägnant zu machen, Aussagen über die interaktiv-narrativen Ausformungen von Medien und Phänomenen bzw. deren qualitativen Eigenschaften zu treffen.

Die graduelle Verortung spielt zwar auf allen drei Ebenen eine zentrale Rolle, sie ist aber nirgends so gewichtig wie auf der Attributebene. Hier ist ihr heuristischer Wert, besonders mit Blick auf die drei genannten Untersuchungsperspektiven, am größten. Was aber alle Ebenen zugleich betrifft, ist, dass sich prinzipiell drei Arten des Interaktiv-Narrativen ergeben. Am Beispiel der Interaktivität-Narrativität verdeutlicht, heißt das, dass es eine interaktive, eine interaktiv-narrative und eine narrative Interaktivität-Narrativität gibt. Das interaktiv-narrativ Interaktiv-Narrative stellt dabei stets die markanteste Form der Hybridisierung, das interaktiv Interaktiv-Narrative eine interaktiv-ludische und das narrativ Interaktiv-Narrative eine narrativ-darstellerische Ausgestaltung dar. Wodurch sich die Ebenen hierbei voneinander abheben, sind die zentralen Leitfragen bzw. das zentrale Einordnungskriterium, das zu der entsprechenden Verortung auf dem Kontinuum führt. Auf der Attributebene ist dies die Frage, wie die interaktiv-narrativen Eigenschaften eines Phänomens oder Mediums ausgeprägt sind. Dementsprechend sind drei Typen auf der Attributebene unterscheidbar, die sich mit allen drei Untersuchungsperspektiven bestimmen lassen: die interaktiv-interaktiv-narrative, die interaktiv-narrativ-interaktiv-narrative und die narrativ-interaktiv-narrative Form. ${ }^{236}$ Die folgenden Beispiele anhand der drei Untersuchungsperspektiven illustrieren dies.

\footnotetext{
${ }^{236}$ Aus Gründen der Einfachheit wird im Folgenden - zumindest dann, wenn der Bezug auf das InteraktivNarrative eindeutig und unmissverständlich ist - nicht von einer interaktiv-interaktiv-narrativen Form usw. gesprochen. Dem Prinzip der Kürze verpflichtet wird die interaktiv-interaktiv-narrative Form lediglich als interaktive, die interaktiv-narrativ-interaktiv-narrative als interaktiv-narrative und die narrativ-interaktivnarrative als narrative bezeichnet.
} 


\subsubsection{Die Makroperspektive}

In der Makroperspektive lassen sich Phänomene ${ }^{237}$ und Medien auf dem Kontinuum verorten (siehe Abbildung 5). An den beiden Polen als Punkte, die sich der InteraktivitätNarrativität entziehen, findet man auf der interaktiven Seite Gesellschafts- oder Sportspiele und auf der narrativen Seite genuin narrative Medien wie den Roman oder den (Spiel-)Film. Als interaktive Phänomene/Medien stechen bspw. Hypertext und Pen-\&-Paper-Rollenspiel hervor, wobei die Interaktivität von Hypertexten stärker ausgeprägt ist als die der Pen-\&Paper-Rollenspiele. Dies liegt letztlich daran, dass sich letztere kaum ohne narrative Elemente realisieren lassen, wohingegen erstere nicht zwangsläufig medial narrativ sein müssen. Man denke an diverse Hypertextsysteme im Internet, deren Knoten keine narrativen Funktionen erfüllen oder narrative Charakteristika aufweisen. Zudem ist auch die Verknüpfung der Knoten via Kanten nicht narrativ motiviert.

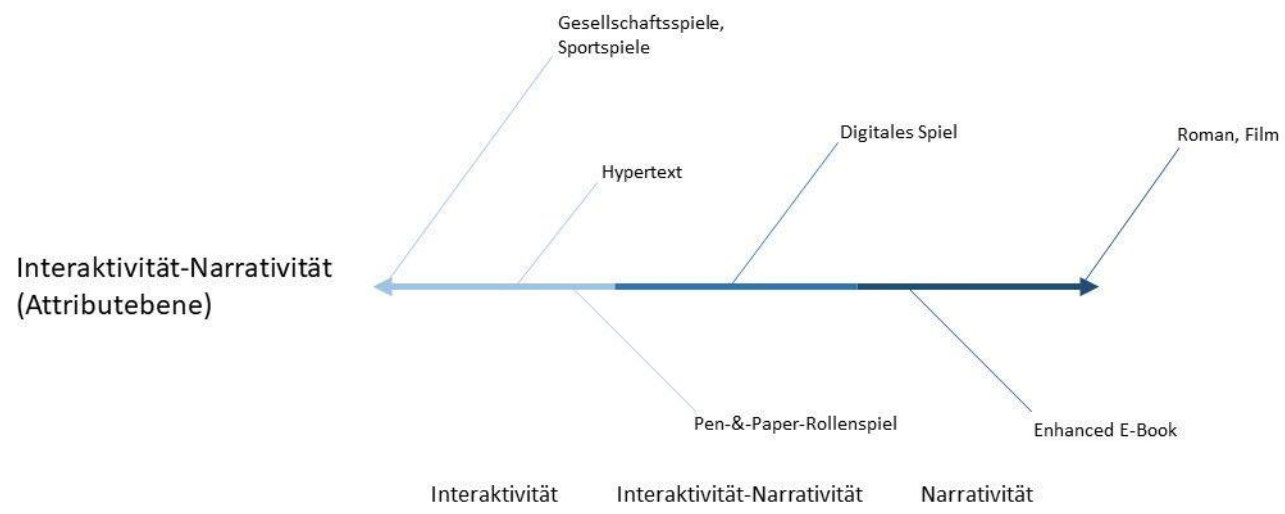

Abb. 5: Makroperspektive

\footnotetext{
${ }^{237}$ Im Folgenden werden hierunter Erscheinungen verstanden, bei denen das Erleben der Entität gar nicht oder kaum an ein physisches Artefakt gebunden ist. Im Gegensatz dazu ist das Erleben eines Mediums weitaus stärker vom Medium oder dessen Medienträger abhängig. Von analytischem Belang ist diese Differenz deshalb, weil gerade im Zuge von Hybridisierungen beide zuweilen miteinander verschmelzen können und sie andernfalls weder in ihrer Reinform noch als Hybride untersuchbar wären. Dies verdeutlicht das digitale Spiel als Medium, das u.a. aus dem Phänomen Spiel entsteht. Zudem lassen sich somit zusätzliche Perspektiven und Erklärungsansätze für die Rolle des performativen Erlebens während der Rezeption digitaler Medien gewinnen und hierdurch der Wandel der Medienkultur besser verstehen, den digitale Medien induzieren.
} 
Anders sieht dies beim Enhanced E-Book aus, welches zwar auch zur deskriptiven Informationsvermittlung eingesetzt werden kann, somit eher didaktisch-kommunikative ${ }^{238}$ Interessen verfolgt, in den meisten Fällen aber als fiktionales Medium auftritt, das transmediale Erzählverfahren durch seine mediale Hybridisierung einsetzt, indem es mehrere Medien remedialisiert. Die Form der Interaktivität-Narrativität ist in diesem Fall narrativ. Digitale Spiele sind unter den gegenwärtigen populären digitalen Medien (avantgardistische Spielarten interaktiver Medienkunst ausgenommen) diejenigen mit der stärksten interaktivnarrativen Ausprägung, weshalb sie als interaktiv-narrativ zu bezeichnen sind. Durch diese intensive Ausprägung der Interaktivität-Narrativität eignen sich digitale Spiele besonders als Untersuchungsgegenstand für die geplante Analyse.

Bereits diese exemplarische Darstellung aus der Makroperspektive lässt einige Schlüsse in Bezug auf die Interaktivität-Narrativität zu. So kann man tendenziell sagen, dass sich eine interaktive Interaktivität-Narrativität eher bei Phänomenen finden lässt als bei Medien, wohingegen narrative Interaktivität-Narrativität anscheinend eher bei Medien nachweisbar ist. $^{239}$ Freilich müsste man derartige Thesen mit konkreten empirischen Untersuchungen belegen, jedoch können sie schon in dieser Form einige interessante Ansätze bieten. Wenn man die angestellte Überlegung als stichhaltig erachtet, so ergibt sich hieraus im interaktivnarrativen Hybridraum eine interessante Schlussfolgerung. Wenn Phänomene primär im Bereich interaktiver und Medien hauptsächlich im Bereich narrativer InteraktivitätNarrativität zu finden sind, dann liegt die Vermutung nahe, dass im interaktiv-narrativen Hybridbereich eine Vermengung von Medium und Phänomen vorherrscht, d.h. beide im digitalen Spiel zunehmend verschwimmen. Und tatsächlich gibt es hierfür einige plausible Gründe, da ein Spiel an sich zwar meistens ein Phänomen in dem oben skizzierten Sinne ist, ${ }^{240}$ welches aber als digitales Spiel zum Medium wird, das an einen elektronischen Medienträger gebunden ist. Die technologischen Rahmenbedingungen dieses Medienträgers

\footnotetext{
${ }^{238}$ Nicht zuletzt aus diesem Grund finden Enhanced E-Books zunehmend Verwendung in der Schule, wobei Fragen der ,digitalen Literarizität‘ ebenso im Fokus stehen wie der Vergleich mit dem printbezogenen Lesen. Vgl. dazu die von Stefanie LANGE (voraussichtlich 2018) am GRK 1787 „Literatur und Literaturvermittlung im Zeitalter der Digitalisierung" an der Georg-Universität-Göttingen verfasste Dissertation Enhanced E-Books. Eine Untersuchung zum Leseprozess einer neuen Literaturform sowie MüLLER (2017).

239 Darüber kann auch nicht die Tatsache hinwegtäuschen, dass interaktiven Phänomenen ebenso Narrativität zugeschrieben wie genuin narrativen Medien Interaktivität vom Rezipienten unterstellt werden kann. Man denke einerseits an personale Narrationen und andererseits an konstruktivistisch-rezeptionsästhetische Ansätze in den Medienwissenschaften. In beiden Fällen handelt es sich aber um subjektive Interpretationsleistungen, die nur in sehr eingeschränktem Maße Rückschlüsse auf die konkrete Beschaffenheit der jeweiligen Entität zulassen.

${ }^{240}$ Dies betrifft vornehmlich Spiele, die ganz ohne physisch fassbare Objekte auskommen wie bspw. der Wettlauf. So gefasst sind Spiele Phänomene, die interaktiv ausagiert und gemeinsam von allen Beteiligten erlebt werden, wobei (Regel-)Festsetzungen, Ergebnisevaluation und Ergebnisverkündung intersubjektiv psychisch wahrgenommen und verarbeitet werden.
} 
bieten dem digitalen Spiel einerseits eine definitive Form, wie sie für Medien kennzeichnend ist, zugleich ermöglichen sie aber vielgestaltige und vielfältige Operationen, die eigentlich für die Ambivalenz von Phänomenen charakteristisch sind.

Solche Hybridisierungen werden noch durch zwei weitere Faktoren unterstützt interaktiv-narrative Polyvalenzen und strukturelle Äquivalenzen. Ersteres wurde bereits angesprochen und wird im Abschnitt zum Interaktiv-Narrativ detaillierter ausgeführt werden, sodass es an dieser Stelle ausgeklammert wird. Auf letzteres wird hingegen eingegangen. Besonders deutlich zeigen sich die strukturellen Äquivalenzen in den beiden Übergangsbereichen, wenn die interaktive bzw. narrative Interaktivität-Narrativität an den Bereich der größten Hybridität stoßen. Phänomene und Medien, die in diesem Bereich zu verorten sind, weisen eine große Offenheit für den entgegengesetzten Pol auf, woraus sich eine Dreiteilung der Bereiche ergibt. So kann man bei der narrativen Interaktivität-Narrativität zwischen interaktionsoffenen, -neutralen und -abgewandten Formen narrativer InteraktivitätNarrativität sprechen. Die Affinität für die Gegenseite steigt mit zunehmender Nähe zum interaktiv-narrativen Bereich und nimmt mit geringer werdender Distanz zu den Polen ab. Somit ergeben sich für den interaktiven Bereich des Kontinuums narrationsoffene, -neutrale und -abgewandte Formen interaktiver Interaktivität-Narrativität.

Zwei Beispiele sollen dies illustrieren. Nimmt man ein narrationsoffenes interaktives Phänomen wie das Pen-\&-Paper-Rollenspiel, so stellt sich die Frage, worin sich die Narrationsoffenheit manifestiert bzw. welche strukturellen Äquivalenzen vorherrschen, damit eine Narrationsoffenheit gegeben ist. Selbstverständlich können nicht sämtliche Äquivalenzen angeführt werden, vielmehr soll ein Aspekt herausgegriffen werden, der für diese Spiele typisch ist - der Game Master. Dieser erfüllt nur auf den ersten Blick die Aufgaben eines gewöhnlichen Spielleiters. Es trifft zwar zu, dass eine wichtige Aufgabe des Game Masters darin besteht, Verstöße aller Art zu sanktionieren, entscheidender ist aber sein Wirken als koordinierende Instanz der Narration. Pen-\&-Paper-Rollenspiele wie Dungeons \& Dragons stellen eine bemerkenswerte Hybridisierung medialer und personaler Narrationen dar, da sie zum einen auf bestimmten Narrativen beruhen, deren konkrete Umsetzungen im Spielverlauf aber zum anderen von den Aktionen der Spieler abhängen. ${ }^{241}$ Es ist die Aufgabe des Game Masters, spielerische Handlungen und deren Folgen für die Spielwelt, den Plot und die

\footnotetext{
${ }^{241}$ Eine konzise aber sehr informative Erklärung von Dungeons \& Dragons im Besonderen sowie Pen-\&-PaperRollenspielen im Allgemeinen bietet das folgende Video von ORKENSPALTER TV https://www.youtube.com/watch?v=H_zLvsvghXc (30.06.2018).
} 
Figuren in Einklang zu bringen. Dementsprechend wird er - neben seiner Funktion als Spielleiter - zur maßgeblichen Instanz, die die narrative Ordnung erhält, indem er die Kohärenz des Plots bewahrt. Anders gesagt: Der Game Master übernimmt partiell und temporär Funktionen, die in narrativen Medien mit dem Erzähler (sofern vorhanden) bzw. der narrativen Instanz verbunden werden. Durch diese strukturelle Äquivalenz ,öffnen“ sich Spiele wie Dungeons \& Dragons für den narrativen Bereich des Kontinuums.

Betrachtet man mit dem Enhanced E-Book ein interaktionsoffenes narratives Medium, so offenbaren sich auch hier strukturelle Äquivalenzen. Exemplarisch sei auf die Multioptionalität des Rezipienten verwiesen. Liest man einen Roman (als Kodex) oder sieht einen Spielfilm, so hat man stets nur zwei Optionen - man kann rezipieren oder man kann die Rezeption abbrechen, indem man das Buch beiseitelegt oder den Film abschaltet bzw. den Kinosaal verlässt. Man kann aber nicht bestimmen, was, wann, wie erzählt wird. Beim Enhanced E-Book jedoch hat der Rezipient diese Optionen, wenn er sich bspw. entscheidet, ob er sich ein integriertes Video ansieht oder nicht oder es nur teilweise rezipiert. Es besteht also eine Vielzahl an Handlungsmöglichkeiten, die eigentlich kennzeichnend für die Multioptionalität von Spielen ist. Mit Brenda LAUREL (1993) gesprochen kann man auch sagen, dass die Interaktivität des Enhanced E-Books eine höhere Frequenz, Reichweite und Signifikanz aufweist als die anderen beiden medialen (narrativen) Rezeptionssituationen. Hierdurch erhalten Enhanced E-Books eine Interaktionsoffenheit, die für die InteraktivitätNarrativität förderlich ist.

\subsubsection{Die Mesoperspektive}

Greift man aus den Beispielen aus Abbildung 5 eines heraus und verwendet hierbei dasjenige, welches sich im mittleren Bereich des Kontinuums befindet, so kann man dieses weiter untersuchen, indem man die Untersuchungsperspektive kategorial verkleinert. In diesem Fall betrachtet man digitale Spiele nicht mehr in Relation zu anderen Phänomenen oder Medien, man untersucht stattdessen verschiedene Genres des digitalen Spiels. (siehe Abbildung 6) Am interaktiven Pol sind all jene Genres zu verorten, und diese sind zahlreich, die nicht medial narrativ und dementsprechend nicht interaktiv-narrativ sind. Als Beispiele dienen hier das Maze und das Puzzle Game. ${ }^{242}$ Der narrative Pol ist nicht besetzt, da digitale

\footnotetext{
${ }^{242}$ Andere Beispiele findet man im sehr vitalen Bereich des Mobile Gamings, da ein Großteil der Mobile Games, aufgrund des Spielkontextes, für den sie designt wurden, keine medialen Narrationen in die mediale Vermittlung integriert. Mediale Narrationen bieten sich tendenziell in digitalen Spielen an, die der Spieler getrennt von anderen, also eher privat als öffentlich spielen kann. Durch diese räumliche Trennung ergibt sich aber auch eine zeitliche Differenz. Denn digitale Spiele, die im privaten Raum gespielt werden, können die Spielzeit sehr viel
} 
Spiele ohne Interaktivität keine Spiele mehr sind, sondern Filme. Denn, wie oben ausgeführt, ist die Narrativität im Unterschied zur Interaktivität keine zwingende Komponente der Ludizität digitaler Spiele. (vgl. 2.2.1)

Im interaktiven Bereich sind all jene digitalen Spielgenres situiert, für die die Interaktivität wichtiger ist als narrative Elemente. Bei (digitalen) Sportspielen wie der NHL-Reihe (1991 ff.) geht es um die Simulation von diversen (analogen) Sportspielen, Narrativität kommt hier nur sehr spärlich vor und in den allermeisten Fällen gar nicht. Das Jump'n'Run (z.B. die Mario-Reihe (1983 ff.)) weist dagegen oft zumindest eine Rahmenhandlung sowie eine zaghafte, stereotype Figurenkonzeption und -konstellation auf, die aber auch nicht unbedingt notwendiger Bestandteil der Ludizität dieses Genres sind. Shooter (z.B. die Halo-Reihe (2001 ff.)) und Beat'em up (z.B. die Street Fighter-Reihe (1987 ff.)) sind dagegen oft deutlich narrativer. Beide setzen auf eine sehr agonale Queststruktur, die sich ideal durch Narrative unterstützen lässt, deren Abfolge von narrativen Funktionen und Figurenkonstellation sehr antagonistisch ist (man denke hier an das mythologische Narrativ). Auf diese Weise wird die genrebestimmende Spielmechanik narrativ verstärkt und das Spielerlebnis des Spielers intensiviert. Diese Genres sind narrationsoffen und markieren damit den Übergang zu dem Bereich, an dem Narrativität ein zwingender Bestandteil digitaler Spiele wird, denn interaktivnarrative sowie narrative digitale Spielgenres sind ohne mediale Narrativität nicht existent.

individueller gestalten als digitale Spiele, die stark von äußeren Faktoren bestimmt werden wie die kurze Fahrzeit in der U-Bahn. 


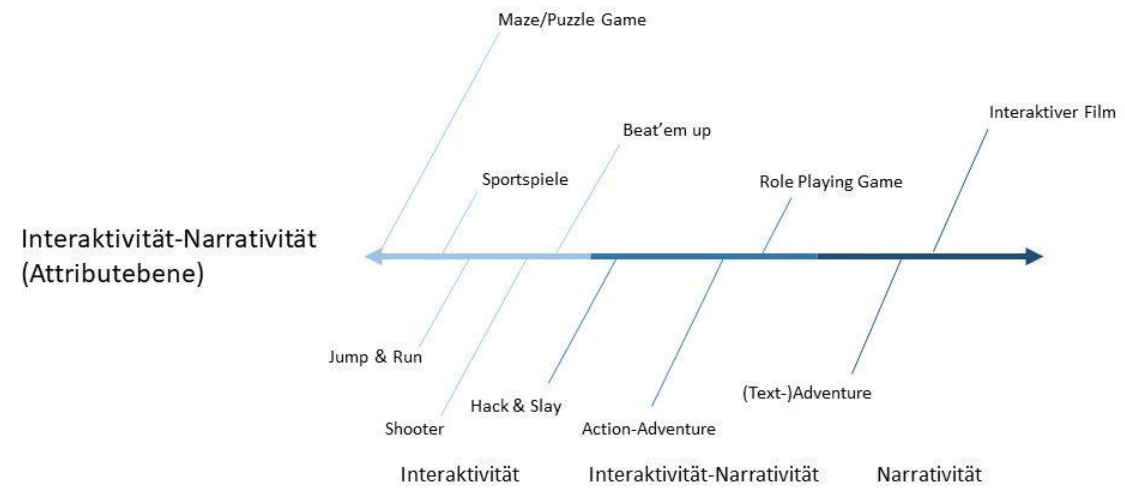

Abb. 6: Mesoperspektive

Die interaktiv-narrativen Genres unterscheiden sich aber von den narrativen Genres dadurch, dass sie ein Gleichgewicht von Interaktivität und Narrativität bei allen Aspekten des Spiels anstreben und somit eine, vollkommene“ Hybridität (als Ideal) erreichen wollen. Dies trifft in besonderem Maße auf Hack \& Slay (z.B. die Diablo-Reihe (1996 ff.)), ActionAdventure und RPG (z.B. die The Elder Scrolls-Reihe (1994 ff.)) zu. Sie sind, wenn man so will, die medial ,interaktiv-narrativsten“ Genres digitaler Spiele. Diese InteraktivitätNarrativität nimmt im narrativen Bereich mit dem Adventure und dem Interaktiven Film schon deutlich $\mathrm{ab}$, da diese die Interaktivität sehr stark reduzieren und sich Medien wie Literatur oder Film annähern. Interessant ist eine Beobachtung, die mit Rückgriff auf Roger CAILlois (1960) möglich wird. Betrachtet man das Kontinuum von links nach rechts, dann fällt auf, dass die Vielfalt an Spielformen abnimmt bis nur noch eine übrigbleibt - der Agôn. Spätestens ab dem Jump'n'Run werden alle folgenden Genres von einem agonalen Spielprinzip dominiert, wobei der Antagonist mal mehr und mal weniger abstrakt ist. Dies legt eine Schlussfolgerung nahe: Mit der Zunahme der Narrativität interaktiv-narrativer digitaler Spiele steigt auch die Agonalität der Ludizität im Allgemeinen. Es scheint also einen Zusammenhang zwischen der Narrativität und der Agonalität in digitalen Spielen zu geben. Ein Grund hierfür ist sicherlich die antagonistische Gestalt vieler Narrative, die sich besonders deutlich am mythologischen Narrativ und seinen modernen Abwandlungen zeigen lässt. Ausgehend vom mythologischen Narrativ rekurrieren viele dieser Derivate auf den konstitutiven Gut-Böse-Antagonismus, der aber nicht mehr mythologisch-religiöser, sondern 
eher ,profaner ${ }^{\star}$ Art ist, auch wenn mythologische und religiöse Aspekte (zumindest substantialistisch betrachtet) noch immer virulent sind. Jene Überlegungen lassen sich durch den Übergang von der Meso- auf die Mikroperspektive weiter fortführen.

\subsubsection{Die Mikroperspektive}

In der Mikroperspektive kann man verschiedene Vertreter eines Genres auf dem Kontinuum verorten. Wie beim Wechsel von der Makro- zur Mesoperspektive wird im Folgenden jenes Genre betrachtet, dessen Interaktivität-Narrativität am signifikantesten ausgeprägt ist - das Action-Adventure. Im Unterschied zum Hack \& Slay, welches stärker interaktive Aspekte fokussiert, und dem RPG, das sich eher an narrativen Aspekten orientiert, ist die Balance zwischen Interaktivität und Narrativität in interaktiv-narrativen digitalen Spielen beim Action-Adventure am größten. ${ }^{243}$ Als Beispiel dienen im Folgenden ActionAdventures die bereits mehrfach exemplarisch hinzugezogen wurden (siehe Abbildung 7). The Legend of Zelda ist das interaktivste dieser interaktiv-narrativen Action-Adventures, was nicht zuletzt daran liegt, dass es, im Vergleich zu den anderen, konsequent auf das OpenWorld-Prinzip setzt, wohingegen die anderen auf eine mehr oder weniger strikt lineare Levelstruktur vertrauen, die dem Spieler räumlich Grenzen setzt, die sich auf das Gameplay auswirken. Hierdurch lässt sich auch die hohe Interaktivität (mit Blick auf die Frequenz, Signifikanz und Bandbreite der Interaktionen) von The Legend of Zelda erklären, da es wesentlich mehr Paidia-Spiele gestattet, als die anderen Genrevertreter, welche keine so große Ausgewogenheit zwischen Ludus und Paidia anstreben. Was bei allen diesen Spielen aber auffällt, sind die Ähnlichkeiten zwischen den Narrativen. The Legend of Zelda verwendet ein mythologisches Narrativ, die Batman: Arkham-Reihe (2009 ff.) ein Detektivnarrativ ${ }^{244}$ und Uncharted sowie Tomb Raider ein Abenteuernarrativ. Beyond: Two Souls als Hybrid aus Action-Adventure und Interaktivem Film legt ein Narrativ zugrunde, das sehr nah beim mythologischen Narrativ bleibt (v.a. unter religiösen Gesichtspunkten), dieses aber aus dem Kontext der Weltenrettung löst und - gemäßer für die Postmoderne - den Aspekt der Selbstfindung der Protagonistin hervorhebt (auch wenn die Welt natürlich immer noch gerettet werden muss). Diese Aufzählung könnte man noch um ein Spiel wie The Last of Us (2013) erweitern, welches auf das in den letzten Jahren sehr populäre Narrativ der

\footnotetext{
${ }^{243}$ So bemerkt etwa Julian Kücklich: „Auf der Mittelposition zwischen Narrativität und Interaktivität wäre dann das Hybridgenre der Action-Adventures anzusiedeln, das sich durch die Gleichwertigkeit von momentanem Geschehen und Gesamthandlung auszeichnet.“ KüCKLICH (2001), 31.

${ }^{244}$ Ein anderes Beispiel hierfür ist L.A. Noire.
} 
Zombieapokalypse $^{245}$ rekurriert. Betrachtet man die Struktur des Narrativs sowie die Figurenkonzeptionen und Figurenkonstellationen näher, so wird deutlich, dass all diese Narrative (Detektivnarrativ, Abenteuernarrativ, Zombieapokalypse, Selbstfindungsnarrativ ${ }^{246}$ ) Abwandlungen des mythologischen Narrativs sind. Auf je spezifische Weise übertragen sie Aspekte des mythologischen Narrativs in die Moderne.

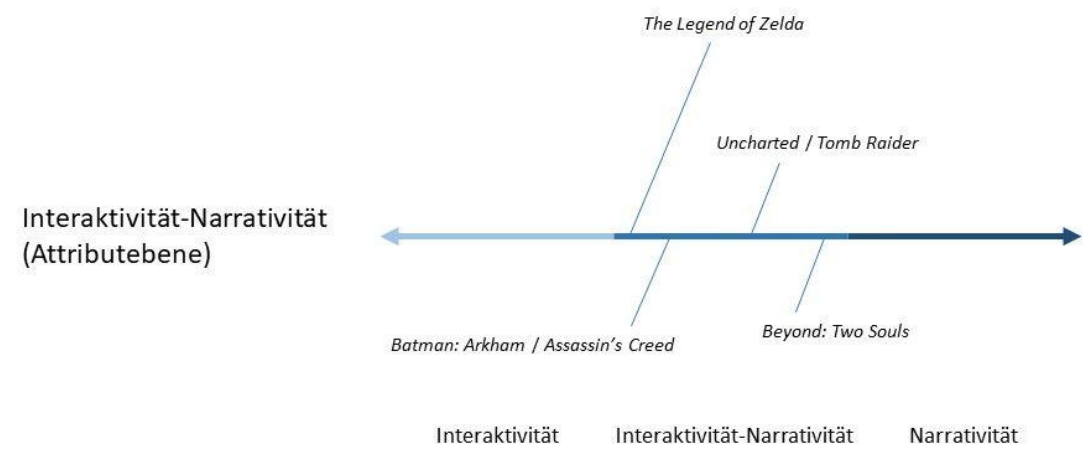

Abb. 7: Mikroperspektive

\footnotetext{
${ }^{245}$ Bemerkenswert ist hierbei, dass der Zombie als Aspekt des Voodoo eigentlich unmittelbar einem religiösen Kontext entstammt und durch sein fortwährendes Umherirren in der immanenten Welt nach seinem Ableben zudem Thematiken berührt, die in sehr vielen Religionen nachweisbar sind. Dennoch, trotz seines religiösen Ursprungs, tritt eine zunehmende Säkularisation des Zombies bzw. seiner Entstehung durch naturwissenschaftliche Paradigmen ein. Ursprünglich Resultat eines Fluches geschieht die Zombiewerdung in gegenwärtigen populärkulturellen Adaptionen meistens, nicht nur im digitalen Spiel, durch eine virale Infektion und steht somit stellvertretend für die Säkularisierung von Inhalten historischer Religionen in großen Teilen der populären Medienkultur. Vgl. dazu Filme wie I Am Legend (2007). Was für den Zombie gilt, betrifft auch die Apokalypse. Einst waren Endzeitszenarien fester Bestandteil von mythologischen oder religiösen Eschatologien, sind aber spätestens seit Hiroshima und Nagasaki aus mythologisch-religiösen Sphären heraus- und in die naturwissenschaftlichen eingerückt worden. Wie der Zombie wurde auch die Apokalypse unter naturwissenschaftlichen Paradigmen säkularisiert. Vgl. dazu Filme wie 2012 - Das Ende der Welt (2009).

${ }^{246}$ Populäre Beispiele für dieses Narrativ sind in den letzten Jahren Filme wie Eine Nacht in Rom (2010) oder die Romanverfilmung Eat, Pray, Love (2010). Charakteristisch für dieses Narrativ sind Protagonisten, die von Krisen gebeutelt sind oder vor einer schwierigen Entscheidung stehen, diese aber nicht in ihrer Heimat lösen können, sondern dafür in die Welt ausziehen müssen. Die Reise ins Innere der Figur, die nach ihrer Identität, ihrem Platz in der Welt sucht, verknüpft sich hierbei mit einer Reise in ferne Länder, um in der Ferne sich selbst zu finden. Dabei offenbart dieses Narrativ zwar Ähnlichkeiten zum mythologischen Narrativ, diese verweisen aber eher auf eine ,entfernte Verwandtschaft' zwischen beiden. So findet zu Handlungsbeginn meistens eine Störung des Gleichgewichts statt, diese hat aber keine kosmische Tragweite, sondern betrifft lediglich das innere Gleichgewicht der Figur und auch das Verlassen der gewohnten Welt geschieht nicht, um die Welt insgesamt zu retten, sondern dient der Suche nach dem eigenen Sein. Vor diesem Hintergrund sind die Orte der Reise auch keine gefahrvollen Schauplätze, sie sind Sehnsuchtsräume wie Italien.
} 
Das Detektivnarrativ urbanisiert den mythologischen Helden und versetzt ihn in die moderne Großstadt, für deren Hybris und Verkommenheit z.B. Gotham ${ }^{247}$ als Metapher steht. Das Abenteuernarrativ profaniert die Reise des Helden, indem sowohl die Figuren als auch die gesamte Diegese ,entzaubert‘ werden. Kaum ein Spiel macht dies so deutlich wie Uncharted, das in den ersten drei Teilen der Reihe stets mythologisch-religiöse Erwartungen weckt, Übernatürlichkeit als evident und unwiderlegbar erscheinen lässt, um es dann nur umso wirkungsvoller zu demaskieren, auf simple physikalische Tatsachen zurückzuführen und somit die Konventionen des mythologischen Narrativs stets aufs Neue zu unterlaufen, den Mythos zu dekonstruieren. ${ }^{248}$ Das Resultat einer Profanierung ist auch die Zombieapokalypse, die Zombies nicht länger als Opfer religiöser Repräsentanten, sondern als viral Erkrankte oder parasitär Befallene darstellt. Auch die Figurenkonstellation, die schier unüberschaubare Masse an Zombies, die meist wenigen Überlebenden gegenüberstehen, ist ein Reflex auf das Leben des Individuums in der Postmoderne, das im Zuge der Digitalisierung mehr und mehr zum Knoten in einem Netzwerk wird, auf das es immer weniger Einfluss ausüben kann, sodass die Frontstellung zwischen Individuum und gesichtslosem Kollektiv unausweichlich scheint. Und auch Narrative, wie man sie in Beyond: Two Souls findet, handeln hiervon. Jodie sucht nach sich selbst und nach ihrem Platz in der Welt, nach einem Ort, an den sie gehört. Als kleines Mädchen wird Jodie nicht bloß wie der mythologische Held genötigt, die heile Welt und deren Ordnung zu verlassen, sie wird regelrecht deportiert, die Bindung zwischen Figur und Welt aufgelöst. Der mythologische Held weiß immer, dass er die Welt retten muss, hat somit ein Ziel, einen Orientierungspunkt, Jodie aber hat all dies nicht. Sie wird von einem Ort an den anderen gehetzt, die größeren schicksalhaften Zusammenhänge werden Figur und Spieler erst gänzlich durch eine auflösende Analepse am Handlungsende klar.

\footnotetext{
${ }^{247}$ Ursprünglich ein Spitzname für New York City erlangte Gotham City v.a. als fiktive US-Metropole durch DCs Batman-Comics ab den 1940er Jahren weltweite Bekanntheit. An den negativen Seiten seines realen Vorbildes orientiert kaprizierten sich die DC-Autoren zumeist auf die bedrohlichen und kriminellen Aspekte der Großstadt, die Batman und seine Mitstreiter fortan bekämpften.

${ }^{248}$ In Uncharted: Drakes Schicksal (2007) sucht Nathan Drake gemeinsam mit seinen Mitstreitern nach dem sagenhaften El Dorado, das aber keine Stadt aus Gold, sondern eine goldene Statue zu sein scheint. Umso näher sie ihrem Ziel kommen, umso gefährlicher werden die Hindernisse, auf die sie stoßen. So begegnen sie unter anderem ,Gollum-artigen“ Kreaturen, die ursprünglich Menschen waren. Gerade aber, als man ernsthaft zu glauben beginnen kann, dass von der Statue magische Kräfte ausgehen, erfährt man, dass die Goldstatue ein Sarkophag ist, in dem sich ein infizierter Leichnam befindet, der andere Menschen bei Kontakt mutieren lässt. In Uncharted 2: Among Thieves versuchen Drake und seine Verbündeten des magischen Cintamani-Steins habhaft zu werden, der sich in der legendären Stadt Shambala befinden soll. Auch hier steigern sich die Gefahren, umso näher sie ihrem Ziel kommen. So treffen sie auch hier auf eigenartige Wesen, die wie Yetis aussehen. Ebenso wie im ersten Teil, als der Spieler beginnt, Magie in Betracht zu ziehen, wird entdeckt, dass es sich auch hierbei um mutierte Menschen handelt. Diese haben vom Harz es Baumes des Lebens in Shambala gegessen, der ihre Körper dementsprechend veränderte. Uncharted 3: Drake's Deception (2011) funktioniert nach demselben Prinzip, nur dass das Ziel dieses Mal die verschollen Stadt Iram ist.
} 
Auch wenn all diese Narrative auf den ersten Blick sehr verschieden sein mögen, so sind sie doch Varianten des mythologischen Narrativs. (vgl. 3.2) Hierdurch lässt sich zum einen erahnen, welchen nachhaltigen Einfluss das mythologische Narrativ auf die gegenwärtige populäre Medienkultur immer noch hat und zum anderen wird deutlich, wie wandelbar und somit adaptierbar dieses Narrativ ist. ${ }^{249}$ Aus diesem Grund wird ihm auch derart viel Beachtung in dieser Arbeit geschenkt und aus diesem Grund wird auch The Legend of Zelda zum Untersuchungsgegenstand erhoben, da es im Kontext des Action-Adventures dem am nächsten kommt, was man vielleicht so etwas wie den Archetypus des mythologischen Narrativs nennen kann, wie ihn Joseph CAMPBELL in seinem Der Heros in tausend Gestalten (2011) herausstellen wollte.

Zieht man alle drei Perspektiven zusammen, die sich für die Analyse des InteraktivitätNarrativitätskontinuums ergeben, so wird zudem deutlich, wie unterschiedlich sich Interaktivität-Narrativität manifestieren kann. Hieraus kann man dann auch die Minimaldefinition der Interaktivität-Narrativität profilieren. Interaktivität-Narrativität liegt demnach vor, wenn Interaktivität und Narrativität in die Ontologie und Ästhetik eines Phänomens oder Mediums integriert werden und dies unabhängig davon, wie sich dies konkret ausgestaltet.

\subsubsection{Die Strukturebene}

Die Interaktivität-Narrativität digitaler Spiele konkretisiert sich letztlich immer erst in der Interaktion-Narration, jedoch bedarf es des Interaktiv-Narrativs, welches abweichende (mediale) Interaktion-Narrationen ermöglicht. Die zentrale Aufgabe des Interaktiv-Narrativs ist es, die Offenheit des Spiels und die Geschlossenheit des Plots auszugleichen. Das Interaktiv-Narrativ konstruiert jene korrespondierende Relation zwischen dem interaktiven und dem narrativen Pol, die die interaktiv-narrative Hybridität digitaler Spiel ausmacht. Zentral ist hierbei die Frage, wie der Designer das Interaktiv-Narrativ gestaltet bzw. gewichtet. Tendiert er $\mathrm{zu}$ einer interaktiven, einer interaktiv-narrativen oder $\mathrm{zu}$ einer narrativen Ausgestaltung? Wie sind diese angelegt? Liegt eine interaktionsoffene, -neutrale oder -abgewandte narrative Ausrichtung vor usw.? Woran kann man dies analytisch festmachen?

\footnotetext{
${ }^{249}$ Dies ist wahrscheinlich auch ursächlich dafür, dass Christopher VoGLERs Odyssee des Drehbuchschreibers (2010) einen so großen Einfluss auf die Theorie des Drehbuchschreibens wie auf das Hollywood-BlockbusterKino der vergangenen Jahrzehnte hat.
} 
Damit fokussiert sich das Interaktiv-Narrativ bzw. die Strukturebene bewusst auf die Produzentenseite interaktiv-narrativer digitaler Spiele und fragt nach deren konkreter Machart. Damit das Interaktiv-Narrativ als vermittelnde Instanz zwischen InteraktivitätNarrativität und Interaktion-Narration fungieren kann, sind v.a. zwei Aspekte im Designprozess wichtig. Zum einen die Anlage von Interaktiv und Narrativ, welche die Ordnung digitaler Spiele etablieren und zum anderen die interaktiv-narrative Polyvalenz ${ }^{250}$ von zentralen Elementen wie Figuren, Welt und Struktur. Aus diesem Grund werden im Folgenden nacheinander Interaktiv und Narrativ sowie interaktiv-narratives Figuren-, Weltund Strukturdesign betrachtet, um die Wirkungsweisen des Interaktiv-Narrativs zu verdeutlichen.

An dieser Stelle wird verständlich, wie stark die verschiedenen Ebenen des Kontinuumsmodells miteinander interagieren. Prinzipiell findet zwischen allen Ebenen bzw. zumindest den ,benachbarten“ eine zirkuläre Bewegung gegenseitiger Bezugnahmen statt. Zwischen der Attribut- und der Strukturebene ist dies der bereits angesprochene ,Designprozess', zwischen Struktur- und Realisierungsebene der ,Spielprozess'. Die Attributebene ist nicht bloß eine reine Beschreibungsebene, sondern enthält darüber hinaus auch eine ontologische Dimension, die sich am deutlichsten in den strukturellen Äquivalenzen und den interaktiv-narrativ polyvalenten Elementen offenbart, welche das Designteam nutzt, um das Interaktiv-Narrativ zu generieren. Die Strukturebene beeinflusst aber auch wiederum durch die gewählten Designparadigmen (dazu unten ausführlicher) die strukturellen Äquivalenzen und die interaktiv-narrativ polyvalenten Elemente auf der Attributebene. Die Einordnung von diversen digitalen Spielgenres auf der Attributebene (aus der Mesoperspektive) ist, so gesehen, das Ergebnis einer diskursiven Verdichtung von (etablierten) Designparadigmen. Insofern können sowohl der Design- als auch der Spielprozess (als zirkuläre Bewegungen) im Sinne von Uwe SchIMANKs Handeln und Strukturen (2010) verstanden werden. Die Attributebene definiert die Agency der Designer, welche diese auf der Strukturebene konkret nutzen, hierdurch neue Designparadigmen produzieren oder bereits bestehende popularisieren können, was wiederum zu einer (möglichen) Veränderung der Interaktivität-Narrativität auf der Attributebene führt, welche sich in einer modifizierten Agency für die designerischen Folgehandlungen niederschlägt. Ebenso definiert die Strukturebene aber die Agency der Spieler, welche diese auf der

\footnotetext{
${ }^{250}$ Polyvalenz bedeutet in diesem Zusammenhang, dass sich bspw. Entitäten wie Figuren interaktiv, narrativ und interaktiv-narrativ umsetzen lassen. So kann eine Figur entweder als Spielfigur oder narrativer Charakter ebenso auftreten wie als hybrider Avatar, der die Eigenschaften der anderen beiden ,Figurentypen` auf sich vereint.
} 
Realisierungsebene konkret nutzen können. Verdichten sich hier bestimmte spielerische Nutzungsweisen, so kann dies wiederum Folgen auf der Strukturebene haben, indem Designer zukünftig bspw. unerwünschte Handlungsoptionen eliminieren oder sanktionieren oder bestimmte Präferenzen der Spielerschaft stärker berücksichtigen. (vgl. dazu ausführlicher MatusZKIEwICZ 2016) Ein simples Beispiel: Die PlayStation 3 erlaubte zum Unmut vieler Spieler aufgrund einer Signalverschlüsselung nicht das Capturen von Spielsessions (mit Ausnahme weniger Titel). Da dies aber im Rahmen einer mehr und mehr auf das Teilen von Spielerlebnissen fokussierten (Hardcore-)Spielkultur immer wichtiger wird, verfügt die PlayStation 4 über diese Option, was eine unmittelbare Reaktion der Designer auf der Strukturebene auf Handlungen der Spieler auf der Realisierungsebene darstellt. Agency wird dem Spieler aber hauptsächlich durch das Interaktiv zugewiesen, womit wir zum nächsten Punkt kommen.

\subsubsection{Das Interaktiv}

In 2.3.4 wurde das Interaktiv wie folgt definiert: Das Interaktiv ist ein Set aus (vom Designer) definierten Handlungsoptionen und designten Interaktionen, die an einem dominanten Spielprinzip orientiert sind. Das dominante Spielprinzip bestimmt die Genrezugehörigkeit eines digitalen Spiels. Ist Schießen das dominante Spielprinzip, dann handelt es sich um einen Shooter, ist die Simulation des Aufbaus eines Imperiums vorherrschend, dann liegt eine Aufbausimulation vor usw. Das Interaktionsdesign ist immer auf das dominante Spielprinzip hin ausgerichtet, da beide immer korrespondieren müssen, um die ludische Kohärenz des Spiels zu garantieren. Dabei fungiert das Interaktiv als Sanktionsinstanz digitaler Spiele, da es - je nach Evaluation des Spielausgangs - über Belohnung oder Bestrafung, entscheidet‘. Das Interaktiv ist somit kein Phänomen der Spieloberfläche, ${ }^{251}$ es reicht vielmehr weit in den Programmcode des Spiels hinein, da der Dialogbetrieb nur interaktiv umgesetzt werden kann und die Interaktivität (durch das Interaktionsdesign) dementsprechend gestaltet sein muss. So drückt sich ein wesentlicher Aspekt der Wirkweise des Interaktivs in den implementierten Algorithmen aus. Dabei wirkt

\footnotetext{
${ }^{251}$ Stephan SCHWINGELER (2014) arbeitet in seiner Dissertation ein Oszillationsverhältnis zwischen Transparenz und Opazität in digitalen Spielen heraus, das zwischen der transparenten Oberfläche und der opaken Unterfläche vorherrscht. Als Oberfläche sind prinzipiell alle audiovisuellen Elemente digitaler Spiele zu verstehen, die dem Spieler das digitale Spiel vor Augen und Ohren führen, ihm das Spiel repräsentieren, aber auch auf seine Eingaben reagieren. Die Unterfläche macht der Programmcode aus, welcher für den Spieler im Vergleich zur transparenten Oberfläche meistens opak bleibt. An Bolters und Grusins Konzept der ,Hyper- ' und ,Immediacy anschließend oszillieren digitale Spiele zwischen dem Unsichtbarmachen einerseits wie dem bewussten Herausstellen der eigenen medialen Form andererseits. Zu Transparenz und Opazität vgl. ebd., 21 f. sowie 155182. Eine tabellarische Übersicht, die Transparenz und Opazität gegenüberstellt, findet sich auf 181.
} 
aber weniger die informatische auf die designerische Seite ein als umgekehrt. So richtet sich nicht das Interaktiv nach dem Programmierparadigma, sondern dieses nach dem Interaktiv. Der Programmierer setzt die Vorgaben des Designers programmierparadigmatisch (imperativ, deklarativ etc.) um.

Dies informatisch auszuführen, würde an dieser Stelle den Rahmen sprengen, allerdings ist es wichtig, sich stets zu vergegenwärtigen, dass all das, was von Kulturwissenschaftlern als Oberflächenphänomen digitaler Spiele untersucht wird, immer im Programmcode angelegt sein muss. Das Interaktionsdesign ist, und v.a. die HCI hebt dies hervor, zugleich ein künstlerischer wie ein informatischer Prozess. Kehrt man zu den Oberflächenerscheinungen zurück, so sind im Kontext des Interaktivs primär Spielregeln und Spielmechaniken von Interesse. Sie legen fest, was Spieler im Spielsystem machen können und werten diese Aktionen zugleich aus. Daneben etabliert das Interaktiv aber zudem die Spielwelt als ,soziale“ Welt, indem sie soziale Konventionen und diskursive Sagbarkeitsregeln ebenso definiert wie moralische Werte und Normen.

Hier liegt dann auch ein wesentlicher Faktor, der für ein korrespondierendes Verhältnis zwischen Interaktiv und Narrativ sorgt - die moralisch-narrative Rollenerwartung an die Figur. (vgl. dazu 2.3.3) Für das Interaktionsdesign eines interaktiv-narrativen digitalen Spiels ist es entscheidend, ein Figurenpersonal zu etablieren, dessen Figurenkonzeptionen mit einem bestimmten Wertehorizont verbunden sind. Der Held einer Geschichte ist hierbei nicht im Sinne der klassischen griechisch-römischen Mythen $\mathrm{zu}$ verstehen. Er ist durch die Heldenkonzeption der mittelalterlichen Artusepen, über die biedermeierlichen Märchen der Brüder Grimm bis zu den Superhelden des Mainstreamcomics des 20. Jahrhunderts (unter moralischen Gesichtspunkten) erheblich positiver konnotiert, als dies noch in den antiken Mythen der Fall war. Oft sind diese Helden von jeder Ambivalenz befreit, die Personifikation des unzweifelhaft Guten, des Kämpfers gegen das Böse. ${ }^{252}$ Dieser Antagonismus sowie die

\footnotetext{
${ }^{252}$ Das anschaulichste Beispiel für den über alle Maßen idealisierten Heldentypus des 20. Jahrhunderts ist Superman, der - schon bedingt durch seine propagandistischen Einschläge während des Zweiten Weltkrieges als Figur frei von jeder moralischen Fragwürdigkeit ist. Erst das ,Bronzene Zeitalter (zur Geschichte des Superheldencomics vgl. KNIEP (2009)) des Comics machte u.a. mit Frank MiLlERs Batman. Die Rückkehr des Dunklen Ritters wieder einen Heldentypen im Sinne eines Antihelden populär, der zwar für das Gute kämpft, dessen Vorgehensweisen aber nicht immer moralisch eindeutig als ,gut' zu beschreiben sind. Dies manifestiert sich in einer ,gesellschaftlich“ ambivalenten Bewertung des Helden innerhalb der Diegese, der fortwährend soziale Konventionen unterläuft und hierdurch zu einem gesellschaftlichen Außenseiter wird. Aktualisiert wird dieser Antiheldentypus filmisch durch Christopher Nolans Batman-Reihe (2005-2012) oder die zahlreichen Marvel-Verfilmungen wie Guardians of the Galaxy (2014) oder Deadpool (2016). Obwohl der Antiheld als Held in den vergangenen zehn Jahren an Popularität innerhalb der Mainstream-Populärkultur gewonnen hat, muss
} 
hieraus resultierende Figurenkonstellation samt -konzeptionen ist vom populärkulturellen Rezipienten derart internalisiert worden, dass es naheliegt, anzunehmen, dass dieser dazu tendieren wird, die Rollenzuschreibung der narrativen Figur bei der Realisierung seines interaktiv-narrativen Avatars zu übernehmen bzw. die Vorgaben auszuagieren. (vgl. hierzu RAUSCHER 2015) Als Beispiel kann man diesbezüglich Telltale Games Umsetzung von The Walking Dead nehmen. Am Ende einer jeden Episode erhält der Spieler eine Auswertung, die ihm anzeigt, wie andere Spieler sich in den Entscheidungsmomenten verhalten haben. Es fällt auf, dass es hier häufig zu deutlichen Akkumulationen kommt, die jeder statistischen Normalverteilung widersprechen. ${ }^{253}$ Wie kann das sein? Bei genauem Hinsehen offenbart sich, dass jene Entscheidungen, die besonders oft getroffen wurden, jene sind, die im Vergleich zu den alternativen Handlungsoptionen vom Spieler zweifelsfrei als ,moralischer oder ,gerechter' wahrgenommen werden. ${ }^{254}$

So wird der Spieler gleich zu Beginn der fünften Episode der zweiten Staffel von The Walking Dead vor die Wahl gestellt, das Baby AJ während eines Feuergefechtes zu retten und möglicherweise das Leben des eigenen Avatars Clementine zu riskieren oder hinter einer

dennoch der Heldentypus à la Superman weiterhin als dominante Figurenkonzeption des Helden gelten, da er in seinen vielfältigen Abstufungen weiterhin die Populärkultur bestimmt.

${ }^{253}$ Dieses Phänomen findet man aber nicht nur in digitalen Spielen, sondern es kann grundsätzlich im Kontext von Narrationen in interaktiven Rezeptionskontexten von (digitalen) Medien mit mindestens binärer Entscheidungsoption beobachtet werden. So führte die ARD am 17. Oktober 2016 mit Terror - Ihr Urteil (2016) ein breit beworbenes ,TV-Experiment' durch, bei dem es den Zuschauern als Schöffen überlassen wurde, das Urteil über den Kampfjet-Piloten Lars Koch zu fällen. Dieser hat ein mit 164 Menschen besetztes Passagierflugzeug abgeschossen, welches ein Terrorist entführt hatte und auf ein ausverkauftes Fußballstadion mit 70.000 Fans zusteuerte. Dabei ist aber in diesem Zusammenhang weniger interessant, wie der als Kammerstück inszenierte Film (eine Verfilmung von Ferdinand von Schirachs Theaterstück Terror (2015)) die Aktualität des Grundgesetzes in Zeiten des Terrors thematisiert bzw. das Verhältnis zwischen Rechtwidrig- und Rechtsmäßigkeit auslotet, sondern wie sich die Zuschauer entscheiden. Hierbei ist bemerkenswert, dass Lars Koch mit überwältigender Mehrheit ,freigesprochen' wurde. So stimmten die Zuschauer in Deutschland $(86,9 \%)$, Österreich $(86,9 \%)$ und in der Schweiz (84\%) allesamt mit über $80 \%$ für ,nicht schuldig'. http://www.daserste.de/unterhaltung/film/terror-ihr-urteil/voting/index.html (30.06.2018). Beachtlich ist dabei die Eindeutigkeit der getroffenen Entscheidung v.a. vor dem Hintergrund der gravierenden Konsequenzen der Handlung von Lars Koch und den sich hieraus ergebenden moralischen und ethischen Dilemmata. Meines Erachtens verweist die Klarheit der Verhältnisse aber darauf hin, dass der ,Freispruch“ vielleicht die intendierte Handlungsoption in diesem Fall ist. Vereinfacht wird dem Zuschauer nämlich die Übernahme der Sichtweise von Koch und sein sich daraus ergebendes Handeln durch den simplen Umstand, dass die Insassen des Flugzeugs in jedem Fall (Abschuss oder Absturz ins Stadion) sterben, die Fußballfans aber nicht. Dies stellt einen wesentlichen Unterschied zu den meisten anderen, Weichenstellfall'-Szenarien dar, da hierbei meistens eine der beiden betroffenen Gruppen stets überlebt. Vgl. zum ,Weichenstellfall' oder ,Trolley-Dilemma“ ŠVELCH (2010), 54 f. Des Weiteren ist der Unterschied der potenziellen Opferzahl in den allermeisten anderen Weichenstellfällen nicht derart groß wie in diesem (164 gegen 70.000 Menschenleben).

${ }^{254}$ Wie sich moralisches Handeln in digitalen Spielen mit schwierigen Entscheidungssituationen in komplexen Beziehungen zwischen Avataren, NPCs und dem Spieler konkret entfalten kann, hat Reto SCHÖLLY (2017) am Beispiel Clementines aus Telltale Games The Walking Dead dargelegt. Von besonderem Interesse ist dabei für Schölly, wie sich Clementine im Spielverlauf entwickelt, wobei nicht bloß verschiedene Endszenarien in den Blick geraten, sondern auch die Reziprozität jener Kommunikationssituationen, die während des Spielens ablaufen und welche Rolle emotionale Aufladungen dabei spielen. 
Mauer direkt in Deckung zu gehen. In der Endauswertung der Entscheidungen erfährt man, dass sich deutlich über $50 \%$ der Spieler dafür entschieden haben, ${ }^{255}$ AJ zu retten, obwohl beide Handlungsoptionen potenziell gleichwertig sind. ${ }^{256}$ Der Grund für diese Akkumulation ist simpel. Es gehört zu den moralischen Basiskonzepten, Mitmenschen in Notsituationen zu helfen, v.a. wenn es sich hierbei um hilflose Subjekte handelt. ${ }^{257}$ Moralisch erscheint, und die Auswertung belegt dies, es naheliegend, AJ in Deckung zu bringen, zumal diese moralisch richtige Entscheidung auch noch durch die emotionalen Komponenten aufgeladen wird, die Menschen im Allgemeinen mit Babys verbinden.

Durch die moralische (und damit oft auch emotionale) Aufladung einer Handlungsoption im Rahmen des Interaktionsdesigns wird es wahrscheinlicher, dass Spieler diese wählen, auch wenn das System ihnen dies nicht explizit vorschreibt, sondern auf subtile Art und Weise suggeriert. Das bedeutet, dass das Vorhandensein eines Figurenpersonals sowie die Akzeptanz des dargebotenen Wertehorizonts Spieler dazu verleiten kann, Handlungsoptionen zu wählen, die unter dem Gesichtspunkt der Rollenerwartung als logisch und kohärenzstiftend erscheinen.

Exempel dieser Art demonstrieren, wie wichtig narrationsoffene Elemente interaktiver Interaktivität-Narrativität für die Gestaltung des Interaktivs sind. Diese Offenheit muss aber auch das Narrativ aufweisen, damit die Korrespondenz zwischen Interaktiv und Narrativ erzeugt werden kann.

\footnotetext{
${ }^{255}$ Man sollte hierbei jedoch bedenken, dass diese Zahlen nicht immer als verlässlich anzusehen sind. Denn insbes. mehrfache Spieldurchläufe können hier dazu beitragen, dass sich die ausgewiesenen Werte verändern. Zuweilen lässt es sich bspw. in Let's Plays, Foren oder in Gesprächen mit Fans beobachten, dass bestimmte digitale Spiele gezielt mehrfach durchgespielt wurden, um verschiedene (End-)Szenarien auszuprobieren. Dies gilt nicht nur für die Telltale Games-Spiele, sondern auch für jene von Quantic Dream oder von Supermassive Games wie Until Dawn (2015). Meine Überlegungen beziehen sich im Folgenden daher eher auf das erste Durchspielen, wenn die Spieler noch nicht wissen, was passieren wird und welche Konsequenzen Handlungen haben. Bei anschließenden Spieldurchläufen ist dieses Wissen dann nämlich vorhanden und es ist davon auszugehen, dass insgesamt und aufgrund des spielerisch erworbenen Kenntnisstandes reflektierter gespielt wird oder bewusst andere Optionen gewählt werden als ursprünglich. Dies können Faktoren sein, die den Wert möglicherweise, verfälschen'.

${ }^{256}$ Vgl. dazu exemplarisch das Let's Play von JACKSEPTICEYE, dass für Ende August 2014 einen Wert von 56\% ausweist https://www.youtube.com/watch?v=9CZ2AKhohI0 (30.06.2018).

${ }^{257}$ Tobias STAABY (2015) hat eine didaktische Anleitung vorgelegt, wie sich The Walking Dead in den Ethik-, Religions- oder Philosophieunterricht der Oberstufe einbinden lässt, um ethische Dilemmata zu diskutieren oder moralphilosophische Modelle wie Aristoteles' Tugendethik zu vermitteln. Dabei eignen sich, so Staaby, digitale Spiele wie The Walking Dead besonders für derartige Vorhaben, da sie moralisch und ethisch diffizile sowie emotional aufgeladene Situationen kreieren, die für eine Diskussion in der Gruppe prädestiniert sind.
} 


\subsubsection{Das Narrativ}

Narrative beinhalten in interaktiv-narrativen digitalen Spielen eher interaktionsoffene Elemente narrativer Interaktivität-Narrativität. Das artikuliert sich einerseits in Bezug auf die soeben skizzierte Funktion der Rollenerwartungen, die in gewisser Weise die Aufgaben eines ,verallgemeinerten Anderen' übernimmt. Es betrifft aber auch das Narrativ an sich, welches dieses Figurenpersonal als einen Teil seiner selbst mitbringt. Damit die Korrespondenz zwischen Interaktiv und Narrativ konvergente Züge annehmen kann, müssen das dominante Spielprinzip des Interaktivs und das dominante Motiv des Narrativs zueinander passen. Anders gesagt: Es muss eine ,Korrespondenz der Handlungsmuster` (im performativen wie im narrativen Sinne) gegeben sein. Ein Beispiel hierfür haben wir im Abschnitt zur Mesoperspektive bereits gesehen. Das mythologische Narrativ (mit seinen modernen Abwandlungen) zeichnet sich auf der (narrativen) Handlungsebene prinzipiell durch zwei Eigenschaften aus: der Kampf Gut gegen Böse sowie die Reise. Dieses Narrativ korrespondiert mit allen Interaktiven, die eine weit ausgreifende Raumbemächtigung des Spielers durch den Avatar sowie eine Umsetzung als Agôn erfordern. Deshalb lässt es sich auch gut in digitalen Spielgenres wie dem Action-Adventure, dem RPG oder dem Hack \& Slay umsetzen, wohingegen es für eine Aufbausimulation ungeeignet ist, obwohl diese Spiele auch auf ein agonales Spielprinzip bauen. Hierbei sind aber einerseits die vom mythologischen Inhalt bedingten Implikationen weniger wichtig und andererseits wird der Spielraum hier wesentlich limitierter und punktueller genutzt. Kulturwissenschaftlich gesprochen evoziert das mythologische Narrativ die Nutzung eines Spielraums als Raum, Aufbausimulationen hingegen benötigen für ihr dominantes Spielprinzip aber Orte. ${ }^{258}$

Wie dominant das mythologische Narrativ und seine Abwandlungen in gegenwärtigen interaktiv-narrativen digitalen Spielen wie in der Mainstream-Populärkultur im Allgemeinen sind, zeigt sich daran, wie diffizil es ist, ein Beispiel für ein anderes Narrativ zu finden. Geht man vom soziokulturellen Diskurs aus, so ist immer wieder ein bestimmtes Narrativ anzutreffen - das Verfallsnarrativ. Diese Narrative etablieren zu Beginn einen nahezu idealen Zustand, der sich in hohem Ansehen, großem Einfluss, persönlicher Erfüllung und finanziellem Wohlstand manifestiert. Protagonisten dieser Narrative können einzelne Figuren oder Figurengruppen sein, von der Familie bis zum gesamten Volk. Verfallsnarrative finden sich in der Literatur in Thomas Manns Buddenbrooks (1981), in der Geschichtsschreibung in Werken, die die Geschichte einer Gruppe als Niedergang erzählen, und im sozialen Diskurs in

\footnotetext{
${ }^{258}$ Weitere Ausführungen hierzu in Kapitel 3.
} 
Form von Medienkritik und Kulturpessimismus, wobei der bestehende Zustand in der Regel mit einem (idealisierten) historischen Zustand verglichen wird. ${ }^{259}$ Diese Narrative zersetzen den Idealzustand zu Handlungsbeginn immer weiter, bis an ihrem Schluss stets Niedergang und Ende stehen. Der Verfall wird durch Intrigen der Antagonisten begünstigt, primär aber durch das Unvermögen des Protagonisten verursacht, welches häufig an amoralisches Verhalten zurückgebunden wird. Die historistische Geschichtswissenschaft interpretierte, besonders unter christlichem Einfluss, den Verfall antiker Kulturen wie der Römer oft unter Aspekten wie Zügel- und Maßlosigkeit, fehlender Demut und Weitsicht sowie allgemeiner Dekadenz, um den Verfall an die moralische Verkommenheit zurückzubinden und hierdurch eine didaktische Funktion auszuüben. ${ }^{260}$

Die Tatsache, dass man Verfallsnarrative aber in digitalen Spielen nicht nachweisen kann, legt die Vermutung nahe, dass ein Narrativ wie das Verfallsnarrativ nicht geeignet ist, um in digitale Spiele übertragen zu werden. Es stellt sich aber die Frage, warum es anscheinend nicht adäquat in digitalen Spielen umgesetzt werden kann? Ursächlich ist eine Inkompatibilität zum Phänomen des Spiels an sich. Alle Spiele, zumindest jene, die als Ludus angelegt sind, eint, unabhängig vom dominanten Spielprinzip, eine Eigenschaft - der (mögliche) Sieg. Je nachdem, wie geschickt sich der Spieler anstellt, kann er gewinnen oder verlieren. Dies markiert die Offenheit des Spiels, da der Sieg zu Spielbeginn und während des Spielverlaufs immer möglich ist, auch wenn er unwahrscheinlich sein mag. Beim

\footnotetext{
${ }^{259}$ Die Mediengeschichte zeugt im Wesentlichen von einer Dichotomie zwischen Medienenthusiasten und kritikern. Erstere verbinden neue Medien oft mit gewissen ,Heilserwartungen“ und konstruieren ,Aufstiegsnarrative' gemäß dem stufenartigen Fortschrittsmodell, gegen welches sich Thomas S. KuHN (2012) wendet, und betrachten jede mediale Errungenschaft als Schritt hin zu jener idealisierten Welt, die sie herbeiwünschen. Medienkritiker verfahren umgekehrt, sehen die (Medien-)Kultur gewissermaßen nicht wie die Medienenthusiasten die Treppe hinaufgehen, sondern herunterfallen. Jedes neue Medium ist dann eine weitere Entfernung vom Idealzustand, der als Ausgangspunkt des Verfallsnarrativs dient, wohingegen er beim Aufstiegsnarrativ der Zielpunkt ist. Die Verwendung des Verfallsnarrativs hat in der Geschichte der Medienkritik eine lange Tradition, reicht von der Erfindung des Buchdrucks mit beweglichen Lettern über Film, Comic und Fernsehen hin zu den elektronischen Medien. Einen der nachhaltigsten medienkritischen Vorstöße der letzten zwanzig Jahre findet man in der ,Killerspieldebatte', die nach den Attentaten von Littleton und Erfurt die öffentliche Wahrnehmung von digitalen Spielen prägte. Vgl. dazu MATUSZKIEWICZ (2015b); zur ,Killerspieldebatte' in Deutschland und Australien vgl. SCHROEDER (2011). Zur Gewalt in digitalen Spielen im Allgemeinen vgl. Christoph BAREITHERs ethnografisch angelegte Studie Gewalt im Computerspiel. Facetten eines Vergnügens (2016). Neuere Studien wie KüHN et al. (2018) widerlegen mittlerweile mittels empirischer Vergleichsstudien sogar den lange und häufig von Kritikern unterstellten Kausalzusammenhang zwischen dem Spielen gewalthaltiger digitaler Spiele wie GTA V und einer Aggressionszunahme der Probanden im Alltag.

${ }^{260}$ Wie zentral die didaktisch-kritische Funktion derartiger Arbeiten sein kann, illustriert Ludwig Quiddes berühmte Studie über den römischen Kaiser Caligula, die als Parabel zugleich den ,Cäsarenwahnsinn' auf den deutschen Kaiser Wilhelm II. überträgt. Vgl. QUIDDE (1926). Wie persistent durch Verfallsnarrative etablierte Deutungsmuster sein können, wird dadurch herausgestrichen, dass sich das Caligula-Bild des 19. Jahrhunderts fast das gesamte 20. Jahrhundert lang halten konnte. Erst Aloys WinTERLINGs (2003) Caligula-Biografie kann als eine Arbeit angesehen werden, die die moderne Mythenbildung bezüglich Caligula (und anderer ,wahnsinniger` Kaiser) in der Alten Geschichte konsequent auf ihre Stichhaltigkeit hin überprüft.
} 
Verfallsnarrativ liegt das dominante (narrative) Handlungsmuster aber im Scheitern des Protagonisten. Als Narrativ hat dies einen Reiz, spielerisch aber nicht, denn wer will ein Spiel spielen, das er von Beginn an nicht gewinnen kann? Das Verfallsnarrativ steht den Charakteristiken von Spielen diametral entgegen und kann somit nicht (oder nur sehr schwierig und reduziert) spielerisch umgesetzt werden. Dies zeigt, dass die Handlungsmuster von Interaktiv und Narrativ nicht immer korrespondieren können, sondern dass dies von der Kompatibilität zwischen Interaktiv und Narrativ abhängt. Diese Kompatibilität ist beim mythologischen Narrativ gegeben, welches stets vom Sieg des Protagonisten handelt. Insofern ist das mythologische Narrativ (wie auch das Aufstiegsnarrativ) ein Gegenentwurf zum Verfallsnarrativ.

Man darf aber keinesfalls davon ausgehen, dass die korrespondierende Relation zwischen Interaktiv und Narrativ stets in dem Sinne ausgeprägt ist, dass eine Konvergenz ${ }^{261}$ zwischen beiden zu einer größtmöglichen Hybridisierung im interaktiv-narrativen Bereich führt. Die Grade der Ausprägung bzw. Gewichtung zwischen Interaktiv und Narrativ können (z.T. stark) variieren. Andernfalls wären interaktive oder narrative interaktiv-narrative digitale Spiele gar nicht möglich. Wie sich die Beurteilung der Interaktivität-Narrativität eines digitalen Spiels auf der Attributebene ausnimmt, folgt letztlich aus dem Designparadigma ${ }^{262}$ des InteraktivNarrativs. Es bietet sich deshalb an, in Bezug auf das Interaktiv-Narrativ, zwischen drei Designparadigmen zu unterscheiden. Die Rede ist dann von einem interaktiven, einem interaktiv-narrativen oder einem narrativen Designparadigma. Diese Designparadigmen werden vom Designer bestimmt und prägen die ontologische wie rezeptiv-ästhetische Dimension des betreffenden interaktiv-narrativen digitalen Spiels. Beim interaktiven Designparadigma nimmt das Interaktiv die stärkste Position innerhalb der InteraktivitätNarrativität des jeweiligen digitalen Spiels ein. Ein digitales Spiel, das diesem Designparadigma folgt, ist Red Dead Redemption (2010). ${ }^{263}$ Dieses Spiel hat zwar eine

${ }^{261}$ Durch eine Konvergenz von narrativem und performativem Handlungsmuster wird letztlich ein Phänomen wie transmediales Erzählen erst möglich, da jene Konvergenz die Grundvoraussetzung für eine transmediale Übersetzbarkeit ist.

262 Das Designparadigma bzw. die drei Designparadigmen wurden vom informatischen Konzept des ,Programmierparadigmas‘ abgeleitet. Vgl. hierzu GabBrielli/Martini (2010). Unter einem Designparadigma verstehe ich im Folgenden die Verdichtung von bestimmten designerischen Prinzipien und Vorstellungen zu einem leitenden Muster.

${ }^{263}$ Red Dead Redemption ist, schon thematisch und ikonografisch bedingt, dem Western-Narrativ verpflichtet, welches ebenfalls ein Derivat des mythologischen Narrativs ist. Dies wird an der Verkettung der Kardinalfunktionen signifikant: John Marston muss den heilen Mikrokosmos (seine Farm und Familie) auf Druck von US-Bundesagenten verlassen (Ruf des Abenteuers), wobei er Mentoren findet (z.B. Bonnie MacFarlane) sowie auf andere NPCs trifft, die ihn unterstützen (z.B. Nigel West Dickens) und mit deren Hilfe er nach und nach die Mitglieder seiner alten Bande eliminiert. Dies mündet alles in den finalen Showdown mit 
Handlung, welche aber eher dazu dient, um den Status des Avatars, John Marston, eines Outlaws, der unfreiwillig wieder zur Waffe greifen muss, zu unterstreichen. Im Rahmen des interaktiv-narrativen Figurendesigns regt der Plot vermehrt zu personalen Narrationen des Spielers an, die versuchen, die Rezeptionserfahrungen des Spielers mit Westerngeschichten $\mathrm{zu}$ (re-)aktivieren, indem narrative Rezeptionsangebote gemacht werden, um das dominante Spielprinzip narrativ anzureichern. Allerdings kann das Spiel auch weitestgehend ohne diese narrativen Elemente gespielt werden, da Open-World-Prinzip und zahlreiche Nebenquests ein intensives Spielerlebnis jenseits medialer oder personaler Narrationen bieten. ${ }^{264}$ Die Interaktivität bestimmt bei solchen digitalen Spielen eindeutig die Interaktivität-Narrativität. Dies wird auch daran deutlich, dass bestimmte ludische Elemente des Spiels, die für SandboxGames von Rockstar typisch sind, im Fokus stehen wie die Shooter-Lastigkeit, das OpenWorld-Prinzip oder die Erkundung der Welt mit wechselnden Vehikeln.

Anders ist dies bei digitalen Spielen wie Uncharted, die einem interaktiv-narrativen Designparadigma verpflichtet sind. Diese Spiele werden von einem (annähernden) Gleichgewicht zwischen Interaktiv und Narrativ bestimmt. Dies drückt sich in der massiven Nutzung von interaktiv-narrativem Figuren-, Welt- und Strukturdesign und der damit verbundenen hohen Hybridität zwischen Interaktivität und Narrativität aus. Narrative und interaktive Spielphasen alternieren permanent und nehmen fast identisch viel Spielzeit in Anspruch, die Figuren changieren als Avatare ständig zwischen Charakter und Spielfigur, die Spielwelt zwischen Diegese und Spielraum und die Spielstruktur zwischen Erzähl- und Queststruktur.

Ein narratives Designparadigma liegt bei einem digitalen Spiel wie Heavy Rain vor. Das Narrativ ist hier deutlich stärker profiliert und die Interaktivität-Narrativität dieses Spiels sehr narrativ ausgeprägt. Dies äußert sich in vielen Cutscenes wie auch dem Stellenwert und Einfluss, den die Narrativität auf die Entscheidungsfindung ausübt. Oben ist davon gesprochen worden, dass die Rollenzuschreibungen einer narrativen Figur in interaktivnarrativen digitalen Spielen dazu führen sollen, diese als Avatare gemäß der Rollenerwartung zu realisieren. In diesem Fall, und The Walking Dead war hier das Exempel, regt die

seinem ehemaligen Bandenführer, Dutch van der Linde, den er ebenfalls ausschalten muss, um die Welt zu ,retten` und zu seiner Familie zurückkehren zu können. Zur ikonografischen Umsetzung des filmischen WesternGenres und dessen Realisierungsmöglichkeiten im Action-Adventure am Beispiel von Red Dead Redemption vgl. KIRSTEN (2016).

${ }^{264}$ Das Designparadigma bzw. dessen Offenlegung bietet den analytischen Vorteil, Einordnungen von z.B. digitalen Einzelspielen auf der Attributebene (aus der Mikroperspektive) genauer untersuchen zu können, indem man das Figuren-, Welt- und Strukturdesign näher betrachtet. 
Figurenkonzeption Spieler dazu an, gemäß dieser zu interagieren. Spiele wie Heavy Rain überschreiten dies, indem aus diesem Handlungsangebot fast schon ein Handlungszwang wird, der es Spielern zu einem großen Teil unmöglich macht, anders als nahegelegt zu interagieren. Digitale Spiele mit narrativem Designparadigma neigen zu einer markanten Geschlossenheit, die neben dem Plot auch die Entscheidungsfindungen des Spielers sowie die Realisierung der Interaktion-Narration im Allgemeinen umfasst. Ein interaktives Designparadigma hingegen bedingt in der Regel eine große Offenheit auf allen Ebenen des Spiels.

Die Designparadigmen lassen sich letztlich durch die Nutzung der interaktiv-narrativen Polyvalenzen umsetzen. Deshalb soll die Aufmerksamkeit im Folgenden auch dem interaktivnarrativen Figuren-, Welt- und Strukturdesign gelten, um zu zeigen, wie sich Designparadigmen im Designprozess manifestieren.

\subsubsection{Das interaktiv-narrative Figurendesign}

Das interaktiv-narrative Figurendesign nutzt die interaktiv-narrative Polyvalenz der Figuren, als Spielfigur (interaktiv), Charakter (narrativ) und als Avatar (interaktiv-narrativ) realisierbar zu sein. Die Spielfigur ist die Schnittstelle zwischen Spieler und Spielsystem, ist ein wichtiger Bestandteil der Interaktivität eines digitalen Spiels, da sie einerseits dazu dient, virtuelle Interaktionen auszuführen und andererseits zugleich die Reaktionen des Systems auf die Aktionen der Spieler im Interaktionsprozess widerzuspiegeln. Sie ist somit stets ein Element der Eingabe wie auch der Ausgabe. Eine Spielfigur wird über ihre semiotische Funktion als Spielelement bestimmt. Dabei ist die optische Erscheinung einer Spielfigur von sekundärem Interesse, entscheidend ist vielmehr, dass sie durch die Handlungen, die man mit ihr ausführen kann, kompatibel zum dominanten Spielprinzip ist. Anders gesagt: Die Spielfigur eines Shooters muss schießen können, damit der Spieler interaktiv das Spiel gemäß des dominanten Spielprinzips spielen kann. Diese Rolle kann das Raumschiff in Space Invaders ebenso übernehmen wie der Cowboy in Mad Dog McCree. Die anthropomorphe Gestaltung eines Avatars kann in interaktiv-narrativen digitalen Spielen aber dahingehend sinnvoll sein, dass sie die Immersion der Spieler ins digitale Spiel unterstuitzen kann.

Eine narrative Figur erfüllt vornehmlich ihre Rolle als Funktionsträger in einem Narrativ. Sie bringt den Plot voran, kann identifikationsstiftend wirken oder (im Fall einer homodiegetischen Erzählerinstanz) selbst Teil des narrativen Modus sein. Somit kommt einer narrativen Figur eine nicht unerhebliche Rolle in der narrativen Vermittlung zu. In gewisser 
Weise ist also auch die narrative Figur ein ,Schnittstellenelement', da sie (zumindest partiell) Zugangsfunktionen übernimmt, die den Rezipienten den Eintritt, die Immersion ins Medium erleichtern. Man muss dabei aber vorsichtig sein, Spielfigur und narrativen Charakter in eins zu setzen. Dafür unterscheiden sich beide zu sehr im Hinblick auf die Einflussnahme des Spielers/Rezipienten. Eine Spielfigur ist ein performatives Element des Spielens digitaler Spiele, ohne welches die realen Interaktionen des Spielers im virtuellen Raum nicht umsetzbar wären. Ein narrativer Charakter aber ist ein darstellerisches Element, das von der Performanz entkoppelt ist. Der performative Akt bei der Rezeption eines Romans bspw. beschränkt sich auf den Leseprozess, d.h. auf den Moment, in welchem der Leser den Plot durch seine Rezeption aktualisiert. Der narrative Charakter ist zwar ein wichtiges Element des Plots eines Romans, er ist aber für den performativen Akt an sich eher peripher. Verkürzt könnte man auch festhalten, dass die Spielfigur ein aktives Element des Spielgeschehens ist, wohingegen die narrative Figur ein passives Element des Plots ist, die sich Eingriffen des Rezipienten weitestgehend entzieht.

Bedenkt man nun, dass ein Wechsel zwischen aktiven und passiven, zwischen anspannenden und entspannenden, zwischen interaktiven und narrativen Spielphasen interaktiv-narrative digitale Spiele bisher größtenteils auszeichnet, so kann dies nur gelingen, wenn ein Avatar sowohl als interaktive Spielfigur als auch als narrativer Charakter fungieren kann. Dies macht erst den Avatar eines interaktiv-narrativen digitalen Spiels aus. Lara Croft als Avatar aus Tomb Raider fungiert in diesem Sinne. In den interaktiven Spielabschnitten ist sie die Spielfigur, mit deren Hilfe der Spieler, dem dominanten Spielprinzip des ActionAdventures verpflichtet, die Spielwelt explorativ erkundet, indem er den Avatar als Raumerkundungsvehikel einsetzt, Rätsel löst, indem er Lara als virtuell ausführende Schnittstelle seiner Handlungen im Prozess des Rätsellösens instrumentalisiert oder Gegner kämpfend eliminiert, indem er den Avatar zur Ausschaltung der gegnerischen NPCs benutzt. ${ }^{265}$ Darüber hinaus ist Lara Croft in den narrativen Phasen eine Figur des Plots, kann aber auch, durch ihre Stimme wie Bildlichkeit als Instanz der narrativen Vermittlung (mit)wirken; dies betrifft in erster Linie die jüngeren Titel der Reihe. Durch die narrativen Cutscenes erschließt sich dem Spieler Lara Croft als eine fiktive Figur, in deren Gefühlswelt er mehr und mehr eintaucht und deren Identität maßgeblich für die Realisierung des Avatars von Tomb Raider in seiner Interaktion-Narration wird. Ragnhild Tronstad hebt diesen Effekt

\footnotetext{
${ }^{265}$ Adventure und Action-Adventure gehören zu den sog. ,Quest Games', in welchen neben der Suche (Quest) an sich v.a. das Lösen von Rätseln eine große Rolle spielt. Vgl. dazu TRONSTAD (2014), 410 f.
} 
interaktiv-narrativer digitaler Spiele ebenso hervor, betont dabei zudem die Wichtigkeit des mythologischen Narrativs in diesem Kontext. „Quest narratives [bzw. das mythologische Narrativ] may also be instrumental in shaping an identity for the player character, as distinguished from that of the player". (TRONSTAD 2014, 412)

Es ist aber nicht nur wichtig, dass ein Avatar alternierend interaktiv oder narrativ wirken kann, sondern dass sich dessen Interaktivität-Narrativität auch gleichzeitig zeigt und somit dessen Hybridität herausstellt. In Kapitel 2.2.2.1.4 war von einem zunehmenden Verschwimmen von Interaktivität und Narrativität in interaktiv-narrativen digitalen Spielen die Rede, was beispielhaft an Uncharted 4 illustriert wurde. Nimmt man dieses Beispiel nun wieder auf, betrachtet ein interaktiv-narratives digitales Spiel, dessen Spieler um die Interaktivität-Narrativität, wenn auch nur unbewusst, weiß und der zudem erkannt hat, dass solche digitalen Spiele oft auf Formen der, reduzierten Interaktivität' durch Beschränkung der Interfaceeingaben zurückgreifen, so kann man Folgendes beobachten: Es kann vorkommen, dass diese Spieler von einem gegnerischen NPC getötet werden oder einen Abhang hinterfallen, ohne dass sie reagieren. ${ }^{266}$ Wie kann dies sein, zumal, wenn es sich um versierte Spieler handelt? Ursächlich hierfür ist oft die Annahme des Spielers, dass er noch in einer narrativen Spielphase sei. Entweder hat der Spieler in diesem Fall den ,Übergang ${ }^{6}$ nicht erkannt (wenn er überhaupt markiert war) oder versucht eine Interfaceeingabe auszuführen, die ihm aktuell verwehrt ist, da diese im Rahmen der ,reduzierten Interaktivität‘ vorübergehend deaktiviert ist. Als Folge dessen lässt er die gegnerischen NPCs auf sich zukommen, da er annimmt, dass alle PCs/NPCs zu dem Zeitpunkt als narrative Charaktere fungieren und nicht als Spielfiguren. Somit erkennt er seine Fehleinschätzung oft erst zu spät und sein Avatar stirbt.

Die neuen grafischen Möglichkeiten und deren konkrete künstlerische Umsetzung erlauben nun eine weitaus weitreichendere Verschränkung von Interaktivität und Narrativität und somit eine stärkere Interaktivität-Narrativität, als dies bisher der Fall war. Was vor knapp zehn

\footnotetext{
${ }^{266}$ Bei der Beobachtung von Spielsessions derartiger Spiele lässt sich z.B. zuweilen bemerken, dass Spieler den ,Wiedereinstieg' in die interaktive Spielphase ,verpassen', da (aufgrund des Verschwimmens zwischen interaktiven und narrativen Spielphasen) der Wechsel aus der narrativen Phase heraus für den Spieler nicht immer ersichtlich ist. Dies führt nicht selten zum Tod des Avatars. In Let's Plays lässt sich dieses Phänomen hingegen weniger feststellen. Einerseits hängt dies damit zusammen, dass das Rohmaterial für die Veröffentlichung auf bspw. Youtube bearbeitet wird, wobei i.d.R. Fehlversuche herausgeschnitten werden und andererseits legen gerade manche als Walkthrough konzipierte Let's Plays aufgrund der Zielsicherheit der Aktionen des Spielers die Vermutung nahe, dass dies nicht der erste Spieldurchlauf für diesen ist. Im zweiten Spieldurchlauf überraschen derartig fließende Wechsel den Spieler aber nicht mehr und fallen daher auch nicht ins Gewicht.
} 
Jahren mit dem QTE seinen Siegeszug antrat, zeigt sich mittlerweile fernab dieser Spielmechanik in vielen interaktiv-narrativen digitalen Spielen - die Simultanität von Interaktion und Narration. Dies führt zu einer ästhetischen Vermengung, sodass Spieler nicht mehr immer unterscheiden können, ob sie es mit narrativen oder interaktiven Figuren zu tun haben. Diese ontologischen und rezeptiv-ästhetischen Veränderungen des InteraktivNarrativen führen zu einer erheblichen Dynamisierung von Figur, Welt und Handlungen, die das interaktiv-narrative digitale Spieldesign massiv verändern. So wird es in den kommenden Jahren nicht nur zu klären sein, was ästhetisch noch möglich ist, es gilt auch dem nachzugehen, wie weit man diese Entwicklung noch treiben kann, bevor es zu zunehmenden Konfusionen beim Spielen kommt bzw. wie man diese neuen ästhetischen Möglichkeiten durch neue Auszeichnungen der Vermittlung in das Gamedesign integrieren kann.

Im Rahmen des interaktiv-narrativen Figurendesign ergeben sich drei Formen (interaktiv, interaktiv-narrativ und narrativ), die sich im Wesentlichen dadurch voneinander unterscheiden, dass sie der Figur Agency in unterschiedlichem Maße einräumen. Eine interaktive Spielfigur schreibt dem Spieler eine hohe Handlungsmacht zu, der narrative Charakter entzieht diesem die Handlungsmacht hingegen vollkommen. ${ }^{267}$ Eine Mischform dessen findet man dann beim interaktiv-narrativen Avatar, dessen Wechsel zwischen Entzug und Zuteilung der Handlungsmacht an den Spieler nicht immer von letzterem umgehend zu erkennen ist. ${ }^{268}$

267 Vgl. dazu exemplarisch das Let's Play von DenNisTheMenACEGr zu GTA: Vice City (2002) https://www.youtube.com/watch?v=amWjKW2n76U (30.06.2018). Hierbei handelt es sich um die Mission, in welcher der Drogenboss Ricardo Diaz getötet werden muss. Sie beginnt - für GTA sehr klassisch - mit einer narrativen Cutscene, in welcher Tommy Vercetti und Lance Vance an der Villa von Diaz' ankommen. Zwei weitere kurze Cutscenes erscheinen, bevor man Diaz tötet sowie danach bzw. währenddessen. Diese rahmen das Spielgeschehen funktional gesehen und sollen dem Spieler zusätzliche Immersionspotenziale anbieten. Besonders im Vergleich mit den interaktiven Spielphasen, in denen man sich durch Diaz' Leibwache schießt oder diesen selbst eliminiert, werden die Unterschiede zwischen den beiden Figurentypen deutlich. In der narrativen Spielphase hat der Spieler keinen Einfluss auf den narrativen Charakter Tommy Vercetti, die einzige Handlungsoption, die er besitzt, besteht darin, die Cutscene zu überspringen. In den interaktiven Spielabschnitten hingegen kann der Spieler die Spielfigur Tommy (frei) bewegen, kann schießen, hierbei verschiedene Waffen einsetzen und sich abweichender Strategien bedienen (offensiv, defensiv etc.). Außerdem kann er bestimmen, in welcher Zeit er diese Mission absolviert. Das verlinkte Let's Play dokumentiert einen sehr linearen Spieldurchlauf, es sind aber auch Spieldurchläufe realisierbar, in denen die Villa und deren Anlage intensiver erkundet werden.

${ }^{268}$ Ein anschauliches Exempel für diesen Figurentyp findet man z.B. im Let's Play von XCV zu Life Is Strange https://www.youtube.com/watch?v=NqS2ppt3NQU (30.06.2018). In diesem geht es darum, dass der Avatar Max ihre Mitstudentin Kate Marsh von deren geplantem Suizid abhält, den diese begehen möchte, da sexuell verfängliche Aufnahme von ihr im Umlauf sind. Insgesamt sind das Spiel und dieser Abschnitt sehr narrativ, jedoch bricht die Agency des Spielers regelrecht in das Spiel hinein und überträgt hierdurch spielfigürliche Aspekte auf den narrativen Charakter, der hierdurch zum simultan existierenden Avatar wird. Dies ist insbes. in den Entscheidungsmomenten der Fall, deren Ausgang maßgeblich den weiteren Spielverlauf bestimmt und in diesem konkreten Fall bedeutet, ob Kate weiterlebt oder eben nicht. 
Ein letzter Punkt, der im Kontext des interaktiv-narrativen Figurendesigns nach kurz angesprochen werden sollte, ist die Rolle der Figurenkonzeption. Jedes Narrativ, wie oben ausgeführt, bedingt eine bestimmte Figurenkonstellation und damit einhergehende Figurenkonzeptionen. Dabei neigen verschiedene Narrative $\mathrm{zu}$ abweichenden Figurenkonzeptionen. Betrachten wir exemplarisch zwei aktuell populäre Interaktiv-Narrative mit der Superheldengeschichte und der Zombieapokalypse sowie deren Protagonisten. Einerseits fällt auf, dass die Superheldengeschichte dazu tendiert, einen Helden als Protagonisten $\mathrm{zu}$ etablieren, der alle narrativen Figurenfunktionen auf sich vereint und in seiner Figurenkonzeption idealisiert dargestellt wird. In der Zombieapokalypse wird die Protagonistenrolle aufgespalten. Mehrere Figuren übernehmen diese nun, teilen den einen Protagonisten auf ein Figurenkollektiv auf. So gibt es den patenten Anführer, seinen alten und weisen Mentoren, einen durchgreifenden Adjutanten, die zaghafte Frau, die verängstigten Kinder usw. Andererseits ist die Figurenentwicklung interessant. Während sich der Superheld im Handlungsverlauf nicht verändert, ändern sich die Protagonisten der Zombieapokalypse z.T. grundlegend. Die Statik der Superheldenfigur und die Dynamik der Figuren in der Zombieapokalypse hat zum einen mit unterschiedlichen Spielraumkonzepten, zum anderen aber auch mit dem moralischen Wertehorizont der Figuren zu tun. Der Superheld (z.B. Superman) ist unzweifelhaft tugendhaft und alle seine Handlungen zeugen von einer , hohen“ Moral. Das Narrativ der Zombieapokalypse hingegen erhält seinen Reiz größtenteils dadurch, dass es den zivilisatorischen Verfall skizziert, der sich ideal am moralischen ,Verfall` der Figuren verdeutlichen lässt. ${ }^{269}$ Die neuen Anforderungen an ein Leben nach der Katastrophe, fernab übergreifender sozialer Ordnungen und der hieraus folgenden lokalen Zersplitterung, zwingen die Figuren, ihre moralischen Ansichten zu überdenken bzw. aufzugeben, um zu überleben. Deutlich zeigt sich dies in Bezug auf die Tötung von NPCs.

So ist Ellie aus The Last of Us anfänglich eher passiv und auch Joel will verhindern, dass sie jemanden tötet. Beide müssen aber erkennen, dass ihr Überleben als Gruppe nur dann möglich scheint, wenn sie sich von Rollen- und Moralvorstellungen lösen, die sich zunehmend als Relikt einer vergangenen Zeit offenbaren, die unwiederbringlich verloren ist.

\footnotetext{
${ }^{269}$ Obwohl der Verfall in der Zombieapokalypse ebenfalls eine große Rolle spielt, weist sie dennoch einige Unterschiede zum Verfallsnarrativ wie Thomas Manns Buddenbrooks auf. So wird der Verfall einerseits nicht primär durch das Unvermögen der Protagonisten vorangetrieben, sondern hat externe Ursachen, die sich der Agency der Figuren entziehen. Andererseits sehnen sich die Protagonisten zwar gelegentlich nach dem Zustand vor der Katastrophe, ehe der Verfall einsetzte, sie neigen aber weniger stark dazu, diesen zu idealisieren. Im Kontrast zu den Protagonisten des Verfallsnarrativs versuchen die Protagonisten der Zombieapokalpyse bspw. stets moralisch zu handeln und verhandeln dabei stets aufs Neue, was als moralisch zu gelten hat. Vgl. dazu auch 2.5.2.2.
} 
Dementsprechend greift auch Ellie zur Waffe und trägt, unter Ausübung letaler Gewalt, zum Überleben der Gruppe bei. ${ }^{270}$ Der ,Superheld“ Batman hingegen ist auch am Handlungsende von Arkham City (2011) nicht bereit, einen einzigen Menschen zu töten, auch wenn er hierdurch Millionen anderer Menschen retten könnte. Die Dialoge mit Talia oder dem Joker stellen brachial die Statik Batmans heraus, werfen die Frage auf, welche Rolle ein Superheld erfüllt, der sich dogmatisch an Werte hält, an die sich alle anderen nicht mehr halten. ${ }^{271}$ Die Dynamik der Figuren steht aber auch unter dem Einfluss der Handlungsmacht der Figuren. Im Handlungsverlauf der Zombieapokalypse werden aus den machtlosen Figuren zu Handlungsbeginn am Handlungsende machtvolle Gestalter des eigenen Schicksals, die für den Fortbestand der Gruppe als Restgesellschaft kämpfen. Batman ist aber bereits zu Handlungsbeginn machtvoll, muss sich deshalb als narrativer Charakter weniger verändern. Die beiden Beispiele zeigen jedoch darüber hinaus, dass es nicht nur bedeutend ist, welche Handlungsmacht narrative Figuren haben, sondern auch, wie sie diese konkret nutzen. Die Figuren der Zombieapokalypse zeichnet eine hohe Handlungsbereitschaft aus, Batman jedoch verweigert konsequent Handlungen, die seiner Moral widersprechen und wird hierdurch paradoxerweise zum machtlosen Objekt von Vorgängen, die er nicht aufhalten kann.

Im interaktiv-narrativen Figurendesign sind Aspekte der Figurenkonstellation und konzeption bedeutsam, da sie maßgeblich zum Ausgleich zwischen Narrativ und Interaktiv beitragen können und auch auf andere Bereiche des interaktiv-narrativen Designs ausgreifen, da die Fähigkeit zu unterschiedlichen Raumbemächtigungen zum einen das Spielweltdesign tangiert und zum anderen auch den Aufbau der interaktiv-narrativen Spielstruktur maßgeblich beeinflusst.

\subsubsection{Das interaktiv-narrative Spielweltdesign}

Wie der Avatar eines interaktiv-narrativen digitalen Spiels muss auch die Spielwelt polyvalent sein, sich interaktiv, interaktiv-narrativ und narrativ umsetzen lassen. Interaktiv fungiert sie dabei als Spielraum, in dem die Spieler umfassende Handlungskompetenzen haben und mit dem System interagieren. Dies bedeutet aber auch, dass ein Spielraum auf das Vorhandensein einer Spielfigur angewiesen ist, durch welche Spieler erst im digitalen Spiel handeln können. Es zeigt sich die enge Verbindung, die Dependenz zwischen Figur- und Spielweltdesign. Der Spielraum als konfigurativer Raum performativen Spielerhandelns wird

270 Vgl. dazu das folgende Let's Play von IsHKOTEN https://www.youtube.com/watch?v=L7I3ILw hqA (30.06.2018).

${ }^{271} \mathrm{Vgl}$. dazu das folgende Let's Play von GAMER4EVER https://www.youtube.com/watch?v=6W27Zkh9lng (30.06.2018). 
durch die Agency der Spielfigur mitkonstituiert. Der Spielraum ist deshalb vollkommen auf Spielfigur und Spieler bzw. dessen Handlungen fokussiert. Im Spielraum gibt das System, wenn man so will, seine Handlungsdominanz an den Spieler ab.

Wird die Spielwelt narrativ geprägt, liegt eine Diegese vor, die die Handlungsdominanz beim System belässt und Spieler somit - im wahrsten Sinne des Wortes - zu Zuschauenden macht, da die Handlungskompetenzen des Spielers diesem (nahezu) vollkommen entzogen werden. Diese Welten bedürfen narrativer Charaktere, da sie nur durch diese ,besiedelt` werden können. Zudem geben narrative Figuren dem Spieler einen Zugang zum Narrativ, indem sie dies (in gewisser Weise) anthropomorphisieren. Des Weiteren weisen beide Welten verschiedene Konzepte von ,Welthaftigkeit` auf. Spielräume sind simulative, Diegesen sind fiktionale Räume. Im Zuge der Interaktivität-Narrativität hybridisieren sich auch diese, sodass interaktiv-narrative Spielwelten sowohl simulativ als auch fiktional sind. Hieraus ergeben sich dann auch die oben skizzierten Fehleinschätzungen von Spielern, die die konkrete Gestalt der Welthaftigkeit der Spielwelt missinterpretieren - mit den beschriebenen Folgen.

Im Zusammenhang mit dem Spielweltdesign ist ein Aspekt besonders relevant, der zwar auch die anderen beiden Bereiche tangiert, aber hier bildlich am deutlichsten wird. Es geht um die Anlage von Paidia-Spielen bzw. um personale Narrationen. Manche interaktiv-narrativen digitalen Spiele gestatten sehr viele Paidia-Spiele und stellen diesen Aspekt ihrer Ludizität auch markant heraus, wie das folgende Beispiel demonstrieren soll. ${ }^{272}$ Was wir hier sehen, sind Links erste Schritte in der ,Hylianischen Steppe“ in Ocarina of Time. Das Spiel beginnt mit einer narrativen Exposition, die das mythologische Narrativ etabliert, indem der GutBöse-Antagonismus sowie das Auserwähltsein des Helden angedeutet werden. Dem folgt (bzw. ist damit verbunden) ein Tutorial, in welchem die Spieler das Spiel erlernen sollen, indem das dominante Spielprinzip, die Spielmechaniken und die Steuerung vorgeführt werden und geübt werden müssen. Es schließt sich der erste Dungeon an, der spielrhetorisch den ersten Test der spielerischen Skills ${ }^{273}$ der Spieler darstellt und diese bei Erfolg belohnt. Link muss nun, um seiner Aufgabe als auserwählter Held gerecht zu werden, seine vertraute Welt verlassen, was emotional durch den Abschied von, vertrauten' NPCs unterstrichen wird. In diesem Zustand betritt der Avatar die Hylianische Steppe und trifft auf seinen Mentor - die mysteriöse Eule Methusa.

\footnotetext{
272 Vgl. dazu das folgende Let's Play von MAHALOVIDEOGAMES https://www.youtube.com/watch?v=DXJeRYqHvig (30.06.2018).

${ }^{273}$ In der digitalen Spielkultur bezeichnet der Begriff ,Skill‘ sowohl die Fähigkeiten des Avatars als auch die Fertigkeiten des Spielers in Bezug auf das Spiel.
} 
Diese dient spielrhetorisch als ,loser ${ }^{6}$ Navigator, da sie zwar beschreibt, welche Orte es gibt und an mehreren Orten anzutreffen ist, wo der Spieler dann ausführlichere Informationen zum Ort und den angrenzenden Ortschaften erhält, sie schreibt aber keineswegs vor, wohin sich der Spieler zu wenden hat. Methusa als interaktiv-narrative Figur fungiert als Spielelement, das Angebote und Möglichkeiten aufzeigt, Spieler nicht auf dem Pfad des Ludus' und Narrativs halten will, sondern zur multioptionalen Nutzung der interaktivnarrativen Spielwelt anregt. Evident wird dies, wenn Methusa (bei einem späteren Aufeinandertreffen) ihre Ausführungen mit der Frage danach abschließt, wohin Links Schritte ihn als nächstes lenken werden. Inhalt und Frageform des Satzes implizieren eine Wahlmöglichkeit, auf die Methusa den Spieler hinweist und die sich dann auch räumlich manifestiert. Der erste Dialog ${ }^{274}$ mit Methusa ist gerade beendet und der Spieler steht vor der Wahl, wohin er gehen soll. Das Open-World-Prinzip von Ocarina of Time zeigt sich hier sehr früh im Spiel und verweist auf die multikursorischen Optionen sowie Paidia-Interpretationen. Bezeichnenderweise ist nämlich der Weg, der zum Schloss von Hyrule und damit zu Prinzessin Zelda sowie der nächsten Quest und narrativen Funktion führt, nicht ,durchgezeichnet", sondern lediglich angedeutet. Es ist charakteristisch für Ocarina of Time, dass Wege sehr fragmentarisch sind. Was bedeutet dies spielrhetorisch? Es heißt, dass das Spiel zwar den Fortgang des Ludus' bzw. Narrativs aufzeigt, dies aber zurückhaltender tut, da ohnehin in den meisten Fällen davon auszugehen ist, dass Spieler, wie ihnen aufgetragen, zum Schloss von Hyrule gehen werden. Um von Beginn an ein zu ,lineares' Spielen von Ocarina of Time zu verhindern, wurden Spielelemente wie Methusa integriert, die die Multioptionalität der interaktiv-narrativen Spielwelt unterstützen. Spieler könne zwar, strikt der Hauptmission folgend, von einem diegetischen Abschnitt zum nächsten springen, wobei der Spielraum dazwischen zugunsten der Narrativität erheblich reduziert wird, sie können aber auch, und das Spiel lädt hierzu ein, den Spielraum als solchen nutzen und spielen; mit oder ohne personale Narration.

\subsubsection{Das interaktiv-narrative Strukturdesign}

Am aktuellen Exempel kann man auch die interaktiv-narrative Struktur von interaktivnarrativen digitalen Spielen aufzeigen. ${ }^{275}$ Die ,interaktiv-narrative Spielstruktur ${ }^{6}$ eines interaktiv-narrativen digitalen Spiels besteht aus der Erzählstruktur auf der einen sowie der

\footnotetext{
274 Dialoge sind, und Methusas Beispiel zeigt dies, für interaktiv-narrative Spielwelten, besonders bei entsprechender räumlicher Ausdehnung, wichtig, um einerseits Informationen zu übermitteln und andererseits Orientierung und Navigation für Spieler zu bieten.

${ }^{275} \mathrm{Zu}$ narrativen Strukturen in digitalen Spielen vgl. IP (2011a sowie 2011b).
} 
Quest-/Missionsstruktur auf der anderen Seite. Die Erzählstruktur ist dabei strukturell im Wesentlichen identisch mit dem grundlegenden Muster eines Narrativs in Form der Verkettung von Kardinalfunktionen, das dem betreffenden digitalen Spiel zugrunde liegt (freilich abgesehen von Modifikationen des Narrativs). ${ }^{276}$ Ocarina of Time beruht auf dem mythologischen Narrativ, das am Beispiel Christopher Voglers aufgezeigt werden soll. Bekanntlich stellt dieses eine Abwandlung von Joseph Campbells Modell dar. Beschränken wir uns, um Kapitel 4 nicht zu weit vorzugreifen, lediglich auf die ersten fünf Stationen des Modells der Heldenreise bzw. die Kardinalfunktionen des mythologischen Narrativs: Gewohnte Welt, Ruf des Abenteuers, Weigerung, Begegnung mit dem Mentor und Überschreiten der ersten Schwelle. (vgl. VogLer 2010, 74) Was in Filmen wie George Lucas' Star Wars: Krieg der Sterne (1977), der selbst ein großer Anhänger von Joseph Campbell ist, gut ein Drittel der Handlung des Filmes ausmacht, wird in Ocarina of Time vergleichsweise schnell besorgt.

Link wird in seiner gewohnten Welt, Kokiri, eingeführt, wo ihn der Ruf des Abenteuers ereilt, als ihm (hier noch indirekt) die Aufgabe übertragen wird, gegen Ganondorf und dessen (finstere) Absichten zu kämpfen. Was fast gänzlich ausbleibt, ist die Weigerung Links, da er überraschenderweise sofort dazu bereit ist, Kokiri zu verlassen, um Hyrule (und damit auch Kokiri) vor dem Bösen, verkörpert durch Ganondorf, zu retten. Das Treffen mit Methusa stellt zugleich die erste Begegnung mit dem Mentor wie auch das Überschreiten der ersten Schwelle dar, indem die gewohnte Welt in Form des Mikrokosmos Kokiri als idealisierte Kindergesellschaft hinter Link liegt.

Die Queststruktur ist parallel zur Erzählstruktur des mythologischen Narrativs aufgebaut. Nimmt man als erste narrative Funktion das Leben des Protagonisten in der gewohnten Welt und untersucht, was Spieler in diesem Spielabschnitt interaktiv machen können, so fällt auf, dass die narrative Darstellung der gewohnten Welt mit dem Tutorial einhergeht, dass narrative Exposition und Tutorial eng miteinander verbunden sind. Dies setzt sich auch im Spielverlauf fort, denn der Ruf des Abenteuers erreicht Link mit dem ersten Dungeon, dem Deku-Baum, und stellt somit auch die erste spielerische Prüfung dar. Und auch beim Überschreiten der ersten Schwelle findet ein Wechsel auf spielerischer Ebene statt, da der Spieler nicht nur

\footnotetext{
${ }^{276}$ Im Unterschied zum Narrativ bezeichnet die Erzählstruktur aber lediglich die strukturell-snytagmatische Verkettung von narrativen Funktionen, umfasst also nicht wie das Narrativ auch bestimmte standardisierte Figuren oder eine bestimme Diegese.
} 
Links vertrauten Abschnitt der Diegese verlässt, sondern erstmals auch den paidianischen Spielraum be- und hierdurch vollends in den liminalen Zustand des Spielens eintritt.

Die Prozeduralität digitaler Spiele als prozessbestimmter Systeme verbindet Erzähl- und Queststruktur zur interaktiv-narrativen Spielstruktur. Am deutlichsten wird diese Strukturäquivalenz in der Parallelisierung von narrativen Funktionen und Einzelmissionen der Hauptmission. So ist es auch zu erklären, warum Storyline und mainquest in interaktivnarrativen digitalen Spielen kaum voneinander zu trennen sind. Als verbindendes Element muss als Interaktiv-Narrativ stets ein Narrativ wie das mythologische wirken, das sich mit dem Interaktiv synchronisieren lässt. Insofern fungiert der Mythos (und seine modernen Abwandlungen) in vielen interaktiv-narrativen digitalen Spielen als verbindendes Element, das das Spiel auf der Strukturebene in vielerlei Hinsicht strukturiert. Die Symbiose kann man sich in Bezug auf die Spielstruktur im besten vorstellen, wenn man sie als ,Doppelhelix“ begreift. Legt man die Erzähl- und die Queststruktur (bildlich gesprochen) nebeneinander bzw. die strukturell äquivalenten narrativen Funktionen und Einzelmissionen, so lässt sich die Verwobenheit beider zur interaktiv-narrativen Spielstruktur metaphorisch ausdrücken, indem man sie wie eine Doppelhelix ineinander dreht.

Die Punkte, an denen sich die beiden Helices überschneiden, stellen dabei die Verbindung zwischen Erzähl- und Queststruktur dar und die Zwischenräume jenen Bereich, der die sich hieraus ergebenden (Handlungs-)Möglichkeiten umfasst. So kann man den Raum zwischen den Helices als Frei-, als Spielraum auffassen. Die Form der interaktiv-narrativen Spielstruktur als Doppelhelix lässt sich neben der Makro- auch auf der Mikroebene interaktivnarrativer digitaler Spiele nachweisen. Denn das Spiel ist spielstrukturell im Großen wie im Kleinen als Doppelhelix aufgebaut. Die Einzelmissionen sind bspw. oft auf dieselbe Art verkettet wie die Spielstruktur (als Hauptmission) in Gänze. ${ }^{277}$ Bricht man Einzelmissionen, narratologisch betrachtet, auf ihre basalen narrativen Elemente herunter, so umfassen diese strukturell betrachtet - wenigstens Anfang, Mitte und Ende, was den Basiselementen einer Erzählung im Sinne Aristoteles' entspricht. Die Queststruktur der Einzelmissionen ist ebenso aufgebaut. Am Anfang erteilt ein Questgeber die Aufgabe und die Einzelmission beginnt. Der mittlere Teil der Einzelmission nimmt die meiste Zeit in Anspruch, da er das Spielen an sich

\footnotetext{
${ }^{277}$ Anstelle von Spiel-, Queststruktur oder Hauptmission werden gelegentlich auch Begriffe wie ,quest chain verwendet, die auf die Verkettung der Einzelmissionen im Rahmen der Queststruktur hinweisen. Sebastian Domsch bemerkt dazu: „Quest chains are usually tied together by an overarching objective or narrative.“ Domsch (2013), 83. Durch den Verweis auf das (Spiel-)Ziel und auf das Narrativ macht Domsch deutlich, dass die Spielstruktur eines interaktiv-narrativen digitalen Spiels immer sowohl aufgrund ludischer als auch narrativer Kausalitäten verkettet wird.
} 
umfasst und in kleine Zwischenmissionsziele untergliedert sein kann, die sich mit Katalysen vergleichen lassen. Die Einzelmission endet, wenn das Questziel erreicht wurde, die Mission dementsprechend vom Spielsystem als erfolgreich evaluiert und der Spieler sanktioniert ${ }^{278}$ wurde. Somit ergibt sich, dass die Doppelhelix-Struktur interaktiv-narrativer digitaler Spiele, die sich als Korrespondenz der Handlungsmuster zwischen Quest- und Erzählstruktur darstellt, durch das Verbundensein zwischen Einzelmission und narrativer Funktion entsteht, die sich auf der Makro- wie auch der Mikroebene der Spielstruktur nachweisen lässt.

Wie diese Integration von Einzelmissionen in die Hauptmission aussehen kann, demonstriert u.a. L.A. Noire. Jeder Kriminalfall (so nebensächlich er anfangs auch erscheinen mag), den der Avatar Cole Phelps in den verschiedenen Dezernaten des Los Angeles Police Department lösen muss, ist als eine Einzelmission Teil der Hauptmission. Jeder Spielabschnitt (Jagd auf den ,Schwarze Dahlie'-Serienmörder, ${ }^{279}$ Diebstahl von Morphium von einem Schiff der US-Armee, Brandstiftungsserie etc.) gehört, und spätestens in der Retrospektive wird dem Spieler dies bewusst, zu dem Muster, das Erzähl- und Queststruktur leitet - Phelps verzweifelter (und letztlich wohl erfolgloser) Kampf gegen die Korruption. Diese hat die Wirtschaft und alle öffentlichen Stellen bis in die höchsten Führungsebenen hinein durchdrungen, Los Angeles fungiert somit, gemäß den Konventionen des Detektivnarrativs, als Metapher der (moralisch) verkommenen Metropole. ${ }^{280}$ Die doppelte Verbindung zwischen Quest- und Erzählstruktur in L.A. Noire wird auf der Makro- wie auch auf der Mikroebene durch die Korrespondenz der Handlungsmuster gewährleistet, die zwischen Detektivnarrativ und dem Action-Adventure bzw. den für dieses Genre typischen Interaktiven besteht und sich, grob gesagt, in dem Erkunden un d Lösen von Enigmatischem manifestiert. In Kapitel 4 wird genauer darauf eingegangen, wie korrespondierende Handlungsmuster im Rahmen eines interaktiv-narrativen Strukturdesigns digitaler Spiele eingesetzt werden können.

Damit eine interaktiv-narrative Spielstruktur entstehen kann, bedarf es polyvalenter Avatare, die sowohl Teil der Erzähl- als auch der Queststruktur sein können sowie sie auch

\footnotetext{
278 ,Sanktion“ wird im Folgenden nicht als Synonym zu Bestrafung etc. und damit negativ verstanden, sondern prinzipiell neutral. Im Anschluss an die Evaluation des Spielergebnisses sanktioniert das Spielsystem entweder positiv oder negativ, d.h. es kann sowohl ,bestrafen' als auch ,belohnen'. In diesem Kontext meint Sanktion dann den abschließenden bestätigenden Akt, der vom Spielsystem als Autorität ausgeht.

${ }^{279}$ Vgl. dazu exemplarisch ein Let's Play von OFFENSIVE JAKE https://www.youtube.com/watch?v=WUh-5JSZDA (30.06.2018). Als ,Schwarze Dahlie‘ ging die US-Amerikanerin Elizabeth Short in die Geschichte ein, welche im Januar 1947 in Los Angeles brutal verstümmelt und ermordet wurde. Der bis heute ungelöste Mordfall inspirierte neben L.A. Noire auch weitere Medien der Populärkultur, was sich bspw. in dem Film The Black Dahlia (2006) niederschlägt.

${ }^{280}$ Diese Lesart wird durch die Machart des Spiels unterstrichen, das von seiner Motivik und seinen filmsprachlichen Erzählverfahren her eine Hommage an den ,Film Noir` darstellt.
} 
imstande sein müssen, in Fällen starker hybrider Ausprägung interaktiv-narrativ verwendet werden zu können. Zudem ist dazu eine polyvalente Spielwelt notwendig, da ohne diese weder ein interaktiv-narratives Spielstruktur- noch Figurendesign möglich ist. Man kann festhalten, dass die interaktiv-narrativen Polyvalenzen die Interaktivität-Narrativität designerisch erst ermöglichen, dabei darf aber nicht vergessen werden, dass sie sich zudem gegenseitig bedingen, nicht unabhängig voneinander wirken, sondern nur zusammen.

\subsubsection{Die Realisierungsebene}

Mit der Interaktion-Narration wechselt das Kontinuumsmodell von der Produzenten- auf die Rezipientenseite. Bei der Interaktion-Narration sind nicht die Vorgaben des Designers von primärem Interesse, sondern das, was Spieler mit diesen Angeboten des Designers konkret im Spielprozess machen, wenn sie das Interaktiv-Narrativ in der Interaktion-Narration realisieren. Damit wechselt aber zugleich auch die Selektionsinstanz. Bei der Erstellung des Interaktiv-Narrativs wählt der Designer interaktiv-narrative Elemente aus, gestaltet hierdurch das Interaktiv-Narrativ, indem er die potenziellen Möglichkeiten der Interaktivität-Narrativität im Zuge einer Konkretisierung erster Ordnung nutzt. Somit ist der Designer die Selektionsinstanz der Konkretisierung der ersten Ordnung. Das Interaktiv-Narrativ ist zwar im Vergleich zur Interaktivität-Narrativität konkret, da es die interaktiv-narrativen Möglichkeiten in tatsächliche Nutzungsangebote überführt, allerdings ist das Interaktiv-Narrativ gegenüber der Interaktion-Narration immer noch potenziell, da es eine Vielzahl an InteraktionNarrationen bieten soll. ${ }^{281}$ Die Auswahl an angebotenen Elementen findet durch die Spieler statt, weshalb die Selektionsinstanz der Konkretisierung zweiter Ordnung die Spieler sind.

Die Frage nach der Selektionsinstanz ist deshalb so wichtig, da sie die Aufmerksamkeit auf den jeweiligen dominierenden Akteur lenkt und hiermit auch Betrachtungen des Übergangs nicht nur zwischen den Ebenen, sondern auch zwischen den Handelnden ermöglicht. Im Kontext der Selektionsinstanz nimmt, neben den beiden menschlichen Akteuren, das Programm eine gesonderte Rolle ein, da es zwar vom Designer angelegt wird und somit eindeutig ein Bestandteil und Produkt des Interaktiv-Narrativs ist, es zugleich aber ebenso über selektive Kompetenzen verfügt und diese auch wahrnimmt, wenn das Programm dem

\footnotetext{
${ }^{281}$ Aus der Polyvalenz der im Designprozess funktionalisierten Entitäten folgt eine Polysemie. Polysem in dem Sinne, dass allen konkret realisierten Interaktion-Narrationen zu einem digitalen Spiel zwar ein gemeinsamer Ursprung (besagtes Spiel) zugrunde liegt, dieses aber sehr unterschiedlich interpretiert und umgesetzt werden kann, sodass viele verschiedene Spieldurchläufe (v.a. bei digitalen Spielen mit Open-World-Prinzip) möglich sind. Polysemie bedeutet aber auch, dass einzelne Spieldurchläufe von den Spielweisen her von unterschiedlichen Spielern unterschiedlich interpretiert werden können. Hieraus folgt die weiter unten angebotene Typologie von interaktiv-narrativen Spielertypen.
} 
Spieler Vorgaben macht oder allgemein den operativen Betrieb ausführt. Das bedeutet einerseits, dass der Spieler als Selektionsinstanz der Konkretisierung zweiter Ordnung durch das System eingeschränkt wird, es bedeutet aber auch, dass der Einflussnahme des Systems in der Interaktion-Narration künftig eine größere Bedeutung beigemessen werden sollte und dies nicht nur in informatischen Kontexten von der HCI bis zum Interfacedesign, sondern auch in den diversen Ansätzen der Kultur- und Geisteswissenschaften, was freilich mit einer gesteigerten Bedeutung der Digital Humanities einhergeht. Ein Aspekt, die Selektionskompetenz im Kontext der Interaktion-Narration betreffend, soll kurz angesprochen werden, auch wenn die Arbeit im analytischen Teil nicht primär auf die technologischen Belange interaktiv-narrativer digitaler Spiele eingehen wird.

Wie die selektiven Kompetenzen auf der Realisierungsebene interaktiv-narrativer digitaler Spiele zwischen Mensch und Maschine aufgeteilt sind, zeigt schon der Übergang zwischen Nutzer-System-Interaktion und der medialen Narration. Im Zuge der medialen Narration wählt das System Elemente aus, die im Interaktiv-Narrativ angelegt sind und präsentiert diese. Das System ist in diesem Fall aktiv und der Spieler eher passiv (abhängig von den eingesetzten Formen medialer Narration). Die Interaktion zwischen Nutzer und System zeichnet sich jedoch dadurch aus, dass ersterer Elemente selbst auswählt und das System diese Handlung im Kontext des Dialogbetriebs umsetzt, indem es die Handlung des Nutzers auswertet. Das bedeutet, dass interaktiv-narrative digitale Spiele wie Uncharted bspw. während der Interaktion-Narration zwischen der Präsentation von Ausgewähltem (mediale Narration) und dem eigenständigen Auswählen des Spielers (Interaktion) oszillieren. Dies verdeutlicht, wie sich die Hybridität interaktiv-narrativer digitaler Spiele in der Prozeduralität des Spiels niederschlägt. (vgl. dazu BoGOST 2010)

Interaktiv-Narrative bieten zwar verschiedene Möglichkeiten der Umsetzung in der Interaktion-Narration, dabei sollte aber keineswegs davon ausgegangen werden, dass sich diese Interaktion-Narrationen verschiedener Spieler fundamental voneinander unterscheiden. Einzelne personale Narrationen können zwar erheblich voneinander abweichen, jedoch sollte man bedenken, dass dies dann schon oft nicht mehr gegeben ist, sobald die personale Narration die gesamte Spieldauer umfassen soll. In solchen Fällen greifen mediale und personale Narration i.d.R. ineinander, was aber zugleich bedeutet, dass sich die personale Narration am Narrativ orientieren muss, das der medialen Narration zugrunde liegt, sodass das ,emergente ${ }^{6}$ Narrativ der personalen Narration mit dem ,eingebetteten' Narrativ der medialen Narration korrespondieren muss. Durch diese Annäherung der personalen an die 
mediale Narration reduziert sich die Vielzahl und Vielfalt der personalen Narrationen erheblich und in der Folge sinkt auch die Diversität der Interaktion-Narrationen. Zudem muss man bedenken, dass personale Narrationen in interaktiv-narrativen digitalen Spielen, die oft mehr als zehn Stunden Spieldauer haben, selbst wenn man nur strikt der Hauptmission folgt, i.d.R. temporär begrenzt sind. Hieraus ergibt sich, dass interaktiv-narrative digitale Spiele oft mehrere personale Narrationen ein und desselben Spielers hervorrufen, sodass zwar sehr viele verschiedene Interaktion-Narrationen möglich sind, aber dennoch eine bestimmte Grundstruktur immer zu erkennen ist.

Betrachtet man Let's Plays ${ }^{282}$ eines beliebigen interaktiv-narrativen digitalen Spiels, die (als Walkthrough, Speedrun etc.) das Spielerlebnis eines Spielers über die (nahezu) komplette Spieldauer dokumentieren, so fällt auf, dass sich diese verschiedenen Interaktion-Narrationen zwar partiell und temporär sehr voneinander abheben (können), dass sie aber durch eine Tatsache immer verbunden bleiben, die auf einer Prämisse beruht, die nie hinterfragt wird. Ein Walkthrough (als Text, als Video etc.) dokumentiert immer den gesamten Spielverlauf. Was diese Interaktion-Narrationen eint, ist, dass sie alle das ,Durchspielen“ des jeweiligen Spiels bezeugen. Dabei ist es unerheblich, ob es sich um ein interaktiv-narratives digitales Spiel handelt, das linear oder non-linear aufgebaut ist. Nicht die Struktur des Spiels ist entscheidend, sondern die Spielart, der Ludus. Der Ludus ist, wenn man so will, die intendierte Spielart eines interaktiv-narrativen digitalen Spiels, die im Interaktiv-Narrativ bzw. in der interaktiv-narrativen Spielstruktur angelegt ist und die sicherstellt, dass das Spiel trotz seiner Multioptionalität seine Kohärenz nicht verliert. Die Vielfalt der InteraktionNarrationen beruht also auf dem Ludus als intendierter Spielart, der Konsistenz verleiht, und den Paidia-Spielen, die es den Spielern ermöglichen, das Spiel in ihrem Sinne zu personalisieren und sich somit auf ihre Art und Weise zu eigen zu machen, ohne Gefahr zu laufen, die einheitliche Grundform einzubüßen. Bei der Analyse von Interaktion-Narrationen muss es also einerseits darum gehen, den Ludus offenzulegen, aber auch zu zeigen, wie Paidia-Spiele an diese anknüpfen, welche Verhältnisse sich hieraus ergeben. Hierbei ist es von ganz entscheidendem Interesse, näher zu betrachten, welche Verbindung zwischen dem

\footnotetext{
${ }^{282}$ Zum Let's Play vgl. den von Judith AcKermann (2017) herausgegebenen Sammelband Phänomen Let's Play-Video. Interessant ist bei Let's Plays die Vielseitigkeit der Rezeptionsanlässe. Neben der Unterhaltungsfunktion helfen Let's Plays den Rezipienten in den (passiven) Rezeptionsgenuss von digitalen Spielen zu kommen, die sie aufgrund fehlender technischer Hardware nicht spielen können oder sie dienen der Informationsbeschaffung. Vgl. dazu die explorativ-testende und quantitativ ausgerichtete Studie von BiERMANN/BeCKER (2017). Zu Rezeption und Nutzung von Let's Plays vgl. auch die qualitative Arbeit von WIMMER (2017).
} 
Ludus und den narrativen Rezeptionsangeboten besteht und wie dieses Zusammenspiel die personalen Narrationen der Spieler steuern bzw. induzieren soll. ${ }^{283}$

Die Interaktion-Narration ist immer, bedingt durch die Interaktivität des Mediums, eine zirkuläre Bewegung zwischen Spieler und System. Die Leitfrage, unter der sich spezifischere Fragestellungen fassen lassen, richtet sich demnach primär darauf, wie Spieler das InteraktivNarrativ in der Interaktion-Narration umsetzen. Unabhängig von den Vorgaben des InteraktivNarrativs bzw. dem Designparadigma kann man, äquivalent zu den anderen beiden Ebenen, drei Spielertypen ausmachen - den interaktiven, den interaktiv-narrativen und den narrativen. Die folgenden Ausführungen umreißen Charakteristika des jeweiligen Typus kurz, wobei zu betonen ist, dass diese anhand eines ,Idealtypus ‘ dargestellt werden, der so nicht immer zu finden ist, da auch innerhalb eines Spielertyps zum einen erhebliche graduelle Unterschiede möglich sind, da ein narrativer Spieler seine Interaktion-Narration narrationsoffen oder narrationsabgewandt umsetzen kann, wodurch sich gravierende Differenzen innerhalb eines Spielertyps ergeben. Zum anderen ist es denkbar, besonders bei digitalen Spielen mit sehr hoher Genrehybridität, dass ein und derselbe Spieler u.U. in seiner Interaktion-Narration eines

\footnotetext{
${ }^{283}$ Mit Blick auf die zunehmende Präsenz von personalen Narrationen im Kontext Neuer Medien stellt sich die Frage, ob sich diese letztlich bloß aufgrund der neuartigen medialen Potenziale digitaler Medien erklären lässt, personale Narrationen spielerisch erzeugen zu können, oder ob die Hochkonjunktur dieser Narrationsart nicht auch mit dem veränderten Nutzungsverhalten der Menschen in Verbindung steht. Sind personale Narrationen nicht auch Ausdruck von Mediennutzern, deren digitale Mediennutzung zunehmend von Personalisierbarkeit bestimmt wird, die es gewohnt sind, dass sich die dargebotenen Medieninhalte ihren individuellen Präferenzen und Bedürfnissen anpassen? Erscheinen personale Narrationen vielen Mediennutzern deshalb so verlockend, weil sie im Gegensatz zu medialen Narrationen weitaus dynamischer sind, weil es für sie konstitutiv ist, sich nach den Wünschen des narrativierenden Subjekts zu richten? Ist der ,Bedeutungsverlust des Narrativs', der narrativen Struktur in medialen Narrationen, wie ihn Moritz Baßler in den letzten Jahren postuliert, nicht auch ein Beleg für den Wunsch des Rezipienten, seine eigenen Plots zu erzeugen? (vgl. BAßLER 2014) Treten narrative Strukturen gegenüber der Welthaftigkeit und den figurativen Aspekten immer mehr zurück, weil es dem Rezipienten dann einfacher möglich ist, anhand eines eigentlich fixierten medial narrativen Angebots seine eigene personale Narration zu erzeugen? Derartigen Fragestellungen nachzugehen, wird in Zukunft ein interssantes Unterfangen der Mediennutzungsforschung sein, v.a. dann, wenn sie den Veränderungen unserer narrativen Kultur durch die Nutzung digitaler Medien und deren generellen Effekten auf die Mediennutzung nachgehen will. Dass dies fruchtbar sein kann bzw. notwendig ist, demonstriert die Forschung zum ,intimate computing', das einst von Alan Kay und seinem Umfeld als gegenkulturelles medienpädagogisches Konzept erdacht wurde, von der Industrie aber seit den 1990er Jahren zunehmend invertiert wird: „Mit dem Design der Produkte sollen Affekte und Emotionen angesprochen werden, AnwenderInnen werden als Konsumenten imaginiert, denen eher ein bestimmtes, hochpersonalisiertes Angebot unterbreitet wird, als dass sie selber eine aktive Medienkompetenz ausbilden müssten.“ KAERLEIN (2016), 39. Insofern legt das Agieren diverser alltagsbestimmender IT-Unternehmen im Kontext der HCI und anderer Mediennutzungskonzepte der (narratologischen) Medienwissenschaft eine gesteigerte Aufmerksamkeit für die individuellen Präferenzen des Mediennutzers nahe. Zumal sich dieser Wunsch der Rezipienten nach Personalisierbarkeit und Individualität vor dem Hintergrund, das Smartphone und Smartwatch als Nahkörpertechnologien immer populärer werden, noch verstärken dürfte. Vgl. dazu ausführlich KAERLEIN (2018).
} 
bestimmten Spiels, abhängig vom Spielabschnitt und vom jeweils dominanten Spielprinzip, ${ }^{284}$ zwischen mehreren Spielertypen changiert.

Die folgende Typologie ${ }^{285}$ beruht, das sei hier ausdrücklich betont, nicht auf konkreten empirischen Befunden, sondern ist das Resultat von Beobachtungen, die nicht Teil eines systematischen mediensoziologischen Forschungssettings sind. Freilich sind diese aber gerade erforderlich, um die Tragfähigkeit dieser Typologie zu überprüfen. Stichprobenartige Tests legen aber die Vermutung nahe, dass die Unterteilung in die drei dargebotenen Spielertypen interaktiv-narrativer digitaler Spiele plausibel und heuristisch lohnenswert ist. Dabei haben sich interviewgestützte Erhebungsverfahren oder mediensoziologische Auswertungen von Let's Plays ${ }^{286}$ auf Youtube oder Walkthroughs in Fanforen als sehr vielversprechende Methoden erwiesen. Darüber hinaus scheinen netnografische Analysen, (vgl. dazu KozINETS 2010) die bspw. Threads in Fanforen oder Blogeinträge in den Fokus rücken, ebenso belastbare Ergebnisse liefern zu können wie die Anfertigung von Spielbiografien. (vgl. zur Spielbiografie auch MÄYRÄ 2010, 11 f.) Die Spielbiografie sollte mit einem Brainstorming beginnen, bei dem die Probanden alle digitalen Spieltitel (jeden Titel auf einen Zettel) aufschreiben sollen, die sie gespielt haben. Anschließend werden sie gebeten, die Titel in drei Kategorien einzuordnen: 1) Spiele, in die sehr viel Spielzeit investiert wurde, 2) Spiele, die gelegentlich gespielt wurden und 3) Spiele, die kaum gespielt wurden. Innerhalb dieser drei Gruppen werden die Titel dann nach Genres sortiert, wobei Genrehybriden zwischen den betreffenden Genres eingeordnet werden (wenn möglich). Somit ergeben sich dann bestimmte Genreakkumulationen, aus denen man die Präferenzen des Probanden ableiten kann. Anhand einer Auswertung dieser Akkumulationen unter besonderer Berücksichtigung der

\footnotetext{
${ }^{284}$ In diesem Kontext gilt es dann mittels mediensoziologischer Studien zu ermitteln, ob sich die Spielertypen durch eine Präferenz zu bestimmten dominanten Spielprinzipien oder Spielmechaniken auszeichnen. Spielt der interaktive Spielertyp gern Shooter und bevorzugt der narrative Spielertyp hauptsächlich digitale Spiele mit QTEs? Diese Fragen können aufgrund der Ausrichtung der vorliegenden Arbeit an dieser Stelle leider nicht beantwortet werden.

285 BATEMAN et al. (2011) bieten einen sehr guten Überblick über verschiedene Studien und Typologisierungsversuche von Spielertypen, kaprizieren sich dabei aber sehr stark auf Aspekte, die eher zum interaktiven Spielertyp gehören.

${ }^{286}$ Jochen Venus merkt zu den erkenntnistheoretischen Möglichkeiten von Let's Plays im Kontext der digitalen Spielkultur an: „Der epistemische Beitrag, den Let's Play-Videos zum Computerspielwissen leisten, lässt sich so zusammenfassen: Let's Play-Videos betonen und differenzieren das Wissen über die subjektiven Zustände, die sich während des Computerspielens ergeben. Let's Play-Videos protokollieren vor allem das subjektive Erleben der spielenden Person, machen dieses Erleben audiovisuell explizit und ermöglichen dadurch seine explizite Reflexion. Let's Play-Videos erschließen einen Gegenstandsbereich des Computerspielwissens, der in anderen Ausdrucksformen des Computerspielwissens tendenziell unartikuliert bleibt: die phänomenale Präsenz des Computerspielwissens im Bewusstsein der spielenden Person.“ Venus (2017), 20.
} 
Interaktivität-Narrativität der häufig bis kaum frequentierten Genres kann man die Probanden dann einem der drei Spielertypen zuordnen. ${ }^{287}$

Unabhängig von den empirischen Erhebungsverfahren existieren aber bereits Spielertypologien, die ähnlich verfahren wie bspw. die Unterscheidung zwischen ,Gamist` und ,Narrativist" (nicht zu verwechseln mit Narrativisten im Sinne des Narrativismus). „) Gamist $<$ is a term of RPG lexicon, referring to the player attitude and style of action which focuses on the game challenges and the optimal strategies on how to overcome them. This is opposed with the $>$ dramatist $<$ (or $>$ narrativist $<$ ) and $>$ simulationist $<$ attitudes or player styles and types“. (ebd., 82) Der Gamist kommt dabei dem besonders nahe, was im Folgenden unter dem interaktiven Spielertyp verstanden wird, der Narrativist entspricht im Wesentlichen dem, was ich unter dem Begriff narrativer Spielertyp fasse. Interessant ist diese Unterscheidung, da sie am RPG und damit an einem Genre mit stark ausgeprägter Interaktivität-Narrativität entwickelt wurde, ohne aber letztlich einen hybriden Spielertyp zu beschreiben. Diese Lücke möchte die anschließende Typologie zu schließen versuchen.

\subsubsection{Der interaktive Spielertyp}

Der interaktive Spielertyp bevorzugt tendenziell interaktiv-narrative digitale Spiele, deren Interaktivität deutlich stärker ausgeprägt ist als deren Narrativität, die einem interaktiven Designparadigma folgen. Im Allgemeinen wird man an seiner digitalen Spielbiografie feststellen können, dass er eher digitale Spiele mit wenigen narrativen Elementen bevorzugt. Hierdurch ergibt sich zumeist eine Präferenz für interaktive digitale Spielgenres, wie man sie aus der Mesoperspektive auf der Attributebene verorten kann (z.B. Jump'n'Run, Beat'em up etc.). Interaktionen sind für diesen Spielertyp wichtiger als mediale oder personale Narrationen. Sein Hauptaugenmerk liegt dementsprechend auf Spielmechaniken, Spielregeln und Spielrhetoriken, also auf dem Interaktiv. Wenn man untersucht, welche Vorgaben des Interaktiv-Narrativs die Spieler umsetzen, so gilt dem interaktiven Spielertyp der Avatar eher als Spielfigur, die Spielwelt eher als Spielraum und die Spielstruktur eher als Queststruktur. (vgl. 2.5.2.3.-5) Anders gesagt: Der interaktive Spielertyp interpretiert interaktiv-narrativ polyvalente Elemente größtenteils interaktiv.

Dieser Spielertyp lässt sich bspw. daran erkennen, dass er das Spiel stets als System wahrzunehmen und zu seinem Vorteil zu manipulieren versucht. Des Weiteren, und damit

${ }^{287}$ Idealerweise, um mögliche Störfaktoren zu vermeiden, können derartige Erhebungen softwaregestützt durchgeführt werden, was durch die grafischen Ausgabemöglichkeiten der diversen Programme einen zusätzlichen Vorteil bietet. 
zusammenhängend, lässt sich beobachten, dass ihm bspw. die Funktionalisierung eines Avatars als narrativem Charakter eher fern liegt. Ein Beispiel: Ein interaktiver Spielertyp spielt ein interaktiv-narratives digitales Spiel, bei dem er mehrere Charaktere spielen muss, die aber nicht unbedingt alle ,überleben' müssen, damit er das Spiel gewinnt, wie man es des Häufigeren in digitalen Spielen vorfindet, die dem Interaktiv-Narrativ der Zombieapokalypse verpflichtet sind. ${ }^{288}$ So kann es zu Situationen kommen, in denen es taktisch Sinn ergibt, eine Spielfigur (!) zu opfern, hierdurch aber einen Vorteil zu erhalten, durch welchen das Spiel einfacher oder überhaupt zu gewinnen ist. Wie ein Schachspieler eine Schachfigur opfern würde, um die Schachpartie zu gewinnen, opfert auch der interaktive Spielertyp seine Spielfigur, um zu gewinnen. Dies macht er aber nur, weil er den Avatar kaum als narrativen Charakter wahrnimmt, ihm somit mögliche Auswirkungen auf die Handlung relativ gleichgültig sind. Durch die primär interaktive Interpretation des Interaktiv-Narrativs in der Interaktion-Narration durch diesen Spielertyp haben das Narrativ wie auch die mediale Narration wenig Einfluss auf ihn, sodass auch keine zusätzliche emotionale Aufladung der Spielfigur zustande kommt, die den Spieler u.U. davon abhalten würde, seine Spielfigur wie einen Bauern zu opfern.

Dass mediale Narrationen für diesen Spielertyp oft eher sekundär sind, kann man auch daran erkennen, dass dieser Spielertyp z.T. Cutscenes, wegklickt ${ }^{\star}$, eine der bedeutendsten Instanzen narrativer Vermittlung in interaktiv-narrativen digitalen Spielen einfach ausschaltet, wenn sie seinem interaktiven Erleben des Spiels im Wege stehen. Des Weiteren tendiert dieser Spielertyp eher seltener dazu, seine Interaktion-Narration (holistisch oder partiell) personal zu narrativieren. In Bezug auf das Spielverhalten dieses Spielertyps im Allgemeinen lässt sich konstatieren, dass er dazu neigt, auch andere Spiele (digital oder nicht) zu spielen, deren Ludizität maßgeblich durch ihre Interaktivität bestimmt wird.

\subsubsection{Der narrative Spielertyp}

Das Gegenteil des interaktiven Spielertyps ist der narrative. Er interpretiert das InteraktivNarrativ in der Regel narrativ und bevorzugt dementsprechend interaktiv-narrative digitale Spiele mit hohen narrativen Anteilen, wie man sie bei narrativen Spielgenres wie dem Interaktiven Film findet. Er realisiert den Avatar vornehmlich als narrativen Charakter, die Spielwelt als Diegese und fokussiert sich primär auf die Erzählstruktur des interaktiv-

\footnotetext{
${ }^{288}$ Ein weiteres gutes Beispiel für einen derartigen Versuch ist This War of Mine. Dieses Survival Game ist in einem Kriegsszenario angesiedelt, in dem es gilt, mit der eigenen Gruppe an Avataren das Kriegsende zu erleben.
} 
narrativen digitalen Spiels. Neben der medialen Narration neigt dieser Spielertyp zu personalen Narrationen, die nahezu jedes Paidia-Spiel bestimmen (können). Oft kann man, zusammenhängend mit der Affinität für bestimmte digitale Spielgenres, bei diesem Spielertyp beobachten, dass er ein bestimmtes oder eine kleine Gruppe von ähnlichen Narrativen präferiert. ${ }^{289}$ Dies zeigt sich auch an seinem Konsum von (populärkulturellen) narrativen Medien im Gesamten. Vor diesem Hintergrund lässt sich auch erklären, warum Genres wie Fantasy, Science Fiction oder Mystery nicht nur in der Medienindustrie so stark vernetzt sind (bspw. im Marketing), sondern auch, warum sie in der Fankultur so oft gemeinsam auftreten. ${ }^{290}$ Einen ersten, aber dennoch umfassenden Eindruck hiervon kann man bereits gewinnen, wenn man sich auf digitale Feldforschung im Internet begibt und hier v.a. einschlägige Foren oder Wikis untersucht. (vgl. dazu KozINETS 2010) Jenseits der Interaktion-Narration kann sich die Tendenz des narrativen Spielertyps zur personalen Narration nämlich auch in bestimmten Online-Aktivitäten manifestieren, wenn das Bedürfnis zur narrativen Ausdifferenzierung des digitalen Spiels auch über dessen eigentliche Rezeption wie auch die anderen narrativen Medien der transmedialen Welt (wenn vorhanden) des betreffenden Spiels hinausgeht. Dieser Spielertyp ist grundsätzlich sehr interessiert daran, sein narratives Erleben zu intensivieren und (v.a. im Rahmen einer transmedialen Welt, zu der die meisten AAA-Spieltitel gehören oder welche sich um sie herum aufbaut) ${ }^{291}$ durch die Hinzunahme mehrerer medialer Kanäle auszuweiten. So sucht er in Foren oder auf SharePlattformen nach narrativem Content, der ihm bisher entgangen ist oder befasst sich intensiv mit Fantheorien zu seiner favorisierten narrativen Welt. ${ }^{292}$ Es kann aber auch sein, dass dieser

\footnotetext{
${ }^{289}$ Zuweilen lässt sich auch feststellen, dass diese Spieler immer wieder interaktiv-narrative digitale Spiele eines bestimmten Entwicklers konsumieren, dessen Spiele designparadigmatisch den eigenen Präferenzen der Spieler entsprechen. Hierbei fällt v.a. eine Fixierung auf Telltale auf, was aber auch daran liegen mag, dass Telltale in diesem Marktsegment das vielleicht breiteste Produktportfolio hat.

${ }^{290}$ So kann man auf Fan-Conventions oder Messen i.d.R. hauptsächlich Cosplayer beobachten, die Figuren aus Franchise cosplayen, die einem der drei Genres zuzuordnen sind.

${ }^{291}$ So ist Telltales Game of Thrones-Spiel ein Exempel dafür, wie eine transmediale Welt in einem Medium entsteht (in diesem Fall George R.R. Martins Romanreihe A Song of Ice and Fire (1996 ff.)), über ein anderes popularisiert wird (die Fernsehserie Game of Thrones (2011 ff.)), um sich schließlich auch ins digitale Spiel auszudehnen. Dabei ist zu beobachten, ausgehend von der Tatsache, dass das ,Urmedium ' einer transmedialen Welt in der gegenwärtigen Medienkultur i.d.R. ein narratives ist, dass die meisten dieser Spiele, die als Expansion oder Adaption Teil einer transmedialen Welt sind, in narrativen digitalen Spielgenres umgesetzt werden. Ein gegenläufiges Beispiel zum Game of Thrones-Spiel ist u.a. Assassin's Creed, das 2016 mit Michael Fassbender, Jeremy Irons und Marion Cotillard seine erste Verfilmung erhielt und hierdurch einen bedeutenden Ausbau der transmedialen Welt vornahm, die um Assassin's Creed herum entstanden ist. Zu transmedialen Welten im Allgemeinen vgl. GABRIEL et al. (2015).

${ }^{292}$ Eine der meist diskutiertesten Fantheorien der vergangenen Jahre, auch wenn sie nicht aus einer transmedialen Welt stammt, deren Urmedium ein digitales Spiel ist, betrifft die Abstammung Jon Snows aus der Serie Game of Thrones. Unter Eingeweihten wurde sie i.d.R. unter der Abkürzung „R+L=J“ diskutiert. Vgl. dazu exemplarisch das folgende Video von EMERGENCY AwESOME https://www.youtube.com/watch?v=OOcD_MzVZw (30.06.2018). Am Ende der sechsten Staffel der Fernsehserie bestätigt sich diese Annahme als korrekt.
} 
Spielertyp seine Rezipientenrolle verlässt und sich zu einem sog. ,prosumer' entwickelt. Dies ist i.d.R. dann der Fall, wenn dem Rezipienten das vorhandene Angebot nicht ausreicht bzw. er selbst am Ausbau der transmedialen Narration teilhaben möchte und sich deshalb selbst als Produzent von neuem Content betätigt, indem er bspw. Fan-Fiction anfertigt. (vgl. JAMISON 2013)

Aber auch Feldforschungen im analogen Raum scheinen vielversprechend, um die Zusammenhänge zwischen Fankulturen zu analysieren, die auf ähnlichen Narrativen basieren. (vgl. dazu JENKINS 2006) Interessante Untersuchungsorte sind diesbezüglich Messen oder Conventions, die in den letzten Jahren zunehmend unter dem Einfluss des ,Cosplays ‘ stehen, das längst nicht mehr bloß auf die japanische Populärkultur beschränkt ist, sondern zunehmend auch in die westliche Populärkultur ausgreift. (vgl. dazu HEINRICH 2013) Grundsätzlich ist im Cosplay eine bedeutende Form des Community-Buildings transmedialer Welten zu sehen, das v.a. Fans mit Vorliebe für Narrative und mediale Narrationen anzuziehen scheint. Abgesehen davon kann eine vergleichende Betrachtung des Mediennutzungsverhaltens auch Rückschlüsse auf den narrativen Spielertyp erlauben, v.a. wenn sich hieran eine verdichtete Rezeption von narrativen Medien ergibt, die Teil der transmedialen Welt der gespielten digitalen Spiele sind. Dass medienkomparatistische Erhebungsverfahren von Vorteil sein können, um den narrativen Spielertyp zu identifizieren und analysieren zu können, liegt daran, dass die Rezeption von narrativen Medien grundsätzlich einen sehr wesentlichen Aspekt der Mediennutzung dieses Spielertyps darstellt.

Man kann für den narrativen Spielertyp festhalten, dass er interaktiv-narrativ polyvalente Elemente größtenteils narrativ interpretiert. Dieser Spielertyp legt deshalb beim Spielen eines interaktiv-narrativen digitalen Spiels einen besonderen Wert auf Cutscenes, die sich in Extremfällen bis auf Spielfilmlänge ausweiten können. Dieser Spielertyp ist häufig in der japanischen digitalen Spielkultur zu finden. Dies spiegelt bereits der japanische digitale Spielmarkt wider, ${ }^{293}$ da die japanische digitale Spielbranche auf die Präferenzen des narrativen Spielertyps reagiert und dementsprechende Genres bzw. Varianten von Genres geschaffen hat, die sich nach dessen Vorlieben richten. ${ }^{294}$ Digitale Spiele wie Asura's Wrath

\footnotetext{
${ }^{293}$ Bei der Bestimmung von Spielertypen ist es überaus interessant, wie sich an dieser Stelle bereits andeutet, regionale, kulturelle oder soziale Faktoren in empirische Erhebungsverfahren miteinzubinden, um mögliche Verbindungen offenzulegen. Dieses Unterfangen kann aber im Rahmen dieser Arbeit ebenfalls leider nicht besorgt werden.

${ }^{294}$ Eine Gegenbewegung dazu stellen in den vergangenen Jahren zunehmend die digitalen Spiele von From Software dar, die mit der Souls-Reihe oder Bloodborne einen interaktiven Spielertyp ansprechen, der digitale Spiele mit extremem Schwierigkeitsgrad bevorzugt.
} 
oder japanische RPGs (JRPG) wie Final Fantasy zeugen davon. Diese Spiele betonen besonders die narrativen Figurenkonstellationen und versuchen hierdurch narrativ motivierte Emotionalisierungen zu evozieren. ${ }^{295} \mathrm{Zudem}$, und dies untermauert den Stellenwert, den Narrativität in diesen Genres einnimmt, werden solche digitalen Spiele besonders oft, wenn sie zu transmedialen Welten werden, in jenen medialen Kanälen adaptiert oder expandieren in diese, die genuin narrativ sind wie Mangas, Animes oder Filme. Neben Reihen wie Final Fantasy gilt dies u.a. auch für Persona oder Metal Gear (1987 ff.). Hieran wird aber auch evident, warum es sich anbietet, diesen Spielertyp unter dem Aspekt eines transmedialen Mediennutzungsverhaltens zu analysieren. Es liegt die Vermutung nahe, und dies bedarf einer Verifizierung mittels medienkomparatistischer Nutzungsstudien, dass dieser Typus (narrativ)interaktiv-narrative digitale Spiele nicht unbedingt aufgrund ihrer Ludizität spielt, sondern aufgrund ihrer Narrative, ihrer Themen, Inhalte und Motive oder für ihn interessanter digitaltransmedialer Erzähltechniken.

\subsubsection{Der interaktiv-narrative Spielertyp}

Dieser Spielertyp ist am schwierigsten zu identifizieren, da er Eigenschaften der beiden anderen Spielertypen aufgrund der Tatsache in sich vereint, dass er nach einem Maximum an Interaktivität-Narrativität sucht und auch bestrebt ist, diese interaktiv-narrativ zu realisieren. Im Hinblick auf Figuren, Spielwelt und Strukturen interessieren ihn gerade deren Polyvalenz und die sich hieraus ergebende Hybridität. Am einfachsten kann man ihn diskursiv bestimmen, indem man seine Spielbiografie aus der Mesoperspektive der Attributebene betrachtet. Hierbei ist entscheidend, zu ermitteln, welche interaktiv-narrativen digitalen

\footnotetext{
${ }^{295}$ Wie gut diese Emotionalisierung gelingen kann, lässt sich an einem Beispiel aus Final Fantasy VII (1997) bzw. den Reaktionen der Fans hierauf illustrieren. In einer Sequenz tötet der Antagonist Sephiroth nämlich den NPC Aeris. Auf diversen Plattformen im Internet wird rasch ersichtlich, dass dieses Ereignis einer der emotionalsten Momente, zumindest für die vielen affizierten Fans der Reihe, der gesamten digitalen Spielgeschichte war. Vgl. dazu CHANDLER (2009), 14. Die Äußerungen über die ,Tat' Sephiroths sind sehr stark emotional bestimmt, was sich sprachlich und textuell niederschlägt. Ein wesentlicher Grund dafür, dass diese Sequenz bis heute so emotional von Fanseite aus bewertet wird, liegt in den Figurenkonzeptionen der beiden beteiligten NPCs und deren Position im konstellativen Gesamtbild. Aeris wird, gemäß dem mythologischen Narrativ, als unzweifelhaft, gute' Figur dargestellt, die sich um andere sorgt und auch unter Gefährdung ihres eigenen Lebens nicht davon abbringen lässt, sich Sephiroths Plänen entgegenzustellen. Sephiroth hingegen erscheint als das personifizierte Böse, das das Schicksal der gesamten Welt Gaia aufs Spiel setzt, um seine egoistischen Plänen skrupellos umzusetzen. Zusätzlich wird dieses Szenario noch dadurch emotional aufgeladen, dass Sephiroth die wehrlose Aeris hinterrücks ersticht, als diese betet bzw. einen Zauber bewirkt. In den letzten Jahren und mit zunehmendem Abstand zum Veröffentlichungsjahr des Spieles gestalten sich die Diskussionen über die Sequenz aber differenzierter, sodass sich Sephiroths ,Handlung' und der Fandiskurs hierüber mittlerweile neutraler und objektiver gestalten. Vgl. hierzu exemplarisch http://forums.qhimm.com/index.php?topic=10706.0 (30.06.2018). Andere Strömungen der Fankultur des Spiels invertieren das Verhältnis zwischen Aeris und Sephiroth und kreieren Fanfiction, in welcher es um Liebesbeziehungen zwischen Aeris und Sephiroth geht. Vgl. dazu exemplarisch https://www.fanfiction.net/community/Aeris-x-Sephiroth-Love/5966/ (30.06.2018).
} 
Spielgenres er bevorzugt. Häufig neigen Spieler dieses Typus bspw. dazu, Genres wie ActionAdventure oder RPG zu spielen, die per se stark interaktiv-narrativ ausgeprägt sind. Diese Spiele werden für ihn zunehmend interessanter, wenn sie auch noch einem interaktivnarrativen Designparadigma folgen. ${ }^{296}$

Ein Negativbeispiel, das die Präferenzen dieses Spielertyps gut verdeutlicht, ist Beyond: Two Souls, das - ebenso wie andere digitale Spiele von David Cage - von Spielern (ob professionelle Spielekritiker oder nicht) häufig als $\mathrm{zu}$,filmisch' eingestuft wird. (vgl. LETOURNEUR 2016) In diesem Fall bewerten Spieler die narrative Ausgestaltung des Spiels als zu hoch und damit negativ, da sie es für ein (interaktiv-narratives) Spiel für unangemessen halten. Interessant ist dies unter dem Aspekt, dass Beyond: Two Souls auch als ActionAdventure anzusehen ist, somit einem Genre zugerechnet werden kann, dessen InteraktivitätNarrativität eigentlich sehr stark hybrid ist. Jedoch, und das macht Beyond: Two Souls auch zu einem Interaktiven Film, folgt dieses Spiel einem (für ein Action-Adventure ungewöhnlich) narrativen Designparadigma. Jenes Designparadigma wird tendenziell von Spielern kritisch betrachtet, die dem interaktiven oder dem interaktiv-narrativen Spielertyp zu zuordnen sind. Für die Einordnung in den letzteren Typus spricht die Tatsache, dass interaktive Spielertypen eher seltener Action-Adventure spielen und wenn, dann in der Regel nur solche, die einem interaktivem Designparadigma folgen und sich hierdurch ihren ludischen Präferenzen annähern.

Was dieses Beispiel nochmals unterstreicht, ist, dass eine Einteilung in die drei Spielertypen mediensoziologisch nicht nur mit Einbezug konkreter Interaktion-Narrationen möglich wird, sondern dass darüber hinaus auch Spielertypenbestimmungen anhand des transmedialen Mediennutzungsverhaltens und von Fanaktivitäten im Internet und an vergleichbaren Orten, an denen sich die Community zeigt wie konstituiert, möglich sind. Konkret lassen sich die Spielertypen, abgesehen von einigen generelleren Merkmalen, aber nur in Analysen konkreter Interaktion-Narrationen (oder Äußerungen) bestimmen. Dennoch sollte man sich davor hüten, (wie oben bereits betont) die dargebotenen Spielertypen als absolut zu betrachten. Stattdessen scheint es ratsam, sie als Tendenz zu verstehen, d.h. dass ein Spieler primär einem Typ zugeordnet werden kann, was aber nicht bedeutet, dass sein

\footnotetext{
${ }^{296}$ Stichprobenartige Tests legen die Vermutung nahe, dass die Akkumulationen von Genrepräferenzen bei diesem Spielertyp nicht so stark bzw. eindeutig ausfallen wie bei den digitalen Spielbiografien der Spieler der beiden anderen Typen, auch wenn breit angelegte empirisch-quantitative Studien hierzu freilich noch ausstehen. So spielen Spieler des interaktiv-narrativen Typs tendenziell einerseits digitale Spiele vieler verschiedener Genres, wobei diese Genres andererseits aus allen drei Bereichen des interaktiv-narrativen Kontinuums stammen können.
} 
Mediennutzungsverhalten in Bezug auf digitale Spiele vollkommen homogen im Sinne der Spielertypologie sein muss.

Im Rahmen der stichprobenartigen Erhebungen ist bspw. ein Fall aufgetreten, der zur Vorsicht anhält. ${ }^{297}$ Besagter Proband ließ sich (anhand seiner Spielbiografie) primär dem narrativen Spielertyp zurechnen, da sich seine Mediennutzung digitaler Spiele hauptsächlich auf das Genre des Interaktiven Films bzw. von digitalen Spielen bezieht, die Elemente dieses Genres im Rahmen einer Genrehybridisierung stark integrieren. Interessanterweise ergab sich aber eine zweite Akkumulation im Bereich nicht-narrativer Mobile Games, welche für den narrativen Spielertyp eher untypisch ist. Diese Akkumulation lässt sich zwar teilweise dadurch erklären, dass die gespielten Mobile Games-Titel zu einer narrativen transmedialen Welt gehören, die das Mediennutzungsverhalten des Probanden bestimmt und seinen narrativen Präferenzen entspricht. Dies gilt aber nicht für alle digitalen Spiele dieser Akkumulation. Einerseits untermauert dieses Beispiel, dass die Spielertypen definitiv tendenziell verstanden werden sollten, andererseits eröffnet es aber zugleich den Weg für mediensoziologische Studien, die versuchen, die angedeuteten Unstimmigkeiten zu erklären, um möglicherweise Verbindungen aufzudecken, die bisher nicht offensichtlich sind. ${ }^{298}$

In diesem Zusammenhang kann es dann auch lohnenswert sein, Sandbox-Games ${ }^{299}$ wie GTA $V$ (2013) zu analysieren. Wie viele Sandbox-Games folgt GTA $V$ einem interaktiven Designparadigma, das sich im Figuren-, Welt- und Strukturdesign niederschlägt. Die mediale Narrativität von GTA $V$ ist eher schwach ausgeprägt, da narrative Cutscenes verhältnismäßig

\footnotetext{
${ }^{297}$ An dieser Stelle sollte kurz ausgeführt werden, warum die stichprobenartigen Erhebungen nicht als konkrete Belege angeführt werden. Ursächlich sind hierfür zwei Faktoren, die ich kurz darlegen möchte. Erstens entstanden diese Erhebungen als Testmethode, um zu eruieren, ob die aus allgemeinen Beobachtungen abgeleiteten typologischen Einordnungen stichhaltig sind. Dies bedeutet aber, dass sie nicht von Beginn an als empirischer Teil dieser Studie konzipiert wurden, sodass ihnen keine einheitliche Systematik der Erhebung zugrundeliegt. Die Auswahl der Erhehungsorte sowie der Probanden sind dementsprechend ebenso wenig einheitlich wie die gestellten Fragen und eingesetzten Erhebungsverfahren. Darüber hinaus gelten dieselben Probleme für die Dokumentation der so erhobenen Daten. Zweitens bedingt die Tatsache, dass eine derartige Erhebung nicht von Beginn an geplant war, auch forschungsethische Bedenken. Es lässt sich nicht in jedem Fall zweifelsfrei klären, gerade bei den Interviews, ob sich die Probanden darüber im Klaren waren, dass das Gesagte in meine Arbeit einfließen könnte. Diese beiden Gründe haben letztlich - trotz interessanter Einblicke - dazu geführt, dass die Ergebnisse dieser Erhebungen nicht unmittelbar in diese Arbeit eingeflossen sind.

${ }^{298}$ Darüber hinaus ist die Frage interessant, wie konstant Spielertypenzugehörigkeiten sind und unter welchen Bedingungen sie sich wandeln können. Einige Befragungen lassen nämlich den Schluss zu, dass sich der Spielertyp (aus einer historischen Perspektivierung heraus betrachtet) im Laufe der Zeit ändern kann. Sollten repräsentative Mediennutzungsstudien derartige Vermutungen untermauern können, so wäre es bspw. überaus interessant, zu ermitteln, welchen Einfluss soziale, kulturelle oder wirtschaftliche Faktoren in bestimmten Lebensabschnitten auf Spieler ausüben und sich in den angedeuteten Effekten niederschlagen.

${ }^{299}$ Unter Sandbox-Games versteht man digitale Spiele, die dem Spieler eine hohe individuelle Agency zuweisen und die von der Frequenz, Signifikanz und Bandbreite der Interaktionen her eine hohe Interaktivität aufweisen, wodurch sie gewissermaßen einen sehr großen Möglichkeitsraum kreieren.
} 
wenig Spielzeit einnehmen, der narrative Modus allgemein wenig profiliert ist und Figuren wie Welt kaum (außer in den Cutscenes) narrativ aufgeladen sind. Zudem ist die Erzählstruktur im Vergleich zur Quest- wie zur gesamten Spielstruktur deutlich schwächer angelegt. Gemäß den Konventionen des Sandbox-Games können Spieler die Spielwelt bzw. den Spielraum mithilfe diverser Fortbewegungsvehikel (Autos, Boote, Flugzeuge, Motorräder etc.) oder zu Fuß erkunden, mit Waffen nahezu jeden NPC töten, Unternehmen erwerben und aufbauen, die drei Spielfiguren profilieren oder diverse Minigames spielen (Yoga, Tennis etc.). GTA $V$ bietet hierdurch eine extreme Akkumulation von Genres, die Sandbox-Games ausmacht und sich mit Blick auf dieses konkrete Beispiel in einer Amalgamierung von Rennspiel, Shooter, Adventure, Aufbausimulation sowie Geschicklichkeitsspiel ausdrückt. (vgl. dazu BEIL 2015, 52 ff.) Da GTA $V$ aber auch viele narrative Rezeptionsangebote macht, lädt es, trotz schwächerer medialer Narrativität, zu personalen Narrationen ein. Insofern ist dieses Spiel, wie prinzipiell alle interaktiv-narrativen Sandbox-Games, potenziell für alle drei Spielertypen von Interesse. Dies offeriert mediensoziologischen Studien z.B. die Möglichkeit, Spieler beim Spielen dieser digitalen Spiele zu beobachten, um anhand ihres Spiel- bzw. Nutzungsverhaltens Spielertypeneinordnungen vornehmen zu können.

Die Ausführungen zum Kontinuumsmodell werden v.a. in Kapitel 4 klarer werden, wenn es um die tatsächliche Applikation des Modells am Beispiel von Ocarina of Time geht. Kapitel 3 leistet insofern einen Übergang zwischen den Kapiteln 2 und 4, als es einerseits das bereits Dargelegte am Mythos als Interaktiv-Narrativ in digitalen Spielen weiter expliziert, dies aber unter ausführlicher Bezugnahme und mit Hinblick auf Ocarina of Time tut, um die Funktionen des Interaktiv-Narrativs exemplifizieren zu können. 


\section{Mythos und interaktiv-narrative digitale Spiele}

Zerfallen sind die Tempel. Mit den Töpferscherben Zersprang, was Mythos war, in tausend Kurzgeschichten.

(GRÜNBEIN 2002, 133)

In seinem Epistel an einen englischen Arzt, das den englischen Mediziner und Schriftsteller Sir Thomas Browne (1605-1682) adressiert, befasst sich Durs Grünbein im weitesten Sinne mit Prozessen der Säkularisierung bzw. deren Auswirkungen auf unser Alltagsleben, das zunehmend hedonistischer und konsumorientierter sei. Mit Bezug auf den frühneuzeitlichen Arzt als Projektionsfolie einer vergangenen religiös-mythologischen (voraufklärerischen) Epoche konstatiert Grünbein in den beiden Versen eine Abkehr vom Mythischen, wobei er Mythos und Religion synonym gebraucht. Insofern bedient Grünbein gängige Topoi der Säkularisierungstheoretiker und jener Intellektueller, die von ,Entmythologisierung ${ }^{6}$ oder ,mythenloser Zeit' sprechen. ${ }^{300}$ Ein genauerer Blick auf die (europäisch-westliche) Rezeptions- und Wirkungsgeschichte von Mythos und Religion, und Peter L. Berger hat dies mit Blick auf die (De-)Säkularisierung herausgestellt, entlarvt den Mythos von der Mythenlosigkeit als eben solchen - einen Mythos. (vgl. BERGER 1999) Odo Marquard merkt dazu an:

Die Geschichte des Prozesses der Entmythologisierung ist - meine ich - selber ein Mythos; und daß so der Tod des Mythos selber zum Mythos wird, beweist ein wenig des Mythos relative Unsterblichkeit. Es ist zumindest ein Indiz dafür, daß wir ohne Mythen nicht auskommen. [...] Die Menschen können ohne Mythen nicht leben; und das sollte nicht verwunderlich sein, denn was sind Mythen? [...] Mythen sind - ganz elementar - justament dieses: Geschichten. Man kann sagen: Ein Mythos ist fiktiver als eine »history « und realer als eine »story«; aber das ändert nichts am Grundbefund: Mythen sind Geschichten. (MARQUARD 2000, 93; Herv.i.O.)

Religion und Mythos waren nie wirklich aus unserem Alltag verschwunden, sie wandeln lediglich ihre Gestalt vor dem Hintergrund soziokultureller Veränderungen. In der Bemühung, eine sinnstiftende Erzählung von einer mythenlosen Welt zu schaffen, fallen jene Vertreter einem selbstperformativen Widerspruch anheim, indem sie selbst (moderne) Mythenbildung

\footnotetext{
${ }^{300}$ Bei vielen Säkularisierungstheorien fällt auf, dass diese nicht primär Glaubens vorstellungen oder Religion an sich angreifen, sondern ihre Kritik vielmehr auf die institutionalisierten Aspekte der jeweiligen Religion richten. So lässt sich häufig eine Religionskritik als Institutionskritik an Amtsträgern, Dogmen oder hierarchischen Strukturen mit stets wiederkehrenden Vorwürfen wie bspw. Simonie nachweisen. Repräsentanten von Religionen erscheinen dabei nicht nur als amtsmissbräuchlich, sie scheitern obendrein an den eigenen proklamierten moralischen Standards. Grünbeins Gedicht symbolisiert dies im Verfall der Tempel.
} 
betreiben (wie Jean-François Lyotard mit seinem großtheoretischen Entwurf vom Ende aller Meistererzählungen ironischerweise zugleich wieder eine Meistererzählung etabliert und somit deren Persistenz unterstreicht). (vgl. LYOTARD 1986)

Darüber hinaus verweist Grünbeins Gedicht aber auch auf einen Aspekt, der in vielen Mythentheorien eine zentrale Bedeutung hat - die Narrativität. Was viele Mythentheorien eint, und da hat sich seit Aristoteles relativ wenig geändert, ist, dass Mythen als Erzählungen (bestehend aus Anfang, Mitte und Ende) aufgefasst werden. ${ }^{301}$ „Mythen sind ein vielfältiges, weltweit verbreitetes und dauerhaftes kulturelles Phänomen. Es gründet darin, dass Menschen sich Geschichten erzählen, um sich in der Welt zu orientieren.“ (JAMME/MATUSCHEK 2014a, 8) Mythen sind, wenn man die oben eingeführte Definition eines Narrativs als „kulturell verfestigte Erzählstruktur, die auf einer spezifischen Verkettung von Kardinalfunktionen beruht und die auf ein bestimmtes Figurenpersonal sowie Raum-Zeit-Gefüge zurückgreift“", verwendet, Narrative. (2.4.3) Sie bieten dabei aber keinesfalls nur dem Individuum eine Orientierungs- bzw. Sinnstiftungsfunktion, sondern leisten dies auch auf kollektiver Ebene als bedeutsame Kulturtechnik. ${ }^{302}$ So gesehen sind sie nicht nur Narrative, sie sind Metanarrative.

Dadurch wird auch deutlich, dass sich Mythen, auch wenn der Begriff Mythos in der Auseinandersetzung der antiken Griechen mit ihrer Mythologie ${ }^{303}$ zu einem diskursiv dominanten Terminus aufstieg, nicht auf jene Mythen und die aus ihnen hervorgegangenen beschränken dürfen, dass Mythen nicht nur als Ausdruck einer antik-humanistischen Tradition relevant sind, sondern dass Mythenbildung an sich eine zentraler Aspekt menschlicher Kultur(en) ist; eine anthropologische Konstante. Dies bedeutet aber auch, dass die Aufklärung nicht, wie lange angenommen, das Ende eines mythischen Zeitalters endgültig besiegelte, indem sie Mythen als unwahr und naiv entlarvte und somit als zu überwinden darstellte. Es bedeutet vielmehr, dass ,,wir heute nicht in einer Zeit ohne Mythen [leben], sondern in einer solchen, die sich über die Präsenz und Funktion des Mythischen kritisch Rechenschaft zu geben versucht"“. (ebd.) Insofern hat die Aufklärung zu einer ,positiven“ Hinterfragung des

\footnotetext{
${ }^{301}$ „Ein Ganzes aber ist, was Anfang, Mitte und Ende hat. Anfang ist, was selbst nicht aus innerer Notwendigkeit auf etwas Anderes folgt, nach dem aber naturgemäß etwas anderes ist oder entsteht. Ende dagegen ist, was selbst nach etwas Anderem ist und zwar entweder | notwendig oder meistens, nach dem aber nichts anderes (folgen muss). Mitte ist das, was selbst nach etwas Anderem ist, und nach dem etwas Anderes ist.“ ARISTOTELES (2008), 12.

${ }^{302}$ Zum Erzählen als Kulturtechnik vgl. KosCHORKE (2013).

${ }^{303}$ Unter Mythologie wird im Folgenden „die Gesamtheit der Mythen eines jeweiligen Kulturkreises“ verstanden. MAtuscheK (2014), 13. Der Begriff bezeichnet also nicht, wie man leicht annehmen könnte, die wissenschaftliche Disziplin oder jenes Forschungsfeld, das sich mit Mythen befasst, es bezeichnet alle Mythen einer Kultur. So kann man bspw. zwischen griechischer, ägyptischer oder nordischer Mythologie unterscheiden.
} 
Mythos geführt, ohne welche die moderne Mythenforschung nicht zu denken wäre. ${ }^{304}$ Nur auf dieser Grundlage kann „Mythos als ein allgemeines Phänomen menschlicher Gesellschaft“ untersucht werden. (ebd., 9)

Hieran anschließend stellen Aleida und Jan Assmann fest, dass die Postmoderne keinesfalls eine mythenlose, sondern, ganz im Gegenteil, eine „mythophil[e]“ Zeit sei. (Assmann/Assmann 1998, 197) Der Blick auf die aktuelle Populärkultur unterstützt diese Annahme. Filme, Fernsehserien, Comics oder eben digitale Spiele greifen nicht nur auf Inhalte, Themen und Motive diverser Mythologien zurück, sie tragen selbst in erheblichem Maße zur Mythenbildung bei. Eine der virulentesten Bewegung der modernen Mythenbildung mit Blick auf die populäre Medienkultur sind in den letzten Jahren die diversen Fantheorien, wie sie bspw. im Kontext transmedialer Welten wie Game of Thrones entstehen. Hierbei bauen Fans nicht nur den mythologischen Background ihrer favorisierten transmedialen Welt aus, indem sie neue Inhalte ergänzen, sie erzeugen bzw. erhalten darüber hinaus die Fandiskurse, welche eine nicht unerhebliche mythologische Dimension besitzen und tragen somit zum ,Mythos‘ der betreffenden transmedialen Welt bei. Dies lässt sich z.B. aus funktionalistischer Sicht erörtern, wenn man bedenkt, dass die Fantheorien als Teil des Fandiskurses Funktionen für das Subjekt wie die Gruppe erfüllen, die traditionell auch von Mythen bedient wurden wie Orientierung und Ordnung oder Deutung und Sinnstiftung.

Fasst man die streiflichtartigen Ausführungen zum gegenwärtigen Stellenwert des Mythos zusammen, so zeigen sich in der Forschung wie auch im allgemeinen Diskurs mit der ,Entmythologisierung ‘ und ,Mythophilie‘ zwei Tendenzen, die gewissermaßen die Pole eines Kontinuums bilden, zwischen denen die Argumentationen pendeln und die von ihren Annahmen und Analysen her unterschiedlicher kaum sein könnten. Kennzeichnend ist hierbei, wie für viele andere kulturelle Diskurse auch, ${ }^{305}$ dass eine enge Verbindung zu einem der beiden Pole gesucht wird, was nicht unproblematisch sein kann, da es zwangsläufig

\footnotetext{
${ }^{304}$ Etwas anders sieht dies noch Kurt Hübner: „Während der Aufklärung die Beschäftigung mit dem Mythos nur die willkommene Gelegenheit bot, vorangegangene Weltdeutungen als Ausdruck der Unwissenheit, der Naivität und des Aberglaubens für endgültig überwunden zu erklären, ist heute eher die Absicht erkennbar, im Mythischen etwas für das Wesen des Menschen Kennzeichnendes zu sehen. [...] In der sich heute ausdehnenden Mythos-Forschung zeigt sich daher die fortdauernde Faszination von ihm, ja, seine fortdauernde Wirksamkeit.“ HÜBNER (1986/87), 16. Hierbei konzentriert sich Hübner primär auf die Mythenkritik der Aufklärung, die die Dichotomie zwischen ,mythos` und ,logos' stark machte und übersieht dabei die positiven Auswirkungen jener Kritik, die letztlich zu der „,fortdauernde[n] Faszination“ des Mythos in den Wissenschaften führen und auch stärker dessen funktionalistische Aspekte in den Mittelpunkt rücken.

${ }^{305}$ Man denke hier z.B. an die Debatten über die Auswirkungen von Medien auf deren Nutzer im Besonderen wie die Kultur im Allgemeinen, die sich zwischen Medienkritik und Medienenthusiasmus bewegen. Ein weiteres Beispiel hierfür, wie im vorherigen Kapitel diskutiert, ist die Narratologen-Ludologen-Debatte.
} 
impliziert, dass die eigene Position einen Anspruch auf vollumfängliche Richtigkeit beanspruchen kann, welcher hierdurch (ex negativo) der Gegenseite abgesprochen wird. Dass dies freilich nicht zutreffend ist, sondern meistens von der Beurteilung eines konkreten Sachverhalts abhängt, wird im Laufe des Kapitels deutlich werden.

Um sich den ästhetischen Funktionen des Mythos wie dessen inhaltlichen Reaktualisierungen in interaktiv-narrativen digitalen Spielen zu nähern, ist es unvermeidlich, einen Überblick über die moderne Mythenforschung des 20. Jahrhunderts zu geben. (3.1) Dies scheint nicht zuletzt deshalb notwendig, um zu zeigen, wie vielfältig und reichhaltig diese ist und welche (bisher weitestgehend ungenutzten Möglichkeiten) sich hieraus für die Erforschung digitaler Spiele ergeben. Hiervon ausgehend wird v.a. jener Pfad weiter verfolgt, den am prominentesten Joseph CAMPBELL (2011) mit seiner strukturalistischen Studie Der Heros in tausend Gestalten anlegte und den nicht zuletzt Christopher VOGLER (2010) durch seine Modifikation des Campbell'schen Modells in seiner Odyssee des Drehbuchschreibers einer breiten Öffentlichkeit bekannt machte. (3.2) Die Rede ist hierbei von der Identifikation einer erzählerischen Grundstruktur, eines Narrativs, das sich in nahezu allen Mythen der verschiedensten Kulturen an verschiedenen Orten und zu verschiedenen Zeiten, wobei Kulturkontakte teilweise nicht nachweisbar sind, in erstaunlich konstanter Form wiederfinden lässt. Diese Beobachtung hat nicht zuletzt auch die Digital Game Studies affiziert und hier zu einer breiten Rezeption von Campbells Studie beigetragen, wodurch sich nicht nur viele Arbeiten dieses Forschungsfeldes auf ihn als Autorität berufen, sondern v.a. seinem Modell der Heldenreise als Analyseinstrument folgen. (3.3) In besonderem Maße wurde dabei die Verbindung zwischen Mythos und Quest ${ }^{306}$ betrachtet, wobei letztere sowohl Erzählungen als

\footnotetext{
${ }^{306}$ Aus spielwissenschaftlicher Sicht ist die Minimaldefinition der Quest nach Espen Aarseth besonders empfehlenswert, da sie es ermöglicht, Quests in verschiedenen digitalen Spielgenres und verschiedenen Ausprägungen fassen zu können. Aarseth definiert eine Quest wie folgt: „If we examine a number of adventure games, they all seem quite similar in terms of form: the player-avatar must move through a landscape in order to fulfill a goal while mastering a series of challenges. This phenomenon is called a quest. The purpose of adventure games is to enable players to fulfill quests." AARSETH (2004b), 368. Im Unterschied zu Missionen in digitalen Spielen im Allgemeinen spielt in Quests das Reisen eine sehr große Rolle sowie das Ziel der Quest stets einen agonalen Spielverlauf bedingt, bei dem es gilt, Gegner zu überwinden. Quests bringen oft ludische Praktiken wie das ,Looten“ und ,Farmen' mit sich. Beim ,Looten' wird ein besiegter Gegner seiner Habseligkeiten (meist Items) beraubt, sprichwörtlich vom siegreichen Spieler ausgeplündert. Unter ,Farmen“ versteht man in der digitalen Spielkultur Wiederholungen bestimmter ludischer Muster wie das Sammeln und Horten von Materialen (meist zum Upgrade eigener Items) bzw. das Beseitigen von schwächeren Gegnern. Das Genre, dessen Quest-Struktur am massivsten vom ,Looten ' und ,Farmen' bestimmt wird, ist das RPG. Interessant sind in diesem Zusammenhang aber auch die Verbindungen der Quest zu antiken Mythen, denn auch hier geht es immer wieder um das Liquidieren von Feinden sowie die Inbesitznahme bestimmter (magischer) Artefakte. Insofern zeigen sich bereits hier strukturelle Äquivalenzen zwischen ludischer und narrativer Quest.
} 
auch Spiele kennzeichnet. ${ }^{307}$ Abgeschlossen wird dieses Kapitel mit den Ausführungen zum Mythos als Interaktiv-Narrativ in interaktiv-narrativen digitalen Spielen. (3.4)

\subsection{Ansätze der modernen Mythenforschung - eine Skizze}

Einer der bekanntesten Beiträge zur neueren Mythenforschung ist sicherlich der Artikel zum ,Mythos‘ im Handbuch religionswissenschaftlicher Grundbegriffe von Aleida und Jan Assmann. ${ }^{308}$ Ihnen geht es nicht darum, einen „zu engen Mythos-Begriff“ zu vertreten, sondern mehrere Mythosbegriffe voneinander zu trennen. (ebd., 179) Dabei konzentrieren sie sich primär auf eine substantialistische Begriffsverwendung, wenn sie den ,gemeinsamen Nenner“ der diversen Auffassungen des Mythos darin sehen, dass dieser ein „Fundus an Bildern und Geschichten“ sei. (ebd.) Insgesamt differenzieren sie zwischen sieben Mythosbegriffen, die zu erörtern sich lohnt. Lohnenswert ist dieses Vorgehen, da hierdurch die vielfältigen Möglichkeiten der mythentheoretischen Ansätze bzw. deren Erkenntnispotenziale für die Erforschung digitaler Spiele sowie der digitalen Spielkultur schlaglichtartig aufgezeigt werden können.

Eine Verwendung des Ausdrucks Mythos, die uns in der Alltagssprache in journalistischen Kontexten immer wieder entgegentritt, ist (1) der ,polemische[] Begriff“, welcher sich ,auf Mythos als ein überwundenes Stadium kulturhistorischer Entwicklung“ bezieht. (ebd.) Nach diesem Verständnis sind Mythen an sich unwahr, stehen im Gegensatz zum Logos. Mythos ist in diesem Sinne ein Synonym für Trugschluss, Irrglaube, Fiktion oder Unwahrheit und somit negativ konnotiert. ${ }^{309}$ Stefan Matuschek merkt zum Verhältnis von Mythos und Logos etwa an:

Das altgriechische Wort >mythos` ( $>$ Rede $<$, $>$ Erzählung $\triangleleft)$ ist, wenn es nicht neutral nur den Handlungsverlauf einer Erzählung meint, einseitig negativ konnotiert und hebt die Dichtererzählungen von der Geschichtsschreibung, den Tatsachendarstellungen und der begrifflichen Argumentation ab. `Mythos` steht hier im Kontrast zu 〉logos`, der im Gegensatz $\mathrm{zu}$ den unbeweisbaren Dichtererzählungen die überprüfbare und beweisbare Rede meint. (MATUSCHEK 2014, 12)

Allerdings muss man Mythen nicht zwangsläufig als wahr klassifizieren, um dennoch davon ausgehen zu können, dass sie (Teil-)Wahrheiten beinhalten. Mythen als Produkt von Mythenbildung sind in der Regel eine Reaktion auf die Konfrontation von Subjekten oder

\footnotetext{
307 Jeff Howard unterscheidet deshalb zwischen, Quest-Narratives` und,Quest-Games`. Zur ersten Kategorie kann man Mythen zählen und die zweite beinhaltet (digitale) Spiele mit einer sehr ausgeprägten Quest-Struktur. Vgl. HOWARD (2008).

${ }^{308}$ Einen anderen, überaus lesenswerten und breit rezipierten Handbuchartikel zu ,Mythos/Mythologie findet man im Historischen Wörterbuch der Philosophie. Vgl. BuRKERT/HORSTMANN (1984).

${ }^{309}$ (1) ist in der Regel jene Auffassung von Mythos, die traditionell von der Mythenkritik vertreten wird.
} 
einer Gruppe von Subjekten mit Umständen, die sich deren Verständnis entziehen und die diese nun zu ordnen versuchen, indem sie diese in einen Mythos überführen. Das gilt für die Mythen der klassischen Antike ebenso wie für moderne Mythen wie den ,American Dream‘. Beim Vergleich antiker Mythen mit modernen fällt oft auf, dass moderne Mythen auf Inhalte antiker Mythen zurückgreifen. Hierbei findet eine Tradierung von Wahrheiten statt, die für die antiken Mythen offenbar genauso wichtig waren, wie für ihre gegenwärtigen Formen. Die Zeitlosigkeit des Mythos scheint demnach nicht nur durch seine Ästhetik und Funktionen zu begründen zu sein, sondern auch dadurch, dass er Inhalte transportiert, die kontextunabhängig relevant sind. Aleida und Jan Assmann nennen dies, als „differenziertere Variante“ von (1), den (2) „historisch-kritische[n] Begriff“, welcher sich durch „die zeitbedingte Einkleidung einer an sich zeitlosen Wahrheit“ auszeichnet. (Assmann/Assmann 1998, 179) Auch wenn Mythen den Mitgliedern der jeweiligen Gemeinschaft, für die der Mythos Wirkung beansprucht, zeitlose Wahrheiten übermitteln, von anthropologischen Konstanten handeln, so wandelt sich doch ihre Erscheinungsform, passt sich dem Kontext der Zeit an, um seine Rezipienten zu erreichen.

Problematisch an der Einteilung von Aleida und Jan Assmann ist (3). Hierunter fassen sie den „funktionalistische[n] Begriff“, der „Mythos als einen kulturellen Leistungswert“ definiert. (ebd., 180) Diffizil ist hieran, dass die anderen Mythosverständnisse zwar primär substantialistisch aufgefasst werden, dass sie aber dennoch z.T. nicht unerhebliche funktionalistische Dimensionen umfassen. So ist (4) der Alltagsmythos, wie ihn v.a. Roland Barthes geprägt hat. (vgl. ebd.) Als ,Paradebeispiel` dient der Mythenforschung stets der American Dream, welcher zwar bestimmte Inhalte aufweist, die für ihn konstitutiv sind, der darüber hinaus aber aufgrund seiner Funktionen für die westlichen Gesellschaften zu einem der populärsten modernen Mythen aufstieg. Denn der American Dream erzählt nicht nur die Geschichte des Aufsteigers, der von ganz unten nach ganz oben gelangt, er versichert den Rezipienten darüber hinaus, dass es stets, und mag die Lage noch so misslich sein, einen Ausweg aus dem Prekariat gibt, und dass dieser in Fleiß und harter Arbeit liegt. Auch wenn dieser Weg steinig ist, wartet am Ende doch die gerechte Entlohnung. Dabei hat der Alltagsmythos eine doppelte Funktion, die Roland Barthes in seinen Mythen des Alltags treffend identifiziert hat. (vgl. B ARTHES 2010)

Einerseits dient der American Dream dem Großteil der Bevölkerung, die sich in z.T. prekären Verhältnissen befindet, als Mythos, der der Aussichtslosigkeit eines Lebens am Existenzminimum mit allen dazu gehörenden Schwierigkeiten einen Sinn verleiht und eine 
Orientierung bietet, auch wenn das Ziel weit entfernt ist und nur die Wenigsten es wirklich erreichen. Allein die Möglichkeit, dies schaffen zu können, genügt, um über den tristen Alltag hinweg zu trösten. Andererseits ist den Obrigkeiten diese Funktion des Alltagsmythos bewusst, und sie setzen diesen gezielt ein, um die Massen von der sozialen, ökonomischen und politischen Realität abzulenken, wie dies schon im antiken Euergetismus der Fall war. (vgl. KOKKINIA 2000 sowie GofFIN 2002) In diesem Sinne erfüllen der Alltagsmythos Roland Barthes' und Max Horkheimers und Theodor W. Adornos ,Kulturindustrie‘ eine ähnliche (euergetische) Funktion mit ähnlicher Stoßrichtung. (vgl. HORKHEIMER/ADORNO 1997) Der antike Euergetismus, die Kulturindustrie und moderne Mythen dienen dazu, die bestehenden Verhältnisse, die im Sinne der Obrigkeit sind, zu erhalten, zu festigen, indem der Großteil der Bevölkerung von deren eigener prekärer Lage ,abgelenkt ${ }^{\star}$ wird. Hierdurch wird eine Funktion von Mythen deutlich - die Stabilisierungsfunktion. Da diese und andere Funktionen elementar für Mythen sind, erscheint eine vollständige Abkopplung des substantialistischen vom funktionalistischen Mythenbegriff schwierig und wird deshalb im Folgenden auch nicht vorgenommen.

(5) betrachten Aleida und Jan Assmann den Mythos als „narrative[n] Begriff“, als „eine integrale Erzählung mit den strukturierenden Konstituenten von Anfang, Mitte und Ende“, d.h. im Sinne Aristoteles'. (ASSMAnN/AsSmanN 1998, 180) Dabei ist es aber nicht unproblematisch, dass diese Betrachtung des Mythos in vielen Verständnissen von Mythen eine zentrale Rolle spielt, da eigentlich alle Mythen in einer narrativ-deskriptiven Art vermittelt werden, sodass Erzählen für eigentlich alle Auffassungen von Mythos eine zentrale Rolle spielt, was es schwierig erscheinen lässt, hieraus ein separates Konzept des Mythos zu gestalten. Warum es problembehaftet ist, die narrativen Komponenten des Mythos unter einem separaten Mythosbegriff subsumieren $\mathrm{zu}$ wollen, verdeutlichen bereits (6) die „literarische[n] Mythen“, worunter die Autoren „die europäische [griechisch-römische] Mythentradition und deren Bedeutung für die abendländische Schriftkultur“ und deren fortwährende Aktualisierungen verstehen. (ebd.) Besonders ist an der Rezeption und Verarbeitung der Mythologie der griechisch-römischen Antike, und auch die nordische oder keltische Mythologie bilden da keine Ausnahme, dass sie uns, neben Medien wie Malerei oder Bildhauerei, hauptsächlich durch Geschichten vermittelt wurde und wird. Somit werden Mythen im Sinne von (6) also immer narrativ vermittelt. Dies gilt auch für Alltagsmythen wie den American Dream, der uns gegenwärtig primär in Romanen und Spielfilmen begegnet. Das bedeutet, dass immer dort, wo es um die Inhalte des Mythos geht (von der Mythenkritik 
als Sonderfall an dieser Stelle abgesehen) oder wo er als Mythos wirkt, eine narrative Vermittlung stattfindet, sodass es - ähnlich wie beim funktionalistischen Mythenbegriff wenig Sinn ergibt, diesen zentralen Aspekt von Mythen separieren zu wollen. (7) betrachten Aleida und Jan Assmann Metanarrative bzw. ideologische Strömungen von globalem Anspruch als Mythen und rechnen diese wie (4) zu den wichtigsten Formen der Mythenbildung in der (Post-)Moderne. (vgl. ebd., 180 f.)

Auch wenn (4) und (7) mythomotorisch ${ }^{310}$ interessant sind, so gehen sie extensional über das hinaus, was diese Arbeit anstrebt, auch wenn derartige Mythenverständnisse v.a. im Bereich der Untersuchung der digitalen Spielkultur als Fankultur überaus lohnenswert erscheinen. Auch (1) und (2) werden nicht Gegenstand der folgenden Überlegungen sein, da mythenkritische Auseinandersetzungen in und mit digitalen Spielen zwar partiell vorkommen, aber dennoch eher zu den randständigen Phänomenen gehören. Hauptsächlich widmet sich diese Arbeit einem Mythenverständnis nach (5), wird aber ebenso nach den Funktionen des Mythos (3) im Allgemeinen wie dessen Mehrwert für digitale Spiele im Besonderen fragen und kann dabei aber auch nicht die Aktualisierungen der (europäischen) Mythentradition (6) in digitalen Spielen außer Acht lassen. ${ }^{311}$

\subsubsection{Mythos heute}

Aber warum sind Mythen heute so aktuell? Warum konstatieren Aleida und Jan Assmann gar eine Mythophilie der Postmoderne? Beide führen für ihre These mehrere Gründe an. Neben der Ästhetisierung des Mythos und der neuen Mythenbildung betonen sie einen Aspekt, der funktionalistisch von erheblicher Bedeutung ist, den sie aber leider nicht weiter ausführen. (vgl. ebd., 195 ff.) Demzufolge ist die Mythophilie, ist die moderne Mythenbildung eine Reaktion auf die Deutungskrise des Subjektes, die im Zeitalter der Postmoderne erheblich an Bedeutung gewinnt. Interessanterweise verhält es sich hier beim Mythos ähnlich wie bei der Religion.

Seit Mitte der 1990er-Jahre wurde in der kulturwissenschaftlichen Forschung, im Feuilleton oder in der öffentlichen Debatte vermehrt ein Wiedererstarken religiöser Themen, Inhalte und Motive sowie deren Niederschlag in gegenwärtigen Medien wie der Literatur verzeichnet, das unter Termini wie »Respiritualisierung«, »Renaissance der Religion« oder Zeitalter der

\footnotetext{
310 Zum Begriff der Mythomotorik, wie er aktuell zumeist gefasst wird, vgl. Assmann (1992). Jan Assmann unterscheidet bei der Mythomotorik im Wesentlichen zwischen der ambivalenten Wirkweise von Mythen, zum einen bestehende Verhältnisse stabilisieren und zum anderen destabilisieren zu können. Entscheidend für die jeweilige Wirkung von Mythen ist die Einstellung einer Gesellschaft, sich verändern oder die bestehende Form beibehalten zu wollen.

${ }^{311}$ Die Mythenbegriffe (3) und (5) werden dabei aber nicht als derart hermetisch gedacht wie bei Aleida und Jan Assmann.
} 
»postsäkularen Gesellschaft« firmiert. Ob es sich hierbei um eine >Wiederkehr des Religiösen an sich oder nur um eine wiederkehrende Fokussierung auf religiöse Belange handelt, die im Zuge des viel beschworenen >Kampfs der Kulturen des Antagonismus zwischen kapitalistischem Westen und sozialistischem Osten die Religion erneut als ideologische Legitimation anführe, wurde und wird vielfach kontrovers diskutiert. (MATUSZKIEWICZ 2015a, 645)

Es ist sicherlich kein Zufall, dass mit dem Ende eines dualistisch-antagonistischen politischen Klimas der Mythos wieder stärker ins Bewusstsein rückt. (vgl. HunTINGTON 2011) Dualistische Strukturen suggerieren (wie der Binärcode) dem Subjekt eine eindeutige Ordnung, die dem Individuum seinen Platz in der Gesellschaft anweist. ${ }^{312}$ Der Verlust dieses Dualismus kann dann dem Verlust der Ordnung gleichkommen, nach der das Subjekt sucht. Schon die ältesten Mythen, die uns heute noch überliefert sind, zeugen von dem Bedürfnis des Menschen, dem Chaos zu entkommen und eine Lebensordnung zu erhalten, die unzweifelhaft ist, da man entweder der einen oder der anderen Gruppe angehört. Und auch heute noch bedienen Mythen als Erzählungen dieses Bedürfnis. Sie etablieren antagonistische Narrative, die die Figuren und die Welt in Gut und Böse teilen und dabei dem immer selben Muster folgen, wenn sie vom langen, beschwerlichen Kampf des ,Guten` gegen das ,Böse‘ erzählen, der anfänglich als nicht zu gewinnen erscheint, der aber dennoch aufgenommen werden muss, da die Alternative der Untergang der gesamten Welt ist. Letztlich trägt das Gute doch den Sieg davon, die Welt ist gerettet, die (idealisierte) Ordnung bleibt erhalten.

Hier wird eine zentrale Funktionsdimension des Mythos ersichtlich. Mythen geben Orientierung, verleihen dem Leben Sinn und helfen dem Subjekt die Welt zu deuten sowie den status quo zu legitimieren. In diesem Sinne ist auch die Mythomotorik, wie Jan Assmann sie versteht und nachhaltig geprägt hat, von großer Wichtigkeit. Mythomotorisch betrachtet, ist der Mythos „erinnerte[] Geschichte“. (Assmann/Assmann 1998, 197) Damit betont Jan Assmann aber auch, dass die Frage der traditionellen Mythenkritik nach der Wahrheit des Mythos unangebracht ist. „Auch Mythen sind Erinnerungsfiguren: Der Unterschied zwischen Mythos und Geschichte wird hier hinfällig. Für das kulturelle Gedächtnis zählt nicht faktische, sondern nur erinnerte Geschichte.“ (ASSMANN 2007, 52) Für den Eingang in das kulturelle Gedächtnis ist also nicht entscheidend, ob etwas faktisch geschehen ist oder fingiert wurde. Entscheidend ist vielmehr, was erinnert, was geglaubt wird. Unterstrichen werden derartige Thesen von Hayden Whites Untersuchungen zur Geschichtsschreibung. White

\footnotetext{
${ }^{312}$ Wie stark dualistische Strukturen bzw. Dichotomien unsere Wahrnehmung und Verarbeitung der Wirklichkeit determinieren, illustriert ein simples Beispiel. So ordnen wir die Gesellschaft oft, v.a. mit Blick auf Konflikte, in ,Oben' und ,Unten', ,Alt' und ,Jung', ,Arm' und ,Reich' etc. Auf diese Weise vereinfachen Dichotomien zwar die Komplexität der Realität, erlauben uns aber, uns einer von beiden Gruppen als zugehörig zu definieren. Dies geht i.d.R. aber zu Lasten eines antonymen Denkens.
} 
erkennt, dass Historiografie nicht auf der genauen Dokumentation dessen beruht, was wirklich gewesen ist, sondern darauf, was als erinnerungswürdig angesehen wird. Dabei folgt das 〉Emplotment` in der Regel vier Archetypen, die Northrop Frye identifizierte und die für die moderne Mythenforschung des 20. Jahrhunderts von großer Bedeutung waren - Satire, Romanze, Tragödie und Komödie. ${ }^{313}$ (vgl. WHITE 2008) Überspitzt gesagt, könnte man, mit Bezug auf Jan Assmann und Hayden White, feststellen, dass Mythen nicht Wirklichkeit dokumentieren, sondern konstruieren und dass dies nicht nur die Mythenbildung, sondern auch die Historiografie betrifft. Dabei folgen Mythen einem zutiefst menschlichen Bedürfnis:

Sie [die Mythen] sind der immer wieder durch Weitererzählung akzeptierte und erfolgreiche Versuch, sich durch die Erzählfantasie ein Verständnis der Zusammenhänge zu schaffen, die durch begriffliche Abstraktion oder Berechenbarkeit nicht menschlich befriedigend erfasst werden können. [...] Deshalb ist es falsch, die Geschichte der Mythen zweizuteilen in eine Zeit, in der die Menschen noch an sie geglaubt, und eine Zeit, in der sie sich durch Aufklärung von diesem Glauben gelöst hätten. Es gibt nicht die beiden Epochen in und nach den Mythen. (MATUSCHEK 2014, 13; Herv.i.O.)

Wir leben also nicht wieder in einem mythophilen Zeitalter, wir leben immer noch in ihm. Die Aufklärung bzw. deren kritische Reflexion der Mythologie(n) mag zwar die einstige religiöse Funktion des Mythos (nahezu) beseitigt haben, sie hat aber erstens keineswegs alle Funktionen des Mythos abgeschafft und sie hat zweitens auch nicht alle religiösen Funktionsweisen eliminiert. Ordnungs- und Sinnstiftung, Deutung und Legitimation sind beides bedeutenden Funktionen, die sich Religion und Mythos teilen und die Mythen auch heutzutage immer noch aufweisen. So ist es die Aufgabe der gegenwärtigen Mythenforschung, stärker nach den Funktionen des Mythos und dessen Aktualisierungen zu fragen, sich endgültig von einer helleno- und eurozentrischen Perspektive zu lösen. Einen bemerkenswerten Schritt in diese Richtung haben Christoph Jamme und Stefan Matuschek mit ihrem bereits mehrfach zitierten Handbuch der Mythologie unternommen, indem sie sich nicht nur den europäischen Mythen zuwenden, sondern den Blick auch über den Orient, Ägypten, Asien, Amerika sowie Australien und Ozeanien schweifen lassen, um einen global angelegten Überblick über Mythen zu offerieren. (vgl. JAMME/MATUSCHEK 2014b) Einen deutlichen Gegensatz markiert dazu die überaus kenntnisreiche Studie von Northrop Frye und Jay Macpherson, die ein Kondensat des Lebenswerks der beiden Mythenforscher darstellt. (vgl. FrYe/MACPHERSON 2004) Beide Sektionen des Buches verbindet, und hierin unterscheiden sie sich von dem funktionalistisch orientierten Ansatz von JAMME/MATUSCHEK

\footnotetext{
313 „Wir haben nunmehr die Frage beantwortet: Gibt es erzählerische (narrative) Kategorien der Literatur, die weiter oder logisch früher sind als die gewöhnlichen Gattungen? Es gibt deren vier: die romantische, die tragische, die komische und die ironische oder satirische.“ FRYE (1964), 164; Herv.i.O.
} 
(2014b), ein substantialistischer Mythosbegriff, der sich an den kodifizierten Schriften des Christentums (Frye) bzw. der griechischen Mythologie (Macpherson) ausrichtet, also auf die kanonischen Werke rekurriert, die bis ins 18. Jahrhundert hinein den vielleicht nachhaltigsten Einfluss auf die europäische und westliche Kultur hatten. Im Folgenden wird der Versuch unternommen, kanonische Werke der neueren Mythenforschung in substantialistisch und funktionalistisch, wo es möglich erscheint, zu trennen. Dies geschieht aber mit der Intention, die Unterschiede zwischen beiden zu betonen, um so die Punkte aufzuzeigen, an denen man sie zusammenführen kann, wo sie sich gegenseitig befruchten. Dies ist auch das Anliegen dieser Arbeit; aufgrund der Vielgestaltigkeit, des Reichtums, den Mythen auch immer noch in unserer digitalen Medienkultur haben, scheint es illusorisch, beide Definitionsstrategien exkludierend zu verwenden, vielmehr ist es sinnvoll, beide zu vereinen.

\subsubsection{Mythenforschung heute}

Mythen werden seit ihrem Aufkommen in der Frühgeschichte überliefert, kodifiziert, diskutiert, reflektiert und auch theoretisiert. Dabei brachte jede Zeit neue Untersuchungsperspektiven, neue Fragestellungen mit sich. Am prägendsten für die Folgezeit und v.a. für die neuere Mythenforschung war die Aufklärung und im Anschluss an diese die Romantik. ${ }^{314}$ Die Auseinandersetzungen jener Zeit bestimmten die Mythenforschung des 19. und 20. Jahrhunderts maßgeblich, da sie nicht nur mythenkritisch im Sinne von (1) vorgingen, sondern da sie auch danach fragten, was Mythen immer noch leisten können. Hieraus ergibt sich dann auch die Basis, auf der funktionalistische Ansätze der modernen Mythenforschung stehen.

Letztlich haben Aufklärung und Romantik somit auch zur Entstehung der Mythentheorie in ihrer gegenwärtigen Form beigetragen. Denn Mythenforschung als wissenschaftliche Auseinandersetzung mit Mythen im Allgemeinen gibt es bereits seit der griechisch-römischen Antike, Mythentheorie als Teilgebiet der Mythenforschung, das sich dezidiert auf eine kritisch-differenzierende Theoriebildung konzentriert, ist hingegen ein modernes Phänomen. Einen exzellenten Überblick über diese mythentheoretischen Ansätze (mit Fokus auf das 20. Jahrhundert) bieten BARNER ET AL. (2007) mit ihrem Reader Texte der modernen Mythentheorie. Unter den ausgewählten Texten bzw. Autoren befinden sich Klassiker der modernen Mythentheorie wie Roland Barthes, Mircea Eliade, Joseph Campbell, Hans Blumenberg oder Northrop Frye ebenso wie Arbeiten Marshall McLuhans, Jan Assmanns

\footnotetext{
${ }^{314}$ Als Überblick über die Überlieferungs-, Rezeptions- und Wissenschaftsgeschichte des Mythos sei nochmals auf den Artikel von BURKERT/HORSTMANN (1984) verwiesen.
} 
oder Christopher G. Floods, die erst in jüngerer Vergangenheit stärker im Kontext der Mythenforschung rezipiert werden.

Hierdurch wird zweierlei ersichtlich: Erstens zeigt sich anhand der verschiedenen Herangehensweise der diversen Studien, wie vielgestaltig ein Mythenbegriff aufgefasst werden muss bzw. dass eigentlich nur ein Pluralismus an parallel existierenden Mythenbegriffen in der Lage ist, den theoretisch-methodischen Ansprüchen einer breit angelegten modernen Mythenforschung gerecht $\mathrm{zu}$ werden. Zweitens wird evident, dass Mythenforschung ein hochgradig interdisziplinäres Forschungsfeld ist, dass die wissenschaftliche Beschäftigung mit Mythen in vielen verschiedenen Disziplinen wie Theologie, Religionswissenschaft, Philosophie, Soziologie, Politologie, Geschichtswissenschaft, Literatur- und Medienwissenschaft, Film- und Kunstwissenschaft, Psychologie oder Narratologie umfasst. Wenn man bedenkt, wie unterschiedlich und vielfältig sich die Forschungszweige in diesen Disziplinen zudem ausgestalten, dann kommt man nicht umhin, festzustellen, dass ein Forschungsüberblick zur Mythenforschung allenfalls kursorisch erfolgen kann und sich somit an jenen Werken orientiert, die im Kontext der vorliegenden Studie von großer Relevanz sind. Dies gilt es zu bedenken, wenn im Folgenden eine Unterscheidung zwischen substantialistischen und funktionalistischen Mythosauffassungen vorgenommen wird, die, wie bereits gesagt, nicht exkludierend verstanden werden soll, sondern die vielmehr dazu dient, im Verschiedenen das Gleiche aufzuzeigen.

\subsubsection{Substantialistische Mythenforschung heute}

Tendenziell lässt sich konstatieren, dass ein Großteil der klassischen bzw. kanonischen Werke der modernen Mythentheorie eher zu substantialistischen Mythosbegriffen tendiert, deren gemeinsamer Ansatzpunkt der Mythos als Geschichte, Erzählung oder Narrativ ist. Unter Rückgriff auf die Unterscheidung der sieben Mythosverständnisse nach Aleida und Jan Assmann verwenden diese Werke der modernen Mythentheorie den Mythos im Sinne von (5) oder (6). Das bedeutet, sie beziehen sich auf den Mythos als Narrativ sowie auf den Mythos als eine literarisch-künstlerische Tradition des Okzidents. Die kritischen Mythenauffassungen wie (1) oder (2) gehören in der Regel auch zu den substantialistischen Betrachtungsweisen, haben aber als Folge der aufklärerischen Auseinandersetzung mit dem Mythos erheblich an Popularität verloren. Wie stark sich die Forschung v.a. auf den Mythos als Narrativ konzentriert hat, wird im Folgenden deutlich werden. 
Einer der wohl bekanntesten Mythenforscher des 20. Jahrhunderts war Mircea Eliade. Er vertritt ein Mythoskonzept, das sehr eng mit Kosmologien verbunden ist. „Der Mythos erzählt eine heilige Geschichte, d.h. ein primordiales Ereignis, das am Anbeginn der Zeit, ab initio, stattgefunden hat.“ (ELIADE 1984, 85) Besonders am Figurenpersonal des Mythos ist dabei, dass es sich nicht um gewöhnliche Menschen handele, sondern um „Götter oder Kulturheroen“ und somit um Figuren, die per definitionem außerhalb des Gewöhnlichen stehen. ${ }^{315}$ (ebd.) „Der Mythos ist also die Geschichte dessen, was sich in illo tempore zugetragen hat, der Bericht über das, was die Götter oder die göttlichen Wesen am Anbeginn der Zeit getan haben.“ (ebd.) Insofern erfüllen Mythen, und hier schimmert auf, wie schwer sich substantialistische und funktionalistische Definitionsstrategien beim Mythos voneinander unterscheiden lassen, oft auch eine Art ,Ursprungsfunktion', die entweder kosmologischer Natur oder schlicht eine origo gentis-Erzählung sein kann. ${ }^{316}$ Mythen vergewissern die Rezipienten aber nicht nur ihrer Herkunft und der Genese der gegenwärtigen Welt, sie wirken darüber hinaus in einem hohen Maße alltagsstrukturierend.

Die Hauptfunktion des Mythos besteht darin, die exemplarischen Modelle für alle Riten und alle wesentlichen Betätigungen des Menschen (Ernährung, Sexualität, Arbeit, Erziehung usw.) zu »fixieren«. Der Mensch, der sich wie ein voll verantwortliches menschliches Wesen verhält, ahmt die beispielhaften Taten der Götter nach, wiederholt ihr Tun, gleich, ob es sich um eine einfache physiologische Funktion wie die Ernährung oder um eine gesellschaftliche, wirtschaftliche, kulturelle oder militärische Tätigkeit handelt. (ebd., 87)

Die wichtigste Funktion des Mythos ist nach Eliade eine didaktisch-pädagogische, eine Art Vorbildfunktion. Mythen stellen einen ,Leitfaden“ für den Alltag dar, den auch Religionen in Form ihrer kodifizierten Glaubensinhalte oder Dogmen vermitteln. Damit ist aber auch ein Punkt angesprochen, der leicht übersehen werden kann, wenn man Mythen nur als Narrative

\footnotetext{
${ }^{315}$ Dies lässt sich anhand des Figurenpersonals vieler digitaler Spiele nachweisen, die sich des mythologischen Narrativs bedienen. So geht es in den The Legend of Zelda-Spielen stets um die Konfrontation mit einer übernatürlichen ,bösen` Kraft, die der dämonischen Sphäre zugeschrieben wird. Ganondorf als Hauptantagonist der Reihe erlangt seine Macht z.B., indem er einen Teil des Triforce als Symbol der Macht der drei Hauptgöttinnen Hyrules an sich reißt, wodurch aber zugleich die anderen beiden Fragmente in den Besitz des Helden Link sowie der Prinzessin Zelda gelangen. Auch wenn alle drei Figuren streng genommen keine göttlichen Wesen sind, so wird durch die Aufteilung der drei Fragmente des Triforces auf die drei Hauptfiguren deren quasi-göttlicher Status begründet und ihre exponierte Stellung innerhalb der Figurenkonstellation durch diese figurenkonzeptionelle Überhöhung legitimiert. Sie sind keine gewöhnlichen Charaktere mehr, sondern die einzigen drei Figuren, denen es innerhalb des Narrativs erlaubt ist, maßgeblich auf den Handlungsverlauf einzuwirken.

${ }^{316}$ Die heute ziemlich obskur wirkenden origo gentis-Erzählungen vieler europäischer Nationen des Mittelalters und der Frühen Neuzeit zeigen, dass zur Legitimation eigener Macht- und Territorialansprüche nicht nur historisch nachweisbare Ursprünge wie das antike Rom als Herkunft des eigenen Volkes betrachtet wurden, sondern auch bspw. mythische Orte wie Troja. Mythos und origo gentis-Erzählung liegen hier nah beieinander und sind somit ein sehr anschauliches Exempel für die Assmann'sche Mythomotorik. Als Beispiel für eine derartige frühneuzeitliche origo gentis-Erzählung sei auf den polnischen ,Sarmatismus' verwiesen. Vgl. dazu exemplarisch BÖMELBURG (2006); HEYNOLDT (1998) sowie KERSKEN (2004).
} 
oder Geschichten begreift. Im Unterschied $\mathrm{zu}$ anderen Narrativen vermittelt das mythologische nicht bloß Inhalte, Themen und Motive, sondern umfasst auch eine, implizite Performanz.${ }^{317}$ Das bedeutet zwar nicht, dass der Mythos an sich eine Handlung ist (außer vielleicht für den (realen) Erzähler im Sinne einer Narration), es heißt aber wohl, dass Mythen den Rezipienten zu bestimmten Handlungen anregen (können), die das mythologische Narrativ ihm nahelegt. Diese Funktion des Mythos ist v.a. im Kontext digitaler Spiele von Belang und wird deshalb weiter unten noch ausführlicher zu besprechen sein.

In eine ähnliche Richtung wie Eliade argumentiert auch Kurt Hübner. „Das Urmotiv des Mythos und der mit ihm unlöslich verbundenen Rituale ist demnach die Wiederherstellung der Lebensordnung, die ebenso unvermeidlich wie schuldhaft beständig vom Menschen gestört wird.“ (HÜBNER 1986/87, 18) Wie Eliade geht auch Hübner davon aus, dass Mythen eine Art Urzustand abbilden und dass sich hieraus verschiedene Folgen für das Leben der beteiligten Menschen ergeben. Neben den Ritualen, ${ }^{318}$ die einen nicht unwesentlichen Teil der (impliziten) performativen Anlage des Mythos ausmachen, gibt es eine vom Mythos vorgegebene ideale Ordnung, die in jedem Fall aufrechterhalten werden muss. Mythen entwerfen ein Utopia, das in beständiger Gefahr schwebt, zerstört zu werden. Die Gefahr geht dabei aber weniger, wie Hübner meint, von (gewöhnlichen) Menschen aus, vielmehr sind es (nahezu) omnipotente Kräfte, die dieses Gleichgewicht ins Wanken bringen. Mythische Welten sind autopoietische Systeme, die nur durch massiven äußeren Einfluss bzw. Eingriff in ihrer Selbsterhaltung bedroht werden. Aufgrund ihrer fest definierten narrativen Grundstruktur zeigen Mythen aber stets den Sieg des systemisch ,Guten` gegen das äußere

${ }^{317}$ Christian Wessely etwa bemerkt dazu: „Dem Inhalt nach lassen sich Mythen grob in zwei verschiedene Gruppen einteilen: Solche, die begründen, warum etwas ist und solche, die erklären, warum etwas nicht ist. In beiden Fällen ist es wichtig zu beachten, daß der Mythos performativ ist: Er ist Sprach-Handlung im zweifachen Sinne - zum einen gleichzeitiges Handeln und Sprechen, und zum anderen erneutes Handeln durch Sprechen. Der Mythos wird nicht nur erzählend weitergegeben, er wird begangen“. WESSELY (1995), 359; Herv.i.O.

${ }^{318}$ Mircea Eliade und Kurt Hübner verstehen hierunter religiöse Rituale, d.h. Rituale als Handlungen im Zuge eines religiösen Aktes, wie Victor Turner sie untersucht hat. Vgl. TURNER (2005). Sicherlich lassen sich auch Rituale in modernen Mythen finden, die sich strukturell treffend mit Turner beschreiben lassen. Allerdings sollte man darüber hinaus nicht ignorieren, dass die Funktionen, die diese Rituale ausüben, in der Regel keine religiöse Funktionsdimension mehr haben, sondern bspw. soziale. Nehmen wir ein banales Beispiel anhand des Alltagsmythos American Dream. Der Aufsteiger vollbringt das Kunststück, unermesslich wohlhabend zu werden. Durch dieses ökonomische Kapital generiert er einerseits symbolisches und andererseits soziales Kapitel, welche beide, wenn sie einen bestimmten Level erreichen, zur Konsekration des Aufsteigers beitragen. Diese Aufwertung des sozialen Status' des Aufsteigers kann durch die Aufnahme in einen renommierten Country Club erfolgen, welche oft ,rituell` begangen wird. Mit Turner kann man diesen Vorgang wie folgt fassen: In der Trennungsphase löst sich der Aufsteiger aus seinem bisherigen sozialen Milieu und betritt die Schwellenphase, in welcher er exponiert wird, indem angesehene Mitglieder des Clubs/der Gesellschaft ihn ehren. Als Resultat dessen erlangt er in der Angliederungsphase einen neuen sozialen Status - er gehört nun den höchsten Gesellschaftskreisen an. Obwohl es sich hier um ein Ritual handelt, ist es kein religiöses mehr, auch wenn derartige Riten häufig dazu tendieren, bestimmte Aspekte religiöser Riten zu imitieren (Trinken aus einem Becher etc.), um sich hierdurch zu legitimieren. 
,Böse', wodurch sie sinnstiftend und legitimierend wirken (können). ${ }^{319}$ Dass der vom Mythos legitimierte Zustand nicht immer derjenige sein muss, der für den Großteil der Bevölkerung vorteilhaft wäre, hat Roland Barthes am Beispiel der Alltagsmythen herausgestellt. Ein anderer einflussreicher Kritiker der Wirkungsweisen von Mythen ist Odo Marquard. Dabei wendet sich Marquard aber nicht gegen Mythen an sich, sondern gegen eine bestimmte Form des Mythos, den Monomythos.

Es gibt giftige Mythen, und ich will hier zu sagen versuchen, welche das sind. Meine These eine Arbeitshypothese - ist diese: Gefährlich ist immer und mindestens der Monomythos; ungefährlich hingegen sind die Polymythen. Man muß viele Mythen - viele Geschichten haben dürfen, darauf kommt es an; wer - zusammen mit allen anderen Menschen - nur einen Mythos - nur eine einzige Geschichte - hat und haben darf, ist schlimm dran. Darum eben gilt: Bekömmlich ist Polymythie, schädlich ist Monomythie. (MARQUARD 2000, 98; Herv.i.O.)

Geprägt wurde der Monomythos durch Joseph Campbell und sein Modell der Heldenreise. Für schädlich hält Marquard den Monomythos deshalb, weil er den Wahrnehmungs- und Denkhorizont des Menschen dabei derart verengt, dass dieser nur noch einen Weg vor sich sieht - den der Heldenreise. Und Marquard hat dabei nicht Unrecht, wenn er die Suggestionskraft dieses Mythos kritisiert. Ein Beispiel für die Wirkungsweise des Monomythos stellt kaum jemand so stark heraus (wenn auch unbeabsichtigt) wie Christopher Vogler. Vogler, und dies ist keinesfalls eine Übertreibung, erlebte bei der Lektüre des Heros in tausend Gestalten von Campbell als Filmstudent anscheinend eine Art ,Epiphanie‘. Er verhehlt dies auch nicht in seinem Buch und lässt unumwunden seine Verehrung für Campbell durchschimmern. Dies kulminiert in der Annahme, dass alle Geschichten nach diesem von Campbell identifizierten Narrativ gestrickt seien. Und freilich, derart formalistisch-strukturalistische Arbeiten haben - wie auch Vladimir PropPs (1972) Studie zum russischen Zaubermärchen - eine immense Suggestionskraft, erscheinen augenblicklich eine Weltformel für Geschichten aller Art zu sein. Dass dies aber nicht unproblematisch ist, darauf wird weiter unten einzugehen sein. Entscheidend ist an dieser Stelle aber, und da laufen auch die Digital Game Studies Gefahr, dem Campbell'schen Monomythos aufzusitzen, dass man sich stets bewusst hält, dass Mythen mehr sind als Narrative und dass Mythen auch mit anderen Narrativen als dem Campbell'schen erzählt werden können. Damit soll aber keinesfalls die umfassende kulturelle Wirkung des Monomythos bestritten werden, es soll vielmehr unterstrichen werden, dass man für alle Erscheinungsformen des Mythos offen sein sollte. In diesem Sinne ist die Marquard'sche Polymythie nicht bloß als ein Nebeneinander

\footnotetext{
${ }^{319}$ Man denke hier erneut an Luhmanns Ausführungen zum System und dessen Umwelt. Vgl. LuHMANN (2009).
} 
verschiedener mythologischer Narrative zu betrachten, sondern als eine Koexistenz diverser Mythenkonzepte.

Im Folgenden konzentriert sich die Arbeit aber dennoch, wie ein Großteil der substantialistischen Mythenforschung, auf den Monomythos. Dies hat einen pragmatischen Grund - neben den wenigen digitalen Spielen, die nicht narrativ sind, aber dennoch auf Mythologien rekurrieren wie Age of Mythology (2002), folgt die überwiegende Mehrheit jener digitalen Spiele, die den Mythos integrieren, dem Monomythos. Besonders erhellend und heuristisch wertvoll ist der Monomythos, nicht bloß bei der Analyse digitaler Spiele, in struktureller Hinsicht. Neben Campbells strukturalistischen Arbeiten zum Mythos hat sich auch der französische Strukturalist Claude Lévi-Strauss mit der Struktur des Mythos auseinandergesetzt.

In einem Mythos kann alles vorkommen; es scheint, daß die Reihenfolge der Ereignisse keiner Regel der Logik oder der Kontinuität unterworfen ist. Jedes Subjekt kann ein beliebiges Prädikat haben, jede denkbare Beziehung ist möglich. Dennoch entstehen diese anscheinend so willkürlichen Mythen mit denselben Charakterzügen und oft denselben Einzelheiten in den verschiedensten Regionen der Welt. Daher stellt sich das Problem: wenn der Inhalt eines Mythos ganz zufällig ist, wie läßt sich dann verstehen, daß die Mythen von einem Ende der Welt zum anderen einander so sehr ähneln? (LÉVI-STRAUSS 1972, 228)

Wie Campbell stellt auch Lévi-Strauss fest, dass Mythen, wenn man sie strukturalistisch betrachtet, global wie historisch frappierende Ähnlichkeiten aufweisen, die selbst dann gegeben sind, wenn kein Kulturkontakt zwischen den betreffenden Kulturen vorherrschte. Von dieser Beobachtung ausgehend folgert Lévi-Strauss, dass es ein „Strukturalgesetz des betreffenden Mythos“ geben müsse. (ebd., 240) Dies betont auch Hans Blumenberg in seiner Arbeit am Mythos, wenn er konstatiert: „Mythen sind Geschichten von hochgradiger Beständigkeit ihres narrativen Kerns und ebenso ausgeprägter marginaler Variationsfähigkeit.“ (BlumEnberg 2006, 40) Mythen, und allen voran der Monomythos, sind Narrative von erstaunlicher Konstanz.

Wie Eliade und Hübner hebt auch Blumenberg auf die funktionalistische Dimension des Mythos ab. „Die Geschichte sagt, daß schon einige Ungeheuer aus der Welt verschwunden sind, die noch schlimmer waren als die, die hinter dem Gegenwärtigen stehen; und die sagt, daß es schon immer so oder fast so gewesen ist wie gegenwärtig.“ (ebd., 41) Für Eliade fungieren Mythen als Vergewisserung der (eigenen) Ursprünge, für Hübner als Anleitung zum alltäglichen Leben und für Blumenberg als Bestärkung, dass sich auch die aktuellen Hürden überwinden lassen, weil man es bereits vermochte, Hindernisse hinter sich zu lassen, die größer und bedrohlicher waren. Allen ist gemein, dass sie auf die Ordnungsfunktion des 
Mythos abheben, wenn man unter Ordnung nicht nur einen bestimmten systemischen Zustand, sondern auch Orientierung versteht. Bei Eliade dienen Mythen der Orientierung des Subjekts im Jetzt, indem sie einen Bezug zu einem vergangenen mythischen Urzustand herstellen, bei Hübner ist dieser Zustand noch erhalten und manifestiert sich in einer idealen Ordnung, die der Mythos seinen Anhängern didaktisch, und damit orientierend, vermittelt und bei Blumenberg helfen Mythen dem Individuum bei der Orientierung in gegenwärtig schwierigen Situationen, die es zu meistern gilt, um den idealen Ordnungszustand künftig wieder zu erreichen.

Diese drei Mythenforscher verdeutlichen zugleich, dass die Orientierungsfunktion des Mythos alle drei Zeitebenen betrifft - Vergangenheit (Eliade), Gegenwart (Hübner) und Zukunft (Blumenberg). Dementsprechend weitgreifend ist die Ordnung und Orientierung stiftende Funktionsmacht des Mythos zu sehen. Dieser funktionale Aspekt von Mythen findet sich auch in mythologischen interaktiv-narrativen digitalen Spielen wieder, welche häufig vom Aufbau der Spielwelt, ihrer sozialen Struktur sowie den ihnen inhärenten Kulturen komplex sind und bedingt durch ihre lange Spieldauer viele Spielsessions erfordern, die z.T. Wochen (besonders bei berufstätigen ${ }^{320}$ Spielern) auseinander liegen können. ${ }^{321}$ All diese Faktoren tragen zu einer potenziellen Unüberschaubarkeit des digitalen Spiels bei, die es aus designerischer Sicht zu vermeiden gilt. Die Implementierung des Mythos kann hierbei helfen. Durch die Anbindung an das (mythologische) Narrativ kann sich der Spieler besser an den bisherigen Spielverlauf erinnern (Vergangenheit), er kann aber auch aus der Rollenerwartung, (vgl. dazu auch DAHRENDORF 2010) die an den mythischen Helden (als standardisierte Figur)

\footnotetext{
${ }^{320}$ Diese Tatsache ist von zunehmender Bedeutung für die digitale Spielindustrie. Unabhängig davon, welche der zahlreichen Studien zur (digitalen) Mediennutzung man betrachtet und unabhängig davon, für wie sinnvoll man das entworfene Forschungssetting der umfragebasierten Studien befindet, kann man doch den Trend verzeichnen, dass Spieler durchschnittlich immer älter werden. Die meisten Studien weisen ein Alter von über 30 Jahren aus. Vgl. dazu exemplarisch: https://www.game.de/blog/2016/06/07/der-durchschnittliche-gamer-indeutschland-ist-35-jahre-alt/ (30.06.2018). Dies bedeutet aber auch, dass sich digitale Spiele den Präferenzen wie persönlichen Kontexten dieser Zielgruppe anpassen müssen. Freilich muss man differenzieren. Der Altersanstieg wird primär mit dem zunehmenden Erfolg des Mobile Gamings zu erklären sein. Erfahrungsgemäß lassen sich in diesem Bereich der Spielkultur eher weniger Hardcore-Titel finden, Casual Games dominieren dagegen. Die Frage nach dem Hardcore Gaming wäre aber nicht zuletzt deshalb von großer Relevanz, da die meisten interaktiv-narrativen digitalen Spiele, welche massiv auf Mythen zurückgreifen, eben eher Hardcore Games sind. Betrachtet man exemplarisch einige populäre digitale (Hardcore-)Spieltitel der letzten Jahre unter thematischen Gesichtspunkten wie Heavy Rain oder GTA V, so fällt auf, dass beide Protagonisten, also sowohl Ethan Mars als auch Michael Townley Kinder haben, welche als NPCs auftreten, und mit denen der Spieler (intensiv) interagieren muss. Dies legt aber die Vermutung nahe, dass es für das Gameplay positiv sein kann, wenn der Spieler selbst Erfahrungen mit Kindern gemacht hat, um die emotionale Immersion empfinden zu können, die das Spiel ihm offeriert. Dementsprechend lässt sich annehmen, dass sich die Altersentwicklung im Hardcore Gaming ähnlich verhalten wird wie insgesamt, auch wenn (wissenschaftliche) empirisch valide Studien hierzu bislang fehlen.

${ }^{321}$ Man denke hier u.a. an mythologische interaktiv-narrative digitale Spiele wie Skyrim, welches zwischen 70 bis 100 Stunden vom Spieler abverlangen kann, um es durchzuspielen.
} 
gestellt wird, erschließen, wie er sich verhalten soll, auch wenn das im Programmcode nicht voll umfassend definiert ist (Gegenwart). Und letztlich sichert ihm das mythologische Narrativ bei aller Unsicherheit und allen Unwägbarkeiten, die vor ihm liegen, stets zu, dass er diese überwinden werde, da dies schon immer gelungen ist (Zukunft). Ähnlich wie andere Narrative dient der Mythos damit einem besonderen Zweck - der Komplexitätsreduktion.

„Die Welt verliert an Ungeheuern. Sie wird in einem zunächst gar nicht ethischen, eher physiognomischen Sinne >freundlicher`. Sie nähert sich dem Bedürfnis des dem Mythos zuhörenden Menschen an, in der Welt heimisch zu sein.“ (BluMENBERG 2006, 127) Am Anfang erscheint die Aufgabe des Helden unlösbar zu sein, zu groß wirkt die schiere Masse an Gegnern, die ihm entgegentreten, zu zahlreich die Gefahren, die auf ihn lauern. Nimmt er sich dieser Aufgabe aber an und arbeitet sich Stück für Stück am Mythos ab, so bemerkt man irgendwann, dass die Zahl der Gegner und Gefahren abgenommen hat und die Rettung der Welt plötzlich als möglich erscheint. Parallel dazu wird die Welt mit jedem überwundenen Widersacher ein anheimelnderer Ort. Die Verbindung zwischen Mythos und Aufgabe oder Quest wird im Abschnitt zum mythologischen Narrativ sowie im daran anschließenden Kapitel zum Mythos in digitalen Spielen noch von Bedeutung sein.

Was dieser Abschnitt verdeutlicht hat, ist, dass man einerseits die inhaltlichen wie funktionalen Aspekte von Mythen nur schwer voneinander trennen kann, dass es aber wohl Ansätze gibt, die einer Definitionsstrategie näher stehen als der anderen. In diesem Kapitel waren dies die substantialistischen Begriffe des Mythos, deren inhaltliche Schnittmenge in der Betrachtung des Mythos als Narrativ liegt. Darüber hinaus wurden kennzeichnende Charakteristika des Monomythos bisher allenfalls implizit erwähnt, sodass die Explikation dieser noch nachzuholen ist. Dies wird im Abschnitt zum mythologischen Narrativ besorgt. Damit zusammenhängend wurde Campbells Arbeit in diesem Abschnitt vernachlässigt, obwohl sie zu den wichtigsten gehört, die dem substantialistischen Paradigma verpflichtet sind. Dies liegt schlichtweg daran, dass ihr im Kapitel zum mythologischen Narrativ eine besondere Bedeutung zukommt. Abschließend sei zudem nicht verschwiegen, dass die Arbeit bewusst eine Perspektive ausblendet, die zwar ein lohnenswerter Zugang ist, aber aus Platzgründen leider ignoriert werden muss. Die Rede ist hierbei von jenen Gattungen, die traditionell eine große Nähe zum Mythos aufweisen wie Märchen oder Legende. Beide sind, gerade mit Blick auf The Legend of Zelda, bedeutsam, da nicht nur der Name der Reihe selbst auf die Legendenliteratur verweist, sondern auch die Figurenkonzeptionen bzw. konstellationen Einflüsse des Märchens aufweisen. Wo immer es in der Analyse notwendig 
erscheint, wird hierauf hingewiesen, auch wenn eine Betrachtung vergleichender Forschung $\mathrm{zu}$ diesem Thema leider ausbleiben muss.

\subsubsection{Funktionalistische Mythenforschung heute}

Greift man erneut auf die Assmann'sche Typologie zurück, so lassen sich die Mythenbegriffe (3), (4) und (7) als jene auffassen, die sich primär auf die funktionalistischen Aspekte von Mythen kaprizieren. Am prominentesten wurde dieser Ansatz von Roland Barthes vertreten sowie jenen Studien, die sich auf seine Arbeiten zur Mythenforschung beziehen. (vgl. BARTHES 2010) Jener Bereich der modernen Mythenforschung befasst sich nicht vorrangig mit der Aktualisierung von antiken Mythen in der Gegenwartskultur, sondern mit der Bildung moderner bzw. „nachantike[r] Mythen“. (WodianKa/EberT 2014, v sowie vgl. Wodianka/Ebert 2016) Stephanie Wodianka und Juliane Ebert haben mir ihrem Metzler Lexikon moderner Mythen ein beeindruckendes Buch vorgelegt, das ganz in der Tradition Roland Barthes' steht. ${ }^{322}$ Beeindruckend deshalb, weil es auch international als der bisher ambitionierteste Versuch betrachtet werden kann, eine Auswahl der gängigsten modernen Mythen anzubieten. Der Ausdruck ,nachantik‘ kann aber leicht irreführen, wenn man davon ausgeht, dass somit auch mittelalterliche oder frühneuzeitliche Mythenbildung in den Fokus rücken; das ist nicht der Fall. Stattdessen, der klassischen Dichotomie zwischen Vormoderne und Moderne der Geschichtswissenschaft (weitestgehend) verpflichtet, bezieht sich das Lexikon vornehmlich auf die Mythen des 20. Jahrhunderts.

Dabei begegnen die Herausgeberinnen entschieden jenen Sichtweisen, die moderne Mythenbildung mit ,postmoderner Beliebigkeit‘ gleichsetzen wollen. „In der Moderne kann alles zum Mythos werden - aber nicht alles wird in der Moderne zum Mythos.“ (ebd.) Zum modernen Mythos wird letztlich nur das, was auch eine konkrete Funktion zu erfüllen vermag, weshalb es nur konsequent ist, dass sich die neuere und neueste Mythenforschung mit Blick auf die Definitionsstrategien des Mythos neu auszurichten begonnen hat. „In den Vordergrund rückte in den letzten Jahrzehnten das Interesse am ästhetischen Funktionieren und an möglichen Funktionalisierungen von Mythen, das die Behauptung eines exklusiv antiken Phänomens ad absurdum führte.“ (ebd.) Mit der zunehmenden Abkehr vom Helleno- und Eurozentrismus der Mythenforschung nimmt sukzessive auch die Fokussierung auf substantialistische Mythenverständnisse ab, auch wenn dies keinesfalls zu einer vollständigen

\footnotetext{
${ }^{322}$ Dass derartige Forschungsausrichtungen auch lohnenswert für Arbeiten in den Digital Game Studies sein können, zeigt exemplarisch Eugen Pfisters Projekt zu ,politischen Mythen “ in digitalen Spielen, dessen Fortschritte er in seinem Blog regelmäßig zugänglich macht. Vgl. https://spielkult.hypotheses.org/1114\#more1114 (30.06.2018). Zu politischen Mythen im Allgemeinen vgl. FLOOD (2002).
} 
Abwendung von antiken bzw. ,historischen`323 Mythen führt - im Gegenteil. Christoph Jamme und Stefan Matuschek zeigen u.a. mit ihrem Handbuch der Mythologie, dass sich durch die funktionalistische Perspektive neue Zugänge zu traditionellen Gegenständen der Mythenforschung erhalten lassen. Letztlich führen diese beiden Herangehensweisen aber zu einer Aufspaltung der Mythenforschung.

So konstatieren Stephanie Wodianka und Juliane Ebert eine zunehmende wissenschaftliche Auseinandersetzung mit Mythen seit der zweiten Hälfte des 20. Jahrhunderts, wobei zwei Strömungen voneinander zu unterscheiden seien. Einerseits jene Tradition, die bestrebt ist, die Rezeption antiker Mythen in der gegenwärtigen Kultur zu untersuchen und andererseits diejenigen Studien, die die Entstehung neuer moderner Mythen in der Kultur untersuchen. (vgl. ebd.) Die erste Strömung ist eher substantialistisch orientiert, wohingegen die zweite eher funktionalistisch ausgerichtet ist. Prinzipiell wäre es aber begrüßenswert, beide Ansätze zu verbinden. Es ist zwar überaus wichtig, Mythen stärker funktionalistisch zu untersuchen, da dies einen Großteil ihrer Attraktivität über Zeitalter und Kontinente hinweg ausmacht, es wäre aber bedauerlich, dabei aus dem Blick zu verlieren, dass die mythologischen Inhalten eine große Anziehungskraft besitzen, was nicht zuletzt ebenso stark zu ihrer kontinuierlichen Produktion wie Rezeption beitragen dürfte. So legen vergleichende Betrachtungen von historischen wie modernen Mythen nahe, dass beide von ihren Inhalten wie ihren Funktionen her sehr ähnlich zu sein scheinen.

Die Herausgeberinnen des Metzler Lexikons moderner Mythen fassen unter den modernen Mythen fiktive und historische Figuren, Ereignisse, Orte, Ideen und Konzepte sowie Institutionen zusammen. Somit rekurrieren sie auf einen Aspekt, den Jan Assmann mit Bezug auf historische Mythen herausarbeitet. Es ist von sekundärer Relevanz für die Wirkkraft des Mythos bzw. dessen Eingang ins kulturelle Gedächtnis, so Assmann, ob die mythologisierte Entität von ihrem Status her fiktiv/fiktional oder faktisch/faktual ist; entscheidend ist, dass sie als relevant betrachtet wird. (vgl. ASSMANN 2007) Somit liegt die Vermutung nahe, dass die Kontinuität des Mythos nicht nur durch die fortwährende Aktualität seiner Inhalte und Funktionen $\mathrm{zu}$ erklären ist, sondern dass auch seine Genese sowie Weiterverarbeitung konstanten Mustern zu folgen scheint. Dieser Anfangsverdacht lässt sich mit Blick auf historisch-diachrone Studien zum Mythos erhärten.

\footnotetext{
${ }^{323}$ Hier und im Folgenden als Analogon zum Terminus ,historische Religion` verwandt.
} 
Eine Arbeit, die dies in prägnanter Form aber unter Berücksichtigung der Wirkung des Mythos von der Stein- bis zur Neuzeit besorgt, ist Eine kurze Geschichte des Mythos der britischen Religionswissenschaftlerin Karen Armstrong. Die Konstante der Mythen über die Jahrtausende hinweg ist dabei der Mensch als sinnsuchendes Subjekt. (vgl. ARMSTRONG 2007, 8) Die Existenz von Mythen bzw. deren Bildung führt Armstrong auf das „mythische[] Denken“ zurück, welches gegenwärtig in „Misskredit geraten“ sei. (ebd.) Durch mythisches Denken suchen Subjekte nach Sinn und ordnen auf diese Weise ihr Leben und ihre Umwelt. Von zentraler Bedeutung ist dabei, so Armstrong, die Fantasie. ${ }^{324}$ „Fantasie ist die Fähigkeit, die Religion und Mythologie hervorbringt.“ (ebd.) Mythisches Denken ist eine fantasievolle Tätigkeit, ein ästhetischer Prozess. So gesehen ist nicht nur die Funktion des Mythos als Produkt einer Bewältigung für die Menschen bedeutsam, sondern auch die Mythenbildung als Prozess dieser Bewältigung selbst. Dabei wendet sich Armstrong entschieden gegen die Vorstellung, dass Mythen etwas Eskapistisches oder Weltfremdes seien. „Die Mythologie erweitert den Horizont des Menschen ebenso wie die Wissenschaft. Sie befasst sich nicht mit einem Ausstieg aus dieser Welt, sondern [...] wie wir intensiver in ihr leben können“. (ebd., 9) Mythisches Denken ist demnach eine immanente Bewältigungsstrategie von immanenten Problemen, auch wenn Mythen (zumindest historische) oft innerhalb ihrer selbst Bezüge zu transzendentalen Welten herstellen.

Karen Armstrong hebt fünf Aspekte hervor, die für Mythen von zentraler Bedeutung sind. Mythen erwachsen (1) aus „der Erfahrung des Todes und der Angst vor Auslöschung“, sind (2) in der Regel mit Ritualen verbunden und (3) bewegen sich Mythen ,an der Grenze des menschlichen Lebens“, sie „befassen sich mit Extremen, sie zwingen uns, über unsere Erfahrung hinauszugehen“ und mit dem „Unbekannte[n]“ in Verbindung zu treten. (ebd.) Demnach sind Mythen Reaktionen auf menschliche Urängste, auf Grenzerfahrungen. ${ }^{325}$ Eine der wichtigsten Funktionen von Mythen ist deshalb der Abbau dieser Ängste und die

\footnotetext{
${ }^{324}$ Zur Rolle der Fantasie bei der Genese ,sekundärer Welten` bei J.R.R. Tolkien und The Legend of Zelda vgl. TALLON (2011).

${ }^{325}$ C.G. Jung merkt diesbezüglich an: „Das Absinken in die Triebsphäre führt darum nicht zur bewußten Realisierung und Assimilation des Triebes, weil das Bewußtsein sich sogar mit Panik dagegen sträubt, von der Primitivität und Unbewußtheit der Triebsphäre verschlungen zu werden. Diese Angst ist ja der ewige Gegenstand des Heldenmythus und das Motiv zahlloser Tabus." Jung (1954), 575. Das Chaos, dem sich Mythen somit aus funktionalistischer Sicht entgegenstellen, ist das Triebhafte und das Primitive als Kräfte des rohen Unkalkulierbaren. Die Triebe und das Primitive werden dabei vom „Archetypus [als] ein[em] Formprinzip der Triebkraft" geformt, hierdurch fass- und verstehbar. Ebd. Der Archetypus wird weiter unten erneut aufzugreifen sein. Vgl. dazu 3.4.2.
} 
Herstellung von Kontinuität und Sicherheit. ${ }^{326}$ Aus diesem Grund handeln Mythen als Erzählungen auch i.d.R. von einer bedrohten idealisierten Welt, die es zu retten, zu bewahren gilt. Mythen werden dabei (4) aber nicht zum Selbstzweck erzählt, sondern um Anweisungen für Situationen zu sein, in denen Menschen nicht weiter wissen. (vgl. ebd., 9 f.) Diese Funktion des Mythos haben bereits Kurt Hübner und Hans Blumenberg beschrieben. Was die religionswissenschaftliche Arbeit von Karen Armstrong im Unterschied zu vielen anderen aber hervorhebt, ist (5) die Existenz transzendentaler Welten in Mythen. (vgl. ebd., 10) Diese transzendentalen Götterwelten fungieren dabei als Vorbild der realen immanenten Welt, welche als Kopie der mythologischen Welt erscheint. Die Götterwelt, ob idealisiert oder nicht, erscheint als Welt von erstrebenswertem Zustand, sodass die Rezipienten dazu angeregt werden sollen, diesen dargestellten Verhältnissen zu folgen. „Mythen verleihen einer Realität, die die Menschen intuitiv spürten, Form und Gestalt.“ (ebd.) Diese Formgebung durch den Mythos wird dabei durch Nachahmung geleistet. Diese Nachahmungsfunktion des Mythos ist im Zusammenhang mit digitalen Spielen von signifikanter Bedeutung. Durch die Verwendung des Mythos in digitalen Spielen kann der Spieler, bewusst oder unbewusst, dazu angehalten werden, die für den Mythos üblichen (narrativen) Rollenerwartungen zu übernehmen. Auf diese Weise findet eine implizite Regulierung der Interaktionen des Spielers statt, ohne dass der Programmcode diesbezüglich explizite Verbote oder Sanktionen enthalten muss. Mythen tragen somit zur Etablierung eines (temporären), verallgemeinerten Anderen“ in digitalen Spielen und hierdurch zur handlungsbezogenen Selbstregulierung des Spielers mit Blick auf ludische Handlungen bei. (vgl. MEAD 1995)

„Die Mythologie diente uns also dazu, mit der misslichen menschlichen Lage fertig zu werden. Sie half Menschen, ihren Platz in der Welt und die richtige Orientierung zu finden.“ (ARMSTRONG 2007, 11) Diese Orientierungsfunktion, ob missliche (spielerische) Lage oder nicht, ist für Situationen des alläglichen Lebens ebenso zutreffend wie für das Spielen digitaler Spiele. Daneben betont Armstrong aber auch, dass Mythen Kunst seien, ein Teil ihres Reizes also auch im künstlerisch-ästhetischen Genuss ihrer Rezeption liege. „Mythologie ist eine Kunstform, die über die Geschichte hinaus auf das Zeitlose der menschlichen Existenz verweist und uns hilft, jenseits des chaotischen Flusses zufälliger Ereignisse den Kern der Wirklichkeit zu erfassen.“ (ebd., 13) Menschen suchen immer „ein

\footnotetext{
${ }^{326}$ Zum Erzählen und Schreiben als Kulturtechniken zur Angstbewältigung des Subjekts im Allgemeinen vgl. PenNeBAKer/Evans (2014). Digitale Spiele mit mythologischen Inhalten und Funktionen können aber eine ähnlich gelagerte angstnehmende Funktion für das Subjekt erfüllen. Im Unterschied zum Erzählen und Schreiben als strukturierenden, angstabbauenden Tätigkeiten geht es beim Spielen aber um die angstbewältigende Handlung, indem das Subjekt seine Angst performativ überwindet, wenn es sich dieser stellt.
} 
Transzendenzerlebnis“, einen Moment vollkommener Ekstase, den die Menschen heute aber immer seltener in der Religion, sondern in „Kunst, Musik, Lyrik, Rock, Tanz, Drogen, Sex oder Sport“ finden. (ebd.) Ebenso muss ein Mythos den Menschen in Entzückung versetzen bzw. ihn entrücken können, und wenn „ein Mythos das nicht mehr [1eistet], so hat er sich überlebt und stirbt.“ (ebd.) An diesem Punkt werden auf mehrfache Weise Verbindungen zum Spiel aufgezeigt. ${ }^{327}$ Erstens können Mythen genau wie Spiele, Roger Caillois hat hierauf mit seinem Ausdruck ,Ilinx“ hingewiesen, Rauschzustände im Subjekt auslösen. Zweitens teilen sich Mythen, Spiele und Rituale hierdurch das, was Victor Turner unter ,liminalem‘ Zustand versteht und drittens wird zudem eine Verbindung zwischen Mythos, Spiel und Religion ersichtlich, die sich mit Clifford Geertz' funktionalistisch-kulturalistischer Religionsdefinition fassen lässt. Eine Religion ist demzufolge:

(1) a system of symbols which acts to (2) establish powerful, pervasive, and long-lasting moods and motivations in men by (3) formulating conceptions of a general order of existence and (4) clothing these conceptions with such an aura of factuality that (5) the moods and motivations seem uniquely realistic. (GEERTZ 2002b, 90)

Diese Definition lässt sich zu großen Teilen auch verwenden, um heuristisch gewinnbringende funktionalistische Begriffsdefinitionen von Mythos, Spiel und Ritual aufzustellen, wenn man den systembezogenen Ansatz akzeptiert. Freilich folgen hieraus weitere Begriffsauffassungen, wie sie funktionalistische Begriffsstrategien häufiger aufweisen, die es aber auch ermöglichen, Phänomene jenseits historischer Religionen oder Mythen zu untersuchen. ${ }^{328}$ Interessant sind bei Geertz' Definition im Besonderen die Funktionen. Religionen erzeugen Stimmungen und Motivationen sowie generelle Ordnungen. Diese beiden Aspekte teilen sich Religionen, Mythen und Spiele. Sie sind auf bestimmte Stimmungen und Motivationslagen der Beteiligten angewiesen, damit diese an ihnen partizipieren können, sie sind darüber hinaus, als autopoietische System, aber imstande, diese selbst zu generieren. Die Ordnungssysteme, auf denen sie beruhen, sind dabei nicht nur relevant für ihre systeminternen Operationen, sie strahlen auch nach außen, indem sie anregen, diese Ordnungen auf die Systemumwelt, den Alltag zu übertragen. Im Vergleich zu

\footnotetext{
${ }^{327}$ Mythen und Spiele sind in der gegenwärtigen Medienkultur aber nicht bloß durch digitale Spiele verbunden. Ein weiteres Beispiel sind aktuell analoge wie digitale Trading Card Games (TCG) wie Magic: The Gathering, Yu-Gi-Oh! (1999 ff.) oder Hearthstone: Heroes of Warcraft (2014 ff.). Hierzu existieren bereits erste Studien wie diejenige Christoph STAubs (2011), der den mythologischen Hintergrund der Romane zur transmedialen Welt von Magic und deren Auswirkungen auf das und Manifestationen im TCG selbst betrachtet.

${ }^{328}$ So versuchen Arbeiten wie diejenigen von Geertz' durch ihr weites Verständnis des Gegenstandsbereichs auch Strömungen wie den Nationalsozialismus zu fassen, die zwar keine religiösen Bewegungen sind, die aber im Rahmen ihrer Inszenierung massiv auf religiöse oder quasi-religiöse Elemente zurückgreifen, um ihre Suggestionskraft zu erhöhen.
} 
Mythos und Religion mag dies mit Blick auf Spiele nicht intuitiv verständlich sein. Es sei in diesem Zusammenhang aber auf das Phänomen der ,Gamification‘ hingewiesen. (vgl. dazu FuCHS ET AL. 2014) Durch Gamification wird ein Phänomen, oft im Zusammenhang mit Simulationen, spielähnlich. Die Intention hierhinter ist, dass man Spiele als Ordnungssysteme einsetzt, um alltägliche Prozesse für die Beteiligten einerseits deutlicher werden zu lassen sowie andererseits interessanter $\mathrm{zu}$ machen, d.h. intrinsische Motivationen $\mathrm{zu}$ wecken. ${ }^{329} \mathrm{In}$ diesem Sinne wird Gamification zunehmend in der Wirtschaft sowie im Bildungssektor eingesetzt. (vgl. ReINERS/Wood 2015) Die Schnittstellen zwischen Mythos, Religion, Spiel und Ritual zu ergründen, ist ein interessantes Unterfangen, das an dieser Stelle aber leider nicht weiter verfolgt werden kann, da es den Rahmen der Betrachtung überschreiten würde. (vgl. Droogers 2012) Es sei nur erwähnt, da diese funktionalen Gemeinsamkeiten zwischen diesen vier Phänomenen in Kapitel 4 noch von Belang sein werden.

Darüber hinaus ist es wichtig, die Perspektive auf die Wirkungen und Funktionen von Mythos und Spiel zu lenken, wenn man deren ästhetischen Funktionen in interaktiv-narrativen digitalen Spielen nachgehen möchte.

Ein Mythos ist also wahr, weil er wirkt, nicht weil er uns faktische Informationen liefert. [...] Solange ein Mythos wirkt, wenn er uns also dazu bringt, unser Denken und unsere Gefühle zu ändern, uns neue Hoffnung gibt und uns zu einem erfüllteren Leben zwingt, besitzt er Geltung. (ARMSTRONG 2007, 15; Herv.i.O.)

Und dies gilt auch für das Spiel. Wo das Spiel nicht mehr wirkt, bricht Huizingas Zauberkreis in sich zusammen und das Spiel hört auf, ein Spiel zu sein. ${ }^{330}$ Deshalb sind funktionalistische Betrachtungsweisen derart bedeutsam - weil Spiele funktionale Ordnungssysteme sind. Mythos und Spiel brauchen beides; sie können in ihren Inhalten, in ihren Formen noch so konsistent sein, wenn sie ihre Wirkung verlieren, wenn die Menschen sich von ihnen abwenden, sie weder rezipieren, noch spielen, sind sie nicht mehr existent. Wirkung heißt im Sinne Jan Assmanns erinnern, heißt aktualisieren. Unterbleiben diese Aktualisierungen, dann enden Mythos wie Spiel gleichermaßen. ${ }^{331}$ Ein Grund für Die nicht endende Geschichte des Mythischen, wie Kurt Hübner seinen berühmten Aufsatz so treffend

\footnotetext{
${ }^{329}$ Im Zuge der Gamification findet auch die ,Selbstbestimmungtheorie“ von RYAN/DECI (2017) immer mehr Beachtung, da sie eine gezieltere Motivationssteuerung von Subjekten in spiel- oder spielähnlichen Kontexten unterstützt.

${ }^{330}$ So betont Huizinga etwa, dass der Spielverderber dadurch, dass er die Regeln des Spiels als nicht gültig betrachte, die Illusion des Spiels breche und dieses damit letztlich zerstöre. Vgl. HuIZINGA (1991), 20.

${ }^{331}$ Banale aber anschauliche Beispiele für dieses Phänomen mit Blick auf digitale Spiele lassen sich v.a. dann finden, wenn Online-Spiele eingestellt werden, da ihre Zugriffs- und Nutzungszahlen anhaltend zu gering sind. In solchen Fällen ist die endende Existenz eines digitalen Spiels aufgrund ausbleibender Rezeption nicht nur ein konstruktivistisches Gedankenspiel, sondern wirtschaftlicher Ernst, der ,Zauberkreis “ bricht tatsächlich zusammen. Exemplarisch sei an dieser Stelle an Age of Empires Online (2011-2014) erinnert.
} 
betitelt, und Gleiches gilt auch für das Spiel, ist deren Funktion als „Richtschnur“, als System, das seine Ordnung in die Systemumwelt überträgt. (vgl. HÜBNER 1986/87 sowie ARMSTRONG 2007, 15) Jene Aspekte werden weiter unten wieder aufgegriffen, wenn es konkret um den Mythos in digitalen Spielen geht. (vgl. 3.3) Im folgenden Abschnitt liegt der Fokus aber zunächst auf dem Mythos als Narrativ bzw. dem mythologischen Narrativ. Dabei sollen, neben der Darlegung seiner Struktur und Gestalt, auch zentrale Funktionen dieses Narrativs detaillierter beleuchtet werden, besonders diejenigen, die im Kontext digitaler Spiele von Relevanz sind.

\subsection{Der Mythos als Narrativ - das mythologische Narrativ}

Joseph CAmpbell (2011) stellt in seinem Werk Der Heros in tausend Gestalten ein dreiphasiges Reisemodell des Helden ${ }^{332}$ vor, das er aus Vergleichsanalysen von zahlreichen Mythen, Religionen, Märchen und Sagen aus verschiedenen Kulturen auf der ganzen Welt und aus unterschiedlichen Epochen gewinnt. Nach Campbell findet sich der Archetypus ${ }^{333}$ der Heldenreise ${ }^{334}$ in vielen Geschichten wieder und kennzeichnet sich durch eine Abfolge von siebzehn Stationen. Mit dem russischen Formalisten Vladimir Propp gesprochen könnte man auch von „Funktionen der handelnden Personen“ anstatt von Stationen sprechen, unter denen Propp „wiederkehrende[] konstante[] Größen“ versteht, die konstitutiv für die von ihm untersuchten russischen Märchen sind. (PROPP 1972, 26) Diese Modifikation kann man ebenfalls um Roland Barthes' berühmte Unterscheidung von narrativen Funktionen in Kardinalfunktionen und Katalysen erweitern. (vgl. BARTHES 1988) Unter Kardinalfunktionen versteht er dabei jene Funktionen, die für die narrative Struktur einer Erzählung unerlässlich sind, wohingegen Katalyse jene Funktionen bezeichnet, die Kardinalfunktionen näher beschreiben, attribuieren und somit rein additiv sind. (vgl. dazu auch 2.4 sowie CHATMAN 1993, 53 ff.) Dies bedeutet aber auch, dass Katalysen substituierbar und dementsprechend nicht notwendig für das Vorhandensein eines Narrativs sind. Im Folgenden wird - angesichts

\footnotetext{
${ }^{332}$,Held` heißt in diesem Fall nicht bloß Protagonist, sondern Held meint den mythischen Helden. Campbell selbst merkt dazu an: „Der Heros, wie er im zusammengesetzten Monomythos erscheint, ist eine Gestalt von außergewöhnlichen Gaben.“ CAMPBELl (2011), 50. Jedoch findet man diesen mythischen Helden in der gegenwärtigen Medienkultur nicht mehr in derselben figurenkonzeptionellen Ausgestaltung vor wie in den Mythen der griechisch-römischen Antike. Der Held hat sich im Laufe der westlichen Rezeptionsgeschichte gewandelt, was v.a. in Medien wie dem Superhelden-Comic evident wird. Vgl. dazu BACKE (2011).

${ }_{333}$ Zur Kritik an einem archetypischen Mythosverständnis im Lachmann'schen Sinne vgl. BLUMENBERG (2006), 192.

${ }^{334}$ Campbell fasst seine Ausführungen zu den Abschnitten und Stationen der Heldenreise in einem Diagramm zusammen. Vgl. CAMPBELL (2011), 264.
} 
der skizzierten Modifikationen - nicht mehr von Stationen der Heldenreise gesprochen, sondern von Kardinalfunktionen der Heldenreise (als mythologisches Narrativ).

Die drei Phasen von Campbells Modell der Heldenreise orientieren sich an den drei Stadien der ,rites de passage‘ des französischen Ethnologen Arnold van Gennep, wie sie auch Victor Turner gebraucht. (vgl. GENNEP 2005) „Der Weg, den die mythische Abenteuerfahrt des Helden normalerweise beschreibt, folgt, in vergrößertem Maßstab, der Formel, wie die Abfolge der rites de passage sie vorstellt: Trennung - Initiation - Rückkehr, einer Formel, die der einheitliche Kern des Monomythos genannt werden kann.“ (CAMPBELL 2011, 42; Herv.i.O.) Die Phase der Trennung ist dabei die Phase des Aufbruchs und besteht aus den folgenden fünf Kardinalfunktionen: „Berufung“, „Weigerung“, „,[ü]bernatürliche Hilfe“, „[d]as Überschreiten der ersten Schwelle“ sowie „[d]er Bauch des Walfischs“. (vgl. ebd., 63108) In dieser ersten Phase geht es darum, dass der Held seine Aufgabe erhält, wozu er seine gewohnte Welt aber verlassen muss. Aus Furcht vor dem Unbekannten weigert er sich zunächst, kann aber dennoch mithilfe eines (übernatürlichen) Mentors umgestimmt werden, woraufhin der Held seine Reise aufnimmt. Während des zweiten Abschnitts warten die folgenden Kardinalfunktionen auf den Heros: „Der Weg der Prüfungen“, „,[d]ie Begegnung mit der Göttin“, „[d]as Weib als Verführerin“, „Versöhnung mit dem Vater“, „Apotheose“ und „[d]ie endgültige Segnung“. (vgl. ebd., 109-209) Dieser Teil der Heldenreise stellt sich als eine einzige fortwährende Prüfung dar. Zudem wird hieran die strikte dichotomische Teilung der Diegese des mythologischen Narrativs in ,Gut' und ,Böse', wie sie für Mythen konstitutiv ist, auch an deren narrativen Aspekten deutlich. So besteht die Welt ebenso aus ,guten', hellen, freundlichen wie ,bösen', dunklen, gefährlichen Orten. Auf diese Weise werden auch die menschlichen Urängste vor dem Dunklen und Unbekannten, die Mythen zu bewältigen helfen sollen, artikuliert. Der mythische Held hat keine Wahl, er muss sich diesen Ängsten stellen und sie somit überwinden. ${ }^{335}$ Dabei ist er aber keinesfalls, auch wenn ihn die Aura des Auserwähltseins umgibt, allein, sondern er kann auf die Hilfe vieler verbündeter Figuren vertrauen. Dem stehen aber mindestens genauso viele, böse‘ Figuren gegenüber, die den Held davon abhalten wollen, seine Aufgabe zu vollenden. Die dichotomische Teilung der Diegese betrifft also letztlich auch die Figuren. ${ }^{336}$ (vgl. MATUSZKIEWICZ 2015a, 658 f.)

\footnotetext{
${ }^{335}$ Einen interessanten Aufsatz zum Verhältnis von (Handlungs-)Freiheit und vorbestimmten Schicksal des Helden findet man bei RASMUSSEN/RASMUSSEN (2011).

${ }^{336}$ Dies wird daran sichtbar, dass es keine oder nur sehr wenige Figuren gibt, die zwischen dem ,guten` und dem ,bösen“ Figurenlager angesiedelt sind. So zeichnen sich insbes. die Figuren der The Legend of Zelda-Reihe dadurch aus, dass sie sich einer der beiden Gruppen eindeutig zuordnen lassen, wobei ihre Zugehörigkeit v.a.
} 
Dieser Schwellenzustand des Geprüftwerdens endet in der Regel mit dem ultimativen Kampf. Der Held muss sich an den gefährlichsten Ort der mythischen Welt begeben, um dem personifizierten ,Bösen“ gegenüberzutreten. Der Held obsiegt und begibt sich auf die Rückreise, die Rückkehr in seine gewohnte Welt, womit die dritte und letzte Phase der Heldenreise anbricht. Der Held hat aber seine finale Prüfung noch nicht überstanden, auch wenn das personifizierte ,Böse‘ überwunden wurde. Dieser letzte Abschnitt besteht aus den folgenden Kardinalfunktionen: „Verweigerung der Rückkehr“, „[d]ie magische Flucht“, „Rettung von außen“, „Rückkehr über die Schwelle“, „Herr der zwei Welten“ und „Freiheit zum Leben“. (vgl. CAMPBell 2011, 210-263) Hat der Held sich anfangs geweigert, die Aufgabe anzunehmen und die erste Schwelle zu übertreten, so zögert er nun erneut, paradoxerweise aber, obwohl die Rückkehr in die vertraute Welt winkt. Je nach Umsetzung kann gerade dieser dritte Akt sehr unterschiedlich ausfallen. Gemein ist ihnen aber dennoch, dass der Held sich dann doch noch dazu entschließt, den Schwellenübertritt erneut zu wagen und in die Heimat zurückzukehren, wobei er in der Regel die Weltenrettung vollbringt oder das Mittel zur Weltenrettung (bspw. in Form eines Elixiers) mit sich führt.

Auch wenn Campbells Fokus primär substantialistisch ist und er hierdurch sein Modell der Heldenreise herausarbeiten kann, wozu er immense Textmengen verarbeitet und dieses intensive Quellenstudium anhand seiner unzähligen Textbeispiele immer wieder durchschimmern lässt, fragt Campbell am Ende seiner Arbeit dennoch nach den Funktionen des Mythos.

Denn den Anliegen und Bedürfnissen der Individuen, Rassen und Zeitalter kommen sie [die Mythen] so aufgeschlossen entgegen wie das Leben selbst, wenn die Frage nicht auf ihr Wesen, sondern auf ihre Funktion dringt, darauf, wie sie in der Vergangenheit der Menschheit gedient haben und wie sei es heute könnten. (ebd., 404)

Obwohl Campbell ausschließlich historische Mythen behandelt, betont er erstens als einer der ersten in der modernen Mythentheorie die Wichtigkeit von funktionalistischen Ansätzen und wirft zweitens darüber hinaus die Frage auf, inwieweit neben den Funktionen historischer Mythen nicht auch die Funktionen moderner Mythen oder aktualisierter historischer Mythen untersucht werden müssten. Wie die meisten bereits erwähnten Studien hebt Campbell auf drei funktionale Elemente von Mythen ab, die uns weiter oben schon mehrfach begegnet sind

durch ihr Verhalten gegenüber dem Avatar deutlich wird. ,Gute' Figuren helfen dem Avatar oder behelligen ihn zumindest nicht, wohingegen die ,bösen“ Figuren permanent versuchen, dem Avatar auf die eine oder andere Art und Weise zu schaden. Mittlerweile spielt die Reihe selbst mit der habitualisierten Annahme der Spieler, dass Figuren, die dem Avatar anfangs gegenüber freundlich auftreten, gute Figuren sind. In Breath of the Wild (2017) versuchen Attentäter der Yiga-Bande bspw., den Spieler zu täuschen, ehe sie ihn angreifen. Vgl. hierzu exemplarisch das Let's Play von MIKEL https://www.youtube.com/watch?v=pl6SLnY11CE (30.06.2018). 
- Ordnung, Sinnstiftung und -suche. Darüber hinaus gibt Campbell aber einige interessante Anstöße, wie diese Funktionen operativ arbeiten. Die Ordnungsfunktion des Mythos ist nach Campbell vorrangig eine Unterordnungsfunktion. Im Mythos zähle nicht primär das Individuum, es hat nur so weit Bedeutung, wie es seine Subjektivität am Kollektiv ausrichtet, sich diesem unterordnet, um seine (vom Kollektiv) zugeordnete Rolle zu übernehmen. Dementsprechend stellt Campbell fest, ,daß so, wie das Individuum ein Organ der Gruppe ist, der Stamm, die Stadt und schließlich die ganze Menschheit nichts anderes sind als Phasen des kosmischen Riesenorganismus.“ (ebd., 406)

Wir erkennen, dass Unterordnung ein Mechanismus ist, der stratifikatorisch durchdringend wirkt. Er betrifft den Makrokosmos und seine Bestandteile ebenso wie den Mikrokosmos und dessen Elemente. Diese Funktionalisierung der mythologischen Ordnungsfunktion finden wir auch heute noch in Mythen, z.B. in Ocarina of Time. Es geht hier, wie auch in allen anderen Teilen der Serie, nicht um die Bedürfnisse des Individuums, auch wenn dieses handelnd im Mittelpunkt steht. Es handelt nämlich nicht, um sich persönliche Vorteile zu verschaffen, sondern um das Kollektiv in Form des idealisierten Königreiches Hyrule zu retten. Handlungsmovens ist also nicht Egoismus, sondern Altruismus. Der Mensch findet seinen Platz in der Welt, indem er dabei hilft, diese zu erhalten. Zweitens wendet sich Campbell der Sinnstiftung durch „das Motiv des Sich-Schickens ins Unabwendbare“ zu. (ebd.) Was kryptisch klingt, wird an Exempeln schnell konkret. Betrachtet man die Jahresfeste, welche Bestandteil sehr vieler historischer Mythen sind, so muss man sich die Frage stellen, warum Menschen diese begingen, wenn das Gefürchtete dennoch nicht abzuwenden war. ${ }^{337}$ Nach Campbell bestand der Zweck dieser Rituale aber auch nie darin, etwas aufzuhalten, sondern die Gemeinschaft darauf einzustimmen, etwas auszuhalten. Mythische Rituale erfüllen demnach die Funktion, dem Unvermeidlichen einen Sinn zu verleihen und hierdurch die Belastung zu reduzieren. Insofern helfen Mythen also weniger beim Überwinden von Bedrohungen, sondern beim Verwinden einer permanenten Drohkulisse.

Drittens fokussieren Mythen einen Aspekt der individuellen Sinnsuche, der nicht intuitiv verständlich sein mag. Mythen helfen dem Menschen, sich in sich selbst zu suchen. (vgl. ebd., 407 f.) Wenn der mythische Held in der Initiation auszieht, um gegen das ,Böse‘ zu kämpfen und die Welt zu retten, indem er sich in Gefahr begibt, indem er sich mit menschlichen

337 Zur Bedeutung von Jahreszeiten für Mythen vgl. auch FRYE (1964), 165-243, welcher seine vier identifizierten ,Mythen` - Komödie (Frühling), Romanze (Sommer), Tragödie (Herbst) sowie Ironie und Satire (Winter) - den vier Jahreszeiten zuordnet. 
Urängsten konfrontiert sieht, um diese letztlich zu über- bzw. verwinden, so kann auch der Rezipient, wenn auch passiv, ${ }^{338}$ seine eigenen Ängste zu bewältigen lernen. Überspitzt gesagt, könnte man festhalten, und Joseph Campbell bezieht sich nicht ohne Grund auf die Arbeiten Sigmund Freuds und Carl Gustav Jungs, dass die Reise des mythischen Helden in eine gefahrvolle Welt zugleich die Reise des Rezipienten in seine eigenen Psyche ist, wodurch der Mythos zu einer metaphorischen Seelenreise des Rezipienten wird. ${ }^{339}$

Vielleicht erklärt sich hierdurch die anscheinend allzeitige Mythophilie, auch wenn Campbell selbst hieran nicht glaubt. „Nicht nur haben die forschenden Augen der Teleskope und Mikroskope den Göttern keinen Schlupfwinkel mehr gelassen: auch die Gesellschaft, wie sie einst sich von den Göttern tragen ließ, existiert nicht mehr.“ (ebd., 409) Wie bei Durs Grünbein verschwimmen Religion und Mythos hier ineinander, sodass Säkularisierung und Entmythologisierung eins werden. Aus der Sicht der neuesten Mythentheorie hat sich diese Feststellung Campbells aber nicht bewahrheitet. Zwei Gründe mögen ursächlich dafür sein, dass Campbells Prognose nicht eintraf. Einerseits darf der zeithistorische Kontext nicht außer Acht gelassen werden. Als Campbells Studie entstand, zerstörten Atombomben Hiroshima und Nagasaki. Neben den sozialen, kulturellen und politischen Umwälzungen, die dies mit sich brachte, wurde das naturwissenschaftliche Paradigma $\mathrm{zu}$ einem noch dominanteren Wahrnehmungsdispositiv. Hatten die fulminanten Erkenntnisfortschritte der Physik in der ersten Hälfte des 20. Jahrhunderts den Menschen von Allwissenheit träumen lassen, so addierten die Nutzungsmöglichkeiten der Nuklearenergie noch die Vorstellung von Allmacht hinzu. Der Mensch, so die gängige Überzeugung dieser Schule der Säkularisierungstheorie, werde selbst gottgleich und benötige weder Schutzgötter noch göttlichen Rat und entferne sich dadurch zunehmend von Religion und Mythos.

Passenderweise greift Campbell mit dem Teleskop eine der prominentesten Metaphern auf, wenn es darum geht, die (kosmische) Allwissenheit des Menschen hervorzuheben. Der wissenschaftliche Fortschritt lässt den Mythos somit als naiv und unglaubwürdig erscheinen,

\footnotetext{
${ }^{338}$ Eine Besonderheit des Mythos in digitalen Spielen liegt nun aber darin, dass der Spieler im Unterschied zum Leser oder Zuhörer historischer Mythen nicht passiv ist, sondern aktiv via Avatar in das Geschehen eingreifen kann. Das bedeutet letztlich, dass der Spieler nicht bloß Passagier seiner Seelenreise ist, sondern eher der Reiseführer.

${ }^{339}$ Christopher Vogler merkt hierzu an: „Campbells Gedanken laufen hier parallel zu denen des Schweizer Psychologen C.G. Jung, der seine Archetypen auf ähnliche Weise [wie Campbell] beschrieb: als beständig wiederkehrende Charaktere oder Kräfte, die in den Träumen aller Menschen und den Mythen sämtlicher Kulturen erscheinen. [...] Bei seiner Arbeit hatte er [Jung] eine auffällige Übereinstimmung zwischen den Gestalten aus den Träumen seiner Patienten und den geläufigen Archetypen aus Mythen festgestellt. Daraus zog er den Schluß, daß Träume wie Mythen aus einer tieferen Quelle gespeist werden: aus dem kollektiven Unbewußten der Menschheit.“ VOGLER (2010), 51; Herv.i.O.
} 
wodurch freilich ein mythenkritischer Mythenbegriff offenkundig wird. Auch wenn ihn die Mythentheorie heute nur noch für bedingt sinnvoll hält, so darf man seine Wirkmacht dennoch nicht unterschätzen, v.a. nicht in der unmittelbaren Nachkriegszeit. Einer Zeit, in der Bertolt Brecht Sagredo seinen Freund Galilei in Anbetracht dessen euphorischer Einschätzung der Folgen seiner astronomischen Forschung via Fernrohr fragen lässt: „Gott! Wo ist Gott?“ (BRECHT 1963, 33)

Zweitens zeigt sich, dass eine Fokussierung auf historische Mythen leicht dazu führen kann, von einer aktuellen Mythenlosigkeit auszugehen. So stellt Karen Armstrong noch vor wenigen Jahren fest: „Heutzutage ist mythisches Denken in Misskredit geraten“. (ARMStrong 2007, 8) Wie Campbell folgt auch Armstrong einem Mythenverständnis, das sich primär an historischen Mythen als Untersuchungsgegenstand ausrichtet. Diese nehmen aktuell sicherlich nicht mehr den Stellenwert ein, den sie Jahrtausende lang inne hatten, dass man hieraus aber keineswegs eine Entmythologisierung ableiten sollte, haben die Arbeiten der modernen funktionalistischen Mythenforschung gezeigt, welche den Mythenreichtum unserer Gegenwart in seiner Vielfalt herausarbeiten konnten, indem sie sich von der überkommenen helleno- und eurozentrischen Fixierung lösten. Freilich kann man Campbell jedoch keinen Vorwurf machen, schon deshalb nicht, weil das Konzept der modernen Mythen erst zehn Jahre nach Campbells Werk mit den Arbeiten Roland Barthes’ an Profil gewann.

Man könnte u.U. auch noch einen dritten Grund anführen, der sich in einer Verschiebung der Schwerpunktsetzung manifestiert: „Lag bei ihnen [den Mythen] aller Sinn im Kollektiv, in den großen anonymen Formen und nicht im mündigen Individuum, so ist heute das Kollektiv wie die Welt überhaupt jeden Sinnes bar, und alles ist im Individuum.“" (CAMPBELL 2011, 410) Eine (aufgeklärte) Gesellschaft, in der das Individuum mehr gilt als das Kollektiv, ist per definitionem mythenlos. Hierdurch verändert sich auch die Rolle des Helden als Heros, der sich selbst dem Gemeinwohl unterordnet. „Nicht die Gesellschaft hat den schöpferischen Heros zu lenken und zu erretten, sondern er sie.“ (ebd., 414) Freilich ist dies in einer Zeit zunehmender globaler Vernetzung, besonders im Zuge der Digitalisierung, vollkommen illusorisch. Vielmehr gilt, was Friedrich Dürrenmatt bereits in den 21 Punkten zu seinen Physikern unter Punkt 17 betont: „Was alle angeht, können nur alle lösen.“ (DüRRENMATT 1998, 92) Problemlösung für das Kollektiv kann heute nur noch kollektiv erfolgen und nicht mehr vom Erlöserindividuum geleistet werden. Hierin liegt meines Erachtens aber auch ein Großteil der Strahlkraft des Mythos in der Gegenwart. Unsere Welt ist undurchsichtig und zu komplex, als dass wir sie noch in Gänze begreifen könnten. Mythen bieten uns nicht nur 
Deutungsangebote, um dem Chaos zu entfliehen, sondern sie versichern uns, dass unsere individuelle Agency, die immer kleiner wird, trotzdem ausreichen kann, um die Welt zu retten und wenn auch nur für die kurze Zeit der Rezeption des Mythos.

Christopher Vogler hat in seiner Auseinandersetzung mit Joseph Campbells Der Heros in tausend Gestalten zweierlei erkannt. Einerseits die unglaubliche Kontinuität der Grundstruktur des Mythos, wie Joseph Campbell sie beschreibt. Auch wenn man konstatieren muss, dass Vogler die Extension des mythologischen Narrativs erheblich überschätzt. „Alle Geschichten bestehen im Grunde aus einer Handvoll stets wiederkehrender Bauelemente, die uns auch in Mythen, Märchen, Träumen und Filmen immer wieder begegnen. Der Oberbegriff für all diese Bauelemente lautet: die Reise des Helden."340 (VoGler 2010, 35; Herv.i.O.) Es soll dabei keineswegs bestritten werden, dass das mythologische Narrativ und seine modernen Abwandlungen zu den populärsten der Kultur des 20. Jahrhunderts gehören, es wäre allerdings etwas reduktionistisch, die Grundstruktur aller Geschichten auf dieses Narrativ zurückführen zu wollen. ${ }^{341}$

Andererseits hat Vogler aber auch verstanden, dass sich die Zeiten gewandelt haben, dass Mythen immer noch aktuell sind, dass sie ihre Erscheinungsform aber dem gegenwärtigen Kontext anpassen. ${ }^{342}$ Dementsprechend hat Vogler auch Campbells Modell modifiziert. „Ich habe mir hier die Freiheit genommen, Campbells eigenen Entwurf leicht abzuändern, um die immer wiederkehrenden Filmthemen - wie ich sie zeitgenössischen Produktionen sowie einigen Klassikern entnommen habe - besser herauszustellen.“ (ebd., 53) Er hat das

\footnotetext{
${ }^{340}$ Zur Überschätzung der Reichweite des Reisemodells des Helden vgl. auch folgenden Abschnitt: „Die Grundvorstellungen, die wir in allen Mythen finden und die Campbell in Der Heros in tausend Gestalten beschrieben hat, können uns helfen, nahezu jedes menschliche Problem besser zu verstehen." VoGLER (2010), 52; Herv.i.O. Es ist zwar zweifellos richtig, dass Mythen, unter funktionalistischen Gesichtspunkten, Menschen Ordnung, Struktur und Orientierung geben und somit auch eine Problemlösungsstrategie sein können, es darf jedoch stark bezweifelt werden, dass dies auf ,nahezu jedes menschliche Problem“ zutrifft. Ein weiterer Punkt, der an der Extension des Reisemodells des Helden bei Vogler oft kritisiert wird, ist sein Verständnis von ,Reise‘. „Doch genauso oft gibt es Geschichten, in denen der Held eine Reise nach innen antritt, eine Reise des Herzens, der Seele, des Geistes.“ Ebd., 55. Begreift man Reise auf diese Weise, so wird jede intensivere Auseinandersetzung im Inneren des Protagonisten, jedes figureninterne Hadern, Zweifeln und Zerwürfnis bzw. dessen Verlauf zu einer inneren Reise. Will man jedoch das Reisemodell des Helden als das erhalten, was es ist, nämlich ein mythologisches Narrativ mit mythologischen Elementen, dann erscheint eine derartige Auffassung von Reise unzulässig, auch wenn CAMPBELL (2011) selbst diese Deutung nahelegt, indem er psychoanalytische Zugänge wählt.

${ }^{341}$ Die Gründe für die umgreifende Präsenz dieses Narrativs, v.a. in audiovisuellen Medien der Populärkultur, haben vielfältige Ursachen. Zum einen gibt es Filmschaffende wie George Lucas, der als großer Anhänger des Campbell'schen Modells gilt und seine wohl bekannteste Filmreihe, Star Wars (1977 ff.), bewusst nach dem Muster der Heldenreise nach Campbell aufgebaut hat. Zum anderen darf man auch den Einfluss von Christopher Voglers Praktischer Einführung nicht unterschätzen, die lange als Standardlektüre der Drehbuchschreiberausbildung in Hollywood verwendet wurde und die eine kondensierte Zusammenfassung von Campbells Werk darstellt. Vgl. dazu VogLeR (2010), 49-77.

${ }^{342}$ Vgl. hierzu den Mythosbegriff (2) nach Aleida und Jan Assmann.
} 
Reisemodell nach Campbell um jene Aspekte gekürzt, die zwar prototypisch für historische Mythen sind, die aber in ihren modernen Aktualisierungen wie auch modernen Mythen an sich kaum eine Rolle mehr spielen.

Vogler behält Campbells dreiaktigen ${ }^{343}$ Aufbau bei, reduziert die Kardinalfunktionen aber auf zwölf. ${ }^{344}$ Der erste Akt besteht aus der „Gewohnten Welt“, dem „Ruf des Abenteuers“, der „Weigerung“, der „Begegnung mit dem Mentor“ und dem „Überschreiten der ersten Schwelle“. Am Beispiel von George Lucas Star Wars: Krieg der Sterne kann man dies gut verdeutlichen. Luke Skywalker lebt auf Tatooine (gewohnte Welt), bis er auf die Droiden C3PO und R2-D2 trifft, die im Auftrage Leias Obi Wan suchen. R2-D2 folgend findet Luke Obi Wan und sie empfangen Leias Hilferuf (Ruf des Abenteuers/Begegnung mit dem Mentor). Der Ruf des Abenteuers ist dabei für das Reisemodell des Helden von so zentraler Bedeutung, da die „Aufforderung zum Abenteuer offenbart, um welchen Preis es gehen wird; sie steckt das Ziel des Helden deutlich ab“. (ebd., 60) Obi Wan ersucht Luke, ihn nach Alderaan zu begleiten, was Luke aber ablehnt, da er seine Familie nicht verlassen möchte (Weigerung). Bei seiner Rückkehr findet Luke seine Familie aber ermordet vor und beschließt, mit Obi Wan zu reisen und Tatooine zu verlassen (Überschreiten der ersten Schwelle). Entscheidend ist für die Annahme des Rufs des Abenteuers durch den Helden, dass er ein persönliches Motiv hierfür hat. In Lukes Fall ist dies die Ermordung seiner Familie durch die Sturmtruppen des Imperiums, wodurch das Imperium nicht länger ein abstraktes Böses ist, sondern für Luke eine „persönliche Bedeutung“ annimmt. (ebd., 61)

Der zweite Akt besteht aus „Bewährungsproben“, wobei Verbündete gewonnen werden, die dem Helden helfen, gegen seine Feinde zu bestehen. Während der Held diesen Bewährungsproben ausgesetzt ist, „,begreift er allmählich die Regeln in der anderen Welt“, in diesem Fall, dem vom Imperium beherrschten Universum. (ebd., 63) Dabei dringt der Held „zur tiefsten Höhle“ vor, unterzieht sich einer „[e]ntscheidende[n] Prüfung“, um daran anschließend eine „Belohnung“ zu erhalten. Luke trifft auf Han Solo und Chewbacca sowie später auf Leia, die ihm auf seiner Reise helfen, gegen seine Feinde (Darth Vader, Tarkin etc.) anzutreten. Dabei muss sich Luke mehreren Bewährungsproben wie Leias Rettung und der

\footnotetext{
${ }^{343}$ Vogler bemerkt dazu: „Filme lassen sich sehr häufig in drei Akte einteilen: Im ersten geht es um die Entscheidung des Helden zu handeln, im zweiten um die Handlung selbst und im dritten um die Konsequenzen, die daraus entstehen." VOGLER (2010), 63.

${ }^{344}$ Für eine tabellarische Gegenüberstellung der Reisemodelle Campbells und Voglers vgl. VogLER (2010), 54. Eine Aufzählung aller „Stadien im Abenteuer des Helden“ findet man (samt Schaubild des dramaturgischen Verlaufs der Heldenreise) ebenso bei Vogler. Vgl. ebd., 56. Eine etwas ausführlichere Zusammenfassung der zwölf Kardinalfunktionen der Heldenreise bietet Vogler auf 74 f. an.
} 
anschließenden Flucht aus dem Todesstern unterziehen. Nach der Planung der Zerstörung des Todessterns durch die Rebellen kehrt Luke zum Todesstern zurück (Vordringen zur tiefsten Höhle) und stellt sich, bei dem Versuch den Lüftungsschacht zu treffen, der die einzige Schwäche des Todessterns ist, Darth Vader indirekt in einem Raumschiffkampf (Entscheidende Prüfung), den er jedoch nur besteht, da Han Solo ihm zur Hilfe eilt. Durch Obi Wans Rat kann Luke letztlich den Todesstern zerstören und die von ihm ausgehende Gefahr abwenden (Belohnung).

Im dritten und letzten Akt begibt der Held sich auf den „Rückweg“, wobei er eine Art „Auferstehung“ durchläuft und mit dem „Elixier“ zurückkehrt. Lukes Rückweg ist dabei aber nicht die Rückkehr nach Tatooine, sondern die Rückreise nach Yavin IV, dem Hauptstütztpunkt der Rebellen, seiner neuen Heimat. Die Auferstehung ist in Star Wars: Krieg der Sterne nicht als solche gegeben, sondern wird durch die besondere Auszeichnung ersetzt, die Luke und seine Freunde für ihren Einsatz erhalten. Die „Rückkehr mit dem Elixier" ist ebenso eher metaphorischer Art und besteht darin, dass Luke sich den Rebellen anschließt, um gegen das Imperium zu kämpfen. ${ }^{345}$ Für das Reisemodell des Helden nach Vogler gilt, dass es verschiedene „Variationsmöglichkeiten“ der narrativen Struktur gibt. (ebd., 75) Das bedeutet, dass Kardinalfunktionen anders angeordnet, weggelassen, modifiziert oder gar ergänzt werden können, auch wenn sich massive Umstrukturierungen im mythologischen Narrativ als Reisemodell des Helden selten beobachten lassen.

Der Grund dafür, dass zwar, wie auch schon Claude Lévi-Strauss bemerkt, theoretisch unendlich viele Variationsmöglichkeiten vorliegen, um das mythologische Narrativ umzusetzen, diese Optionen aber dennoch kaum genutzt werden, d.h. dass mehr eine Variantenarmut als ein Variantenreichtum vorherrscht, hängt mit der Erzähllogik des mythologischen Narrativs zusammen. (vgl. dazu 2.4) Der Narratologe Tzvetan Todorov definiert das mythologische Narrativ nämlich nicht bloß (wie Campbell) über eine Verkettung von bestimmten Kardinalfunktionen, sondern weitet die Perspektive, indem er die Abfolge der narrativen Funktionen bzw. die damit einhergehende Transformation der Zustände analysiert. So kommt er zu einer Unterscheidung zwischen zwei verschiedenen Organisationsformen von Narrativen - dem mythologischen und gnoseologischen Narrativ. Unter dem mythologischen Narrativ versteht er dabei, ,a type which combines the principle of succession and the first kind of transformation“. (TODOROV 1971, 40) Charakteristisch für diesen Typus von

\footnotetext{
${ }^{345}$ In gewisser Weise wird Luke, wird der Held somit selbst quasi zum Elixir.
} 
Transformation ist, dass ein Zustand in sein Gegenteil verkehrt wird. (vgl. ebd., 39) Und tatsächlich zeichnen sich gerade Mythen dadurch aus, schon bedingt durch ihren dichotomischen Aufbau, dass ihre Erzähllogik immer mit der Abänderung eines Zustandes in dessen Gegenteil arbeitet.

So muss der Held den gewohnten Mikrokosmos verlassen, um in den ungewohnten Makrokosmos einzuziehen, was mit einer Veränderung des Zustandes der Diegese einhergeht, die sich von einer friedvoll-vertrauten in eine kriegerisch-feindliche Welt wandelt. Zudem handeln Mythen immer wieder vom Sterben bzw. Auferstehen, d.h. dass auch die Grenzen zwischen Leben und Tod mehrfach überquert werden, ebenso wie diejenigen zwischen Menschen- und Götterwelt. ${ }^{346}$ Man könnte hier noch weitere Beispiel anführen, was aber bereits an dieser Stelle ersichtlich wird, ist, dass die für das mythologische Narrativ konstitutive Gut-Böse-Dichotomie alle narrativen Elemente aufteilt und einem der beiden Lager zuordnet, sodass jede Veränderung zwangsläufig eine Verkehrung ins Gegenteil sein muss. Hierdurch gewinnt auch die antagonistische Erzähllogik des mythologischen Narrativs, die es für interaktiv-narrative digitale Spiele so interessant macht, an Kontur. Mythen handeln von einer, guten` Welt des Friedens, die von einer ,bösen` Welt des Krieges bedroht wird. Diese Bedrohung lässt sich letztlich nur kämpfend abwenden, sodass sich die antagonistische Erzähllogik des mythologischen Narrativs in ,Kampfmythen“ niederschlägt. Kenneth Burke bemerkt dazu:

For, in one sense the »combat myth« is misnamed. It is really a »victory myth «. It isn't just the story of a fight; it is the story of a radical triumph (with qualifications still be considered). (BURKE 1960, 288)

Das Ziel des mythologischen Narrativs ist stets die Überwindung des Bösen und die Abwendung des Chaos. Somit handelt das mythologische Narrativ nicht nur von einem Kampf, sondern von einem allumfassenden Sieg des ,Guten“ über das ,Böse‘. The Legend of Zelda untermauert dies, da das friedvolle Hyrule zwar immer wieder (im Laufe der Spielserie) von Ganondorf und seinen dämonischen Truppen bedroht wird, sich somit in einem Zustand einer permanenten (latenten) Drohkulisse befindet. Jedoch steht der Sieg des ,Guten` über das „Böse“ nie wirklich in Frage oder wie Blumenberg es ausdrückt: „Die Geschichte sagt, daß schon einige Ungeheuer aus der Welt verschwunden sind, die noch schlimmer waren als die, die hinter dem Gegenwärtigen stehen; und die sagt, daß es schon immer so oder fast so

\footnotetext{
${ }^{346}$ Auch Frye weist auf diesen Umstand hin, indem er die Zyklenartigkeit von Mythen herausstellt, die sich in immer wiederkehrenden Mustern von Geburt und Tod, Aufstieg und Niedergang oder Aufbruch und Heimkehr ausdrücken. Vgl. FRYE (1964), $161 \mathrm{f}$.
} 
gewesen ist wie gegenwärtig.“ (Blumenberg 2006, 41) Das bedeutet, dass die antagonistische Erzähllogik des mythologischen Narrativs immer durch die Gewissheit des Sieges angereichert ist, was die Unsicherheit, die der Kampf zwischen ,Gut' und ,Böse ' für den Rezipienten mit sich bringt, sogleich wieder nivelliert. Der Mythos ist, so kann man zumindest folgern, ein konservatives Narrativ, das am Handlungsende immer wieder den idealisierten Anfangszustand zu Handlungsbeginn herstellt.

Insofern ist die antagonistische Erzähllogik des mythologischen Narrativs maßgeblich für die funktionale Ausgestaltung des Mythos. Da Narrative, wie oben ausgeführt wurde, (vgl. 2.4) aber immer auch ein bestimmtes Figurenpersonal sowie eine Diegese mit bestimmten chronotopischen Qualitäten benötigen, scheint es wenig sinnvoll, eine zu weite Definition des mythologischen Narrativs zu verwenden, wie sie etwa Christopher Voglers Überlegungen zugrunde liegt. Vom ,mythologischem Narrativ' soll im Folgenden deshalb nur dann gesprochen werden, wenn das selbige auch mythologisch aufgeladen ist, d.h. wenn mythische Figuren, Welten, Topoi oder Thematiken eine (zentrale) Rolle spielen, wie sie bereits angerissen wurden. Nur durch diese Berücksichtigung der inhaltlichen Aspekte des mythologischen Narrativs (und einer damit einhergehenden Lösung der Fixierung auf das rein narrativ Funktionale) ist es möglich, das mythologische Narrativ anhand motivischthematischer Unterschiede von dessen modernen Derivaten wie Detektiv- oder Abenteuernarrativ zu trennen.

\subsection{Mythos in den Digital Game Studies}

Wie dominant der Monomythos in der gegenwärtigen populären Medienkultur und deren Erforschung ist, demonstriert ein Blick auf die Digital Game Studies. Hier wurde der Mythos in digitalen Spielen bisher primär unter dem Gesichtspunkt der Heldenreise bzw. der QuestStruktur betrachtet. Als mögliche Erklärung für die Fokussierung der Digital Game Studies auf nur eine Form des Mythos, wenn auch eine seiner prägnantesten, benennt Christopher Vogler den Variantenreichtum des Monomythos.

Die Reise ${ }^{347}$ des Helden eignet sich vorzüglich für Computerspiele und interaktive Formen. Mit den Tausenden von Variationen, die im Lauf der Jahrhunderte zum ursprünglichen Paradigma beigesteuert wurden, bieten sich unendliche Möglichkeiten zur Entwicklung unendlicher Handlungsgewebe. (VOGLER 2010, 27)

\footnotetext{
${ }^{347}$ Dabei findet die Reise des Helden nicht nur in digitalen AAA-Spielproduktionen Verwendung, sondern prägt auch Titel, die zur künstlerischen Independent-Szene zählen wie das vom Videoinstallationskünstler Bill Viola entwickelte The Night Journey (2010), welches sich der Entschleunigung des Lebens und der Suche nach Erleuchtung in einer Welt nahezu vollkommener Dunkelheit widmet. Vgl. dazu auch die Homepage des Projekts http://www.thenightjourney.com/ (30.06.2018).
} 
Man kann auch, mit Ernst Cassirer gesprochen, von einer „Einheit der Vielfalt“ des Monomythos reden. (CASSIRER 2002, 53) Der Monomythos besteht zwar meistens aus einer bestimmten erzähllogischen Verkettung von Kardinalfunktionen, die ihm eine feste Form verleiht, die die Geschlossenheit des Mythos garantiert, zugleich können die Kardinalfunktionen aber (wie oben ausgeführt), wenn auch nur geringfügig, in ihrer Abfolge variiert oder gar weggelassen werden. Darüber hinaus können sogar die Kardinalfunktionen selbst (minimal) abgeändert werden, um sich einem bestimmten Szenario anzupassen, solange ihre narrative Funktion im Narrativ dabei erhalten bleibt. Zudem können Katalysen eingesetzt werden, um die Grundform des mythologischen Narrativs zu verändern, sodass die narrative Grundstruktur des Monomythos zwar vorliegt, die spezifische Ausprägung dieser Grundstruktur aber erheblich von anderen Ausprägungen abweichen kann. Dies macht den Monomythos im Gamedesign zu einem sehr beliebten, da sehr gut einsetzbaren Narrativ und dementsprechend das Reisemodell des Helden zu einem sehr praktikablen Analysetool für die Digital Game Studies.

Unter den Arbeiten, die dem Modell der Heldenreise verpflichtet sind, sind hier u.a. die (vornehmlich substantialistischen) Arbeiten von Christian Wessely zu nennen, der sich in seinen Arbeiten an Campbells Variante des Modells orientiert. Dabei arbeitet er heraus, welche Rolle mythologische Motive wie das ,verwunschene Land' oder die ,verwunschene Prinzessin` in digitalen Spielen mit mythologischen Implikationen spielen. Wessely führt zum Motiv des , verwunschenen Landes' aus:

Ein ehemals blühendes und glückliches Land fällt dem Unheil anheim, weil eine übermächtige böse Persönlichkeit, etwa ein Zauberer oder außerirdisches Wesen, es in seine Gewalt gebracht hat. Der Spieler übernimmt die Rolle des Erlösers, ${ }^{348}$ weil er entweder eine besondere Beziehung zu diesem Land hat oder ein Auserwählter ist, der sich durch seine besonderen Fähigkeiten auszeichnet. Seine Mission ist es, das übermächtige, personalisierte Böse zu lokalisieren und zu vernichten, damit der heile Urzustand wieder hergestellt werden kann. (WESSELY 1995, 362)

Und tatsächlich lässt sich diese mythologische Grundstruktur in vielen interaktivnarrativen digitalen Spielen nachweisen. In Ocarina of Time z.B. wird Hyrule als Sinnbild des ,glücklichen Landes“ schlechthin vom personifizierten Bösen in Form von Ganondorf überfallen und dessen Inbesitznahme des glücklichen Landes in dem Moment am signifikantesten, in dem er in den Besitz des Triforce-Fragments der Kraft gelangt und via Usurpation de facto Herrscher Hyrules wird, das sich unter Ganondorfs Herrschaft in eine

\footnotetext{
${ }^{348}$ Zum Erlösermythos in digitalen Spielen vgl. PIRNER (2001); zum Erlöser in digitalen Spielen vgl. ABESSER (2009).
} 
dunkle Einöde verwandelt. Gerettet werden kann Hyrule nur vom auserwählten Helden Link, dessen Auserwähltsein sich primär darin ausdrückt, dass er der Einzige ist, der in der Lage ist, das (magische) Masterschwert zu führen. Letztlich gelingt es Link, Zugang zu Ganondorfs Schloss zu erlangen, wo er die (verwunschene) ${ }^{349}$ Prinzessin Zelda zu retten und den ,Urzustand“ wiederherzustellen vermag. Wessely betont in seinen Arbeiten über die inhaltlichen Aspekte des Mythos hinaus aber auch die Strukturäquivalenz zwischen Mythos und digitalem Spiel, die sich nicht darin erschöpft, dass digitale Spiele eine künstlerische Aktualisierung von historischen Mythen sind. ${ }^{350}$

Der mitteleuropäische Rezipient hat erstmals seit Jahrhunderten [im digitalen Spiel] wieder die gesellschaftlich sanktionierte Möglichkeit, den mythischen Zyklus nicht nur nachzulesen oder in verfilmter Form zu sehen, sondern ihn selbst zu vollziehen und so in eigener Person mythisches Geschehen zu reaktualisieren. (ebd., 365; Herv.i.O.)

Wenn aus der impliziten Performanz des Mythos im digitalen Spiel eine explizite Handlung des Spielers wird, die durch die Rollenerwartungen der narrativen Konzeption des mythologischen Narrativs angeregt wird, dann wird die strukturelle Äquivalenz zwischen Mythos und digitalem Spiel offensichtlich. Was jedoch etwas opak bleibt, ist die Frage, wie weit diese Äquivalenz reicht und wie sie sich in digitalen Spielen konkret manifestiert. Wessely behauptet: „Die Struktur von Mythos und Computerspiel gleicht sich in vielen Fällen sogar in Details.“ (WESSELY 1997, 173) Diese Detailanalyse holt er wiederum (durchaus plausibel) durch die Zuhilfenahme des Reisemodells des Helden ein. Raffael Schuppisser jedoch moniert zwei Schwächen der Modelle von Joseph Campbell und Christopher Vogler: Erstens sei die Grundstruktur des Monomythos „zu starr“, stelle „lediglich einen Idealtypus der Heldenreise dar“ und sei zweitens „zu grobmaschig“. (SCHUPPISSER 2014, 87) ,Grobmaschig‘ deshalb, weil es sich bei digitalen Spielen nicht um eine Quest handele, sondern um eine Vielzahl an Quests, die einander folgen, eine ,Quest Chain` bilden. ${ }^{351}$ Der erste Einwand Schuppissers erscheint weniger bedenkenswert, da Campbell in seiner Modellbildung nicht normativ, sondern deskriptiv verfährt, d.h. sich an konkreten Realisierungen von mythologischen Narrativen in seiner Studie orientiert, die auf einem sehr

\footnotetext{
${ }^{349}$ Nach Wessely zeichnet sich die ,verwunschene Prinzessin“ dadurch aus, dass sie eine Figur ist, ,die hoher Sympathieträger ist“ und „,von einer übermächtigen bösen Persönlichkeit entführt“ wird. WESSELY (1995), 363. All diese Attribute treffen, wie in Kapitel 4 auszuführen sein wird, auf Prinzessin Zelda in The Legend of Zelda $\mathrm{zu}$.

${ }^{350}$ Man denke hier den Mythosbegriff (2) nach Aleida und Jan Assmann.

${ }^{351}$ Sebastian Domsch führt zur ,quest chain“ aus: „Quest chains are usually tied together by an overarching objective or narrative.“ DoMSCH (2013), 83. Diese Strukturierung der Verkettung der einzelnen Quests zu einer ,quest chain' bzw. Quest-Struktur wird daher notwendig, da ohne sie weder ein kohärentes Spielerlebnis noch eine Koordination von ,main' und ,side quest' möglich scheint. Vgl. dazu auch ebd., 84.
} 
breiten Quellenstudium basiert. Auch wenn man (wie Odo Marquard aus guten Gründen) gegen den Monomythos plädiert, so kann man (und Lévi-Strauss und Blumenberg haben dies betont) dennoch dessen Wirkmacht in der europäisch-westlichen Kulturgeschichte nicht bestreiten. Die Starrheit des Monomythos ist somit weniger ein Kritikpunkt am Modell der Heldenreise selbst als vielmehr an der Monotonie unserer narrativen Kultur. Der zweite Punkt, den Schuppisser anführt, ist aber überaus interessant. Denn ,grobmaschig ${ }^{6}$ ist das Modell von Campbell und Vogler mit Blick auf digitale Spiele v.a. in einem Punkt, wie Schuppisser zu Recht ausführt. Als problematisch betrachtet er hierbei die sechste Station des Reisemodells nach Vogler (,Bewährungsproben, Verbündete, Feinde`), welche einen Großteil der Spielzeit digitaler Spiele einnehme, was aber nur unzureichend im Modell widergespielt werde. ${ }^{352}$ (vgl. ebd., 88)

Um diesem Defizit zu begegnen, greift Schuppisser auf Algirdas Julien Greimas' Strukturale Semantik zurück. Dieser geht von Propps Überlegungen aus, reduziert aber einerseits die narrativen Funktionen sowie er sie andererseits kategorisiert. (vgl. GREIMAS 1971, 178-205) Dabei interessieren Schuppisser vornehmlich jene drei Kategorien, die „eine zusammenhängende Sequenz“ bilden - Kontrakt, Kampf und Kommunikation - und welche Greimas unter dem Begriff der ,Prüfung“ zusammenfasst. (SCHUPPISSER 2014, 91) Von zentraler Bedeutung ist dabei, so Schuppisser, der Kampf, „da nur in dieser Kategorie der Avatar als Agens auftritt.“ (ebd., 97) Um sich nicht demselben Vorwurf auszusetzen, den er Vogler mit Blick auf dessen sechste Station der Heldenreise macht, greift Schuppisser erneut auf Greimas zurïck, um diesen Abschnitt, der der eigentliche Aushandlungs- bzw. Spielabschnitt der Quest ist, konziser fassen und präziser analysieren zu können. Hierzu verwendet er das ,narrative Programm‘ von Greimas. (vgl. dazu CoURTÉs 1991)

Es bleiben jedoch im Rahmen seiner Ausführungen zwei Aspekte unklar, so erhellend seine Analysen auch erscheinen mögen. (vgl. SCHUPPISSER 2014, 99 ff.) Erstens wird nicht ersichtlich, worin die Vorteile des Greimas'schen Modells gegenüber der etablierten Terminologie der Erforschung von Quests in den Digital Game Studies liegen. Anstelle des ,Kontraktes‘ kann man bspw. von der ,Erteilung der Quest‘ durch den Quest-Geber sprechen, welcher das Questziel artikuliert und eine bestimmte Sanktion verspricht. Anstatt des ,Kampfes' kann man auch vom ,ludischen Quest-“ oder ,Spielerverlauf ' sprechen, in

\footnotetext{
352 Dennoch sollte man sich davor hüten, Campbells und Voglers Modell vorschnell als zu unpräzise abzutun. Eher ist es so, dass das Reisemodell des Helden eine Analyse aus der Makroperspektive ermöglicht, wohingegen Schuppissers Rekurs auf Greimas eher mikroperspektivistisch vorgeht. Insofern heben sich beide Ansätze insbes. dadurch voneinander $\mathrm{ab}$, dass sie extensional eine unterschiedliche Reichweite der Analyse beanspruchen.
} 
welchem der Spieler spielt usw. (vgl. DoMSCH 2013, 81) Und hiermit kommen wir dann auch zum zweiten Punkt. Es scheint fraglich, selbiges gilt auch für Greimas, ob jeder durch das narrative Programm erfassbare Prozess sowie dessen Darstellung wirklich narrativ zu nennen ist. Freilich ist Greimas mit seinem Credo, dass die Welt (vollumfänglich) erzählbar sei, ein entschiedener Vertreter personaler Narrationen, es darf dabei jedoch nicht übersehen werden, dass der Charakter vieler aufgezeigter syntaktischer und semiotischer Relationen (bei Greimas wie Schuppisser) oft eher deskriptiver als narrativer Art ist. ${ }^{353}$ Genau genommen ist der Kampf der einzige Abschnitt einer Quest in digitalen Spielen, in dem nicht oder kaum erzählt wird. Wenn Niko Bellic in GTA IV (2008), um ein Beispiel Schuppissers aufzugreifen, eine Mission ausführt, d.h. NPCs eliminiert, bestiehlt etc., so tut der Spieler dies performativ durch Niko als Spielfigur, die nicht Teil einer medialen Narration ist, die keine narrative Funktionalisierung aufweist.

Hierdurch zeigt sich zugleich der hybride Charakter interaktiv-narrativer digitaler Spiele mit Blick auf die Quest bzw. deren Struktur. Die Quest selbst erscheint nämlich als eine Vermengung von interaktiven Spielphasen und narrativen Darstellungen. Und gerade der Kampf als interaktiver Handlungsraum schlechthin unterstreicht, dass eine narratologische Analyse allein hier zu kurz greifen muss. Der ,Kampf ${ }^{*}$ in Greimas' und die ,Bewährungsproben“ in Voglers Modell haben als rein narratologische Überlegungen zwangsläufig blinde Flecken, die sich nur durch eine Kombination von spielwissenschaftlichen und erzähltheoretischen Ansätzen beheben lassen. So räumt selbst Schuppisser ein:

Die Quest kann bei einem narrativen Spiel sowohl aus ludologischer Sicht als eine an den Spieler gestellte, meist klar eingegrenzte Spielaufgabe bezeichnet werden, als auch aus narratologischer Perspektive als eine Prüfung, die der Protagonist innerhalb der Storyworld erfüllen muss. (ebd., 77; Herv.i.O.)

Das bedeutet aber auch, dass eine ludologische bzw. spielwissenschaftliche Sichtweise berïcksichtigt werden muss.

Quest in games can actually provide an interesting type of bridge between game rules and game fiction in that the game can contain a predefined sequence of events that the player has to actualize or enact. (JUUL 2005, 17)

Ein zentraler Punkt an den ludologisch orientierten Ansätzen zur Quest bzw. QuestStruktur in digitalen Spielen liegt darin, dass diese das Handeln des Spielers als (spielerisches) Handeln in den Vordergrund rücken, wohingegen narrativistische Studien jede

\footnotetext{
${ }^{353}$ Vgl. zum Verhältnis von Erzählung und Deskription etwa ToDOROv (1971), 38.
} 
isolierbare Einheit als narratives Element betrachten. Damit geht auch eine interessante Beobachtung einher, wenn man sich wieder ins Gedächtnis ruft, dass man es bei der Quest (als zu bewältigende Aufgabe/Prüfung) mit einem (erzählerischen wie performativen) mythologischen Muster zu tun hat. Die performative Ausrichtung der Ludologen bedingt dabei eher eine Fokussierung auf die funktionalistischen Aspekte des Mythos, die erzählerische Ausrichtung der Narratologen bzw. zuweilen auch Narrativisten eher eine Konzentration auf die substantialistischen Aspekte des Mythos und dessen Auswirkungen auf die narrativen Funktionen. Dies wird mit Blick auf ludologisch ausgerichtete Arbeiten wie diejenige von Ragnhild Tronstad deutlich:

Quests [...] are basically performative: they belong first and foremost to the order of the act. [...] The reason quests can easily be confused with »stories « is that we are normally analysing the quest in retroperspective, after we've already solved it. To ignore the performative aspect of quests this way is fundamentally to misjudge questing as practice. (TRONSTAD 2001)

Tronstad wendet sich hier gegen narrativistische Ansätze, die personale Narrationen als mediale betrachten und dementsprechend die performativen Aspekte von Quests verkennen. Eine Quest, und hiermit weist sie auf einen zentralen Punkt hin, ist (ludisch betrachtet) v.a. eine Praktik, die von fundamentaler Bedeutung für das Gameplay von Genres wie ActionAdventure oder RPG ist. Nicht unproblematisch ist an Tronstads grundsätzlich sehr überzeugenden Arbeiten, dass sie eine traditionell ludologische Position vertritt:

From this theoretical perspective, a quest narrative is considered only potentially present in the quest as performed and experienced by the player, as a sequence of events that may be realized and retrospectively contemplated in the form of a story after the player character's accomplishment of the quest. (TRONSTAD 2014, $409 \mathrm{f}$.)

Narrationen kommen in digitalen Spielen, nach Tronstad, nur in Form personaler Narrationen vor, d.h. dass digitale Spiele (aus ludologischer Sicht) keine mediale Narrativität in Bezug auf die Quest-Struktur aufweisen. Somit ergibt sich innerhalb des Forschungsdiskurses die komplexe Situation, dass auf der einen Seite Arbeiten wie diejenigen Wesselys oder Schuppissers zu verorten sind, die narratologisch-substantialistisch vorgehen, die personale Narrationen zuweilen als mediale einstufen, was $\mathrm{zu}$ narrativistischen Forschungssettings führen kann. Auf der anderen Seite befinden sich Studien wie diejenige Tronstads, die ludologisch-funktionalistisch ausgerichtet sind, mediale Narrationen kaum gelten lassen und personalen Narrationen nur einen untergeordneten Status beimessen. Beide Orientierungen der Forschung sind für Hybridansätze in den Digital Game Studies problembehaftet, da sie nicht selten ein exkludierendes Denken evozieren. Dennoch ist dieser Befund von großem Interesse für die Erforschung der Interaktivität-Narrativität digitaler 
Spiele, da er unterstreicht, wie virulent die Narratologen-Ludologen-Debatte immer noch ist und dies im doppelten Sinne - einerseits als allgemeiner Forschungsdiskurs über die interaktiv-narrativen Potenziale digitaler Spiele (NLD II) und andererseits als NarratologenLudologen-Debatte im klassischen Sinn (NLD I). (vgl. dazu 2.1)

Die Queststruktur von digitalen Spielen gehört nämlich auch zu jenen Aspekten, die Gegenstand der NLD I waren und besonders energisch von den Ludologen gegen narratologisch/narrativistische Vorstöße verteidigt wurden. Einer dieser ludologischen Verteidigungsversuche, der große Resonanz in den Digital Game Studies erfuhr, ist Espen Aarseths Aufsatz mit dem vielsagenden Titel Quest Games as Post-Narrative Discourse. (AARSETH 2004b) Aarseth stellt zu Beginn dieser Arbeit fest, dass die „Computer game studies needs to be liberated from narrativism, and an alternative theory that is native to the field of study must be constructed.“ (ebd., 362) Diese neue, ,ursprüngliche“ Theorie soll, so Aarseth, eine „Quest Game Theory“ sein. (ebd., 375) „Instead of looking at games as stories, we might benefit from looking at some games (games with specific goals) as quest games." (ebd.; Herv.i.O.) Diesem Gedanken möchte auch die vorliegende Arbeit folgen und ihn weitertreiben, wenn auch der Begriff, digital quest games' im Besonderen interaktiv-narrative digitale Spiele meinen soll, die funktional wie inhaltlich auf mythologische Wirkungsweisen und Formen rekurrieren.

\subsection{Mythos als Interaktiv-Narrativ in digitalen Spielen}

Der Überblick über die moderne Mythenforschung, der in Kapitel 3.1 gegeben wurde, stellt heraus, wie vielfältig die Mythenforschung seit dem 20. Jahrhundert ausgerichtet ist, zugleich wird im Kontrast mit Kapitel 3.3 aber ersichtlich, wie wenige Impulse sich hieraus für die Digital Game Studies bisher ergeben haben. Dabei erscheinen besonders die funktionalistischen Ausrichtungen der modernen Mythenforschung besonders geeignet zu sein, um die bereits bestehenden substantialistischen Ansätze anzureichern. Kaum jemand hat im 20. Jahrhundert ein so überzeugendes Plädoyer für die Funktionen des Mythos gehalten wie Ernst Cassirer:

[Der Mythus] kann ein Abbild von allem machen, »das im Himmel droben, auf Erden hienieden oder im Wasser unter der Erde ist«. So kann der Hauptinhalt des Mythus, mag auch sein Studium sehr interessant sein und unsere wissenschaftliche Wißbegierde erregen, an sich keine endgültige Antwort geben. Denn was wir zu wissen wünschen, ist nicht bloß der Stoff des Mythus; es ist eher seine Funktion im sozialen und kulturellen Leben des Menschen. (CASSIRER 2002, 50) 
Cassirer, ${ }^{354}$ der mittlerweile zu den Klassikern der modernen Mythentheorie zählt, geht es darum, mythisches Denken funktionalistisch $\mathrm{zu}$ analysieren. Dabei entdeckt er die erstaunliche Einheitlichkeit, die Mythen aufweisen. „Aber die Motive mythischen Denkens und mythischer Vorstellung sind in gewissem Sinne immer dieselben. In allen menschlichen Tätigkeiten und in allen Formen menschlicher Kultur finden wir eine »Einheit der Vielfalt «. [...] Religion und Mythus geben uns eine Einheit des Fühlens.““(ebd., 53) Dieses Fühlen manifestiert sich in einem Einfühlen in jemand anderen, einen Gott oder Partner, der von dem sich einfühlenden Subjekt raumzeitlich entfernt ist, zu dem dieses aber (z.B. durch Rituale) eine Verbindung durch Identifikation aufbaut. Auf diese Weise wird die eigene Individualität überwunden und der Einzelne geht in der Universalität des Kollektivs auf. Diese Situation wandelt sich für den Rezipienten, und Wessely hat hierauf bereits hingewiesen, im digitalen Spiel. Hier wird aus dem passiven Rezipienten, der sich gewissermaßen in den Mythos flüchtet, um seiner eigenen Ohnmacht zu entgehen, der aktive mythische Held selbst, der allein das Schicksal bestimmen kann. Die Urängste des Menschen, die Mythen zu verwinden helfen, auch wenn sie diese letztlich nie ganz überwinden können, werden somit auf eine direkte Weise angegangen, indem sich das Individuum nicht dem Kollektiv eingliedert, um hier Schutz und Orientierung zu erfahren, sondern indem es aus dem Kollektiv heraustritt, um Schutz zu gewähren und Orientierung zu stiften. Mythen sind stets (in beiden Stoßrichtungen) ,symbolische Formen` im Sinne Cassirers, die menschliches Fühlen formen.

Mythus kann nicht als bloßes Gefühl bezeichnet werden, weil er Ausdruck des Gefühls ist. Der Ausdruck eines Fühlens ist nicht das Fühlen selbst - er ist Gefühl in Bild gewandelt. Diese Tatsache bedingt einen radikalen Wechsel. Was bisher dunkel und undeutlich gefühlt wurde, nimmt nun eine bestimmte Gestalt an; was ein passiver Zustand war, wird ein aktiver Prozeß. (ebd., 60; Herv.i.O.)

Mythen kleiden somit Gefühle ein, für die dem Menschen (andere) Erklärungsmuster fehlen. ${ }^{355}$ „Wenn die Vernunft uns im Stiche gelassen hat, bleibt immer die ultima ratio, die Macht des Wunderbaren und Mysteriösen.“(ebd., 363) Mit anderen Worten: Mythen helfen

${ }^{354}$ Cassirers Bedeutung für die Mythentheorie des 20. Jahrhunderts und insbes. für die funktionalistischen Ausrichtungen dieser, ist mit seiner Rolle als einer der Begründer der politischen Mythentheorie zu erklären. Aufgrund seiner Erfahrungen mit dem Nationalsozialismus beurteilt er eine Mythisierung der Politik als kritisch, da diese - verkürzt gesprochen - oftmals von zweifelhaften politischen Kräften zu deren eigenen Gunsten betrieben werde und rationale Handlungsmuster in den Hintergrund dränge. Um diese Prozesse dezidiert untersuchen zu können, wendet sich Cassirer intensiv den funktionalisischen Aspekten von Mythen zu. Sein Vom Mythus des Staates ist bis heute relevant, da es sich auf prägende Folgearbeiten wie TUDOR (1972) oder FLOOD (2002) auswirkte.

${ }^{355}$ Insofern fungierten Mythen auch als eine historisch frühe Form des Ausdrucks und der Bewältigung von Gefühlen und griffen somit den wissenschaftlichen Reflexionen aus Psychologie und Philosophie voraus. Zur wissenschaftlichen Auseinandersetzung mit Gefühlen vgl. HARTMANN (2010). Von zentraler Bedeutung, wie oben ausgeführt, war dabei die Bewältigung der Angst, weshalb Mythen ihre Rezipienten auch immer wieder mit menschlichen Urängsten in Berührung brachten, um diese anschließend (besser) aushalten zu können. 
dem Menschen, Fragen $\mathrm{zu}$ beantworten und Emotionen $\mathrm{zu}$ bewältigen, die sich der Rationalität der modernen Naturwissenschaften entziehen. Mythen verfügen als ordnende Instanz des Schwer-Fixierbaren, des Irrationalen über die Kraft, Leitung zu offerieren und Sinn aufzuzeigen, wo andere Wahrnehmungs- und Erklärungsdispositive versagen. Diese Funktion besitzen aber auch Spiele, welche wie Mythen funktionale Ordnungssysteme sind. ${ }^{356}$ Die Parallelen zwischen beiden werden in den Prozessen selbst ersichtlich, also wenn Menschen spielen, oder wenn sie sich dem mythischen Denken zuwenden. Spielen und mythisches Denken vollbringen dabei beide gleichermaßen eine strukturierende Leistung, die komplexere Prozesse verständlich macht, indem sie diese formt und in einer dem menschlichen Bewusstsein zugänglichen Form darstellt. In diesem Zusammenhang rekurriert das menschliche Bewusstsein aber auf bestimmte wiederkehrende Muster, Bilder und Motive - die Archetypen. Diese sind dem menschlichen Bewusstsein, wie unten noch ausgeführt wird, nicht unmittelbar zugänglich, obwohl sie einen zentralen Aspekt bei der Deutung von Sachverhalten des alltäglichen Lebens einnehmen. Entscheidend ist dabei, und hierdurch wird die strukturelle Äquivalenz zwischen Spiel und Erzählung (Mythos) erst möglich, dass sich Archetypen als polyvalente Elemente sowohl ludisch als auch erzählerisch umsetzen lassen.

Insofern lassen sich beide kulturellen Formen ebenso wenig vollends voneinander trennen wie funktionalistische und substantialistische Begriffsbestimmungen des Mythos, wie in 3.1 ausgeführt, da die Inhalte auf die Funktionen einwirken und umgekehrt. Obwohl sich diese Arbeit stärker als andere auf die funktionalistischen Aspekte des Mythos konzentriert, kann bzw. muss man bspw. fragen, welche Rolle bestimmte Mythologeme ${ }^{357}$ in Bezug auf die analysierten Funktionen des Mythos in digitalen Spielen einnehmen. ${ }^{358}$ Aus diesen Gründen widmen sich die beiden folgenden Teilkapitel einerseits den funktionalistischen und andererseits den substantialistischen Aspekten des Mythos in interaktiv-narrativ digitalen Spielen.

\footnotetext{
${ }^{356}$ Bei beiden meint Ordnung in gewisser Weise stets auch Unterordnung. Der Mythos bzw. dessen Funktionen besitzen nur Gültigkeit für die Menschen, wenn sie geneigt sind, an diese zu glauben und sich somit den (ordnenden) Konventionen des Mythos zu fügen. Ähnlich ist dies beim Spiel. Dieses besitzt nur dann Wirkmacht, wenn alle Spieler die ordnungsstiftenden Regeln des Spiels anerkennen. Ist dies nicht mehr der Fall, wie beim Spielverderber, dann endet die Wirkung der Illusion des Spiels. Vgl. Huizinga (1991), 20.

357 Zum Mythologem vgl. LÉVI-STRAusS (1972). Ein Mythologem bezeichnet (äquivalent zu ähnlich gefassten Termini aus der Linguistik oder Semiotik) die kleinste semantische, konstante und konstitutive Einheit eines Mythos.

${ }^{358}$ Ulrich Nersinger z.B. sieht die „Faszination“, die von digitalen Spielen ausgeht, v.a. in Faktoren begründet, die unter den funktionalistischen Aspekten von Mythen bereits mehrfach angesprochen wurden. NERSINGER (2008). „Ich kann mich als Spieler ungefährdet in die Welt des Unerklärlichen begeben, mich uralten Ängsten aussetzen und sie auch bewältigen, Seite an Seite mit übernatürlichen Wesen kämpfen und sogar ein wenig Gott spielen: Möglichkeiten, die ich in der Realität nicht habe." Ebd.
} 


\subsubsection{Funktionalistische Aspekte des Mythos in interaktiv-narrativen digitalen Spielen}

Im Rahmen der bisher erfolgten Ausführungen zu den Funktionen von Mythen wurde immer wieder auf zwei Funktionen abgehoben, die ich aus der Vielzahl herausgreifen und näher beleuchten möchte - die ,Orientierungs- und Ordnungsfunktion“ sowie die ,Entrückungsfunktion`. Dabei soll es mir primär um die Ordnungs- und Orientierungsfunktion gehen. Dies lässt sich einerseits damit erklären, dass (wenn man den Mythos als strukturierende Instanz von interaktiv-narrativen digitalen Spielen betrachtet) diese maßgeblich für die Gestaltung des Interaktiv-Narrativs im Designprozess sowie für die Realisierung dieser Anlagen durch den Spieler im Spielprozess ist. Andererseits kann die Analyse der Entrückungsfunktion von interaktiv-narrativen digitalen Spielen, die den Mythos als strukturierende Instanz verwenden, nur mittels empirisch-quantitativer mediensoziologischer Zugänge zufriedenstellend geleistet werden, die jedoch nicht Bestandteil des vorliegenden Forschungssettings sind. Der Umstand, dass dennoch nicht bloß auf die strukturierenden Effekte der Orientierungs- und Ordnungsfunktion eingegangen wird, lässt sich damit begründen, dass die Reichhaltigkeit und Produktivität mythentheoretischer Zugänge zur Analyse digitaler Spiele unter funktionalistischen Gesichtspunkten zumindest angedeutet und hierdurch ein interessantes Untersuchungsfeld der Digital Game Studies aufgezeigt werden soll, dass nicht nur den vertrauten kulturwissenschaftlichen Pfaden substantialistischer Ansätze folgt. Des Weiteren werden in Kapitel 4.2.3 kurze Seitenblicke auf diese Funktion des Mythos bei der Realisierung interaktiv-narrativer digitaler Spiele geworfen.

\subsubsection{Die Orientierungs- und Ordnungsfunktion}

Im Rahmen dessen, was unter der Orientierungs- und Ordnungsfunktion von Mythen verstanden wird, möchte ich auf drei Aspekte detaillierter eingehen, die als bedeutende Unterfunktionen dazu beitragen, dass der Mythos dem Spieler interaktiv-narrativer digitaler Spiele Ordnung und Orientierung gewähren kann. Dabei werde ich mich auf die Strukturierung, die Deutung und Sinnstiftung sowie auf die Vorbild- und Nachahmungsfunktion beschränken.

\subsection{Strukturierung durch den Mythos}

Der Mythos strukturiert interaktiv-narrative digitale Spiele in zweifacher Weise. Erstens durch die Verwendung des Monomythos als strukturgebendem Element während des 
Designprozesses (Produktion). Durch den Monomythos wird ein bekanntes Narrativ etabliert, das Rezipienten tendenziell, wenn auch unbewusst, erkennen und anerkennen. Hiervon verspricht sich das Designteam einerseits, ein narratives Setting aufzurufen, dass für eine möglichst große Zielgruppe (v.a. jene Zielgruppe, die eine starke Affinität zu Genres wie Fantasy, Mystery oder Science Fiction aufweist) interessant ist, andererseits korrespondiert dieses narrative Handlungsmuster mit performativen Handlungsmustern, die für Spiele im Allgemeinen sowie für Genre konstituierende Spielmechaniken digitaler Spiele im Speziellen kennzeichnend sind. Auf diese Weise etabliert der Mythos nicht nur das Narrativ, sondern auch das Interaktiv und dementsprechend auch das Interaktiv-Narrativ. Es wird klar, dass interaktiv-narrative digitale Spiele, die das mythologische Narrativ integrieren, dementsprechend auch ein ,mythologisches Interaktiv' sowie, mythologisches InteraktivNarrativ ${ }^{6}$ erzeugen. Als Reaktion auf die grundlegenden Merkmale des mythologischen Narrativs (Erzähllogik, Figurenkonzeption und -konstellation etc.) muss das Designteam ein Interaktiv designen, das von den Interaktionen, der Agency des Spielers, den Spielmechaniken und -regeln her gesehen, eine Symbiose mit dem Narrativ eingehen kann. Auf diese Weise wird das Interaktiv, wenn man so will, ,mythologisiert'. 359 Wenn beide mythologisches Interaktiv und Narrativ - sich in einem symbiotisch-synergetischen Verhältnis zueinander befinden, d.h. wenn eine möglichst weitreichende Zusammenführung beider im Designprozess angestrebt wird, dann entsteht das mythologische InteraktivNarrativ, welches auf einer höheren Ebene als das mythologische Interaktiv und Narrativ anzusiedeln ist. Ausschlaggebend hierfür ist die Tatsache, dass mythologisches Interaktiv und Narrativ (theoretisch gesehen) unabhängig voneinander vorkommen können, auch wenn das betreffende interaktiv-narrative digitale Spiel dann wohl kaum als designerisch gelungen zu bezeichnen wäre. Das Vorhandensein eines mythologischen Interaktiv-Narrativs ist also auch für ein interaktiv-narratives digitales Spiel keineswegs eine Selbstverständlichkeit. Vielmehr scheint es von Interesse zu sein, zu untersuchen, auf welche Weisen sich mythologische Interaktiv-Narrative aus dem Zusammenspiel zwischen mythologischem Interaktiv und Narrativ ergeben. Dies kann die vorliegende Studie bedauerlicherweise leider nicht umfassend leisten, da derartige Arbeiten eines Forschungsdesigns bedürfen, das komparativ bzw. diskursiv vorgeht und eine dementsprechend große Anzahl an interaktiv-narrativen digitalen Spielen mit (vermeintlichem) mythologischem Interaktiv-Narrativ z.B. diskursanalytisch auf

\footnotetext{
${ }^{359}$ Dabei muss das mythologische Interaktiv nicht unbedingt auf das mythologische Narrativ folgen. So kann die Verwendung eines bestimmten Interaktivs bspw. dazu führen, dass das Designteam auf das mythologische Narrativ zurückgreift, da dieses das größte symbiotische Potenzial mit dem vorliegenden Interaktiv verspricht.
} 
deren Designparadigmen hin untersucht. Dennoch sollten das mythologische Interaktiv und Narrativ sowie Interaktiv-Narrative erwähnt werden, da ihre strukturierende Wirkung von zentraler Wichtigkeit für das Design interaktiv-narrativer digitaler Spiele ist. Wie sich das mythologische Interaktiv-Narrativ in Bezug auf ein bestimmtes Beispiel darstellt, wird in Kapitel 4 mit Blick auf Ocarina of Time noch ausgeführt werden.

Wechselt man nun zweitens von der Produzenten- auf die Rezipientenseite, so wirkt der Mythos auch hier strukturierend. Ein wesentlicher Aspekt von Mythen besteht darin, und Ernst Cassirer hat dies betont, dass sie „Ausdruck des Gefühls“ sind. (CASSIRER 2002, 60; Herv.i.O.) Mythen übertragen Gefühle und andere Abstrakta in Bilder, ${ }^{360}$ in feste kulturelle Deutungsmuster und machen sie somit leichter oder überhaupt erst verständlich für den Menschen. ${ }^{361}$ Wenn Mythen also Abstraktes konkret machen, so funktioniert dies nur, weil sie die Fähigkeit besitzen, Komplexität reduzieren zu können, ohne dabei die ,Grundaussage‘ des Abstraktums zu verändern. Konkret bedeutet das z.B. für digitale Spiele, dass das mythologische Narrativ dem Spieler, der es erkennt, helfen kann, den Aufbau sowie die Funktionen der Spielwelt unter Berücksichtigung der Agonalität des mythologischen Narrativs zu ,entschlüsseln‘. Die narrativen mythologischen Komponenten unterstützten den Spieler dabei, die interaktiven zu verstehen. Ein Beispiel: Ein (erfahrener) Spieler beginnt ein interaktiv-narratives digitales Spiel mit mythologischem Interaktiv-Narrativ. Als Erstes sieht

\footnotetext{
${ }^{360}$ So fasst die mythologische Erzählung des Ödipus zwei ambivalente Gefühle Heranwachsender in eine konkrete Geschichte, wie Sigmund Freud im Kontext seines ,Ödipuskonfliktes' herausstellt. Da ist zum einen der Wunsch des Kindes, mit dem gegengeschlechtlichen Elternteil sexuell zu verkehren und zum anderen das hasserfüllte Aufbegehren gegen das gleichgeschlechtliche Elternteil, das als Gegenspieler aufgefasst wird. Vgl. FREUD (2013).

${ }^{361}$ Somit können Mythen dem Subjekt auch zur Reflexion dienen. Dies trifft auf Mythen in digitalen Spielen ebenso zu wie auf historische und moderne Mythen im Allgemeinen. Als ein Beispiel hierfür sei abermals auf die Online-Fan-Diskurse zu Final Fantasy VII verwiesen, in denen es um Aeris' Tötung durch Sephiroth geht. Diese Sequenz gilt vielen Fans der Spielreihe als einer der emotionalsten Momente der digitalen Spielgeschichte. Vgl. dazu 2.5.3.2. In jüngerer Zeit wird aber vermehrt von Fans die Theorie diskutiert, ob es nicht Sephiroth ist, der Aeris ermordet, sondern Jenova (ein außerirdisches Wesen, dessen DNA in Sephiroth als Embryo eingepflanzt wurde) durch/als Sephiroth. Vgl. dazu exemplarisch http://www.gamefaqs.com/boards/197341final-fantasy-vii/55550339 (30.06.2018). Dabei wird infrage gestellt, ob Sephiroth wirklich der Antagonist von Final Fantasy VII ist oder ob dieser nicht durch Jenova gelenkt und so zu seinen Taten veranlasst wird, Jenova dementsprechend eigentlich das personifizierte Böse und der Antagonist ist. In diesem Fall ermöglichte das mythologische Narrativ des Spiels den Anhängern dieser Fantheorie eine Reflexion des vermeintlich Offensichtlichen, was zur Aufdeckung alternativer Deutungen und somit zur Polysemie des Spiels führte. Der Mythos kann dabei aber nicht nur zur Reflexion von Inhalten eines digitalen Spiels führen, er kann Spieler vielmehr auch dazu verleiten, ihre eigenen Lebenskontexte zu reflektieren. So fasst Jonathan L. Walls, Herausgeber des Sammelbandes The Legend of Zelda and Theology, der versucht, christliche Perspektiven auf diese populäre Spielreihe aufzuzeigen, den Einfluss von Ocarina of Time auf sein eigenes Leben in der Einleitung wie folgt zusammen: „The game changed my life.“ WALLS (2011a), 12. Ursächlich hierfür ist nicht bloß die Konfrontation mit mythologischen Inhalten, so Walls, sondern vielmehr die Tatsache, dass „I was living out an ancient mythology“. Ebd. Die reflektierende Dimension des Mythos in digitalen Spielen lässt sich in der Fankommunikation noch besser aufzeigen, liegt aber ebenfalls nicht im Fokus des Erkenntnisinteresses dieser Arbeit.
} 
er eine Cutscene, die der narrativen Exposition dient. Diese deutet bspw. die Agonalität zwischen Held und Antagonist an oder umfasst gar zentrale Kardinalfunktionen des ersten Aktes der Heldenreise. Angenommen der betreffende Spieler wisse nichts über das Spiel, das er gerade begonnen hat, so kann er dennoch, würde man ihn fragen, bestimmte Spielmechaniken richtig benennen oder eine Genrezuordnung korrekt vornehmen. Warum ist das so? Weil er das mythologische Narrativ erkannt hat, davon ausgeht, dass ein mythologisches Interaktiv-Narrativ vorliegen muss, welches zwangsläufig auch ein mythologisches Interaktiv umfasst. Anhand der Erfahrungen aus seiner persönlichen digitalen Spielbiografie ruft er nun digitale Spielgenres und deren typische Interaktive auf, die er mit dem mythologischen Interaktiv-Narrativ verbindet. Mittels Deduktion kann mithilfe nur einer einzigen narrativen Cutscene u.U. relativ viel über das Interaktionsdesign des Spiels gesagt werden, ohne auch nur eine Sekunde (interaktiv) gespielt zu haben. ${ }^{362}$

Selbiges funktioniert aber auch umgekehrt. So können bestimmte Interaktionsmuster zwischen Held und NPCs dazu führen, dass der Spieler die Funktion bestimmter NPCs als narrativer Figur innerhalb des Narrativs erst durch die Interaktion bzw. die Interaktionsmöglichkeiten mit diesen versteht oder er überspannende narrative Handlungszusammenhänge erst hierdurch gewahr wird. Auch dies wird in Kapitel 4 ausführlicher zu betrachten sein. Was aber an dieser Stelle bereits festgehalten werden sollte, ist, dass der Mythos mythologisches Interaktiv und Narrativ zum mythologischen InteraktivNarrativ verbindet, was sogleich mit einer Vereinigung der Quest- und Erzählstruktur zur interaktiv-narrativen Spielstruktur einhergeht.

\subsection{Deutung und Sinnstiftung durch den Mythos}

Im vorherigen Abschnitt wurde bereits angesprochen, dass es der Mythos im Rahmen seiner strukturierenden Effekte ermöglicht, Abstraktes zu konkretisieren bzw. Komplexes zu simplifizieren, indem es der Mythos in Ausdrücke verwandelt, die an andere kulturelle Deutungsmuster oder Dispositive anknüpfen. Insofern hängen Strukturierung und Deutung als Unterfunktionen der Orientierungs- und Ordnungsfunktion des Mythos eng zusammen. Allerdings gehen die mythischen Deutungsangebote über die reine Strukturierung als Transfer

\footnotetext{
${ }^{362}$ The Elder Scrolls V: Skyrim etabliert in der narrativen Exposition - die dem Spieler zwar geringe interaktive Optionen einräumt wie den Wechsel der Perspektive oder (kennzeichnend für viele westliche RPGs) die Festlegung einer Rasse, ihn aber sonst zum passiven Zuschauer macht - das mythologische Narrativ und lässt den Spieler hierdurch erahnen, wie das Interaktiv des Spiels beschaffen sein könnte. Dabei ist der Ruf des Abenteuers bzw. die Störung des Gleichgewichts durch die Ankunft des Drachen Alduins prominent markiert. Vgl. hier exemplarisch das Let's Play von KINGDAVIDGAMING https://www.youtube.com/watch?v=5CdoyqsNdaE (30.06.2018).
} 
eines Abstraktums in etwas Konkretes hinaus. Dies ist v.a. dann der Fall, wenn es um die Legitimation eines Zustandes geht. Diese Legitimation holen Mythen oft durch den Einsatz bestimmter mythologischer Inhalte und Themen ein. So kann die Legitimation als mittelalterliche und frühneuzeitliche origo gentis- oder allgemeiner als ätiologische Erzählung erfolgen; beiden ist gemein, dass sie den status quo als Resultat vergangener Ereignisse und Gegebenheiten betrachten und hieraus die Legitimität des Gegenwärtigen ableiten. ${ }^{363}$ Dies trifft in erster Linie auf ,Schöpfungsmythen`oder ,kosmologische Erzählungen`zu.

Diese etablieren eine Erzählung der Anfänge, der primordialen Zeiten, erzählen, wie die Welt und der Kosmos entstanden sind und wie die Wesen in die Welt kamen. (Vgl. EliadE 1984, 85) Nach Joseph Campbell erfüllt diese ,schöpferische Mythologie‘ vier Funktionen.

Die erste Funktion einer Mythologie ist es, das Wachbewußtsein mit dem mysterium tremendum et fascinans dieses Weltalls, so wie es ist, zu versöhnen, und die zweite, eine deutende Gesamtschau dieses Weltalls, so wie es sich dem Bewußtsein seiner Zeit erschließt, zu geben. [...] Ein dritte Funktion jedoch ist die Durchsetzung einer sittlichen Ordnung: die Formung des Einzelnen nach den Erfordernissen seiner von ihrer Landschaft und ihrer Geschichte geprägten sozialen Gruppe, und hierbei kann es zu einem tatsächlichen Bruch mit der Natur kommen, etwa (als extremes Beispiel) im Falle eines kastrierten Sängers. (CAMPBELL 1992, 15; Herv.i.O.)

Mit anderen Worten: (Schöpferische) Mythen schaffen (1) immer eine Brücke zwischen uns und dem (Göttlichen), das uns zugleich erschreckt wie anzieht, vermitteln (2) ein Deutungsangebot, das den Makrokosmos in Relation zum zeitlichen Kontext der Menschen setzt und formen den (natürlichen) Menschen (3) nach den soziokulturellen Erfordernissen der jeweiligen Zeit, was in einer extremen Ausformung zu einer derartigen Überlagerung des natürlichen durch den kulturellen Körper kommen kann, sodass letzterer ersteren überformt. Diese drei Funktionen ergänzt Campbell um eine vierte, die er als die zentralste erachtet:

Die vierte und wichtigste, die entscheidende Funktion einer Mythologie ist es demnach, eine ganzheitliche Gründung und Entfaltung des Einzelnen zu fördern, in Einklang d) mit sich selbst (dem Mikrokosmos), c) mit seiner Kultur (dem Mesokosmos), b) mit dem Weltall (dem Makrokosmos) und a) mit dem ehrfurchtgebietenden letzten Geheimnis, das sowohl jenseits von als auch in ihm und allen Dingen ist. (ebd., 17)

Fasst man all diese vier Funktionen einer schöpferischen Mythologie nach Campbell zusammen und überträgt sie auf interaktiv-narrative digitale Spiele mit mythologischem Interaktiv-Narrativ, dann wird deutlich, dass diese vier Funktionen auch im Rahmen der Deutung und Sinnstiftung durch den Mythos in digitalen Spielen von Bedeutung sein können. So vermittelt das kosmologische Setting (auch durch seine Verbindung zur eschatologischen

\footnotetext{
${ }^{363} \mathrm{Zu}$ den Charakteristiken ätiologischer Erzählungen vgl. BALZAMO (2004).
} 
Komponente mythologischer Erzählungen) stets zwischen dem ,Guten`, das uns anzieht und dem ,Bösen“, das uns abschreckt (1). ${ }^{364}$ Bezeichnenderweise kann dies auch im digitalen Spiel in nur einem einzigen Element zusammenkommen. Ocarina of Time stellt in einer narrativen Cutscene die Schöpfung und Beseelung der Welt Hyrule als Schöpfungsakt der drei Göttinnen Din, Farore und Nayru dar, die nach getaner Arbeit das Triforce als Symbol ihrer Schöpfung wie ihrer göttlichen Macht hinterlassen. ${ }^{365}$ Somit steht das Triforce für das, was den Menschen am Göttlichen und dessen schöpferischer Kraft fasziniert. Zugleich ist es aber auch das Triforce, durch welches Ganondorf überhaupt erst quasi-göttliche Macht erlangen kann, indem er das Triforce-Fragment der Kraft in seinen Besitz bringt und so zu einem unsterblichen Dämon mit nahezu grenzenloser Macht wird. Aber auch hiernach steht das Triforce gleichermaßen für das ,mysterium tremendum et fascinans', da es zwar die Quelle von Ganondorfs Macht ist, es ist darüber hinaus aber auch der einzige Weg, ihn zu töten, da das Masterschwert lediglich die Macht besitzt, ihn (temporär) zu bannen.

Die Gut-Böse-Dichotomie des Monomythos erhält zwar eine unmissverständliche Deutung des Spiels durch den Spieler, strebt eine Aussöhnung zwischen den beiden Facetten des Göttlichen an, ruft hierdurch zugleich aber stets eine Ambivalenz im Spieler wach, die für die Interaktion-Narration des Spielers von erheblicher Signifikanz ist. Indem der Spieler mit dem Schöpfungsmythos in Berührung kommt, wird ihm (ätiologisch betrachtet) nahegelegt, was der schützenswerte und zu verteidigende Zustand der Welt ist (2). Auf diese Weise werden ihm die Zusammenhänge der Spielwelt erschlossen und sein Platz in der Welt zugewiesen. Die damit einhergehende Überformung des Körpers des Protagonisten, der vom gewöhnlichen jungen Menschen zum auserwählten Helden werden muss, wird hierdurch eingeleitet und plausibilisiert (3). Der Spieler wird an den Spieleravatar gebunden, wie an die interaktivsozialen Ausprägungen der Spielwelt und letztlich auch an die virtuelle Spielwelt als holistische Umgebung selbst (4). Diese vielfache Anbindung des Spielers an die verschiedenen Referenzrahmen des digitalen Spiels rekurriert aber ebenso wieder auf die erste Funktion der schöpferischen Mythologie. Der Schöpfungsmythos vermag es zwar, dem

\footnotetext{
364 Das Strategiespiel Black \& White (2001), das dem Subgenre der Göttersimulation zuzurechnen ist, thematisiert die Beziehung zwischen dem Menschlichen und dem Göttlichen sehr anschaulich, indem es den menschlichen Spieler in die Rolle eines Gottes versetzt und es diesem überlässt, ein ,guter ' oder ein ,böser ${ }^{6}$ Gott zu sein. Gerade jene Freiheit des Spielers, selbst entscheiden zu können, was für eine Art von Gott er sein möchte, war es, die dem Spiel im Zuge seiner Rezeptionsgeschichte derart viel Aufmerksamkeit einbrachte.

365 Vgl. dazu exemplarisch das Let's Play von ZELDAPEDIAVIDEO https://www.youtube.com/watch?v=r4tHItL1xLs (30.06.2018).
} 
Spieler ein durchgehendes Gefühl der Sicherheit und Kontinuität ${ }^{366}$ des Spiels zu geben, er unterstreicht mit seinen Deutungsangeboten aber auch eine gewisse, wenn auch minimale, Unsicherheit; die Frage, ob die Zusammenhänge wirklich so sind, wie sie zu sein scheinen, oder ob der Spieler sich irrt oder getäuscht wird. ${ }^{367}$ Auf diese Weise kann das mythologische Interaktiv-Narrativ einen Rückbezug auf die Offenheit des Spiels herstellen, die maßgeblich von Ambiguität und Ambivalenz lebt. ${ }^{368}$ The Legend of Zelda setzt diese Ambiguität und Ambivalenz nur sehr limitiert ein. Dennoch existieren immer wieder gewisse Irritationsmomente, die den Spieler an der Legitimität der bestehenden Zustände zweifeln lassen. So drängt sich dem Spieler, wenn er sich dezidiert mit der Mythologie von The Legend of Zelda auseinandersetzt, u.a. die Frage danach auf, wie gerechtfertigt das Handeln der drei Göttinnen wie ihrer Vertreter letztlich ist. Diese ,verkappte Theodizee-Frage' formuliert The Legend of Zelda: The Wind Waker (2002) am eindringlichsten. ${ }^{369}$

Dieses Spiel ist in der Zeitlinie angesetzt, in der der Held nicht eingreifen kann, als Ganondorf erneut aufersteht. ${ }^{370}$ Die drei Göttinnen Hyrules schicken die Hylianer hieraufhin auf die Berge, versiegeln das Königreich mit einem magischen Bann und versenken es mittels einer Sintflut. Diese Tat der Göttinnen wird dem Spieler erst spät im Spielverlauf bewusst, ist

\footnotetext{
${ }^{366}$ In dieser Hinsicht erweisen sich die strukturierenden Aspekte der Orientierungs- und Ordnungsfunktion auch als stabilisierend. Hier aber nicht (wie oben) als eine ,negative' Stabilisierung im Sinne von Alltagsmythen begriffen, die bestehende sozioökonomische Zustände zum Wohle weniger erhalten, sondern als ,positive“ Stabilisierungsfunktion aufgefasst, bei der die (subjektive) Identität gefestigt wird. So können Mythen in interaktiv-narrativen digitalen Spielen einerseits dazu beitragen, die Identität des einzelnen Spielers als temporäre Verschmelzung zwischen Spieler und Avatar zu stabilisieren und andererseits können sie dabei helfen, eine stabile Gruppenidentität entweder einer Gruppe von Spielern in einem Mehrspielerspiel oder als größere Fan-Gruppe eines Franchise zu erzeugen.

${ }^{367}$ In diesem Zusammenhang sind auch Fragen nach der ,Unzuverlässigkeit des Erzählens` von Interesse, obwohl diese Erzähltechnik bisher eher spärlichen Einsatz in interaktiv-narrativen digitalen Spielen gefunden hat. Zum ,unzuverlässigen Erzählen' allgemein vgl. KÖPPE/KINDT (2014), 236-256.

${ }^{368} \mathrm{Vgl}$. dazu SutTON-Smith (2001). Beachtenswert unter den sieben Spielrhetoriken nach Sutton-Smith sind im Kontext des Mythos v.a. jene, die er bereits in der griechisch-römischen Antike identifiziert: im Besonderen die Rhetoriken des Schicksals, der Macht und der Identität.

${ }^{369}$ Wie weit die Sinnstiftung von Mythen oder Religionen digitaler Spiele in die Lebensrealität der Fans ausgreifen kann, verdeutlichen einige fankulturelle Praktiken. So muss die Sinnstiftung keinesfalls innerhalb der Grenzen der Spielwelt eines digitalen Spiels verharren, sondern kann sich in die umgebende transmediale Welt ausdehnen, wodurch sie auch Zugang zur Realität erhält. Exemplarisch, auch wenn empirisch valide Studien hierzu noch ausstehen, sollen einige Aspekte quasi-religiöser Fanpraktiken genannt werden, um dies zu verdeutlichen. Die Erwerbung von Merchandise transmedialer Welten weist bspw. ebenso Parallelen zu religiösen Praktiken des Reliquienkaufs auf wie deren Inszenierung in der Wohnung von Fans, die an Ikonenverehrung erinnern kann. Zudem können einfache Spielsessions oder gemeinsame Spielabende sehr stark rituell aufgeladen sein und dementsprechend prozessiert begangen werden. Extremere Formen der Sinnstiftung kann man beobachten, wenn Fans sich Tattoos ihrer favorisierten Spiele stechen lassen, die von ihrer Funktionalität manchen religiösen Tatowierungspraktiken ähneln, die ebenfalls die Religion im Alltag präsent halten sollen.

${ }^{370} \mathrm{Zu}$ den drei Zeitlinien der (seriellen) Erzählung von The Legend of Zelda vgl. die von Patrick Thorpe herausgegebene Hyrule Historia. Vgl. THORPE (2013), 69. Vgl. dazu ebenso das sehenswerte Video von ERNIE GoNZALEZ https://www.youtube.com/watch?v=ak8jzShE3Vk (30.06.2018).
} 
gewissermaßen das „ehrfurchtgebietende[] letzte[] Geheimnis“. (CAMPBELL 1992, 17) Bis dahin betrachtet der Spieler seinen Avatar lediglich als den Bewohner einer karibisch anmutenden Inselwelt (die Inseln sind die Bergspitzen Hyrules). Dieses Szenario kulminiert in der letzten narrativen Cutscene vor dem Endkampf mit Ganondorf. Dieser scheint, wie über den gesamten Spielverlauf hinweg, trotz seiner Allmacht als gebrochener Charakter. ${ }^{371} \mathrm{Er}$ setzt Link und Tetra (Prinzessin Zeldas Reinkarnation) außer Gefecht und vereint die drei Triforce-Fragmente zum Triforce, um seinen letzten Wunsch auszusprechen - Hyrule aus den Fluten auferstehen zu lassen. Der Geist des Königs des untergegangenen Hyrules berührt jedoch vor Ganondorf das Triforce und artikuliert wiederum seinen Wunsch - den Siegelkreis, der Hyrule vor den Wassermassen beschützt, aufzuheben. Folglich geht Hyrule langsam in den Fluten unter. Der verzweifelte Ganondorf greift daraufhin Link und Tetra an und läutet hiermit die finale Phase des Endkampfes ein.

Der Grund, weshalb gerade dieses Spiel so interessant in Bezug auf die Ambivalenz und Ambiguität ist, ist folgender. Das Spiel verkehrt die Rollen zwischen Ganondorf und dem hylianischen König. In den meisten Titeln der Hauptserie tritt der König von Hyrule als Wächter von Hyrule auf, der von Ganondorf bezwungen wird, woraufhin das Land in Chaos und Finsternis versinkt. Ganondorf nimmt hierbei die Funktion der (permanenten) Bedrohung Hyrules ein, die es abzuwenden gilt. Wind Waker vertauscht diese Rollen nun, indem es Ganondorf zum Wächter Hyrules macht und den König zur Bedrohung, die letztlich auch zur Zerstörung des Reiches führt (was Ganondorf paradoxerweise trotz aller Bemühungen nie gelingt). Ganondorfs Motive erscheinen in seinem letzten Monolog altruistischer Art zu sein, ${ }^{372}$ wohingegen der König Hyrule wortwörtlich untergehen lässt, damit Ganondorf es nicht erhalten kann, gewissermaßen egoistisch agiert. Was den Unterschied zwischen Wind

371 Vgl. dazu das Let's Play des Endkampfes gegen Ganondorf von GaMEXPLAIN https://www.youtube.com/watch?v=p71I8slrgrI (30.06.2018).

372 Dies wird bspw. auch dadurch unterstrichen, dass Ganondorf in Wind Waker weniger als dämonischer Usurpator und Personifikation des ,Bösen“ dargestellt wird. Stattdessen erscheint er gerade in seinem Schlussmonolog als der König des Nomadenvolks der Gerudo (eines ,Vasallenstaats“ Hyrules), wodurch die politische Dimension der Szenerie zu Ungunsten der mythologischen aufgewertet wird. Die politische Motivation Ganondorfs drückt sich in seinem diffusen Wunsch aus, dass er (und sein Volk) am Wohlstand Hyrules partizipieren wollen, eines Landes, das weitestgehend von fruchtbarer Steppe geprägt ist und hiermit einen deutlichen Kontrast zu jener Wüste bildet, die die Gerudo bewohnen. Dementsprechend verkehrt sich nicht nur die Position zwischen hylianschem König und Ganondorf, sondern auch zwischen deren Völkern. Erscheinen die Gerudo im mythologischen Kontext als Aggressoren und Invasoren Hyrules, so wird Hyrule im politischen Kontext zur Hegemonialmacht, die imperialistisch über ihre Vasallenstaaten verfügt. Insofern ist Wind Waker in vielerlei Hinsicht eines der ambivalentesten Spiele der gesamten Spielserie. Diese Tendenz einer eher, entmythologisierten' Deutung von Wind Waker teilt auch Mathias Mertens, wenn er anmerkt, dass der Avatar Link in diesem Teil der Serie weniger als auserwählter, legendärer Held gestaltet sei, sondern eher als „ein austauschbarer Jedermann“, der keine höhere Aufgabe zu erfüllen hat und deshalb auch nicht von höheren Mächten konsekriert wird. MERTENs (2004), 285. 
Waker und vielen anderen Titeln der Serie bedingt, ist, dass Wind Waker weniger eine kosmologische Erzählung als vielmehr eine eschatologische ist. Das alte Hyrule geht unter, damit ein neues auferstehen kann. Und tatsächlich sind die Folgetitel dieser Zeitlinie - wie Spirit Tracks (2009) - größtenteils im ,neuen Hyrule' angesiedelt. Als Teil eines Schöpfungsmythos, auch wenn sie apokalyptisch inszeniert sein und sich dementsprechend eher wie das Ende allen Seins als wie der Beginn einer neuen Welt ausnehmen mögen, sind eschatologische Erzählungen immer Teil eines Zyklus, der aus einer Kosmo- und einer Eschatologie besteht. Durch die Zyklenartigkeit legitimieren Schöpfungsmythen nicht nur die Ursprünge, sondern prinzipiell jeden Abschnitt des Zyklus und somit auch das (apokalyptische) Ende. Ein Teil folgt immer auf den nächsten, sodass selbst der Weltuntergang weitestgehend folgenlos bleibt, da ihm immer die Gewissheit eines neuen Anfangs innewohnt. Das bedeutet, dass Schöpfungsmythen dem Spieler interaktiv-narrativer digitaler Spiele bei aller Offenheit des Spiels doch die Gewissheit eines bestimmten und vorhersehbaren Ausgangs suggerieren, die den Spieler bei aller Unsicherheit, bei all den Mühen wiederholter Anläufe, schwierige Spielsituationen zu überwinden, doch nie an ,dem einen Ende` zweifeln lässt. Dabei können Schöpfungsmythen als Deutungs- und Sinnstiftungsangebote aber nicht nur das ,Durchspielen“ eines interaktiv-narrativen digitalen Spiels unterstützen, sondern sie eignen sich als ,serielles Ordnungsprinzip“, um ganze Spielereihen und -serien organisieren und strukturieren $\mathrm{zu}$ können. ${ }^{373}$ Durch ihren zyklenartigen Aufbau kann am Ende eines jeden Reihentitels die Welt untergehen, da zwangsläufig immer eine neue entsteht, die lediglich eine geringfügig modifizierte Version der vorangegangenen Welt darstellt, formal und strukturell gesehen dementsprechend identisch ist. ${ }^{374}$ Auf die seriellen Aspekte des Mythos wird am Ende dieses Kapitel kurz eingegangen.

Die Deutungs- und Sinnstiftungsangebote von interaktiv-narrativen digitalen Spielen, und der Ausblick auf The Legend of Zelda hat dies untermauert, dienen im Rahmen einer schöpferischen Mythologie primär dazu, Sicherheit und Kontinuität zu vermitteln, darüber

\footnotetext{
${ }^{373}$ Man kann hierin aber freilich nicht nur eine gelungene serielle Gestaltung erkennen, sondern diese auch als monoton und einfallslos kritisieren. Mathias Mertens führt etwa aus: „[Shigeru Miyamoto hat] mit seiner Serie Legend of Zelda seit fast zwei Jahrzehnten das Genre des Action-Adventures immer weiter definiert. Da Legend of Zelda auf der Oberfläche eine klassische Heldenerzählung darstellt, in der ein Auserwählter die Rettung der Welt betreiben muss, hat die Fortsetzungsreihe mit einer Aporie zu kämpfen: Wie kann der neueste Titel The Wind Waker (Nintendo, 2002) gleichzeitig alle Standards liefern, also als Legend of Zelda wieder erkennbar sein, und eine neue Geschichte darstellen? Nach Legend of Zelda (1987), The Adventure of Link (1988), A Link to the Past (1991), Ocarina of Time (1998) und Majora's Mask (2000) scheint zumindest das Narrative des Spiels selbst in einer ewigen Schleife gefangen." MERTENS (2004), 284; Herv.i.O.

${ }^{374}$ Man denke hier z.B. an den Ragnarök.
} 
hinaus erzeugen sie aber auch Irritationsmomente bzw. Ambivalenzen, die eine gewisse Pluralität an Deutungen zulassen. Man kann also sagen, dass digitale Spiele mit mythologischem Interaktiv-Narrativ dem Spieler eine , unsichere Sicherheit" offerieren, somit zu einem Ausgleich zwischen Geschlossenheit des Mythos und Offenheit des Spiels beitragen. Dabei, das sei hier nur kurz angemerkt, erscheint es fraglich, wie sinnvoll es ist, sklavisch bestehenden Arbeiten zur Schöpfungsmythologie zu folgen. So lässt der kritische Blick auf Joseph Campbells vier Funktionen von Schöpfungsmythen z.B. aufschimmern, dass digitale Spiele Mythen zwar oft funktionalisieren, um bestimmte Kontexte oder Settings ${ }^{375}$ aufzurufen (2) und den Spieler intentional zu formen bzw. zu beeinflussen (3), demgegenüber steht aber die Feststellung, dass digitale Spiele kaum zwischen dem Menschen und dem Göttlichen bzw. ,mysterium tremendum et fascinans' (1) vermitteln sowie sie auch kaum, zumindest unter mythologischen und religiösen Gesichtspunkten, zur Entfaltung des spielerischen Individuums beitragen (4). ${ }^{376}$ Allerdings, darauf sei hier nur kurz verwiesen, können mythologische und religiöse Elemente sehr wohl zur Entfaltung des Individuums beitragen, wenn auch nicht oder zumindest nicht primär zu einer mythologisch-religiösen. In diesen Fällen fungieren mythologische oder religiöse Elemente sinnstiftend bzw. induzieren eine Ausbreitung der Individualität des Subjekts. Dies betrifft aber oft weniger das Spielen an sich, als vielmehr die kollektive Teilhabe an den kommunikativen Austauschprozessen innerhalb der transmedialen Welt des jeweiligen Spiels über dieses. Insofern scheint die Fankultur (im Internet) ein lohnenswerter Gegenstand für künftige Forschungsvorhaben zu sein, die sich damit befassen, inwiefern mythologische digitale Spielserien und -reihen wie The Legend of Zelda oder The Elder Scrolls moderne Mythenbildung im Kontext ihrer Fankulturen anregen und wie diese sich konkret ausgestalten. ${ }^{377}$ Für den Spielprozess an sich ist jedoch die Formung des Spielers bzw. seiner Verhaltensweisen durch den Mythos unter

\footnotetext{
${ }^{375}$ Zur Verwendung von Religion als Setting in digitalen Spielen vgl. MATUSZKIEWICZ (2015a).

${ }^{376} \mathrm{Zu}$ den digitalen Spielen, die dies dezidiert versuchen, gehören jene, die im Auftrag religiöser Institutionen entwickelt werden oder diesen nahestehen. Exemplarisch sei auf die folgende Sammlung christlicher Browserspiele verwiesen http://www.theology.de/theologie/fachbereiche/praktischetheologie/religionspaedagogikonlinespiele.php (30.06.2018). Diese streben bspw. die Vermittlung christlicher Glaubensinhalte sowie von bestimmten Werten und Normen an. Für sie gilt aber leider meistens, was der Theologe Ulrich Nersinger feststellt: „Die wenigen unter Mithilfe von Theologen publizierten religiösen Games (es handelt sich fast ausschließlich um Bibelspiele) finden beim jungen Publikum, aber auch bei der älteren Klientel, kaum Zuspruch. Sie packen den Gamer nicht. Sie quälen ihn mit einer unverständlichen Sprache, vergraulen ihn durch einen ständig erhobenen moralischen Zeigefinger - oder sind einfach nur langweilig. Ein weiterer Schwachpunkt dieser Spiele liegt in deren technischer Präsentation. Graphik und Bedienung sind hoffnungslos veraltet und rufen im günstigsten Fall ein bemitleidendes Schmunzeln hervor, eher jedoch herbe Enttäuschung, manchmal sogar pure Verzweiflung." NERSINGER (2008).

${ }^{377}$ Für mögliche Erhebungen im Internet bieten sich in Bezug auf The Legend of Zelda bspw. Foren wie Zelda Europe, Wikis wie Zelda-Wiki oder Zeldapedia oder Fanseiten wie Zelda Universe an (alle 30.06.2018).
} 
den vier Funktionen von Schöpfungsmythen im Sinne Campbells am relevantesten und wird im kommenden Kapitel beleuchtet.

\subsection{Vorbild- und Nachahmungsfunktion}

Im Verlauf des Kapitels wurde bereits vielfach auf die Vorbild- und Nachahmungsfunktion des Mythos und deren Auswirkung auf die mögliche Realisierung einer bestimmten (narrativen) Rollenerwartung abgehoben. Durch den Vorbildcharakter, den mythologische Welt und deren Figuren einnehmen, soll der Rezipient des Mythos dazu angeregt werden, die narrative Figurenkonzeption im Sinne der Erzähllogik performativ auszuagieren. (vgl. dazu 2.3.3) Die implizite Performanz des Mythos spiegelt sich in der Korrespondenz der narrativen und performativen Handlungsmuster wider sowie sie sich in den (interaktiven) Handlungen des Spielers stets aktualisiert. Hierbei ist besonders der Vorbildcharakter des Spieleravatars als auserwählter Held und den hiermit verbundenen (idealisierten) Figurenzuschreibungen von Interesse. (vgl. dazu auch 2.5.2.1) Nehmen wir hier den Protagonisten aus The Elder Scrolls IV: Oblivion als Beispiel. Dieser wird in der Einführungsphase des Spiels als vom Schicksal auserwählter Held inszeniert. ${ }^{378}$ Er befindet sich im Gefängnis der Kaiserstadt, wo er unerwartet auf Kaiser Uriel Septim VII. trifft, welcher (begleitet von seiner Leibwache) versucht, den Meuchelmördern der Geheimorganisation ,Mythische Morgenröte` zu entgehen, der auch schon seine drei Söhne zum Opfer gefallen sind. Der Spieleravatar schließt sich dem Kaiser und seinen Leibwächtern an, kann jedoch auch nicht verhindern, dass dieser von der Mythischen Morgenröte ermordet wird. Sterbend fleht der Kaiser den Spieleravatar an, seinen letzten (unehelichen) Sohn Martin aufzuspüren und ihm das Amulett der Könige zu überreichen, damit dieser erneut die Tore in die dämonische Parallelwelt Oblivion verschließen kann. Nachdem der Ruf des Abenteuers derart an den Spieleravatar ergangen ist, macht dieser sich nun auf den Weg, den Kaisersohn Martin zu finden.

Im Unterschied zu The Legend of Zelda unterbindet der Programmcode in Oblivion jedoch kaum ,unmoralische“ Aktionen, die ,moralischen Basiskonzepten` widersprechen. (vgl. dazu 2.3.3) Link kann bspw. keine ,unschuldigen` NPCs töten, sondern immer nur seine Gegner und er kann auch niemanden bestehlen. Demgegenüber kann der Spieler via Avatar in Oblivion rauben, stehlen und morden, was mittel- bis unmittelbare Konsequenzen für den Spieler hat. Entscheidend ist hierbei jedoch, wie oft Spieler letztlich im Rahmen der Realisierung von Handlungsoptionen tatsächlich gegen ,moralische Basiskonzepte‘ verstoßen.

${ }^{378}$ Vgl. dazu das Let's Play von VAZZ https://www.youtube.com/watch?v=IKLRq2iNfHQ (30.06.2018). 
Wenn man z.B. im Zuge von Mediennutzungs- oder Medienwirkungsstudien feststellt, dass viele Spieler nie oder selten ,unmoralische‘ Handlungsoptionen realisieren und das, obwohl sich ludische Interaktivität v.a. auch durch ihren explorativ-testenden Charakter auszeichnet, die digitale Spiele wie Portal 2 (2011) zu dem machen, was sie sind, so stellt sich die Frage nach den Ursachen. ${ }^{379}$ Warum tendieren Spieler in Portal 2 eher dazu, die Bandbreite an Interaktionsmöglichkeiten umfassend auszuschöpfen, wohingegen dies in digitalen Spielen wie Oblivion unterbleiben kann ${ }^{380}$

In Form von Mitleid oder moralisch orientiertem Verhalten, das sich in konkreten Interaktionen mit NPCs dokumentiert, wird den computergesteuerten Spielpartnern eine Anerkennung als Person entgegengebracht, die im soziologischen Sinne bislang nur Menschen vorbehalten war. (HARTH 2016)

Die NPCs digitaler Spiele werden, folgt man Jonathan Harth, beim Spielprozess, wenn die emotionale Immersion gelingt, zu Partnern des Spielers, der denjenigen Empathie entgegenbringt, die er sucht, vor Unheil zu bewahren. Damit ist der NPC nicht länger nur eine narrative Figur, in der Wahrnehmung des Rezipienten erhält er etwas ,Lebendiges‘, das ihn als Entität für den Spieler aufwertet. Dieser Effekt wird durch ein Phänomen evoziert, das in

${ }^{379}$ Bisher fehlen jedoch breit angelegte empirisch-quantitative Studien, die den Zusammenhang zwischen den Gegebenheiten des Spiels und der Realisierung dieser Anlagen durch den Spieler unter moralischen Gesichtspunkten in den Blick nehmen. Trotz des Fehlens derartiger Studien in den Digital Game Studies, der Medien- und Kommunikationswissenschaft oder der Moralpsychologie gibt es dennoch Arbeiten, die sich diesem Phänomenbereich (wenn auch primär theoretisch) systematisch nähern. Vgl. hierzu exemplarisch SCHRIER/GIBSON (2010).

${ }^{380}$ Dass es durchaus legitim erscheint, diesen Kausalzusammenhang trotz fehlender Ergebnisse empirisch ausgerichteter Studien herzustellen, untermauert in den letzten Jahren der Gegenstandsbereich selbst. Die Auswertung der Entscheidungssituationen in den digitalen Spielen von Telltale Games, die Spieler erhalten, wenn sie online spielen, beinhalten nicht nur, wie sich der betreffende Spieler selbst entschieden hat, sondern sie weisen auch aus, wie sich der Spieler im Verhältnis zu anderen Spielern entschieden hat. Dabei unterliegen die Auswertungen permanent gewissen Schwankungen, da sie sich stets dem aktuellen wie vergangenen Spielgeschehen anpassen. Dennoch lässt sich selten feststellen, dass eine Ausgewogenheit zwischen (binären) Entscheidungen vorherrscht. Vielmehr zeigt sich i.d.R. auf einer der beiden Seiten eine deutliche Akkumulation. Hierbei, auch wenn dies in dieser Arbeit nicht explizit ausgeführt werden kann, werden intendierte Handlungsoptionen via moralischer Basiskonzepte herausgearbeitet. Ein kurzes Beispiel soll dies verdeutlichen: Am Ende der dritten Episode von The Wolf Among Us wird der Spieler vor die Wahl gestellt, den zwielichtigen Kleinkriminellen Dee bei einem Wutanfall des Spieleravatars Bigby Wolf zu töten oder zu verschonen. Obwohl die Auswertung immer gewissen Schwankungen unterliegt, lässt sich bei dieser Entscheidung doch beobachten, dass eine große Mehrzahl an Spielern Dee nicht getötet hat, (ca. 88\% im Juli 2016) obwohl dieser im Spielverlauf mehrfach mit dem Spieleravatar zusammenstößt, diesen verletzt und eindeutig dem zu bekämpfenden Verbrechersyndikat angehört. Stichprobenartige Sichtungen von Fanforen unterstreichen die temporalen Schwankungen der Auswertungen, wie das folgende Beispiel zeigt: http://steamcommunity.com/app/250320/discussions/0/558752450235742885/?l=german (30.06.2018). Zugleich hebt das Stream-Forum zum Spiel aber auch hervor, wie kontrovers und ausgreifend die Diskussion im Laufe einer überschaubaren Zeitspanne (8. April 2014 bis 7. Juli 2014) geführt wurde. Darüber hinaus helfen derartige Beobachtungen aber auch, zukünftige Forschungssettings zu präzisieren. So wird im Diskussionsverlauf, wenn auch implizit, immer wieder auf wiederholte Spieldurchläufe abgehoben, wobei häufig zum Ausdruck kommt, dass man sich in einem späteren Spieldurchlauf anders entschieden habe als vorher. Dabei gilt es zu klären, inwiefern sich wiederholte Spieldurchläufe auf die statistischen Auswertungen insgesamt auswirken, d.h. in welchem Maße sie u.U. dazu beigetragen haben, dass sich die Entscheidungen der Spieler in den vergangenen Jahren dahin verlagert haben, Dee zu verschonen. 
der Forschung unter dem Begriff des ,moralischen Engagements“ (des Spielers) firmiert: „We have, however, observed that there may be a link between someone's moral sentiment and the events in the fictional world. When this link is maintained, we can speak of moral engagement.“ (ŠvelCH 2010, 54; Herv.i.O.) Es ist dabei eine zentrale Erkenntnis der Moralpsychologie der letzten zwei Jahrzehnte, ,that our moral behavior is principally guided by moral emotions (such as guilt or dignity), rather than by fixed, objective principles.“ (ebd., 55) Das bedeutet letztlich aber auch, dass die persönliche Bindung, die Subjekte zu anderen Entitäten aufbauen, von großer Bedeutung für das moralische Handeln dieser Subjekte ist und dass die Intensität einer persönlichen Beziehung dementsprechend in unterschiedlichem Maße Einfluss auf die Entscheidungsfindung des Subjektes unter moralischen Gesichtspunkten nimmt. Insofern bedingt das, moralische Engagement ${ }^{\star}$ des Subjekts auch stets das ,emotionale Engagement‘ des selbigen. (vgl. ebd., 56) Eine fundamentale Rolle nehmen dabei moralische Emotionen wie die Schuld ein. Digitale Spiele wie diejenigen von Telltale sprechen im Rahmen des Einsatzes, moralischer Basiskonzepte" oft gerade jene grundlegenden moralischen Emotionen des Spielers an. Nehmen wir eine binäre Entscheidungssituation in einem beliebigen digitalen Spiel, in der es gilt, einen NPC zu verschonen oder zu töten. Im ersten Fall verstößt der Spieler gegen keine moralischen Basiskonzepte und setzt sich dementsprechend auch nicht moralischen Emotionen aus, die negativ konnotiert sind. Im zweiten Fall hingegen verletzt der Spieler, moralische Basiskonzepte', was i.d.R. moralische Gefühle wie Schuld in ihm evoziert, die nicht selten von anderen ,negativen“ Emotionen begleitet werden. Angesichts dessen ist anzunehmen, dass Spieler (wahrscheinlich) versuchen werden, einen Verstoß gegen moralische Basiskonzepte zu vermeiden, um so die damit einhergehende Auseinandersetzung mit moralischen Emotionen zu verhindern. ${ }^{381}$

In diesem Zusammenhang geht es bei der Profilierung intendierter Handlungsoptionen im Designprozess um „designing moral gameplay“. (ebd., 60) Eine der Möglichkeiten im Rahmen des Gamedesigns, dieses ,moral gameplay‘ zu evozieren, liegt, so Jaroslav Švelch, im Rollenspiel. „When role-playing, we take on a moral profile different from our own. [...] And this is, obviously, one of the biggest attractions of video games. Role-playing a character

\footnotetext{
381 Korrespondierend hierzu haben Mediennutzungsstudien seit dem Aufkommen des ,Nutzen- und Belohnungsansatzes` in der zweiten Hälfte des 20. Jahrhundert zunehmend festgestellt, dass die mediale Zuwendung von Nutzern sehr selektiv erfolgt, d.h. dass Nutzer sich tendenziell medialen Objekten und Inhalten zuwenden, die ihren Weltbildern und Präferenzen entsprechen, die - anders gesagt - von diesen als mit ihrer Persönlichkeit und ihren Vorstellungen konform betrachtet werden. Vgl. zum Nutzen- und Belohnungsansatz auch SCHENK (2007).
} 
with a different moral profile can be both fun and an interesting experiment.“ (ebd., 64) Rollenspiel in digitalen Spielen rekurriert somit weniger auf das Genre, sondern eher auf das Phänomen als solches, es bedeutet, die Rolle eines anderen zu übernehmen, sich zu eigen zu machen. Diese Übernahme gezielt zu steuern, ist Aufgabe des Gamedesigns. „Effective visual and emotional design may re-connect the player with the character he is role-playing.“ (ebd.) Ein effizienter Weg, Spieler derart zu beeinflussen, sind Figurenkonzeptionen und konstellationen interaktiv-narrativer digitaler Spiele. Gemeinsam können sie im Gamedesign eingesetzt werden, um moralische Standards in digitalen Spielen als , geschlossenen ethischen Systemen` zu implementieren und an den Spieler zu vermitteln. (vgl. SiCART 2009)

The player has a vague notion of what is right and wrong, but does not encounter the game's morality as a coherent system. The consequences of actions are realized after the actions are made. It does not teach a particular morality. (SCHULZKE 2009)

Dabei geht es, so Marcus Schulzke, weniger um eine Vermittlung in einem belehrenden Sinne, sondern darum, dass digitale Spiele Deutungsangebote machen, die es dem Spieler ermöglichen, zwischen eher ,guten“ und eher ,schlechten' moralischen Handlungen zu differenzieren. Ein Streifzug durch gegenwärtige Mainstream-Produktionen digitaler Spiele legt die Vermutung nahe (selbst wenn man nur Titel von bekannten Studios wie Quantic Dream, Telltale Games oder Bethesda betrachtet), dass digitale Spiele bisher keine leuchtenden Exempel für Anleitungen zu einem moralisch oder ethisch erstrebenswerten Leben sind. Vielmehr kommt Moral immer dann ins (digitale) Spiel(design), wenn es gilt, intendierte Handlungsoptionen herauszuarbeiten oder die geringe Agency sowie Signifikanz, Frequenz und Bandbreite an Interaktionen zu kaschieren. (vgl. EngELNS 2015) Dieser Mangel an Agency und Interaktivität lässt sich im Designprozess stets durch eine dementsprechende Umstrukturierung des Interaktivs unterbinden, indem man bspw. die individuelle Agency des Spielers erhöht. Da dies aber oft mit einem immensen technischen und finanziellen Aufwand verbunden ist, unterbleibt es i.d.R. Um dem Spieler aber dennoch das Gefühl großer Agency und weitreichender Interaktivität $\mathrm{zu}$ geben, ist der Gamedesigner gezwungen, andere Möglichkeiten der Spielersteuerung einzusetzen. An die Stelle einer direkten Regulierung der Spielerhandlungen durch das Interaktiv tritt somit eine indirekte durch das Narrativ.

Insofern ist es (aus designerischer Sicht) naheliegend, (vorbildhafte) narrative Figurenkonzeptionen einzusetzen, um auf die interaktive Realisierung des Spieleravatars durch den Spieler einzuwirken. Ziel dieses Einsatzes der Figurenkonzeption ist es, dabei Realisierungen $\mathrm{zu}$ evozieren, die sich dieser Figurenkonzeption gemäß verhalten. (vgl. 
RAUSCHER 2015) Dies ist möglich, weil die Figurenkonzeption, will sie der Spieler ausagieren, (aufgrund einer Korrespondenz der Handlungsmuster) dazu führt, dass die intendierten Handlungsoptionen i.d.R. realisiert werden. Spielern, bei denen die Manipulation der Entscheidungsfindung durch ,moralisierende' Figurenkonzeptionen gelingt, wird kaum auffallen, dass ihre Annahmen über ihre individuelle Agency wie die Interaktivität des betreffenden digitalen Spiels unzutreffend, zu optimistisch sind. Andere Spieler hingegen, die diese Illusion erkennen, (vgl. CHARLES 2009) zeigen sich oft unzufrieden mit der Monotonie und geringen Auswahl an Handlungsoptionen. ${ }^{382}$ (vgl. ŠVELCH 2010, 59) Ob ein digitales Spiel also durch die intendierten Handlungsoptionen den Spieler zu einem ,moralischen` oder einem ,amoralischen` Handeln verleitet, hängt somit letztlich in nicht unerheblichem Maße vom Narrativ und der damit verbundenen Konzeption des Protagonisten ab. Da der Held des Monomythos, unabhängig von seiner Positionierung auf dem Kontinuum zwischen den Polen Held und Antiheld, per definitionem aber immer ,gut ' ist, legt dies dem Spieler ein (gutes) ,moralisches' Handeln nahe. Das bedeutet, dass im Rahmen des moralischen und emotionalen Engagements des Spielers seltener, negative‘ moralische Emotionen aufgerufen werden, sondern eher positive. Bedingt durch seine Figurenkonzeption ist der Held nämlich nicht jener, der (moralische) Schuld auf sich lädt, sondern der Schuld sühnt. Deshalb wird im Folgenden genauer zu betrachten sein, wie interaktiv-narrative digitale Spiele, die auf den Monomythos rekurrieren, versuchen, den Spieler zu einem positiven Handeln gemäß der Figurenkonzeption und -konstellation anzuleiten. Dabei fällt grundsätzlich auf, dass der Spieleravatar in derartigen digitalen Spielen wie Oblivion als Avatar und nicht als Spielfigur realisiert wird. (vgl. dazu 2.5.2.3) Dies ist bei Portal 2 hingegen anders, hier fungiert der Spieleravatar (hauptsächlich) nur als Spielfigur, da das Narrativ des Spiels durch die Figurenkonzeption weniger starke Auswirkungen auf die potenziellen Realisierungen des Avatars durch den Spieler hat. Warum ist das so?

\footnotetext{
${ }^{382}$ Exemplarisch sei hier auf die online stattfindenden Diskurse innerhalb der Fankultur der Telltale-Spiele verwiesen, wo den begeisterten Fans immer wieder jene entgegenstehen, die genau jenen Umstand beklagen. Bei den ,Verteidigern' der Spiele lässt sich häufig in den Kommentaren ablesen, dass die Immersion in die narrativen Elemente des Spiels bei diesen gelungen ist, was ursächlich für die positive Evaluation des Spiels sein kann. Die ,Kritiker ' hingegen scheinen einerseits eine weniger intensive Immersion in die narrativen Elemente gehabt zu haben bzw. zeigen sich oft auch enttäuscht von der geringen ludischen Ausprägung dieser Spiele. Insofern könnte es zukünftig lohnenswert sein, zu eruieren, ob die Manipulation der interaktiven Realisierung der Anlagen des Spiels gemäß Figurenkonzeption und -konstellation bei dem narrativen Spielertyp besser gelingt als bei den anderen beiden. Der folgende Thread umfasst viele Argumente beider Seiten, die in den Diskussionen um Telltales Game of Thrones immer wieder zirkulieren https://www.reddit.com/r/gameofthrones/comments/4119dv/no_spoilers_is_the telltale_game_really that_bad/ (30.06.2018).
} 
Ausschlaggebend hierfür ist, dass Oblivion mit dem mythologischen Narrativ ein Narrativ verwendet, dessen Figurenpersonal tendenziell relativ eindeutige moralische Implikationen aufweist und Portal 2 dies eben nicht hat. Durch die ,Anpassung' an das Narrativ bzw. an die nahegelegten Verhaltensweisen der Figuren reguliert sich der Spieler in Oblivion performativ gewissermaßen selbst (vgl. dazu 2.3.2) und entscheidet sich eher dagegen, Handlungsoptionen im Rahmen seiner Agency zu realisieren, die der narrativen Konzeption des Helden widersprechen. Bemerkenswert ist dabei, dass Bethesda im Vergleich zu Nintendo auf ein Interaktiv setzt, das weniger stark mythologisiert ist, da es Handlungsoptionen einräumt, die im Rahmen des paidianischen Spielens oder von personalen Narrationen zu Situationen führen können, die der medialen Narration, welche dem Monomythos folgt, diametral entgegenstehen (können). Insofern sind, unter dem Aspekt der Vorbild- und Nachahmungsfunktion, die digitalen Spiele der Elder Scrolls-Reihe ab The Elder Scrolls III: Morrowind (2002) prädestiniert, um diese Funktionalisierung von Funktionen des Mythos im Designprozess zu zeigen. ${ }^{383}$ Aufgrund des Rahmens dieses Forschungssettings muss dies leider in dieser Arbeit unterbleiben. Allerdings wird die Vorbild- und Nachahmungsfunktion bzw. deren Auswirkung auf die Interaktion-Narration des Spielers in Kapitel 4 mit Blick auf Ocarina of Time ausführlicher beleuchtet.

Abschließend möchte ich noch kurz auf die Folgen der Funktionalisierung der Vorbildund Nachahmungsfunktion für das interaktiv-narrative Spielweltdesign eingehen, da dies unmittelbar mit dem Figurendesign zusammenhängt. Da Agency dem Individuum stets vom Kontext zugewiesen wird, bestimmt auch die Spielwelt die Handlungsmöglichkeiten des Spieleravatars. Als ,Unterflächenphänomen“ manifestieren sich diese designerischen Entscheidungen in der Ausprägung der individuellen Agency sowie in der Bandbreite an möglichen Interaktionen im Programmcode. (vgl. dazu ScHWINGELER 2014) Als ,Oberflächenphänomen` drückt sich dies in einer stärkeren Ambivalenz der Spielwelt und der NPCs aus. In The Legend of Zelda prägt die Gut-Böse-Dichotomie des Monomythos die Spielwelt durchgehend. Es gibt entweder eindeutig ,gute' oder ,böse“ Orte. Motivik, Farbgebung sowie das Verhalten der ortsgebundenen NPCs markieren dabei deutlich, an was

\footnotetext{
${ }^{383}$ Mythos und mythologische Funktionen können aber im Rahmen des Designs eines digitalen Spiels anderen Zielen dienen, als nur ein Unterhaltungsprodukt zu schaffen. Das Biofeedback-System The Journey to Wild Divine (2001 ff.) verbindet bspw. ein mythologisches Spielsetting mit diversen Entspannungsübungen mit dem Ziel von Entspannung und Stressabbau beim ,Spieler'. Vgl. dazu exemplarisch das folgende Let's Play von XAXTON REVOLUTION https://www.youtube.com/watch?v=UUNcPhyCa84 (30.06.2018). Inwiefern derartige Spiele aber die behaupteten Intentionen zu erreichen vermögen, scheint zweifelhaft zu sein. Dennoch kann es als ein anschauliches Beispiel für die Verwendung mythologischer Inhalte und Funktionen im Rahmen der ,Gamification“ dienen.
} 
für einem Ort sich der Spieleravatar befindet. In Oblivion hingegen gibt es zwar eindeutig ,böse' Orte wie Oblivion oder die diversen Minidungeons in Form von Höhlen oder verlassenen Festungen, die von Dämonen, Geistern, Trollen oder Untoten bewohnt werden, die ,guten“ Orte sind aber von einer größeren Ambivalenz bestimmt, als dies in The Legend of Zelda der Fall ist. So findet man selbst in den ,guten“ Städten einzelne Orte, die von fragwürdigen Personen oder Organisationen besiedelt bzw. kontrolliert werden. Oblivion folgt in seiner Darstellung der Spielwelt also auch der Gut-Böse-Dichotomie, die für den Monomythos kennzeichnend ist, nivelliert diese aber intensiver als digitale Spiele wie The Legend of Zelda. ${ }^{384}$ Für die Interaktion-Narration des Spielers hat dies zur Folge, dass die Vorbild- und Nachahmungsfunktion des Mythos zwar auch in Oblivion genutzt, dass die Art und Weise der Umsetzung im Designprozess aber bedingt, dass das Interaktiv ,mythologisch“ gespielt werden kann, aber nicht muss. Diesbezüglich wären zukünftig Studien von Interesse, die z.B. in den Blick nehmen, ob der interaktive Spielertyp in Oblivion weniger dazu neigt, dass Spiel ,mythologisch`zu interpretieren, als u.a. der interaktiv-narrative Spielertyp.

\subsubsection{Die Entrückungsfunktion}

Bevor ich mich den substantialistischen Aspekten des Mythos in interaktiv-narrativen digitalen Spielen zuwende, möchte ich kurz einige Anmerkungen zur Entrückungsfunktion des Mythos in interaktiv-narrativen digitalen Spielen machen, um zu zeigen, dass die Funktionen des Mythos nicht allein unter ordnenden Gesichtspunkten für digitale Spiele relevant sind. ,Entrückende“ Augenblicke sind jene, in denen das rezipierende Subjekt seiner gewöhnlichen Umgebung im Zuge der Rezeption von etwas bzw. Partizipation an etwas entzogen wird. Damit ist keinesfalls eine Entrückung im theologischen oder religionswissenschaftlichen Sinne gemeint, die den (temporären) Transfer eines Subjektes von einem menschlich-immanenten in einen göttliche-transzendenten Raum bezeichnet. ${ }^{385}$ Welche Punkte die religiöse Entrückung und die ,mythologisch induzierte Entrückung ' in digitalen Spielen aber teilen, ist die Tatsache, dass beide mit ,entrückenden' Zuständen des entrückten Subjektes einhergehen wie Trance oder Rausch. An dieser Stelle werden (wie oben bereits angesprochen) erneut die Parallelen zwischen dem Mythos und anderen kulturellen Formen wie dem Spiel, dem Ritual oder der Religion deutlich. (vgl. dazu 3.1.2.2) Die entrückenden Zustände, die Spieler in digitalen Spielen erfahren können, und die durch eine mythologische Funktionalisierung noch verstärkt werden können, ähneln sehr dem, was Victor Turner als

\footnotetext{
${ }^{384}$ Insofern decken sich diese Befunde mit denen, die sich aus dem Vergleich der Gestaltung der Protagonisten der beiden Spiele auf Figurenebene ergeben haben.

${ }^{385}$ Zur Entrückung im christlichen Sinne vgl. LINDSEY (1986).
} 
liminalen Zustand des Subjektes während der Schwellenphase oder Johan Huizinga als Zauberkreis des Spiels bezeichnet, der den Spieler aus seiner gewöhnlichen Welt (temporär) herauslöst. (vgl. dazu 1.2.1)

Bei der Spielform Ilinx, so Roger Caillois, geht es um das Erreichen eines Rauschzustandes, wie ihn Kinder beim Drehen um die eigene Achse oder Partizipierende mancher mexikanischer Volksfeste erlangen. (vgl. CAILLOIS 1960, 32) Der Rausch, wenn man Caillois' Beispiel aufnimmt, ist sowohl psychischer als auch physischer Art, da er einerseits zwar primär die Wahrnehmung des Subjektes betrifft, sich als Rauschzustand andererseits aber auch körperlich manifestiert. So wird Menschen, die sich im Rausch befinden, seit jeher nachgesagt, imstande zu sein, außergewöhnliche Kraftanstrengungen zu vollbringen. Selbst wenn man sich von derartigen Schilderungen vermeintlicher Wundertaten löst, kann man immer noch die physischen Auswirkungen des Rausches herausstellen, wie Caillois dies mit seinem Beispiel getan hat. In dem Moment, in dem sich das Kind derart schnell um die eigene Achse dreht, dass ihm schwindelig wird, sodass es einen berauschenden Zustand durch die Überforderung seiner Sinnesorgane erfährt, so hat dies auch eine körperliche Dimension. Denn häufig ist es Kindern in dieser Situation nicht oder kaum möglich, sich fortzubewegen. Die kognitive Überlastung bedingt offensichtlich auch eine Einschränkung der motorischen Fähigkeiten des berauschten Subjektes. ${ }^{386}$

Die Frage ist nun, ob und inwiefern sich diese rauschbedingten Entrückungszustände mit denen anderer Medien wie Film oder Literatur vergleichen lassen, die ebenfalls intensiv auf Mythologien rekurrieren. Meines Erachtens ist dies nicht der Fall bzw. nicht in der Intensität, was ich kurz ausführen möchte. Betrachtet man diskursiv, wie Film oder Literatur Mythen verwenden, so fällt auf, dass diese eher dazu tendieren, die substantialistische Dimension des Mythos aufzurufen, indem sie auf den Monomythos oder mythologische Archetypen und Mythologeme zurückgreifen. Dies legt die Vermutung nahe, dass die Medienspezifik dieser

\footnotetext{
${ }^{386}$ Interessante Möglichkeiten, diese Rauschzustände in digitalen Spielen mediensoziologisch zu untersuchen, stellen die sog. ,Rage Vids' dar, die das ,Ausrasten“ eines Spielers als Folge einer bestimmten Spielsituation dokumentieren. Vgl. exemplarisch hierzu das Let's Play von BoogIE2988 zu Skyrim https://www.youtube.com/watch?v=cLWrT7qoZaA (30.06.2018). Ein Rage ist i.d.R. eine (heftige) Reaktion des Spielers auf eine abrupte Störung des Spiels (meist den Tod des Avatars), die immersionsbrechend wirkt. Zukünftige Studien könnten diesbezüglich z.B. der Frage nachgehen, inwiefern der Rage intensiver ausfällt, wenn die Immersion mythologisch induziert worden ist. Andere Optionen, Rausch und Entrückungszustände bei digitalen Spielen zu beobachten, offerieren VR-Umgebungen und VR-Geräte. Diese fallen bisher dadurch auf, dass sie zuweilen die Wahrnehmung des Spielers überfordern und somit zur ,motion sickness' führen. Aus diesen wie aus Kostengründen ist es denkbar, dass in den kommenden Jahren insbes. AR-Anwendungen populärer werden, da sie keine motion sickness hervorrufen und die für sie benötigten Geräte i.d.R. (z.B. Smartphone) ohnehin vorhanden sind. Deshalb bieten sie gute technologische Möglichkeiten, Spieler (mythologisch induziert oder auch nicht) beim Spielen digitaler Spiele entrücken zu lassen.
} 
beiden Medien u.U. weniger dazu ausgelegt ist, die funktionalistische Dimension von Mythen zu evozieren. Das bedeutet keinesfalls, dass sie gänzlich ungeeignet seien, mythologische Funktionen nutzen zu können. Ein Blick auf die reichhaltige Fankultur zeigt, dass viele transmediale Welten, die sich um Romane oder Filme herum entwickelt haben, ordnend und deutend auf das Alltagsleben ihrer Fans einwirken können, es ist zugleich aber bemerkenswert, dass sich diese Effekte oft in einer der medialen Rezeption nachgelagerten Reflexion des Rezipienten einstellen. Somit fallen die mediale Rezeption und die Wirkung der mythologischen Funktionen zeitlich auseinander. Der Grund hierfür ist ein simpler. Wenn wir heute an Mythen denken, vergessen wir oft, dass die historischen Mythen, deren Mythologien der Kunst heute lediglich als ,Steinbrüche' für Motive und Themen dienen, einst Teil aktiv gelebter Religionen waren, die in Ritualen und Kulten Einzug in die Lebenswelt ihrer Glaubensanhänger hielten. Gerade jene Rituale und Kulte waren es aber, die ein aktiv handlungsfähiges Subjekt voraussetzten. Mit anderen Worten: Mythen als Teil einer aktiv praktizierten Religion sind ein interaktives Phänomen, das zwingend Agency vom glaubenden Subjekt verlangt.

Literatur und Film sind aber Medien, deren Medienspezifik sich nicht vorrangig dadurch auszeichnet, dem Rezipienten eine hohe Agency zuzuweisen oder in einem (medien)soziologischen Sinne interaktiv zu sein. Dies wird für die funktionalistische Dimension von Mythen aber zum Problem, wenn man bedenkt, dass die Funktionen des Mythos zwar in den diversen mythologischen Narrativen angelegt sind, dass sie ihre Wirkung als Funktion aber erst im performativen Vollzug erhalten. Somit sind Agency und Interaktivität gewissermaßen Prämissen für eine umfassende Wirkungsentfaltung der Funktionen des Mythos. Hierin unterscheiden sich Medien wie Literatur und Film, wie Christian WESSELY (1995 sowie 1997) betont, signifikant von digitalen Spielen. Indem letztere dem Spieler Agency und Interaktivität zuweisen, machen sie ihn zum aktiven Partizipierenden, was grundlegend für eine intensive Ausschöpfung der funktionalistischen Potenziale des Mythos in interaktivnarrativen digitalen Spielen ist. Dies manifestiert sich einerseits, mit Blick auf den Monomythos, in der Funktionalisierung der Orientierungs- und Ordnungsfunktion im Designprozess zum Zwecke der Spielersteuerung. Andererseits liegt die Vermutung nahe, dass die berauschende Entrückung dazu beitragen kann, das immersive Erlebnis des Rezipienten zu intensivieren, indem die Entrückung einen schnelleren Weg in den liminalen 
Spielzustand begünstigt, der die Immersion katalysiert. ${ }^{387} \mathrm{Ob}$ dies wirklich so ist, müssten kognitionswissenschaftliche Studien belegen, die das Verhältnis zwischen Entrückung und Immersion in interaktiv-narrativen digitalen Spielen in den Blick nehmen. Unter dem Gesichtspunkt der konkreten Mediennutzung von Spielern interaktiv-narrativer digitaler Spiele kann dann auch beleuchtet werden, inwiefern die ohnehin schon ,ritualartige“ Spielsituation durch die individuelle Ausprägung der Ritualhaftigkeit des Spielens ${ }^{388}$ eines Spielers mit mythologischen Funktionen korrespondiert. Derartige Überlegungen können allerdings in Kapitel 4 allenfalls tangiert werden.

\subsubsection{Substantialistische Aspekte des Mythos in interaktiv-narrativen digitalen Spielen}

Eine der vielleicht einflussreichsten substantialistischen Studien der modernen Mythenforschung ist Northrop Fryes Arbeit Analyse der Literaturkritik. Hier profiliert Frye sein Konzept der Archetypen. Ein „Archetyp“ ist nach Frye „ein typisches oder wiederkehrendes Bild“. (FRYE 1964, 102) Präzisierend, wenn auch etwas vage bleibend, führt er aus: „Unter Archetyp verstehe ich ein Symbol, das ein Gedicht mit einem anderen verbindet und so dazu beiträgt, unsere literarische Erfahrung zu größerer Einheit und Ganzheit zu führen.“ (ebd.) In diesem Sinne sind das Meer, der Wald oder auch der Wal Archetypen, deren Bedeutung als Symbol v.a. dadurch entsteht, dass sie auf eine abendländische Wissenstradition rekurrieren, deren Anfänge auf die Mythen der griechisch-römischen Antike oder die Bibel zurückgehen. Diese Tradition, und das macht Fryes Ideen, die deren Symbolik zu ergründen suchen, immer noch aktuell, ist nun aber nicht im Zuge der Populärkultur unbedeutend geworden - im Gegenteil. Die Figuren des Superheldencomics USamerikanischer Prägung wie Flash (Hermes), Hawkman (Horus) oder Aquaman (Poseidon) sind nach antiken Göttern konzipiert und selbst das Hollywoodkino mit seiner Mainstreamausrichtung orientiert sich immer noch an klassischen mythologischen Stoffen. Filme wie Kampf der Titanen (2010) belegen dies und verhandeln selbst dort zutiefst mythisch-religiöse Themen wie Tod, Trauer und Verlust, wo wir sie auf den ersten Blick kaum erwarten wie im Science Fiction-Genre, wie die Matrix-Trilogie (1999-2003) belegt. Die anhaltende Präsenz der Archetypen führt Frye selbst auf universelle Gründe zurück.

\footnotetext{
${ }^{387}$ Diesbezüglich können Typologien wie jene Jan-Noël THONs (2006 sowie 2008) hilfreich sein, der zwischen räumlicher, ludischer, narrativer und sozialer Immersion unterscheidet. Im vorliegenden Kontext ist dabei von primärem Interesse, welche Immersionstypen vorrangig hierdurch angesprochen werden und welche Zusammenhänge sich zwischen den einzelnen Immersionstypen aufzeigen lassen.

388 Zur Ritualhaftigkeit des Spiels vgl. GAZZARD/PEACOCK (2011); HARVIAINEN (2012) sowie HARVIAINEN/LIEBEROTH (2012).
} 
Aus der Tatsache, daß der Archetyp in erster Linie ein mitteilbares Symbol ist, erklärt sich weitgehend die Leichtigkeit, mit der Volkslieder, Märchen und Mimen, wie so viele ihrer Helden, über alle Sprach- und Kulturgrenzen hinweg durch die Welt ziehen. (ebd., 111; Herv.i.O.)

Insofern hebt Frye auf Feststellungen ab, die sich auch schon bei Campbell finden lassen, was Fryes Werk aber interessant macht, ist, dass er einen Aspekt herausstellt, den Campbell nicht derart explizit macht. Damit ein mythologisches Narrativ funktioniert, damit es überhaupt existieren kann, bedarf es nicht nur bestimmter archetypischer Figuren, sondern auch Orte oder Motive. Den Archetyp unterscheidet dabei vom Mythologem, dass ersterer nicht zwangsläufig ein mythologisches Element im engeren Sinne sein muss, auch wenn beide oft identisch sein können. Prinzipiell kann man aber sagen, dass Archetypen eine größere extensionale Dimension haben als Mythologeme, da sie auch in Narrativen Verwendung finden können, die nicht dem (Mono-)Mythos folgen.

Frye weist auf die zyklischen Symbole (Archetypen) von Mythen hin, die sich in immer wiederkehrenden Mustern von Geburt und Tod, Aufstieg und Niedergang oder Aufbruch und Heimkehr ausdrücken. Diese können ein gesamtes Leben, ein Jahr oder auch nur einen Tag umspannen. Denn wichtiger als ihre zeitliche Ausdehnung ist die Gewissheit, dass dieser Zyklus nie endet, dass eine Autopoiesis vorherrscht, die diesen Rhythmus stets erhält. (vgl. ebd., 161 f.) Diese Erzählstruktur erachtet Frye als derart relevant, dass er den Mythos als „ein Strukturprinzip der Dichtung“ einordnet. (ebd., 163) Bei der Identifikation der vier ,Mythen“, die er als zentral für unsere Kultur betrachtet, konzentriert sich Frye aber weniger auf Erzählungen, die sich durch mythologische Inhalte auszeichnen, sondern auf grundlegende literarische Erzählmuster wie Komödie, Romanze, Tragödie und Ironie/Satire. Somit bieten sich für makrostrukturelle Analysen eher die Arbeiten von Campbell und Vogler an, obwohl Fryes Verständnis der Archetypen eine heuristische Bereicherung für das Forschungssetting dieser Arbeit ist. So kann man mit Berücksichtigung der Archetypen (nur um ein mögliches Anwendungsfeld abseits dieser Studie aufzuzeigen) Werke des Fantasy-Genres ${ }^{389}$ wie Game

\footnotetext{
${ }^{389}$ Zum Zusammenhang von Mythos und Fantasy vgl. allgemein ATTEBERY (2014). In der vorliegenden Arbeit wird diese interessante Schnittstelle aber nicht weiter verfolgt, da The Legend of Zelda zwar (für ein japanisches digitales Spiel ungewöhnlich) intensiv auf die europäisch-substantialistische Mythentradition rekurriert und dementsprechend auch viele mythologische Elemente aufgreift und implementiert, die sich im (westlichen) Fantasy-Genre in diversen Medien nachweisen lassen, dies aber auf eine amalgamierende Art und Weise tut, die für japanische Werke zuweilen bezeichnend ist. Hierdurch entsteht eine besondere Verbindung zwischen westlichen und japanischen Elementen, deren Entstehungsprozess derart eklektizistisch verfährt, dass er hier nicht adäquat betrachtet werden kann. Neben dieser besonderen Entlehnung und Verarbeitung von westlichen kulturellen Elementen weist das japanische Fantasy-Genre aber auch motivisch-inhaltliche Merkmale auf, die sich so nicht in der westlichen Kultur finden lassen. Ein fundamentaler Unterschied zwischen westlichem und japanischem Fantasy-Genre (wenn man aufgrund der Spezifik japanischer Genretraditionen überhaupt hier von einer Äquivalenz sprechen kann) zeigt sich z.B. in den Filmen, Anime, Manga oder digitalen Spielen, die sich
} 
of Thrones auf ihre mythologischen Implikationen hin untersuchen, die nicht dem Monomythos verpflichtet sind, da sie bspw. dessen dichotome und eindeutige Einteilung der Figuren und der Orte der erzählten Welt bewusst durchbrechen und stattdessen auf antonyme Konturierungen zurückgreifen. Für die Analyse interaktiv-narrativer digitaler Spiele werden Archetypen und Mythologeme v.a. dann interessant, wenn sie im Rahmen komplexer Erzählverfahren und damit verbundenen komplexen Figurenzeichnungen Figurentypen aufrufen, die sich nicht oder nur bedingt im Monomythos finden lassen.

Für die Untersuchung von Archetypen sind nicht zuletzt die Arbeiten Carl Gustav Jungs wegweisend. ${ }^{390}$ Dieser bemerkte in den Träumen seiner Patienten, dass immer wieder

mit Kaijus befassen. Diese leviathanähnlichen Wesen (im Westen am ehesten durch die an Ishirō Hondas Godzilla (1954) anschließende Filmreihe bekannt) sind beliebte Figuren des japanischen ,Fantasy-Genres“, die immer wieder den Kontakt und den Konflikt zwischen Mensch und Natur thematisieren und sich auch in digitalen Spielen wie der Monster Hunter-Reihe (2004 ff.) etabliert haben. Auf den ersten Blick scheint das Setting von Monster Hunter mit einer westlichen RPG-Reihe wie Dragon Age (2009 ff.) durchaus vergleichbar zu sein, bei genauerem Hinsehen offenbaren sich beide jedoch als sehr in ihrem Kulturkreis verhaftet, sodass es nicht zulässig erscheint, sie ohne Weiteres in Beziehung zu setzen. Monster Hunter zeugt bspw. von dem Verhältnis zwischen Japanern und der Topografie ihres (bergigen und zerklüfteten) Landes und Dragon Age ist ohne die Geschichte des europäisch-westlichen Mittelalters nicht rezipierbar. Gerade der enge Zusammenhang zwischen dem westlichen Fantasy-Genre und dem westlichen Mittelalter bzw. der Frühen Neuzeit scheint ein Problem zu sein, wenn es gilt, das westliche Fantasy-Genre mit dem anderer Kulturkreise zu vergleichen, deren historische Entwicklung signifikant anders verlaufen ist, sodass auch die Epocheneinteilungen der westlichen Geschichtswissenschaft unzutreffend sind. Diese Problemlage intensiviert sich noch, wenn man bedenkt, dass sich die Fantasy-Genres diverser Kulturkreise primär aus deren eigenen Mythologien speisen. Dies angemessen und differenziert zu betrachten, bedarf eigener Studien. Digitale Spiele wie Asura's Wrath lassen sich nur mit detaillierter Kenntnis südostasiatischer Religionen und Mythologien sowie Vertrautheit mit den spezifischen Konventionen und historischen Entwicklungen japanischer digitaler Spielgenres umfassend als kulturelle Artefakte untersuchen. Vgl. zur Rolle japanischer Medien in der westlichen Populärkultur am Beispiel der Rezeption des Animes und seiner Fan-Kultur in den USA NAPIER (2007).

${ }^{390}$ Freilich kann man fragen, ob Jungs Studien immer noch zeitgemäß sind. Eine Verneinung dieser Frage würde eine Abwendung von selbigen und eine Zuwendung $\mathrm{zu}$ empirischen Medienwirkungsstudien bedeuten. Allerdings, so muss man konstatieren, gibt es bisher keine neurologischen oder empirisch angelegten Immersionsstudien, die das Mediennutzungsverhalten von Spielern digitaler Spiele unter mythologischen Gesichtspunkten analysieren. Ursächlich hierfür könnte sein, wie Eugen Pfister ausführt, dass „,die Frage der Wirkung digitaler Spiele von einer extrem aufgeheizten öffentlichen Debatte über die spezifische Frage der Wirkung gewalthaltiger Spiele verdeckt wird“. PFISTER (2016). Die ,Killerspieldebatte“, und trauriger Weise zeigt der Amoklauf eines Schülers am 22. Juli 2016 im Olympia-Einkaufszentrum in München bzw. zeigen die sich hieran anschließenden Diskurse, dass diese Diskussion weiterhin das dominierende Thema der Medienwirkungsforschung digitaler Spiele bleibt und folglich alle anderen möglichen Zugänge überlagert. Zur Nutzung und Wirkung von digitalen und virtuellen Welten im Allgemeinen vgl. FRITZ (2011). Aber nicht nur das Fehlen alternativer valider Medienwirkungsstudien macht Jung immer noch attraktiv für gegenwärtige Forschungsprojekte, sondern auch die Rolle, die er im Rahmen der Mythenforschung generell einnimmt. Durch Campbells und Voglers Werke, die nach wie vor $\mathrm{zu}$ den einflussreichsten Arbeiten der medienwissenschaftlichen substantialistischen Mythenforschung zählen, besitzen Jungs Archetypen immer noch einen großen Einfluss, sodass sie kaum ignoriert werden können. Die Wirkmacht, die Campbells und Voglers Modelle aktuell in den Medienwissenschaften ausüben, illustriert ein exemplarischer Blick in die Filmwissenschaft und auf Michaela KRÜTZENs Habilitation Dramaturgie des Films (2011) sehr eindrucksvoll. Zudem beschäftigen Jungs Überlegungen zum Archetyp wie Studien anderer Forscher auch, die sich mit grundlegenden (Erzähl-)Schemata aus einer strukturalistischen Perspektive befassen wie Vladimir Propp, Victor Turner oder eben Joseph Campbell, die Narratologie bis heute, v.a. wenn es darum geht, interkulturell beständige Erzählschemata auf anthropologische Konstanten zurückzuführen. Jens Eder merkt zur Wirkung von Jungs Werk auf die Filmwissenschaften etwa an: „Bei Drehbuchratgebern besonders beliebt sind C.G. Jungs Annahmen eines 
bestimmte Strukturen und Symbole auftraten, die sich auch in Mythen, Märchen, Sagen und anderen kulturellen Formen wiederfinden lassen. Der Archetyp, und das ist von höchstem Interesse für diese Arbeit, ist „nicht bewusstseinsfähig“, er ist Teil dessen, was Jung unter dem ,kollektiv Unbewussten` fasst. (JUNG 1954, 576 sowie vgl. JUNG 1976a)

Die archetypischen Vorstellungen, die uns das Unbewußte vermittelt, darf man nicht mit dem Archetypus an sich verwechseln. Sie sind vielfach variierte Gebilde, welche auf eine an sich unanschauliche Grundform zurückweisen. Letztere zeichnet sich durch gewisse Formelemente und durch gewisse prinzipielle Bedeutungen aus, die sich aber nur annähernd erfassen lassen. (JUNG 1954, 576; Herv.i.O.)

Selbst wenn man sich dabei vornehmlich auf den ,Archetypus an sich“ fokussiert und die ,archetypischen Vorstellungen' ausblendet, so ergibt sich dennoch ein interessanter Ansatz. Der Archetyp, wenn auch nach Jung nicht exakt extensional wie intensional bestimmbar, weist immer bestimmte formgebende Elemente auf, die für ihn kennzeichnend sind. Durch diese universell gültigen Formprinzipien wirkt sich der Archetyp immer auf das Subjekt aus, das mit ihm in Kontakt gerät. ${ }^{391}$ Somit affiziert der ,Archetypus an sich“ die menschliche Wahrnehmung und damit zusammenhängend auch das menschliche Handeln. Insofern ist der Archetyp für die implizite Performanz des Mythos in digitalen Spielen überaus bedeutsam, er ist in Bezug auf die Figuren in interaktiv-narrativen digitalen Spielen das Element, das ihre Polyvalenz ausmacht. Der Archetyp mag dem Spieler zwar unbewusst sein, er ist aber dennoch derart wirkmächtig, dass er die Realisierung der mythologischen Anlagen des Interaktiv-Narrativs in der Interaktion-Narration maßgeblich beeinflusst. Die narrativ wie performativ zugewiesene archetypische Rolle wird nämlich vom Spieler erkannt und demgemäß ausagiert oder wie Jung mit Blick auf unbewusste Prozesse allgemein ausführt: Der Archetyp bedinge „die Art und den Ablauf der Gestaltung [dieser Prozesse] mit einem anscheinenden Vorwissen oder im apriorischen Besitz des Zieles.“ (JUNG 1976b, 235; Herv.i.O.) Das bedeutet, anders gesagt, dass der Archetyp das Subjekt dazu veranlasst, einen

kollektiven Unbewussten und kulturübergreifender Archetypen. Der Unterscheidung verschiedener archetypischer Figuren folgen etwa die einflussreichen Hollywood-Dramaturgen Linda Seeger (1990) und Christopher Vogler (1992).“EDER (2008), 54. Was man bei Jung aber definitiv kritisieren muss, ist die Methode, mit der er seine Archetypen profiliert. In seinen zahlreichen Studien zum Archetyp amalgamiert er nämlich stets diverse Arten von Quellen und Referenzen, aus denen er seine Beispiele bezieht. Die Träume von Pfarrerssöhnen, Romane, Märchen, antike Mythen und Sagen wechseln sich permanent ab, ohne dass eine kohärente Systematik erkennbar wäre. Deshalb sollten Jungs Arbeiten methodisch weniger als Vorbild für archetypische Studien begriffen werden, sondern aus heuristischen Gründen lediglich die Folgerungen, die er aus seinen Beobachtungen zieht. Einen Überblick über die aktuellen Ansätze der psychoanalytischen Forschung in der Medienwissenschaft bietet das zweite Heft der Zeitschrift für Medienwissenschaft in 2017, das sich namentlich mit ,psychischen Apparaten ' befasst. Vgl. GeSELLSCHAFT Für MEdIENwisSENSCHAFT (2017).

${ }^{391}$ Auch wenn die universelle Gültigkeit dieser Formprinzipien mittlerweile heiß zwischen Befürwortern und Kritikern diskutiert wird, wird im Folgenden ihre Wirkmacht als gegeben angenommen, auch wenn man sich der Schwierigkeit des endgültigen Nachweises der Korrektheit dieser Annahme stets bewusst sein sollte. 
Prozess auf eine bestimmte Art und Weise, in einer definierten Form zu realisieren, die auf ein bestimmtes Ende hinausläuft, ohne dass das Subjekt glaubt, gesteuert zu werden. Man könnte deshalb auch sagen, dass der Archetyp ein ,unbewusstes Formprinzip“ ist. (vgl. JuNG 1954, 575) Der Archetyp ist eine universale, (raumzeitlich) konstante Größe, die sich aber dennoch beim Individuum in unterschiedlichen bzw. unterschiedlich gestalteten Bildern ausprägen kann. ${ }^{392}$ Prinzipiell gibt es kein abgeschlossenes Konglomerat an Archetypen, sodass sich eine große und schwer zu überblickende Anzahl an Archetypen finden lässt. Dennoch gibt es einige Archetypen, die immer wieder hervortreten, besonders häufig nachweisbar sind.

Diese sind, so wiederum Christopher Vogler, „Funktionsträger“. (VOGLER 2010, 81) Zu den besonders populären Archetypen zählt Vogler den Helden, den Mentoren, den Schwellenhüter, den Herold, den Gestaltwandler, den Schatten und den Trickster. (vgl. ebd., 84) Dadurch betont Vogler einen Aspekt, der bei Jung zwar stets mitschwingt, aber selten expliziert wird. Archetypen sind nicht bloß irgendwelche beliebigen Größen oder Symbole: sie sind in erster Linie Figuren. Der ,mythologische Archetyp“, und so soll er im Folgenden auch begriffen werden, ist (im Unterschied zu Fryes Ausführungen) eine standardisierte Figur, die nicht nur spezifische Eigenschaften aufweist, sondern auch bestimmte Funktionen innerhalb einer mythologischen Erzählung einnimmt. So werden der Held oder der Schatten nicht nur durch ihre (inhaltliche) Gestaltung als solche erkennbar, sondern sie verfügen auch über (mit ihrer Figurenkonzeption verbundene) Funktionen, die eng mit den Kardinalfunktionen des Monomythos verwoben sind. ${ }^{393}$ Der mythologische Held ist der Weltenretter und -erlöser, was zugleich aber bedeutet, dass nur er die Handlung ausführen kann, mit der das personifizierte ,Böse‘ überwunden und die Welt gerettet wird. Der Terminus ,Mythologem “ wird in dieser Studie als standardisiertes Symbol oder Motiv verwandt, welches kennzeichnend für Mythen ist. ${ }^{394}$ Mythologeme weisen dabei stets eine bestimmte Bedeutung oder ein spezifisches Set an Bedeutungen auf. Oftmals benötigen mythologische Archetypen bestimmte Mythologeme, um spezifische Handlungen

\footnotetext{
${ }^{392}$ Diese unterschiedlichen Ausprägungen sind die ,archetypischen Vorstellungen`.

${ }^{393} \mathrm{Zu}$ den Archetypen als Figuren vgl. die folgenden Kapitel.

394 Derartige Unterscheidungen zwischen Figur und Symbol sollten nicht mit einflussreichen Figurenanalysemodellen wie dem von Jens Eder verwechselt werden. Dieser differenziert zwischen vier Analysedimensionen, die man bei der Untersuchung von Figuren unterscheiden kann: Figuren „als fiktive Wesen, Symbole, Symptome und Artefakte“. EDER (2008), 135. Bei Eder geht es jedoch um die Figur als Symbol bzw. die „Analyse indirekter Bedeutungen“ der Figur und nicht um Symbole in figurativer Form. Ebd., 141. Diese potenzielle Missverständlichkeit lässt sich z.B. aber dadurch überwinden, wenn man sich vergegenwärtigt, dass Mythologeme meistens nicht als Figuren vorkommen, sondern als allgemeine Objekte innerhalb der Erzählung. Mythologeme in diesem Sinne sind bspw. der Zaubertrank oder das Labyrinth.
} 
auszuführen. Das ,heilige Schwert‘, welches mythologische Erzählungen von der Artus-Sage bis zu The Legend of Zelda durchzieht, ist, so verstanden, ein Beispiel für ein Mythologem. Es symbolisiert die zukünftige Rettung (und Reinigung) der Welt vor dem personifizierten ,Bösen“ durch den Helden, verweist durch die Tatsache, dass es hierfür von dem Helden aber instrumentalisiert werden muss, darauf hin, dass es auch eine narrative Funktion hat. Es fungiert als Hilfsmittel des Helden, durch welches dieser die Weltenrettung erst zu vollbringen vermag. Deshalb haben Mythologeme oft insofern eine eher untergeordnete Rolle gegenüber dem Archetyp. Ohne die verschiedenen Archetypen (v.a. Held, Schatten und Schwellenhüter) sind bestimmte Kardinalfunktionen nicht umsetzbar. Demgegenüber sind Mythologeme nicht unbedingt notwendig, sie nehmen oft eher eine katalysierende oder die Erzählung plausibilisierende Funktion ein. (vgl. dazu auch BARTHES 1988) Es soll aber auch angemerkt werden, dass sich Archetyp und Mythologem nicht pauschal voneinander unterscheiden lassen, sondern dass Zuordnungen oft nur im Kontext möglich sind.

Zwei Beispiele sollen dies kurz illustrieren: Im Film Harry Potter und die Kammer des Schreckens (2002) fungiert der Phönix als Archetyp, der dem Helden in der höchsten Not zur Hilfe eilt und ihm hilft, den Basilisken zu überwinden sowie den Helden von einer schweren Vergiftung zu heilen. Die Figurenkonzeption des Archetyp Phönix, in diesem Fall seine heilenden Kräfte, dient hier dazu, den Sieg des jungen und unerfahrenen Helden über einen eigentlich übermächtigen Gegner zu plausibilisieren. Anlage und Handlung machen den Phönix eindeutig als Figur und somit als Archetyp erkennbar. In The Legend of Zelda ist dies fundamental anders. Dort kommt der Phönix nicht als Archetyp, sondern als Mythologem vor. In den meisten Versionen des Wappens der königlichen Familie von Hyrule ist unterhalb des Triforce der Phönix zu sehen, dargestellt als roter Vogel mit ausgebreiteten Flügeln. ${ }^{395}$ Damit wird auf die symbolische Dimension des Phönixes abgehoben, der für Unsterblichkeit und Auferstehung steht. Auf diese Weise unterstreicht das Mythologem Phönix die Unsterblichkeit bzw. den ewigen Fortbestand des Reichs Hyrule bzw. der regierenden Dynastie. ${ }^{396}$ Kommen wir zum zweiten Beispiel. In der ,Verschlingungsepisode“ im Buch Jona dient der ,große[] Fisch“, (Jona 2,1) der den Propheten Jona verschlingt, der christlichen Typologie als Vorausdeutung auf die Wiederauferstehung Jesu Christi am dritten Tage. „Und

\footnotetext{
395 Vgl. dazu die Darstellung des Phönix auf dem sog. ,Hylianischen Schild‘. Vgl. hierzu exemplarisch http://zelda.wikia.com/wiki/Hylian_Shield (30.06.2018).

${ }^{396}$ Dies belegt auch der erneute Blick auf die Serientitel Wind Waker und Spirit Tracks. Auch wenn Hyrule am Ende von Wind Waker untergeht, so ersteht es wie der sprichwörtliche Phönix aus der Asche vor dem Beginn der Handlung von Spirit Tracks in (zumindest formal betrachtet) nahezu identischer Form wieder auf.
} 
Jona war im Leibe des Fisches drei Tage und drei Nächte.“397 (ebd.) Der Fisch bzw. Wal tritt im zweiten Kapitel des Buches Jona somit weniger als Archetyp auf, der handelnd den Helden vor dem Ertrinken bewahrt, sondern erscheint als Instrument Gottes, um Jona zu retten. Entscheidender als eine figurative Bedeutung des Wals ist seine symbolische - er steht (ebenso wie der Phönix) für die Auferstehung. Im Falle Christi im wörtlichen, in Jonas in einem metaphorischen Sinn. Der vor Gottes Aufgabe fliehende Prophet ,stirbt' und wird am dritten Tage in Form des Ausspeiens, wiedergeboren', um endlich (folgsam) nach Ninive zu reisen. Dies ist wiederum beim walförmigen Himmelsgeist Narisha in The Legend of Zelda: Skyward Sword (2011) anders. Beim ersten Aufeinandertreffen muss der Avatar gegen ihn kämpfen und ihn überwinden, da Narisha von einem bösartigen Parasit befallen ist, der ihn dazu bringt, den Helden zu attackieren. Im weiteren Fortlauf des Spiels unterstützt dieser den Avatar dann jedoch und versorgt diesen immer wieder mit wichtigen Informationen, an die der Held andernfalls nicht gelangen könnte. Narisha spielt in seiner Figurenkonzeption zwar auf verschiedene Motive an, die sich häufig in Mythen finden lassen wie Allwissenheit, ist im Allgemeinen aber stärker als Archetyp herausgearbeitet, der den Helden auf seiner Heldenreise unterstützt. Narisha in Skyward Sword wie der Phönix in Harry Potter gehören beide zu jener Gruppe von Archetypen, die mit dem Helden verbündet ist, um ihm bei der Weltenrettung zu helfen. Am markantesten wird diese Gruppierung von Archetypen durch die Figur des Mentors verkörpert, der neben dem Herold zum wahrscheinlich wichtigsten Verbündeten des Helden zählt.

Im Kontext des vorliegenden Erkenntnisinteresses ist es neben der narrativen Funktion zudem wichtig, nach der ludischen Funktion eines Archetyps zu fragen. Um zu zeigen, dass sich auch auf figurativer Ebene die strukturellen Äquivalenzen zwischen ludischer Interaktivität und textueller Narrativität offenbaren, sollen im Folgenden drei kurze Beispiele der (figurativen) Archetypen deren Wirken in interaktiv-narrativen digitalen Spielen erläutern. Als Beispiel fungiert, und leitet hierdurch gewissermaßen zum kommenden Kapitel über, Ocarina of Time.

\subsubsection{Der Schwellenhüter ${ }^{398}$}

Der Schwellenhüter nimmt nur selten die Position des eigentlichen Schurken oder des wichtigsten Gegenspielers des Helden ein. Eher wird er einer der Gefolgsleute des Bösewichts

\footnotetext{
397 Vgl. dazu Mt 12,40: „Denn wie Jona drei Tage und drei Nächte im Bauch des Fisches war, so wird der Menschensohn drei Tage und drei Nächte im Schoß der Erde sein.“

${ }^{398} \mathrm{Vgl}$. hierzu sowie zu den folgenden Unterkapiteln ausführlicher Kapitel 4.
} 
sein, zu den kleineren Ganoven oder zum gedungenen Gesindel zählen, das das Hauptquartier des Anführers bewacht. (VOGLER 2010, 121)

Im narrativen Sinne sind Schwellenhüter Figuren, die der Held im Rahmen der Handlungen und Geschehnisse der Kardinalfunktionen überwinden muss, um in einen Abschnitt der Diegese zu gelangen, der ihm bisher verschlossen ist. Die Überwindung des Schwellenhüters geht in der Regel mit einer Aufgabe oder Prüfung einher, die der Held lösen muss, indem er sich als würdig erweist. So gelangt Iwein in Hartmann von Aues gleichnamigen Artusroman nur zu Laudines Burg, indem er den Ritter Askalon im Kampf besiegt und den tödlich Verwundeten, der zu Laudines Burg flieht, verfolgt und hierdurch die andersweltlich markierte Schwelle übertritt. (vgl. HARTMANn 2001, 20 ff.) Dieser Ort der erzählten Welt wird der Figur also nur zugänglich, indem er die Prüfung besteht. Mit Blick auf interaktiv-narrative digitale Spiele stellt sich dies ähnlich dar. Link kann Kokiri in Ocarina of Time nur verlassen, wenn er die Riesenspinne ${ }^{399}$ Gohma eliminiert, den DekuBaum $^{400}$ hierdurch von dessen Fluch befreit, mit dem Ganondorf ihn belegte, woraufhin dieser ihm (sterbend) den Weg nach Schloss Hyrule, zu Prinzessin Zelda und auf seine Mainquest weist. Schwellenhüter sind in digitalen Spielen demnach oft Endgegner in Dungeons, kleinere Minibosse in Mini-Dungeons oder allgemein gegnerische NPCs, die sich dem Spieler entgegenstellen, wenn er eine bestimmte Schwelle übertreten will. Das Spiel, so kann man festhalten, versagt dem Spieler das Betreten bestimmter Orte des Spielraums, gibt diese erst frei, wenn eine bestimmte Prüfung erfolgreich bestanden wurde. Zusammengefasst zeigt sich, dass die Figur des Schwellenhüters interaktiv und narrativ für die (narrative wie performative) Quest-Struktur interaktiv-narrativer digitaler Spiele eine der bedeutendsten Figuren ist, da sie, gewissermaßen als stete Vorausdeutung auf den Endkampf zwischen Protagonist und Antagonist, den Helden immer wieder fordert und von Neuem dazu zwingt, diese und sich selbst zu überwinden, somit ein wesentliches Element der agonalen Ausprägung der Prüfungen interaktiv-narrativer digitaler Spiele ist.

\subsubsection{Der Herold}

Im ersten Akt tritt oft eine neue Kraft in Erscheinung, die den Helden mit einer Herausforderung konfrontiert. Dies ist die Energie, die sich im Archetypus des Herolds verkörpert. Wie die Herolde der Ritterzeit haben auch alle anderen Herold-Gestalten die Funktion, Herausforderungen und bevorstehende große Wandlungen anzukündigen. (ebd., 127; Herv.i.O.)

\footnotetext{
${ }^{399}$ Populärer mythologischer Archetyp, der oft im westlichen Fantasy-Genre Verwendung findet bspw. in den Tolkien-Verfilmungen Der Herr der Ringe: Die Rückkehr des Königs (2003) oder Der Hobbit: Smaugs Einöde (2013).

${ }^{400}$ Der lebende Baum ist ebenfalls ein populärer mythologischer Archetyp, der auch in Tolkien-Verfilmungen vorkommt. Man denke an die Ents im Der Herr der Ringe: Die zwei Türme (2002). Diesen Archetyp zeichnet aus, und Deku-Baum wie Ents belegen dies, dass er als Hüter des Waldes dient.
} 
Im vorherigen Unterkapitel wurde bereits darauf verwiesen, dass Link vom Deku-Baum auf die Mainquest von Ocarina of Time geschickt werde. Hierdurch wird dessen Funktion als Herold im narrativen wie im interaktiven Sinne deutlich. Narrativ vermittelt er Link via Cutscene die vorherrschende Konstellation und schickt ihn anschließend via textueller medialer Narration auf dessen Heldenreise. Somit leistet der Deku-Baum als Herold einen wesentlichen Aspekt der narrativen Exposition und macht zugleich unmissverständlich, auch wenn der Spieler dies nur unbewusst wahrnehmen mag, dass ihm eine Interaktion-Narration bevorsteht, die sich am Interaktiv-Narrativ des Monomythos ausrichtet. Interaktiv gesehen macht er dem Spieler klar, dass ihm ein agonales Spielerlebnis bevorsteht, bei dem es gilt, die (wahrscheinlich große und, offene‘ Spielwelt) reisend zu erkunden und diverse Prüfungen zu bestehen. Dabei überbringt der Herold aber keineswegs die Kunde irgendeiner Herausforderung, sondern er kommuniziert an die Spieler ,die“ Herausforderung. „Der Ruf zum Abenteuer ergeht an ihn [den Helden], und dies nicht selten aus dem Munde einer Figur, die den Archetypus des Herolds repräsentiert.“ (ebd., 128) Der Herold übernimmt somit (narrativ und interaktiv) die zentrale Funktion, dem Helden den Ruf des Abenteuers zu übermitteln.

\subsubsection{Der Schatten}

In einer Geschichte werden die negativen Aspekte des Schattens auf Charaktere wie Bösewichte, Feinde oder Antagonisten projiziert. Bösewichte und Feinde sind üblicherweise auf den Tod, die Vernichtung oder Unterwerfung des Helden aus. (ebd., 143 f.)

So gesehen ist der Schatten sehr allgemein gehalten, da er mehrere gegnerische Figurentypen subsumiert. Er kann sowohl den Antagonisten als auch den Schwellenhüter oder kleinere Gegner bezeichnen. In Ocarina of Time manifestiert sich der Schatten dementsprechend als Ganondorf (Antagonist), Gohma (erster Schwellenhüter) sowie als Knochengänger (kleinerer zombieähnlicher Gegner). Da dies aber eine sehr weite Begriffsverwendung darstellt, die mit Blick auf das vorliegende Forschungssetting wenig sinnvoll erscheint, soll im Folgenden unter dem Schatten lediglich der kleinere und unbedeutende Gegner verstanden werden, der schnell überwunden ist und narrativ wie interaktiv lediglich eine katalysatorische Funktion hat. Der Schatten übernimmt dergestalt die Rolle eines Elements des ,foreshadowings', das auf die kommenden und größeren Übel hindeutet. Die anderen beiden Figurentypen sind - im Gegensatz dazu - in die zentralen narrativen wie interaktiven Funktionen eingebunden. So muss der Antagonist im dritten Akt der Heldenreise im Rahmen einer Kardinalfunktion vom Helden besiegt werden, wie auch die Schwellenhüter im zweiten Akt immer wieder im Rahmen der Kardinalfunktion der 
Prüfungen und Bewährungsproben überwunden werden müssen. Für den Schatten im hier verwendeten Sinne gilt das nicht. Er begleitet narrativ lediglich Schwellenhüter oder Antagonisten, um die Bedrohung durch das ,Böse‘ ${ }^{‘} \mathrm{zu}$ intensivieren. Interaktiv kann er Schwellenhüter-Endgegnern beigestellt sein, um den Schwierigkeitsgrad eines Endkampfes zu erhöhen oder er taucht in Abschnitten von Open-World-Spielen auf, deren agonale Ausprägung als Spielraum andernfalls zu schwach wäre. Insofern erfüllt der Schatten die Funktion, die Bedrohung narrativ und interaktiv permanent präsent zu halten, auch wenn die von ihm selbst ausgehende Bedrohung narrativ und interaktiv eher gering ist. Der Schatten symbolisiert und evoziert eine Atmosphäre ${ }^{401}$ anhaltender Gefahr, wenn auch auf eine sehr latente Art und Weise.

\subsubsection{Modifikation des Modells der Heldenreise für die Analyse interaktiv-narrativer digitaler Spiele}

Das Reisemodell des Helden als Monomythos mit seinen Archetypen und Mythologemen ist ein zentrales Interaktiv-Narrativ interaktiv-narrativer digitaler Spiele. Es strukturiert als zentrale Instanz dieser Spiele die interaktiven und narrativen Anlagen des Spiels und lenkt die Spieler (unbewusst) in deren Interaktion-Narration. Deshalb scheint es ratsam, dem Reisemodell des Helden auch in der Analyse derartiger Spiele zu folgen, wie dies auch im nächsten Kapitel geschehen soll. Da sich Campbells und Voglers Modelle aber nicht ohne weiteres auf die Analyse digitaler Spiele übertragen lassen, soll im Folgenden eine weitere Modifikation des Modells von Vogler vorgenommen werden, die sich an der Medienspezifik digitaler Spiele orientiert.

\footnotetext{
401 Atmosphäre wird hier im Sinne Gernot BöHMEs (2014) verstanden, also als eine spezifische raumzeitliche Beziehung, die zwischen einem Subjekt und dessen Umgebung besteht und welche von objektiven Stimmungen geprägt ist, die sich im Zusammenspiel entfalten. Somit ist Böhmes Konzept hochgradig affektiv und für neue Medienumgebungen geeignet. Was Atmosphäre im digitalen Spiel meint, lässt sich an The Last Guardian (2016) ausstellen. Die Atmosphäre dieses Spiels wird nämlich maßgeblich durch die Beziehung zwischen dem Protagonisten und dem aufwendig animierten Mischwesen Trico geprägt, das v.a. in Bezug auf sein Verhalten gegenüber dem Avatar deutliche Unterschiede zu vergleichbaren Produktionen aufweist.
} 


\begin{tabular}{|c|c|c|c|}
\hline & Campbell & Vogler & Matuszkiewicz \\
\hline Akte & \multicolumn{3}{|c|}{ Stadien/Narrative Funktionen } \\
\hline $\begin{array}{l}\text { Aufbruch/ } \\
\text { Erster Akt }\end{array}$ & $\begin{array}{l}\text { Alltagswelt } \\
\text { Ruf des Abenteuers } \\
\text { Weigerung } \\
\text { Übernatürliche Hilfe } \\
\text { Überschreiten der ersten } \\
\text { Schwelle } \\
\text { Im Bauch des Wals }\end{array}$ & $\begin{array}{l}\text { Gewohnte Welt } \\
\text { Ruf des Abenteuers } \\
\text { Weigerung } \\
\text { Begegnung mit dem Mentor } \\
\text { Überschreiten der ersten } \\
\text { Schwelle }\end{array}$ & $\begin{array}{l}\text { „Heile Welt‘ (Mikrokosmos) } \\
\text { „Störung des Gleichgewichts““402 } \\
\text { Ruf des Abenteuers } \\
\text { (Erste Probe) } \\
\text { Begegnung mit dem Mentor } \\
\text { Übertritt in die,gestörte“ Welt } \\
\text { (Makrokosmos) }\end{array}$ \\
\hline $\begin{array}{l}\text { Initiation/ } \\
\text { Zweiter Akt }\end{array}$ & $\begin{array}{l}\text { Weg der Prüfungen } \\
\text { Begegnung mit der Göttin } \\
\text { Das Weib als Verführerin } \\
\text { Versöhnung mit dem Vater } \\
\text { Apotheose } \\
\text { Der endgültige Segen }\end{array}$ & $\begin{array}{l}\text { Bewährungsproben, } \\
\text { Verbündete, Feinde } \\
\text { Vordringen zur tiefsten Höhle/ } \\
\text { zum empfindlichsten Kern } \\
\text { Entscheidende Prüfung } \\
\text { (Feuerprobe) } \\
\text { Belohnung }\end{array}$ & $\begin{array}{l}\text { Akt(e) der Prüfung(en), } \\
\text { Verbündete, Feinde }\end{array}$ \\
\hline $\begin{array}{l}\text { Rückkehr/ } \\
\text { Dritter Akt }\end{array}$ & $\begin{array}{l}\text { Weigerung zur Rückkehr } \\
\text { Die magische Flucht } \\
\text { Rettung von innen } \\
\text { Überschreiten der Schwelle } \\
\text { Rückkehr } \\
\text { Der Herr der zwei Welten } \\
\text { Freiheit zu leben }\end{array}$ & $\begin{array}{l}\text { Auferstehung } \\
\text { Rückkehr mit dem Elixier }\end{array}$ & $\begin{array}{l}\text { Betreten des ,zerstörtesten` Ortes } \\
\text { Sieg über das personifizierte } \\
\text { Böse/ „Wiederherstellung des } \\
\text { Gleichgewichts“4 } 403 \\
\text { Rückkehr in die ,heile‘ Welt }\end{array}$ \\
\hline
\end{tabular}

\section{Abb. 8: Modifikation des Modells der Heldenreise}

Um das in Abbildung 8 Ausgeführte deutlicher zu machen, soll kurz, der Dreiteilung der Akte folgend, expliziert werden, warum die vorgenommenen Modifikationen mit Blick auf interaktiv-narrative digitale Spiele notwendig erscheinen. $\mathrm{Da}$ sich das folgende Analysekapitel in seinem argumentativen Aufbau maßgeblich an dem Reisemodell des Helden orientieren wird, verstehen sich die nun kommenden Erläuterungen lediglich als

\footnotetext{
402 WESSELY (1995), 354.

${ }^{403}$ WESSELY (1995), 354.
} 
Skizzen, deren Abstraktheit anschließend durch die exemplarische Analyse von Ocarina of Time konkretisiert wird.

\subsection{Erster Akt der Heldenreise}

$\mathrm{Zu}$ Beginn des Spiels wird der Held in seiner gewohnten Umgebung gezeigt, welche von einer idealisierten Grundordnung geprägt ist und die sich in einem systemischen Gleichgewicht befindet, sodass sie als ,heile‘ zu klassifizieren ist. Der Held und alle anderen Bewohner leben in einer Welt der ,Glückseligen', die oft mit den positiven Aspekten des Mikrokosmos assoziiert wird. ${ }^{404}$ So unterstreichen die hiermit verbundene Beschaulichkeit des Raumes und die hieraus wiederum folgenden sehr engen, sozialen" Beziehungen zwischen den Figuren den idealen Charakter dieser Form des (natürlichen) Zusammenlebens. Diese ideale Grundordnung wird gestört und das Gleichgewicht des Mikrokosmos sowie auch des ihn umgebenden Makrokosmos gerät ins Wanken. Das störende Element ist hierbei der Antagonist als Personifikation des ,Bösen“, der nur von dem Auserwählten in die Schranken gewiesen werden kann.

Bei dem Ereignis, das die mythische Erzählung ins Blickfeld rückt (Kampf oder Prüfung,

Problem oder Suche), geht es meist um eine schwierige Aufgabe für einen exponierten Protagonisten, von deren erfolgreicher Bewältigung ein allgemeines Geschick abhängt. (ASSMANN/ASSMANN 1998, 188)

Den Helden als Auserwählten zeichnet demnach aus, dass er als Weltenretter und Erlöser par excellence agieren können muss. Deshalb sucht der Herold den hierfür Auserkorenen auf oder bestellt diesen ein und übermittelt diesem seine Aufgabe, von dessen Gelingen das Schicksal der gesamten Welt abhängt. In genuin narrativen Medien erfolgt hierauf i.d.R. die Weigerung des Helden. Diese Funktion lässt sich jedoch in digitalen Spielen kaum nachweisen. Ursächlich hierfür dürfte sein, dass die Handlungsverweigerung der narrativen Figur in Bezug auf eine zwingend erforderliche Realisierung als Avatar im weiteren Spielverlauf, die auch die interaktive Spielfigur umfasst, wenig kohärenzstiftend ist, wenn man bedenkt, dass sich die Spielfigur vornehmlich durch Interaktivität und Agency auszeichnet. Mit anderen Worten: Es ist wenig plausibel, dass sich ein Charakter anfangs einer Aktion verweigert, im Folgenden aber stets durch seine uneingeschränkte

\footnotetext{
${ }^{404}$ In Horizon Zero Dawn (2017) wird der Mikrokosmos als Idylle bspw. dadurch noch weiter idealisiert, dass die anfänglich ausgestoßene Protagonistin ihre gesamte Kindheit und Jugend trainiert, um in die Stammgemeinschaft aufgenommen zu werden, nur um im Moment der Aufnahme zugleich mit dem Ruf des Abenteuers konfrontiert zu werden, der sich in Form eines Hinterhalts im Anschluss an die ,Große Erprobung darstellt.
} 
Handlungsbereitschaft auszeichnet. Um diesem Widerspruch $\mathrm{zu}$ entgehen, verzichten interaktiv-narrative digitale Spiele auf dieses Stadium der Heldenreise. ${ }^{405}$

Statt einer Weigerung unterzieht sich der Held oft einer ersten Probe, die i.d.R. der erste (wenn auch kleine) Dungeon ist. Hierdurch wird einerseits die narrative Agonalität des mythologischen Narrativs verstärkt, es werden zugleich aber auch die Funktionsweisen des Interaktivs des Spiels angedeutet und können vom Spieler erlernt werden. „Der Held nimmt nun das Ziel in Besitz. Dieses Ziel versinnbildlicht seine Selbstüberwindung in materieller Form, ist also repräsentatives Symbol für immanentes Geschehen.“ (WESSELY 1995, 356) Dieses Ziel ist in interaktiv-narrativen digitalen Spielen gleichermaßen das Ende der Erzählund der Queststruktur. Da der Held sich narrativ wie interaktiv aber auf einem permanenten Lernprozess befindet, der sich auch in der unentwegten Wiederholung von ähnlichen QuestMustern ausdrückt, bedarf er verschiedener Verbündeter. Ein zentraler Archetyp ist hierbei der Mentor, welcher sich primär dadurch exponiert, dass er über Fähig- und Fertigkeiten verfügt, die der Held erlernen muss, um seine Aufgabe erfüllen zu können. In digitalen Spielen ist dieser Mentor oft auf mehrere NPCs aufgespalten, die an unterschiedlichen Orten und zu unterschiedlichen Zeiten aufgesucht werden müssen. ${ }^{406}$ Ein wichtiger Mentor für Link ist in Ocarina of Time, wie im vorherigen Kapitel erwähnt, die weise Eule Methusa, welche den Spieler einerseits räumlich leitet bzw. lose Navigationsangebote macht und ihn andererseits mit Hintergrundinformationen versorgt, die den Spieler animieren sollen, die enigmatischen Zusammenhänge des Makrokosmos allmählich aufzulösen. Der Mentor markiert somit oft den endgültigen Übertritt vom Mikro- in den Makrokosmos. Sobald der Held mit dem Ruf des Abenteuers konfrontiert wird, beginnt sich die ,heile' Welt endgültig zu zersetzen, da der Held nun um die Störung des Gleichgewichtes weiß. Die folgende erste

\footnotetext{
${ }^{405}$ Allgemein gibt es recht wenige Beispiele in der digitalen Spielgeschichte für Avatare, die Handlungen verweigern. Eine der wenigen Ausnahme bildet John Marston in Red Dead Redemption, das, wie oben ausgeführt, mit dem Westernnarrativ immerhin einem modernen Derivat des mythologischen Narrativs folgt. Allerdings ist es hier jedoch auch so, dass sich diese Weigerung Marstons lediglich in den Cutscenes ausdrückt, aber bereits nach dem Ende der jeweiligen narrativen Phase keine unmittelbaren Auswirkungen auf die anschließende interaktive Phase hat. Somit kann Red Dead Redemption weniger als wirkliche Ausnahme angesehen werden, als vielmehr als eine ironisch-subversive Anspielung auf diese Konvention digitaler Spiele, wie es stilistisch für Titel von Rockstar kennzeichnend ist. Zudem untermauert Rockstar selbst mit GTA V, dass eine verweigernde Haltung bei Avataren in digitalen Spielen bisher eher unüblich zu sein scheint. Die sehr kontrovers diskutierte Folterszene, bei der es darum geht, eine Personenbeschreibung zu erlangen, kann vom Spieler nicht verweigert werden, obwohl deren Sinnlosigkeit sogar explizit ausgestellt wird. Vgl. dazu das folgende Let's Play von CALLOFTREYARCH https://www.youtube.com/watch?v=_NrsicTLC5Q (30.06.2018).

${ }_{406}$ Als Mentoren treten bspw. auch die ,Graubärte“ in Skyrim auf, die dem Spieler dabei helfen, die Drachenschreine zu finden und die Drachenschreie zu erlernen. Von ihrer Erscheinung entsprechen sie einem westlichen Mentorentypus, der optisch sehr von ,Gandalf, dem Grauen' geprägt wurde. Vgl. dazu das folgende Let's Play von StEven HeARTSTONE https://www.youtube.com/watch?v=VetpEnQvWjc (30.06.2018).
} 
Probe findet zwar geografisch noch im Mikrokosmos statt, sie transzendiert dessen Grenzen aber schon, indem sie vom Helden Handlungen verlangt, die eigentlich nicht seinen Verhaltens- und Handlungsmustern entsprechen.

Wenn sich die Welt von einer, heilen“ in eine ,gestörte‘ wandelt, so wandelt sich auch der Avatar. Aus dem gewöhnlichen Menschen in einer gewöhnlichen Welt wird durch außergewöhnliche Umstände der auserwählte Held. Dieser Prozess der ,Heldenwerdung` setzt sich im Makrokosmos zwar noch fort, ist also mit dem Übertritt in diesen bereits keineswegs abgeschlossen, jedoch ist der Weg des Helden ab diesem Moment vorgezeichnet, unveränderbar.

\subsection{Zweiter Akt der Heldenreise}

Bemerkenswert ist, dass der erste Akt der Heldenreise die meisten narrativen Funktionen umfasst, in digitalen Spielen aber i.d.R. recht schnell (im Vergleich zur Gesamtspielzeit) abgehandelt ist. Nimmt der erste Akt in vielen Spielfilmen, die nach dem Modell der Heldenreise konzipiert sind, ca. ein Drittel des gesamten Filmes ein, so benötigt der versierte Spieler in Ocarina of Time weniger als eine halbe Stunde, um in den Makrokosmos und somit in den zweiten Akt einzutreten. Der Grund hierfür liegt in der Interaktivität und Agency des Spielers, denn betrachtet man die narrativen Funktionen des ersten Aktes, so fällt eines auf der Held handelt nicht bzw. kaum. Das Handeln des Protagonisten ist, so Marie-Laure Ryan, jedoch ein Aspekt, der einerseits den (Mono-)Mythos (sie verwendet stattdessen die Termini ,Epic Plot‘ bzw. „Epic Narrative') besonders auszeichnet sowie hierdurch andererseits gewährleistet, dass dieses Narrativ eine hohe Offenheit gegenüber der Interaktivität aufweist. „Epic narratives focus on physical actions, and the human relations that motivate the hero to act remain fairly simple.“407 (RYAN 2014b, 395 f.)

Bei der Einführung des Helden als Teil der ,heilen“ Welt ist dieser passiv bzw. zeichnet sich keineswegs durch eine außergewöhnliche Aktivität aus. Selbiges gilt für die folgenden Funktionen: Das Gleichgewicht wird vom Antagonisten gestört, der Ruf des Abenteuers ergeht an den Helden vom Herold und bei der Begegnung mit dem Mentor ist der Held eher der Schüler, der unterwiesen wird, dementsprechend kaum als aktiv handelnd zu betrachten. Die einzigen beiden Ausnahmen im ersten Akt bilden die Erste Probe und der Übertritt in die

\footnotetext{
${ }^{407}$ Die Offenheit des mythologischen Narrativs gegenüber der Interaktivität ist bei diesem Narrativ nicht zuletzt auch deshalb so groß, da sich digitale Spiele, bedingt durch das Interface, oft auf einfache physische Aktionen beschränken, die sich ideal in das Interaktionsdesign von digitalen Spielgenres wie Action-Adventure oder RPG integrieren lassen.
} 
,gestörte Welt', hier handelt die Figur aktiv. Interessant ist hierbei, dass gerade die Erste Probe genau genommen weniger narratives als vielmehr interaktives Ereignis ist, das weitestgehend im Spielraum stattfindet. Dementsprechend nimmt sie auch (relational gesehen) die meiste Spielzeit im ersten Akt in Anspruch.

Ähnliches gilt für den Übertritt in die ,gestörte‘ Welt. Diese ist (neben der Ersten Probe) jene Funktion, die maßgeblich durch spielerisches (navigierendes) Handeln bestimmt wird. Die Funktionalisierung dieser beiden Funktionen im Kontext des ersten Aktes der Heldenreise deutet auf einen zentralen Aspekt hin, der für den zweiten Akt besonders wichtig ist. Es scheint, dass sich narrative Funktionen besonders gut in das Interaktionsdesign interaktivnarrativer digitaler Spiele übertragen lassen, in denen der Held (inter-)aktiv handeln muss. Das bedeutet, dass die Korrespondenz der (narrativen und performativen) Handlungsmuster maßgeblich davon abhängt, dass dem Helden als narrativer Figur im Rahmen einer narrativen Funktion eine weitreichende individuelle Agency zugewiesen wird. Ist dies nicht der Fall, dann lassen sich die betreffenden narrativen Funktionen nicht oder nur sehr unzureichend in interaktive Spielphasen interaktiv-narrativer digitaler Spiele übertragen.

Aus diesem Grund bietet sich auch die Quest besonders als narratives wie als interaktives Handlungsmuster an. Sie evoziert eine permanente Abfolge von Prüfungen des Helden, bei denen er sich immer wieder verschiedenen Ausprägungen des Schatten stellen, bei denen er final immer Schwellenhüter überwinden muss, um in den Besitz magischer Artefakte zu gelangen, welche es ihm ermöglichen, den Antagonisten auszuschalten. 408

Freilich hat SCHUPPISSER (2014), das sei hier nochmals betont, Recht, wenn er dieses Analyseraster als zu ,grobmaschig' bezeichnet. Es stellt sich aber auch die berechtigte Frage, und dies wurde oben auch angesprochen, ob narratologische Herangehensweisen hier grundsätzlich zielführend sind oder ob diese Aspekte interaktiv-narrativer digitaler Spiele letztlich nur spielwissenschaftlich und handlungstheoretisch untersucht werden können. Dieser Frage möchte auch das folgende Analysekapitel nachgehen. Dabei wird ein besonderes Augenmerk darauf gerichtet, auf welche Weise die einzelnen Akte der Prüfung miteinander sowie mit anderen Spielelementen verkettet sind.

\footnotetext{
${ }^{408}$ Christian Wessely merkt hierzu an: „Er [der Held] kann es [den finalen Kampf] aber nur bestehen, wenn er auch alles einsetzt, was er im Laufe der Reise erworben und gelernt hat, also Gebrauch von seinen Zaubermitteln und seinen neu erworbenen Kenntnissen macht.“WESSELY (1995), 357.
} 


\subsection{Dritter Akt der Heldenreise}

Grundsätzlich legt eine vergleichende Betrachtung von interaktiv-narrativen digitalen Spielen, die den Mythos als Interaktiv-Narrativ verwenden, die Vermutung nahe, dass der Held als Avatar, als Verschmelzung von narrativem Charakter und interaktiver Spielfigur, die performative Realisierungsinstanz, das Bindeglied, die Schnittstelle zwischen dem narrativen und dem performativen Handlungsmuster ist. Dies vergegenwärtigt auch der dritte Akt der Heldenreise, welcher - ähnlich wie der erste Akt - relational gesehen relativ wenig Spielzeit einnimmt. Er unterscheidet sich aber vom ersten dadurch, dass er narrative Funktionen umfasst, die (bis auf die letzte) von einer hohen individuellen Agency des Helden als narrativer Figur geprägt sind. Nach der erfolgreichen Meisterung der Akte der Prüfungen gelangt der Held zum finalen Dungeon, dem ,zerstörtesten` Ort. Die Funktion dieses Ortes wird in Ocarina of Time zusätzlich durch Anspielungen auf die europäisch-westliche Darstellungstradition der christlichen Hölle unterstrichen, welche sich durch das Vorhandensein von Lava, einer sehr dunklen Farbgebung etc. auszeichnet. Zugleich ist dieser Ort der Ort der letzten Prüfung. Letzte Rätsel müssen gelöst, letzte Schatten und Schwellenhüter eliminiert werden, bevor der Held dem personifizierten ,Bösen` entgegentritt. In einem dreiphasigen Endkampf wird Ganondorf schließlich bezwungen und das ,Böse“ hierdurch augenblicklich besiegt und gebannt.

Das Gleichgewicht der Welt ist wiederhergestellt. Die Transformation eines Zustandes in dessen Gegenteil, die Todorov als kennzeichnend für das mythologische Narrativ erachtet, wird nun in einem doppelten Sinne erneut umgekehrt, die Störung des Gleichgewichtes wird aufgehoben, wodurch der Held in seine ,heile‘ Welt zurückkehren kann; alles ist wieder wie zu Handlungsbeginn. Vergleicht man den dritten Akt der hier dargebotenen Modifikation mit denen in den Modellen von Campbell und Vogler, so fällt einerseits auf, dass der dritte Akt der Heldenreise in digitalen Spielen allgemein recht kurz ausfällt und dass die finale Konfrontation mit dem personifizierten ,Bösen“ erst im dritten und nicht im zweiten Akt stattfindet. Der Grund hierfür ist recht simpel. Aufgrund ihrer hybriden medialen Struktur enden digitale Spiele i.d.R. mit dem Endkampf, sodass das klassische (ausführlichere) Ende der Heldenreise, das man aus Spielfilmen kennt (Heimkehr etc.), in digitalen Spielen oft fehlt. (vgl. dazu EICK 2014, 115) Die Rückkehr des Helden in die ,heile‘ Welt wird in interaktivnarrativen digitalen Spielen (wenn vorhanden) bspw. nicht spielerisch ausagiert, sondern lediglich in einem narrativen Outro besorgt, das zudem oft mit den Credits des Spiels simultan 
stattfindet, sodass es nicht mehr derart stark in das Spiel integriert ist wie die vorangegangenen narrativen Funktionen.

Ein Aspekt soll abschließend noch kurz angesprochen werden, der besonders mit Blick auf interaktiv-narrative digitale Spiele wie The Legend of Zelda relevant ist, in der folgenden Analyse jedoch aufgrund des Erkenntnisinteresses der vorliegenden Arbeit nicht weiter verfolgt werden kann. Nehmen wir nochmals Todorovs Feststellung auf, dass das mythologische Narrativ sich neben einer bestimmten (erzähllogischen) Abfolge von narrativen Funktionen durch eine Transformation von Zuständen auszeichnet, die derartiger Gestalt ist, dass sich Zustand A in sein Gegenteil B verkehrt (aus der ,heilen“ wird eine ,zerstörte‘ Welt usw.). Am Ende, wie eben ausgeführt, wird diese Verkehrung rückgängig gemacht, aus B wird erneut A, sodass sich folgendes Schema ergibt: A > B > A. Insofern kommt der Mythos immer wieder zu seinem Ursprung zurück oder wie Christian Wessely es ausdrückt: „Durch seine Struktur und den Weg seines Helden bestimmt, endet der Mythos in sich selbst und kann somit zum Ausgangspunkt einer neuen mythischen Erzählung werden.“ (Wessely 1995, 353) Das bedeutet, und digitale Spiele wie The Legend of Zelda sind ein treffendes Beispiel hierfür, dass das mythologische Narrativ (und all seine modernen Derivate) sich besonders eignet, um digitale Spielreihen oder Spielserien zu produzieren. Da aus B immer wieder (bedingt durch die erzähllogische Transformation) A wird, können hieran anschließende Erzählungen immer wieder auf dasselbe Anfangssetting zurückgreifen oder wie Aleida und Jan Assmann es formulieren. Das mythologische Narrativ ist die stete „Wiederkehr des Gleichen“. (Assmann/Assmann 1998, 192) Dabei kehrt die Reihe lediglich zum formal gleichen Ausgangssetting zurück, wohingegen die Serie in ihren diversen populärkulturellen Ausprägungen oft sowohl die formale als auch die inhaltliche Dimension im Ausgangsszenario aufruft und die Handlung mit jeder neuen Folge weiter ausbaut. (vgl. zur Serialität in digitalen Spielen DENSON/J AHN-SUDMANN 2013 sowie SCHLICKER 2016)

Insofern bietet es sich an, die Funktion des mythologischen Narrativs bzw. dessen Auswirkungen auf das serielle Erzählen in interaktiv-narrativen digitalen Spielen näher zu beleuchten. Dass ein derartiges Unterfangen lohnend sein kann, unterstreicht Robert Cassar mit einer Studie zum seriellen Erzählen in digitalen Spielen, die dem Monomythos folgen, am Beispiel von God of War. (vgl. CASSAR 2013) 


\section{Eine Analyse von The Legend of Zelda: Ocarina of Time (1998) anhand des Kontinuumsmodells ${ }^{409}$}

The Legend of Zelda zählt mit über 95 Millionen verkauften Einzelspielen weltweit zu den erfolgreichsten digitalen Spielserien. ${ }^{410}$ Regelmäßig werden Neuerscheinungen von Fans und Kritikern gleichermaßen gefeiert und gehypt, ${ }^{411}$ sodass sie sich in der Regel schnell im ,Kanon ${ }^{4} 12$ der digitalen Spielkultur etablieren. The Legend of Zelda wird in diesen Diskursen oft als ,genreprägend ${ }^{4} 13$ betrachtet, da es das Explorative (in Form der topografischen Navigation und dem Lösen von Rätseln) des Adventures in actionreiche Settings übertrug und dadurch erst das Genre des Action-Adventures erschuf, das heute mit digitalen Spielreihen wie Tomb Raider, Assassin's Creed oder Uncharted zu den erfolgreichsten überhaupt gehört. Mittlerweile ist The Legend of Zelda ein nicht mehr wegzudenkender Teil der globalen Populärkultur, und wird oft zitiert wie etwa in dem Kinofilm Scott Pilgrim gegen den Rest der Welt (2010). In Fachkreisen gilt das Spiel als Citizen Kane (1941) der digitalen Spiele und wird dementsprechend zu den bedeutendsten digitalen Spielen aller Zeiten gezählt. ${ }^{414}$ Obwohl The Legend of Zelda von solch gewaltiger kultureller Bedeutung ist, ist es von der Forschung bisher kaum beachtet worden. ${ }^{415}$ Dieser Befund gilt aber nicht nur für The Legend of Zelda

\footnotetext{
${ }^{409}$ Für die folgende Analyse muss die Kenntnis von Ocarina of Time leider vorausgesetzt werden, da eine umfassende Darlegung dieses Spiels derart deskriptiv und ausufernd wäre, dass sie den vorliegenden Rahmen sprengen würde. Zudem gibt es zahlreiche (interaktiv-performative) Elemente, die sich nicht im Rahmen einer deskriptiven textuellen Darstellung ausreichend vermitteln lassen. Aus diesem Grund wird immer dort, wo es um konkrete Spielabschnitte geht, auf ausgewählte Let's Plays verwiesen.

${ }^{410}$ Eine detaillierte Auflistung der Verkaufszahlen der einzelnen Titel findet man unter dem folgenden Link: http://www.vgchartz.com/gamedb/?page $=1 \&$ results $=200 \&$ name $=$ zelda $\&$ platform $=\&$ minSales $=0$ \&publisher $=\& \mathrm{~g}$ enre $=\&$ sort $=$ GL (30.06.2018).

${ }^{411}$ Eine kritische Auseinandersetzung mit dem Hype um Ocarina of Time bietet der folgende Artikel: http://www.gamezone.com/originals/is-the-legend-of-zelda-ocarina-of-time-overrated-another-look (30.06.2018).

${ }^{412} \mathrm{Zu}$ Kanonisierung und Wertung von digitalen Spielen vgl. JANNIDIS (2012).

${ }^{413}$ So konstatiert Seth Sivak: „Many gamers believe The Legend of Zelda to be the quintessential actionadventure title; some believe it to be the game that really defined the genre." SIVAK (2009), 297; Herv. KM.

${ }^{414}$ Auf der Games Convention 2007 wurde eine Liste der sechzehn einflussreichsten digitalen Spiele aller Zeiten veröffentlicht, die The Legend of Zelda beinhaltet. http://www.jesperjuul.net/ludologist/the-most-influentialgames-of-all-time (30.06.2018). Im selben Jahr wurde The Legend of Zelda (neben GTA und Starcraft (1998)) im Rahmen eines Vortrages an der University of California, San Diego als ein Citizen Kane der digitalen Spiele bezeichnet, da es ein tiefes Verständnis seines Mediums aufweise und die Grenzen desselben erweitere. http://www.jesperjuul.net/ludologist/sorry-but-you-cant-do-that-talk-at-university-of-california-san-diego-april18th (30.06.2018). Derartige Einschätzungen werden aber nicht nur auf ,Bestenlisten“ oder auf Konferenzen geteilt, sondern auch in wissenschaftlichen Publikationen fixiert. Nachdem Bill Loguidice und Matt Barton in ihrer digitalen Spielhistoriografie wegweisender Spieletitel einleitend behaupten, The Legend of Zelda bedürfe keiner Einführung, begründen sie dies wie folgt: „Love it or hate it, The Legend of Zelda is a foundational game, one of only a handful of titles that can truly be said to have helped to define the industry as we know it today." LOGUIDICE/BARTON (2009), 303; Herv.i.O. The Legend of Zelda erscheint demgemäß nicht nur als genre- oder mediendefinierend, es prägte, so die Autoren, die gesamte digitale Spielindustrie.

${ }^{415}$ Zwei der wenigen Beispiele stellen die Sammelbände von Luke CUDDY (2009a) und Jonathan WALLS (2011b) dar, die auf eine breitere Resonanz stießen.
} 
allein, sondern grundsätzlich für digitale Spiele aus dem südostasiatischen Kulturkreis, die seltener Forschungsgegenstand der westlich dominierten Digital Game Studies sind als Spieltitel von westlichen Entwicklern wie Blizzard Entertainment, Naughty Dog, Quantic Dreams, Electronic Arts oder Ubisoft. ${ }^{416}$ Und wenn südostasiatische digitale Spiele dann doch Berücksichtigung in der Forschung finden, dann bleibt es hierbei oft beim simplen Verweis. Insofern versteht sich dieses Kapitel nicht nur als beispielhafte Analyse anhand des Kontinuumsmodells, sondern auch als Beitrag zu einem wichtigen gegenstandsbezogenen Desiderat.

Deshalb wird zuerst die transmediale Welt von The Legend of Zelda kurz skizziert und hierbei besonderes Augenmerk auf das transmediale Franchise und die transmediale Erzählung gelegt. (4.1) Anschließend wird Ocarina of Time aus dieser transmedialen Welt herausgegriffen und zum Untersuchungsgegenstand der Analyse anhand des Kontinuumsmodells gemacht, die dem in Kapitel 2 dargestellten Aufbau des Modells folgt. (4.2) Ausschlaggebend für die Auswahl dieses Spiels ist neben den Tatsachen, dass es sich hierbei um den plattformübergreifend ökonomisch am erfolgreichsten (fast 12 Millionen verkaufte Einheiten) und in der professionellen Spielkritik am besten bewerteten Titel handelt, ${ }^{417}$ auch das Faktum, dass es innerhalb der transmedialen Erzählung das wichtigste Einzelspiel ist. Hier etabliert sich der Konflikt zwischen Link, Zelda und Ganondorf, der die meisten Erzählungen der Hauptserie ${ }^{418}$ dominiert. Neben dem ökonomischen Erfolg, der spielkulturellen Relevanz und der zentralen ästhetischen ${ }^{419}$ Bedeutung für die transmediale Welt von The Legend of Zelda spricht zudem die intensive Implementierung von

\footnotetext{
${ }^{416}$ Hier ist als eine der wenigen Ausnahmen Mia Consalvos Studie Atari to Zelda. Japan's Videogames in Global Contexts (2016) zu nennen. Consalvo untersucht in ihrer Studie, inwiefern das ,Japanische‘ japanischer digitaler Spiele vom Gamedesign implementiert wird und warum und wie westliche bzw. nordamerikanische Spieler dies wahrnehmen. Dabei vermag sie zu zeigen, wie reichhaltig die gegenseitigen kulturellen Bezugnahmen verschiedener digitaler Spielkulturkreise und Spielkonzerne aufeinander sind. Mia Consalvo ist aber eine der wenigen renommierten westlichen Forscherinnen und Forscher, die sich bereits früh mit japanischen digitalen Spielen im Allgemeinen und The Legend of Zelda im Besonderen unter spielkulturellen Gesichtspunkten auseinandergesetzt hat. So untersuchte sie bspw. Walkthroughs zu Majora's Mask als erlebte und dokumentierte Geschichten der Spieler. Vgl. Consalvo (2003).

${ }^{417}$ Metacritic rankt Ocarina of Time mit 99 von 100 Punkten auf Platz eins der ewigen Bestenliste. Vgl. http://www.metacritic.com/browse/games/score/metascore/all/all/filtered (30.06.2018). GameRankings führt Ocarina of Time mit einem Score von 97,54\% unmittelbar hinter Super Mario Galaxy (2007) mit 97,64\% auf Platz zwei der ewigen Bestenliste. Vgl. http://www.gamerankings.com/browse.html (30.06.2018).

${ }^{418}$ Gute überblicksartige Darstellungen von The Legend of Zelda, die sich primär auf die Hauptserie beziehen, findet man bei LOGUIDICE/BARTON (2009), 303-317 sowie BUDZISZEWSKI (2012). Letzterer konstatiert dabei etwas pauschalisierend aber nicht verfehlt: „Most entries share the core cast of archetypal characters, setting, basic themes (coming-of-age, good versus evil), and ludo-narrative structure." BUDZISZEWSKI (2012), 360.

${ }^{419}$ Jonathan Walls merkt hierzu an: ,If The Legend of Zelda is The Beatles of video games, then this installment [Ocarina of Time] was Sergeant Pepper's.“ WALLS (2011a), 12; Herv.i.O.
} 
mythologischen Inhalten wie Funktionen für Ocarina of Time als Gegenstand der folgenden Untersuchung. ${ }^{420}$

\subsection{Einführung in die transmediale Welt von The Legend of Zelda}

Die folgende Betrachtung der transmedialen Welt von The Legend of Zelda ist eher ein flüchtiger Blick auf selbige als eine ausschöpfende Analyse, insofern man dies bei ,lebendigen“ Konstrukten wie transmedialen Welten überhaupt noch annehmen kann. Ausgeblendet wird hierbei bspw. erneut die reichhaltige Fan-Aktivität (online wie offline), die schlicht im Rahmen dieser Arbeit nicht zu leisten ist und die lediglich anhand ausgewählter Beispiele in die Analyse Einzug halten wird, was aber in keiner Weise der Diversität, Quantität und Qualität dieser im Allgemeinen gerecht werden kann. Ebenso wird mit dem Merchandise ein weiterer wesentlicher Aspekt dieser transmedialen Welt ausgelassen. Zugegebenermaßen ist Merchandise keine Erfindung transmedialer Welten oder tritt erst vermehrt seit deren Aufkommen besonders hervor, wenn auch die transmediale Welt von Star Wars Merchandise sehr früh und gezielt im Kontext des World Buildings einsetzt. ${ }^{421}$ Bemerkenswert ist aber aus kulturwissenschaftlicher Sicht, wie stark Merchandise den Alltag hochgradig involvierter Fans einer transmedialen Welt affiziert und hierdurch ersichtlich macht, wie intensiv diese ursprünglich fiktionale Welt mit der realen Welt der Fans verschmilzt. ${ }^{422}$

Ebenso bedarf die Einbettung der transmediale Welt von The Legend of Zelda einer tiefergehenden Betrachtung in Bezug auf ihre Positionierung innerhalb des von Nintendo als Produzenten erschaffenem transmedialen Universum $^{423}$ und dem sich hieraus ergebenden Beziehungsgeflecht zu den anderen transmedialen Welten dieses Universums. Dass derartige Fragestellung nicht nur interessant, sondern auch überaus relevant sind, illustriert die Entstehungsgeschichte des ersten Titels The Legend of Zelda (1986), das sich - zumindest

\footnotetext{
${ }^{420}$ Hierzu erneut Jonathan Walls: „I wasn’t just playing a game, I was living out an ancient mythology“. WALLS (2011a), 12 .

${ }^{421}$ Eine lesenswerte Studie zu transmedialer Weltenbildung und Kapitalismus hat Dan HASSLER-ForeST (2016) vorgelegt.

${ }^{422}$ Ein anschauliches Beispiel hierfür findet man in dem jungen Paar, das in der ZDF-Dokumentation Die Nintendo Story Einblicke in $\mathrm{ihr}$,Nintendo-Zimmer ${ }^{6}$ gewährt. Vgl. https://www.youtube.com/watch?v=yJNhbIJ7wAI (30.06.2018). Hierbei geht die Immersion in die transmediale Welt so weit, dass Nintendo-Figuren wie Link oder der ,Power Star' aus Marios transmedialer Welt sich als Tätowierungen auf den Körpern der Fans wiederfinden, die transmediale Welt somit figurativ wie symbolisch in den eigenen Körper eingeschrieben wird.

${ }^{423}$ Unter transmedialem Universum wird im Folgenden ein Organisationsprinzip verstanden, das verschiedene transmediale Welten miteinander verbindet und sie koordiniert. Im vorliegenden Fall ist die organisierende Entität dieses transmedialen Universums das Unternehmen Nintendo in seiner Rolle als Produzent und/oder Rechteinhaber.
} 
von den Figurenkonzeptionen und -konstellationen her - sehr an Super Mario Bros. (1985) orientiert. ${ }^{424}$ Dennoch konzentrieren sich die folgenden Ausführungen lediglich an den beiden für die Fragestellung dieser Arbeit relevantesten Elementen der transmedialen Welt von The Legend of Zelda - dem Franchise und der transmedialen Erzählung.

\subsubsection{The Legend of Zelda als transmediales Franchise}

Der wesentlichste mediale Kanal des transmedialen Franchise von The Legend of Zelda ist ohne Zweifel der des digitalen Spiels. ${ }^{425}$ Bis November 2016 sind insgesamt 52 digitale Spieltitel erschienen, womit dieses Medium als ,Mother Ship“ und zugleich ,Urmedium“ dieser transmedialen Welt gelten kann. ${ }^{426}$ Von diesen 52 Titeln gehören 18 zur sogenannten ,Hauptserie‘. Diese bilden den Kanon dieser transmedialen Welt und werden von Nintendo ${ }^{427}$ stets als Flaggschiffe eingesetzt, um die gegenwärtige stationäre wie portable Konsolengeneration zu pushen. Deshalb ist es auch nicht weiter verwunderlich, dass lediglich sechs Titel für Non-Nintendo-Plattformen erschienen sind und dass diese Strategie lediglich in den Jahren von 1988 bis 1997 verfolgt worden ist. Seit der Jahrtausendwende wird stattdessen der Politik nachgegangen, erfolgreiche Titel der Hauptserie (remastert oder nicht) für die jeweils aktuelle Konsolengeneration neu aufzulegen. Diese 22 Neuauflagen werden dabei in den meisten Fällen über Nintendos hauseigenen Online-Marktplatz ,Virtual Console“ angeboten. Somit zeigt sich ein zaghafter Wandel Nintendos hin $\mathrm{zu}$ moderneren Unternehmerverständnissen, wie sie seit der Jahrtausendwende in der Medienbranche üblich sind. Hier spielt die Vermarktung der eigenen ,Backlist` bzw. deren digitale Distribution eine zunehmend größere Rolle und deren deutlichster Ausdruck Geschäftskonzepte wie die von Netflix sind, die auf stete digitale Zugänglichkeit setzen. Auch andere gängige Verwertungskonzepte wie Cross-Over bzw. digitale Spiele, die nicht zum Action-Adventure Genre gerechnet werden oder Sondereditionen werden bisher kaum eingesetzt (erst vier bzw.

\footnotetext{
${ }^{424}$ Am nachhaltigsten schlägt sich dies bis heute in der ikonografischen Darstellungen der Figuren nieder. Prinzessin Zelda ist ebenso stark an Prinzessin Peach orientiert wie Ganon an Bowser. Vgl. dazu die folgenden Abbildungen: http://www.smashbros.com/images/og/zelda.jpg; http://static.giantbomb.com/uploads/scale_small/0/7003/204916-peachmp8a.png; http://vignette1.wikia.nocookie.net/zelda/images/9/94/Ganon_\%28Ocarina_of_Time\%29.png/revision/latest?cb= 20090528093513 sowie http://www.smashbros.com/images/og/koopa.jpg (alle 30.06.2018).

${ }^{425}$ Einen sehr konzisen, wenn auch journalistischen Überblick über die ersten 20 Jahre von The Legend of Zelda bietet SAUTNER (2006).

${ }^{426} \mathrm{Zu}$ Theorie und Terminologie transmedialer Welten vgl. GABRIEL et al. (2015). Vgl. insbes. die dortige Fallstudie zum transmedialen Franchise von The Legend of Zelda. Ebd., 186-190.

${ }^{427}$ Zur Unternehmens- und Wirkungsgeschichte von Nintendo vgl. SHEFF (1999) sowie KOHLER (2005).
} 
zwei Spieltitel). Auch Lizenzierungen, mittlerweile einer der rentabelsten Geschäftsbereiche vieler Medienunternehmen, werden kaum vorgenommen. ${ }^{428}$

Der Blick auf Nintendos Unternehmensgeschichte legt einen verblüffenden Schluss nahe. Einerseits hat man es mit einem Unternehmen zu tun, das sich technologischen Innovationen gegenüber sehr aufgeschlossen zeigt. Nicht nur, dass Nintendo früh Ende der 1970er Jahre erkannte, dass der Heimkonsolenmarkt ein lohnendes zukünftiges Absatzfeld sein könnte, sondern auch das Interface-Design Nintendos war und ist für die globale digitale Spielindustrie (ebenso wie ihre Spielkonzepte) wegweisend. Zudem betrieb man in der Vergangenheit ,laterale Diversifikation', indem Nintendo das Unternehmensportfolio z.B. erweiterte, indem man u.a. Taxiunternehmen erwarb. Andererseits vertritt Nintendo in Bezug auf die Interpretation der Produzentenrolle sehr konservative bis autoritäre Ansichten. So geht Nintendo weitaus energischer und empfindlicher mit Eingriffen in die eigene Rechtssphäre um als die meisten anderen Rechteinhaber transmedialer Welten. Das von Fans anlässlich des 30. Jubiläums von The Legend of Zelda kreierte und grafische überarbeitete Remake des ersten Titels von 1986 ist, obwohl kostenlos im Browser spielbar und damit nicht kommerziell, nicht mehr verfügbar, da Nintendo hiergegen rechtlich vorgegangen ist. ${ }^{429}$ Retrospektiv betrachtet erhält die in Giga Games' Artikel zu diesem Fan-Projekt artikulierte Einschätzung damit nicht nur einen ,prophetischen' Charakter, sondern sagt vielmehr etwas Generelles über Nintendos Einstellung zu Rechtsfragen. „Wenn ihr das Remake spielen wollt, solltet ihr das wahrscheinlich möglichst bald tun: Nintendo ist solchen Fan-Projekten für gewöhnlich nicht wohlgesonnen.“(MOITZHEIM 2016)

Damit geht auch ein sehr traditionelles Autorenkonzept einher, das sich nirgends deutlicher äußert als in der Inszenierung des Spieldesigners und Entwicklers Shigeru Miyamoto. 430 Dieser wird von Nintendo als Schöpfergenie klassischer Prägung bis hin zum ,transmedialen Schöpfergott‘ in Szene gesetzt. ${ }^{431}$ Fragwürdig sind solche Vorstellungen nicht zuletzt allein

\footnotetext{
${ }^{428}$ Eines der jüngsten Gegenbeispiele ist Pokémon Go, jedoch sollte man dabei nicht vergessen, dass Nintendo an diesem Franchise lediglich Minderheitsanteile hält.

${ }^{429} \mathrm{Vgl}$. http://zelda30tribute.com/ (30.06.2018).

${ }^{430} \mathrm{Zu}$ Miyamoto und seinem Werk ist die Monografie von Jennifer DEWINTER (2015) empfehlenswert. Zur Inszenierung ist der Artikel von Nick PAUMGARTEN (2010) im New Yorker sehr aufschlussreich.

${ }^{431}$ Vgl. dazu die folgende Abbildung: https://myhero.com/S_Miyamoto_mflandres_FR_2016_ul (30.06.2018). Miyamoto nimmt die zentrale Position ein und dominiert von hieraus Perspektive und Bildkomposition. Die auf ihn zentrierten Strahlen stellen eine Verbindung zwischen ihm und seiner Schöpfung her, wobei jeder der abgebildeten Charaktere pars pro toto für eine von ihm geschaffene transmediale Welt steht (neben den bereits erwähnten transmedialen Welten sind dies Donkey Kong (1981 ff.), Pikmin (2001 ff.) und Ice Climber (1984 ff.)). Auf diese Weise wird Miyamoto zum Schöpfer eines transmedialen Universums stilisiert, deren Welten durch ihn als ,Schöpfergott‘ verbunden sind.
} 
schon deshalb, weil sie der Produktionsrealität großer digitaler Spieleproduktionen widersprechen, die gegenwärtig mehrere hundert Involvierte erfordern. ${ }^{432}$ Miyamoto fungiert vielmehr - zumal die Verantwortung für die digitalen Spielproduktionen seiner populärsten Werke wie eben The Legend of Zelda längst bei anderen liegt wie dem von Miyamoto protegierten Eiji Aonuma, seines Zeichens Serien- und Produktmanager von The Legend of Zelda - als Personifikation eines internationalen Medienkonzerns, der teilweise entschieden rechtlich gegen seine eigenen Rezipienten vorgeht. Nintendo erhält durch Miyamoto gewissermaßen ein freundlich lachendes und überaus kreatives Gesicht.

Dabei möchte sich die Arbeit im Folgenden nicht auf die ebenfalls interessante bildliche Inszenierung ${ }^{433}$ von Miyamoto im Rahmen öffentlicher Auftritte beschränken, sondern auf Interviewaussagen eingehen. Konkret geht es hierbei um seine Äußerungen zu den Inspirationsquellen seiner Spiele. Nick Paumgarten fasst Miyamotos Schilderung, wie er auf die Idee zu The Legend of Zelda kam, wie folgt zusammen:

One day, when he was seven or eight, he came across a hole in the ground. He peered inside and saw nothing but darkness. He came back the next day with a lantern and shimmied through the hole and found himself in a small cavern. He could see that passageways led to other chambers. Over the summer, he kept returning to the cave to marvel at the dance of the shadows on the wall. Miyamoto has told variations on the cave story a few times over the years, in order to emphasize the extent to which he was surrounded by nature, as a child, and also to claim his youthful explorations as a source of his aptitude and enthusiasm for inventing and designing video games. The cave has become a misty but indispensable part of his legend, to Miyamoto what the cherry tree was to George Washington, or what LSD is to Steve Jobs. (PAUMGARTEN 2010)

Hierbei ist weniger interessant, wie authentisch oder eben nicht die Darstellungen von Miyamoto sein mögen, auch wenn man anhand der Tatsache, dass es mehrere Versionen dieser Geschichte gibt, berechtigte Zweifel an deren Korrektheit haben kann. Wahrhscheinlich handelt es sich hierbei, und das ist entscheidend, um eine Form moderner Mythenbildung, die Frage ist nur, wozu dient dieser Mythos? Ein weiteres Beispiel, das Paumgarten aufgreift, gibt hier Aufschlüsse.

\footnotetext{
${ }^{432}$ So räumt Shigeru Miyamoto in seinem Grußwort zum Begleitbuch der Symphonie-CD populärer The Legend of Zelda-Lieder anlässlich des 25-jährigen Jubiläums der Serie etwa ein: „Mehr als 200 Nintendo-Mitarbeiter haben dabei geholfen, die The Legend of Zelda ${ }^{T M}$-Reihe zu erschaffen, und die 25-jährige Geschichte dieser Reihe ist selbst eine Legende für sich." The Legend of Zelda 25th Anniversary Symphony, o.P.; Herv.i.O.

${ }^{433}$ Dabei ist einerseits die Inszenierung Miyamotos mit Figuren seiner transmedialen Welt interessant. Vgl. dazu exemplarisch http://www.zeldaeurope.de/include/designs/queen/img/miya_22.jpg (30.06.2018). Andererseits verdient die Art und Weise, wie das Merchandise der diversen transmedialen Welten von Nintendos transmedialem Universum von Miyamoto bei öffentlichen Auftritten eingesetzt wird, eine größere Beachtung. Vgl. dazu exemplarisch http://vignette2.wikia.nocookie.net/zelda/images/8/83/Shigeru_Miyamoto_at_E3.png/revision/latest?cb=201006 $\underline{05230158}(30.06 .2018)$.
} 
He [Miyamoto] also studies himself. Miyamoto is the closest thing there is to an autobiographical game creator. His experience with his family's pet Shetland sheepdog, and, more to the point, with other dogs owners, gave him the idea for Nintendogs, a popular game in which you create a simulation of a pet and look after it an the DSi. (ebd.)

Auch wenn es wirklich zweifelhaft ist bzw. mindestens unklar, was von Miyamotos Aussagen über seine eigene Vergangenheit stimmt, so unterstreichen beide Beispiele in der Zusammenschau doch, dass es ein verbindendes Element in seinen Erzählungen gibt - die Kindheit. ${ }^{434}$ Dabei ist m.E. Paumgartens Einschätzung zu widersprechen, dass Miyamoto stets versucht habe „his childhood wonderment“ zu rekreieren. (ebd.) Vielmehr erschafft er mithilfe seiner Ursprungserzählungen ein Kindheitswunderland, ${ }^{435}$ an das sich die Rezipienten gern selbst zurückerinnern oder das sie gern gehabt hätten. Miyamoto evoziert durch seine Interviewaussagen eine (Rück-)Besinnung auf basale und positiv besetzte menschliche Erfahrungen. Die Neugier, die uns befällt, wenn wir einen unbekannten Ort wie eine Höhle erkunden, oder die Freude aufgrund der Gewissheit, immer einen treuen Freund zu haben, der stets loyal ist und einen nie verlässt. Dabei werden mögliche negative Begleiterscheinungen wie die Angst vor dem Unbekannten und Dunklen oder die Trauer, die mit dem Verlust des vierbeinigen Freundes einhergeht, bewusst ausgespart. Es bleibt nur das Positive und das implizite Versprechen, dass diese Wunderwelten nicht ganz verloren sind, sondern temporär zurückgeholt werden können; wenigstens für die Spielzeit eines MiyamotoSpiels. So kommt auch Paumgarten trotz aller Begeisterung für Miyamoto nicht umhin festzustellen:

He is a salaryman. Miyamoto's business card says that he is the senior managing director and the general manager of the entertainment-analysis and -development division at Nintendo Company Ltd., the videogame giant. What it does not say is that he is Nintendo's guiding spirit, its meal ticket, and its playful public face. (ebd.)

Freilich sollte man deshalb Miyamotos herausragende kreative Leistungen für Nintendo wie für die digitale Spielbranche insgesamt nicht vergessen und man kann sie auch kaum überschätzen. Eine kritische Hinterfragung kann aber zu Erkenntnissen führen, die andernfalls vielleicht nicht so offensichtlich wären; und damit kommen wir zum Narrativen. Auch wenn Miyamoto stets aktuelle wie potenzielle Spieler mit seinen origo-Erzählungen zu begeistern versucht, so kann man dabei jedoch nicht übersehen, dass - zumindest jenseits des Marketings

\footnotetext{
${ }^{434}$ Seth Sivak stellt deshalb auch richtigerweise fest: „The inspiration for The Legend of Zelda is rooted deep in the childhood adventures of Shigeru Miyamoto in the wilderness surrounding his home in Kyoto, Japan. [...] Miyamoto has explained that The Legend of Zelda games were created as an attempt to bring a »miniature garden« to life for the players." SIVAK (2009), 298.

${ }^{435}$ So stellt auch deWinter mit Blick auf Miyamotos Werk fest: „Each game refers back in some way to childhood spaces: the playground for Super Mario Bros. and the woods and caves that Miyamoto whiled away time in, Sonobe, for Zelda." DEWINTER (2015), 36; Herv.i.O.
} 
- Erzählungen eine eher untergeordnete Rolle im transmedialen Universum von Nintendo einnehmen. Worum es eher geht, ist, ein positives Gameplay mittels Interaktions- und UX$\operatorname{Design}^{436} \mathrm{zu}$ evozieren und dieses an positive und basale menschliche Emotionen rückzubinden. Diese designerische Ausrichtung geht zulasten narrativer Elemente. Jene liegen, und das zeigt der folgende Abschnitt, aber auch gar nicht im primären Interesse Nintendos.

\subsubsection{The Legend of Zelda als transmediale Erzählung(?)}

Wie gering der Stellenwert ist, den Erzählungen in der transmedialen Welt von The Legend of Zelda einnehmen, wird ersichtlich, wenn man genauer betrachtet, wie niedrig frequent mediale Kanäle genuin narrativer Medien bedient werden, die im Kontext anderer transmedialer Welten wie Der Herr der Ringe, Game of Thrones oder The Walking Dead von zentraler Wichtigkeit sind - nämlich Film, Fernsehen, Literatur und Comic. Bis heute existieren 15 Manga und zwei Comics, lediglich eine Fernsehserie mit dem Titel The Legend of Zelda (1989), die nach nur einer Staffel wiedereingestellt wurde, zwei Romane ${ }^{437}$ und (trotz gelegentlicher Spekulationen) kein einziger offizieller Film. ${ }^{438}$ Zudem fällt bei all diesen Werken die Strategie des Weltausbaus via transmedialer Erzählung ins Auge. Mark J.P. Wolf unterscheidet bei der Expansion transmedialer Welten im Wesentlichen zwei Strategien Adaption und ,Growth`. Unter Adaption versteht er hierbei ganz klassisch die Übertragung einer existierenden Geschichte in ein anderes Medium der transmedialen Welt, wohingegen er unter ,Growth` den Ausbau der (kanonischen) ${ }^{439}$ Erzählung der transmedialen Welt versteht. (vgl. WOLF 2012, 245)

Ohne allzu sehr genieästhetischen Implikationen dieser Differenzierung zu folgen, so muss man doch konstatieren, dass der Weltausbau via ,Growth“ nicht nur der künstlerisch , anspruchsvollere', sondern auch aufwendigere Prozess ist, wohingegen bei der Adaption oft nur mediale Spezifika bei der Übertragung zu berücksichtigen sind. Insofern geht Nintendo eher den ,leichteren“ Weg beim transmedialen Weltausbau von The Legend of Zelda, wenn es (fast ausschließlich) auf Adpationen bereits bestehender medialer Artefakte von The Legend

\footnotetext{
${ }^{436} \mathrm{Vgl}$. einführend MOSER (2012) sowie NORMAN (2005).

${ }^{437}$ Dies sind Jason R. Richs Adaption von Ocarina of Time (1998) sowie Craig WesseL's Oracle of AgesAdaption (2003).

${ }^{438}$ Ausnahmen bilden hier lediglich Fan-Filmprojekte wie The Legend of Zelda: Oblivion Rising (2016). Vgl. dazu http://zelda-oblivion.com/ (30.06.2018).

${ }^{439}$ Der Begriff ,Kanon` hat in der Theorie transmedialer Welten im Unterschied zur literaturwissenschaftlichen Kanonauffassung eine etwas weitere Dimension und bezeichnet jene Inhalte einer transmedialen Welt, die von der Mehrheit der Rezipienten akzeptiert werden. Vgl. zur Verwendung des Ausdrucks Kanon in der Literaturwissenschaft BEILEIN et al. (2012).
} 
of Zelda setzt. Eine Einschätzung, die sich noch dadurch erhärten lässt, dass sich alle angeführten Beispiele sehr nah an den Vorlagen orientieren, nur in seltenen Fällen Katalysen hinzufügen, die für das jeweilige Narrativ aber eher von untergeordneter Signifikanz sind und die gar keine Wirkung auf den narrativen Kanon insgesamt haben. ${ }^{440}$ Vergegenwärtigt man sich, dass die meisten Manga, die Comics, die Fernsehserie oder die Romane direkt oder in den unmittelbaren Folgejahren nach den Titeln erschienen sind, die sie adaptieren, so kommt man zu dem Schluss, dass diese lediglich die jeweilige adaptierte Publikation additiv begleiten. ${ }^{441}$ Hierbei muss beachtet werden, dass sich alle Adaptionen ausnahmslos auf die Hauptserie beziehen, womit die Vermutung naheliegt, dass ihre Funktion seitens Nintendos primär darin gesehen wird, dass sie lediglich als Support für die Hauptserie dienen. Kurz gesagt: Die narrativen Adaptionen von Titeln der Hauptserie sind Marketinginstrumente, um die Hauptserie zu pushen, indem auch eher narrativen Nutzer- bzw. Spielertypen der transmedialen Welt von The Legend of Zelda Rezeptionsangebote gemacht werden, die aber in keiner Weise die Rezeption der eher interaktiv ausgerichteten (Haupt-)Spielerschaft beeinträchtigen, da sie den Kanon nicht affizieren. ${ }^{442}$

Das traditionelle Autoren- bzw. Produzentenverständnis von Nintendo schlägt sich somit in einem eher konservativen Worldbuilding-Verständnis nieder, das radikal an der Zielgruppe orientiert ist und deren Entry-Anlass offenbar von Nintendo als nicht-narrativ angesehen wird. Dass diese Beurteilung Nintendos durchaus plausibel scheint, legen einerseits Flops innerhalb der transmedialen Welt von The Legend of Zelda wie die genannte Fernsehserie nahe. Andererseits sind die Gründe hierfür auch außerhalb dieser transmedialen Welt zu suchen und im transmedialen Universum von Nintendo zu finden. Die Mario-Verfilmung Super Mario Bros. (1993) gilt als eines der größten Fiaskos der Filmgeschichte der 1990er Jahre, das tiefe Spuren bei Nintendo hinterlassen hat. Gemeinsam mit dem Flop der Zelda-Serie hat es anscheinend dazu geführt, dass Nintendo davon Abstand genommen hat, filmische und Fernsehadaptionen anfertigen $\mathrm{zu}$ lassen. Jedenfalls steht diesen durchaus ambitionierten Versuchen Ende der 1980er und Anfang der 1990er Jahre seit Mitte der 1990er Jahre bis

\footnotetext{
${ }^{440} \mathrm{Zu}$ den prominentesten Beispielen für diese Vorgehensweise zählen noch die Bonuskapitel zum zweibändigen Manga von Akira Himekawa zu Ocarina of Time (2009), 133 ff. Diese dienen aber allgemein eher dazu, die Figurenkonzeption Links weiter zu profilieren und ihn in der Figurenkonstellation stärker zu positionieren. So tritt Link in beiden Bonuskapiteln als Retter auf, der für andere in Notlagen eintritt und der besonders zu seinen Freunden steht. Hierdurch wird Link stärker als klassischer Heros herausgearbeitet, was aber kaum eine Auswirkung auf den Kanon der transmedialen Welt von The Legend of Zelda gehabt hat.

${ }^{441}$ So erschienen, um ein Exempel zu wählen, die gleichnamigen Manga zu den Game Boy Color-Titeln Oracle of Ages (2001) und Oracle of Seasons (2001) von Akira Himekawa in Japan ebenfalls 2001.

${ }^{442}$ Ins gesamt lässt die spärliche Veröffentlichung von genuin narrativen Medien darauf schließen, dass Nintendo die Zielgruppe der transmedialen Welt von The Legend of Zelda eher als interaktiv ausgerichtet einschätzt.
} 
heute ein völliges Ausbleiben von umfangreichen Film- und Fernsehprojekten entgegen. Nintendo scheint medialer Narrativität (zumindest genuin narrativer Medien) gegenüber mittlerweile sehr skeptisch zu sein. Diese Skepsis ist nicht nur in der transmedialen Welt von The Legend of Zelda zu beobachten, sondern betrifft aktuell alle transmedialen Welten von Nintendos transmedialem Universum. Dies drückt sich dabei auch in einem ,Desinteresse“ aus, das für Nintendos Unternehmens- wie Designphilosophie ${ }^{443}$ bezeichnend ist. Während Fan-Projekte, die ludisch sind, auf interaktive Handlungen setzen, energisch rechtlich verfolgt werden, gilt dies nicht für narrative Vorhaben ungeachtet ihrer medialen Form. So gibt es neben filmischen Fan-Projekten wie dem oben erwähnten Oblivion Rising eine lebendige Fanfiction-Szene, die von Nintendo kaum behelligt wird. ${ }^{444}$ Dies lässt den Schluss zu, dass Nintendo eher an den interaktiven Belangen seines Werkes orientiert ist und weniger an den narrativen, weshalb auch nur erstere penibel geschützt werden, wohingegen letztere ein nahezu ,freies“ Betätigungsfeld für Fans dieser transmedialen Welt zu sein scheinen. Derartige Schlussfolgerungen lassen sich mit Blick auf Nintendos Gamedesign im Allgemeinen untermauern. Eigentlich alle digitalen Spiele von Nintendo lassen sich nämlich auf der linken Seite des Kontinuums der Attributebene verorten wie bspw. bereits ein streiflichtartiger Schwenk über die von Miyamoto kreierten transmedialen Welten Donkey Kong, Pikmin oder eben Mario illustriert. Viele digitale Spielproduktionen Nintendos wie die Sportbewegungsspiele Wii Fit (2007) und Wii Sports (2006) oder populäre Denkspiele wie Dr. Kawashimas Gehirn-Jogging (2005) haben gar keine narrativen Anteile. Das von Nintendo präferierte Designparadigma scheint eindeutig ein interaktiv-interaktiv-narratives bzw. zuweilen gar ein rein interaktives zu sein.

Ein Designparadigma, das fundamental an einem Gameplay orientiert ist, das sich in dem Erfahren und Erleben des Spiels radikal an (interaktiven) Handlungen ausrichtet, lässt sich letztlich nur schwer in genuin narrative Medien übertragen, die aufgrund der Passivität des Rezipienten die hierfür notwendige Agency vermissen lassen. Einen Protagonisten eine Höhle erkunden oder mit einem Hund spielen zu sehen, ist eben etwas anderes, als dies selbst (wenn auch im digitalen Raum) auszuagieren. ${ }^{445}$ Die Ausrichtung dieses interaktiv ausgelegten

\footnotetext{
${ }^{443}$ Unter Designphilosophie werden im Folgenden die designerischen Leitvorstellungen einer Person oder einer Gruppe von Personen verstanden, die sich aus designerischen Idealen und Maximen speisen. Im Unterschied zum Designparadigma muss eine Designphilosophie nicht vollständig konkret realisiert werden, sondern liegt oft dem Designparadigma als Umsetzung der Designphilosophie zugrunde.

${ }^{444}$ So lassen sich allein auf der Seite Fanfiction.net zum Stichwort „Legend of Zelda“ über 25.000 Einträge und eine täglich aktive Community finden. Vgl. https://www.fanfiction.net/game/Legend-of-Zelda/ (30.06.2018).

${ }^{445}$ Damit möchte ich keineswegs jenen kritischen Stimmen Wort reden, die eine Übertragbarkeit des (digitalen) Spiels in einen Film grundsätzlich bestreiten. Vielmehr geht es darum, die Spezifika des Gameplays bei der
} 
Designparadigmas, das die meisten digitalen Spiele des transmedialen Universums von Nintendo bestimmt und damit in gewisser Weise zu einem ,Metadesignparadigma' des japanischen Unternehmens wird, ist deshalb für die folgende Analyse so interessant, da es nahezu die gesamte Untersuchung hindurch einen roten Faden bildet, der zeigt, wie interaktiv Nintendo selbst interaktiv-narrative digitale Spiele wie Ocarina of Time interpretiert. Dies ist für das Gesamtbild des transmedialen Universums von Nintendo so interessant, da The Legend of Zelda wahrscheinlich die komplexeste (transmediale) Erzählung von Nintendo ist. Im Bestreben, diese Komplexität zu reduzieren, haben Fans immer wieder versucht, eine Chronologie in die transmediale Erzählung zu bringen. Sean C. Duncan und James Paul Gee untersuchen ausgewählte Fantheorien und die Online-Kommunikation über die ,Timelines‘ der transmedialen Welt von The Legend of Zelda. Sie zeigen dabei, wie differenziert diese Argumentationen und wie philologisch die zugrundeliegenden Analysen sein können. Final kommen sie dabei zu dem Schluss: „Like all knowledge, Zelda timeline knowledge is constructed socially.“446 (DUNCAN/GEE 2009, 101; Herv.i.O.) Ihre Studie stellt nicht nur heraus, warum Fantheorien und Fankommunikation von der Forschung ernst genommen werden müssen, sie rekurrieren zugleich (wenn auch implizit) auf das soziale Gefüge einer transmedialen Welt, zu der nicht nur die Kommunikation zwischen Fans gehört, sondern auch zwischen Fans und Produzenten. So ist es weniger verwunderlich, dass Nintendo mit einer eigenen Timeline auf diese Fantheorien reagierte, einer offiziellen Chronologie. Diese wurde in der Hyrule Historia ${ }^{447}$ (2013) vorgestellt. (vgl. ebd., 69) Wesentlich für die folgenden Ausführungen ist dabei, dass die derart entstandene Verkettung der Titel der Hauptserie einem Spiel besondere Aufmerksamkeit schenkt - Ocarina of Time.

\footnotetext{
Adaption in die Rezeptionserfahrung des Films zu transferieren. Hierbei sollten dementsprechend weniger Inhalte im Vordergrund stehen, sondern eher Funktionen und Erfahrungen. Ein Film, dem es m.E. ausgezeichnet gelingt, das Gameplay des Spiels in den Film zu überführen, ist die Verfilmung Silent Hill (2006) der gleichnamigen digitalen Spielreihe (1999 ff.). Das Gefühl der Angst, Hilf- und Orientierungslosigkeit, das das Genre des Survival-Horror kennzeichnet, wird mittels atmosphärischer Verdichtung und geschickter Instrumentalisierung der reihentypischen Ikonografie genutzt, um eine Rezeptionserfahrung zu evozieren, die auf das Gameplay der Spiele referiert und mit der Passivität der filmischen Rezeptionssituation korrespondiert.

${ }^{446}$ Carl Matthew Johnson merkt zur Rolle der Fans in der transmedialen Welt von The Legend of Zelda an: „Zelda demonstrates that a work need not have a single author with a unitary vision in order to have meaning. Meaning is the product of a group of people working together for some common end with common agreement about the sorts of things that count as evidence, principles, and progress towards the end, but disagreements about the best interpretation that unites it all into a whole. What the Zelda fan community does is to create a deeper and richer experience by investing meaning in the games they seek to explain." JOHNSON (2009), 117. Johnsons Studie ist ein Plädoyer für eine stärkere Fokussierung auf Fanaktivitäten und gegen eine zu strikte Beschränkung auf den Autoren als Schöpfergenius.

${ }^{447} \mathrm{Im}$ japanischen Original wurde sie bereits 2011 veröffentlicht. Eine aktualisierte Version der Timeline, die auch die Titel nach 2011 berücksichtigt, findet man hier: http://www.nintendolife.com/news/2016/01/the_official_legend_of_zelda_timeline_has_been_updated (30.06.2018).
} 
Dieses Spiel etabliert den für die gesamte transmediale Erzählung zentralen Konflikt zwischen Link, Zelda und Ganondorf, indem das Triforce aufgebrochen und an je eine der Figuren gebunden wird. Hierdurch beginnt die Auseinandersetzung um Hyrules Schicksal zwischen Link und Zelda ${ }^{448}$ auf der einen und Ganondorf auf der anderen Seite, die sich durch die meisten Titel der Hauptserie zieht. Nach Ocarina of Time spaltet sich die Timeline in drei Zeitlinien auf, die die drei möglichen Ausgänge des finalen Kampfes gegen Ganon berücksichtigen (Link unterliegt Ganon, Link besiegt Ganon, reist aber in der Zeit zurück und Link besiegt Ganon und reist nicht in der Zeit zurück). ${ }^{449}$ Die meisten Titel der Hauptserie spielen (in der Chronologie der transmedialen Erzählung) nach Ocarina of Time und rekurrieren (wenn auch implizit) auf die Ereignisse am Ende von Ocarina of Time. Deshalb kommt Ocarina of Time in der transmedialen Erzählung von The Legend of Zelda eine ganz besondere Bedeutung unter narrativen Gesichtspunkten zu. Erzählerisch ist es der signifikanteste Titel der Serie, der Punkt, an dem aus einer linearen eine multilineare Erzählung wird. Mit Blick auf die Timeline muss man aber auch bemerken, dass die übergreifende Erzählung von The Legend of Zelda nicht primär transmedial erzeugt wird, sondern seriell. ${ }^{450}$ Genau genommen sind die einzelnen Titel der Hauptserie je ein narratives Ereignis oder eine narrative Funktion, die Timeline dementsprechend das (Meta-)Narrativ der Serie, das immer weiter ausgebaut wird. Und eben dieses Narrativ wird seriell organisiert. Das dem so ist, verdeutlicht auch der Blick auf die transmediale Welt im Gesamten. Wie oben herausgestellt, bedient Nintendo kaum genuin narrative mediale Kanäle, mehr noch, hat sich

\footnotetext{
${ }^{448}$ Die Bedeutung, die diesen beiden Figuren in der Fankultur der transmedialen Welt von The Legend of Zelda zukommt, sollte nicht unterschätzt werden. Neben zentralen Symbolen wie dem Triforce oder dem Masterschwert haben gerade diese beiden Figuren eine immense Wirkmacht auf die visuelle Identität der gesamten transmedialen Welt. Die unzähligen Beispiele von Fanvideos auf Youtube belegen dies. In dieser Fankunst geht es den kreativen Fans oft weniger darum, eine eigene Geschichte zu erzählen, als vielmehr die Konstellation zwischen beiden Figuren auszubauen bzw. an dieser teilzuhaben. Ein anschauliches Beispiel ist dafür das folgende Video von WASTED LINK: https://www.youtube.com/watch?v=1I oZAT7C0s (30.06.2018). In diesem Mashup aus Cutscenes aus Hyrule Warriors (2014) und Taylor Swifts Song Love Story geht es primär darum, die in Hyrule Warriors angedeutete Beziehung zwischen beiden Figuren als Liebesgeschichte zu vertiefen. Diesem Wunsch seitens der Fans scheinen auch viele Fan Arts zu folgen. Vgl. dazu exemplarisch http://orig06.deviantart.net/d8be/f/2014/220/3/f/link_x zelda for_the love_of_a princess_by_aerisuked7uaf8h.jpg (30.06.2018). Ebenso gibt die Konstellation zwischen beiden Figuren anscheinend auch Anlass dazu, diese Beziehung via Cosplay real auszuagieren, da beide nicht selten als Paar gecosplayt werden. Vgl. dazu exemplarisch http://www.gamergirls.de/wp-content/gallery/3/aktuell-zeldacosplay/link_and_zelda_acen_2010_by_forcebewitya.jpg (30.06.2018).

${ }^{449}$ So schreibt sich die Ludizität des Spiels in Form der Offenheit des Ausgangs in die transmediale Erzählung ein.

${ }^{450}$ Ein Gegenbeispiel hierzu ist, wenn auch Disney als neuer Rechteinhaber hier mittlerweile massiv eingegriffen hat, die transmediale Welt von Star Wars. Kaum eine andere populäre transmediale Welt betreibt derart stark die Expansion der transmedialen Welt durch die Strategie des, Growth'. So bleibt das filmische Medium nach wie vor zwar das Mother Ship, aber die transmediale Erzählung wird dennoch durch Fernsehserien wie Star Wars: The Clone Wars (2008-2015) oder Star Wars: Rebels (2014 ff.), durch digitale Spiele wie Star Wars: The Force Unleashed oder die zahlreichen Romane aktiv ausgebaut.
} 
im Laufe der letzten beiden Jahrzehnte die Distanz zu diesen noch vergrößert. Der einzige genuin narrative mediale Kanal, der noch mit höherer Frequenz eingesetzt wird, sind Manga. (vgl. GABRIEL et al. 2015) Da diese aber in direkter Verbindung mit dem Titel der Hauptserie erscheinen, den sie (marketingtechnisch) unterstützen sollen, richtet sich auch hier die transmediale Adaption nach dem seriellen Produktionsprinzip der transmedialen Welt von The Legend of Zelda. Man kann also festhalten: The Legend of Zelda erzählt kaum transmedial, sondern hauptsächlich seriell über das ,Mother Ship“. Die Erzählungen in anderen Medien der transmedialen Welt sind entweder Adaptionen mit großer Nähe zur Erzählung des Mother Ships oder sie sind ,außerhalb‘ der kanonischen Erzählung von The Legend of Zelda angesiedelt wie das Crossover Hyrule Warriors.

Abschließend lässt sich konstatieren, dass Nintendo sehr auf das serielle Mother Ship, die Hauptserie, der transmedialen Welt von The Legend of Zelda fokussiert und dementsprechend bemüht ist, dieses auch zu kontrollieren. Einer geringen transmedialen Ausprägung der Medienproduktion steht aber zugleich ein transmedial ausgerichtetes Merchandise und Marketing gegenüber, das bspw. intensiv Shigeru Miyamoto und in den letzten Jahren auch zunehmend Eiji Aonuma als schöpferische Genies inszeniert. Ein eher konservatives Autorenverständnis geht somit eine bemerkenswerte Symbiose mit einem progressiven Marketing ein. Dass diese Symbiose aber aufgeht, zeigt sich an der Fangemeinschaft, welche die Fokussierung auf das Mother Ship (vgl. dazu DunCAN/GEE 2009) und auf Shigeru Miyamoto weitestgehend kritiklos anerkennt. Zugleich sind die Fans aber bestrebt, die transmediale Welt auszubauen und sich dabei auch von Nintendo zu emanzipieren, wodurch die für viele transmediale Welten kennzeichnende Spannung zwischen, commercial‘ (Nintendo) und , social property (Fans) sichtbar wird. ${ }^{451}$ Ocarina of Time kann letztlich als wohl bedeutendster Teil dieser transmedialen Welt nicht lediglich werkimmanent betrachtet werden, sondern muss stets auch in den sozialen Strukturen der transmedialen Welt von The Legend of Zelda kontextualisiert werden. So greifen das Spiel bzw. dessen interaktive Handlungsangebote in die Realität der Fans aus. Fan Art, Videos, Vlogs, Blogs, Foren, Wikis, Cosplays, Fanclubs oder Fanfiction sind aktuell ein nicht mehr zu ignorierender Bestandteil eines Kunstwerkes, ${ }^{452}$ das nicht länger nur in den vom Autor definierten Grenzen verharrt,

\footnotetext{
${ }^{451}$ In der transmedialen Welt von The Legend of Zelda nehmen (wie in anderen transmedialen Welten mit dem medialen Kanal digitales Spiel als Mother Ship auch) Let's Plays eine große Bedeutung innerhalb der Fanproduktion ein. Interessant ist an diesen, dass sie eine Art verbindendes Element zwischen passiver Rezeption und aktiver Partizipation darstellen. Vgl. dazu Tilgner (2017). Dabei kann das Erstellen von Let's Plays zuweilen durchaus als subversive Tätigkeit begriffen werden. Vgl. dazu VERSTÄNDIG/HolZE (2017).

${ }^{452} \mathrm{Zu}$ The Legend of Zelda als Kunst(werk) vgl. den kunstphilosophischen Aufsatz von Luke CuDDY (2009b).
} 
sondern diese transzendiert. Auch wenn hiermit keinesfalls Utopien kollaborativer Autorschaft wahr werden, so deutet sich doch ein signifikanter Wandel in der Mediennutzungskultur an, den auch eher, werkzentrierte ${ }^{6}$ Analysen stets mitdenken müssen. Dies gilt vielleicht umso mehr für transmediale Welten, deren Mother Ship ein derart interaktiv-performatives Medium wie das digitale Spiel mit all seinen (impliziten) Handlungsangeboten ist.

\subsection{Analyse von Ocarina of Time anhand des Kontinuumsmodells}

Die folgende Analyse richtet sich nach dem Aufbau der drei Ebenen des Kontinuumsmodells. Bei der Untersuchung mittels der Attributebene (4.2.1) werden Interaktivität und Agency, die Narrativität sowie die attributive Hybridität in Ocarina of Time untersucht. Mit Blick auf die Strukturebene (4.2.2) rücken das Interaktiv, das Narrativ, das mythologische Interaktiv-Narrativ, die interaktiv-narrativ polyvalenten Elemente sowie das Designparadigma von Ocarina of Time in den Fokus. Abschließend wird die Realisierungsebene (4.2.3) eingehender betrachtet. Hierbei sind v.a. reale und virtuelle Interaktionen, die mediale Narration, potenzielle personale Narrationen und die Spielertypen von Ocarina of Time von Belang. Um den Rahmen des ohnehin extensiven Analysesettings nicht allzu sehr zu strapazieren, beschränken sich die meisten Unterkapitel auf ein paradigmatisches Beispiel. Sollte es für die Argumentation erforderlich sein, so werden in gesonderten Fällen weitere Beispiele hinzugezogen. Dennoch verstehen sich die folgenden Analysen keinesfalls ausschöpfend, sondern lediglich als weiterer Schritt auf einem noch wenig beschrittenen Pfad.

\subsubsection{Analyse anhand der Attributebene}

Die Analyse auf der Attributebene wird etwas kürzer ausfallen, als Kapitel 2 dies vermuten lässt. Ursächlich hierfür ist, dass ein Großteil dieser Ebene auf das Diskursive konzentriert ist, das aufgrund des Forschungsdesigns dieser Arbeit keine Rolle spielt, auch wenn umfangreiche Betrachtungen der transmedialen Welt von The Legend of Zelda bisher ein Desiderat der Forschung sind. Dennoch lassen sich einige Feststellungen, die man anhand der Analyse von Ocarina of Time gewinnen kann, zumindest für die Hauptserie und somit für einen der bedeutendsten Aspekte der transmedialen Welt verallgemeinern. Dies betrifft z.B. die interaktiv-narrative Ausprägung von Ocarina of Time. Wenn man diese auf der Attributebene aus der Mikro-Mikroperspektive verortet, so ergibt sich daraus folgendes Bild: 
Interaktivität-Narrativität (Attributebene)

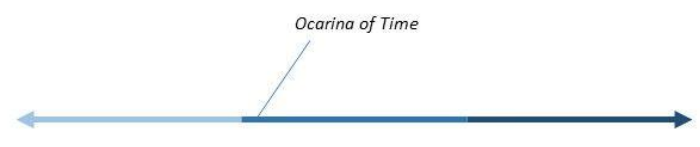

Interaktivität Interaktivität-Narrativität Narrativität

Abb. 9: Mikro-Mikroperspektive

Ungewöhnlich ist daran, dass das Action-Adventure als Genre eigentlich eine sehr intensive attributive Hybridität aufweist, also insgesamt die narrative Ausprägung der meisten anderen populären Vertreter dieses Genres stärker ist, als dies bei Ocarina of Time und der gesamten Hauptserie der Fall ist. ${ }^{453}$ Wie sich im Fortlauf der Analyse zeigen wird und wie es oben bereits angedeutet wurde, interpretiert Nintendo das Genre des Action-Adventures sehr interaktiv. Die Gründe dafür dürften einerseits in Miyamotos Konzentration auf aktives Erleben, Erfahren und Handeln durch den Spieler zu finden sein. Andererseits stellt sich aber auch die Frage, ob man es hier nicht mit einer kulturellen Besonderheit zu tun hat. Ist es ein Zufall, dass die meisten anderen populären Action-Adventure-Serien, die narrativer sind, westliche Produktionen sind? Zeigt sich hier eine japanische Besonderheit? (vgl. ConsALvo 2016) Dies wäre umso bemerkenswerter, da das japanische Rollenspiel z.B. stärker narrativ ausgeprägt ist als die westlichen Pendants. Wahrscheinlicher als Ursache für die besondere interaktiv-narrative Ausprägung von Ocarina of Time dürfte aber sein, dass es dem OpenWorld-Prinzip folgt. Dies gibt dem ludischen Handeln sprichwörtlich mehr Raum und damit

\footnotetext{
${ }^{453}$ Ocarina of Time stellt hier stellvertretend für die gesamte Hauptserie eine Art ,Mittelwert' dar. Das bedeutet, dass nicht alle Titel der Serie gleich interaktiv-narrativ sind. Diskursiv betrachtet weisen bspw. die Titel für die stationären Konsolen oft eine ausgeprägtere mediale Narrativität auf als diejenigen für die portablen Konsolen. Insofern bedarf es weiterer Analysen, um verlässliche Aussagen über die diskursive Interaktivität-Narrativität der Hauptserie treffen zu können, die sich nochmals anders darstellen, wenn alle digitalen Spielpublikationen der transmedialen Welt mit einbezogen werden. So müssten in einer derartigen Untersuchung u.a. die situativen Spielkontexte sowie die Leistungsfähigkeit der Hardware berücksichtigt werden. Da aber auch eine solche Studie kaum signifikante Abweichungen (mit Ausnahme der Titel für Non-Nintendo-Plattformen vielleicht) von der hier skizzierten Interaktivität-Narrativität erwarten lässt, werden derartige Überlegungen in der Folge vernachlässigt.
} 
auch mehr Zeit. Im Vergleich zur reinen ,Spielzeit‘ nimmt die Erzählzeit also ab. Vor dem Hintergrund, dass die meisten interaktiv-narrativen digitalen Spiele (wie auch Ocarina of Time) die mediale Narration an den Ludus binden, sinkt die mediale Narrativität logischer Weise, wenn die Zeit zum Erzählen weniger wird. Interessant ist dabei, dass die interaktivnarrative Ausprägung von Ocarina of Time zwar für ein Action-Adventure untypisch ist, dafür aber einem anderen Genre entspricht - dem Sandbox-Game. (vgl. dazu BEIL 2015, 52 ff.) Interaktiv-narrative Vertreter dieses Genres wie GTA (1997 ff.), Red Dead Redemption oder auch die Mafia-Serie (2002 ff.) haben eine ähnlich interaktive Ausprägung der interaktiv-narrativen Hybridität wie Ocarina of Time. Sie gewichten das Verhältnis interaktiver und narrativer Phasen nicht nur vergleichbar, sondern vertrauen alle auf das Open-World-Prinzip. Insofern kann man Ocarina of Time als Action-Adventure mit erheblichen Anleihen im Sandbox-Game begreifen. ${ }^{454}$ Die Einordnung von Ocarina of Time sowie der gesamten Hauptserie in diesem Abschnitt des Kontinuums wird anhand der folgenden Analysen deutlicher und von Ebene zu Ebene konkreter werden.

\subsubsection{Interaktivität und Agency in Ocarina of Time}

Für die Beurteilung der Interaktivität werden die drei Kriterien von Brenda Laurel herangezogen: Frequenz, Reichweite bzw. Bandbreite und Signifikanz. (vgl. LAUREL 1993, 20) Es soll in diesem Zusammenhang und im Sinne eines graduellen Interaktivitätsverständnisses aber nochmals deutlich gemacht werden, dass Interaktivität nicht nur dann gegeben ist, wenn alle drei Kriterien in einem hohen Maße vorhanden sind. Eine derartige Auffassung entspräche eher der „responsiveness“ bei Rafaeli. (RAFAELI 1988, 119) Es soll hier also nicht darum gehen, zu beurteilen, wie ,vollwertig' die Interaktivität in Ocarina of Time ist, sondern vielmehr darum, wie sie beschaffen ist, um den Weg für die Analysen zum Interaktiv und zur Interaktion auf den anderen beiden Ebenen zu bereiten.

Die Frequenz an interaktiven Handlungsoptionen ${ }^{455}$ ist in Ocarina of Time durchweg sehr hoch. Dies liegt letztlich aber auch daran, dass die Navigation durch die Spielwelt mittels der

\footnotetext{
${ }^{454}$ Zur Schwierigkeit einer eindeutigen Genrebestimmung bei Ocarina of Time Seth Sivak: „In OoT [Ocarina of Time] and most other Zelda titles, there is no single type or core gameplay. Instead there are several core gameplay mechanics that all come together in the world, making it almost impossible to truly classify under a particular standard subgenre. One of the reasons I feel OoT is so highly reviewed and considered one of the best games ever made is because it manages to wrap several gameplay mechanics all together inside a cohesive story that gives the player new challenges in a variety of different areas." SIVAK (2009), 300.

${ }^{455}$ Handlungen sind in Ocarina of Time durchweg physische Handlungen. So muss der Avatar laufen, angreifen, sich verteidigen und selbst die Kommunikation zwischen Avatar und NPCs werden als physische Handlungen ausgeführt. Zur Kritik an der ,Oberflächlichkeit” der ,Spielverben“ vgl. erneut RYAN (2014a) und SCHELL (2015).
} 
diversen Fortbewegungsmöglichkeiten die potenziellen Handlungsoptionen (gekoppelt mit den diversen Minispielen) enorm erhöht. Das bedeutet, dass die offene Spielwelt sowie die ausgiebigen Möglichkeiten, paidianisch $\mathrm{zu}$ spielen, $\mathrm{zu}$ einer hohen Frequenz an Handlungsoptionen führen. Dabei ist für Ocarina of Time aber kennzeichnend, dass die Frequenz und die Bandbreite an interaktiven Handlungsmöglichkeiten sehr eng miteinander verknüpft sind. Ein simples paidianisches Navigationsspiel soll dies verdeutlichen. ${ }^{456}$ Der Spieler hat die ersten drei Tempel der Kindheit durchgespielt, das Zeitportal geöffnet und befindet sich nun im Erwachsenenalter, wo er vor der Aufgabe steht, die sieben Weisen wiederzuerwecken, indem er deren Tempel vom Bösen befreit. In diesem Spielabschnitt verfügt der Spieler über das Maximum an Fortbewegungsoptionen. Angenommen, er wolle von ,Kakariko‘ zum ,Hylia-See' reisen. Er kann sich zu Fuß auf den Weg machen, um die Hylianische Steppe auf mehreren Pfaden zu durchqueren, er kann aber auch einen Schlenker über das ,Gerudo-Tal‘ machen oder via Tunnel vom ,Zora-Reich` aus zum Hylia-See reisen. Diese Möglichkeiten verändern sich, wenn er das Pferd,Epona' reitet, da er dann zwar nicht durch das Gerudo-Tal oder Zoras Reich einreisen kann, er hat dafür aber die Möglichkeit, Hindernisse zu überspringen, um das Navigationsspiel so zu einem Springparcours werden zu lassen. Als dritte Option verfügt der Spieler aber auch über die Fähigkeit, sich mithilfe der ,Serenade des Wassers' schlicht zum Hylia-See zu teleportieren. ${ }^{457}$

An diesem simplen Beispiel sehen wir, dass paidianisches Spielen in Ocarina of Time nicht nur hochfrequent, sondern auch reich an potenziell äquivalenten Handlungsoptionen ist. Mit Blick auf den Ludus stellt sich dieses Bild anders dar. Hier gibt es zwar auch Beispiele für eine hohe Frequenz und Bandbreite an Handlungsoptionen, diese sind aber eher selten. Eine der wenigen Ausnahmen ist der Bergpfad, den der Spieler nehmen muss, wenn er von Kakariko nach ,Goronia‘, die Stadt des Bergvolkes der ,Goronen', gelangen möchte. Hier muss er Felsen ausweichen bzw. Monstern, die ihn angreifen, wobei er bei letzteren auch die Möglichkeit hat, diese zu eliminieren. Des Weiteren kann er farmen, indem er Steine zerschmettert, wodurch er Items und Rubine erhält, die er für den Kampf bzw. für den Erwerb von weiterer Ausrüstung benötigt. Bei diesem Beispiel fällt aber auch auf, dass der Ludus ,paidianisiert‘ ist, da der Spieler das Beschriebene zwar alles machen kann, er muss es aber

\footnotetext{
456 Zur $\quad$ Orientierung vgl. $\quad$ diese $\quad$ Karte $\quad$ der $\quad$ Spielwelt http://strategywiki.org/wiki/The_Legend_of_Zelda:_Ocarina_of_Time/Maps (30.06.2018).

${ }_{457}$ Die Teleportationsoption (auch Schnellreisefunktion genannt) wird bei vielen digitalen Spielen mit offener Spielwelt mit zunehmender Spieldauer eingesetzt, damit das Durchqueren des Raumes spielrhetorisch nicht redundant wird. So erhält der Spieler entweder die Option, den Raum konkret zu durchschreiten oder ihn zu ,überfliegen“.
} 
nicht unbedingt, zumindest nicht zu diesem Zeitpunkt. Theoretisch kann er auch einfach nach Goronia laufen und allen Widersachern ausweichen und auch nichts farmen. Das Interaktiv verlangt zwar vom Spieler permanent stärker zu werden, will er den Ludus erfüllen, er muss dies aber keinesfalls an dieser Stelle vollziehen. Hierbei wird aber auch deutlich, wie sich Paidia-Spiel und Ludus-Spiel in Ocarina of Time gegenseitig aufeinander beziehen. So wird der Ludus paidianisiert, wie das Bergpfad-Beispiel gezeigt hat, umgekehrt wird aber auch das Paidia-Spiel ,ludisiert‘.

Dies kann man mit Blick auf die Bandbreite an interaktiven Handlungsmöglichkeiten sehr gut illustrieren. Im Kontext des Ludus offeriert Ocarina of Time nämlich stets nur eine einzige Handlungsoption, ${ }^{458}$ die der Spieler gezwungen ist, umsetzen, will er das Spiel nicht abbrechen. Vom Ludus her betrachtet ist Ocarina of Time also ein sehr lineares Spiel, das die Non-Linearität des Paidia-Spiels steuern muss, damit der Ludus nicht aus dem Blick des Spielers gerät. Dies gelingt, indem dem Spieler stets bewusst gehalten wird, dass er auch paidianisch spielend Items und Ausrüstungsgegenstände erhält, die er für die Meisterung des Ludus benötigt. Ein anschauliches Exempel hierfür sind die Dungeons. Neben den neun Haupt-Dungeons ${ }^{459}$ existieren nämlich diverse Mini-Dungeons, die zuerst für den Ludus ganz unerheblich zu sein scheinen, da man sie teilweise nur paidianisch spielend finden kann. Bei einer genaueren Betrachtung der Spielmechaniken wird aber deutlich, dass diese von großer Wichtigkeit für den Ludus sind, da sie nach erfolgreicher Meisterung den Spieler mit einem Item sanktionieren, das dieser zwingend benötigt, wenn er bestimmte Haupt-Dungeons absolvieren möchte. So ist der Wassertempel nicht vom Bösen zu befreien, wenn der Spieler nicht über die ,Eisenstiefel` verfügt, die er aber nur in der ,Eishöhle‘ erhalten kann und auch der ,Schattentempel‘ kann nicht durchgespielt werden, wenn der Spieler nicht das ,Auge der Wahrheit' sein eigen nennt, in dessen Besitz er wiederum aber nur gelangt, wenn er den MiniDungeon ,Grund des Brunnens‘ erkundet. Somit muss der Spieler letztlich alle Dungeons des

\footnotetext{
458 Seth Sivak beurteilt dies etwas anders, da er bspw. im Kontext der Heldenreise davon ausgeht, dass der Spieler den Ruf des Abenteuers sehr wohl ablehnen könne. Als Beleg führt er an, dass Link die Frage des DekuBaums, ob Link bereit sei, auch verneinen könne. Vgl. SivaK (2009), 319. Diese Weigerung bedeutet aber lediglich, dass der Spieler kurz ins Dorf Kokiri zurückkehren kann, um die Frage des Deku-Baums anschließend dennoch bejahen zu müssen, wenn er das Spiel nicht aufgeben will. Die Möglichkeit der Negation ist also eher eine ,Pseudo'-Option, zumal die Änderung der Haltung von Link als narrativem Charakter nicht plausibilisiert wird, wie dies z.B. in Star Wars der Fall ist. Luke gibt seine verweigernde Haltung, Obi Wan zu begleiten, nur auf, weil das Imperium seine Familie ermordet.

${ }^{459}$ Drei davon muss Link als Kind bewältigen (,Deku-Baum‘, ,Dodongos-Höhle‘ und ,Jabu-Jabus-Bauch`) und sechs als Erwachsener (,Waldtempel`, ,Feuertempel ${ }^{\star}$, ,Wassertempel`, ,Schattentempel', ,Geistertempel ${ }^{\star}$ und ,Ganons Schloss').
} 
Spiels meistern, um den Ludus erfolgreich zu bezwingen. Die Motivation des Spielers beim paidianischen Spielen wird also eingesetzt, um den Ludus durchzuspielen.

Da sich Paidia- und Ludus-Spiel (trotz der gegenseitigen Rekurse) in Bezug auf die Interaktivität in Ocarina of Time stark voneinander abheben, sollen Paidia- und LudusInteraktivität als Formen der explorativ-testenden ludischen Interaktivität kurz separat voneinander zusammengefasst werden. Die Ludus-Interaktivität zielt bei Ocarina of Time weniger darauf $a b$, dass Spielmechaniken, -regeln und -rhetoriken des Ludus aufgedeckt werden, wie dies in den Souls-Spielen die Regel ist. Die Grundzüge des Kampfsystems, die Bewegungsmöglichkeiten des Avatars (Rennen, Springen, Rolle, Rückwärtssalto etc.) und das Farmen werden bereits im Tutorial vermittelt. Gegnerische NPCs werden das ganze Spiel hindurch von der begleitenden Fee ,Navi‘ angezeigt und können via ,Lock-on` auch kameraperspektivisch fixiert werden, was das Entdecken ihrer Schwachstellen erleichtert. Zudem wird der Spieler permanent über neue Orte oder Items mit (textuellen) Informationen versorgt, sodass im Kontrast zu z.B. den Souls-Spielen schon fast ein Informationsüberschuss vorhanden ist. ${ }^{460}$ Die Ludus-Interaktivität in Ocarina of Time zeichnet sich also nicht durch die Entschlüsselung des Ludus aus, sondern durch das Einüben und Internalisieren von (auf den Ludus bezogenen) Interaktionen.

Die Paidia-Interaktivität hebt sich von der Ludus-Interaktivität dadurch ab, dass nicht nur die Handlungsoptionen und -muster aufgedeckt werden sollen, die für den Ludus relevant sind, vielmehr gilt es, möglichst alle Handlungsoptionen aufzuspüren, um den Möglichkeitsraum maximal auszudehnen. Was in Warren Robinetts Adventure (1979) mit einem Easter Egg begann, hat sich in Action-Adventures mit offenen Spielwelten wie Ocarina of Time vom Sidekick zum integralen Bestandteil des Spielprinzips erhoben. Simple Beispiele wie das Auffinden von Herzteilen, die sich zu einem Herzcontainer zusammensetzten lassen und hierdurch dauerhaft die Lebensenergie des Avatars erhöhen, zeigen dies bereits. Im Fall des Herzteils hinter dem Wasserfall im Gerudo-Tal ${ }^{461}$ verbindet sich das Erkunden der ansprechenden Spielwelt mit der Suche nach den sprichwörtlich lebensnotwendigen Herzteilen. Nicht nur aufgrund der Freude am paidianischen Spielen, sondern auch aufgrund der Relevanz dessen für den Ludus fordert das Spiel den Spieler unentwegt zum paidianischen Sidetracking auf. Garant hierfür ist die gekonnte Paarung aus

\footnotetext{
${ }^{460} \mathrm{Zu}$ Navis Funktionen im Spiel vgl. SIVAK (2009), 302.

${ }^{461}$ Vgl. dazu dieses Let's Play von ANGTFT https://www.youtube.com/watch?v=rv3NOLhLR_E (30.06.2018).
} 
offener Spielwelt und Spielmechaniken (v.a. Navigation und Farmen). Toni Fellela bringt das Markante der Paidia-Interaktivität von Ocarina of Time treffend auf den Punkt.

The side tasks of the game are endlessly enjoyable because they are not only made important by being essential to the ultimate completion of the game, but they are also immediately rewarding. [...] Although people are free, much more free than characters in a fixed storyline, restrictions exist in everday life just as they do in Zelda. The difference is that these real-life restrictions are more fluid and less transparent than they are in a videogame. (FELlELA 2009, 53 f.; Herv.i.O.)

Die Ausführungen über die Gewichtung zwischen Paidia- und Ludus-Interaktivität lassen sich auch in Bezug auf Laurels drittes Kriterium erhärten. So ist die Signifikanz von interaktiven Handlungsoptionen beim Paidia-Spiel potenziell sehr hoch, jedoch lässt sich nur im konkreten Einzelfall und in exakter Betrachtung der jeweiligen Realisierung und Evaluation durch den Spieler sagen, wie hoch sie genau ist. Während die Belohnung des paidianischen Spielens durch das Finden verborgener Orte oder Items in Ocarina of Time unmittelbar erfolgt und somit dessen Bedeutung direkt herausstellt, ist dies nicht unbedingt bei jedem individuellen Paidia-Spiel der Fall. So kann die offene Spielwelt z.B. für Gedankenspiele genutzt werden, die sich ähnlich wie personale Narrationen nur in der Wahrnehmung des Spielers niederschlagen. Wie signifikant die interaktiven Handlungsoptionen eines derartigen Paidia-Spiels sind, hängt letztlich vom kognitiven Horizont des spielenden Subjekts ab. Die Signifikanz von auf den Ludus bezogenen Handlungen ist in Ocarina of Time stets gegeben, da die Handlung des Spielers (bspw. Kampf gegen einen gegnerischen NPC), Evaluation durch das System (Schadensberechnung) und Sanktion (NPC stirbt, NPC stirbt nicht und muss weiter bekämpft werden oder Avatar stirbt) stets in einem unmittelbaren zeitlichen wie kausalen Zusammenhang stehen. Aufgewertet kann dies noch werden, wenn die positive Sanktion durch eine Cutscene verstärkt wird. Das vielleicht bedeutendste Beispiel in Ocarina of Time hierfür ist das Öffnen des Zeitportals. ${ }^{462}$ Hier werden die gesamten notwendigen Vorleistungen, die erforderlich sind, um das Portal zu öffnen, auf eine Handlung reduziert, welche gewissermaßen pars pro toto für den ersten Spielabschnitt dessen Signifikanz betont.

Über die Agency in Ocarina of Time lässt sich Ähnliches sagen wie über die Interaktivität. Um also Redundanzen zu vermeiden, möchte ich mich auf einen Aspekt von Handlungsoptionen beschränken, der aus der Perspektive der Agency deutlicher wird als aus der der Interaktivität. Freilich ist die Agency im Spiel nahezu allgegenwärtig, was v.a. auch

462 Vgl. dazu das folgende $\begin{array}{llll}\text { Let's } & \text { Play } & \text { von } & \text { BLUEKNIGHTNIGHT }\end{array}$
https://www.youtube.com/watch?v=Qt1NBnq35xY (30.06.2018). 
darin begründet liegt, dass sich die ,freie“ Navigation in einer offenen Spielwelt letztlich auch in einer hohen individuellen Agency manifestieren muss. Bei genauerer Betrachtung wird aber deutlich (und für die Interaktivität gilt im Umkehrschluss selbiges), dass die Handlungsmacht des Spielers via Avatar im Spielverlauf deutlich ansteigt. Bedingt durch das dominante Spielprinzip von Ocarina of Time erhält der Avatar nicht nur neue Items und Ausrüstungsgegenstände, neue Fähigkeiten und Fertigkeiten, vielmehr wird er auch stärker, indem seine Lebensenergie steigt und er vermehrt in der Lage ist, Feen einzusetzen, die ihn im Fall des Ablebens wiederbeleben können. Neben der offensichtlichen Tatsache, dass dieser sukzessive Ausbau der individuellen Agency des Avatars primär dazu dient, den Ludus erfolgreich zu meistern, trägt er aber auch dazu bei, dass neue Orte erreicht werden können, zu denen der Avatar ohne bestimmte Items keinen Zugang hätte. So kann die Wüste westlich der ,Gerudo-Festung، (wie viele andere Orte) nur dann vom Spieler erkundet werden, wenn er das Auge der Wahrheit besitzt. Passend zum mythologischen Narrativ, das den Weg der Prüfungen des Helden als narrativem Charakter beschreibt, von seiner Heldenwerdung und der damit einhergehenden Zunahme an Stärke berichtet, nehmen auch die Interaktivität und die Agency des Avatars zu. In einem interaktiv-performativen wie auch in einem narrativen Sinne wird Hyrule somit zu einem friedvolleren Ort oder, wie Blumenberg es ausdrückt: „Die Welt verliert an Ungeheuern. Sie wird in einem zunächst gar nicht ethischen, eher physiognomischen Sinne >freundlicher . Sie nähert sich dem Bedürfnis des dem Mythos zuhörenden Menschen an, in der Welt heimisch zu sein.“ (BLumENBERG 2006, 127) Der Avatar wird im Spielverlauf als narrativer Charakter und als interaktive Spielfigur mehr und mehr zum Erlöser und Weltenretter, was sich letztlich v.a. in der deutlichen Zunahme an (interaktiven) Handlungsoptionen niederschlägt. Auch wenn Ocarina of Time keine strukturellen, simultanen Verschmelzungen zwischen interaktiven und narrativen Elementen hervorbringt, so nutzt es dennoch strukturelle Äquivalenzen zwischen beiden, wie auf der Strukturebene genauer zu erörtern sein wird.

\subsubsection{Narrativität in Ocarina of Time}

Da sich bei der Fokussierung auf die Agency des Avatars auch die Gemeinsamkeiten zwischen narrativem Charakter und interaktiver Spielfigur angedeutet haben, scheint es ratsam, sich der Narrativität von Ocarina of Time zuzuwenden. Diese Ausführungen sind aber an dieser Stelle eher als einführend zu verstehen, da sie in den Kapiteln zum Narrativ (4.2.2.2), zur narrativen Figur (4.2.2.4.1.2), zur Erzählstruktur (4.2.2.4.2.2), zur Diegese (4.2.2.4.3.2), zur medialen Narration (4.2.3.2) und zur personalen Narrationen (4.2.3.3) noch 
dezidiert zu untersuchen sind. Deshalb beschränkt sich dieses Teilkapitel lediglich auf eine Hinführung zu Fragen der medialen und personalen Narrativität.

Grundsätzlich lässt sich konstatieren, dass Ocarina of Time zeitlich nur sehr limitiert auf den narrativen Modus zur Vermittlung zurückgreift. So wird der narrative Modus quantitativ am häufigsten in Form eines textuellen Erzählens via Textboxen eingesetzt. Dies ergibt sich aus Gesprächen, die zwischen dem Avatar und den NPCs stattfinden, wobei sich nicht jede Kommunikation zwischen Avatar und NPC als mediale Narration auffassen lässt. Es gibt Redebeiträge von NPCs, deren Sprachgestaltung rein informativ-deskriptiv aufgebaut ist. Dies trifft v.a. auf die Verkäufer ${ }^{463} \mathrm{zu}$, deren primäre ludische Funktion darin besteht, den Spieler über die Beschaffenheit und die Einsatzmöglichkeiten von angebotenen Items zu informieren. Figuren, die als Spielfiguren angelegt sind, die keine unmittelbare Rolle im Narrativ spielen, bedienen auch den narrativen Modus seltener als Figuren, die für das Narrativ relevant sind. Es hängt also offenbar von der Funktionalisierung im Narrativ ab, ob eine Figur auch im narratologischen Sinne, erzählt‘, oder ob sie lediglich berichtet. Betrachtet man bspw. Shiek, der in dem Erwachsenenalter die Rolle des Mentors von Link übernimmt, so fällt auf, dass dessen Redebeiträge oft narrativ gestaltet sind und Literarizitäts- und Fiktionalitätsmarker aufweisen. ${ }^{464}$ Dies zeigt sich auch daran, dass die narrativ beschaffenen Figuren in Ocarina of Time in den narrativen Cutscences vorkommen bzw. eine Verbindung zwischen textueller und visueller medialer Narration hergestellt wird.

Man muss zugleich aber auch anmerken, dass nicht alle Cutscenes im Spiel narrativ sind, sondern oft lediglich instrumentalisiert werden, um dem Spieler eine Orientierung im Spielraum zu geben oder die Atmosphäre aufzuladen. ${ }^{465}$ Somit bezieht sich nicht jede Cutscene unmittelbar auf die Diegese bzw. stellt deren Manifestation in audiovisueller Form dar. Darüber hinaus wird auch deutlich, dass nicht jede Form von Darstellung in Ocarina of Time narrativ erfolgt, sondern dass Bilder und bewegte Bilder als eigenständige (wenn auch

463 Vgl. dazu exemplarisch das folgende Let's Play von ROB124IN https://www.youtube.com/watch?v=IaJ70jeYkEY (30.06.2018). Interessant ist dieser Abschnitt, weil er auch eine der wenigen Ausnahmen darstellt, in denen die Ausführungen des Verkäufers zumindest teilweise als narrativ angesehen werden können. Allerdings trägt die Referenz auf den Wachsoldaten in Kakariko weniger dazu bei, die Figurenkonstellation zu profilieren, als vielmehr zu begründen, warum der Spieler einen Rabatt erhält. Dennoch kann die Referenz aber als ein narratives Rezeptionsangebot betrachtet werden, diese beiden Spielfiguren zu narrativen Charakteren der eigenen personalen Narration zu machen und die Erzählung somit um Figuren zu erweitern, die nicht zum narrativen Personal der medialen Narration gehören.

${ }^{464}$ Vgl. dazu exemplarisch die erste Begegnung zwischen Shiek und Link in der ,Zitadelle der Zeit' im Let's Play von WKCWAKKA https://www.youtube.com/watch?v=zh6813ehnXQ (30.06.2018).

${ }^{465}$ Dies trifft besonders auf die Cutscenes zu, die gezeigt werden, wenn der Spieler erstmals ein neues Areal der Spielwelt betritt. Vgl. dazu exemplarisch die Cutscene beim Betreten des Hylia-Sees im Let's Play von OCTANEBLUE https://www.youtube.com/watch?v=4hDa8kLwJos (30.06.2018). 
remedialisierte) Kunstform eine signifikante Rolle einnehmen, sich aber auch als solche narrationsinduzierend auf personale Narrationen auswirken können. (vgl. WoLF 2002) Wie schwach die mediale Narrativität in Ocarina of Time eigentlich ist, unterstreicht der Blick auf die quantitativen Anteile der narrativen Cutscenes an der Gesamtspielzeit. Oben wurde bereits festgestellt, dass sich die hohe Interaktivität des Spiels auch in einer hohen, reinen“ Spielzeit ausdrückt, die zu Lasten der Erzählzeit geht. Dieser zeitliche Überhang an interaktiven Phasen im Vergleich zu narrativen Phasen im alternierenden Perlenkettenmodell von Ocarina of Time lässt sich aber auch ,beziffern'. So beläuft sich die Gesamterzählzeit aller Cutscenes (je nachdem, welche man als narrativ und nicht-narrativ betrachtet) auf ca. eineinhalb bis zwei Stunden. ${ }^{466}$ Selbst wenn man hier den Höchstwert von zwei Stunden annimmt, ist der Unterschied zur Gesamtspielzeit immer noch erheblich. Der 89 Let's Plays umfassende 100\%-Walkthrough von ZELDA DUNGEON-INFORMER ${ }^{467}$ beläuft sich - alle Videos addiert auf über zwölf Stunden. Dabei ist zu beachten, dass er sich einerseits nur am Ludus orientiert und dementsprechend keine bzw. keine weitreichenden Paidia-Spielphasen beinhaltet, und dass er andererseits gerade jene navigierenden Abschnitte videotechnisch zeitraffend darstellt, die die Bewegungen des Avatars von einem Ort zu einem anderen umfassen. Das bedeutet, dass nicht nur paidianisches Spielen ausgeblendet und paidia-ähnliche Abschnitte gerafft werden, es heißt vielmehr, dass die Gesamtspielzeit in der Darstellung im Let's Play nicht der realen Gesamtspielzeit des Let's Players entspricht, die höher anzusetzen ist. Bedenkt man zudem, dass es sich bei diesem Let's Player um einen versierten Spieler handelt, der das Spiel (anhand seiner Spielweise und seiner Vorkenntnisse) offensichtlich bereits mehrfach durchgespielt haben muss, der die Interaktionen und Handlungsoptionen des Ludus bereits internalisieren konnte, so muss man davon ausgehen, dass eine realistische Gesamtspielzeit (je nach Fähigkeiten und Fertigkeiten des Spielers) von Ocarina of Time mit zwischen 15 bis 25 Stunden anzusetzen ist. Aber selbst wenn man den künstlich reduzierten Zeitwert annimmt, so zeigt sich, dass der Anteil der medialen Narration an der Gesamtspielzeit unter 17\% liegt, ergo eine erhebliche Differenz zwischen der Gesamterzählzeit und der Gesamtspielzeit besteht.

Freilich kann man anmerken, dass rein quantitative Faktoren nicht unbedingt direkte Rückschlüsse auf den konkreten Stellenwert eines Teilaspekts in einem größeren Ganzen erlauben müssen, da qualitative Gesichtspunkte hier zu Nivellierungen führen können. Jedoch

\footnotetext{
${ }^{466}$ Vgl. dazu exemplarisch das folgende Let's Play von JHNINGAMER, das aber auch teilweise nicht-narrative Cutscenes enthält https://www.youtube.com/watch?v=FX8YkcOeOfQ (30.06.2018).

${ }^{467} \mathrm{Vgl}$. dazu https://www.youtube.com/watch?v=i9OV4K05EHA\&list=PL8C7A9D9AD3CC39F8 (30.06.2018).
} 
ist eine derartige stichprobenartige Erhebung als ein erster Anhaltspunkt bereits aussagekräftig in Bezug auf die Gewichtung von interaktiven und narrativen Elementen innerhalb des Designparadigmas von Ocarina of Time. Dies auch qualitativ zu überprüfen, dem widmet sich im Besonderen die Analyse auf der Strukturebene. Jedoch lässt sich auch dort der an dieser Stelle gewonnene Eindruck bestätigen. Betrachtet man z.B., wie es weiter unten geschehen wird, das Figurenpersonal aus einem narratologischen Blickwinkel, so wird deutlich, wie wenig Figuren eigentlich Bestandteil der narrativen Figurenkonstellation des Spiels sind. Neben Link, Zelda und Ganondorf als Protagonisten und Antagonist gibt es sehr wenige Figuren wie Salia, ,Darunia‘, Prinzessin Ruto oder Shiek, die figurenkonfigurativ gesehen eine differenziertere Figurenkonzeption aufweisen, die zudem im Handlungsverlauf weiter profiliert wird. Zugleich ist es aber bemerkenswert, dass ein Spiel wie Ocarina of Time, dessen mediale Narrativität nachweislich deutlich schwächer ausgeprägt ist als die interaktiv-performative Gestaltung, dessen Fokus derart stark auf Interaktivität und Agency liegt, dennoch oft so stark narrativ wahrgenommen wird. Wie kann das sein? Wie ist es möglich, dass die personalen Narrationen der Spieler dabei oft solch starke Ähnlichkeiten aufweisen, obwohl gerade die - so dürfte man annehmen - Paidia-Interaktivität des Spiels dies unterlaufen müsste?

Ursächlich ist hierfür m.E. der Einsatz von narrativen Rezeptionsangeboten, die personale Narrationen steuern und somit eine gemeinsame intersubjektive Basis für personale Narrationen schaffen. Auch wenn die personale Narrativität von Ocarina of Time von Spieler zu Spieler variiert und stark davon abhängt, inwiefern die Narrationsinduktion gelingt, also nur am konkreten Beispiel untersucht werden kann, so ergeben sich dennoch Anhaltspunkte. Obwohl dieser Komplex weiter unten eingehender untersucht wird, so möchte ich dennoch vorab kurz auf ein zentrales narrationsinduzierendes Muster verweisen, das die folgenden Analysen gewissermaßen rahmt: die Reise. Die Reise als räumlich mehr oder weniger weit ausgreifendes Ereignis schlägt sich strukturierend in vielen verschiedenen Narrativen nieder. Allein das mythologische Narrativ und seine modernen Derivate werden von diesem kulturellen Muster organisiert. Wesentlich ist dabei die Dreiaktigkeit, die sich in den theoretischen Entwürfen verschiedener Intellektueller von Aristoteles bis Arnold van Gennep und Victor Turner wiederfinden lässt. Gemein haben diese Konzepte dabei auch eine bestimmte Regelhaftigkeit, die den Ablauf der drei Akte leitet. In der ersten Phase wird die gewohnte Lebenswelt des Protagonisten (freiwillig oder nicht) verlassen und der Weg in die zweite Phase, in das Ungewisse beginnt, ehe der Protagonist nach Vollendung der Reise in die 
gewohnte Heimat zurückkehrt. Der Grund, weshalb die Reise so oft Erzählungen (zumindest in Grundzügen) als organisierendes Muster dient, ist die Kombination aus formaler Geschlossenheit und thematischer Offenheit. Formal sind Reisegeschichten äußerst starr und kaum wandelbar in ihrer Form (durch den dreiaktigen Aufbau), wohingegen sie in ihrer inhaltlichen Gestaltung sehr flexibel sind. So können die Reiseanlässe, die Stationen der Reise und auch die dort vollzogenen Geschehnisse sehr verschieden sein. Dies macht sie besonders für Medienkontexte interessant, die dem Rezipienten eine hohe Agency zugestehen, aber dennoch eine intersubjektive Vergleichbarkeit zwischen personalen Narrationen erreichen wollen, damit solche Rezeptionserlebnisse auch kollektiv erfahrbar bleiben. Die formale Statik definiert demgemäß den Auftakt der Erzählung, den Verlauf und auch den Ausgang, obwohl die narrativierenden Subjekte zuweilen sehr unterschiedlich sein können. Dass diese Narrationen aber dennoch als ansprechend evaluiert werden, liegt daran, dass das Subjekt ihren Ablauf zwar nicht verändern, dafür aber gestalten kann. Das Subjekt erfährt die starke formale Einschränkung seiner individuellen Agency kaum, da es über eine hohe Agency in Bezug auf die inhaltliche Gestaltung verfügt. Um es mittels eines Gleichnisses auszudrücken - Nutzer sind in solchen Kontexten wie Innenausstatter eines Raumes. Im Unterschied zum Architekten oder Statiker können sie keinen Einfluss auf den strukturellen und formalen Aufbau des Raumes ausüben, sie können den Raum optisch aber nach ihren eigenen Wünschen gestalten. Auf diese Weise kann ein Raum sehr viele verschiedene Raumnutzungsund -gestaltungsformen erlauben, ohne dass sich der Raum an sich ändern muss.

Was für Räume im Allgemeinen gilt, besitzt auch für Möglichkeitsräume im Besonderen Gültigkeit. Der Normalnutzer kann nicht in die Architektur des Möglichkeitsraumes interaktiver Medienumgebungen eingreifen, jedoch ist dies für eine positive Evaluation des Mediennutzungserlebnisses auch nicht erforderlich, solange der Nutzer über die inhaltliche Gestaltungskompetenz verfügt. Möglichkeitsräume wie der von Ocarina of Time laden Spieler zwar dazu ein, Reisegeschichten zu erzählen, die formal gesehen identisch sein mögen, jedoch können sie inhaltlich sehr divers sein, vom Familienbesuch über eine Rundreise bis hin zur Weltenrettung. Die Architekten bleiben dabei nach wie vor die Designer. (vgl. JENKINS 2004) Es kann in solchen Kontexten zielführender sein, sich nicht zu enthusiastischen oder kritischen Stimmen zu verhalten, da es weniger (zumindest wenn man ideologische Implikationen extrahiert) darum geht, in solchen Mediennutzungsoptionen Formen der Freiheit oder Sklaverei zu sehen, vielmehr ist es bedeutsam, wie sich beide Seiten zueinander verhalten, indem man derartige Medienumgebungen als Symbiose aus 
Produzenten- und Rezipientenseite versteht. Darum wird es auch im Folgenden gehen, wenn auf der Strukturebene danach gefragt wird, welche und wie Architekten Bauwerke entwerfen und sich daran die Realisierungsebene mit der Frage anschließt, wie Rezipienten diese Bauwerke nutzen und (um-)gestalten.

\subsubsection{Attributive Hybridität in Ocarina of Time}

Die attributive Hybridität - also die Verschmelzung von Kulturformen und -techniken (vgl. 2.2.1) - stellt sich in Ocarina of Time mit Blick auf das Verhältnis zwischen interaktivperformativen und medial narrativen Phasen lediglich alternierend in Form des Perlenkettenmodells dar. Simultanität und Verschmelzung zwischen interaktiv-performativen und personal narrativen Phasen können vorkommen, hängen aber jeweils vom Einzelfall ab, auch wenn die Wahrscheinlichkeit der Generierung personaler Narrationen im Zusammenhang mit dem Spielen von Ocarina of Time sehr hoch ist. Verschmelzungen von Elementen innerhalb der medialen Struktur (wie in 2.2.2.1 skizziert) kommen gar nicht vor.

Die interaktiv-performativen Elemente dominieren eindeutig die repräsentativ-narrativen, was sich unmittelbar auf die Ludizität und Interaktivität-Narrativität von Ocarina of Time auswirkt. Seth Sivak merkt dazu an: „The story must support these transitions for the player and also tell a compelling narrative. OoT [Ocarina of Time] does this exceptionally well and is able to balance both the story of Link and the crafted narrative that players creates for themselves.“ (SIVAK 2009, 299) Auch wenn die Verlockung der medialen Narration von Ocarina of Time weniger in der Komplexität des Narrativs liegt und eher konventionelle Modelle des interaktiven Erzählens eingesetzt werden, so muss man Sivak doch beipflichten, dass es im Spiel dennoch ausgesprochen gut gelingt, mediale und personale Narrationen aufeinander abzustimmen bzw. zu induzieren. Im vorhergehenden Abschnitt wurde kurz darauf abgehoben, inwiefern die Reise als ein kulturelles Muster angesehen wird, das offensichtlich sehr geeignet ist, um personale Narrationen zu evozieren, weshalb sich letztlich auch viele strukturalistisch-formalistische Erzähltheorien dieser zuwenden. ${ }^{468}$ An dieser Stelle möchte ich aber den Fokus etwas verkleinern und untergeordnete Elemente betrachten, die aber auch im Kontext der Reise als Funktionselemente von Bedeutung sind: narrationsoffene interaktive und interaktionsoffene narrative Elemente.

\footnotetext{
${ }^{468}$ Neben offensichtlichen Beispielen wie Campbell und Vogler gehören auch Arbeiten wie diejenige von Propp in diese Kategorie, auch wenn er die Reise weniger explizit in den Vordergrund rückt. Aber auch die 31 narrativen Funktionen von Propp zeugen von der Bedeutung der Reise, die sich in seinen Funktionen nicht nur als eine in die Diegese darstellt, sondern auch als eine ins Innere des Protagonisten selbst, der sich finden und überwinden muss, um das finale Ziel der Aussöhnung zu erreichen, die in Hochzeit und/oder Thronbesteigung gipfelt. Vgl. PropP (1972).
} 
$\mathrm{Zu}$ den narrationsoffenen interaktiven Elementen zählt in Ocarina of Time (wie in den meisten Titeln der Serie) das Masterschwert. Spielmechanisch betrachtet ist es das - von der Schadensberechnung her gesehen - zweitstärkste Schwert im Spiel, bietet aber im Unterschied zum stärksten Schwert (dem Zweihänder, das man von dem goronischen Schmied ,Biggoron“ erhält) die Option, sich mittels eines Schildes noch verteidigen zu können. Narrativ wird es in der medialen Narration funktionalisiert, da es die einzige Waffe ist, die das Böse bannen kann. Insofern erhält es somit in den Augen der Spieler eine Aufwertung via narrativer Funktionalisierung, indem es zu einer heiligen Waffe stilisiert wird, die dringend benötigtes Hilfsmittel des Helden bei der Weltenrettung ist. Das Masterschwert fungiert also als interaktives Spielelement, nimmt aber auch als narratives Mythologem eine bedeutende Rolle in der medialen Narration ein. Darüber hinaus besitzt es aber ein erhebliches Potenzial, personale Narrationen induzieren zu können. Dies wird gewährleistet, indem die Auffindungssituation im ,Zeitenfels ${ }^{6}$ einen unmissverständlichen Bezug zu Excalibur darstellt. Der Rekurs auf die umfangreiche Sagentradition von König Artus ${ }^{469}$ stellt als narratives Rezeptionsangebot eine direkte Verbindung zwischen Link und Artus sowie zwischen Masterschwert und Excalibur her. Wie Artus sich dadurch als auserwählter Held würdig erweist, dass er als Einziger in der Lage ist, das Schwert aus dem Stein zu ziehen, so vermag es auch lediglich Link, das Masterschwert aus dem Zeitenfels zu entnehmen. Das Auserwähltsein des Helden drückt sich zudem auch darin aus, dass beide (Artus und Link) durch dieses an besondere magische Kräfte gelangen. Insgesamt dient dieses narrative Rezeptionsangebot einerseits dazu, die Profilierung Links als auserwähltem Helden zu schärfen und andererseits kann ein derartiges narratives Rezeptionsangebot auch die personalen Narrationen steuern. Oben wurde festgestellt, dass die Spieler zwar nicht in die formale Gestaltung der Reise als ,Metanarrativ` eingreifen können, dass sie aber über die Freiheit der thematischen Konfiguration verfügen. Dies wird aber geschickt durch Elemente wie das Masterschwert eingeschränkt, da es unmittelbar auf den mythologischen Kontext verweist und die potenzielle Diversität der personalen Narrationen somit in Richtung mythologischer Reiseerzählungen bugsiert, deren bekanntestes Exempel der Monomythos ist. Insofern vermögen es auch eigentlich interaktive Spielelemente, personale und mediale Narration synchronisieren zu können bzw. dazu beizutragen.

Interaktionsoffene narrative Elemente sind in Ocarina of Time eher rar, da genuin narrative Elemente im Spiel grundsätzlich seltener sind. Eines der anschaulichsten Beispiele hierfür

\footnotetext{
${ }^{469}$ Zur Figur des Artus in der Populärkultur vgl. OHLENDORF (2015).
} 
findet man dennoch in der Figur der Prinzessin Zelda. Anders als in Titeln wie Wind Waker, wo Zelda/Tetra Link im Endkampf gegen Ganondorf als ludischer NPC unterstützt, dieser also von beiden gemeinsam spielerisch überwunden wird, tritt sie in Ocarina of Time bloß als narrativer Charakter auf. Die Offenheit zu den interaktiven Komponenten des Spiels wird aber auf zweierlei Weise erreicht, die ich kurz darlegen möchte. Erstens (und ganz banal) ist Zelda jene Verbündete, die Link mit fundamental wichtigen Items ausstattet. So erhält Link von Zelda die titelgebende Okarina, durch welche er erst Zugang zum Masterschwert bekommt und sie ist es auch, die ihm die Lichtpfeile aushändigt. Somit ist sie jener narrative Charakter, der Link in den Besitz der beiden Items bringt, durch welche Ganondorf ludisch erst zu besiegen ist. Zweitens evoziert Zeldas Position in der Figurenkonstellation von Ocarina of Time extrinsische Handlungsmotivationen im Spieler bzw. unterstützt die intrinsische Motivation. Durch die Entführung ${ }^{470}$ Zeldas durch Ganondorf kurz vor dem finalen HauptDungeon wird z.B. auf das gängige Motiv der , damsel in distress ${ }^{4} 471$ abgehoben, das den Spieler dazu anregen soll, Zelda umgehend zu retten. Verhindert werden soll hierdurch ein paidianisches Spielen, da es von diesem Moment nicht mehr notwendig ist, um den Ludus zu meistern. Der Spieler hat kurz vor der Entführung von Zelda die Lichtpfeile erhalten und ist dementsprechend (spielstrukturell gesehen) in der Lage, Ganondorf zu besiegen. Paidianische Ausflüge erscheinen somit als überflüssig und werden durch die Jungfrau in Nöten auch narrativ als fernliegend inszeniert.

Dadurch wird auch eine entgegengesetzte Bewegung interaktiver und narrativer Elemente deutlich. Narrationsoffene interaktive Elemente wie das Masterschwert dienen in Ocarina of Time dazu, die mediale Narration weiter herauszuarbeiten und zu plausibilieren sowie aber auch personale Narrationen induzieren zu können, die diese in Richtung der mythologischen medialen Narration lenken. Zugleich versteckt sich hierhinter aber auch ein Plädoyer bzw. eine Ausrichtung auf das paidianische Spielen. Interaktionsoffene narrative Elemente wie Zelda hingegen fokussieren den Spieler auf den Ludus, da sie diesen mit benötigten Items ausstatten oder auf die Spielersteuerung in einer offenen Spielwelt einwirken, den Spieler anhalten sollen, dem Ludus zu folgen. Diese Absatzbewegungen verkörpern zugleich die

\footnotetext{
${ }^{470}$ Vgl. dazu das folgende Let's Play von MASAEANELA https://www.youtube.com/watch?v=2YkIEgS2xBA (30.06.2018).

${ }^{471}$ Dieses beliebte Motiv diverser Narrative findet auch oft im Monomythos Verwendung. Allerdings haben feministisch ausgerichtete Studien in den letzten Jahren berechtigterweise auf die sehr problematischen Implikationen derartiger Motive verwiesen, da die Inszenierung weiblicher Charaktere als Objekte männlichen Handelns verfehlte Geschlechterbilder perpetuiere. Vgl. dazu die Untersuchung von HAvSTAD/JAHNG (2009), die The Legend of Zelda unter feministischen Fragestellungen analysieren. Zu Frauen und deren Rolle in der digitalen Spielkultur vgl. den aktuellen Überblick von HAHN (2017).
} 
Unterschiede wie auch die Gemeinsamkeiten, die für die Oszillation zwischen interaktiven und narrativen Aspekten in interaktiv-narrativen digitalen Spielen im Kontext von deren attributiver Hybridität typisch sind. Die auf der Attributebene aufgezeigten Fäden weiter zu verfolgen und aufzulösen, wird Gegenstand der folgenden Analysen auf der Strukturebene sein.

\subsubsection{Analyse anhand der Strukturebene}

Im Rahmen der Analysen von Ocarina of Time auf der Strukturebene wird die Konzentration auf dem Designprozess liegen bzw. den im Designprozess implementierten Anlagen. Zuerst wird deshalb das Interaktiv betrachtet, (4.2.2.1) um Aussagen über Handlungsoptionen, das Interaktionsdesign, die Spielregeln und -mechaniken oder die Spielrhetoriken treffen zu können. Beim Narrativ (4.2.2.2) ruht der Fokus auf dem Monomythos als ordnende Instanz sowie dem modifizierten Reisemodell des Helden zur Analyse digitaler Spiele. Die Analyseergebnisse dieser Teilkapitel werden in 4.2.2.3 zusammengeführt, wenn es gilt, das mythologische Interaktiv-Narrativ von Ocarina of Time eingehender zu untersuchen. Hierdurch wird es möglich, die Funktionalisierung interaktivnarrativ polyvalenter Elemente im Design genauer betrachten $\mathrm{zu}$ können. (4.2.2.4) Abgeschlossen wird das Kapitel mit Ausführungen über das Designparadigma von Ocarina of Time, (4.2.2.5) die sich final aus den vorangegangen Analysen ergeben. Da das Analyseraster mit jedem Wechsel der Untersuchungsebene immer konkreter wird, so sollte auch hier mitbedacht werden, dass es ein Anliegen der Strukturebene ist, die Überlegungen, die aus den Beobachtungen der Attributebene resultieren, einerseits differenzierter zu überprüfen sowie identifizierte Erkenntnisinteressen weiter zu verfolgen.

\subsubsection{Das Interaktiv in Ocarina of Time}

Die folgende Analyse des Interaktivs ist einem zentralen übergeordneten Aspekt des Interaktivs eines digitalen Spiels verpflichtet: dem Spielprinzip. Bis hierhin ist der Begriff in dieser Studie verwendet worden, ohne ihn zu definieren. Dies ist schlichtweg der Tatsache geschuldet, dass er sich einleuchtender darlegen lässt, wenn er im Kontext konkreter wenn auch beispielhafter Analysen steht. Unter einem Spielprinzip verstehe ich nämlich das (das Design leitende) Muster von wiederkehrenden (interaktiven) Handlung(soption)en, Spielregeln, -mechaniken und -rhetoriken. Was dies intensional meint, wird in den folgenden beiden Teilkapiteln deutlich werden. Bereits Sivak erkennt und betont die Wichtigkeit der Wiederkehr von interaktiven Elementen für die Profilierung eines guten Spielprinzips. 
In OoT [Ocarina of Time] every mechanic is used more than once, but each time the mechanic is used it is given a deeper depth and challenge. This is what I consider to be a

Chain Gameplay (or a gameplay chain), as explained earlier. (SIVAK 2009, 300; Herv.i.O.)

Unter einem ,Chain Gameplay“ versteht Sivak: „The simple, repeatable game mechanics coupled with subtly ramping difficulty and complexity creates gameplay chains.“ (ebd., 299; Herv.i.O.) Er führt weiter aus: „A gameplay chain is any set of interlocking mechanics that must be done together in order to achieve a goal. [...] The chains can also be strung together as fractals creating larger chains that can span entire dungeons or even entire games." (ebd.) So aufgefasst rückt das ,Chain Gameplay‘ einerseits sehr nah an die ,Quest Chain` heran (vgl. DOMSCH 2013, 83) oder an das, was ich unter einer Spielstruktur verstehe. (vgl. 2.5.2.5) Entscheidend ist jedoch weniger, dass diese Verkettungen entstehen, die Frage ist vielmehr, warum und wie sie möglich werden. Neben dem Syntagma als offensichtliches Ergebnis des Designprozesses geht es eher darum, wie man sich innerhalb des Designprozesses der Paradigmen bedient hat, um hieraus jene Verkettung $\mathrm{zu}$ produzieren. Deshalb wird als übergeordneter Begriff der des Spielprinzips präferiert, da er diese Konstellationen mit umfasst. Dennoch kommt man nicht umhin, Sivaks Verdienste um die Analysen der Spielmechanik von Ocarina of Time zu betonen. Er identifiziert in seiner Studie vier zentrale Spielmechaniken, die die interaktiven Handlungsoptionen der Spieler bestimmen: Navigation, Lösen von Rätseln/Puzzeln, Kampf und Sammeln. (vgl. SivaK 2009, 301-314) Wie sich diese durch das Spielprinzip ausnehmen und kombinieren lassen, wird Augenmerk der folgenden beiden Teilkapitel sein, die sich mit der Definition von Handlungsoptionen und dem Interaktionsdesign (4.2.2.1.1) sowie den Spielregeln, -mechaniken und -rheotriken befassen.

\subsection{Handlungsoptionen und Interaktionsdesign}

Im Kapitel zur Analyse auf der Attributebene wurde bereits festgestellt, dass die individuelle Agency des Avatars unter dem Aspekt der Bandbreite an interaktiven Handlungsoptionen mit Blick auf den Ludus sehr gering ist. Es geht bei der LudusInteraktivität zudem weniger darum, Handlungsoptionen aufzudecken, sondern vielmehr darum, diese zu internalisieren. Deshalb erscheint es im Folgenden plausibler, sich der PaidiaInteraktivität zuzuwenden und wie sie in das dominante Spielprinzip von Ocarina of Time eingeschrieben wurde. Um dies zu zeigen, wird ein auf den ersten Blick recht unbedeutend wirkendes Beispiel gewählt, das aber unterstreicht, wie das dominante Spielprinzip von Ocarina of Time selbst unscheinbare Orte strukturiert. Als Exempel fungiert die ,Lon-Lon- 
Farm', die in Mitten der Hylianischen Steppe liegt und somit den geografischen Mittelpunkt von Hyrule bildet. Durch diese Positionierung innerhalb der Spielwelt wird sichergestellt, dass der Spieler sie sehr früh im Spielverlauf finden und erkunden wird, obwohl eine Farm angesichts der weitreichenden, fast schon kosmischen Dimension, die vom Konfliktfeld des Monomythos aufgemacht wird, nebensächlich und dementsprechend u.U. weniger besuchenswert erscheint.

Dennoch lässt sich gerade an diesem Ort in der Spielwelt sehr eindringlich schildern, wie die zentralen Spielmechaniken im Kontext des dominanten Spielprinzips miteinander verwoben werden. Es ist nämlich auffällig, dass auf der Lon-Lon-Farm alle vier Spielmechaniken zu finden sind und auch aufeinander Bezug nehmen. So kann der Spieler im Rahmen der Navigation alle Areale der Farm erkunden, was seinen Wunsch nach Exploration der Spielwelt befriedigen kann und ihn zugleich erst in die Lage versetzt, auf andere Spielmechaniken zurückgreifen zu können. Viele Spielmechaniken bzw. deren Trigger sind nämlich situativ gebunden, d.h. dass sie nur zu einem bestimmten Zeitpunkt und/oder an einem bestimmten Ort ausgelöst werden können. Somit zeigt sich, dass die Navigation nicht nur für Ludus und Paidia wichtig ist, sie ist auch spielmechanisch unerlässlich, da sie gewissermaßen eine Art ,Basisspielmechanik‘ darstellt.

Mit Blick auf das Lösen von Rätseln, Puzzeln oder Minispielen ${ }^{472}$ offenbart die Lon-LonFarm nämlich, dass Navigation erforderlich ist, um die Trigger einerseits zu finden, dass sie andererseits aber auch innerhalb der Spielmechaniken eine wichtige Rolle spielt. So kann Link in seiner Kindheit das ,Hühnerspiel‘ des Farmers spielen, bei welchem er drei spezielle Hühner, die sich optisch aber nicht von den anderen unterscheiden, mit diesen vermengt und der Spieler diese innerhalb von 30 Sekunden finden muss, um eine Belohnung zu erhalten. Die Spielmechanik dieses Rätsels ist also primär erinnerungs- und zeitbasiert. Der Spieler muss sich merken, wo in etwa sich die übrigen Hühner im Raum befinden und muss zudem aufmerksam beobachten, wo die speziellen Hühner nach Spielbeginn landen, was er aufgrund einer verzögerten Drehung aber nie gänzlich kann. ${ }^{473}$ Dem Faktor Zeit kommt an dieser Stelle

\footnotetext{
${ }^{472}$ Im Unterschied zu den meisten Puzzeln oder Rätseln verlangen die Minispiele oft einen bestimmten Einsatz, d.h. sie können nur gestartet werden, wenn die jeweils verlangte Summe entrichtet wird.

${ }^{473}$ Versierte Spieler werden aber recht schnell bemerken, dass es ohne weiteres möglich ist, die übrigen Hühner vor Spielbeginn in einer Ecke des Raumes zu versammeln, die die speziellen Hühner nie anfliegen, sodass das Rätsel ad absurdum geführt werden kann. Vgl. dazu das folgende Let's Play von UBERNoOBSCOMEHERE314 https://www.youtube.com/watch?v=D5W_6V2Hp3E (30.06.2018). Die Entdeckung dieser Handlungsoption (auch wenn sie keinesfalls die intendierte ist) zeugt zugleich aber von einer sehr paidianischen Spielweise, die die Programmstrukturen aller Rätsel zu erkunden sucht.
} 
aber nur eine untergeordnete Bedeutung zu, wie Sivak richtig herausarbeitet. „There are no puzzles in OoT [Ocarina of Time] that use time as the only underlying mechanic, but almost every other type of puzzle is made more intricate with addition of the timing mechanic." (ebd., 306) Die Komplexitätssteigerung durch die zeitliche Limitierung besteht lediglich darin, dass der Spieler unter Druck gesetzt werden soll, was dazu führen kann, dass die Wahrnehmung und Erinnerung des Spielers dahingehend beeinflusst werden können, dass er größere Probleme bekommt, das Rätsel zu lösen. Mit der Störung der Erinnerungsbasiertheit unterstützt die zeitliche Limitierung aber zugleich die Alea-Komponente dieses Spiels. Spieler, die bei diesem Spiel unter dem zeitlichen Druck in Stress und Panik geraten, neigen dazu, wahllos Hühner in der Hoffnung aufzunehmen, die drei richtigen zu finden. ${ }^{474}$ Auf diese Weise resultiert eine mögliche Lösung des Rätsels aber nicht aus den eigentlichen Lösungsfähigkeiten des Spielers, sondern allenfalls aus dem Zufallsfaktor. Dabei lassen sich in Bezug auf die Lösung des Rätsels zwei interessante Nutzungsweisen der Navigation durch den Spieler beobachten. Der rationale rätsellösende Spieler steuert direkt auf die speziellen Hühner (oder die, die er dafür hält) zu, wohingegen der panische Spieler wild umherläuft, um von einem Huhn zum nächsten zu gelangen, wobei ihn lediglich das Prinzip der räumlichen Nähe leiten wird. Im ersten Fall nutzt der Spieler den Spielraum sehr effizient aus, im zweiten Fall eher ineffizient. Bemerkenswert ist jedoch, dass die designerischen Anlagen des Interaktivs beide Navigationsarten innerhalb nur einer Spielmechanik gestatten, um die Varianz an möglichen Lösungsstrategien zu erhöhen.

Die Effizienz oder Ineffizienz der Raumnutzung lässt sich auch mit Blick auf den Kampf konstatieren. Als ,friedlicher Ort' (wie generell alle Dörfer oder Städte) treten auf der LonLon-Farm eher weniger Gegner in Erscheinung und wenn auch nur sehr schwache wie Krähen, die den Spieler in den hinteren Bereichen der Farm aus der Luft angreifen. Der effiziente Spieler, der die agonalen Interface-Eingaben bereits internalisiert hat, den Bewegungsrhythmus der Krähen kennt und weiß, wann er in deren Bewegungskurve im Sinkflug zuschlagen muss, wird sich diesen nähern und diese im richtigen Moment mit einem Schwertstreich niederstrecken. Der Spieler, bei dem die Internalisierung nicht so weit vorangeschritten ist, nähert sich oft zögerlicher und schreckt manchmal zurück, indem er ausweicht, um bei dem nächsten Sinkflug erneut zum Gegenangriff auszuholen. Vergegenwärtigt man sich die Raumnutzung unter dem Aspekt der Effizienz bei diesen

474 Die hier vorgenommene Differenzierung zwischen, rationalen' und ,panischen' Spielern stellt keine terminologisch exakte Distinktion dar, vielmehr soll sie im Zuge der folgenden Ausführungen dazu dienen, zwei tendenziell unterschiedlich agierende Spielertypen unterscheidbar zu machen. 
beiden Spielmechaniken, so muss man feststellen, dass sich relativ genau sagen lässt, was eine effiziente Raumnutzung in Ocarina of Time im Einzelfall konkret ist. Beim Hühnerspiel nimmt der rationale Spieler kurze Wege und steuert Hühner gezielt an, während der panische Spieler metaphorisch wie ein aufgescheuchtes Huhn umherläuft. Anders gesagt: Der rationale Spieler macht den Möglichkeitsraum klein und der panische Spieler vergrößert ihn (wenn auch ungewollt). Beim Kampf gegen die Krähen ist dies ebenso, da diese vom versierten Spieler direkt angesteuert und mit einer richtig getimten Eingabe in die Schnittstelle eliminiert werden, wohingegen der noch übende Spieler wieder den Möglichkeitsraum vergrößert, indem er sich kurz zurückzieht. Entscheidend ist hierbei jedoch stets die Evaluationsfähigkeit des konkreten Spielers, um die jeweilige Situation angemessen beurteilen zu können.

Dass es sich aber für den Spieler lohnt, diese Evaluationsfähigkeit auszubauen, verdeutlicht der Blick auf die letzte Spielmechanik: das Sammeln. Auf der Lon-Lon-Farm kann der Spieler besondere Items wie eine Glasflasche finden, Milch erlangen, die seine Lebensenergie generiert oder Gegenstände wie Herzteile und, goldene Skulltulas‘475 entdecken. Er kann aber auch simpel farmen, indem er Rubine sammelt. In Bezug auf das Sammeln von Rubinen wird der Spieler bereits im Kokiri-Dorf vom Interaktiv behavioristisch konditioniert, indem er lernt, dass man Rubine durch die Zerstörung von Büscheln oder Krügen erhalten kann, sowie dass es mehrere Wertigkeiten von Rubinen gibt. Dem Spieler wird somit im Rahmen intendierter Handlungsoptionen nahegelegt, diese Objekte erstens zu zerstören, um die gewünschten Rubine zu erlangen und zweitens darauf zu achten, höherwertige Rubine zu bekommen. Dabei wird ihm schnell bewusst werden, dass bestimmte höherwertige Rubine durch den Algorithmus immer wieder in bestimmten Objekten zu finden sind. In der Folge wird er (zumindest als rationaler Spieler) dazu übergehen, gezielt jene Objekte zu zerstören, von denen er weiß, dass sie höherwertige Rubine beinhalten. So kann er im Farm-Haus Krüge mit (blauen) Rubinen finden, deren Wertigkeit fünf Mal so hoch ist wie die des (grünen) Standardrubins. Um denselben Wert zu erhalten, müsste er mindestens fünf andere Krüge zerschlagen, wobei er nicht sicher sein kann, dass jeder Krug einen Standardrubin freigibt. Das bedeutet, dass der Aufwand mindestens das Fünffache der

\footnotetext{
${ }^{475}$ Die goldenen Skulltulas stellen ein ludisches Element in Ocarina of Time und im Nachfolger Majora's Mask dar, das v.a. eine Verbindung zwischen den Spielmechaniken des Sammelns und der Navigation schafft. Diese goldenen Spinnenwesen befinden sich an allen Orten der Spielwelt und müssen vom Spieler oft mühsam gesucht werden, zumindest dann, wenn er alle auffinden will. Das Suchen dieser Spinnen spricht somit das Sammelbedürfnis des Spielers an (wobei der Spieler immer wieder motiviert wird, indem es für eine bestimmte Anzahl gesammelter Spinnen Gratifikationen gibt), kann aber letztlich nur mithilfe einer paidianisch ausgerichteten Navigation geleistet werden.
} 
Handlung beträgt, die die Zerstörung des Kruges, der den blauen Rubin enthält, darstellt. Es ist dementsprechend zweifelsfrei effizienter, den Krug mit dem blauen Rubin zu zerstören.

Dies ist auch bezüglich der intendierten Handlungsoptionen interessant. Im Abschnitt zur Attributebene wurde oben festgestellt, dass intendierte Handlungsoptionen innerhalb des Ludus von Ocarina of Time nicht vorkommen. Jedoch lässt das soeben Ausgeführte berechtigte Zweifel hieran aufkommen. Gehören jene Spielmechaniken, gehört ihre Kombination durch das dominante Spielprinzip nicht auch zum Ludus? Aus diesem Grund scheint eine Differenzierung notwendig zu sein. So kann man zwar sagen, und so sollte die Darlegung auf der Attributebene verstanden werden, dass intendierte Handlungsoptionen in Bezug auf den Ludus als Queststruktur unter makroperspektivistischen Aspekten keine Rolle spielen, da es kaum mehrwertige Entscheidungssituationen gibt, die den Ludus auf einer Makroebene betreffen. Die Überlegungen zum Masterschwert oder zur ,damsel in distress“ haben aber gezeigt, dass es im Rahmen des Paidia-Spiel durchaus intendierte Handlungsoptionen und mehrwertige Entscheidungssituationen gibt. Dies lässt sich nun erweitern, indem man angesichts des Beispiels der Lon-Lon-Farm konstatieren kann, dass intendierte Handlungsoptionen nicht nur den Ludus affizieren können, sondern auch in ihn implementiert sind, da sie ins Interaktiv eingebunden sind und somit in Ludus und PaidiaSpiel gleichermaßen hineinwirken. Bemerkenswert ist dabei zudem, wie intendierte Handlungsoptionen herausgearbeitet werden. Bis hierhin wurde hauptsächlich die Moralität als Beispiel hinzugezogen, um zu demonstrieren, wie intendierte Handlungsoptionen im Designprozess herausgearbeitet werden können. Spätestens an dieser Stelle wir aber klar, dass es mehrere Möglichkeiten gibt, diese Handlungsoptionen $\mathrm{zu}$ profilieren. Die Funktionalisierung von moralischen Entscheidungssituationen ist dabei eine, die oft in interaktiv-narrativen digitalen Spielen Verwendung findet, da sie geeignet ist, eine Brücke zwischen Interaktion und Narration schlagen zu können. Die in diesem Teilkapitel erarbeitete Strategie der Definition von intendierten Handlungsoptionen ist hingegen eine rein ludische, wenn nicht sogar eine Art ,Urform` der Definition von Handlungsoptionen (zumindest im Kontext des Ludus): die Effizienz. Als Ludus sind Spiele Systeme, deren Autopoiesis auf Perfektion hinausläuft, wenn auch nur als Ideal. Um diese Perfektion erreichen bzw. die Illusion wahren zu können, dass dem so ist, wird die Effizienzsteigerung als Maxime im Interaktiv installiert.

Kaum ein Beispiel in Ocarina of Time verdeutlicht die Definition und Inszenierung von intendierten Handlungsoptionen sowie deren Niederschlag in Ludus wie Paidia-Spiel so 
prägnant wie die Link begleitende Fee Navi. ${ }^{476}$ Bereits ihr sprechender Name - Navi(-gation) - verweist auf ihre basale Funktion. Navi versorgt den Spieler mit Informationen über Gegner oder bestimmte Besonderheiten, sie ist es aber auch, die ihm immer wieder die nächste Station des Ludus in Erinnerung ruft. Auf diese Weise unterstützt sie die Basisspielmechanik Navigation und deren Einbindung ins Interaktiv des Spiels. Ihre textuelle Informationsvermittlung erfolgt dabei in Form eines (wenn auch sehr simplen) Rätsels. Wenn Link als Kind vor der Herausforderung steht, die Gunst des Goronen-Anführers ,Darunia“ erwerben zu müssen, so benötigt er dazu ,Salias Lied` bzw. dessen beruhigende Wirkung, um den aufgebrachten Herrscher zu besänftigen. Dass dies von Nöten ist, signalisiert Navi mit der enigmatisch anmutenden Anmerkung: „Was würde Salia wohl sagen...“ In dieser Form garantiert Navi, dass der Spieler auch in Anbetracht einer Vielzahl an paidianischen Handlungsoptionen niemals diejenige aus den Augen verliert, die für den Ludus relevant ist.

Man kann also festhalten, dass die Bedeutung der Definition intendierter Handlungsoptionen mit Blick auf Paidia-Spiele zwar weitreichender sein mag als beim Ludus, dennoch spielen sie im Kontext der zentralen Spielmechaniken sowie deren Kombination auch für den Ludus eine nicht zu unterschätzende Rolle. Ebenso gilt es zu bedenken, dass Paidia-Spiel und Ludus in der Zusammenschau dem Spieler derart viele Handlungsoptionen offerieren (zumal, wenn man bedenkt, dass nicht alle Haupt-Dungeons, die der erwachsene Link meistern muss, konsekutiv sind), dass es notwendig wird, explizite Steuerungselemente wie Navi im Interaktiv anzulegen, die sich von der eher impliziten Steuerung mittels moralischer Basiskonzepte abheben.

Dass moralische Basiskonzepte im Kontext der Inszenierung von intendierten Handlungsoptionen in Ocarina of Time eine so geringe Rolle spielen, liegt letztlich auch daran, dass das Interaktiv kaum explizit als Sanktionsinstanz auftritt. Wenn der Spieler in interaktiv-narrativen digitalen Spielen wie The Wolf Among Us sich gegen die als moralisch aufgewertete intendierte Handlungsoption entscheidet, so sanktioniert das Spiel dies oft nicht nur in Form der Auswertung am Episodenende, vielmehr treten auch Figuren wie ,Snow White' als Personifikationen des Interaktivs als Sanktionsinstanz in Erscheinung und konfrontieren den Protagonisten mit den Folgen und Auswirkungen von dessen Handlungen. Die Figurenkonzeption Snow Whites sowie die Figurenkonstellation zwischen ihr und Bigby

${ }^{476}$ In der Fankultur wird Navi meistens als sehr nervig empfunden, was oft Ausdruck im Rekurs auf ihren Ausruf ,Hey, Listen!' findet, dessen sie sich immer dann bedient, wenn sie Link auf bestimme Aspekte aufmerksam machen möchte. Vgl. dazu exemplarisch dieses ironische Fanvideo von MEGASTEAKMAN https://www.youtube.com/watch?v=jZY5owIvLBI (30.06.2018). 
verstärken durch die hierdurch bedingte emotionale Aufladung den Grad an Involviertheit und erhöhen somit die Wahrscheinlichkeit, dass der Spieler beginnt, seine eigenen Handlungen bzw. deren Maximen zu hinterfragen. Diese Form der negativen Sanktion gibt es in Ocarina of Time nicht. Die einzige negative Folge von ludischem Handeln ist das Game over, andernfalls erfolgt auf die Evaluation des Spielergebnisses stets eine positive Sanktion in Form einer Gratifikation. Gewinnt der Spieler das Hühnerspiel auf der Lon-Lon-Farm nicht, so erfolgt umgehend die Frage, ob der Spieler es nicht erneut versuchen möchte. Da die Rubine in den meisten Fällen ausreichen, um diese Handlungsoption zu realisieren und Minispiele nicht derart komplex sind, dass sie viele Wiederholungen zur Einübung verlangen, wird der Spieler in den meisten Fällen nach wenigen Versuchen erfolgreich sein, bevor seine finanziellen Mittel zur Neige gehen. Der Spieler scheitert zwar eigentlich und verliert das Minispiel, da aber umgehend die Aufforderung zu einer neuen Spielrunde ergeht, wird die Niederlage nicht unmittelbar offensichtlich, sondern erscheint als Etappe des Spiels, die i.d.R. mit dem finalen Sieg und der Gratifikation in Form einer mit Milch gefüllten Flasche endet. Andere Möglichkeiten der Sanktionierung im Rahmen des Interaktivs nimmt Navi vor. ${ }^{477}$ Wenn sie dem Spieler die nächste Station des Ludus immer wieder vor Augen führt, so ist dies auch eine Sanktion für allzu ,paidianisches' ${ }^{\circ}$ Spielen. Deshalb wäre es neben der offensichtlichen positiven Sanktion in Form von Gratifikationen für bestandene Quests in Ocarina of Time interessant, näher zu untersuchen, inwiefern Elemente wie Navi im Rahmen des Interaktivs eingesetzt werden, um spielerische Handlungen außerhalb der Quests (negativ) zu sanktionieren. Es ließe sich auch fragen, ob die negative Beurteilung Navis durch die Fans nicht letztlich auch daraus resultiert, dass sie die sichtbarste Oberfläche des sanktionierenden Interaktivs in Ocarina of Time ist, die den Spieler permanent dazu anhält, den paidianischen Möglichkeitsraum zu verkleinern. ${ }^{478}$

\subsection{Spielregeln, Spielmechaniken und Spielrhetoriken}

Anhand der beschriebenen, geschickten Kombination von Elementen des Interaktivs (u.a. Spielmechaniken und (interaktive) Handlungsoptionen) im Designprozess ist zutage getreten, dass Ocarina of Time spielrheotrisch als sehr gelungen angesehen werden kann. Um dies zu explizieren, bietet sich ein Kontrastbeispiel, welches man innerhalb der Hauptserie von The

\footnotetext{
477 Beachtenswert ist in diesem Zusammenhang, dass Navis Steuerungsversuche zuweilen einen ermahnenden Duktus aufweisen.

${ }^{478}$ Hier wäre es bspw. auch interessant, mediensoziologisch zu eruieren, ob Navi aufgrund ihres Ausrufs von Spielern als störend empfunden wird, oder ob dies auch damit zusammenhängt, dass sie derart explizit auf intendierte Handlungsoptionen verweist wie kaum ein anderes interaktives Spielelement in Ocarina of Time und deshalb derart negativ bewertet wird.
} 
Legend of Zelda findet. Skyward Sword weist eine ähnliche Queststruktur wie Ocarina of Time auf, vermag es aber nicht, die spielmechanischen Doppelungen und Wiederholungen wie Ocarina of Time zu verschleiern. So muss der Haupt-Dungeon ,Tempel des Himmelblicks' in Skyward Sword zwei Mal vom Spieler durchquert werden, da der Spieler zwei Mal die dahinter liegende ,Quelle des Himmelblicks‘ aufsuchen muss. Anstelle dem Spieler beim zweiten Besuch die Handlungsoption anzubieten, diesen Ort via Teleportation zu erreichen, lässt man ihn erneut auf Gegner in denselben Räumen treffen, die er beim ersten Besuch bereits von Gegnern ,befreit‘ hatte, sodass im Gameplay der Eindruck entsteht, diesen Dungeon mehrfach durchspielen zu müssen. Selbiges gilt auch für die Kämpfe gegen den ,Verbannten', der bei seinen Ausbruchsversuchen aus seinem magischen Gefängnis immer wieder gestoppt werden muss, wobei sich der Algorithmus kaum verändert, sodass der Spieler auch hier schnell das Gefühl gewinnen kann, er stehe vor einer Sisyphos-Aufgabe.

Dadurch wird deutlich, dass sich die Beruteilung der designerischen Qualität eines digitalen Spiels durch den Spieler aus einer Verbindung aus ästhetischen und technologischen Aspekten zusammensetzt. So müssen die Spielmechaniken nicht nur ästhetisch konsequent zusammengeführt werden, die technologische Umsetzung muss dies unterstützen. So kann man feststellen, dass Skyward Sword nicht nur eine defizitäre Verschleierung oder Neuanordnung von Spielmechaniken aufweist, vielmehr gelingt es ebenso der Algorithmik des Spiels nicht, dies aufzufangen. Im Gegenteil, die immer neuen Versuche des Verbannten, zu fliehen, wirken mit der Zeit langatmig und ermüdend. In Ocarina of Time muss der Gegner keine Dungeons erneut, durchspielen‘. Der einzige Dungeon, der in Ocarina of Time verlassen und wieder aufgesucht werden muss, ist der Geistertempel. Dieser verfügt nämlich über Areale, die Link nur als Kind oder nur als Erwachsener untersuchen kann, das bedeutet, dass der erwachsene Link durch die Zeit reisen muss, um als Kind in den Besitz des Items ,Silberne Handschuhe‘ zu gelangen, um dann nach der Rückreise durch die Zeit als Erwachsener den Tempel meistern zu können. Das mehrfache Aufsuchen des Tempels wird also motiviert und plausiblisiert, sodass es sich als Variation ins Interaktiv spielmechanisch integriert. Darüber hinaus ist auch die Algorithmik von Ocarina of Time dem Variantenreichtum des Interaktivs angemessen. Selbst kleinere und schwache Gegner wie die Fledermäuse zeigen im Spielverlauf eine Komplexitätssteigerung, indem sie von Feuer oder Eisflammen umgeben werden, sodass der Spieler sie nicht mehr (genau wie die Krähen) mit einem Schwertstreich niederstrecken kann, ohne durch die Elementflamme Schaden zu erleiden. (vgl. SIVAK 2009, 312) Diese Komplexitätssteigerung wird außerdem auch an die 
vier zentralen Spielmechaniken zurückgebunden. So ist der ,Wassertempel ' in Ocarina of Time für viele Spieler der vielleicht schwierigste Haupt-Dungeon, weil er ein einziges Rätsel, ein Raumrätsel ist. Die Spielmechanik des Rätsellösens verbindet sich mit der Navigation durch den Dungeon, dem Kämpfen gegen Gegner, die überwunden werden müssen, um bestimmte Areale zu erreichen sowie dem Sammeln von Gegenständen wie Schlüsseln, die manche Bereiche des Wassertempels erst zugänglich machen.

Diese spielrhetorische Variation, die mitverantwortlich für den künstlerischen Wert ist, den Fans und Fachkreise dem Spiel bis heute zuschreiben, manifestiert sich auch in der hohen Komplexität und Synergie von Spielmechaniken innerhalb von Quests in Ocarina of Time. Dies möchte ich an einem Beispiel illustrieren. Will der Spieler Biggorons Langschwert erhalten, so muss er die längste ,Quest Chain“ des Spiels absolvieren. ${ }^{479}$ Er muss für die Besitzerin der Hühner in Kakariko ein normales Huhn ausbrüten, dies gegen das blaue Huhn ihres Bruders eintauschen, diesen in den ,Verlorenen Wäldern` finden, von ihm einen Pilz und die Bitte erhalten, die Hexe in Kakariko aufzusuchen, um aus dem Pilz Medikamente für ihn herstellen zu lassen, mit diesen zu ihm zurückzukehren, ihn nicht mehr zu finden, dafür aber von einem Kokiri-Mädchen seine zurückgelassene Säge zu bekommen, diese bei seinem Vater, dem Chef der Zimmerleute, im Gerudo-Tal gegen das zerbrochene Biggoron-Schwert einzutauschen, den Schmied Biggoron bitten, dies zu reparieren, was dieser nicht kann, da er ein Augenleiden hat, mit einem Rezept für Augentropfen zum ,Zora-König‘ zu gehen, von diesem einen Frosch zu erhalten, welcher dem Labor-Chef am Hylia-See übergeben werden muss, damit dieser die Augentropfen produzieren kann, welche der Spieler nun zu Biggoron bringt, um ein Zertifikat für ein Schwert zu erhalten, welches einige Tage später abgeholt werden kann. Der Aufzählungscharakter dieser Beschreibung soll verdeutlichen, dass es sich nicht bloß um eine komplexe ,Quest Chain“ handelt, potenziell ist auch die Gefahr gegeben, dass sich diese Aneinanderreihung von Tauschgeschäften als monoton ausnimmt (wie in Skyward Sword). Dass dem nicht so ist, hat mehrere Gründe, die ich kurz ausführen möchte. ${ }^{480}$

Erstens fügen sich die zentralen Spielmechaniken des Spiels in Bezug auf das dominante Spielprinzip sehr abwechslungsreich zusammen. Der Spieler muss navigieren, um sich

\footnotetext{
479 Vgl. dazu exemplarisch das folgende Let's Play von ZELDAMASTER https://www.youtube.com/watch?v=mFMU2NLQF88 (30.06.2018).

${ }^{480}$ Abgesehen davon, dass es eine optionale Quest ist, die nicht zwingend gemeistert werden muss, um das Spiel durchzuspielen. Diese Quest ist also weniger ein Element der Ludus-Interaktivität als vielmehr der PaidiaInteraktivität.
} 
einerseits durch die Spielwelt zu bewegen und andererseits muss er navigierend die Spielwelt erkunden, um den Trigger für das nächste Kettenglied dieser ,Quest Chain` zu finden. Er muss aber auch geschickt dabei vorgehen, da manche Tauschgegenstände (Pilz, Frosch, Augentropfen) leicht verderblich sind und innerhalb eines fest definierten Zeitrahmens an ihren Bestimmungsort gebracht werden müssen, sodass hierdurch Druck auf den Spieler ausgeübt werden soll (man denke an das Hühnerspiel) sowie auch Rennelemente in die Quest integriert werden. Das Eruieren der richtigen Tauschpartner sowie die Suche nach denen rekurrieren auf das Lösen von Rätseln. Der Tausch von diversen Gegenständen hebt auf die Spielmechanik des Sammelns in einer Intensität ab, wie es für Quests in diesem Spiel ungewöhnlich ist. Der Kampf ist die einzige zentrale Spielmechanik, die innerhalb dieser ,Quest Chain“ kaum angesprochen wird, jedoch stellt die Implementierung von Rennelementen zumindest einen Rekurs auf die Agonalität dar, die für den Kampf kennzeichnend ist. Der Spieler ist also nicht direkt mit gegnerischen NPCs konfrontiert, er steht aber in einem Wettstreit mit dem Spielsystem, der sich im zeitlich terminierten Rennen widerspiegelt.

Zweitens bindet diese, Quest Chain“ via Navigation nahezu die gesamte Spielwelt von Hyrule ein. Der Spieler muss in den Norden, den Süden, den Osten sowie den Westen reisen, um final das gewünschte Schwert zu erhalten. Dabei ist jedoch die Frage, ob dies den Spieler eigentlich motiviert. Ist der Spieler bereit, eine derart langwierige Verkettung von Tauschgeschäften abzuschließen, nur um in den Besitz eines Schwertes zu gelangen, das er für das Meistern des Ludus gar nicht benötigt? Ein Blick auf Miyamotos Designphilosophie ist hier aufschlussreich.

The games [Miyamotos Spiele] are not about the resolution or the return with the hero's elixir. They are about the actions, the journey, and the time spent doing things in a world. Experiencing frustration and overcoming it through skill and practice are more rewarding than a well-crafted ending. (DEWINTER 2015, 46)

Jennifer deWinter hebt hier pointiert hervor, dass der Einsatz des Modells der Heldenreise in The Legend of Zelda für Miyamoto nicht dazu dient, den Spieler final zu motivieren, indem das Endziel der Heldenreise lockt. Der Weg wird stattdessen zum Ziel, das Reisen und alle interaktiven Handlungen, die sich damit verbinden sowie die Teilhabe an einer interessanten Welt. Die Internalisierung von Spielmechaniken und den Regelhaftigkeiten der Spielwelt ist die Belohnung des Spielers und nicht der erfolgreiche Abschluss dieser, Quest Chain“, es geht nicht darum, ein Schwert zu erlangen, es geht darum, den Weg dorthin zu genießen. Dass dies drittens gelingt, liegt auch daran, dass der Weg zum peripher werdenden Ziel mit 
Gratifikationen nahezu ,gepflastert‘ ist, sodass jedes Kettenglied seine eigene Belohnung in Form eines neuen Tauschgegenstandes enthält. In gewisser Weise sind Miyamotos digitale Spiele somit eine Vorausdeutung auf die überbordenden Belohnungssysteme aktueller Mobile und Browser Games, die heute den Casual Game-Markt bestimmen. Dass Miyamoto mehr als einmal als ,Vater der modernen Videospiele“ oder der Casual Games gefeiert worden ist, (vgl. ebd., 1-27) der digitale Spiele in Millionen von Haushalten auf der ganzen Welt brachte, liegt letztlich auch an seiner Fixierung auf das UX-Design. Miyamoto geht es nicht darum, welcher Spieler ein Spiel gewinnt, sondern darum, dass alle beteiligten Spieler den Spielprozess genießen. Sein Designparadigma hat dabei einen hochgradig systemischen Ansatz, wie auch deWinter bemerkt:

Miyamoto is not necessarily unique in focusing on experience design. In fact, this is what many game designers do: They turn experiences into systems. [...] In many ways, then, Miyamoto was able to switch his attention to experience design and simulations precisely because of the specific affordances of hardware, and this trajectory brings Miyamoto to Nintendo DS and Wii, two consoles that outsold competitors. (ebd., 58)

Dieser Ansatz von Miyamoto schlägt sich aber nicht nur auf Ebene der Hardware (von Plattformen bis hin zu Interfaces) nieder, sondern reicht auch tief in die Regelstruktur des Interaktivs hinein. Dies manifestiert sich darin, dass Regeln nicht explizit in Form von Verboten kommuniziert werden, sondern eher implizit und subtiler vermittelt werden, vermutlich mit dem Hintergrund, das Gameplay des Spielers nicht negativ zu beeinflussen. Mit Blick auf Ocarina of Time möchte ich dies unter zwei Gesichtspunkten umreißen, die bereits im Tutorial des Spiels dem Spieler vermittelt werden: die ,Physik-Engine‘ und die Moralität.

Die Physik-Engine, also die Art und Weise, wie Objekte in Programmen physikalisch simuliert werden und wie sie sich verhalten, wird in ihren grundlegenden Zügen dem Spieler bereits im Kokiri-Dorf nahegebracht. Wenn der Spieler nämlich explizit lernt, welche Spielmechaniken es im Spiel gibt und wie sie funktionieren, dann lernt er (mit Blick auf die Navigation) sogleich implizit aber auch, wie es dem Avatar gestattet ist, sich zu bewegen und welche Folgen Bewegungen für ihn haben. Kurzum: Er wird mit den physikalischen Gesetzen der Spielwelt vertraut gemacht. Intuitiv begreift er, dass sich sein Avatar in einer FantasyWelt befindet, deren Beschaffenheit sich deutlich von der der realen Welt unterscheidet, ${ }^{481}$ dennoch versteht er aber auch, dass sein Avatar denselben physikalischen Regelhaftigkeiten

\footnotetext{
${ }^{481}$ Philip Tallon merkt zu den Gemeinsamkeiten von Spiel und Fantasy an: „Games and fantasy both create worlds that are distinct from our own, but both highlight and make us increasingly aware of elements of this world.“ TALLON (2011), 65.
} 
unterworfen ist wie in der Welt außerhalb der Spielwelt. Ein Sturz aus großer Höhe fügt dem Avatar ebenso Schaden zu, wie er einen realen Menschen schädigt, wenn auch die ,Verletzung' des Avatars weitaus geringer ausfällt als die des realen Pendants. Interessant ist hieran für das Interaktiv als Sanktionsinstanz in Ocarina of Time nicht bloß, dass Spielregeln indirekt vermittelt werden, sondern dass ihre Vermittlung primär nicht-textuell abläuft. Stattdessen werden sie vorrangig spielmechanisch vorgeführt, in der Interaktion zwischen Spieler und System internalisiert.

Selbiges gilt auch für das zweite Beispiel. Moralische Basiskonzepte werden ebenfalls bereits im Kokiri-Dorf etabliert und auch dies geschieht implizit und primär nicht-textuell. Dies ändert aber dennoch nichts an deren Gültigkeit, die das ganze Spiel über Bestand hat. Versucht der Spieler z.B. im Laden etwas zu stehlen oder einen NPC im Dorf zu berauben, so muss er schnell feststellen, dass dies Interaktionen sind, die er nicht ausführen kann, da sie im Programmcode nicht angelegt sind. Er kann sich physisch (via Schlag, Vorwärtsrolle etc.) zwar anderen NPCs oder deren Habseligkeiten nähern, er kann diese aber nicht in seinen Besitz bringen, es sei denn, das Programm erlaubt (wie bei den soeben beschriebenen Tauschgeschäften) die Inbesitznahme. Auffällig ist hierbei, dass es sich ausschließlich um ,legale‘ Austauschprozesse, um eine Form des Tauschhandels prämoderner Prägung handelt eine Ware wird gegen eine andere getauscht, wenn beide als gleichwertig erachtet werden. Ebenso merkt der Spieler bereits im Kokiri-Dorf, dass er NPCs zwar mit dem Schwert attackieren kann, dass dieses aber schlicht durch diese durchgeht, dass das System beim versuchten Raub, Diebstahl oder Mord kein Feedback gibt. Auf dem Weg zum Deku-Baum muss er erkennen, dass dies aber nicht für alle NPCs gilt, da er die ,Dekuranhas‘ (riesige fleischfressende Pflanzen) sehr wohl attackieren darf. Ob er einen NPC angreifen darf, hängt nämlich davon ab, ob es ein freundlicher und neutraler oder ein feindlicher NPC ist. Die GutBöse-Dichotomie des Mythos teilt also nicht nur die narrativen Charaktere in ,gut und ,böse', sondern auch die Spielfiguren dementsprechend ein. ${ }^{482}$ Auf diese Weise schreibt sich der Mythos sehr deutlich in das moralische Regeldesign ein.

Das Interaktiv von Ocarina of Time zeigt sich somit als ein ethisch überaus geschlossenes System mit ,hohen' moralischen und ethischen Wertstandards, die die Figurenkonzeptionen des Monomythos unterstreichen. Dies wird zudem dadurch untermauert, dass es für den

\footnotetext{
${ }^{482}$ Navi als Element des Interaktivs unterstützt die Erkennung der Zugehörigkeit von NPCs zu einer der beiden Fraktionen, indem sie sich in der Nähe von , guten' NPCs blau färbt, wohingegen sie bei ,bösen' NPCs eine gelbe Färbung einnimmt.
} 
Spieler keine Möglichkeit gibt, diese Standards zu subvertieren, noch werden sie im Spiel wirklich reflektiert oder kritisch diskutiert. So werden dann auch Ganondorf und seine Verbündeten unzweifelhaft als ,böse' markiert, da sie die einzigen NPCs sind, die permanent gegen jene moralischen Basiskonzepte verstoßen. Derart wird der gesamte Rest der NPCs der Spielwelt von Hyrule als ,gut‘ herausgestellt, da sie moralisch integer erscheinen. „What or who is the immediate source for morality in Hyrule and why does this matter? The immediate source is the game creator, the game designer(s).“ (DEVAN 2011, 139) Im Anschluss an den Theologen Benjamin B. DeVan kommt man nicht umhin, festzustellen, was es bedeutet, wenn ein Spiel ,ein ethisch geschlossenes System“ im Sinne SICARTs (2009) ist - ein im Designprozess entwickeltes und dem Spieler aufoktroyiertes Set an Werten und Normen, die den Spieler zur (bedingungslosen) Akzeptanz zwingen. Die Spielwelt Hyrule als ,soziale Welt' unterbindet als amoralisch definierte Handlungen vollends gemäß eines strikten Kanons moralischer Basiskonzepte, der fast schon sklavisch verfolgt wird. ${ }^{483}$ Diese moralisch höchst normative Anlage des Interaktivs findet auch, wie oben bereits angedeutet, einen erheblichen Niederschlag im Narrativ.

\subsubsection{Das Narrativ in Ocarina of Time}

Das Narrativ von Ocarina of Time ist (wie weiter oben schon erörtert) ein mythologisches Narrativ im Sinne des Monomythos. (vgl. 3.2) Die Konjunktur dieses Narrativs und der damit verbundenen Inhalte und Funktionen ist Ausdruck - wie Aleida und Jan Assmann feststellen einer „mythophil[en]“ Zeit. (Assmann/Assmann 1998, 197) Dass diese Aussage des Forscherpaares Assmann keineswegs unzutreffend als Charakterisierung des gegenwärtigen Umganges von Menschen mit mythologischen Elementen gelten kann, zeigt auch das offenkundige Vorhandensein dieser Elemente in The Legend of Zelda. Dabei ist jedoch (wie oben ebenfalls betont) keinesfalls nur die Produzentenseite von Belang, sondern auch die Rezipientenseite sowie die Dependenzen und Interaktionen zwischen diesen.

Miyamoto planned for this, designing a game for which one of his objectives was that people would talk to one another about it. Thus, communities could form around imagined places, building mythologies and narratives that have lasted for the previous thirty years. (DEWINTER $2015,47)$

\footnotetext{
${ }^{483}$ In dieser Hinsicht wirkt Ocarina of Time gegenüber aktuelleren digitalen Spielen, die moralische Dilemmas mit mehrwertigen Entscheidungen verbinden, fast schon ,altmodisch'. Ein Aspekt, der bei dieser Analyse ebenfalls außen vorbleiben muss, ist (bedingt durch das Fehlen des betreffenden Modus in Ocarina of Time), die Komplexität moralischen Verhaltens in Mehrspielersituationen, die Art und Weise der Aushandlung abweichender moralischer Standards und Ansichten.
} 
Diese moderne Mythenbildung durch Fans ist (wie deWinter richtig hervorhebt) aber auch ein Resultat einer durchaus Produzenten intendierten Induktion einer Mythenproduktion, die in der Mythophilie der diversen produzentengesteuerten medialen Kanäle dieser transmedialen Welt ihren Ausgangspunkt hat. So instrumentalisiert The Legend of Zelda einerseits - v.a. beim Interaktions- und UX-Design - intensiv mythologische Funktionen, um Spieler zu beeinflussen oder das Gameplay zu intensivieren. Hierauf wurde auch bereits mehrfach abgehoben und es wird auch eine große Rolle bei den Analysen der folgenden Teilkapitel spielen. Worauf bisher aber weniger eingegangen wurde, sind die substantialistischen Aspekte. Aus dieser Perspektive heraus kommt man nicht umhin, zu konstatieren, dass The Legend of Zelda diverse Inhalte, Themen und Motive von Mythen oder verwandten Gattungen amalgamiert. Mittelalterliche Sagen und Legenden (z.B. die ArtusSage) werden ebenso einbezogen, wie der ,Kanon“ europäischer und südostasiatischer Mythologien, Tolkiens Fantasy-Welten ${ }^{484}$ oder der Shintoismus. ${ }^{485}$ Wollte man also die Mythologie von The Legend of Zelda substantialistisch bestimmen oder definieren, so müssten man von einem ,Patchwork-Mythos ${ }^{\text {‘86 }}$ sprechen. Eine derartige Auffassung entspricht einerseits Miyamotos Fokussierung des Monomythos auf Aspekte des Erlebens und Erfahrens und andererseits dem hochgradig divers entlehnenden Charakter von The Legend of Zelda als transmedialer Welt. Da diese Arbeit aber keine dezidiert religionswissenschaftliche ist, werden die einzelnen Quellen und Referenzen der Entlehnungen nur dann thematisiert, wenn sie von unmittelbarer Notwendigkeit sind. Notwendig ist in diesem Zusammenhang auch, darauf hinzuweisen, dass The Legend of Zelda in Bezug auf seine Verwendung mythologischer Inhalte nicht als paradigmatisch für die gegenwärtige japanische Medienkultur und auch nicht für das japanische Fantasy-Genre angesehen werden kann, was sich doch sehr von dem im Westen (von Tolkien maßgeblich geprägten) unterscheidet. Der folgende kurze Exkurs möchte dies verdeutlichen.

\footnotetext{
${ }^{484} \mathrm{Zu}$ dem Verhältnis zwischen Tolkiens Werk und der transmedialen Welt von The Legend of Zelda vgl. TALLON (2011). Vgl. in diesem Zusammenhang exemplarisch die Parallelen zwischen dem Triforce und dem ,einen Ring‘ sowie zwischen Ganondorf und Sauron. Ebd., 63.

${ }^{485}$ Shintō ist eine animistische und polytheistische japanische Religion, die neben dem Buddhismus die meisten Anhänger in Japan hat. Da die diversen Glaubensvorstellungen und Rituale sehr verschieden sind, ist es zuweilen schwer, diese als dem Shintō zugehörig identifizieren zu können. Insofern ist der Shintō ein eklektizistisch anmutendes Sammelsurium und daher in seinem Erscheinungsbild recht heterogen. Einführend zum Shintō vgl. LOKOWANDT (2001). Was viele Ausprägungen des Shintō aber eint, ist die Ahnenverehrung sowie der starke Bezug zur Natur. Zur Bedeutung des Shintō für Miyamoto und dessen Rolle in seinen Werken vgl. DEWINTER (2015), 14.

${ }^{486}$ Als Analogon zum Begriff der ,Patchwork-Religion', die sich auf das Innere des Subjektes bezieht, um „bestimmte Wirkungen im religiösen Subjekt“ auszulösen. Vgl. dazu HöHN (2006), 3-5.
} 
In der japanischen Populärkultur ist The Legend of Zelda jenen (wenigen) Werken zuzuordnen, die stark auf die europäisch-substantialistische Mythentradition ${ }^{487}$ und den Monomythos rekurrieren. ${ }^{488}$ Dadurch kommt der Spielserie ein gewisser ,Sonderstatus“ innerhalb der gegenwärtigen japanischen Medienkultur zu, da v.a. viele Anime wie z.B. Inu Yasha (2000-2010) zwar einerseits (ebenso wie The Legend of Zelda) von mythologischen Elementen durchzogen sind, welche sich aber fast ausnahmslos aus südostasiatischen Mythologien und Religionen speisen. ${ }^{489}$ Andererseits entziehen sich Anime wie Inu Yasha zudem weitestgehend der Gut-Böse-Dichotomie, die die Figurenzeichnungen des Monomythos in der westlichen Welt auch heute noch bestimmt. Die Figuren sind in Anime wie Inu Yasha wesentlich ambivalenter gestaltet, ihr Handeln und ihre Motive sind von Ambiguität geprägt, was sich letztlich in eher antonymen als dichotomischen Figurenkonzeptionen niederschlägt. Inu Yasha, die Priesterin Kikyō, die Dämonenjägerin Sango und selbst der Antagonist Naraku sind vielschichtige Charaktere, die die Verantwortungsadressaten und Sanktionsinstanzen ihres Handelns im Handlung sverlauf z.T. mehrfach ändern. ${ }^{490}$

Im Vergleich zwischen The Legend of Zelda und Inu Yasha fällt auf, und der Seitenblick auf westliche Filmserien wie Star Wars oder Der Herr der Ringe legt dies ebenfalls nahe, dass Werke, die dem Monomythos (westlicher Prägung) folgen, eher zu statischen und weniger zu dynamischen Figurenkonzeptionen neigen. Neben dem Helden des Monomythos durchlaufen kaum andere Figuren einen signifikanten Wandel im Handlungsverlauf, was gerade für viele erzählerische Werke der japanischen Populärkultur nicht gilt. Selbst Main Stream-Anime wie Naruto Shippūden (2007-2017) oder One Piece (1999 ff.) entwerfen

\footnotetext{
${ }^{487}$ Anleihen aus der europäischen Mythentradition finden sich in zahlreichen mythologischen Archetypen und Mythologemen, die in Ocarina of Time auftreten. So stellt die Episode in ,Lord Jabu Jabus' Bauch eine Verbindung zur biblischen Tradition her, die Eule Methusa verweist einerseits auf die Weisheit der Athene sowie andererseits auf die Gorgone Medusa, nimmt also in doppelter Weise Bezug auf die griechische Mythologie. Die Hylianer als Elfenvolk wiederum greifen auf die nordische Mythologie zurück und Links Pferd Epona trägt denselben Namen wie die römische Pferdegöttin. Diesen Patchwork-Charakter der Mythologie in The Legend of Zelda zu untersuchen, ist aber Aufgabe einer religionswissenschaftlichen Studie, die die substantialistische Gestaltung konkret in den Blick nimmt.

${ }^{488}$ Vielleicht ist hierin auch ein Grund für den globalen Erfolg von The Legend of Zelda zu sehen. Im Vergleich zu anderen ,japanischeren' japanischen Medienprodukten entspricht Miyamotos Werk nämlich eher den Präferenzen des mythophilen westlichen Fantasy-Fans.

${ }^{489}$ In Inu Yasha spielen z.B. Entitäten der japanischen Mythologie wie Yōkai (Gruppe von diversen Monstern und Ungeheuern) oder Oni (Gruppe von Ogern, Dämonen oder teufelsähnlichen Wesen) eine zentrale Rolle. Einführend zur japanischen Mythologie vgl. NAUMANN (2011). Zur japanischen Kultur im Allgemeinen sowie deren Mythologie im Besonderen ist auch LÉVI-STRAuSS (2013) überaus lesenswert.

${ }^{490} \mathrm{Zu}$ Verantwortungsadressat und Sanktionsinstanz vgl. SCHMIDT-RELENBERG (1970).
} 
dynamischere Figuren als vergleichbare westliche Produktionen. ${ }^{491}$ Zwar spielt auch in Anime, Manga oder interaktiv-narrativen digitalen japanischen Spielen der Konflikt zwischen ,Gut` und ,Böse‘ oft eine zentrale Rolle, dieser wird aber nicht, wie im Monomythos, als Kampf zwischen ,guten“ und ,bösen“ Figuren als Personifikationen der beiden Kräfte dargestellt. Vielmehr geht es um das Ringen zwischen beiden im Inneren der Figur. Dies wird auch daran deutlich, dass oft Analepsen eingesetzt werden, wenn Naruto bzw. Ruffy (Protagonisten der beiden letztgenannten Anime) vor einer fundamentalen Herausforderung oder Entscheidung stehen, die einen Bogen zwischen Vergangenheit und Gegenwart der Figur spannen, wodurch die Diffizilität der Entscheidungsfindung für die Figur ausgestellt wird. ${ }^{492}$

Diese Unterschiede gilt es in den folgenden beiden Teilkapiteln mitzudenken. Dabei wird es zuerst darum gehen, wie der Monomythos ordnend und strukturierend wirkt. (4.2.2.2.1) Im Anschluss daran gilt der Fokus der Betrachtung der konkreten Analyse von Ocarina of Time anhand des modifizierten Reisemodells des Helden. (4.2.2.2.2)

\subsubsection{Der Monomythos als ordnende Instanz}

Die ordnenden Wirkungsweisen von Narrativen zeigen sich in Nintendos digitalen Spielen nicht nur als mythologisches Narrativ in The Legend of Zelda, sie sind auch in digitalen Spielen wie Donkey Kong (1981) zu finden, dessen rudimentäre, rahmende mediale Narration eine unmissverständliche Referenz auf King Kong und die weiße Frau (1933) darstellt, sodass der Spieler intuitiv das Setting versteht und weiß, wie er handeln muss. ${ }^{493}$ Ursächlich hierfür ist das verbindende Element dieser Spiele - Shigeru Miyamoto.

I have been a big fan of comics since I was a young boy and so one idea I had in creating that game [Donkey Kong] was to apply little bit of story to it in order to help people understand the concepts of the game better. It was a similar way to what you see with comics. (Miyamoto zit. n. DEWINTER 2015, 23) $)^{494}$

\footnotetext{
${ }^{491}$ Man denke hier exemplarisch an Filme wie Kampf der Titanen (2010). Eine der wenigen Ausnahmen in der westlichen Populärkultur bieten hier A Song of Ice and Fire (1996 ff.) bzw. Game of Thrones.

492 Dies kommt u.a. dann zum Tragen, wenn Naruto auf seinen Freund Sasuke trifft, der sich aus einer Gemengelage an Gründen entschieden hat, sein Dorf zu verlassen und aus der Ninja-Gemeinschaft auszutreten, um seine eigenen Ziele mit Mitteln zu verfolgen, die Naruto ablehnt. Vgl. dazu den Kampf zwischen beiden in den Folgen $446 \mathrm{f}$.

${ }^{493}$ Er kann hierdurch sogar bereits Annahmen über die Beschaffenheit der Spielwelt treffen, denn da King Kong Ann auf das Dach des Empire State Buildings verschleppt, so kann der Spieler, was auch der Fall ist, davon ausgehen, dass er sich von unten nach oben bewegen muss, um die ,damsel in distress ${ }^{6}$ zu retten.

${ }^{494}$ An dieser Stelle soll kurz erwähnt werden, weil es im obigen Abschnitt zu Miyamotos Inszenierung in Interviews unterblieben ist, dass die Inszenierung bzw. die inszenierenden Passagen zwar für die Forschung schwer auf ihren Wahrheitsgehalt hin zu bewerten und dementsprechend problematisch sind, dass dies aber keinesfalls für seine Interviews im Allgemeinen gelten darf. Seine Ausführungen zu seinen Werken aus einer designerisch-ästhetischen Sicht sind wichtige Quellen für die Erforschung seiner Werke, deren Aussagen sich oft mit den designerischen Anlagen der Spiele selbst decken.
} 
Die eher interaktive Ausrichtung von Nintendos interaktiv-narrativen digitalen Spielen hängt somit maßgeblich mit Shigeru Miyamotos Ansichten über die Rolle von Narrativität in digitalen Spielen zusammen. Im Rahmen seiner Fokussierung auf das UX-Design dienen narrative Elemente und Strukturen in digitalen Spielen lediglich dazu, dass die Spieler das Konzept oder das dominante Spielprinzip des jeweiligen Spiels besser verstehen. „When discussing The Legend of Zelda, he has famously stated that he is more interested in gameplay than narrative, asking his development team to cut back on the narrative elements." (ebd., 25; Herv.i.O.) Mediale Narrativität ist in digitalen Spielen für Shigeru Miyamoto bloßes Beiwerk, sie ist ein Mittel zum Zweck, um das Gameplay zu intensivieren. ${ }^{495}$ Dies ist eine Tendenz, die im Laufe von Miyamotos Schaffenszeit immer weiter zunimmt, wie Jennifer deWinter herausarbeitet. „This emphasis on experience over narrative becomes even more prevalent in later games, such as Nintendogs (Nintendo 2005), which offers players a cute simulation of dog ownership without any of the negative experiences often associated with real-life pets.“ (ebd., 24; Herv.i.O.)

Dies kann als ein ernüchterndes Urteil betrachtet werden, zumindest dann, wenn man sich Miyamotos Werk nur aus einer narratologischen Perspektive ansehen möchte. Dies würde weder dem Werk noch den Ansichten seines Schöpfers entsprechen. Zugleich ist The Legend of Zelda als sein wohl ,narrativstes “ Werk dennoch ein viel interessanteres Beispiel für hybride Analysen, die auch die Narratologie miteinbeziehen, als viele digitale Spiele mit narrativem Designparadigma, da die interaktiv-narrativen digitalen Spiele Miyamotos für ein interaktives oder stark interaktiv ausgerichtetes interaktiv-narratives Designparadigma stehen, das für seine Spiele kennzeichnend ist. Zudem kann man an seinen Werken (nicht zuletzt auch aufgrund der zahlreichen unverhohlenen Eingeständnisse seinerseits) vortrefflich aufzeigen, wie narrative Elemente und Strukturen im Designprozess eingesetzt werden können, um die Interaktionen und das Gameplay des Spielers zu lenken bzw. zu unterstützen. Will man dies mit einer hohen Wahrscheinlichkeit erreichen, so bieten sich offenbar recht ,holzschnittartige“ Konzepte an, wie Hans-Joachim Backe bemerkt.

Aus dem Bedürfnis einer genügend großen Motivation für Figuren und Spieler resultiert eine Bevorzugung von Konflikten großen Ausmaßes, meist verbunden mit eindeutigen moralischen Positionen, d. h. archetypischen Kämpfen von Gut gegen Böse. Feindliche Invasion, Besatzung und Krieg bieten derartige Situationen, die in Spielen Motivation für Politik, Intrige, Spionage oder offenen Konflikt bieten können. (BACKE 2008, 175 f.)

\footnotetext{
495 Miyamoto geht es diesbezüglich oft auch um die Profilierung der sozialen Dimension: „While Miyamoto is famous for storytelling, his own self-professed interest is in experience design - he wants gamers to have a fun and entertaining experience, one that is often social." DEWINTER (2015), 24.
} 
Hieraus erklärt sich wahrscheinlich auch, warum der Monomythos in interaktiv-narrativen digitalen Spielen so populär ist. Er etabliert Konflikte von globalen oder gar kosmischen Ausmaßen und definiert (auch unter Einsatz mythologischer Archetypen) eine Gut-BöseDichotomie, die sich tief in das Spiel als Wertesystem einschreibt. Aufgrund dieser Zweiteilung wird es dem Spieler erleichtert, sich mit der Figur zu identifizieren. ${ }^{496}$ Dies wird noch vor dem Hintergrund verstärkt, dass sich diese Dichotomie nicht nur in moralischer Hinsicht bemerkbar macht. Der Monomythos von Link ist zugleich nämlich auch die Erzählung eines Jungen, der zum Mann wird, was Anspielungen auf Generationenkonflikte aufbaut, da Ganondorf und seine Gefolgsleute merklich einer älteren Generation angehören. Die Auseinandersetzung der Jungen gegen die Alten wirkt sich letztlich auch auf die Darstellung der Machtverhältnisse aus. So kommt der junge, ,gute‘ Held aus der ruralen Peripherie Hyrules, um den alten, ,bösen“ Antagonisten aus dem (Macht-)Zentrum zu verdrängen, auch wenn dieser das nur durch Usurpation eingenommen hat. Gerade der jüngeren Kernspielerschaft von The Legend of Zelda, die sich beweisen, die auch im realen Leben aufsteigen möchte, bietet der junge Held des Monomythos die ideale Identifikationsund Projektionsfläche. Für Menschen, die ihren Platz in der Welt suchen, sind zweifellos mediale Angebote reizvoll, die mit Figuren aufwarten, deren Position eindeutig ist, die nicht mehr ausgehandelt werden muss. In solchen Kontexten ist der Monomythos als mythologisches Narrativ konservativer Prägung prädestiniert, da ein Zustand nicht mehr hergestellt werden muss, sondern nur bewahrt, allenfalls nach dem altbekannten Muster wiederhergestellt werden soll. Das strikt normative Moralverständnis, das im Interaktiv angelegt ist, lässt sich dem Spieler plausibel mithilfe eines Narrativs vermitteln, das nicht nach Geistern verlangt, die Systeme hinterfragen, sondern nach solchen, die diesen folgen.

So ist auch Miyamotos Designphilosophie aufzufassen. Wenn er in Interviews davon spricht, Erfahrungen zu offerieren, zu unterstützen oder zu intensivieren, so heißt dies immer auch (wie grundsätzlich im Gamedesign), den Spieler zu steuern, sein Erleben zu lenken. Ein Gameplay ist in diesem Sinne ein intendiertes Gameplay. Der Monomythos als Narrativ der Befreiung einer vom ,Bösen` bedrohten Welt ist ironischer Weise im Gamedesign Mittel zum Zweck, um die ludische Freiheit des spielenden Subjektes zu unterlaufen und zu begrenzen.

\footnotetext{
${ }^{496}$ Freilich kann man auch ,mittlere' Charaktere entwerfen, die zwischen beiden Polen angesiedelt sind. Jedoch kann es hierbei vorkommen, dass der Spieler diesen gegenüber skeptischer ist, da ihr Verhalten ambivalent ist und er diesen deshalb nicht so leicht, vertraut'. Da Vertrauen aber oftmals in Zusammenhang mit der Identifikation mit einem Charakter steht, kann ein solches, Vertrauensdefizit' die Immersion des Spielers in die Figur hinein erschweren. Deshalb bieten sich - zumindest zu Spielbeginn - eher eindeutig einschätzbare narrative Charaktere an.
} 
Spieler sind nämlich in jenen digitalen Spielen wie Minecraft besonders frei, bei denen das Phänomen des Spiels möglichst wenig von anderen Kulturtechniken wie dem Erzählen beeinflusst oder gar überformt wird. Aus Produzentenseite mag das Reisemodell des Helden ein handwerklich praktikables Element sein, um Narrationen $\mathrm{zu}$ erzeugen, welche den Rezipienten gefallen. Aus Sicht letzterer (und Odo Marquard hat dies in seiner bereits mehrfach zitierten Kritik am Monomythos deutlich gemacht) können hierdurch aber Limitierungen von kulturellen Wahrnehmungs- und Denkpositiven resultieren, die soziokulturell bedenklich sein können. Das folgende Teilkapitel wird deshalb auch demonstrieren, dass Ordnung durch den Monomythos für den Spieler v.a. eins bedeutet Gefolgschaft.

\subsection{Das (modifizierte) Reisemodell des Helden}

Da der Spieler der durch den Monomythos implementierten interaktiv-narrativen Spielstruktur folgen muss, welche sich sequentiell entfaltet, geht das folgende Kapitel chronologisch und gemäß der in 3.4.2.4 entworfenen Modifikation des Reisemodells des Helden vor. Der erste Akt beginnt mit der Darstellung des Mikrokosmos Kokiri als ,heiler Welt, das in einer Kamerafahrt aus der Sicht der Fee Navi ${ }^{497}$ über- bzw. durchflogen wird. ${ }^{498}$ Kokiri erscheint als idyllischer Ort und von Kindern als Verkörperungen der Unschuld bevölkertes Utopia. ${ }^{499}$ Die Idylle resultiert auch aus der Idealisierung des ruralen Mikrokosmos als Ort, der frei von den Sorgen der Welt der Erwachsenen ist und ein Gegengewicht zur pragmatisch organisierten äußeren Welt, dem Makrokosmos, bildet. Das Kokiri-Dorf ist der Ort des Gleichgewichts schlechthin. Dieses Gleichgewicht wird gestört, als Ganondorf aus der Welt der Erwachsenen (Makrokosmos) in die Kinderwelt

\footnotetext{
${ }^{497}$ Navi stellt im Spielverlauf eine der wichtigsten Verbündeten Links dar, die auch Züge einer Mentorin trägt. Im Unterschied zu genuin narrativen Medien kann es in interaktiv-narrativen digitalen Spielen wie Ocarina of Time diffizil sein, zu bestimmen, ob ein Verbündeter dem Subtyp des Mentors zuzuordnen ist. So versorgt Navi Link zwar mit wichtigen Informationen und unterweist ihn in bestimmten Dingen, jedoch ist die Lehrer-SchülerBeziehung nicht derart ausgeprägt wie im westlichen Fantasy-Genre z.B. üblich. Dadurch, dass Navi nicht als ,weiser alter Mann' etabliert wird (wie viele andere Mentoren im weiteren Spielverlauf auch), ist die Hierarchie zwischen ihr und Link deutlich flacher als zwischen Gandalf und Frodo. Was interaktiv-narrative digitale Spiele von genuin narrativen Medien abhebt, ist die Aufsplitterung der Instanz des Mentoren, der auf mehrere Figuren verteilt wird und somit ähnlich auftreten kann wie ein ,herkömmlicher' Verbündeter. Es ist deshalb von Vorteil, weitere Faktoren hinzuziehen, um eine Figur in interaktiv-narrativen digitalen Spielen als Mentor bestimmen zu können. In dieser Analyse wird dazu die Frequenz verwendet, d.h. Mentoren sind in diesem Fall (verbündete) Figuren, die den Avatar nicht nur belehren und unterweisen, sondern die dies auch mit einer hohen Häufigkeit tun. So gefasst lässt sich Navi als Mentorin begreifen.

${ }^{498}$ Das folgende Let's Play von SARIA dokumentiert den gesamten ersten Akt der Heldenreise in Ocarina of Time https://www.youtube.com/watch?v=InSUxRBsIK8 (30.06.2018).

${ }^{499}$ An dieser Stelle werden auch die Referenzen auf die von J.M. Barrie geschaffene Welt um Peter Pan mehr als deutlich. Die Kokiri tragen grüne Kleidung und werden niemals erwachsen. Die Gemeinschaft der Kokiri zeichnet sich vornehmlich dadurch aus, dass es keine Erwachsenen gibt bzw. diese in den ,Verlorenen Wäldern“ nicht leben könnten.
} 
(Mikrokosmos) eindringt und die Probleme des Makrokosmos damit auf den Mikrokosmos überträgt. Ganondorfs Handeln als mythologischer Archetyp des Schattens als Antagonist wird von seinem subjektiven Denken bestimmt. Sein Wollen manifestiert sich in Begierden, die ihren Zielpunkt im ,Kokiri-Smaragd“ finden, ${ }^{500}$ den der Deku-Baum als Schutzgeist des Waldes und der Kokiri (Schwellenhüter) Ganondorf verwehrt, weshalb dieser ihn verflucht. Hierdurch wird der altruistische, auf das Wohl des Kollektivs ausgerichtete Mikrokosmos von dem egoistischen Begehren des Individuums gestört.

Um dieser Gefahr zu begegnen, beruft der Deku-Baum (jetzt als Herold) den Helden Link ein und zum Abenteuer auf. Der Ruf zum Abenteuer als Antritt einer Reise zum Lösen globaler Probleme geht hiermit aber noch nicht einher. Der Held wird vielmehr nur gebeten, den Deku-Baum als Bewahrer des Mikrokosmos von seinem Fluch zu befreien. Die zu rettende Welt ist aus Sicht des Helden zu diesem Zeitpunkt also nur der Mikrokosmos Kokiri. Um den Fluch zu brechen, muss sich Link im Inneren des Deku-Baums dem ersten HauptDungeon stellen. Als Held wird er somit der ersten Probe unterzogen, um sich als würdig zu erweisen. Hier begegnet er auch mit der Riesenspinne Gohma der ersten ernsthaften Personifikation des Schattens (als Dungeon-Endgegner). Obwohl der Held (die Meisterung des Dungeons vorausgesetzt) den ersten Schatten bezwingt und den Fluch bricht, so muss er doch erfahren, dass er den Deku-Baum und damit den Mikrokosmos trotz seines Sieges nicht retten konnte. In der ersten narrativen Cutscene des Spiels ist Ganondorf erstmals zu sehen, wie er ein Flammenmeer ${ }^{501}$ durchreitet. Die Tragweite der Absichten Ganondorfs wird dadurch noch hervorgehoben, dass der Deku-Baum unmittelbar hieran die Kosmologie ${ }^{502}$ von

$500 \mathrm{Zu}$ Ganondorfs Begierden und dem daraus folgenden Handeln bemerkt Jonathan Walls treffend: „Ganondorf's own lust of power brings about widespread evil, just like the true nature of sin as Christians understand it. [...] Ganondorf's actions are based on the way of life he has chosen and, like sin, cannot be reduced to a specific series of deeds. His selfish pursuit of power infects the world around him. Ganondorf diminishes Hyrule into a place devoid of joy. But joy is a concept quite beyond Ganondorf now. Remember, [C.S.] Lewis says, »Pride gets no pleasure out of having something, only out of having more of it than the next man. «Unfortunately for The Prince of Thieves, he can never have more power than everyone." WALLS (2011c), 37 f.; Herv.i.O.

${ }^{501}$ Als Mythologem kann das Feuer mehrere Bedeutungen haben. So kann es als Element der Schöpfung ebenso auftreten wie als Symbol für Krieg und Zerstörung. In Kombination mit dem Antagonisten steht es aber i.d.R. für letzteres. Es symbolisiert dann die von diesem ausgehende Gefahr bzw. Verwüstung. In vielen Mythologien ist Feuer deshalb als Mythologem mit Drachen verbunden. Tolkien hat dieses Bild durch Smaug nachhaltig in das moderne Fantasy-Genre transportiert, das u.a. auch in George R.R. Martins Fantasy-Welten Aktualisierungen findet.

${ }^{502}$ Von den beiden Kosmologien der Mythologie von The Legend of Zelda, die in A Link to the Past (1991) und Ocarina of Time geschildert werden, gilt in Fan- wie in Fachkreisen mittlerweile diejenige aus Ocarina of Time als ,kanonisch“. Vgl. zur Kosmologie Hyrules HuNTER (2011), insbes. den Vergleich beider Kosmologien auf 113. Die Kosmologie Hyrules bzw. die dort erfolgende Darstellung der Göttinnen ist in der theologischen und philosophischen Forschung zu The Legend of Zelda immer wieder Anlass, um die Theodizee-Frage zu stellen: „Why don't the three goddesses Din, Farore and Nayru just destroy Ganondorf? Or why did they create a Hyrule 
Hyrule anschließt. Ganondorf bedroht somit nicht nur die Welt an sich, sondern das gesamte kosmische Gefüge. Der Held begreift, dass Ganondorf niemals in den Besitz des Triforce gelangen darf. Er versteht, dass der Mikrokosmos nur dann zu retten ist, wenn er auch den Makrokosmos bewahrt, da der Mikrokosmos unweigerlich ein Teil dessen ist. Auf diese Weise gewinnt das globale bzw. kosmische Problem für Link eine persönliche Dimension und er weigert sich deshalb auch nicht, ,Schloss Hyrule' aufzusuchen, was gleichbedeutend mit der Annahme des Rufes zum Abenteuer ist, der erst in diesem Moment vollumfänglich erfolgt. Erst als Link erkennt, dass der Makrokosmos die zu rettende Welt ist, er seine Bedürfnisse unter die anderer ordnet, beginnt er zum Heros im Sinne der Heldenreise zu werden. Während der Held daraufhin Kokiri verlässt, trifft er auf die ihm vertrauteste Figur: Salia. In einer der emotionalsten Cutscenes des gesamten Spiels verabschieden sich beide voneinander. Die von Salia in dieser Szene überreichte ,Feen-Okarina “503 als Symbol der Freundschaft der beiden Figuren ist zugleich das Instrument, mit dessen Hilfe sie im Spielverlauf kommunizieren werden. Salia fungiert von nun an als die freundschaftlichemotionale Mentorin, die den Helden auf dessen Reise mit ihrem Wissen und ihren Fähigkeiten unterstützt.

Diese Cutscene leitet aber auch den Schwellenübertritt in den Makrokosmos als gestörte Welt ein. Durch die Positionierung dieser Abschiedsszene auf einer Brücke wird der Übergangscharakter, die Liminalität dieser Episode symbolisiert. Der Held steht sprichwörtlich zwischen zwei Welten. Mit dem Mikrokosmos verbinden ihn seine persönliche Lebenswelt und seine Nächsten, die von Salia verkörpert werden. Der Makrokosmos hat für ihn keine persönliche Bedeutung, es ist der Ort der Fremde und des Unbekannten. Der Held (und hierdurch unterscheidet er sich vom Antagonisten) zeichnet sich jedoch dadurch aus,

in which an evil presence like Ganondorf can exist in the first place?" WALLS (2011c), 40. Konkreter formuliert Charles Joshua Horn diese Frage, indem er das Triforce als ,Ausgangspunkt ‘ der Theodizee-Problematik mit in den Blick nimmt. „Did the goddesses want the pieces of the Triforce to be used at all? Surely the answer is yes, or why leave them to begin with? [...] The goddesses wanted the Triforce pieces to be used and they obviously didn't like the way that Ganondorf was using his part, because they take it from him at the end of Twilight Princess. The intention of the goddesses was for the Triforce to be used in moderation, as Link and Zelda do." HORN (2009), 216; Herv.i.O. Diese werkbezogene Perspektive erweitert Dwayne Collins unter Einbezug der besonderen Stellung des Bösen unter Theodizee-Aspekten und beantwortet die Theodizee-Frage im Anschluss an das Handeln der Göttinnen wie folgt: „One could argue that the Goddesses actually do consider the amount of evil represented by Ganon and his ilk to be excessive, even for the purpose of soul-making." CollinS (2009), 231.

${ }^{503}$ Als Symbol der Freundschaft zwischen Salia und Link bindet diese Okarina den Helden immer wieder an sein Leben im Mikrokosmos zurück, das er während seiner Abenteuer als kindlicher Held niemals ganz loslassen kann. Bezeichnenderweise wird er erst dann zum Mann und beginnt der Heros des Monomythos zu werden, als er die Feen-Okarina gegen die Okarina der Zeit eintauscht, welche nicht nur erst die Zeitreisen ermöglicht, sondern den Referenzpunkt der Loyalität des Helden endgültig weg vom Mikrokosmos und hin zum Makrokosmos (und zu Zelda) lenkt. 
dass er nicht seinem persönlichen Verlangen nachgibt, sondern seinem Pflichtbewusstsein folgt. ${ }^{504}$ Der Held stellt die Bedürfnisse anderer über die seinen, wohingegen der Antagonist alles seinen individuellen Bedürfnissen unterordnet. Hierin zeigt sich auch die didaktische Nachahmungs- und Vorbildfunktion des Monomythos als ein Plädoyer für den Altruismus und gegen den Egoismus. Vollendet wird der Schwellenübertritt erst durch die Eule Methusa, indem diese den Helden mit dem Makrokosmos vertraut macht und ihn in der Folge auch durch diesen , leitet ${ }^{505}$ Methusa ist dabei jenem Typus des Mentors zuzurechnen, der am ehesten dem von Tolkien popularisierten ,alten weisen Mann` entspricht. Er klärt den jungen Helden als väterlich belehrender Mentor auf und ermutigt ihn auf dessen Reise immer wieder, nicht aufzugeben. ${ }^{506}$

Der erste Akt, der von fundamentaler Bedeutung für die Heldenreise ist und in genuin narrativen Medien nicht selten extensiv ausgebreitet wird, um Held, Konflikt und Welt einzuführen, der eine Bindung zwischen Rezipient und Held bzw. dessen Umgebung ermöglichen soll, wird in Ocarina of Time in etwas mehr als einer halben Stunden abgehandelt. (vgl. dazu auch 3.4.2.4) In Anbetracht der Gesamtspielzeit von Ocarina of Time erscheint dies also ein verschwindend kleiner Teil zu sein. Es stellt sich die Frage, ob aus dieser zeitlichen Marginalisierung des ersten Aktes der Heldenreise auch eine grundsätzliche Marginalisierung der Heldenreise folgt? Dabei sollte man aber zwischen der Heldenreise als Narrativ, das in einer medialen Narration realisiert wird und der Heldenreise als (mit-

\footnotetext{
${ }^{504}$ Diese Entscheidung bzw. die Befähigung dazu stellt in gewisser Weise einen Aspekt des Auserwähltseins des Helden dar. Sich gegen die eigenen Wünsche zu stellen, um dem vermeintlichen Wohl aller in die fremde Ferne zu folgen, erfordert einen mutigen Helden, der sich selbst überwinden kann. Insofern ist dieser Akt eine Vorausdeutung darauf, dass Link das Triforce-Fragment des Mutes erhalten wird, wenn dieses bei Ganondorfs Berührung zerbricht.

505 Zum ersten Aufeinandertreffen zwischen Link und Methusa vgl. das folgende Let's Play von LOGICPRODUCTION https://www.youtube.com/watch? $\mathrm{v}=A N M s D 4 U c X U Y \& l i s t=R D A N M s D 4 U c X U Y \# t=0$ (30.06.2018). Interessant ist dabei, dass Methusa hier nicht nur als narrative Figur fungiert, sondern auch als ludisches Element, das über die Benutzung der Schnittstelle aufklärt und somit extradiegetische Handlungsoptionen aufzeigt. Zudem ist an diesem Video bemerkenswert, dass es sich hierbei um eine reinstrumentalisierte Version handelt und die Melodie allgemein sehr beliebt in Fankreisen ist. Vgl. dazu exemplarisch das folgende Piano-Tutorial von MARIOVEREHRER https://www.youtube.com/watch?v=FbErK0RxAJI (30.06.2018). Insgesamt ist die musikalische Gestaltung von Ocarina of Time des japanischen Komponisten Kōji Kondō nicht nur von Fans geschätzt, sondern auch schon oft Gegenstand von wissenschaftlichen Analysen gewesen. Dabei ist im vorliegenden Kontext v.a. die Frage von Bedeutung, inwiefern die Wahrnehmung der Musik durch den Rezipienten sich auf dessen Erfahrung von Narrativität niederschlägt. „Since my argument is essentially that videogame music encourages and enhances the narrative experience of game play (that is, the music in videogames is one of several elements that make game play a compelling visual and aural experience which immerses players in a fictional space)“. WHALEN (2004). Derartige Fragestellungen können aber nur aus einer Kombination von narratologischen und musikwissenschaftlichen Instrumenten und vor dem Hintergrund der empirischen Immersionsforschung zufriedenstellend beantwortet werden, was aber bisher noch aussteht.

${ }^{506}$ So thematisiert Methusa in späteren Aufeinandertreffen bspw. den Spielfortschritt des Spielers und setzt diesen in Bezug zum auserwählten Helden, dem Link immer mehr ähnele.
} 
)strukturierendem Muster des Möglichkeitsraumes unterscheiden. Betrachtet man die mediale Narration des Monomythos in Ocarina of Time unter dem Aspekt der Vermittlung, so fällt auf, dass nur die Störung des Gleichgewichts, der Ruf des Abenteuers und die Begegnungen mit den Mentoren direkt narrativ vermittelt werden, wobei nur der endgültige Ruf des Abenteuers in einer ,klassischen“ narrativen Cutscene erzählt wird, die auch analeptische Abschnitte aufweist. Die anderen beiden narrativen Funktionen des Monomythos werden nur textuell medial erzählt und dies auch eher konzise und sehr knapp. ${ }^{507}$ Die heile Welt wird nicht-narrativ eingeführt, sondern mittels filmsprachlicher und ikonografischer Elemente, die nicht genuin narrativ oder in einem hohen Maße narrativ induzierend sind. ${ }^{508}$ Die erste Probe sowie der eigentliche Schwellenübertritt sind gar rein interaktive Spielphasen, die performativ ausagiert werden. So kann man am Ende des ersten Aktes, wenn man bedenkt, dass nur drei der sechs Kardinalfunktionen narrativ vermittelt werden, berechtigterweise zu dem Schluss gelangen, dass die Intention des Gamedesigns hier weniger ist, einen ansprechenden Plot zu erzählen, dessen Rezeptionsgenuss sich maßgeblich aus dessen narrativen Elementen speist. Vielmehr dient der Monomythos als strukturierende Instanz hier lediglich als Formgebung.

Diese Funktionalisierung des Monomythos durch das Gamedesign wird im zweiten Akt noch deutlicher. Seth Sivak verwendet das Modell der Heldenreise in seiner bereits mehrfach zitierten Studie im Anschluss an seine Untersuchung der Spielmechaniken von Ocarina of Time im Rahmen seiner „Game Experience Analysis“. (SIVAK 2009, 314)

The real difference between a hero's journey in a movie or a book and the gamer's journey in OoT [Ocarina of Time] takes place in Act 1 or the early parts of the story. In traditional media it is necessary for the audience to be introduced to the hero, but in games the player must not only be introduced to the hero, but she must become the hero. (ebd.)

Der Unterschied zwischen den bisher dargebotenen Modellen der Heldenreise und Sivaks Interpretation besteht darin, dass Sivak die einzelnen Stationen der Heldenreise, die Handlungen des Helden nicht als narrative Funktionen begreift, sondern als Identifikationsangebote zwischen Spieler und Held (Avatar). (vgl. ebd., 315) Der zweite Akt der Heldenreise, diese Aneinanderreihung von Prüfungen, die fortwährende Suche nach Verbündeten und der permanente Kampf gegen die diversen Formen des Schattens lässt sich in Ocarina of Time (und dies machen auch Sivaks Erläuterungen klar) nur in der

\footnotetext{
507 Der Ausbau des Monomythos via Katalysen findet in Ocarina of Time insgesamt nur sehr spärlich statt, sodass sich der Eindruck verstärkt, dass in Ocarina of Time (wie in den meisten Titeln der Hauptserie) der narrative Fokus primär auf den Kardinalfunktionen des Monomythos liegt.

${ }^{508}$ Der einführende ,Kameraflug' oder die Schuss- und Montagetechnik der darstellenden audiovisuellen Sequenzen entstammt auch weniger der narrativen Filmsprache als vielmehr der dokumentarischen und der Art und Weise, wie diese Atmosphäre und Setting zu generieren sucht.
} 
Zusammenschau aller Handlungen und Ereignisse als narrative (Kardinal-)Funktion betrachten, ist so gesehen eine ,konstruierte' Kardinalfunktion. Dies lässt sich auch daran zeigen, dass in diesem Abschnitt, der ca. 90 \% der Gesamtspielzeit ausmacht, die Quantität an medial narrativen im Vergleich mit den interaktiven Spielphasen stark zurückgeht.

Die Akte der Prüfungen und die damit verbundenen Kämpfe werden interaktiv ausgehandelt, narrative Elemente kommen nur dann zum Einsatz, wenn es gilt, die Figurenkonzeptionen von Verbündeten wie Prinzessin Zelda, Impa, Darunia oder Prinzessin Ruto zu schärfen, um dem Spieler das Gefühl zu geben, von tiefgehenden Charakteren umgeben zu sein. ${ }^{509}$ Dies profiliert aber eigentlich nur die Spielwelt als ,soziale ${ }^{6}$ Welt und wirkt somit auf das Gameplay unterstuitzend in Miyamotos Sinne. Es gibt aber im zweiten Akt zwei herausstechende Ausnahmen, die deshalb näher beleuchtet werden sollen: das Öffnen des Zeitportals und die Enttarnung Zeldas.

Nachdem Link alle drei heiligen Steine gesammelt hat und sich nach ,Hyrule-Stadt aufmacht, so triggert bei seinem Eintreffen vor dem Stadttor eine narrative Cutscene. Zelda und Impa fliehen auf einem Pferd aus der Stadt, Zelda kann Link aber noch die Okarina der Zeit zukommen lassen. ${ }^{510}$ Während Link noch den beiden hinterher sieht, steht unvermittelt Ganondorf vor ihm. ${ }^{511}$ Diese Sequenz ist in zweifacher Hinsicht von symbolischer Bedeutung. Erstens entweichen zwei prototypisch ,gute' Charaktere vor der Personifikation des Bösen, was präfigurativ auf die Usurpation des Zentrums des Makrokosmos durch das ,Böse“ vorausdeutet (womit die Störung des Gleichgewichts eigentlich erst vollumfänglich in Kraft tritt). Zweitens ist es die erste direkte Konfrontation zwischen Protagonist und Antagonist, die damit endet, dass der Antagonist den Helden mit nur einem einzigen Angriff außer Gefecht setzt. Dieses Treffen ist ein vorweggenommener Endkampf, in dem der Held kläglich

\footnotetext{
${ }^{509}$ Dass dies durchaus kunstvoll sein kann, verdeutlichen exemplarisch die Cutscenes mit Prinzessin Ruto. Als kindlicher Held rettet Link die junge Zora-Prinzessin aus dem Walbauch und bekommt zum Dank den ,ZoraSaphir (einen der drei heiligen Steine) überreicht. Dieser gilt in der Zora-Kultur aber als Verlobungsring, was eine für Link unvorhergesehene (und wahrscheinlich auch ungewollte) Konsequenz nach sich zieht. Als Erwachsener trifft Link erneut auf Ruto, was die ,heikle Konstellation zwischen beiden Figuren aktualisiert, die letztlich aber aufgelöst wird, indem Ruto (jetzt Weise des Wassertempels) Link von seinem Versprechen entbindet. Ähnlich emotional wird auch die Beziehung zu Darunia aufgeladen, der als väterlicher Freund inszeniert wird. Derartige Beispiele zeigen, dass katalysierendes Erzählen in Ocarina of Time sehr wohl vorkommen kann, dass aber nicht narrative Funktionen katalysiert werden, sondern Figurenkonzeptionen und konstellationen.

${ }^{510}$ Vgl. dazu das folgende Let's Play von COUNTBLECK2009 https://www.youtube.com/watch?v=v3FSsNA78iI (30.06.2018).

${ }^{511}$ Diese Teilsequenz wurde dem Spieler bereits proleptisch unmittelbar nach dem Beginn des Spiels in einer kurzen Cutscene gezeigt und wird nun innerhalb ihres narrativen Rahmens aktualisiert und kontextualisiert.
} 
scheitert. ${ }^{512}$ Link ist lediglich ein ,Abziehbild‘ des Auserwählten Heros, er ist noch nicht würdig, der Weltenretter zu sein. ${ }^{513} \mathrm{Im}$ Anschluss an diese Cutscene sammelt Link die Okarina ein, erlernt die ,Hymne der Zeit‘, sucht die ,Zitadelle der Zeit‘ auf, öffnet das Zeitportal und zieht das Masterschwert aus dem Zeitenfels. Diese Interaktionen münden erneut in eine narrative Cutscene, in der der Spieler sieht, wie Ganondorf ins ,Heilige Reich“ eindringt und das Triforce-Fragment ${ }^{514}$ der Kraft in seinen Besitz bringt. Link ist, wie vor dem Stadttor bereits ersichtlich wurde, (noch) nicht der würdige Held und wird deshalb für sieben Jahre im Heiligen Reich versiegelt. Ganondorf wird unterdessen endgültig (durch das Triforce-Fragment der Kraft) zur Personifikation des Bösen. ${ }^{515} \mathrm{Um}$ sich dennoch als würdig zu erweisen, bricht Link ein zweites Mal zur Heldenreise auf. Der Ruf des Abenteuers wird vom Weisen Rauru als Herold aktualisiert und Link erhält direkt nach seiner Rückkehr aus dem Heiligen Reich mit dem ,Shiekah` (antikes hylianisches Elfenvolk) ,Shiek` einen neuen Mentoren. Die Schwelle, die Link nun übertritt, ist aber keine räumliche wie beim Wechsel vom Mikro- in den Makrokosmos, es ist vielmehr eine zeitliche. ${ }^{516}$ Im Zuge der Heldenwerdung ist Link vom Jungen zum Mann geworden.

\footnotetext{
512 Wie z.B. in Hartmann von AuEs (2001) Iwein ist das Scheitern des Helden erzähllogisch notwendig, damit sich dieser letztlich doch als würdig erweisen kann. Ocarina of Time ist insofern wie einige mittelalterliche Heldenepen dem sog. ,Doppelwegschema' verpflichtet, bei dem der Held erst scheitern muss, ehe er triumphieren kann.

${ }^{513}$ Sivak geht in seinem Modell davon aus, dass der Held bereits am Ende des ersten Aktes zum Helden geworden ist. Mit Blick auf die Immersion des Spielers in den Heldenavatar mag dies korrekt sein, es stimmt aber nicht mit dem Heldsein im Sinne des Monomythos überein. Hier wird der Held erst dann zum wahren Heros, wenn er bereit ist, die Personifikation des Bösen zu überwinden.

${ }^{514}$ Zur Bedeutung des Triforce vgl. HoRN (2009); zur Beziehung zwischen dem Triforce und Ganondorf, die bereits im ersten Teil der Serie angelegt wird, vgl. BURKE (2011). Bemerkenswert ist dabei jedoch, dass das Triforce nicht zerbricht, weil Ganondorf ,böse' ist, sondern weil die drei Kräfte des Triforce in seinem Inneren nicht im Gleichgewicht stehen. Selbiges würde aber, und darauf macht Justus Hunter aufmerksam, auch für Link oder Zelda gelten. Beide weisen ebenfalls ein Ungleichgewicht der Mächte in ihrem Inneren auf, da sie andernfalls vom Triforce nicht auserwählt worden wären, das jeweilige Teilstück zu erhalten. Nur derjenige kann in den Besitz des entsprechenden Teils gelangen, der die jeweilige Eigenschaft in sich klarer verkörpert als jeder andere. Vgl. HunTER (2011), 122. Dass ein wesentlicher Aspekt des Triforce auch in seiner Verwendung liegt, darauf hebt bereits dessen sprechender Name ab (,Try Force').

${ }^{515}$ D.M. Burke bemerkt dazu aus einer christlich theologischen Perspektive: „This rift in relationship, in Christian parlance, is known as sin. Remember from our earlier argument that this is the very definition of evil: anything that hinders loving relationship between God and humanity and among human beings. This, in short, is the doctrine of original sin. While classical Christian teaching does consider the devil to be present and active in this world, the main problem of evil in humanity is not that the devil does all the bad stuff, it is that humanity, because of our bad choices, has lost the ability to be in right relationship with God." BURKE (2011), $166 \mathrm{f}$. Diese Störung des inneren Gleichgewichts von Ganondorf kulminiert darin, dass er das Gleichgewicht der gesamten Welt stört, die Entfernung von den Göttinnen, der Verlust der Beziehung zu diesen gipfelt in Ganondorfs Okkupation des Heiligen Reiches und der Annahme einer quasi-göttlichen Position.

${ }^{516}$ Beide Schwellenübertritte folgen dabei demselben Muster, denn beide Male muss Link von einer liebgewonnenen Freundin (Salia und Zelda) Abschied nehmen und beide Male befinden sich die ,verlassenen Orte auch machtpolitisch in einem liminalen Zustand, da die Herrscher entweder verstorben sind (Deku-Baum) oder sich auf der Flucht befinden (Zelda; auch wenn streng genommen ihr Vater der Regent ist, der aber nie auftritt).
} 
Die zweite Ausnahme bildet die Enttarnung Zeldas. Nachdem Link als Erwachsener alle Tempel vom Bösen befreit hat, offenbart Shiek seine wahre Identität in einer narrativen Cutscene - hinter dieser Maskerade steckt Prinzessin Zelda. Diese händigt Link daraufhin die ,Lichtpfeile‘ aus, bevor sie erneut entschwindet. Dieses Mal flieht sie aber nicht vor Ganondorf, sondern wird von diesem in sein Schloss entführt. Im Unterschied zur Konfrontation vor dem Stadttor ist Link, nun im Besitz der Lichtpfeile als einziger Waffe, die Ganondorf neben dem Masterschwert schaden kann, jetzt aber imstande, sich Ganondorf entgegenzustellen, er ist endgültig zum auserwählten Helden des Monomythos, zum Weltenretter geworden. ${ }^{517}$ Die Frage ist nun, was diese beiden Beispiele samt ihrer narrativen Cutscenes und der damit verbundenen (interaktiven) Handlungen so besonders macht, dass man sie im Rahmen der Analyse herausgreift und derart prominent behandelt. Die Antwort hierauf ist recht simpel - ihre Rolle als strukturierende und ordnende Scharniere des Spiels. Der erste Akt der Heldenreise fungiert als ludische und narrative Exposition, die die folgende Heldenreise des jungen Links plausibilisiert und koordiniert, indem sie einen Zielpunkt steckt, der beim Verlassen des Waldes fern scheint, aber dennoch sehr schnell naht. Das Scheitern des Helden vorm Stadttor und als Ganondorf das Heilige Reich betritt, eröffnet den zweiten Spielabschnitt, indem Link spielrhetorisch wie im ersten Abschnitt des zweiten Aktes der Heldenreise agieren muss, sonst ändert sich spielstrukturell nur wenig. Das bedeutet, dass ein wesentlicher Zweck der Implementierung der Heldenreise in Ocarina of Time darin liegt, dass es eine eventuelle Monotonie des Gameplays verhindern soll. Gemäß der Designphilosophie Shigeru Miyamotos unterstützen die mediale Narration und die narrativen Rezeptionsangebote das UX-Design und reichern derart die Spielwelt an, indem sie zusätzliche Motivationen, Deutungs- und Identifikationsangebote schaffen. Deshalb wird auch vor dem letzten Haupt-Dungeon die Shiek-Zelda-Episode geschaltet, die den Spieler zusätzlich motivieren soll und die ein zu interaktives und paidianisches Spielen an ein Ziel zurückbindet, das Link und der Spieler gleichermaßen als persönlich betrachten.

Deshalb wird der intendierte Spieler auch hieran anschließend den ,zerstörtesten “ Ort betreten, sich mitten ins Zentrum des vom Bösen okkupierten Makrokosmos begeben, um der Personifikation des Bösen entgegenzutreten. Dieser Abschnitt, der zugleich den Beginn des

\footnotetext{
${ }^{517}$ Christian Wessely stellt zur Formung des Charakters des Helden im Zuge der Akte der Prüfungen fest: „Er [der Held] begegnet synergetischen und antagonistischen Kräften, die bisher eher glatte und homogene Oberfläche des Helden, die seiner Selbstsicht weitestgehend entspricht, wird transparenter, seine hellen und dunklen Seiten werden erkennbar, was bedeutet, daß er lernt, seine ihm bisher verborgenen oder von ihm verdrängten Aspekte wahrzunehmen und anzunehmen.“ WESSELY (1995), 356.
} 
dritten Aktes markiert, ist rein interaktiv. Link muss alle Prüfungen, ${ }^{518}$ die er als Erwachsener in den Tempeln bereits bestanden hat, erneut in Miniatur meistern, damit sich endlich der Weg zum personifizierten Bösen öffnet. Der Sieg über das personifizierte Böse ist ebenfalls rein interaktiv, ein dreistufiger Endgegnerkampf, der mit einer narrativen Cutscene eingeleitet und abgeschlossen wird. Link triumphiert, woraufhin Ganondorf von den Weisen verbannt und das Gleichgewicht somit wiederhergestellt wird. ${ }^{519}$ Dabei fällt jedoch auch auf, dass diese narrativen Funktionen des dritten Aktes der Heldenreise weniger medial eingeschriebene als vielmehr personal zugeschriebene sind, da die Handlungen des Helden, die sonst medial narrativ vermittelt werden, hier personal konstruiert werden müssen. Dies stellt umso deutlicher heraus, was der Monomythos in Ocarina of Time letztlich ist, er ist eine Rahmung der interaktiven Spielphasen, die das Gameplay unterstützen soll. Eine derartige Verwendung von narrativen Elementen ist jedoch nicht ungewöhnlich, wenn man Miyamotos Designphilosophie bedenkt, die sich nicht nur in Interviewaussagen niederschlägt, sondern auch kohärent in seinem Gesamtwerk darstellt. Die Strategie der Rahmung und Unterstützung lässt sich nämlich ebenso in der Mario-Reihe finden, auch wenn die medial narrativen Anteile in The Legend of Zelda durch die Etablierung des Monomythos gegenüber Mario deutlich erhöht wurden.

Wie in anderen Werken Miyamotos heißt auch hier Unterstützung Steuerung. „Whether or not the opposition of good and evil comes from slave morality, in videogames it is irrevocably connected to ludus.“ (DRZAIC/RAUCH 2009, 74; Herv.i.O.) Was Kristina Drzaic und Peter Rauch hier in Bezug auf das Moraldesign von Ocarina of Time richtiger Weise und unter Rekurs auf Friedrich Nietzsche feststellen, hat weitreichende Folgen für die Art und Weise, wie das Spiel von Spielern gespielt wird. Zwar ist, wie oben konstatiert, die PaidiaInteraktivität deutlicher ausgeprägt als die Ludus-Interaktivität, die Frage ist jedoch, wie divergent konkrete Interaktion-Narrationen von Spielern wirklich sind, wenn Steuerungselemente wie die ,Sklavenmoral` eingesetzt werden, die Spieler eher zu Sklaven oder Untertanen eines Systems machen als zu dessen Herren. Hieran zeigt sich erneut, wie

\footnotetext{
${ }^{518}$ Prüfungen sind in interaktiv-narrativen digitalen Spielen grundsätzlich Schwellenzustände, allerdings sind sie keine Schwellenzustände, die narrativ vermittelt werden wie z.B. andersweltliche Übertritte in den Artusepen des Mittelalters. Vielmehr werden sie interaktiv ausagiert und müssen deshalb spielwissenschaftlich oder soziologisch untersucht werden. Neben den bereits skizzierten Zugängen sollten zudem stärker (und Victor Turners Arbeiten weisen bereits in diese Richtung) Ansätze der Performance Studies eingesetzt werden, um derartige Phänomene in interaktiv-narrativen digitalen Spielen mit mythologischem Interaktiv-Narrativ zu analysieren. So bieten bspw. die Arbeiten Richard Schechners und Erving Goffmans zum Spielen produktive Möglichkeiten, um Liminalität gezielter und differenzierter betrachten zu können. Vgl. SCHECHNER (1988) sowie GOFFMAN (2007).

${ }^{519}$ Ausgehend vom Sieg, da der Monomythos ein Siegesmythos ist, wie Kenneth BURKE (1960) betont.
} 
stark das ethische System von Ocarina of Time letztlich geschlossen ist und wie viel Gefolgschaft vom Spieler abverlangt wird. Miyamoto und sein Team setzen das Potenzial des Monomythos als konservatives Narrativ, das die Sklaven- der ,Herrenmoral“ vorzieht, gekonnt ein, um den Spieler zu steuern und vermitteln hierdurch auch Weltbilder. Die ,heile‘ Welt, die in Miyamotos Interviews immer wieder durchschimmert, behält am Ende von Ocarina of Time auch wieder die Oberhand. Philip Tallon schreibt über das Gefühl des Sieges am Ende eines Zelda-Spiels. „You put down your controller, your thumbs aching and your palms sweaty. You have done it. You turn off your NES and go outside to walk around and enjoy the moment. For a little while, you feel certain that anything is possible." (TALLON 2011, 69) In diesem Moment überträgt sich die ,heile‘ Welt des Monomythos als heile Welt auf den Alltag. Was unter dem Aspekt, dass Subjekte sich hierdurch euphorisiert fühlen, unproblematisch ist, wird unter dem Gesichtspunkt des Weltbildes kritischer. Link kehrt nicht in die ,heile‘ Welt zurück, Hyrule kehrt zur ,heilen` Welt als einem Makrokosmos zurück, dessen Beschaffenheit kosmologisch dargelegt und in diesem Zuge ,göttlich ${ }^{`}$ legitimiert wird. ${ }^{520}$ Auf diese Weise verengt der Monomythos, wie MARQUARD (2000) betont, die Deutungs- und Wahrnehmungsdispositive der Rezipienten und bestätigt letztlich in seiner Funktion als konservatives Narrativ die bestehenden Zustände, da es nur einen positiven und schützenswerten Weltzustand geben kann, der immer wiederherzustellen ist. ${ }^{521}$ Insofern müsste man Roland Barthes’ Ausführungen zur Funktion von modernen Mythen erweitern. Nicht nur moderne Mythen legitimieren bestehende Herrschaftsverhältnisse, sondern auch antike und somit auch dessen moderne Aktualisierungen wie der Monomythos nicht nur in Ocarina of Time, sondern auch in vielen anderen Beispielen zeigt.

\footnotetext{
${ }^{520}$ Die am Ende der Heldenreise einsetzende Heimkehr des Helden kann über das klassische Happy End (Bilbo und Frodo etc. kehren glücklich heim) genuin narrativer Medien hinaus immense positive Emotionen im Spieler digitaler Spiele freisetzen. Erfahrungsgemäß löst das Durchspielen eines digitalen Spiels im Spieler immer positive Gefühle als Resultat der gemeisterten Widrigkeiten und im Rahmen der Belohnung durch das System aus. Zukünftig wäre es mit Blick auf das UX-Design interessant, zu eruieren, ob die ausgelösten positiven Gefühle am Ende des Monomythos dieses allgemeine Hochgefühl nach dem erfolgreichen Abschluss eines digitalen Spieles noch intensivieren können bzw. wie. Gibt es eine ,Zufriedenheit der Heimkehr', die sich im Rahmen des UX-Design interaktiv-narrativer digitaler Spiele funktionalisieren lässt?

${ }^{521}$ Dieser Weltzustand ist in Ocarina of Time (wie in den meisten anderen Titeln der Hauptserie) die absolutistische Monarchie Hyrules. Wie weiter oben ausgeführt (vgl. 3.4.1.1.2) eröffnet die Abstraktion der mythologischen Inhalte und Funktionen in The Legend of Zelda neue interpretative Ansätze, die auch politisch sehr bedeutsam sind. So bemerkt D.M. Burke: „Perhaps he [Ganondorf] is an anarchist at heart who believes kingdoms and feudal systems should be expunged so everyone can learn to fend for themselves and, thus, become stronger.“ BURKE (2011), 158. Jenseits einer Gut-Böse-Dichotomie, die nur den einen richtigen Weg kennt, werden Bedeutungsimplikationen sichtbar, die weitaus differenziertere Betrachtungen ermöglichen, die aber vom Monomythos weitestgehend ausgeblendet werden.
} 


\subsubsection{Das mythologische Interaktiv-Narrativ in Ocarina of Time}

Im Teilkapitel zum Interaktiv (4.2.2.1) wurde ersichtlich, dass ein mögliche Erklärung für den Erfolg von Ocarina of Time und dessen positiver Bewertung in Fach- wie Fankreisen darauf zurückgeführt werden kann, dass das dominante Spielprinzip des Spiels die vier Spielmechaniken ästhetisch sehr konsequent, komplex und vielseitig verbindet. Darüber hinaus wurde festgestellt, dass das Interaktiv von Ocarina of Time kaum als explizite (negative) Sanktionsinstanz auftritt. Dennoch muss zugleich bemerkt werden, dass die LudusInteraktivität des Spiels, die Meisterung des Ludus, bedeutet, die hierfür notwendigen Handlungsoptionen und -muster zu internalisieren, indem sich der Spieler nicht zuletzt dem Spiel als geschlossenem ethischen (Regel-)System unterwirft, dieses fast schon bedingungslos akzeptiert. Das Moraldesign von Ocarina of Time ist dementsprechend hochgradig normativ. Als geschlossenes ethisches System leitet das Interaktiv des Spiels den Spieler an, die Maxime der Handlungseffizienz zu verinnerlichen, indem das Belohnungssystem des Spiels den Spieler fast schon behavioristisch konditioniert. Wir haben es also mit einem sehr stark ausgeprägten Interaktiv zu tun, welches das mythologische Interaktiv-Narrativ dominiert.

The nature of gameplay chains is that the mechanics never break the immersion of the player and the deeper the player goes into the chain the more immersed they become in the activity. One of the major reasons is that gameplay chains work so well in OoT [Ocarina of Time] is due to how well each mechanic is wrapped into the story. The story of Hyrule and the myth of Link are reinforced through the mechanics of the game, making actual gameplay interactions more meaningful. The story of OoT carries the player through a beautifully crafted myth that allows the player to become the Hero and fulfill Link's destiny. (SIVAK 2009, 298 f.)

Allerdings ist bei Ocarina of Time weniger, wie Sivak meint, das Interaktiv ins Narrativ integriert, sondern das Narrativ ins Interaktiv. Narrative digitale Spiele wie diejenigen von Telltale Games wollen primär erzählen und diese mediale Narration um interaktive Elemente anreichern. Miyamotos Designphilosophie bedingt aber ein anderes Designparadigma, denn ihm geht es primär darum, das spielerische Erleben narrativ zu verstärken. Beide Designphilosophien und die aus ihnen resultierenden -paradigmen setzen als systemische Designansätze auf das Interaktiv-Narrativ, sie gewichten es aber unterschiedlich. Miyamoto und sein Team nutzen den Monomythos, um mythophile Potenziale im Spieler zu aktivieren, die nicht nur den Spielprozess an sich affizieren, sondern auch moderne Mythenproduktion seitens der Fans induzieren, die sich z.B. in mythenaffiner Fankunst niederschlägt.

Dementsprechend dient das Narrativ (wie in 4.2.2.2 gezeigt) dazu, zusätzliche Deutungsangebote $\mathrm{zu}$ offerieren, spielrhetorische Wiederholungen und Doppelungen zu kaschieren und den Spieler mittels des Settings des Monomythos zusätzlich zu motivieren. 
Auf diese Weise intensiviert das mythologische Narrativ durch diesen für die japanische Populärkultur eher untypischen Patchwork-Mythos das Gameplay. Dabei werden neben den inhaltlichen Aspekten v.a. die Funktionen von Mythen gezielt instrumentalisiert. Der Charakter des Monomythos als Siegesmythos verschafft dem Spieler Sicherheit, bietet ihm Orientierung, da das Endziel der Heldenreise bereits zu Beginn des Spiels klar ist, vermittelt Kontinuität durch den konservativen Charakter mythologischer Narrative dieser Prägung, die am Handlungsende stets den Zustand zu Handlungsbeginn wiederherstellen und gewährt letztlich auch Ordnung durch die Gut-Böse-Dichotomie als Sklavenmoral, die dem Spieler einen festen Platz in der Spielwelt zuweist. Die Analysen von Interaktiv und Narrativ haben aber auch gezeigt, dass stets Rückgriffe auf Elemente wie Figuren, Welt oder Struktur notwendig waren. Um also das Interaktiv-Narrativ in seinen Wirkungsweisen konkret verstehen zu können, erscheint es unabdinglich, diese interaktiv-narrativ polyvalenten Elemente bzw. deren Instrumentalisierung und Funktionalisierung im Designprozess näher zu beleuchten. Deshalb werden diese im folgenden Teilkapitel detailliert in allen drei Ausprägungen untersucht.

\subsubsection{Interaktiv-Narrativ polyvalente Elemente in Ocarina of Time}

Zuerst gilt die Aufmerksamkeit im Folgenden dem interaktiv-narrativen Figurendesign von Ocarina of Time. (4.2.2.4.1) Hieran schließen sich unmittelbar die Ausführungen zum interaktiv-narrativen Strukturdesign (4.2.2.4.2) an, ehe die Überlegungen zum interaktivnarrativen Weltdesign (4.2.2.4.3) dieses Teilkapitel abschließen und somit den Blick auf eine fundierte Begründung des Designparadigmas von Ocarina of Time vollenden, was die Analyse auf der Strukturebene beendet. Alle drei Unterkapitel folgen dabei demselben Schema, das sich dergestalt zeigt, dass erstens stets die interaktiv-performativen, zweitens die narrativen und drittens (und resümierend) die interaktiv-narrativen Aspekte beleuchtet werden.

\subsection{Interaktiv-narratives Figurendesign}

Diesem Schema folgend wird Link dementsprechend im Rahmen dieses Unterkapitels als Spielfigur (4.2.2.4.1.1), als narrativer Charakter (4.2.2.4.1.2) sowie final als interaktivnarrativer Avatar (4.2.2.4.1.3) analysiert.

\subsection{Link als Spielfigur}

Betrachtet man Link als Spielfigur, dann stehen primär die interaktiven und performativen Aspekte der Figur im Vordergrund. Kristina Drzaic und Peter Rauch unterscheiden in diesem 
of Zelda.

When a player becomes Link, they play as Link, and are engaging in the ludus game. They are following the designed rules of the game and pursuing the ultimate game goal. The role of the player is that of an actor: some degree of improvisation is allowed, and even encouraged, but ultimately the script must be followed. [...]

When a player leads Link, they play with Link, and are engaging in the paidia game. They are creating their own game rules and goals and playing outside of the game's story, and outside of the moral structure of that story. The role of the player is not to be found in the gamesworld at all. The player can be described as a director, organizing the world's various actors and props to his liking, or a game designer, defining goals to be met and rules to be observed. The player can even be described as aspiring to godhood, since she is not merely playing with Link, but with every element in the game. (DRZAIC/RAUCH 2009, 70 f.; Herv.i.O.)

Im ersten Fall, wenn sich die Realisierung der Spielfigur durch den Spieler gänzlich auf den Ludus konzentriert, dann aktualisiert der Spieler eine Spielfigur, die die Rolle des Helden des Monomythos durch strikten Rekurs auf das zugrundeliegende Narrativ und dessen Moraldesign nutzt, um sich dem Endziel der Heldenreise zu nähern. Dabei verwendet der Spieler in der Manier eines Schauspielers, wie James NAREMORE (1990) sagen würde, die Methode des ,Acting', um sich in die Figur gemäß deren Anlage hinzuversetzen, der Rollenvorgabe vollends zu entsprechen. (vgl. dazu auch RAUSCHER 2015) Der Spieler wird dann Link, er wird zum Helden im Sinne SiVAKs (2009). Diese Form der Spielfigur wird durch ihren starken Bezug auf das Strukturdesign zu einem Folgenden, der sich wie ein Schauspieler im Zuge des ,Actings ‘ fast schon sklavisch an das Skript hält. Entscheiden sich Spieler dafür, die Spielfigur nur derart zu realisieren, so ist der Improvisationsspielraum wirklich sehr gering. Diese Art der Spielfigur wird im nächsten Unterkapitel noch von Interesse sein, da sie sehr eng mit dem Ausagieren des Avatars im Sinne der narrativen Figurenkonzeption zusammenhängt.

Der zweite Fall, den Drzaic und Rauch schildern, ist für die Analyse der Spielfigur grundsätzlich interessanter, auch wenn man betonen sollte, dass sich beide Ausprägungen der Spielfigur nicht trennscharf voneinander abheben, sondern dass es sich hierbei eher um einen fließenden Übergangsbereich handelt. ${ }^{522} \mathrm{Im}$ Rahmen des Paidia nutzt der Spieler die

\footnotetext{
${ }^{522}$ So kann die Realisierung einer Spielfigur mit Blick auf den Ludus sehr viele Anteile haben, die als paidianisch zu klassifizieren sind. Ein Spieler kann bspw. die diversen Handlungsoptionen des Interaktivs i.d.R. nur dann aufdecken, wenn er paidianisch erkundend spielt. Ein gutes Exempel hierfür ist Portal 2. Das gilt aber umgekehrt auch für den anderen Fall. Paidianisches Spielen manifestiert sich in digitalen Spielen mit offener Spielwelt oft im Erkunden dieser, wozu es zuweilen aber notwendig ist, den Ludus weiter voranzutreiben, um neue Areale der Spielwelt freizuschalten. Insofern scheint es angebracht, die beiden beschriebenen Realisierungen der Spielfigur bzw. deren designerische Anlagen nicht als hermetisch abgeschlossen und absolut zu verstehen, sondern als alternierende Arten der Realisierungsmöglichkeiten von Spielfiguren.
} 
Spielfigur, um das Spiel gemäß seiner eigenen Wünsche umzusetzen, weshalb Drzaic und Rauch die Rolle des Spielers bzw. dessen Bemächtigung der Spielfigur diesbezüglich mit der eines Regisseurs oder Designers und in der übersteigerten Form gar mit der eines Gottes vergleichen. Was hierdurch aber deutlich wird, ist das weitreichende konfigurative Potenzial, das die Spielfigur dem Spieler zur Verfügung stellt. Die Spielfigur ist (unabhängig von der Spielform) das Element des Interaktivs, mit dem der Spieler durch Hyrule navigiert, gegen feindliche NPCs kämpft, Rätsel löst oder Items sammelt. So gesehen ist die Spielfigur ein programminternes Schnittstellenelement, das die Verbindung zwischen Spieler und Spielsystem herstellt. Durch die Spielfigur kann der Spieler überhaupt erst mit dem Interaktiv des Spiels interagieren. Wie sich Schach nicht ohne Schachfiguren spielen lässt, so kann der Spieler Ocarina of Time ebenfalls nicht ohne Link spielen. Die Erscheinung der Figuren ist für das Spielsystem hierbei zweitrangig; man kann Schach auch mit simplen Steinen spielen, wenn sie unterscheidbar und zuzuordnen sind. Selbiges gilt für Link, wenn man die Funktionen und Inhalte des Monomythos abstrahiert. Entscheidend sind in diesem Zusammenhang nur die semiotische und die interaktive Verwendbarkeit der Spielfigur. Am deutlichsten wird die Funktion von Spielfiguren in Speedruns, die als Let's Plays dokumentiert und über Plattformen wie Youtube mit anderen Nutzern geteilt werden. ${ }^{523}$

Bei einem Speedrun versuchen Spieler, ein bestimmtes digitales Spiel schnellstmöglich ,durchzuspielen‘. Im Gegensatz zu einem Walkthrough wird das Spiel (oftmals) jedoch nicht in einem herkömmlichen Sinne durchgespielt, sondern es werden Bugs, Glitches und andere Programmfehler genutzt, um derart geringe Gesamtspielzeiten, die sich oft nur auf einen Bruchteil der eigentlichen Gesamtspielzeit belaufen, überhaupt erst möglich zu machen. Die Figur verliert in solchen Spielsessions vollkommen ihre narrative Bedeutung, d.h. dass weder der narrative Charakter noch der Avatar als interaktiv-narrativ hybrider Figurentyp vom Spieler realisiert werden. Der Monomythos kommt weder inhaltlich noch funktionalistisch dazu, sich entfalten zu können und auch der Ludus wird ad absurdum geführt, indem der mühsame Weg diverser Prüfungen einfach umgangen wird, der Spieler mittels Tricks zum Ziel gelangt. Der Spieler ist hierbei aber nicht als, Falschspieler ${ }^{6}$ oder Betrüger ${ }^{524}$ zu betrachten. (vgl. dazu HuIZINGA 1991, 20) Er täuscht nicht, um seine Ziele zu erreichen, vielmehr weist seine Verwendung der Spielfigur eine rege Frequentierung und Kombination der vier Spielmechaniken von Ocarina of Time und somit ein hohes Spielverständnis auf. Der

\footnotetext{
523 Die folgenden Ausführungen beziehen sich auf ToRJEs Speedrun von Ocarina of Time https://www.youtube.com/watch?v=7YdcgFe74RE (30.06.2018).

${ }^{524}$ Zum Betrügen in digitalen Spielen vgl. ConSALVO (2007).
} 
Spieler navigiert die Spielfigur durch die Spielwelt, überwindet Gegner im Kampf, sammelt die wenigen Items, die er benötigt, um den entscheidenden Programmfehler zu verwenden und er löst auch Rätsel. Er entschlüsselt dabei zum einen die vom Spiel erforderten Rätsel, um im Spiel (so weit wie notwendig) voranzuschreiten, er löst aber auch das Interaktiv als Rätsel. Er entdeckt das Interaktiv und sucht gezielt nach den benötigten Programmfehlern, wobei er sehr paidianisch und explorativ vorgehen muss. Hat er diese Entschlüsselung geleistet, dann kann er den Möglichkeitsraum aus Effizienzgründen wieder verkleinern, um seinen Spieldurchlauf für den Speedrun zu starten. Der Speedrun an sich ist das mediale Artefakt, mit dem sich der Spieler im sozialen Raum der Fangemeinschaft präsentiert und hierdurch auch mit anderen Speedrunnern in Konkurrenz tritt, ${ }^{525}$ letztlich ist er aber auch nur das ,Endprodukt` unzähliger Testdurchläufe, zahlloser Trainingsstunden und reger kommunikativer Austauschprozesse innerhalb der Community. Anders gesagt: Ein Speedrun ist eine Manifestation hoher Könnerschaft sowie ausdifferenzierter Fähigkeiten und Fertigkeiten, die sich v.a. in der meisterlichen Handhabung der Spielfigur zeigen. Hier unterscheidet sich die Spielfigur deutlich vom narrativen Charakter. Über den narrativen Charakter kann und muss der Rezipient nur Wissen akkumulieren, das er bei Bedarf abruft. Um eine Spielfigur gekonnt einzusetzen, genügt dies nicht, denn der Spieler muss nicht nur wissen, welche Möglichkeiten, Stärken und Schwächen diese hat, er muss diese auch noch ,bedienen' können, indem er sie konkret realisiert. ${ }^{526}$

\subsection{Link als narrativer Charakter}

Auf diesen Umstand zielen auch Drzaic und Rauch ab: „Observation occurs during cutscenes. When a player loses control of Link, they are observing his choices. Since most of the meaningful narrative events occur during cut-scenes, the process closely resembles film, with the player acting as an audience.“ (DRZAIC/RAUCH 2009, 70) Wenn Link in Ocarina of Time als narrativer Charakter, als Held des Monomythos in Erscheinung tritt, dann ist der Spieler nur Zuschauer, da (bedingt durch die mediale Narration) Figuren i.d.R. nur in den narrativen

\footnotetext{
${ }^{525}$ Speedruns sind in der digitalen Spielkultur zugleich ein soziales wie auch agonales Element.

${ }^{526}$ Dieser kurze Abschnitt kann allenfalls exemplarisch für folgende spielfigurative Untersuchungen stehen, die vom Umfang hier nicht zu leisten sind. Im Rahmen des Forschungssettings dieser Arbeit besteht die Notwendigkeit aber auch primär darin, zu zeigen, was die Spielfigur in Ocarina of Time vom narrativen Charakter abhebt. Das Phänomen des Speedruns ist besonders geeignet, spielfigurative Untersuchungen vorzunehmen, da es eine der wenige Mediennutzungsweisen von interaktiv-narrativen digitalen Spielen ist, bei der die für solche Untersuchungen hinderliche mediale und personale Narrativität abstrahiert werden kann bzw. von den Spielern selbst wird. Auf diese Weise kann man die vielschichtigen Relationen und Interdependenzen zwischen Spielfigur auf der einen und Spielmechaniken und Spielregeln auf der anderen Seite differenziert analysieren.
} 
Cutscenes wirklich als narrative Charaktere auftreten. ${ }^{527}$ Dies trifft nicht nur auf den Protagonisten, sondern auf alle narrativen Charaktere des Monomythos in Ocarina of Time zu. Der Deku-Baum als Herold, Salia als Mentorin oder Ganondorf als Antagonist erscheinen nur in Cutscenes als narrative Charaktere. Das bedeutet einerseits, dass der Spieler gewissermaßen nie automatisch der Held des Monomythos in diesem Spiel ist, da der Spieler ihn nicht, wie Drzaic und Rauch es ausdrücken, als Schauspieler spielen, geschweige denn als Regisseur anleiten, sondern nur als Zuschauer beobachten kann. Der Spieler hat also keinen ,direkten`Zugriff auf den Helden. Andererseits verdeutlicht aber bspw. Salia als Mentorin, dass narrative und interaktive Figuren in Ocarina of Time sehr stark miteinander verzahnt sind. So fungiert Salia im Rahmen der medialen Narration von Ocarina of Time zum einen in narrativen Cutscenes oder via textueller medialer Narration als Mentorin, sie ist aber zugleich auch Mentorin in einem spielmechanischen Sinne, da der Spieler sie stets via Salias Lied kontaktieren kann, um wichtige Informationen für den Fortschritt im Ludus zu erhalten. ${ }^{528}$ Auf diese Weise verstärkt die Figurenkonzeption von Salia (im Sinne Miyamotos) auch die Spielfigur Salia als Informationsgeberin, indem deren spielmechanische Funktion narrativ plausibilisiert wird. Anders gesagt: Die narrativen Angebote der Figuren wirken in Ocarina of Time dahingehend das Interaktive unterstützend, indem sie zusätzliche Sinnstiftungsangebote machen.

Diese Funktion von Mythen machen sich auch Miyamoto und sein Team zunutze, wenn sie Spielfiguren im Interaktiv eine Position zuweisen, deren kritische Hinterfragung durch den Spieler verhindert werden soll, indem auf ein Narrativ und dessen Figurenpersonal zurückgegriffen wird, das den konstellativen Aufbau der einzelnen Entitäten im Interaktiv ,bestätigt ${ }^{`}$. Der Spieler akzeptiert Salias Ratschläge als Spielfigur bzw. sucht den Kontakt zu ihr, weil ihre Beschaffenheit als narrativer Charakter dies nahelegt. Kaum ein Spieler dürfte sich in der fiktionalen Welt Hyrules die Frage gestellt haben, ob es klug sein mag, den Weisungen einer 10-Jährigen zu folgen, was im realen Raum wohl aber kaum unterbleiben würde. Die Steuerung der UX in diesem Sinne wird zudem dadurch lanciert, dass die positive emotionale Aufladung der Figurenkonstellation zwischen Link und Salia als narrative Charaktere eine Bindung schafft, die der Spieler in den seltensten Fällen stören wollen dürfte.

\footnotetext{
${ }^{527}$ Interessant ist bei narrativen Figuren in Ocarina of Time, dass man narrative Figuren auch daran erkennen kann, ob sie in den narrativen Cutscenes vorkommen oder nicht. Figuren, die nur als Spielfiguren eingesetzt werden, finden nämlich keinen Eingang in die narrativen Cutscenes.

${ }^{528}$ Insofern ergänzt Salia die Informationen und Hilfestellungen, die Spieler durch Navi vermittelt und offeriert werden.
} 
Diese Beziehung zwischen narrativer und Spielfigur und wie erstere die Realisierung der letzteren durch den Spieler beeinflussen soll, ist v.a. für den Helden von zentraler Bedeutung. Josh und Rachel Rasmussen rekurrieren diesbezüglich auf das Konzept des ,Compatibilism‘. (vgl. RASMUSSEN/RASMUSSEN 2011, 74 ff.)

Compatibilism is the view that our freedom to choose is compatible with various forces (divine or natural) necessitating our actions. In other words, according to the compatibilist, our choices are free even though God or nature set up the world so that we must make the very choices we make. (ebd., 74; Herv.i.O.)

Das derart entworfene Szenario enthält eine Konstellation, die mit unmittelbaren intendierten Handlungen verbunden ist, die der Handelnde gemäß seines Rollenzuschnitts und der damit verbundenen Rollenerwartung aller Wahrscheinlichkeit nach ausagieren wird. Der Handelnde, wenn er handelt, wird glauben, dass er aus freien Stücken heraus agiert, dass seine Motivation intrinsisch ist, der Schöpfer jedoch weiß, dass der Handelnde durch ihn extrinsisch motiviert und dahingehend manipuliert wurde, dass ihm diese Lancierung gänzlich unbewusst ist. „We see, then, that according to compatibilism, an omniscient mind might be able to foresee the future by setting up the initial conditions and then calculating which future events will necessarily unfold.“ (ebd., 75) Die allwissende Entität ist in Ocarina of Time das Designteam. Dieses impliziert die intendierte Performanz des Mythos im Spiel in der narrativen Anlage des Helden und der anderen Charaktere durch die mythologischen Archetypen des Monomythos.

Hierbei steht v.a. der Held als die Spielfigur und der narrative Charakter mit der größten Agency im Mittelpunkt, da er als programminternes Schnittstellenelement dem Spieler den Zugang zum Spielsystem ebnet. Deshalb ist es besonders zielführend im Designprozess, die durch die Vorbild- und Nachahmungsfunktion von Mythen intendierte Rollenerwartung der narrativen Konzeption des Helden als moralischem Vorbild zur Spielersteuerung einzusetzen. Die Referenzen auf die positiv besetzten figurenkonzeptionellen Vorbilder wie Robin Hood, Peter Pan und auch Artus weisen Links Weg als aufopferungsvollem Helden des Monomythos. „Link's actions in the course of this quest are, by and large, morally unimpeachable. He kills no human innocents, and (with very rare exceptions) he does not steal, even when doing so might help him save Hyrule.“ (ebd., 66) Link erscheint dadurch nicht nur moralisch integer, er wird vielmehr zum moralischen Vorbild, dem es nachzueifern gilt. Das von Josh und Rachel Rasmussen richtig beschriebene Szenario und dessen Einsatz durch das Designteam unter Zuhilfenahme der Funktion von Mythen etablieren ein für den Spieler intuitiv einleuchtendes Setting. „Link is immediately a good and heroic figure and 
Ganon is immediately the »evil enemy«.“ (BURKE 2011, 157) Dergestalt inszeniert, ist die Wahrscheinlichkeit sehr hoch, dass der Spieler diese Rolle und die damit verbundenen Erwartungen und Handlungsweisen akzeptieren und ausagieren wird. „Link’s good deeds may be morally significant in the games's narrative, but a story has been written for Link in which he must perform certain actions, and the player may perform only those actions." (RASMUSSEN/RASMUSSEN 2009, 67) Auf diese Weise wird der Spieler zu Link, zum Helden des Monomythos.

The self-transcendence monomyth underpins many myths, not only those of formal religion but also those of popular culture. [...] Both Link and the player must become the Hero of Time together. This shared journey of self-transcendence is intertwined in every chapter of the game. $(\text { HAYSE 2011, 91) })^{529}$

Auf diese Selbsttranszendenz als eine Form mythisch-religiöser Entrückung wird im Zuge der Ausführungen auf der Realisierungsebene noch zurückzukommen sein. Dass die Rollenübernahme durch den Spieler, die Immersion in die Figur, die Identifikation mit Link gelingt, wird aber bereits bei flüchtigen Blicken in die Fangemeinschaft der transmedialen Welt von The Legend of Zelda evident. Hier lassen sich nämlich kaum kritische Kommentare zu Link als narrativem Charakter finden und auch die diversen Formen der Fankunst spiegeln wider, dass Link überwiegend als überaus positiver Charakter wahrgenommen wird. ${ }^{530}$ Hierbei spielen natürlich einerseits die Inszenierungen Links durch Nintendo, v.a. seine überbordend positiven Präsentationen durch Miyamoto eine gewichtige Rolle und andererseits darf man die Wirkmacht, die eine transmediale Welt mit kontinuierlich hohem und zeitlich dicht getaktetem Output auf die Wahrnehmung der Fans hat, nicht unterschätzen. Die serielle Produktion und Distribution der Hauptserie als Orientierungspunkt der transmedialen Welt schafft ,Gewissheiten“ (es kommt immer ein neuer Titel) und sie hat sich durch ihre permanente Gegenwart und ihren andauernden Fortgang fast schon ritualhaft in das Leben engagierter Fans eingebrannt. So ist es nicht verwunderlich, dass Fans nicht nur über Link als narrativen Charakter in Foren diskutieren, sondern dass sie im Rahmen von Cosplays Link sein wollen.

\footnotetext{
529 Vgl. dazu erneut SIVAKs (2009) Extremposition der Übernahme der Rolle des Helden im Zuge der Heldenwerdung des Spielers.

${ }^{530}$ Dies lässt sich an einem Kontrastbeispiel vorzüglich zeigen. Das Fanvideo von NICOBBQ reflektiert die narrative Figurenkonzeption Links als idealisiertem Helden in Form ironischer Brechungen. Vgl. dazu https://www.youtube.com/watch?v=9mngY8bIZwE (30.06.2018). Bezeichnend für Links überaus positive Bewertung innerhalb der Fankultur der transmedialen Welt ist der Beginn des Videos, in dem NicoBBQ deutlich macht, dass es sich hierbei um einen ,Scherz' handele, um den Unmut der Fans aufgrund von Missverständnissen präventiv abzuwenden.
} 


\subsection{Link als Avatar}

Link entsteht als interaktiv-narrativer Avatar in Ocarina of Time erst in der Zusammenschau der Spielfigur und des narrativen Charakters. ${ }^{531}$ Damit unterscheidet er sich von aktuelleren Formen des Avatars als (konkret nachweisbarer) interaktiv-narrativer Hybridfigur, die (wenn auch nur partiell und temporär) sich durch eine Simultanität des Vorhandenseins von spielfigurativen und narrativ charakterlichen Anteilen auszeichnet wie Nathan Drake in Uncharted 4 oder die Avatare in gegenwärtigen Produktionen von Telltale Games oder Quantic Dreams. Zudem zeigt sich wie in anderen vorangegangenen Unterkapiteln, dass narrative Elemente eher eingesetzt werden, um die interaktiven zu intensivieren. So plausibilisiert der narrative Charakter als Held des Monomythos die vorgegebenen Handlungsoptionen der Spielfigur und hilft dem Spieler, die Immersion in die Spielfigur zu vertiefen und hierdurch das Gameplay zu steigern. Auch wenn der Avatar mehr Spielfigur als narrativer Charakter ist, dementsprechend eher als performative Realisierungsinstanz fungiert und weniger als narrative Identifikationsfigur, so kann man doch konstatieren, dass sich die Hybridität interaktiver und narrativer Elemente auf der Strukturebene dennoch manifestiert. Im Sinne der Alternation des ,Perlenkettenmodells“ wechseln sich nicht nur die Spielphasen ab, sondern mit diesen zugleich die beiden damit verbundenen Figurentypen. (vgl. EICK 2014, 109) Dabei beziehen sich beide gegenseitig stets aufeinander, denn (so hat das Salia-Beispiel unterstrichen) der Mentor tritt zwar nur als narrativer Charakter in narrativen Cutscenes auf und als Spielfigur nur in den interaktiven Spielphasen, jedoch bleibt die narrative Funktion des Mentors auch in den interaktiven Spielphasen in der Wahrnehmung des Spielers erhalten, indem sie legitimiert, warum diese Spielfigur dem Spieler nun Informationen mitteilt. Auf der anderen Seite bestätigt die stete Informationsvergabe der Spielfigur des Mentors an den Spieler zugleich dessen narrative Funktion innerhalb des Monomythos.

Das bedeutet, dass selbst wenn Spielfigur und narrativer Charakter nicht simultan in der hybriden Form des Avatars zu finden sind, so erzeugen die gegenseitigen Bezugnahmen der beiden aufeinander dennoch über die Grenzen der jeweiligen Spielphase hinaus in der Wahrnehmung des Spielers das Gefühl eines hybriden Avatars, der beide Figurentypen auf sich vereint, auch wenn er sie nicht zeitgleich umsetzt. In diesem Zusammenhang wird ersichtlich, dass Link als Avatar v.a. die Funktion hat, dem Spieler als programminternes

\footnotetext{
${ }^{531}$ Das bedeutet, dass sich Link als Avatar in Ocarina of Time sowohl in der Wahrnehmung des Spielers als auch im Rahmen der wissenschaftlichen Analyse nur als Konstrukt begreifen lässt, das entsteht, wenn Spielfigur und narrativer Charakter in Bezug zueinander gesetzt werden.
} 
Schnittstellenelement einen Zugang nach Hyrule zu eröffnen. Dies hat Miyamoto auch immer wieder in Interviews betont, wie Patrick Dugan hervorhebt: „In interviews, he’s [Miyamoto] admitted that he gave the avatar the name »Link « not because it's some Nordic name that's evocative of swords and sorcery, but because the little guy is literally our link to the system.“ (DugAn 2009, 206) Die wenig emotional involvierende Spielfigur wird dabei durch die Anteile des narrativen Charakters für den Spieler ,zugänglicher', er steuert keinen der wenig zur Immersion in die Figur einladenden Avatare (wie die Spielfiguren der meisten ArcadeSpiele der 1970er Jahre), er navigiert vielmehr den auserwählten Helden durch die zu rettende Welt. Es ist für eine positive Evaluation des Gameplays durch den Spieler allerdings nicht zwangsläufig vorauszusetzen, dass der Avatar nur auf diese eine Art und Weise vom Spieler realisiert werden kann. ,The connection between Hero and player is so strong that they should be considered one and the same. The player should be totally invested in the story and believe in the quest of the Hero.“ (SIVAK 2009, 325) Diese Ansicht Sivaks ist unter zwei Punkten nicht unproblematisch. Erstens vermengt er mit dem Spieler und dem Helden (als Avatar) zwei Kategorien, deren fehlende Differenzierung in Analysen digitaler Spiele zu allzu weitreichenden Schlussfolgerungen führen kann wie in diesem Fall. Zweitens laufen derartige Annahmen Gefahr, die Realität der Mediennutzung der Fans dieser transmedialen Welt zu verkennen. So hat das Beispiel des Speedruns z.B. gezeigt, dass keineswegs jeder Spieler die narrativen Anteile interaktiv-narrativer digitaler Spiele auch tatsächlich umsetzt. Die meisten Speedrunner sind eher dem interaktiven Spielertyp zuzurechnen, der oft weniger Interesse an der medialen Narration oder an einer interaktiv-narrativen attributiven Hybridität hat. Ihm geht es einzig und allein darum, das Spiel als System zu besiegen. Freilich scheinen Sivaks Analysen vor dem Hintergrund der starken Spielersteuerung durch das Designteam nicht unbegründet zu sein, sie demonstrieren jedoch auch, dass die interaktiv-narrative Realisierung durch den Spieler nicht immer mit derjenigen anderer Spieler identisch sein muss. Trotz teilweise restriktiver Vorgaben seitens des Designs gibt es in Ocarina of Time (wie in allen anderen digitalen Spielen auch) nicht die eine Wirkung auf die Spieler wie in älteren ,Stimulus-Response-Modellen ${ }^{6532}$ angenommen. Es mag zwar wahrscheinlich sein, dass der Großteil der Spieler ein Gameplay erleben wird, wie Sivak es schildert, dies kann jedoch keinesfalls als absolut angesehen werden. So erlaubt selbst Miyamotos anleitende Designphilosophie sprichwörtlich individuellen Spielraum. Ein wesentlicher Faktor für die Polyvalenz Links als Avatar liegt so z.B. darin, dass er nie spricht (weder in geschriebener,

${ }^{532}$ Vgl. zu den ,behavioristischen Bedeutungstheorien` LyONs (1980), 138 ff. sowie zu deren Bewertung ebd., $145 \mathrm{ff}$. 
noch in gesprochener Sprache). Gelegentlich kann der Spieler zwar vermuten, was Link gesagt haben könnte, wenn er die Reaktionen der NPCs aufmerksam verfolgt, jedoch hat er keine Gewissheit, sodass er selbst (wenn auch nur in seinem Inneren) für Link nicht mit Bestimmtheit sprechen kann. ${ }^{533}$ Dies geht mit der eher schwachen Profilierung des Avatars einher, da eine individuelle Interpretation und Umsetzung durch den Spieler eine weniger stark ausgebaute Figurenkonzeption bedingt. Um die Immersion des Spielers nicht zu gefährden, schweigt Link deshalb und vermeidet somit das Risiko, wie andere Avatare der digitalen Spielgeschichte wie Duke Nukem (Protagonist Duke Nukem-Reihe (1991 ff.)) oder Geralt von Riva, die Hauptfigur aus der The Witcher-Serie (2007 ff.), die Immersion des Spielers bspw. durch sexistische oder ähnlich negative Äußerungen zu erschweren.

\subsection{Interaktiv-narratives Strukturdesign}

Die folgenden Unterkapitel gehen der Frage nach, wie der Monomythos die Quest- und die Erzählstruktur in Ocarina of Time zur interaktiv-narrativen Spielstruktur verbindet und welche Rolle strukturelle Äquivalenzen hierbei spielen. In diesem Zusammenhang ist es auch von Bedeutung, zu klären, wie agonal die Spielstruktur letztlich ist und wie sich die Agonalität auf Ludus und Paidia-Spiel auswirkt. Um dies zu leisten, wird zuerst die Queststruktur (4.2.2.4.2.1), danach die Erzählstruktur (4.2.2.4.2.2) und abschließend die interaktiv-narrative Spielstruktur (4.2.2.4.2.3) von Ocarina of Time genauer betrachtet.

\subsection{Die Queststruktur}

In Kapitel 4.2.2.1.2 wurde bereits die längste Quest-Chain des Spiels analysiert. Die folgenden Ausführungen hingegen folgen einer gröberen Perspektivierung und wenden sich den Strukturen des Spiels unter makroperspektivistischen Ausrichtungen zu. Von einer sehr hohen Warte aus gesehen lässt sich die Queststruktur in Ocarina of Time ähnlich beschreiben wie die der meisten anderen Titel der Hauptserie. So fasst Mathias Mertens die Queststruktur von Wind Waker wie folgt zusammen und dies ist so auch auf Ocarina of Time übertragbar:

Indem man überall in der Spielumgebung Objekte findet oder durch ebenfalls zu findende Wertgegenstände tauscht, wird man in die Lage versetzt, acht Schatzkarten zu finden, die den Weg zu acht Schlüsselteilen weisen, die zusammengesetzt den Zugang zu einem geheimen Ort ermöglichen. Dieser Ort wird dadurch erzeugt, dass man drei andere Schlüssel findet und sie zu bestimmten anderen Orten bringt. Von dem geheimen Ort gibt es einen Weg zu einem noch geheimeren Ort, zu dem man nur mit seinem Schwert Zugang erhält, das aber erst durch die Eskortierung von zwei bestimmten Figuren zu zwei bestimmten Orten zu einem Schlüssel wurde. Die Kombination aller Elemente führt zum Schluss dazu, dass man an dem noch geheimeren Ort auf den Endgegner trifft und ihn vernichtet. Also reinste Logistik, Verschieben

\footnotetext{
${ }^{533} \mathrm{Zu}$ den Gründen, warum Link nicht spricht, vgl. RABY (2010).
} 
von Gegenständen im Raum. Oder, richtiger, das Flussdiagramm eines Computerprogramms. (MERTENS 2004, 285)

Eine derart kondensierte Betrachtung verdeckt jedoch die strukturellen Äquivalenzen zwischen Quest- und Erzählstruktur, weshalb der Fokus im Unterschied zu Mertens hier etwas verkleinert wird. Genauer gesagt folgen die anschließenden Analysen dem dreiaktigen Aufbau des Monomythos. Der erste Akt der Heldenreise setzt direkt mit dem Spielbeginn ein und endet nach knapp einer halben Stunde Spielzeit, wenn der Held Kokiri verlässt. Vom Interaktiv aus betrachtet hat dieser Akt eine Funktion - er ist das Tutorial des Spiels. Der Held wird eingeführt, eine Andeutung der Beschaffenheit der gesamten Spielwelt gegeben, das Spielziel des Ludus aufgezeigt und der Spieler mit zentralen Spielmechaniken und -regeln vertraut gemacht. Die ,Erste Probe` stellt den ersten Test für die Fähigkeiten und Fertigkeiten des Spielers dar und stärkt nach ihrer erfolgreichen Absolvierung das Verhältnis zwischen Spieler und Spielfigur. Insgesamt ist dieser Abschnitt sehr agonal geprägt und stark am Ludus orientiert. Der Held kämpft im Rahmen der ,Ersten Probe‘ nicht nur gegen die ersten Verkörperungen des Schattens, er , $\mathrm{kämpft}^{\star}$ auch gegen das Spielsystem, indem er das Interaktiv zu verstehen und die Steuerung der Spielfigur zu meistern sucht. Hat der Spieler den ersten Akt hinter sich gelassen, so wird das Spiel deutlich paidianischer und auch die Agonalität des Spiels nimmt ab, da der Spieler nun einerseits mehr Handlungsoptionen zur Verfügung hat und andererseits viele dieser Handlungsoptionen mit anderen Spielarten zu tun haben. ${ }^{534}$ Mit der Zunahme des Paidianischen, der Vergrößerung des Möglichkeitsraumes, geht die Abnahme der Agonalität und auch der medialen Narrativität einher. Die Agonalität ist im zweiten Akt zwar immer noch durch den Ludus präsent, sie ist aber nicht mehr derart verpflichtend wie noch im ersten Akt, da der Ludus etwas in den Hintergrund tritt. Diese Form der Queststruktur ist für die meisten Sandbox Games sehr typisch, deren Agonalität in der Ludus zentrierten Einführung in das Spiel deutlich ausgeprägter ist als im weiteren Fortgang des Spiels, in dem auch die mediale Narrativität im Verhältnis zum Spielbeginn deutlich zurückgeht. ${ }^{535}$ In 2.5.1.2 wurde festgestellt, dass sich in interaktiv-narrativen digitalen Spielen oft mit der Zunahme an medialer Narrativität auch eine Steigerung der Agonalität beobachten lässt. Dabei lässt sich bemerken, dass interaktiv-narrative digitale Spiele, die sich auf der Attributebene dem narrativen Bereich zuordnen lassen, nur sehr selten

\footnotetext{
${ }^{534}$ So kann der Spieler mit den Masken des Maskenhändlers, die er für diesen verkauft, die er aber auch benutzen kann, diverse Facetten des Mimicry umsetzen oder sich bei der, Truhenlotterie“ in ,Hyrule-Stadt ${ }^{\star}$ einem Alea-Spiel hingeben. Das Open-World-Prinzip des Spiels erlaubt darüber hinaus (von Spieler zu Spieler verschiedene) Ausformungen des Ilinx.

${ }^{535}$ Dies gilt z.B. für die meisten digitalen Spiele der GTA-Reihe oder für die Mafia-Serie.
} 
auf offene Spielraumkonzepte wie eben die offene Spielwelt setzen. Vor dem Hintergrund, dass die Erzählstruktur in interaktiv-narrativen digitalen Spielen in den meisten Fällen an die Queststruktur gebunden wird, muss die mediale Narrativität letztlich zurückgehen, wenn Queststruktur und Ludus zugunsten des Paidia-Spiels zurücktreten. Anders gesagt: Umso mehr Agency einem Avatar in Bezug auf die Raumbemächtigung zugestanden wird, umso mehr gehen die mediale Narrativität und die Agonalität zurück. Eine extensive und intensive Verwendung der Basisspielmechanik Navigation durch den Spieler scheint weder der Questnoch der Erzählstruktur zuträglich zu sein.

Dies sieht man auch mit Blick auf digitale Spiele wie Minecraft, das auf einen maximalen Möglichkeitsraum setzt, dafür aber weder eine Quest- noch eine Erzählstruktur aufweist. Ocarina of Time verfährt im zweiten Akt ähnlich, nur dass die Spielersteuerung mittels der oben beschriebenen orientierenden und strukturierenden Elemente immer wieder auf den Ludus zurückgeführt wird, auch wenn sich der Spieler letztlich gegen dessen Realisierung entscheidet. Eine derartige Umsetzung wird letztlich aber auch nur dadurch möglich, dass wie SCHUPPISSER (2014) betont - der zweite Akt des Monomythos aus narrativer Sicht derart unbestimmt ist und dementsprechend Freiraum für diverse Interpretationen ermöglicht.

Im dritten Akt kehrt die Queststruktur wieder zu Ludus, Agonalität und (vor, während sowie nach dem finalen Kampf gegen Ganondorf) auch zur medialen Narrativität zurück. Entscheidet sich der Spieler dazu, den paidianischen Spielraum zu verlassen, so kommt er in die interaktiv-narrative Spielwelt zurück, um die Queststruktur gemeinsam mit der Erzählstruktur zu einem Ende zu bringen. Dabei werden im letzten Haupt-Dungeon alle erworbenen spielerischen Fertigkeiten erneut ,abgefragt ‘ und auf höchstem ludischen Level überprüft, ehe der Weg zum Endgegner freigegeben wird. Auch dieser verlangt dem Spieler abermals sprichwörtlich alles ab, dessen Überwindung bildet aber zugleich den Abschluss des Ludus, wie auch die durch die zahlreichen Spielsessions hindurch ersehnte Meisterschaft des Spielers und die damit einhergehende Anerkennung in der eigenen Community.

\subsection{Die Erzählstruktur}

Die Erzählstruktur ist durch alle drei Akte hindurch eng mit der Queststruktur von Ocarina of Time verzahnt. Wenn der Spieler im ersten Akt die Spielfiguren kennenlernt, so begegnet er zugleich dem Figurenpersonal des Monomythos, wenn der Spieler mit dem Spielraum bekannt gemacht wird, so erhält er zugleich Zugang zur Diegese, wenn das Spielziel des Ludus artikuliert wird, so ist dies sogleich der zentrale Konflikt des Monomythos, die Störung 
des Gleichgewichts, die mit dem Abschluss der Queststruktur simultan überwunden wird. Bietet der erste Akt im Zuge der Queststruktur das Tutorial, so stellt es mit Blick auf die Erzählstruktur die narrative Exposition dar.

Mit dem Abschluss des ersten Aktes beginnt eine Ellipse der medialen Narration, da diese deutlich hinter die ludischen Interaktionen des Spielers zurïcktritt, diese oft nur rahmt bzw. eingesetzt wird, um längere interaktive Spielphasen aufzubrechen, wichtige Quests oder Areale einzuführen und aufzuwerten. Präsent bleibt die Erzählstruktur jedoch den gesamten zweiten Akt über, auch wenn hier keine nennenswerten Kardinalfunktionen zu verzeichnen sind. Ursache hierfür ist die finale Motivation des Monomythos, die die kausalen Motivationsstrategien immer wieder überlagert. Wie Kenneth BURKE (1960) feststellte, sind Mythen, ist der Monomythos ein Kampfmythos und Kämpfen heißt in diesem Zusammenhang siegen. Auch wenn die Gefahren und Gegner unüberwindlich scheinen, so werden sie dennoch überwunden und zumindest unbewusst schwingt dieses Wissen im Spieler stets mit, der einen ,Siegesmythos‘ spielt. Auch wenn Jennifer deWinter zurecht konstatiert, dass das zentrale an der Funktionalisierung der Heldenreise in The Legend of Zelda die Reise selbst und nicht ihr Endziel ist, so muss man dennoch anerkennen, dass jede Reise ein Ende hat und dass dieses Ende im Monomythos sehr genau definiert ist. (vgl. DEWINTER 2015, 46) Das bedeutet jedoch nicht, dass der Spieler unbedingt und unmittelbar auf das Reiseziel zusteuern muss, sondern dass (gerade eine offene Spielwelt) sehr viele verschiedene (Reise-)Wege eröffnet, die aber dennoch nie plan- und orientierungslos sind, da ein Siegesmythos stets das eine Ende verheißt.

So gesehen bestimmt der Monomythos als Siegesmythos maßgeblich die Erzähllogik des zugrundeliegenden Narrativs und beeinflusst die Interaktion-Narration durch den Spieler. (vgl. 2.4) Diese Erzähllogik entwirft bestimmte Motivationen in den Figuren, die sich in deren Handlungen niederschlagen, welche nun im Rahmen der Rollenübernahme der narrativen Figurenkonzeption im Zuge der Interaktion-Narration durch den Spieler übernommen werden können, was auch mit entsprechenden personalen Narrationen einhergehen kann, die das narrative Erleben auch dann in Ocarina of Time erhalten, wenn medial kaum oder wenig erzählt wird. Durch eine solche antagonistisch ausgerichtete Erzähllogik bleiben auch stets ,Reste‘ der Agonalität wach, die Quest- wie Erzählstruktur bestimmt. So kann es dann auch nicht verwundern, dass die meisten Reisen durch das Hyrule in Ocarina of Time auch in 
Ganondorfs Schloss und im dritten Akt enden, ${ }^{536}$ dass das personifizierte Böse überwunden und das Gleichgewicht wiederhergestellt wird und der Held siegt. Wie es in Bezug auf die Queststruktur den Spielern ein Bedürfnis ist, das Spiel zu gewinnen, um mit all den positiven Effekten belohnt zu werden, die mit dem Sieg verbunden sind, so ist es dem Rezipienten des Monomythos ein Anliegen, zu sehen, dass die Welt doch gerettet werden kann, was umso reizvoller wird, weil man den Retter jenseits der medialen Narration auch selbst spielen und die Welt somit selbst retten kann. Im Unterschied zu den meisten anderen, passiven Formen der Rezeption des Monomythos in der populären Medienkultur kann der Spieler, und hier hat Christian Wessely vollkommen Recht, den Mythos hier selbst begehen, der Mythos kehrt somit gewissermaßen als performatives Phänomen im digitalen Spiel in unsere Gegenwart zurück. (vgl. WeSSELY 1995, 365) Wie der Spieler um die Polyvalenz der Figuren weiß, so weiß er auch um die Polyvalenz der Strukturen und der sich hieraus ergebenden attributiven Hybridität.

\subsection{Die interaktiv-narrative Spielstruktur}

Auch wenn die Erzählstruktur in Ocarina of Time besonders intensiv im ersten und dritten Akt ausgeprägt ist, somit der rahmende und strukturierende Charakter dieser hierdurch unterstrichen wird, so wäre es verfehlt, in ihr lediglich eine Hilfskonstruktion zu sehen. Denn im Gegensatz zum Figurendesign, wo die Spielfigur im Zuge der Avatarwerdung klar den narrativen Charakter bestimmt, ist dieses Verhältnis mit Blick auf das Strukturdesign nicht derart ausgeprägt. Freilich muss man zugeben, dass das wirkmächtig angelegte Interaktiv letztlich auch eine einflussreiche Queststruktur zur Folge hat, die auch die Erzählstruktur überlagert, aber sie dominiert sie nicht in der Art und Weise, wie die Spielfigur den narrativen Charakter beherrscht. Dies liegt letztlich auch daran, dass die strukturelle Äquivalenz der beiden Strukturen (auch unter Funktionalisierung der Agonalität) weitaus weiter entwickelt ist als bei dem Figurendesign von Ocarina of Time. Die in 2.5.2.5 beschriebene Erscheinung der interaktiv-narrativen Spielstruktur als Doppelhelix, als Verknüpfung aus Quest- und Erzählstruktur lässt sich in dieser Form in Ocarina of Time finden.

Makrostrukturell hat sich zeigen lassen, dass Tutorial und narrative Exposition im ersten Akt ebenso miteinander verwoben sind, wie die Akte der interaktiven Aushandlung und die narrativ dargelegten Akte der Prüfungen des Helden im zweiten Akt oder Spielende und Ende

\footnotetext{
${ }^{536}$ Unter dem Aspekt des Endes wäre es für zukünftige Studien in den Digital Game Studies von Interesse, zu ermitteln, wie hoch der Anteil jener Spieler genau ist, die ein bestimmtes Spiel tatsächlich durchspielen. Vergleichende Betrachtungen verschiedener solcher Erhebungen erlauben Rückschlüsse darauf, wie sich bestimmte Designphilosophien und -paradigmen auf die Motivation des Spielers bzw. deren Erhalt auswirken.
} 
der mythologischen Erzählung im dritten Akt. Mikrostrukturell gesehen offenbart sich diese Symbiose von Quest- und Erzählstruktur bezüglich einzelner Quests ebenso. So weisen einzelne Dialoge im Kontext der ,Quest Chain“ zur Erlangung von Biggorons Langschwert durchaus (wenn auch schwache) narrationsinduzierende Fiktionalitätsmarker auf, die die Erteilung der Quest (Beginn) ebenso begleiten wie die Evaluation des Quest-Ergebnisses mit ggf. anschließender Sanktion (Ende). Selbst wenn man einräumen muss, dass die Implementierung medial narrativer Elemente in einzelne Quests oder ,Quest Chains` in jüngeren interaktiv-narrativen digitalen Spielen, die dem Monomythos folgen, wie die ElderScrolls-Reihe oder Horizon Zero Dawn, freilich umfassender ist, so sind sie doch auch in Ocarina of Time nicht unbedeutend und unterstreichen, dass die strukturelle InteraktivitätNarrativität dieses Spiels durchaus auch in die unteren Schichten reicht.

Die Korrespondenz der interaktiv-performativen und narrativen Handlungsmuster wird dadurch erreicht, dass im Rahmen des Interaktionsdesigns Handlungen und Handlungsoptionen verwendet werden, die sich primär auf physisches Handeln beziehen. Was Jesse Schell (2015) und Marie-Laure RyAN (2014a) noch als Kritik an den „Handlungsverben` digitaler Spiele verstehen, die lediglich physisch und nur selten psychisch und dementsprechend im Unterschied zu genuin narrativen Medien weniger komplex seien, zeigt sich in Ocarina of Time weniger als Gegensatz. Zweifelsfrei ist es korrekt, dass die zentralen Spielmechaniken des Interaktivs (bis auf das Lösen von Rätseln) rein physische Handlungen sind, jedoch muss man konstatieren, dass dies auch für den Monomythos gilt. Die Handlungen der Figuren, die sich in den Kardinalfunktionen des Narrativs niederschlagen, sind auch größtenteils physisch. Es wird kommuniziert, gekämpft oder gelaufen, auch wenn psychisch-kognitive Aspekte als Vorstufe dieser Handlungen oft eine Rolle spielen, so sind die meisten und wichtigsten Handlungen physisch. Wie viele vormoderne Narrative rekurriert auch der Monomythos primär auf solche Handlungsformen. Erst mit dem Beginn der Frühen Neuzeit durch Werke wie Miguel CervanTeS’ Don Quijote (1969) und dann v.a. mit der Moderne, mit dem modernen Roman und neuen Stilelementen wie dem ,Bewusstseinsstrom‘, der mit James JoYCEs Ulysses (2012) oder Knut HaMsuns Hunger (2012) folgende Generationen von Erzählern beeinflusste, gerieten die Innensicht der Figur, ihre Wahrnehmungs- und Gefühlswelt und somit die psychischen Handlungsverben zusehends in den Mittelpunkt von Narrativen. Dass diese aber durchaus in Handlungsverben digitaler Spiele übersetzbar sind, haben Independent-Produktionen wie z.B. Davey Wredens 
The Beginner's Guide unter Beweis gestellt, die nahezu vollends in der psychischen Welt der Figuren (auch als Spielfiguren) situiert sind.

Auch wenn Ocarina of Time weniger moderne oder gar postmoderne Erzählelemente einsetzt wie neuere Produktionen, so kann es doch auch heute noch unter ästhetischen Gesichtspunkten als prägend und vorbildhaft für das Design interaktiv-narrativer digitaler Spiele gelten. Im Zuge der Korrespondenz der performativen und narrativen Handlungsmuster soll abschließend mit der Reise noch eine Handlung bzw. übergeordnetes Handlungsmotiv konkret herausgegriffen werden, um zu illustrieren, wie Quest- und Erzählstruktur in Ocarina of Time im Kontext der interaktiv-narrativen Spielstruktur miteinander verknüpft sind. Bedenkt man die umfangreiche Gesamtspielzeit dieses Spiels, so kann sich dem Spieler die Frage aufdrängen, warum die Weltenrettung ein derart langwieriger Prozess ist. Um dies zu verhindern, unterstützt die Erzählstruktur die Queststruktur und die Spielrhetorik des Interaktivs. Um monotonen Wiederholungen und Doppelungen vorzubeugen, wird die interaktive Reise durch den Spielraum zugleich als die narrative Reise des Helden durch die Diegese inszeniert. Dabei stellt v.a. die Erzählstruktur die interaktiv-narrative Reise und die damit verbundenen Handlungen als eine ,Reise der Verzögerung' dar. In der Exposition ergeht der Ruf des Abenteuers verzögert an den Helden, wie er auch in der ersten Konfrontation mit Ganondorf vor dem Stadttor scheitert, sich der Sieg über das personifizierte Böse somit verzögert, weshalb der Held erneut aufbrechen muss, um Haupt-Dungeons und bereits besuchte Orte zu erkunden, um letztlich die Welt doch retten zu können. Diese (narrative), Verzögerungsstrategie` korrespondiert mit den permanenten Akten der Prüfungen, die notwendig sind, ehe sich der Held als würdig erweisen kann. Auf der anderen Seite bestärken die permanenten interaktiv-ludischen Verzögerungen, die Adventure-Spiele grundsätzlich durchziehen, da der finale Dungeon-Gegner z.B. nie direkt aufgesucht werden kann, sondern erst der Dungeon durchgespielt werden muss, das narrative Erleben des Monomythos durch den Spieler, indem diesem vermittelt wird, wie diffizil diese Prüfungen eigentlich sind und wie beschwerlich aber auch erstrebenswert es sein muss, sich als würdiger Held zu erweisen. Insofern erscheinen die einzelnen Berührungspunkte der Doppelhelix für sich genommen Feedback-Loops gegenseitiger Bezugnahmen zu sein. Bei den Ausführungen zum Figuren- und zum Strukturdesign ist dabei immer wieder angeklungen, wie zentral auch die verschiedenen Weltformen sind und dass nicht nur die Bezüge der einzelnen Typen untereinander bedeutsam sind, sondern auch die zwischen verschiedenen interaktiv-narrativ 
polyvalenten Elementen, weshalb abschließend das interaktiv-narrative Weltdesign von Ocarina of Time betrachtet wird.

\subsection{Interaktiv-narratives Weltdesign}

Wenn in der Folge von Welten die Rede sein wird, dann sind diese unmittelbar mit den Räumen verbunden, aus denen sie entstehen und die sie hervorbringen. Dabei sollte man Raum jedoch nicht bloß als ein geografisches Konstrukt verstehen. Eher scheinen Raumauffassungen, die im Zuge der ,Raumwende' auftreten, hier zielführender zu sein.

So sind fast alle Ansätze des spatial turn auf einen gemeinsamen Nenner bezogen, auf den Raumbegriff von Henri Lefebvre, einem marxistischen Klassiker der Raumtheorie. Er hat die Produktion von Raum in den Blick gerückt, seine unverzichtbare Verknüpfung mit sozialer Praxis. Die soziale Konstituierung des Räumlichen wird hier ebenso betont wie die Rolle des Raums für die Herstellung sozialer Beziehungen. Es sind also die gelebten, sozialen Praktiken der Raumkonstitution, auch der Ein- und Ausgrenzungen, auf die hin die meisten raumbezogenen Untersuchungseinstellungen im Zuge der Raumwende ausgerichtet sind. (BACHMANN-MEDICK 2009, 291; Herv.i.O.) ${ }^{537}$

Räume sind somit Ausgangs- wie Endpunkt sozialer Beziehungen, die in einem hohen Maße von den sozialen Beziehungen in ihrem Inneren bestimmt werden, wie sie diese aber auch determinieren. Mark J.P. Wolf sieht eine Besonderheit des Raumes in digitalen Spielen darin, dass diese (im Unterschied zum Raum im Spielfilm) Navigationen und Interaktionen seitens der Spieler ermöglichen. (vgl. Wolf 2003a, 51) Jesper Juul geht auch von diesem Gedanken aus, leitet hieraus aber eine Dichotomie ab. „Computer games always create space, where the player can move around, but narratives are very focused on skipping uninteresting spaces; a journey is only described when something actually happens.“ (JUUL 1999, 3) Dass sich Raum- und Weltkonzepte aber nicht derart exkludierend und pauschal in interaktivnarrativen digitalen Spielen denken lassen, unterstreicht die folgende Differenzierung. Aus diesem Grund werden nacheinander der Spielraum (4.2.2.4.3.1), die Diegese (4.2.2.4.3.2) und die interaktiv-narrative Spielwelt (4.2.2.4.3.3) in Ocarina of Time anhand kurzer Beispiele untersucht.

\footnotetext{
${ }^{537}$ Zum Raum als kulturwissenschaftlich bedeutsamen Begriff, der mit dem Spatial Turn eine neue Konjunktur erfährt und dabei maßgeblich von Lefebvre wie anderen Theoretikern geprägt wird, vgl. die konzise und differenzierte Einführung von Stephan GüNZEL (2017).
} 


\subsection{Hyrule als Spielraum}

Die ,Erzeugung، des Raumes spielt in Ocarina of Time im Kontext des Spielraums die größte Rolle, ${ }^{538}$ denn dieser wird als Gefüge sozialer Verhältnisse, v.a. als Möglichkeitsraum definiert, der sich aus der Relation zwischen Handlungsoptionen und deren Umsetzungen ergibt. Hyrule ist, so gesehen, der Raum für die Handlungen des Spielers, wobei es sich erneut anbietet, zwischen Ludus und Paidia zu unterscheiden, da beide Formen des Spielraums bzw. deren Erscheinung und Qualität sehr verschieden sein können. Mit Blick auf den Ludus ist der Spielraum jener Raum, in dessen Rahmen der Spieler den strukturellen Vorgaben folgt, um zum vom Designteam definierten Spielziel zu gelangen. Der Möglichkeitsraum wird hierdurch verkleinert, da der Spieler die vorgegebenen Grenzsetzungen des Raumes akzeptiert und gemäß dieser agiert, um seine Handlungseffizienz zu erhöhen. Alle vier Spielmechaniken von Ocarina of Time werden dem Prinzip der Effizienz unterworfen und dementsprechend umgesetzt. Will der Spieler, um mit der Navigation ein konkretes Beispiel zu nehmen, von Kakariko zum Hylia-See gelangen, so wird er, wenn er den Spielraum im Sinne des Ludus nutzt und bereits die ,Serenade des Wassers“ beherrscht, diese spielen, um sich via Teleportationsfunktion dorthin zu begeben. Der Spielraum wird räumlich somit nicht konkret ausagiert und durchschritten, er wird gewissermaßen übersprungen, um eine zeitlich möglichst effizientes Navigieren zu ermöglichen. ${ }^{539}$ Die vom Ludus vorgegebene Logik hält den Spieler somit zu einem dieser entsprechenden Spielraumnutzung an.

In Bezug auf Paidia-Spiele ist dies anders, da die Nutzungsweisen des Raums hier sehr voneinander abweichen können. Der Speedrunner oder der 100\%-Spieler ${ }^{540}$ weisen beide z.B. eine sehr extensive Raumnutzung auf, wohingegen der Spieler, welcher nach individuellen Mimicry-Umsetzungen vorgeht, den Spielraum oft nur auf jene Handlungen und Orte begrenzt, die seinem Maskenspiel zuträglich sind. Will der Spieler z.B. ein Springreiter sein, der einen Parcours durchreitet, so ist es wahrscheinlich, dass sich sein Spielraum (zumindest so lange dieses Spiel andauert) auf die Lon-Lon-Farm beschränkt und auch hier nur auf die Hindernisse auf der Wiese. Alle anderen Orte exisitieren für die Dauer dieses Spiels nicht als

\footnotetext{
${ }^{538}$ Zum Raum bzw. dessen Konstruktion im ersten Teil der Hauptserie hat SiABRA-FraILE (2009) bereits eine Studie vorgelegt, auf die aber aufgrund der Diversität der Beschaffenheit des Spielraums im Laufe der Seriengeschichte von The Legend of Zelda nicht weiter eingegangen wird.

${ }^{539}$ Derartige Funktionen, die mittlerweile in ähnlicher Form in den meisten digitalen Spielen mit offener Spielwelt zu finden sind, widersprechen der eingangs zitierten Feststellung Juuls, mit welcher dieser Spielwelten und Erzählwelten voneinander abzugrenzen versucht.

${ }^{540}$ Der 100\%-Spieler ist prinzipiell eine Extremform des Ludus-Spielers, dem es nicht ausreicht, den Ludus an sich zu meistern, vielmehr möchte er das gesamte Spiel meistern, indem er alle möglichen Quests abschließt und alle Achievements erwirbt. Hierdurch wird er aber auch ein Paidia-Spieler, da er nur paidianisch spielend sein Ziel erreichen kann.
} 
Handlungsoption. Tendenziell lässt sich aber trotz der Vielfältigkeit der Spielraumnutzungen im Zuge des Paidia-Spiels sagen, dass der Möglichkeitsraum gegenüber dem Ludus eher vergrößert wird. Alle vier Spielmechaniken werden nämlich nicht nach der Handlungseffizienz ausgerichtet, sondern nach den subjektiven Bedürfnissen. Somit ist der vom Spieler genutzte bzw. erzeugte Spielraum bei Ludus und Paidia-Spiel extensional wie intensional sehr verschieden. Was beide aber eint, ist das Verhältnis zwischen Spieler, Figur und Welt. Der Spielraum ist eine responsive Umgebung, die eines handlungsfähigen und willigen Subjektes bedarf. Shigeru Miyamoto hat dies in einem Interview metaphorisch sehr treffend ausgedrückt. „Instead of thinking of it [Ocarina of Time] as making a game, think of it as nurturing a miniature garden called Hyrule“. (Miyamoto zit. n. DEWINTER 2015, 50)

Die Metapher des Gartens lässt sich aber nicht nur auf das Anlegen des Gartens beziehen, sondern auch auf die anschließende Pflege, Nutzung und Umgestaltung. ${ }^{541}$ So kann man diesen als Gärtner in seiner vorherrschenden Gestalt pflegen und bewahren. Die Rolle des Gärtners in diesem Sinne ist der des Ludus-Spielers sehr ähnlich, da nach dem bereits Vorgegebenen gehandelt wird. Es ist aber auch denkbar, dass man den Raum des Gartens anderweitig nutzt, indem man Feste in ihm feiert, ein Picknick abhält oder Fangen spielt. Dies mag alles nicht im Sinne desjenigen sein, der diesen Garten z.B. als Rosengarten angelegt hat, es sind aber dennoch mögliche Nutzungsweisen des Raumes und dies ist entscheidend. Jener zweite Gartennutzer kommt dem Paidia-Spieler am nächsten. Zentral ist bei allen Nutzungsarten jedoch, dass man es mit einem Spielraum zu tun hat, der auf die Handlungen des spielenden Subjektes, wie auch immer diese aussehen mögen, dementsprechend reagiert. Der Spielraum ist ein Ort der Konfiguration, der konfigurativ entsteht.

Neben dem Raum - und hierauf hat bereits JUUL (1999) nachdrücklich verwiesen - verhält sich aber auch die Zeit ${ }^{542}$ in digitalen Spielen anders als in den meisten anderen künstlichen Welten. Dies stellt sich zudem in digitalen Spielen besonders dar, deren Spielraum in einer offenen Spielwelt situiert ist. Wenn der Spieler sich des Raumes frei bemächtigen kann, so kann er auch bestimmen, wann er etwas machen möchte. Den Spielraum als Spieler zu realisieren, heißt demgemäß, ihn räumlich und zeitlich zu konstruieren. Aus dem OpenWorld-Prinzip folgt somit auch ein Open-Time-Prinzip. Klar wird dies v.a. dann, wenn man

\footnotetext{
${ }^{541}$ Die metaphorische Rolle des Umgestalters kommt aber nur dem Modder zu.

${ }^{542}$ Zeit ist häufig ein zentrales Motiv in The Legend of Zelda. Neben den Zeitreisen in Ocarina of Time und den sich letztlich hieraus ergebenden drei Zeitlinien innerhalb der Hauptserie ist eines der anschaulichsten Beispiele innerhalb der transmedialen Welt von The Legend of Zelda das Spiel Major's Mask, da die Zeit spielmechanisch hier am weitreichendsten eingebunden worden ist. Vgl. dazu SHERLOCK (2009). Das in Majora's Mask entworfene Szenario ist mit dem aus Und täglich grüßst das Murmeltier (1993) vergleichbar.
} 
bedenkt, wie wenig Abschnitte es in Ocarina of Time gibt, in denen der Spieler gezwungen ist, sich Zeitvorgaben des Spiels zu unterwerfen. Meistens ist dies nur bei Rennen oder in der oben ausführlich dargelegten ,Quest Chain` zur Erlangung von Biggorons Langschwert der Fall. Viele dieser Spielphasen sind aber keineswegs verpflichtend oder in den Ludus integriert, sondern stellen eher optionale Quests oder Minispiele dar. Ebenso erinnert das Interaktiv durch Spielelemente wie Navi den Spieler zwar von Zeit zu Zeit wieder daran, dass es einen Ludus gibt, jedoch sind dies nahezu die einzigen Augenblicke, in denen die Nutzung der Spielzeit thematisiert wird, ansonsten wird diese angesichts ihrer nahezu vollumfänglichen Verfügbarkeit fast unsichtbar. Die Welthaftigkeit des Spielraums wird in einem digitalen Spiel mit offener Spielwelt wie Ocarina of Time durch die räumliche wie zeitliche Konfigurierbarkeit durch den Spieler bestimmt. Somit erscheint der Spielraum als ein chronotopisches ${ }^{543}$ Gefüge, das sich grundlegend von dem in erzählten Welten unterscheidet.

\subsection{Hyrule als Diegese}

Diese Differenz tritt bereits dann zutage, wenn man die diegetische Dimension von Hyrule betrachtet. Die Diegese Hyrule ist dem Spieler nämlich nicht in dem Sinne zugänglich, wie dies beim Spielraum der Fall ist. Sie entfaltet sich im Zuge der medialen Narration von Ocarina of Time primär in den narrativen Cutscenes, die räumlich gebunden sind bzw. nur dann getriggert werden, wenn der Spieler einen bestimmten Ort in der Spielwelt erreicht. Wie JENKINS (2004) illustriert, erzählen interaktiv-narrative digitale Spiele oft räumlich, folgen somit im Rahmen ihrer medialen Narration eher einer räumlichen Ausrichtung als einer zeitlichen, wie man es z.B. aus dem Spielfilm kennt. Jennifer deWinter stellt dazu etwa fest: „In fact, Zelda's narrative is almost all spatial, requiring the player to unfold the story only by going to certain areas.“ (DEWINTER 2015, 23) Dies verdeutlicht zweierlei. Einerseits zeigt es, dass es in der Agency des Spielers liegt, ob oder wann eine bestimmte narrative Cutscene aufkommt, also wann sich die Diegese entfalten kann. Andererseits unterstreicht es aber auch, dass das ,Perlenkettenmodell‘, nach dem sich auch die Alternation zwischen interaktiven und narrativen Phasen in Ocarina of Time richtet, weitreichende Konsequenzen für die Welthaftigkeit der Spielwelt hat. In den interaktiven Spielphasen spielt der Spieler mit der Spielfigur im Spielraum, in den narrativen Phasen präsentiert das Spiel im Zuge seiner medialen Narration dem Spieler den Plot via narrativem Charakter und Diegese. Anders

\footnotetext{
${ }^{543}$ Vgl. dazu insbes. den von Michail BACHTIN (2008) geprägten Terminus des ,Chronotopos‘.
} 
gesagt: Die Diegese kommt in Ocarina of Time immer nur dann zur Entfaltung, wenn der Spielraum abwesend oder sehr stark reduziert ist.

Wenn die Diegese sich aber medial ausbreitet oder die Fangemeinschaft auf sie Bezug nimmt, dann tritt Hyrule meistens als Utopia in Erscheinung. Schon der sprechende Name Hyrule (englisch ausgesprochen ,High Rule‘) deutet auf die hohen moralischen und ethischen Wertstandards und -maßstäbe dieser Welt hin. (vgl. dazu DeVAn 2011) Als Diegese ist Hyrule von einer Verklärung der Gesellschaft und der Kultur geprägt, wobei zwei Aspekte besonders auffallen. Erstens wird das politische System Hyrules (absolutistische Monarchie) häufig thematisiert, auch wenn nie expliziert wird, dass die Könige Hyrules absolutistische Herrscher sind. Die köngliche Familie Hyrules erscheint als unangefochtene (höchstens von sinistren Mächten angezweifelte), weltliche“ Macht, die Garant der politischen Ordnung Hyrules ist und sich durch Bezug auf die Religion ,quasi-göttlich` legitimiert. Diese Version des Königtums durch Gottes Gnaden manifestiert sich in Ocarina of Time z.B. darin, dass zentrale religiöse Artefakte wie die Okarina der Zeit oder magische Lieder wie die Hymne der Zeit im Besitz der könglichen Familie sind. Ebenso befindet sich der Zugang zum Heiligen Reich, in welchem das Triforce lagert, in der Zitadelle der Zeit, die wiederum im unmittelbaren (räumlichen) Machtbereich der Könige liegt. Wenn man bedenkt, dass die Sanktionsinstanz der Königsfamilie wie auch die Legitimationsbasis von deren Herrschaft die drei Hauptgöttinnen Hyrules sind, dann erkennt man zweitens, dass die Verklärung letztlich auch diese betrifft. Die Göttinnen bilden als ,göttliche` Macht Hyrules bzw. dessen Kosmos die höchste Gewalt in der Diegese von Ocarina of Time wie der transmedialen Welt allgemein, die als höchste Sanktionsinstanz fungieren und sich aus sich selbst heraus legitimieren.

Bemerkenswert ist daran, dass die oben bereits mehrfach genannte Theodizee-Problematik, die sich durchaus aus dem Handeln der drei Göttinnen ergibt, in den Spielen selbst nie explizit thematisiert wird. ,Göttliche' wie ,weltliche" Machthaber werden in Ocarina of Time gleichermaßen idealisiert, indem negative Bewertungen (der absolutistischen Staatsform oder der Ungerechtigkeit ,göttlichen Handelns') bewusst vermieden und die Diffizilitäten, die sich aus einer engen Verzahnung beider ergeben können, nicht problematisiert werden. Man hat es also sowohl mit ,göttlichen“ Wesen zu tun, die sich für ihr Handeln oder Nicht-Handeln nur vor sich selbst verantworten, als auch mit, weltlichen“ Machthabern, die sich für ihr Handeln nur vor eben jenen Wesen rechtfertigen, wobei sie auch noch den Zugang zu diesen kontrollieren können. Die in der Diegese von Ocarina of Time dargestellten Machtstrukturen 
können unter politischen wie religiösen Gesichtspunkten in einer aufgeklärten demokratischen Gesellschaft durchaus als kritisch betrachtet werden, jedoch erfüllen sie eine zentrale Funktion im Designprozess. Die in der Diegese des (mythologischen) Narrativs dargestellten Machtstrukturen legimitieren nämlich nicht nur die Zustände innerhalb der narrativen Fiktion, sie bestätigen durch ihren normativen Charakter auch die im Interaktiv angelegten Strukturen, indem die narrativen Strukturen die interaktiven formalistisch unterstützen und indem die dargestellten Inhalte dies thematisch zudem untermauern. Struktur- und Weltdesign von Ocarina of Time greifen hier ineinander, um das Interaktiv und somit auch das interaktiv ausgerichtete Designparadigma des Spiels zu unterstützen.

\subsection{Hyrule als interaktiv-narrative Spielwelt}

Dies schlägt sich auch in der interaktiv-narrativen Spielwelt Hyrule nieder. Diese setzt sich in Ocarina of Time aus dem Spielraum als Möglichkeitsraum und der Diegese als idealisiertem Utopia zusammen. Die Zentralität, die die UX in Miyamotos Designphilosophie einnimmt, drückt sich auch darin aus, dass der Spielraum die Diegese qualitativ und quantitativ dominiert. Die diegetischen Weltanteile wirken wie narrative Elemente in anderen Bereichen der designerischen Anlagen von Ocarina of Time grundsätzlich eher strukturierend unterstützend, entfalten weniger ein eigenständiges narratives oder narrationsinduzierendes Erleben. In der Fankultur kann man bspw. beobachten, dass die Fans weniger Bezug auf die erzählte transmediale Welten nehmen, sondern dass der ,räumliche‘ Referenzpunkt hier eher ein Weltverständnis ist, wie es der Theorie transmedialer Welten in den Transmedia Studies zugrundeliegt. Solche Welten sind Hybride, die ihre Welthaftigkeit aus verschiedenen Quellen speisen, auch wenn die diegetischen Anteile meistens noch eine zentrale Funktion einnehmen. Der Grund, weshalb viele Fans Link oder Zelda cosplayen, dürfte aber weniger darin zu finden sein, dass sie bestimmte Plots der transmedialen Welt nachspielen wollen (häufiger erzeugen sie eigene Plots im Zuge der Fan Fiction), es geht ihnen darum, Link und Zelda zu sein. ${ }^{544}$ Dieses Sein ist kein Partizipieren an einer Narration, es ist die Teilhabe an

\footnotetext{
${ }^{544}$ Entscheidend ist bei dieser Fanpraktik zum einen das Rollenspiel, zum anderen aber auch das Teilen von medialen Artefakten via sozialen Netzwerken, die eben dieses Ausagieren der Rolle festhalten. Bilder (oder auch Videos) dokumentieren dergestalt nicht nur das Erlebte, sondern bieten anderen die Möglichkeit, hieran rezeptiv und kommunikativ teilzuhaben. So können jene Bilder nicht nur betrachtet werden, sondern die Kommunikation über diese stellt einen wesentlichen Aspekt des ,Soziallebens' solcher transmedialer Welten dar. Zur Praktik des Sharens von Bildern vgl. GERLING et al. (2018). Es geht also nicht primär um die Teilnahme an einer Narration, es geht um die Teilhabe an einer sozialen Welt, an ihren Kommunikationen und Interaktionen, an ihren Sanktionen und Gratifikationen. Zur ,Anerkennung' in der digitalen Medienkultur vgl. THOMAS et al. (2017). Das folgende Interview von 10DOTV auf der Gamescom 2011 verdeutlicht die vorrangige Rollenspielbedeutung von Cosplaying als Fankpraktik, bei der es primär um das Ausgieren einer Rolle geht und weniger um narratives Erleben. Vgl. https://www.youtube.com/watch?v=n_gxz5JZ6-M (30.06.2018). Dies lässt sich u.a. auch daran
} 
einer Welt als Raum im Sinne Lefebrves. (vgl. dazu insbes. LEFEBVRE 2008) Es geht um die sozialen Beziehungen, die die transmediale Welt ausmachen und die auch die interaktivnarrative Spielwelt Hyrule in Ocarina of Time und vielen anderen Titeln der Hauptserie bilden. Jene, von Miyamoto durchaus intendierte und immer wieder betonte, Sozialität der Spielwelt wie der sich darum gruppierenden Fangemeinschaft ist eines der wichtigsten Elemente der Welthaftigkeit von The Legend of Zelda.

Mit Moritz Baßlers Worten könnte man auch sagen, dass es das Anliegen vieler Fans dieser transmedialen Welt ist, diese zu ,bewohnen` und zwar unabhängig von narrativen Strukturen. (vgl. dazu BAßLER 2014) So gesehen ist die Rezeptionsmotivation der Fans dann auch keine narrative, sondern eine interaktiv-soziale, da der ,Rezeptionsgenuss` darin besteht, den Reentry in diese Welt zu vollziehen. Ausgangspunkt dieser transmedialen Fanaktivitäten ist die interaktiv-narrative Spielwelt Hyrule als ,Erfahrungsraum‘. Die Qualität dieses ,Erfahrungsraums‘ liegt in dessen Fähigkeit, dem interaktiv-narrativen Gameplay je nach den Wünschen des jeweiligen Spielers Raum geben zu können.

In both his [gemeint ist Miyamoto] narrative and experience designs, what draws his work together is an extreme attention to detail concerning the entire immersive environment. This includes visuals, music, animations, controls, story, game mechanics, and so forth. (DEWINTER $2015,25)$

Dabei ist nicht nur die Detailversessenheit Miyamotos entscheidend, sondern vielmehr sein ganzheitlicher Designansatz, der aus seiner erfahrungs- und erlebenszentrierten Designphilosophie herrührt. Die ästhetische Qualität von Ocarina of Time in ihren vielfältigen Manifestationen umfassend und differnziert zu analysieren, geht weit über das hinaus, was anhand dieses Forschungssettings untersucht werden kann. Als Gemeinsamkeit der verschiedenen ästhetischen Ausformungen von Ocarina of Time kann man aber dennoch bereits das Erfahren und Erleben ebenso hervorheben wie die Polyvalenz von Nutzungsmöglichkeiten der Spielwelt. Um die Hybridität dieses Weltkonzeptes herauszustellen und zu zeigen, dass sie selbst die interaktiv-narrativen Grenzen transgressiert, ist ein Beispiel als Exempel gewählt worden, das außerhalb des Analyserasters liegt, aber dennoch sehr konkrete Folgen für die Interaktivität-Narrativität von Ocarina of Time hat - die Musik. So geht z.B. Zach Whalen davon aus, dass „,videogame music encourages and enhances the narrative experience of game play“. (WHALEN 2004) Diese These exemplifiziert er u.a. an zwei digitalen Spielen von Miyamoto: Super Mario Bros. und Ocarina of Time.

herausstellen, dass nicht selten, wie im Interview zu Beginn ausgeführt, Charaktere verschiedener transmedialer Welten abwechselnd gecosplayt werden. 
Like Super Mario Brothers, Ocarina of Time employs music to function with the same patterns of music, but the complexity of the musical score and the real-time blending and fading allowed by the game engine creates a more lush, cinematic feel. Composer Koji Kondo again uses particular melodic themes to identify specific areas of the gameworld in something like Wagner's leitmotifs acting in reverse. (WHALEN 2004)

Einerseits stützt Whalen hierdurch seine These, dass Musik in digitalen Spielen das narrative bzw. das cineastische Erleben intensiviere. ${ }^{545}$ Andererseits zeigt er aber auch noch weitergehende Funktionalisierungsmöglichkeiten von Musik in Ocarina of Time auf, indem er auf die Bindung bestimmter Melodien an bestimmte Orte rekurriert. Hierdurch können z.B. Immersion und Involviertheit des Spielers gesteigert werden, es hat aber auch noch weitere Konsequenzen, wie Whalen selbst konstatiert.

In the Lost Woods, the looping theme music [...] extends and elaborates Saria's song in a straightforward »theme and variations « structure. Thus, the musical heuristic merges with the fictional space of the Lost Woods' theme. Similarly, the »Temple of Time Theme« restates the »Song of Time« with a chorale effect mimicking a cathedral's echoing dimensions. (ebd.)

Somit schafft Ocarina of Time eine Verbindung zwischen den NPCs, die für Orte charakteristisch sind und diesen Orten via Musik; die Verwendung von Musik an diesen Orten in Ocarina of Time dient insofern als Vorausdeutung auf Lieder, die der Spieler erst im späteren Spielverlauf erlernt, die aber unbewusst schon auf diese Art und Weise vertraut gemacht werden sollen. Dergestalt wird also nicht nur ein narratives Erleben durch die musikalische Gestaltung verstärkt, indem eine narrative Immersion in Diegese oder narrative Charaktere befördert wird, der ganzheitliche Bezug der Designphilosophie Miyamotos trägt hier dazu bei, das Eintauchen bzw. das Erleben des Spiels im Allgemeinen zu bestärken. Die Beziehungen, die die Musik in Ocarina of Time zwischen Orten und Figuren bzw. zwischen Orten und anderen ludischen Objekten erzeugt, evozieren eine Vertrautheit, die die ,Bewohnbarkeit` der interaktiv-narrativen Spielwelt durch den Spieler erhöht. Dies kann man auch daran deutlich machen, dass Musik zwar immersionssteigernd eingesetzt wird, dass es aber noch andere interaktive Funktionalisierungen gibt. So macht die Musik nicht nur ,freundliche' Orte ,freundlicher', sie zeigt auch gefährliche Situationen an, indem die Musik

\footnotetext{
${ }^{545}$ Diese Formen des Erlebens werden in der Fankultur selbst oft unter dem Begriff der ,epicness' verhandelt. Ins Deutsche übersetzt meinen Fans mit ,episch' aber keinen Bezug auf das Narrative, sondern verwenden die deutsche Übersetzung wie das englische ,epic' (,monumental', ,unglaublich' etc.). Bezeichnet werden mit diesem Terminus somit Momente bzw. die damit verbundenen Gefühlslagen, die von einer sehr positiven Rezeptionserfahrung geprägt sind, die bis zu Formen starker Erhabenheit reichen kann.
} 
in diesen ,dramatischer ${ }^{6546}$ gestaltet wird, wohingegen sie in sicheren Umgebungen ,neutral ${ }^{\star}$ klingt. ${ }^{547}$

Eine umfassende Analyse des ,Erfahrungsraumes“ Hyrule steht also vor der Herausforderung, den Fokus bisheriger Analysen in den Digital Game Studies zu erweitern und sich von Positionen zu entfernen, die sich auf welche Weise auch immer aus ludologischen oder narratologischen Perspektiven ableiten. Dennoch lassen bereits diese kurzen Blicke auf die interaktiv-narrative Spielwelt von Ocarina of Time einige Rückschlüsse zu, die v.a. Hyrule als ,Erfahrungsraum' betreffen und welche Rolle Miyamotos Designphilosophie hierbei spielt. Deshalb kann man dieses Unterkapitel mit der treffenden Schlussfolgerung von Jennifer deWinter schließen.

Miyamoto is not simply telling stories (indeed, he tells interviewers often that he leaves storytelling to the writers); he is providing spaces where I can play a game, allowing the story to unfold on the basis of my action, and allowing me to interpolate myself into imaginary worlds. $I$ get to play in the caves of Sonobe; $I$ get to return to the playgrounds of my youth. (DEWINTER 2015, 56; Herv.i.O.)

\subsubsection{Das Designparadigma}

Auf der Attributebene wurde bereits festgestellt, dass die interaktiv-narrative InteraktivitätNarrativität von Ocarina of Time eher interaktiv ausgerichtet ist. Dies lässt sich z.B. daran festmachen, dass die interaktiven Elemente und Phasen die narrativen quantitativ gesehen deutlich dominieren. So macht der zweite Akt der Heldenreise ca. 90\% der Gesamtspielzeit von Ocarina of Time aus, ist aber zugleich auch der Akt, dessen mediale Narrativität am schwächsten ausgegrägt ist. Diese eher interaktiv ausgerichtete interaktiv-narrative attributive Hybridität von Ocarina of Time findet aber auch Ausdruck in einem interaktiv-narrativem Designparadigma mit interaktiver Ausrichtung. So ergab die Analyse, dass das (mythologische) Narrativ (als Monomythos) in diesem Spiel primär dazu verwendet wird, um das Interaktiv zu unterstützen. Einerseits richten sich die substantialistischen Aspekte des (Mono-)Mythos nach den mythophilen Präferenzen der Spieler, die sich im ,Patchwork Mythos' von The Legend of Zelda verdichten. Andererseits werden die strukturierendordnenden Funktionen des (Mono-)Mythos vom Designteam eingesetzt, um dem Spieler das Verständnis des dominanten Spielprinzips zu erleichtern, das Gameplay zu unterstützen, die Steuerung des Spielers in einer offenen Spielwelt gemäß den Dichotomien des Monomythos

\footnotetext{
546 Vgl. zur Musik als dramtischem und interaktivem Element in digitalen Spielen ERNST (2018). Zur Dramaturgie digitaler Spiele unter dem Aspekt ihrer Wirkungspotenziale im Kontext interaktiven Erzählens vgl. BREITLAUCH (2008).

${ }^{547}$ Vgl. dazu das unter ,Object 10‘ in WHALENs (2004) Artikel aufgeführte musikalische Beispiel aus Ocarina of Time.
} 
zu ermöglichen, die moralischen Anlagen des Interaktivs als ,geschlossenes ethisches System“ durch die moralischen Positionen des Monomythos zu legitimieren, den Ludus des Interaktivs durch den Monomythos narrativ zu rahmen oder durch die narrativen Figurenkonzeptionen Identifikationsangebote zu schaffen.

Im Zusammenhang des mythologischen Interaktiv-Narrativs wird das mythologische Narrativ also in das Interaktiv integriert, die Funktionaliserung des Monomythos orientiert sich an dem Interaktiv und unterstüzt dieses, indem z.B. spielrhetorische Redundanzen narrativ kaschiert werden. Detaillierter lässt sich die interaktive Ausrichtung des interaktivnarrativen Designparadigmas von Ocarina of Time aber mit Blick auf Figuren-, Struktur- und Weltdesign herausstellen. Der Avatar existiert in Ocarina of Time z.B. weniger als Enität, die sich aus der Simultanität von Spielfigur und narrativem Charakter generiert wie in aktuelleren interaktiv-narrativen digitalen Spielen, sondern er entsteht erst in der Zusammenschau beider. Hierbei bleibt aber stets die Spielfigur im Avatar dominant, der narrative Charakter unterstützt diese lediglich, indem er bspw. die Handlungsoptionen der Spielfigur narrativ plausibilisiert. Dennoch ist aber eine interaktiv-narrative attributive Hybridität in Bezug auf den Avatar zumindest implizit vorhanden, denn die gegenseitigen Bezugnahmen beider Figurentypen aufeinander bzw. die Problemlosigkeit dieser Bezüge verdeutlichen, dass die figurative Hybridität im Interaktiv-Narrativ angelegt ist, auch wenn sie sich nicht simultan manifestiert. Ähnlich stellt sich dies im Kontext des Weltdesigns dar, wo der interaktive Spielraum die narrative Diegese quantitativ wie qualitativ deutlich beherrscht. Aber auch hier ist im ,Erfahrungsraum‘ Hyrule die welthafte Hybridität implizit angelegt und entfaltet sich in den gegenseitigen Bezugnahmen. Man kann also konstatieren, dass sich die polyvalenten Elemente in Ocarina of Time durch eine gewisse Reziprozität auszeichnen, dass die attributive Hybridität, selbst wenn sie nicht simultan zutagetritt, dennoch stets latent mitschwingt und sich in der Fähigkeit zur gegenseitigen Bezugnahme niederschlägt, auch wenn die interaktiven Elemente im Vordergrund stehen.

Das ,Machtgefälle‘ zwischen Interaktiv und Narrativ ist im Bereich des Strukturdesigns am geringsten ausgeprägt, was v.a. daran ersichtlich wird, dass die Verbindung zwischen Quest- und Erzählstruktur im Rahmen der interaktiv-narrativen Spielstruktur stärker ausgeformt ist als beim Figuren- oder Weltdesign. Diese sind zwar im Sinne einer impliziten Reziprozität miteinander verbunden, sind explizit gesehen aber voneinander getrennt. Beim Strukturdesign ist diese Beziehung zwischen interaktiven und narrativen Elementen nicht nur implizit, sie wird explizit und dies hat zur Folge, dass das Interaktiv das Narrativ mit Blick 
auf das Strukturdesign nicht derart stark dominiert, wie es der Vergleich mit den anderen beiden Designarten nahelegt. Mit anderen Worten: die Doppelhelixstruktur bestehend aus Quest- und Erzählstruktur ist die markanteste Manifestation einer ausgewogenen attributiven Hybridisierung interaktiver und narrativer Elemente in Ocarina of Time. Letztlich können interaktiv-narrative digitale Spiele aber auch abweichend von ihrem Designparadigma umgesetzt werden. Das Designparadigma stellt so etwas wie die intendierte Umsetzung dar, wie das Spiel aber tatsächlich umgesetzt wird, hängt vom Spieler und vom konkreten Einzelfall ab. Deshalb gilt im finalen Teilkapitel nun auch die Aufmerksamkeit der Realisierung.

\subsubsection{Analyse anhand der Realisierungsebene}

Auf der Realisierungsebene fokussiert sich das Kontinuumsmodell auf den Spielprozess, also darauf, wie Spieler konkret die vom Design intendierten Anlagen wahrnehmen und ausagieren. Die Interaktion-Narration als konkrete Umsetzung dieser designerischen Anlagen interaktiv-narrativer digitaler Spiele ist somit stets eine Auseinandersetzung zwischen Spieler und Spielsystem, wobei Fragen danach virulent sind, wie frei die Interaktion-Narration (im jeweiligen Fall) vom Interaktiv-Narrativ, wie individuell die Interaktion-Narration tatsächlich ist. Um derartigen Fragestellungen folgen zu können, geht die Arbeit wie in 2.5.3 beschrieben vor. Das bedeutet, dass v.a. die Spielertypen im Vordergrund stehen. (4.2.3.4) Zuvor werden aber die realen und virtuellen Interaktionen des Spielers in Ocarina of Time ebenso betrachtet (4.2.3.1) wie die mediale Narration anhand eines ausgewählten Beispiels (4.2.3.2) oder personale Narrationen ausgehend von Ocarina of Time. (4.2.3.3) In diesem Kontext sei nochmals ausdrücklich darauf verwiesen, dass die kommenden Ausführungen nicht auf eigenen breit erhobenen quantitativ-empirischen Daten beruhen, die mediensoziologisch gewonnen wurden. Das Folgende erhebt also keinen Anspruch darauf, statistisch gesehen repräsentativ zu sein. Dies betrifft inbes. alle Unterkapitel bis auf 4.2.3.2. Stattdessen stützen sich diese Überlegungen zum einen auf die vorhandene Forschungsliteratur und zum anderen auf ausgewählte Beispiele aus der Fankultur, die hinzugezogen werden, da sie für den jeweiligen Fall als paradigmatisch angesehen werden.

\subsubsection{Reale und virtuelle Interaktionen}

In diesem Unterkapitel werden reale Interaktionen, wie sie in 2.3.5 dargelegt wurden, weitestgehend ausgeblendet. Dies liegt aber weniger an ihrer Irrelevanz für Ocarina of Time als vielmehr an dem Zuschnitt des Forschungssettings der vorliegenden Studie. So sind 
einerseits die Wahrnehmungen bzw. kognitiven Fähigkeiten der Spieler entscheidend, wenn es darum geht, die Spielwelt wahrzunehmen oder Veränderungen dieser oder Reaktionen des Systems auf Eingabe der Spieler zu erkennen, um im ,realen` Raum interagieren zu können. Dies kann aber nur unter Zuhilfenahme kognitionswissenschaftlicher Instrumente adäquat geleistet werden, was den Rahmen dieser Arbeit überschreitet. ${ }^{548}$ Andererseits kann in dieser Arbeit die Rolle der Schnittstelle und deren Bedeutung für die realen Interaktionen des Spielers nicht ausreichend gewürdigt werden, was gerade deshalb besonders interessant wäre, da der Controller des N64 in Fachkreisen in dem Ruf steht, ergonomisch sehr gelungen zu sein. ${ }^{549}$

Stattdessen liegt der Fokus auf den virtuellen Interaktionen bzw. deren Rückkopplung an die Wahrnehmung des Spielers. Es ist v.a. im Kontext dieser Arbeit interessant, welche Rolle mythologische oder religiöse Elemente hierbei spielen. Die theologische und philosophische Forschung zu The Legend of Zelda ist dabei immer wieder auf einen Punkt eingegangen, der unter 3.4.1.2 bereits kurz angerissen wurde: die Entrückungsfunktion. So merkt Philip Tallon etwa an: „Many, many players experience in the land of Hyrule not merely excitement, but enchantment.“ (TALlON 2011, 54) Die Erfahrung, die viele Spieler beim Spielen von The Legend of Zelda-Spielen offenbar machen, ist somit keine, die auf Erregung, Begeisterung oder Spannung beruht, wie sie viele populäre Unterhaltungsmedien im Zuge ihrer immersiven Potenziale auslösen können, sie geht darüber hinaus, sie verzaubert und entzückt den Spieler und erhält hierdurch eine mythisch-religiöse Dimension. ${ }^{550}$ Die damit einhergehende Immersion trägt deshalb auch hochgradig entrückende Züge. Mark Hayse greift diesbezüglich auf den Begriff der ,Sehnsucht` zurück. „Sehnsucht indicates a deep longing or yearning for

\footnotetext{
${ }^{548}$ Einen guten Überblick zu kognitionswissenschaftlichen Zugängen zur Analyse digitaler Spiele bieten bspw. PERRON/SCHRÖTER (2016).

549 Überhaupt gilt Nintendos Interfacedesign als sehr innovativ wie intuitiv. Vgl. zum Interfacedesign allgemein STAPELKAMP (2010). Technologisch fällt auf, um ein Beispiel zu nennen, dass Nintendos Spiele selten unter ,Input lags` leiden, d.h. es entstehen keine auffälligen Verzögerung zwischen der Eingabe in die Schnittstelle und der visuellen Ausgabe am Bildschirm. Dies könnte u.U. ein Ausdruck der Bedeutung sein, die führende Nintendo-Mitarbeiter wie Miyamoto dem Interfacedesign beimessen. Mit Blick auf Ocarina of Times Interfacedesign sind bspw. auch Fragen danach von Interesse, inwiefern sich die realen Interaktionen des Spielers von Ocarina of Time durch die verschiedenen Neuauflagen des Spiels auf diversen Nintendoplattformen voneinander unterscheiden.

${ }^{550}$ Die von Tallon hier angesprochene, Verzauberung' lässt sich in der Fankultur in vielfacher Weise finden. So sind nicht nur die einzelnen medialen Fanartefakte Manifestationen dieses ,Zaubers', sondern auch ihr Entstehungsprozess und die Rolle, die sie im Leben von hochengagierten Fans einnehmen. Hier liegt aber auch der Punkt: die Verzauberung lässt sich vornehmlich bei Fans aufzeigen, deren Immersion in die transmediale Welt von The Legend of Zelda ganz massiv ist. Um also valide ermitteln zu können, wie die entrückenden Potenziale moderner Mythen der digitalen Medienkultur auf Nutzer wirken, müssten umfangreiche mediensoziologische Erhebungen durchgeführt werden, die verschiedene Nutzertypen berücksichtigen, um verlässliche Aussagen treffen zu können. Derartige Studien stehen aber leider noch aus.
} 
something elusive and heavenly.“ (HAYSE 2011, 88; Herv.i.O.) Dieses sehnsuchtsvolle Verlangen nach dem kaum Fassbaren, dem Himmlischen ist für Hayse ein Moment der Transzendenz. Dieses Moment erkennt auch D.M. Burke in The Legend of Zelda.

Years later [...] I came to realize a vital reality that is reflected in Link's quest and the necessity of the Triforce for Ganon's defeat: in order to defeat evil, or for even the ability to define evil, something transcendent, something outside of ourselves, something beyond the physical world, is necessary. (BURKE 2011, 157)

Das mythophile Setting der The Legend of Zelda-Spiele evoziert mythisch-religiöse oder quasi-religiöse Erfahrungsmomente, die den Spieler lockend aus seiner realen Welt ziehen, die Dinge verheißen, die sich von der Immersion nicht-religiöser Mediennutzung abheben. Dabei ist entscheidend, dass der Spieler akzeptiert, dass etwas außerhalb seiner selbst, außerhalb des Spieles entsteht, das nicht unmittelbar fassbar ist. ${ }^{551}$ Diese unmittelbaren Kräfte sind entscheidend, denn sie tragen auch zum enigmatischen Charakter von Adventure-Spielen bei, auch wenn sie im Laufe des Spiels zunehmend abgebaut werden. ${ }^{552}$ Damit geht aber zugleich eine andere Form der Transzendenz einher. „In these ways, the experience of Link and the player can be described as a shared journey of self-transcendence.“ (HAYSE 2011, 90) Der Spieler transzendiert sich selbst in das Spiel hinein, indem er im Sinne SIVAKs (2009)

\footnotetext{
${ }^{551}$ Grundsätzlich zeigen Phänomene wie die ,Desäkularisierung', dass Subjekte auch im digitalen Zeitalter noch nach Sinn, Erfahrung und Erfüllung in religiösen und mythischen Sphären suchen. Vgl. BERGER (1999). Es ist in diesen Kontexten jedoch auch deutlich geworden, dass diese Tendenz größtenteils an den historischen Religionen vorbeigeht. Was im ersten Moment paradox wirkt, lässt sich vor dem Hintergrund der populärkulturellen Religionskritik illustrieren, wie Die Simpsons (1989 ff.) sie als Repräsentant großer Bevölkerungsteile der westlichen Welt artikulieren. Hier wird eine Skepsis offenkundig, die sich vornehmlich gegen die Organisationen von Religion sowie deren Dogmen und Werte richtet. Man könnte auch sagen, dass Kritik an der institutionellen Seite von Religionen geübt wird. Nun ist es aber schwierig, Religion als gemeinschaftliche Praktik auszuüben, wenn man die institutionellen Aspekte ablehnt. Der Religionssuchende muss in diesem Fall auf Subjektreligionen zurückgreifen, die aber seinem Bedürfnis nach sozialen Aktivitäten nicht entsprechen könnten. Ist dies der Fall, so benötigt der Religionssuchende eine gemeinschaftlich praktizierte Religion, die aber nicht institutionalisiert ist, die er zum Teil seines Lebens machen, die aber ohne weiteres auch wieder aus diesem entfernen kann. So lassen sich dann m.E. auch die mythophilen Bestrebungen von Millionen Fans in der digitalen Medienkultur erklären. Dort tritt ihnen ein breites Angebot entgegen, aus dem sie das passende zu ihren eigenen Konditionen auswählen können. Den performativen digitalen Medien wie digitalen Spielen kommt dabei die Rolle zu, dass diese nicht nur die passive sondern auch die aktive Teilhabe ermöglichen. Auf diese Weise werden Erfahrungen wie Transzendenz erlebbar, um Sinn außerhalb der eigenen immanenten Lebenswelt zu suchen, wozu aber nicht umfangreichere und sozial u.U. restriktivere Moralkodizes akzeptiert werden müssten.

${ }^{552}$ Wer einen Eindruck davon erhalten möchte, wie groß der Einfluss von populärkulturellen Mythen und Religionen auf Nutzer von transmedialen Welten aktuell ist, dem sei empfohlen, sich auf einen Streifzug durch die unzähligen Youtube-Videos zur Religion in Tolkiens Werk zu begeben. Dort wird er kreative Produzenten finden, die einen wirklich immensen Output an medialen Fanartefakten erzeugen, er wird aber auch auf Millionen von Nutzer treffen, die diese Angebote rege frequentieren, kommentieren, teilen und diskutieren. Dabei fallen insbes. die Diskurse über die Leerstellen auf, die zu Fantheorien einladen. Fantheorien sind aber letztlich nichts Anderes als das Lösen von Rätseln, die sich daraus ergeben, dass Fans bestehende Unklarheiten beseitigen und ,Lücken' auffüllen wollen. Somit wird das Enigmatische der diskutierten Religionen und Mythen zwar immer weiter entschlüsselt, hierbei werden jedoch neue Mythen entdeckt, die dann wieder enträtselt werden müssen usw. Insofern sind diese Fandiskurse über Religionen und Mythen persistente Kommunikationsund Interaktionsprozesse, die aus der Faszination für das Unbekannte hervorgehen.
} 
zum Helden wird; die Heldenwerdung ist die Selbsttranszendenz des Spielers ins Spiel. Diese gelingt, wie WeSSELY (1995) betont, indem der Spieler via Avatar virtuelle Interaktionen ausführt, die dem Spieler das Gefühl geben, den (Mono-)Mythos zu leben. Dabei ist nicht zu vernachlässigen, dass das spielinterne Schnittstellen-Element, der Avatar Link, als narrativer Charakter der auserwählte Held, das Erlösungsmedium per se ist. Durch Link werden die ludischen Handlungen des Spielers somit zu mythologischen Erlösungshandlungen, der Spieler transzendiert sich selbst zum Helden und wird hierdurch in einem mythisch-religiösen Sinne entrückt.

Durch den reziproken Charakter von Interaktionen ist aber nicht nur bemerkenswert, wie Spieler interagierend entrücken, es ist auch bedeutsam, welche Folgen der entrückte Zustand für die realen wie virtuellen Interaktionen des Spielers haben kann. Nehmen wir als Beispiel ein mögliches Szenario aus dem finalen Kampf gegen Ganondorf in Ocarina of Time. Der Spieler ist in der letzten Phase des Endkampfes angelangt, Ganondorf hat seine dämonische Form Ganon angenommen und der Spieler konnte diesem bereits erheblichen Schaden zufügen, hat aber selbst kaum noch Lebensenergie, sodass zu befürchten steht, dass der nächste Treffer Ganons der letzte sein könnte. Sportpsychologisch ${ }^{553}$ sind zwei Handlungsweisen des Spielers denkbar. Erstens wird der Spieler seiner geringen Lebensenergie gewahr und agiert in der Folge extrem vorsichtig, um nicht getroffen zu werden. Zweitens nimmt der Spieler zwar ebenfalls wahr, dass er kaum noch über Lebensenergie verfügt, aber anstatt zu verzagen und eher defensiv zu agieren, geht er in die Offensive, um Ganon den finalen Schaden beizubringen. Ist die Heldenwerdung des Spielers abgeschlossen, ist er zum Helden, zum Weltenretter geworden, so wird es wahrscheinlicher, dass er all seinen Mut (zugleich Links Triforce-Fragment) zusammennimmt und Ganon entschlossen angreift, um die Welt vom Bösen zu erretten. ${ }^{554}$ Gelingt dem Spieler nun durch geschickte Interaktionen der Sieg über Ganon, so kann sich das Glücksgefühl des Sieges mit dem Entrücken verbinden und den Zustand des Entrücktseins verstärken. Diese durch Interaktionen induzierten wie auch interaktiv ausagierten Entrückungsmomente können dabei auch wörtlich die Grenzen des Spiels transzendieren. Neben die primären, direkt auf das Spiel bezogenen realen und virtuellen Interaktionen treten die ,sekundären' realen und virtuellen Interaktionen, die sich auf die Fangemeinde beziehen.

\footnotetext{
${ }^{553}$ Vgl. zur Sportpsychologie einführend ALFERMANN/StOLl (2016).

${ }^{554}$ Das soll jetzt nicht heißen, dass nicht auch ,profanere‘ Motivationen (wie den Endgegner zu besiegen) geeignet sind, um den Spieler dazu anzuhalten, weiter zu kämpfen. Es soll hier lediglich darauf aufmerksam gemacht werden, dass die Bereitschaft, einen finalen Angriff zu starten, bei Spielern höher sein kann, wenn diese die Immersion in den mythologischen Helden vollzogen haben.
} 
Zelda appears to be a single-player game, forcing player isolation. However, Miyamoto has explained that he wanted people to go to work and talk about the game, share tips, and build community through communication about experiences. (DEWINTER 2015, 44; Herv.i.O.)

Auch wenn die virtuellen Interaktionen Ausgangspunkt der Beschäftigung mit der transmedialen Welt von The Legend of Zelda sind, so sind sie jedoch keinesfalls auch deren alleiniger Zielpunkt. Vielmehr können aus jenen virtuellen Interaktionen schnell soziale Interaktionen im ,realen` Raum werden. Diese soziale Komponente des Spiels verstärkt sich noch durch das Internet bzw. die Kommunikations- und Vernetzungsmöglichkeiten, die dieses bietet und hierdurch zur Bildung von Online-Fangemeinschaften beiträgt. Somit zeigt sich, dass nicht nur die primären realen und virtuellen Interaktionen zwischen Spieler und System, sondern auch die sekundären zwischen Spielern im realen oder digitalen Raum von Relevanz für die Erforschung transmedialer Welten wie The Legend of Zelda sind. Die enge Verzahnung zwischen Kunstwerk und dessen sozialer Umgebung lässt sich bspw. an Mods demonstrieren. ${ }^{555}$ Der hier verlinkte Mod stellt hauptsächlich eine grafisch remastered Version der Hylianischen Steppe aus Ocarina of Time mithilfe der Unreal 4-Engine dar, der es den Zuschauern ermöglicht, in diesen bestimmten Abschnitt der transmedialen Welt einen Reentry in aktuellerer digitaler Spielgrafik zu vollziehen. Bemerkenswert ist dabei aber auch, wie dem Mod die Interaktivität der Community eingeschrieben ist, wenn sich der Modder zu Beginn des Videos bei idellen Followern wie materiellen Förderern bedankt. Zugleich setzt der Prozess des Modding aber eine derart intensive Interaktion mit Ocarina of Time voraus, wie sie herkömmliche Spieler kaum erfahren. Der Modder erkundet das Spiel als System nicht nur interagierend, er greift bis auf den Code zurück, um das Spiel umzuformen. Insofern erlauben dezidiertere Analysen primärer wie sekundärer Interaktionen zum einen ein tieferes Verständnis der interaktiven Handlungsoptionen und den aus ihnen hervorgehenden Handlungen und zum anderen gestatten derartige Untersuchungen noch genauere Bestimmungen der beschriebenen Spielertypen bzw. gar Subkategorisierungen, da der Modder in den meisten Fällen als ein sehr spezifischer interaktiver Spieler angesehen werden kann.

\subsubsection{Mediale Narration in Ocarina of Time}

Neben den Interaktionen zwischen Spieler und System kann die mediale Narration von Ocarina of Time zuweilen in den Hintergrund treten. Es wurde bisher mehrfach betont, dass die interaktiven Komponenten des Spiels die narrativen quantitativ überwiegen und dass die

\footnotetext{
555 Vgl. dazu exemplarisch den folgenden Mod via Unreal 4-Engine von CRYZENX https://www.youtube.com/watch?v=FFx38t4ydY0 (30.06.2018).
} 
Rolle des Narrativen oft eher eine unterstützende ist. Dennoch und trotz Miyamotos eher geringschätzenden Beurteilungen der medialen Narrativität seiner digitalen Spiele verfügt Ocarina of Time über einige Phasen medialer Narration, die künstlerisch aufwendig gestaltet worden sind. Exemplarisch wird im Folgenden deshalb eine narrative Cutscene betrachtet, anhand deren Machart sich sehr wohl verdeutlichen lässt, dass Ocarina of Time als interaktivnarratives digitales Spiel anzusehen ist. Die zweite Form der medialen Narration, jene via Textboxen, wird bei dieser Analyse vernachlässigt, was aber kurz thematisiert werden soll. Die meisten kommunikativen Akte des Systems via Text haben tendenziell einen deskriptivinformativen Charakter, vermitteln Wissen an den Spieler oder geben Anweisungen oder Unterweisungen zur Nutzung des Interfaces. Auch wenn die letzte Art von Texten deutlich den diegetischen Rahmen verlässt, somit als nicht-narrativ zu klassifizieren ist, so können viele andere Texte als Grenzfälle zwischen faktualer Vermittlung und fiktionalem Aufbau angesehen und letztlich nur im Einzelfall zuverlässig entschieden werden. Überhaupt ist das Verhältnis zwischen Deskription und Narration als Modi der Weltwahrnehmung und darstellung in der Narratologie bisweilen sehr unterschiedlich bewertet worden. „Description by itself is not enough to constitute a narrative, but narrative itself does not exclude description.“ (TODOROV 1971, 38) Todorov markiert zwar deutlich, dass es sich um zwei verschiedene Modi handele und dass der narrative zwar teilweise deskriptiv sein könne, sich aber keinesfalls hierin erschöpfe, es wird aber keine exakte Grenzziehung bzw. der Versuch vorgenommen. ${ }^{556}$

Dieser Versuch bleibt auch hier aus, zumal seine Klärung nicht nur die textuelle mediale Narration betrifft, sondern auch die filmische. Denn nicht alle Cutscenes in Ocarina of Time können als narrativ klassifiziert werden, einige dienen u.a. dazu, einen Eindruck, eine grafische Beschreibung bestimmter Orte und Raumverhältnisse zu schaffen. Von derartigen Grenzphänomenen wird im Folgenden abgesehen. Als Beispiel wird deshalb eine Cutscene gewählt, die eindeutig als medial narrativ einzuordnen ist. ${ }^{557}$ Nachdem Link das Masterschwert aus dem Zeitenfels gezogen hat, beginnt der Übergang Links in das Heilige Reich, der durch eine Kamerafahrt nach oben den Eindruck der Bewegung unterstützt. Die

\footnotetext{
${ }^{556}$ Zum Verhältnis zwischen Deskription und Narration vgl. auch Chatman (1993), 74 f. Zudem wurde in der Narratologie immer wieder thematisiert, inwieweit sich Deskription und Interpretation im Rahmen von narratologischen Analysen voneinander trennen lassen, indem bspw. danach gefragt wurde, ob Textbeschreibungen nicht auch schon Textdeutungen sind. Vgl. dazu den Überblick bei KöPPE/KINDT (2014), 34 ff.

${ }^{557}$ Vgl. dazu das folgende Let's Play von COUNTBLECK2009 https://www.youtube.com/watch?v=LIbmCd-GPfw (30.06.2018).
} 
folgende Szene stellt filmsprachlich wie musikalisch eine Zäsur dar. Die dramatische musikalische Untermalung suggeriert ein kommendes Übel, das sogleich mit Ganondorf ins Bild gerät, der in einem ,Close Up“ gezeigt wird und der im Rahmen seiner hier narrativen Figurenrede expliziert, dass er nun endlich Zugang zum Heiligen Reich erlangt habe und dass anscheinend Link als Türöffner hierfür verantwortlich sei. Nachdem Ganondorf ausgeblendet wird, erscheint ein textueller Erzähler aus dem Off, der Link, den Auserwählten, zurückholt aus der weißen Leere des Übergangszustandes. ${ }^{558}$ Hatte sich beim Übergang die Kamera noch gehoben, so senkt sie sich nun und symbolisiert hierdurch die Rückkehr Links aus dem Nichts. Dieser orientiert sich inszeniert als subjektive Kamera aus dem Point of View des narrativen Charakters in einer ihm (und dem Spieler unbekannten Welt). Nach einigen umherirrenden Blicken fixiert die subjektive Kamera schließlich einen alten Mann, der sich sogleich als Rauru vorstellt. Wiederum im Close Up klärt dieser Link nun darüber auf, wo er sich befindet und fordert diesen auf, sich zu selbst anzublicken.

Als Close Up sinkt die Kamera als Gegenschuss aus Raurus Perspektive von oben auf Link herab, zeigt den erwachsen gewordenen Helden und weicht in eine Halbtotale zurück, um diesen vollständig zu abzubilden. An eine verkantete Kamera schließt sich nun eine Totale an, die in einem spiralförmigen Kameraschwenk vor Link fährt und diesen in einer Nahaufnahme zeigt, während Rauru die vergangenen Ereignisse mittels textueller medialer Narration erzählt. Hierbei werden die von Ganondorf in der zweiten Szene artikulierten Vorwürfe, Link sei daran schuld, dass Ganondorf ins Heilige Reich eindringen konnte, aktualisiert. Aktualisiert wird auch der Ruf des Abenteuers, indem Rauru betont, dass es nun Links Aufgabe sei, die Weisen erneut zu erwecken. Auffällig ist bei der Aktualisierung des Rufes, dass die vorher so bewegte Kamera in dieser Szene statisch in einer Halbtotalen verharrt, die beide einander gegenüberstehende Figuren zeigt, als solle der Spieler nicht von den

\footnotetext{
${ }^{558}$ Strukturell betrachtet ist die gesamte narrative Cutscene wie ein Ritual im Sinne Victor TuRNERs (2005) aufgebaut. Nach dem Entfernen des Masterschwerts aus dem Zeitenfels tritt Link in die Trennungsphase ein, die nach Ganondorfs Monolog in die Schwellenphase übergeht, ehe Link in der Angliederungsphase nach Hyrule zurückkehrt. Interessant ist dabei zweierlei. Einerseits gelangt und verlässt Link die Schwellenphase stets begleitet von Raurus Narration aus dem Off. Raurus Figur bestimmt somit nicht nur die Schwellenphase, sondern auch die Übergänge zwischen den Ritualphasen. Andererseits wird hierdurch deutlich, dass jeder Abschnitt von einer anderen narrativen Figur dominiert wird. In der Trennungsphase Ganondorf, in der Schwellenphase Rauru und in der Angliederungsphase Shiek. Die damit verbundenen Archetypen des Monomythos sind in diesem Kontext von Bedeutung. In der Trennungsphase stört der Antagonist das Gleichgewicht, in der Schwellenphase aktualisiert der neue Herold den Ruf des Abenteuers und in der Angliederungsphase begegnet Link seinem neuen Verbündeten bzw. Mentoren. Diese ritualtheoretische Betrachtung illustriert, dass der Monomythos nicht nur die gesamte Erzählstruktur bestimmen kann, sondern auch kleinere narrative Einheiten wie Cutscenes, die zumindest mit Versatzstücken des Monomythos arbeiten.
} 
spielerisch wichtigen und textuell vermittelten Informationen durch allzu überbordenden Einsatz von narrativen filmsprachlichen Mitteln abgelenkt werden.

In diesem Zusammenhang ist auch interessant, dass die Übergabe des Amuletts von Rauru an Link zwar aus einer Halbtotalen hinter diesem stehend beginnt, dass sich die Kamera als eine gewissermaßen angedeutete subjektive Kamera aber nach oben und dem Amulett entgegen bewegt. Im Anschluss fällt die Kamera dann auf Link herab, um umgehend von einer Nahaufnahme abgelöst zu werden, die den Erhalt des Amuletts darstellt. Erneut blendet die Kamera aus, um die endgültige Rückkehr des Helden in die gestörte Welt anzukündigen, die erneut von einem aus dem Off erzählenden Rauru begleitet wird. Stieg die Kamera beim Übergang ins Heilige Reich noch auf, so fährt sie bei der Rückkehr nach Hyrule herab, um in einer Halbtotalen hinter Link zu verharren und dessen Ankunft in Hyrule zu bezeugen. ${ }^{559}$ Wie im Heiligen Reich wird der Kreis, dessen Zentrum der Zeitenfels bildet, erneut aus einer Totalen gezeigt, wobei die Kamera erneut statisch positioniert ist, während Navi dem Spieler wichtige spielerische Informationen über seine Ausrüstungsgegenstände mitteilt. Hinter einem sich vom Zeitenfels entfernenden Link erscheint ein unbekannter narrativer Charakter, der anfänglich nur kurz in einem Close Up dargeboten wird. Das folgende SchussGegenschussverfahren beschleunigt die Szene, indem (was durch das Ziehen des Masterschwerts unterstrichen wird) eine Drohkulisse aufgebaut, die durch das abrupte Wegfallen von Musik und Atmospur noch herausgestellt wird.

Sobald die ,freundliche' Musik einsetzt, verfliegt das Gefühl der Gefahr und die Ausführungen des Unbekannten werden (wie die Aktualisierung des Rufes des Abenteuers durch Rauru) in einer Totalen dargestellt, nur dass die Positionen der narrativen Charaktere vertauscht sind. Diese Ausführungen dienen aber weniger dem Ausbau der medialen Narration, sie sind Präzisierungen der von Rauru angedeuteten Aufgabe, die Weisen finden zu müssen. Nachdem der Unbekannte die Aufenthaltsorte der Weisen nennt, wechselt die Kamera in ein Close Up des Unbekannten, der sich als Shiek vorstellt. Während dieser vom auserwählten Helden spricht, fährt die Kamera an Link hinauf. Gerade diese Phase ist von Kamerawechseln geprägt, eine herauszoomende Totale wird von einer hereinzoomenden Nahaufnahme abgelöst, welche wiederum in eine hinter Link stehende Halbtotale mündet, ehe

\footnotetext{
${ }^{559}$ Die Auf- und Abfahrt der Kamera beim Phasenwechsel im ritualtheoretischen Sinne kann in diesem Kontext auch als ein Marker betrachtet werden, der transzendentale narrative Momente indiziert, ergo den Übergang vom diesseitigen Hyrule ins jenseitige Heilige Reich.
} 
die Sequenz mit dieser statischen Kameraperspektive und einer abschließenden Informationsvermittlung endet.

Einerseits kann man feststellen, dass die perlenkettenartige Interaktivität-Narrativität von Ocarina of Time auch dieser Sequenz eingeschrieben ist, da in den informativen und auf das Spiel bezogenen Phasen die mediale Narrativität der Filmsprache reduziert wird. Andererseits folgt die gesamte Sequenz aber sehr stark der Filmsprache narrativer Spielfilme. ${ }^{560}$ So ist sie nicht nur in die narrativen filmischen Einheiten Einstellung und Szene unterteilt, sie folgt auch einem narrativen Bildaufbau und Kameraperspektiven, die gemeinsam mit den textuell medial narrativen Passagen eine vollständig abgeschlossene narrative Sequenz präsentieren. Darüber hinaus ist diese Sequenz von der Erzählstruktur her betrachtet von zentraler Wichtigkeit für den zweiten Akt der Heldenreise. Die Welthaftigkeit dieser Sequenz ist fast ausschließlich (bis auf die wenigen Abschnitte, die auf den Spielraum verweisen) diegetisch geprägt, stellt jene Zeit und jenen Ort dar, indem das Gleichgewicht endgültig gestört wird und wird von narrativen Charakteren wie dem Helden, dem Antagonisten, dem Herold und Verbündeten (und einem Hauch des Schattens zu Anfang des Auftritts von Shiek) geprägt, die für den Monomythos charakteristisch sind. Die Achsen der Kamera (v.a. die horizontale) werden gezielt eingesetzt, um zwischen Einstellungen und ganzen Szenen zu wechseln und auch die konfigurative Macht der Montagetechniken narrativer Spielfilme findet Entfaltung. Die Stimmigkeit der medialen Narration dieser Cutscene wird auch daran deutlich, dass deren Ende, der schnittlose Übergang zurück in die interaktive Phase, sehr hart und unvermittelt wirkt.

Die anderen narrativen Cutscences weisen eine ähnliche Komplexität der medialen Narration auf und lassen sich dementsprechend ähnlich analysieren. An dieser Stelle geht es aber nicht darum, alle narrativen Cutscenes zu untersuchen, sondern aufzuzeigen, dass die mediale Narration zwar quantitativ deutlich von den realen und virtuellen Interaktionen dominiert sein mag, dass sie aber dennoch, wenn sie stattfindet, (qualitativ ansprechend) Konzepten und Standards der narrativen Filmsprache folgt. Darüber hinaus lässt sich ebenso illustieren, wie die medial narrativen Phasen eingesetzt werden, um personale Narrationen im Spieler zu evozieren. Zum einen, und nachdrücklich von WHALEN (2004) vertreten, hat die musikalische Gestaltung von narrativen Cutscenes nicht bloß als Untermaltung und

\footnotetext{
${ }^{560}$ Neben dem beschriebenen Kameraeinsatz ist diese narrative Cutscene von einem durchgehenden ,Continuity Editing' bestimmt, das neue Einstellungen durch visuell oder auditiv motivierte Blickachsenwechsel stets plausibilisiert und somit zu einer Kohärenz der filmischen Narration beiträgt.
} 
Intensivierung der medialen Narration eine bedeutende Funktion, sie wirkt auch hochgradig personale Narrationen induzierend. (vgl. dazu auch WOLF 2002) Es lassen sich aber noch weitere ,narrative Rezeptionsangebote‘, um es mit den Worten von Markus ENGELNS (2014) zu sagen, in dieser Cutscene finden, wovon eines im folgenden Unterkapitel eingehener betrachtet werden soll.

\subsubsection{Personale Narrationen in Ocarina of Time}

Personale Narrationen von digitalen Spielerlebnissen können in vielerlei Form auftreten, sie können Teil eines Let's Plays sein oder als Fanfiction niedergeschrieben werden. Dabei findet man im Bereich der Fanfiction einerseits Nacherzählungen ${ }^{561}$ und andererseits personale Narrationen, die vollkommen neue Plots entwerfen. ${ }^{562}$ Mit Mark J.P. Wolf gesprochen, kann man auch sagen, dass Fans zum einen adaptieren und zum anderen die transmediale Welt von The Legend of Zelda narrativ ausbauen. (vgl. WoLF 2012, 245) Hierbei beruht v.a. der Ausbau der transmedialen Welt auf der Wahrnehmung und Verarbeitung narrativer Rezeptionsangebote. In der im vorhergehenden Unterkapitel beschriebenen Sequenz gibt es eine Anzahl von narrativen Rezeptionsangeboten, die Fans nutzen können, um Fanfictions anzufertigen. So können personale Narrationen induziert werden, die Ocarina of Time aufgrund der Masterschwert-Symbolik und dessen Auffindesituation näher in Richtung der Artusepik rücken, es können Plots generiert werden, die diegetisch im schemenhaft angedeuteten Heiligen Reich angesiedelt sind oder es können personale Narrationen evoziert werden, die davon handeln, wie Link Hyrule vor Ganondorf rettet, indem er das Masterschwert nicht aus dem Zeitenfels zieht, somit den Zugang zum Heiligen Reich nicht öffnet, den nur er als Auserwählter zu gewähren vermag und dadurch Ganondorf den Zugang zum Triforce versperrt.

Darüber hinaus sind aber auch personal erzeugte Plots denkbar, die von den von Shiek erwähnten Shiekah handeln, einem mysteriösen antiken Elfenvolk Hyrules. Und tatsächlich finden sich zu diesem Volk nicht nur diverse Fantheorien in Wikis, Foren, Blogs und Vlogs, sondern auch Fanfictions. Die Nutzerin CHLOEMORRISON entwirft einen Plot, der von dem narrativen Rezeptionsangebot der obigen Sequenz ausgeht, dieses um Informationen aus Ocarina of Time und anderen Titeln der Hauptserie über die Shiekah anreichert, ehe sie mit

\footnotetext{
561 Vgl. dazu exemplarisch die folgende Nacherzählung der Nutzerin MiKATUK, die bis zum Entfernen des Masterschwertes aus dem Zeitenfels reicht https://www.fanfiktion.de/s/44f139040000044406a01770/1/TheLegend-of-Zelda-Ocarina-of-Time (30.06.2018).

${ }^{562}$ Die Nutzerin SKala entwirft z.B. einen Plot, indem Link und Salia ein gemeinsames Kind haben. Vgl. dazu https://www.fanfiktion.de/s/42a47708000014a806a01770/1/Zelda-Ocarina-of-Time (30.06.2018).
} 
ihrem personalen narrativen transmedialen Weltausbau beginnt. In diesem Plot finden die Shiekah einen dunklen Kristall, den „Diopsid““ ${ }^{563}$ dessen sinistre Kräfte sie fürchten, weshalb sie ihn zu zerstören versuchen, was aber misslingt, da sie ihn nur in neun Teile zu zersplittern vermögen, welche sie anschließend nicht weiter beschädigen können. ${ }^{564}$ Bemerkenswert ist an dieser Fanfiction, dass die transmediale Praxis des Anfertigens und Teilens von personalen Narrationen sich in diesem Fall nicht nur auf Ocarina of Time bezieht, sondern auch andere Titel der Hauptserie wie Twilight Princess, The Legend of Zelda: The Minish Cap (2004), Skyward Sword oder Wind Waker miteinbezieht. ${ }^{565}$ Die Shiekah haben die Kristallsplitter nämlich an verschiedenen Regionen der transmedialen Diegese von Hyrule versteckt, weshalb diese auch an verschiedenen Orten und zu verschiedenen Zeiten wieder in Erscheinung treten.

Der von der Nutzerin erzeugte Plot beginnt im Hyrule von Ocarina of Time nach dem Sieg über Ganondorf. Link, der Held der Zeit, lebt nun als Ritter am Hof von Hyrule, bis er den dunklen Kristall eines alten Händlers berührt und in einem ihm unbekannten Hyrule erwacht, das sich später als das Hyrule aus Twilight Princess herausstellt. ${ }^{566}$ Das dritte Kapitel beginnt in der Welt von Wind Waker, wo Link (der aus Wind Waker) auf seiner Heimatinsel ,Präludien` über einen Stein stolpert und schließlich im (wie sich ebenfalls später herausstellt) Hyrule von Ocarina of Time erwacht. ${ }^{567}$ Hier trifft er auf Links (hier wiederum der aus Ocarina of Time) Schatten (eine Emanation des Helden), (vgl. dazu CAMPBELL 2011, 273 ff. sowie VOGLER 2010, 83) der als Diener Ganondorfs erscheint und unbedingt den Konflikt mit seiner Lichtseite zu suchen scheint und deshalb den jungen Link aus Wind Waker dazu bewegt, ihn ins Schloss zu begleiten. Dort treffen beide auf Prinzessin Zelda, die nach dem verschwundenen Link sucht. Das Kapitel endet mit Salias überraschender Ankunft im Schloss von Hyrule, die vom Tod des Deku-Baums berichtet. Zwei Aspekte, die für diese Fanfiction charakteristisch sind, werden an diesem Kapitel sehr anschaulich. Einerseits wird sehr viel Wert auf die Figurenkonzeptionen und -konstellationen gelegt, was sich in der latent angedeuteten Liebesbeziehung zwischen Link und Zelda ebenso manifestiert, wie in der

\footnotetext{
${ }^{563}$ Eher dunkles, oft grünes Mineral, das nahezu weltweit zu finden ist.

564 Vgl. dazu den Beginn der Fanfiction von ChLOEMorRISON https://www.fanfiktion.de/s/4eceb93000021d8106a01770/1/The-Legend-of-Zelda-Fragments-of-the-old-Shiekah (30.06.2018). Die Thematik der Zerstörung dunkler Artefakte ist gegenwärtig häufiger in transmedialen Welten mit einer Affinität zum Fantasy-Genre anzutreffen. So versucht nicht nur Frodo, den ,einen Ring zu vernichten, sondern auch Harry Potter und dessen Verbündete streben danach, die Horkruxe Voldemorts zu beseitigen.

565 Vgl. dazu insbes. die Anmerkungen zu Beginn von Kapitel 2 https://www.fanfiktion.de/s/4eceb93000021d8106a01770/2/The-Legend-of-Zelda-Fragments-of-the-old-Shiekah (30.06.2018).

${ }^{566} \mathrm{Vgl}$. ebd.

567 Vgl. dazu Kapitel 3 https://www.fanfiktion.de/s/4eceb93000021d8106a01770/3/The-Legend-of-ZeldaFragments-of-the-old-Shiekah (30.06.2018).
} 
dichten Darstellung der narrativen Charaktere insgesamt. Die meisten Verhaltensweisen, die der Wind Waker-Link aufweist, lassen sich fast genauso in besagtem Spiel finden. Hierdurch wird andererseits aber auch die starke ,Intertextualität‘ dieser Fanfiction deutlich. So werden nämlich nicht nur Referenzen zwischen den genannten Spielen hergestellt, sondern es werden auch Bezüge zu nicht genannten Titeln aufgemacht. ${ }^{568}$ Das Motiv des Erwachens, das in den Kapiteln der Fanfiction immer wieder aufgegriffen wird, spielt nämlich in vielen The Legend of Zelda-Titeln eine gewisse Rolle und bildet in The Legend of Zelda: Link's Awakening (1993) gar das Leitmotiv, wenn der Held in einer Welt erwacht, die ihm unbekannt ist und auf ihn bizarr wirkt, wodurch deutliche Referenzen auf das Motiv der ,Traumreise‘ aufgebaut werden.

Diese Fanfiction, wie in Kapitel 4 deutlich wird, ist zwar keine Traumreise, sie zielt aber durchaus bewusst auf die fantastischen Elemente dieser ab, welche bewanderte Bewohner der transmedialen Welt von The Legend of Zelda unweigerlich erkennen müssen. Am Anfang von Kapitel 4 erwacht Ganondorf in einer dunklen Höhle und findet einen Kristallsplitter ehe Vaati ${ }^{569}$ erscheint und sich Ganondorf anschließt. ${ }^{570}$ Gemeinsam finden sie eine Art Altar, wo ihnen ein unbekannter Teil der Kosmologie Hyrules offenbart wird. Die Verfasserin der Fanfiction ergänzt diesen spezifischen Teil der transmedialen Erzählung von The Legend of Zelda um eine vierte Göttin, die die Schöpfung ihrer Schwestern missgünstig betrachtet und zu zerstören versucht, weshalb diese das Triforce erschaffen, um ihre Schwester hieran zu hindern. ${ }^{571}$ Anschließend wird erzählt, dass es neun Welten, neun verschiedene Hyrules gebe und in jedem ein Splitter zu finden sei. Um seine sinistren Pläne in die Tat umzusetzen, beschließt Ganondorf Link und Zelda sowie deren Verbündete zu schwächen, indem er den Deku-Baum vergiftet, was Ganondorf Vaati aufträgt. Am Ende dieses Kapitels wird dem Leser somit zweierlei klar. Einerseits ist die Handlung des vierten Kapitels vor den bisherigen angesiedelt, da es Vaati war, der den Deku-Baum vergiftete und der sich andererseits, als Händler verkleidet, daran machte, Link in eine andere Zeit zu bringen.

\footnotetext{
${ }^{568}$ Die Erwähnung der Figur Linebecks verweist z.B. auf die ,Nachfolgertitel' von Wind Waker - The Legend of Zelda: Phantom Hourglass (2007) und Spirit Tracks.

${ }^{569}$ Durch Vaatis Auftritt wird die Handlung des vierten Kapitels in The Minish Cap verortet.

570 Vgl. dazu Kapitel 4 https://www.fanfiktion.de/s/4eceb93000021d8106a01770/4/The-Legend-of-ZeldaFragments-of-the-old-Shiekah (30.06.2018).

${ }^{571}$ Von ihrer Konzeption und ihrer Einbettung in diese Figurenkonstellation erinnert die vierte Göttin stark an Melkor aus der ,Ainulindale‘, dem ersten Kapitel von Tolkiens Silmarillion. Vgl. dazu TOLKIEN (2015), 19-30. Somit sind also auch intertextuelle Referenzen denkbar, die die Grenzen der transmedialen Welt von The Legend of Zelda überschreiten und andere Quellen des Fantasy-Genres miteinbeziehen.
} 
Zu Beginn des fünften Kapitels kehrt die Handlung zum Link aus Ocarina of Time zurück, der sich in der Welt von Twilight Princess befindet und dort einen Zora trifft, der ihn aus der Stadt hinausbegleitet. ${ }^{572}$ Außerhalb der Stadtmauern begegnet er Link und Zelda aus Twilight Princess sowie der Schattenprinzessin ,Midna“. Im sechsten Kapitel steht das Hyrule aus Ocarina of Time erneut im Mittelpunkt. ${ }^{573}$ Zelda, Salia und der Link aus Wind Waker beraten über die Folgen des Todes des Deku-Baums und welche Maßnahmen als nächstes zu ergreifen sind. Es wird beschlossen, in die Verlorenen Wälder zu reiten, um sich vor Ort ein Bild von der Lage zu machen. Hiermit endet der Plot der personalen Narration, er wurde von der Verfasserin nicht vollendet. Insgesamt zeugt diese Fanfiction von einigen qualitativen Widersprüchen. Einerseits fallen viele orthografische Fehler auf, die Dialoge sind oft sehr schlicht gestaltet und die Erzähltechnik teilweise gar etwas plump. Andererseits zeugen das anachronistische Erzählverfahren und der innovative und kohärente Plot von durchaus profunden erzählerischen Fähigkeiten. Entscheidend ist im vorliegenden Zusammenhang aber weniger die Qualität der Fanfiction, als vielmehr ihr Entstehungsprozess, der sich in der Machart niederschlägt. Zwei Punkte sollen hierbei besonders hervorgehoben werden. Zum einen zeugt die Fanfiction von einer sehr hohen Sachkenntnis, fast schon philologischen Erschließung der Materie der transmedialen Welt von The Legend of Zelda, die auch in Form von Anspielungen Eingang in den Text findet. Um alle Andeutungen und Anspielungen zu entschlüsseln bzw. frühzeitig zu erkennen, ist nicht nur bei der Verfasserin eine hohe Sachkenntnis vorauszusetzen, sondern auch bei den Lesern, deren Rezeptionsgenuss von der ,Freude des Wiedererkennens ${ }^{674}$ gesteigert werden kann. Anders gesagt: Die vorliegende Fanfiction ist der Text einer Expertin für Experten. Neben der hohen Kennerschaft spielt zum anderen aber die extreme Fokussierung auf die Figuren eine große Rolle. ${ }^{575}$ Es ist bemerkenswert, dass zwar die Figuren der diversen aufgerufenen Titel der Hauptserie recht genau adaptiert werden, dass die Narrative, die deren medialen Narrationen zugrundeliegen, aber offensichtlich keine Rolle spielen, sondern durch ein Narrativ ersetzt wurden, das soweit es sich aufgrund des fragmentarischen Charakters der Fanfiction sagen lässt ebenfalls dem Monomythos folgt, auch wenn die anachronistische Erzählweise dies etwas

572 Vgl. dazu Kapitel 5 https://www.fanfiktion.de/s/4eceb93000021d8106a01770/5/The-Legend-of-ZeldaFragments-of-the-old-Shiekah (30.06.2018).

573 Vgl. dazu Kapitel 6 https://www.fanfiktion.de/s/4eceb93000021d8106a01770/6/The-Legend-of-ZeldaFragments-of-the-old-Shiekah (30.06.2018).

${ }^{574}$ Vgl. dazu GADAMER (1999), 119.

${ }^{575}$ Dies kann man ebenso anhand der Übersicht von Fanfictions auf Seiten wie Fanfiction.net nachvollziehen. Neben Informationen wie Genre, Kapitel- und Wortanzahl, Sprache, Veröffentlichungsdatum, Followern etc. weisen die paratextuell beigefügten Metadaten auch aus, um welche Figuren es in der betreffenden Fanfiction geht. Vgl. exemplarisch dazu https://www.fanfiction.net/game/Legend-of-Zelda/ (30.06.2018). 
kaschiert. Wind Waker und Twilight Princess sind z.B. beide verschiedenen Zeitlinien zugeordnet, ${ }^{576}$ weshalb ihre Narrative im Sinne der seriellen Narration unvereinbar sind. Hierdurch wird erneut unterstrichen, dass im Rahmen des Narrativs die Erzählstruktur in Ocarina of Time (wie in den anderen Titeln der Hauptserie) gegenüber Figurenkonzeption und -konstellation in den Hintergrund tritt.

Die hier in aller Kürze analysierte Fanfiction demonstriert, dass (ausgehend von einem narrativen Rezeptionsangebot) personale Narrationen möglich sind, deren so erzeugte Plots sich doch recht weit von dem eigentlichen Ausgangspunkt entfernen können. Zudem ist es bezeichnend, dass der Referenzrahmen von personalen Narrationen in transmedialen Welten oft nicht nur das jeweils aktuell rezipierte oder ,bearbeitete“ Werk ist, sondern oft die gesamte transmediale Welt bzw. wenigstens deren narrative (kanonische) Anteile. Das legt den Schluss nahe, dass selbst die Interaktion-Narration eines bestimmten Spiels, das Teil einer transmedialen Welt ist, nicht unabhängig vom Rest betrachtet werden kann, sondern diesen immer mitdenken muss. Die Interaktion-Narration von interaktiv-narrativen digitalen Spielen wie Ocarina of Time ist dementsprechend nur ein Aspekt einer transmedialen Mediennutzungspraxis. Als solche ist eine personale Narration einerseits das Produkt einer individuellen Rezeptionserfahrung und andererseits die Darstellung dieses Produktes in einem sozialen Kontext mit allen sich hieraus ergebenden Konsequenzen. ${ }^{577}$ Das bedeutet, dass personale Narration nicht gleich personale Narration ist. Erstens erscheinen personale Narrationen als Formen des narrativen Erlebens, die die Interaktion-Narration simultan begleiten. In diesem Fall sind sie eher ephemer, der Forschung nur schwer zugänglich, oft von sehr kurzer Dauer und teilweise wenig kohärent. Zweitens können personale Narrationen der Interaktion-Narration nachgelagert erzeugt und bearbeitet werden wie im oben untersuchten Beispiel. In dieser Form sind personale Narrationen der Forschung zwar gut zugänglich, von ihnen kann aber keinesfalls mehr als Ausdruck eines unmittelbaren Gameplays gesprochen werden, da die vorgenommenen Bearbeitungen dieses, verfälschen'. Dafür erlaubt jene zweite Form der personalen Narration aber einige interessante Rückschlüsse darauf, wie transmediale Fangemeinschaften funktionieren, interagieren und kommunizieren.

\footnotetext{
${ }^{576}$ In beiden Zeitlinien triumphiert der Held zwar, aber in der einen erlebt er seine Kindheit, nachdem er in die Vergangenheit zurückgekehrt ist (Twilight Princess) und in der anderen verschwindet der Held der Zeit einfach (Wind Waker).

${ }^{577}$ Insofern verhält es sich bei personalen Narrationen ähnlich wie bei primären und sekundären realen sowie virtuellen Interaktionen.
} 
Beide Formen sind aber für sich genommen sehr interessante Beispiele für die aktuelle Beschaffenheit des subjektiven narrativen Erlebens und Erfahrens in unserer Medienkultur. Wie personal narrativierende Subjekte miteinander und mit den narrativierten Entitäten umgehen, was dies über beide aussagt und wie man derart gewonnene Erkenntnis im UXDesign einsetzen kann, um zukünftig Rezeptionserlebnisse noch weiter zu intensivieren, werden wichtige künstlerische Fragen der kommende Jahre sein. Wie schreiben Subjekte Entitäten personal Narrativität zu? Welche Rolle spielen dabei chronotopische Besonderheiten wie Open-World- und Open-Time-Prinzip? Welche Auswirkungen hat paidianisches Spielen in diesem Kontext? Welche Bedeutung kommt kulturell dominanten Narrativen wie dem Monomythos als emergentem Narrativ in solchen Situationen zu? Inwiefern können eingebettete, aber fragmentarische Narrative, die eine eher rahmende mediale Narration hervorbringen, vom Subjekt personal narrativ ,aufgefüllt‘ werden? Vielleicht muss man sich aber auch von Fragen wie der letzten lösen, mediale und personale Narration stärker als voneinander getrennte Prozesse auffassen, um die Spezifik personaler Narrationen umfassend würdigen zu können. Man sollte personale Narrationen keinesfalls bloß als Akte begreifen, die defizitäre oder nicht vorhandene mediale Narrationen anreichern, um überhaupt erst ein zufriedenstellendes Rezeptionserlebnis zu erreichen. Dies würde weder nicht-narrativen digitalen Spielen und auch nicht der personalen Narration als menschlicher Kulturtechnik gerecht werden. Dass es lohnenswert ist, sich personalen Narrationen zuzuwenden, illustriert der Bedeutungsaufschwung von narratologischen Arbeiten, die eine eher anthropologische Ausrichtung haben. Studien wie Albrecht KoschORKEs Wahrheit und Erfindung (2013) holen den ,homo narrans` zurück ins Licht der Narratologie. Im 20. Jahrhundert wurde die Narratologie weitgehend von medienwissenschaftlichen (primär an erzählenden literarischen Texten und Filmen ausgerichteten) Untersuchungen bestimmt, die sich fast ausschließlich Untersuchungsgegenständen mit medialer Narration zuwandten. ${ }^{578}$ Überspitzt könnte man sagen, dass das 20. Jahrhundert die Zeit der medialen Narrativität war, jetzt stehen die Zeichen nicht schlecht dafür, dass das 21. Jahrhundert die Epoche der personalen Narrativität sein könnte.

Digitale Medien erlauben zwar eine immer massivere Vernetzung, sie gestatten aber zugleich auch eine intensivere Personalisierung des jeweiligen Rezeptionserlebnisses und dessen Verarbeitung. In einer Zeit, in der Mediennutzer daran gewöhnt sind, dass lernende

\footnotetext{
${ }^{578}$ Ausnahmen bilden hier bspw. Narratologen wie Kurt RANKE, der z.B. die Enzyklopädie des Märchens (19772015) begründete.
} 
Systeme ihre Bedürfnisse verstehen, ${ }^{579}$ scheinen personalisierbare Erzählungen eine konsequente Entwicklung zu sein. Die zahlreichen, oft aufgeregten Debatten um die Potenziale digitaler Medien verstellen oft den Blick auf den nach wie vor wichtigsten Faktorden Menschen. Es ist aber fraglich, ob man hier in Mensch-Maschine-Dichotomien denken sollte. Konzepte wie ,Human Computation‘ zeigen, dass es zukünftig eher von Belang sein könnte, danach zu fragen, wie Mensch und Maschine zusammenwirken. (vgl. dazu MiCHELUCCI 2013) Welche Plots kann der Mensch aufgrund seiner semantischen Fähigkeiten personal mithilfe der syntaktischen Potenziale von (lernenden) Programmen erzeugen? Bevor derartig ,prophetisch ${ }^{\star}$ anmutende Zukunftsverheißungen Realität werden, haben die Kulturwissenschaften aber bereits viele aufschlussreiche Untersuchungsgegenstände wie Fanfiction oder eben den Menschen selbst, dessen personale Narrationen auch mittels mediensoziologischer Verfahren abgerufen werden können.

\subsubsection{Spielertypen und Ocarina of Time}

Aufgrund des eher interaktiv ausgerichteten interaktiv-narrativen Designparadigmas erscheint es durchaus einleuchtend, dass Ocarina of Time und die anderen Spiele der Hauptserie eher den interaktiv-narrativen Spielertyp mit interaktiver Ausprägung oder gar den interaktiven Spielertyp ansprechen. Der vorhandene Analyserahmen erlaubt hier aber keinesfalls verlässliche Aussagen auf einer validen Datenbasis. Es mag sein, dass, wenn man Fanpraktiken vergleicht, die interaktiv motivierten häufiger anzutreffen sind als die narrativen Spieler. Sicherlich finden sich mehr Let's Plays oder Fan Arts mit eindeutig interaktivem Bezug, lassen sich viele Foren, Blogs oder Vlogs nachweisen, in denen es nur darum geht, im Spiel ludisch voranzukommen und gewonnene Informationen mit anderen zu teilen oder diese als Ratsuchender auf diesem Wege zu erlangen und freilich sind die wenigsten performativen Fanbetätigungen im realen Raum wie Cosplayen narrativ inszeniert.

Die bisherigen Beispiele haben aber gezeigt, dass auch der narrative Spielertyp durchaus in der transmedialen Welt von The Legend of Zelda anzutreffen ist. Diesen sprechen einerseits die medial narrativen Elemente wie die in 4.2.3.2 analysierte narrative Cutscene an. Andererseits reichert er diese medial narrativen Elemente aber höchstwahrscheinlich noch an, indem er z.B. die Mangas rezipiert, die sich sehr stark an der Erzählstruktur der Spiele orientieren. Darüber hinaus fertigt er wahrscheinlich häufiger personale Narrationen seiner Spielerlebnisse an, die er in einigen Fällen gar als Fanfiction niederschreibt und mit anderen

\footnotetext{
${ }^{579}$ Vgl. zum maschinellen Lernen den Überblicksband von ENGEMANN/SUDMANN (2018).
} 
teilt. Die in 4.2.3.3 behandelten Exempel zeugen alle von einem derart interessierten narrativen Spielertyp. Zum einen schimmert in vielen Fanfictions von The Legend of Zelda immer wieder (zumindest rudimentär und fragmentarisch) der Monomythos auf, der als Narrativ viele dieser Geschichten strukturiert. Zum anderen lohnt es sich, zukünftig dezidierter im Kontext des narrativen Spielertyps auf dessen mediale Sozialisation einzugehen. Auch wenn Ocarina of Time, auch wenn die Spiele der Hauptserie von The Legend of Zelda insgesamt für ein interaktiv-narratives digitales Spiel weniger medial narrative Elemente aufweisen, so sind die medial narrativen Phasen jedoch durchaus komplex gestaltet. In 4.2.3.2 ist dabei jedoch augenscheinlich geworden, dass sich die mediale Narrativität von Ocarina of Time weniger aus literarischen, sondern aus filmischen Quellen speist. Dieser Trend, so ist anzunehmen, könnte sich in Zeiten der globalen Verfügbarkeit von Film und Fernsehserien, könnte sich unter dem Einfluss von Netflix und anderen vergleichbaren Dienstleistern noch verstärken. Die Anzeichen des Wandels zeigen sich schon heute in den Programmen von Tagungen zur transmedialen Narratologie oder in eben solchen Publikationen. Die Literatur in ihrer traditionellen Form spielt hier nur noch eine sehr untergeordnete Rolle, scheint von Medien abgelöst zu werden, deren mediale Narrativität sich in Darstellung und Vermittlung auch audiovisuell entfaltet. Mit dem Internet steht diesen Nutzern nun ein Hypermedium zur Verfügung, das es erlaubt, in hohem Maße audiovisuell zu wirken. Die Untersuchung narrativer Spieler ist aber keinesfalls nur eine Herausforderung für die Literaturwissenschaft, sie ist eine Chance für die Literatur selbst, da Kunstwerke auch immer Spiegel der medienästhetischen Präferenzen ihrer gegenwärtigen Rezipienten sind. Interaktiv-narrative Werke und deren Nutzer können der Literatur somit möglicherweise neue Wege aufzeigen, wie diese auch im 21. Jahrhundert ein künstlerisches Leitmedium sein kann. ${ }^{580}$

\footnotetext{
${ }^{580}$ Erste Schritte in diese Richtung sind bereits seit den 1980er Jahren gegangen worden, indem verschiedene Spielarten digitaler Literatur experimentell die medialen Möglichkeiten ausloteten. Nun sind fiktionale Hypertexte oder die frühe Netzliteratur aber eher avantgardistische Kunstformen als mainstreamfähig. Will die Literatur, bei aller Vorsicht in Bezug auf Vorhersagen, weiterhin leitkulturell erfolgreich sein, so reicht es nicht aus, Texte nur zu digitalisieren. Zwar ist es entscheidend, dass Texte ubiquitär verfügbar sind, es ist aber nicht der alleinige Erfolgsgarant. Man kann freilich Plattformen wie Netflix für den literarischen Bereich mit einem breiten Angebot ins Leben rufen. Es scheint dabei aber fraglich, ob sich der wirtschaftliche Erfolg so einfach von einem Medium ins andere übertragen lässt. Innovativ wäre eher, sich bestehende Bedarfe seitens der Nutzer anzusehen und sich zu überlegen, inwiefern das literarische Medium besser geeignet ist als andere, um diese mittels künstlerischer Entwicklungen konsequenter zu bedienen. So wäre es vorstellbar, Geschichten zu kreieren, in denen die Leser selbst entscheiden, wie es in bestimmten Situationen mit dem Plot weitergeht. Interaktivnarrative digitale Spiele zeigen, dass Nutzer derartige Medien gerne konsumieren, diese scheitern aber oft daran, dass es nur wenige Entscheidungssituationen gibt und verschiedene Erzählstränge immer wieder zusammengeführt werden. Würde man die Knoten aber nicht kostenintensiv audiovisuell erstellen müssen, sondern textuell, so ließen sich die Ausgaben effizienter kontrollieren und die Erzählstruktur weiter
} 
Der interaktive Spielertyp ist in seiner prototypischen Form ein Nutzer, der nach der ludischen Herausforderung sucht, der das Spielsystem verstehen und beherrschen können möchte. In Miyamotos Sinne ist er vielleicht der idealtypisch intendierte Spieler schlechthin. Zentral ist für jenen Spielertyp, dass er in all seinen Erscheinungen danach strebt, das Spiel zu meistern. Was aber Meisterschaft konkret bedeutet, ist für die verschiedenen Unterarten dieses Spielertyps doch stets verschieden. Der ,normale“ interaktive Spielertyp wähnt sich als Meister des Spiels, wenn er es bis zu den Credits durchgespielt hat (mit oder ohne Hilfe). Eine gesteigerte Variante dieses Spielertyps ist der ,100\%-Spieler', der das Spiel erst dann als gemeistert betrachtet, wenn er alles erfolgreich absolviert hat, was via Achievement als Erfolg ausgewiesen wird. ${ }^{581}$ Es lassen sich aber zunehmend Spieler beobachten, denen dies nicht reicht, die die Spielwelt über die 100\% hinaus intensiv erkunden und sich daran machen, das Spielsystem vollends zu entschlüsseln, indem Programmfehler aufgesucht werden. Hiermit gelangt man dann aber auch zu den Extremformen des interaktiven Spielertyps wie dem oben bereits thematisierten Speedrunner. Dessen Meisterschaft erschöpft sich nicht im Entschlüsseln des Spielsystems oder im Auffinden aller möglichen Glitches oder Bugs, er nutzt diese, um das Spiel in Rekordzeit durchzuspielen. Dadurch beinhaltet dieser Spielertyp Anteile eines interaktiven Spielertyps, der in den letzten beiden Jahrzehnten in interaktivnarrativen digitalen Spielen eher seltener anzutreffen war, der seine Hochzeit vielleicht in den 1970er Jahren, dem Zeitalter der Arcades, erlebte: der Highscore-Spieler. Die Agonalität des Speedrunners ist somit eine doppelte. Einerseits kämpft er gegen das Spielsytem und andererseits gegen die Bestzeiten anderer Speedrunner. Der in 4.2.2.4.1.1 verlinkte Speedrun ist bspw. zeitweise ein Weltrekord gewesen. Diese Extremformen des interaktiven Spielers zu beobachten, die häufig in bestimmten Subkulturen der digitalen Spielkultur auftreten, ist in der Forschung bisher eher randständig geschehen. Dass es aber lohnenswert und notwendig ist, derartige Spielertypen zu erfassen, zeigt z.B. der Modder, die vielleicht extremste Form des interaktiven Spielers. Dieser meistert das Spiel, indem er dessen Oberfläche durchdringt und sich den Programmcode verfügbar macht und diesen modifiziert. Arbeiten wie die von Stephan SCHWINGELER (2014) machen aber deutlich, dass digitale Spiele als Ausgangsmaterial für neue Mods oder digitale Kunstwerke überaus wertvoll sind und wie

ausdifferenzieren. Dies könnte man noch erweitern, indem man der Aufbrechung der Trennung zwischen Produzent und Rezipient folgt und Lesern die Möglichkeit gibt, Teile der Geschichte selbst schreiben zu dürfen. Auf diese Weise ließen sich mediale und personale Narration miteinander verschränken.

581 Auch unter interaktiv-narrativen digitalen Spielen wie Batman: Arkham Knight (2015) ist diese Tendenz mittlerweile erkennbar. Die Entwickler tragen diesem Umstand Rechnung, indem der Spieler im Menü einen Reiter öffnen kann, in dem er sämtliche Quests inklusive aktuellem (prozentual ausgewiesenem) Spielfortschritt einsehen kann. Auf diese Weise wird das Erreichen der 100\% optimiert und vereinfacht. 
bemerkenswert die konfigurative Praxis des Moddens ist. Die Extremformen der Spielertypen verdienen zukünftig mehr Aufmerksamkeit der beteiligten wissenschaftlichen Disziplinen, zumal viele dieser Spieler bzw. die von ihnen erzeugten medialen Artefakte mehr und mehr von der subkulturellen Peripherie ins massenkulturelle Zentrum rücken.

Mit Extremen hat der interaktiv-narrative Spielertyp wohl wenig gemeinsam, kann vielleicht als der moderateste Spielertyp aufgrund der Breite seiner Interessen angesehen werden. So wird dieser Spielertyp im Unterschied zu den beiden zuvor skizzierten eher dazu tendieren, die diversen Möglichkeiten der transmedialen Welt von The Legend of Zelda umfassend zu nutzen und dabei auch teilweise sehr heterogene mediale Artefakte dieser Welt rezipieren. Deshalb lässt sich dieser Spielertyp anhand seiner transmedialen Nutzungspraxis auch nur sehr schwer bestimmen, auch wenn er sich mittels dieser überhaupt erst sichtbar machen lässt. Zukünftig könnte es herbei für die Forschung hilfreich sein, sich dezidiert mit der , selektiven Zuwendung' der drei Spielertypen zu befassen und diese vergleichend zu betrachten. (vgl. dazu ScHENK 2007) Es steht zu erwarten, dass die selektive Zuwendung des interaktiv-narrativen Spielertyps dabei am wenigsten limitiert sein dürfte, und dass seine medial rezeptionsgebundenen Präferenzen recht vielfältig sein dürften. Jenseits der transmedialen Nutzungspraxis lässt sich dieser Spielertyp konkret durch seine unmittelbaren Nutzungsweisen bzw. seine Interaktion-Narration bestimmen. Die in 4.2.3.1 unter Hinzunahme der theologischen Forschung $\mathrm{zu}$ The Legend of Zelda dargelegten (mythologisch-religiös induzierten) entrückenden Potenziale von Ocarina of Time (und anderer Titel der Hauptserie) dürften diese Wirkung nur entfalten können, wenn der betreffende Spieler auf die gesamte Bandbreite der ästhetischen Hybridität von bspw. Ocarina of Time anspricht. Die mediale (und die Anlagen des Monomythos ausagierende) Narration und die narrativen Rezeptionsangebote, die personale Narrationen gemäß dem Narrativ des Spiels induzieren, müssen sich mit den realen virtuellen Interaktionen des Spielers verbinden, um dessen Immersion entrückend nennen zu können. Er muss dazu nicht bloß die vom Gamedesign eingebundenen mythologischen Funktionen wahrnehmen, will er der von Seth SIVAK (2009) beschriebene Held werden, dann muss er ebenso die substantialistischen Aspekte des Mythos im Spiel mitaufnehmen, welche oft an die mediale Narration gekoppelt sind, wie in 4.2.3.2 deutlich wurde. Anders gesagt: Durch den Monomythos werden Interaktionen und Narrationen verbunden und können bei dementsprechender Ausprägung mythisch-religiöse oder quasi-religiöse Erfahrungen auslösen. Derartige Erfahrungsmomente sind also eng an eine hohe hybride Ausprägung des betreffenden Spiels gebunden. Diesen 
zukünftig nachzuspüren wird nicht nur den betreffenden Medien und deren Nutzern gerechter, es kann zugleich (wie von den referierten Forschern in 4.2.3.1 gezeigt) ein unverzichtbarer Beitrag zur Mythophilie und neuen Religiosität unserer digitalen Gegenwart sein. 


\section{Fazit und Ausblick}

Das vorrangige Ziel dieser Arbeit lag darin, mit dem Kontinuumsmodell einen theoretischen Zugang zu digitalen Spielen als interaktiv-narrativen Hybridmedien zu schaffen, der diese möglichst ganzheitlich untersuchen können möchte. Anhand dieses dementsprechend entwickelten Modells lassen sich digitale Spiele erstens auf der Attributebene aufgrund ihrer qualitativen Eigenschaften beschreiben, relational zu anderen Medien und Phänomenen in Beziehung setzen sowie diverse Perspektivierungen im Rahmen des Forschungsdesigns möglich sind, die unterschiedlichen Erkenntnisinteressen folgen können. Zweitens legt dieses Modell auf der Strukturebene, von den Beobachtungen auf der Attributebene ausgehend, ein besonderes Augenmerk auf die Produzentenseite bzw. das Design interaktiv-narrativer digitaler Spiele. Drittens offeriert der entworfene Ansatz auf der Realisierungsebene unterschiedliche Herangehensweisen, um zukünftigen Studien der empirischen Medienwirkungs- und Mediennutzungsforschung Wege zur Erforschung der Nutzung interaktiv-narrativer digitaler Spiele im Besonderen sowie transmedialer Mediennutzungspraxen im Allgemeinen zu eröffnen. Dabei geraten viertens auch immer wieder die Verhältnisse zwischen den verschiedenen Ebenen und deren gegenseitige Bezugnahmen in den Blick. Nicht zuletzt dadurch bietet das Kontinuumsmodell fünftens Möglichkeiten, die komplexen Erscheinungsweisen und -formen der Medienproduktion sowie deren Rezeptionspraxis im digitalen Zeitalter differenzierter zu betrachten.

Das Modell ist somit insgesamt davon gezeichnet, sich von exkludierenden Mentalitäten und den hieraus resultierenden Theoriebildungen $\mathrm{zu}$ verabschieden und sich stattdessen inkludierenden Ansätzen zuzuwenden. Paradoxerweise geraten dabei im Zuge der Strukturebene mit dem Monomythos kulturelle Kräfte in den Blick, deren Faszination und kulturelle Persistenz offenbar auch darin begründet ist, dass sie von Dichotomien durchzogen sind, nicht zuletzt hierdurch ihre ordnenden Funktionen auch entfalten können. Dennoch bieten Mythen als ,Patchwork Mythen“ (substantialistisch betrachtet) in digitalen Spielen wie Ocarina of Time ein immersives Setting, das das Engagement des Spielers in der und die Immersion in die Spielwelt steigern kann. Dabei ist festzustellen, dass selten historische Mythen in Reinform vorkommen (bspw. als Adaptionen), ${ }^{582}$ sondern dass meistens mehrere Mythologien miteinander vermengt werden, wobei der Umgang mit den Mythen

\footnotetext{
${ }^{582}$ Selbst digitale Spiele wie God of War, das im Mainstream der digitalen Spielkultur interaktiv-narrativer digitaler Spiele vielleicht die stärksten Anleihen aus der griechischen Mythologie bezieht, arbeitet mit den Themen und Motiven dieser nur versatzstückhaft, nutzt sie als ,Steinbruch ' zur Erstellung immersiver Settings, die in letztlich sehr, freien Interpretationen' der mythologischen Vorlagen enden.
} 
grundsätzlich ein eklektizistischer ist. Als populärkulturelle Kunstwerke vertreten derartige digitale Spiele keinen klassischen Bildungsauftrag, der auf die Wissensvermittlung bestimmter Mythologien abzielt, sondern fokussieren sich auf das UX-Design. Kaum jemand steht wohl derart für diese Instrumentalisierung von Mythen oder Religionen wie Shigeru Miyamoto und sein Werk The Legend of Zelda.

Mythen verfügen aufgrund ihrer spezifischen strukturellen Beschaffenheit über bestimmte Funktionen, die sich in historischen wie modernen Mythen wiederfinden lassen, gewissermaßen anthropologische Konstanten von Mythen und deren Rezipienten sind. Unter den didaktischen Funktionen von Mythen sind hierbei v.a. (und hierauf hebt auch Miyamoto immer wieder ab) die Ordnungsfunktion und die Vorbild- und Nachahmungsfunktion für das Gamedesign interessant, da erstere dem Spiel eine Form geben kann, die das (strukturbezogene) Verstehen von Spielern befördert. Letztere können Spieler dazu veranlassen, gemäß den Figurenkonzeptionen des Monomythos $\mathrm{zu}$ handeln, die angelegte Rollenerwartung also auszuagieren. Dass beide Funktionen in Ocarina of Time Anwendung finden und von den Spielern auch (positiv) aufgenommen werden, zeigen Blicke auf die Fankultur, da sich diverse Formen der Fankunst auf die in der Hauptserie von The Legend of Zelda entworfene Ordnung beziehen und diese tendenziell auch nicht hinterfragen. Über die von Nintendo hinausgehenden Informationen zu The Legend of Zelda gibt es immer wieder Fantheorien, die v.a. versuchen, die Zusammenhänge zwischen den Titeln der Hauptserie zu erschließen. Dabei richten sich diese stets nach den vom Produzenten in den Spielen intendierten und dargestellten Ordungssystemen. So tendieren z.B. Wiki-Einträge oder Foren nicht dazu, die durchaus problematische Staatsform Hyrules (absolutistische Monarchie) zu hinterfragen, was auch damit zusammenhängt, dass die politische Dimension von der mythologischen überblendet wird. Dass gerade die Vorbildfunktion Links und Zeldas erfolgreich sind, zeigen die zahlreichen Cosplays dieser beiden Charaktere. Auffällig ist in diesem Kontext auch, dass selten die Antagonisten gecosplayt werden und dass positive Darstellungen in der Fankunst vornehmlich auf die positiv inszenierten Charaktere und deren Eigenschaften Bezug nehmen.

Ocarina of Time ist ein digitales Spiel, das einem (für ein Action-Adventure eher unüblichem) interaktiv ausgerichteteten interaktiv-narrativem Designparadigma folgt. Dies lässt sich auf der Strukturebene differenzierter analysieren und hierbei wird klar, dass diese interaktive Ausrichtung insbes. einem stark ausgeprägten Interaktiv geschuldet ist. Die vier 
grundlegenden Spielmechaniken des Spiels (Navigation, Kampf, Rätsellösen, Sammeln) sind spielrheotrisch sehr aufwendig miteinander verbunden und stehen im Mittelpunkt des UXDesigns. Das Narrativ ist demgegenüber eher schwach ausgeprägt und dient (gemäß Shigeru Miyamotos Designphilosophie) dazu, das interaktive Erleben und Erfahren des Spiels, das Gameplay zu intensivieren. Genauere Untersuchungen des Figuren- und Weltdesigns von Ocarina of Time bestätigen, dass narrative Elemente eher nur unterstützend wirken. Die einzige Ausnahme bildet das Strukturdesign, das von einer stärkeren attributiven Hybridisierung interaktiver und narrativer Elemente zu zeugen weiß als die anderen beiden. Jedoch wird auch hier die Erzählstruktur von der Queststruktur dominiert, auch wenn die hegemoniale Stellung des Interaktiven hier weniger deutlich ist.

Analog zu den Analysen auf der Strukturebene kann man auch auf der Realisierungsebene konstatieren, dass The Legend of Zelda für Spielertypen mit starker interaktiver Präferenz von Interesse ist. Die Dominanz des interaktiven oder sehr interaktiv orientiertem interaktivnarrativem Spielertyp lässt sich in den meisten Let's Plays nachweisen, die Spielerlebnisse dokumentieren und teilen und keine personalen Narrationen entwerfen oder mediale diskutieren. Ebenso weisen performative Fanformate wie Cosplaying auf interaktive Präferenzen hin, da hier das Ausagieren einer Rolle das zentrale Handlungsmovens ist. Reenactments sind hier eher selten. Die dennoch vorhandenen narrativen Spieler betätigen sich oft in Fanfiction oder Diskussionsforen, wo sie personale Narrationen mit anderen teilen oder Aspekte der medialen seriellen Narration thematisieren. Die am Ende dieser Arbeit sich hieraus ergebenden Perspektiven für die zukünftige Forschung sind vielfältig. Aus dieser Vielfalt möchte ich drei herausgreifen und abschließend kurz darlegen. Erstens ist hoffentlich deutlich worden, dass The Legend of Zelda ein überaus lohnenswerter Untersuchungsgegenstand auch für die eher westlich orientierten Digital Game Studies sein kann. Neben Fragen nach den interaktiven oder narrativen Aspekten eignet sich diese transmediale Welt auch dafür, um Fankultur in all ihren Facetten im digitalen Zeitalter untersuchen zu können. Dabei ist eine Erforschung dieser transmedialen Welt (wie bei diesen Welten grundsätzlich) immer eine Arbeit am und mit dem lebenden Forschungsobjekt. Die Lebendigkeit dieser transmedialen Welt ist auch weiterhin gegeben, da neue Publikationen der Hauptserie wie Breath of the Wild oder andere Produkte seitens Nintendos stets Trigger für die diversen und zahlreichen Formen der Fanpartizipation bilden. Zweitens macht die Begeisterung für transmediale Welten wie The Legend of Zelda deutlich, dass Mythen und Religionen auch im Kontext der Digitalisierung keinesfalls ausgedient haben. Es ist jedoch 
auch deutlich geworden, dass man hierbei differenzieren sollte. Prozesse der ,Respiritualisierung'583 und dergleichen zeugen zwar von einer Hochkonjunktur mythologisch-religiöser Elemente, allerdings geht dieser kulturelle ,Höhenflug ${ }^{6}$ größtenteils an den historischen Religionen vorbei. Stattdessen werden subjektbezogene Individualreligionen immer wichtiger, in deren Kontexte Gläubige zusehends religiöse Elemente nach eigenem Belieben aus anderen Religionen entlehnen und im Zuge ihrer ,Patchwork Religion‘ amalgamieren. Ähnliches lässt sich auch für die historischen Mythen beobachten. Diese werden kaum in ihrer Gänze oder werkgetreu adaptiert, vielmehr fungieren sie in der Populärkultur eher als Themenspeicher, der stets zur Verfügung steht. Man kann also sagen, dass sich Mythos und Religion aus substantialistischer Sicht durchaus in einer Krise befinden, dass ihre gesamtgesellschaftliche Relevanz abnimmt. Demgegenüber stehen aber die zahlreichen modernen Formen von Mythos und Religion, die gerade im Zuge der von Gerhard SCHULZE (2005) ausgerufenen ,Erlebnisgesellschaft‘ durch die funktionalen Aspekte von Mythen und Religionen nachhaltig zu einer digitalen Medienkultur beitragen. ${ }^{584}$ Insofern scheint es an der Zeit, jener von Roland Barthes inspirierten Ausrichtung der modernen Mythenforschung mehr Aufmerksamkeit zu schenken, den Fokus von den substantialistischen hin zu den funktionalistischen Aspekten zu verlagern. Andernfalls läuft man Gefahr, in Zeiten, in denen historische Mythen immer weniger Platz in unserem Alltag einnehmen, leicht jenen Theorien nachzulaufen, die von ,Entmythologisierung' reden.

Drittens möchte diese Studie ein Anlass sein, sich nicht nur stärker mit der Hybridität von Medien und Phänomenen im digitalen Zeitalter auseinanderzusetzen, sie möchte auch darüber hinaus ins Gedächtnis rufen, dass Hybridität eine Eigenschaft ist, die unsere Kultur und Gesellschaft im 21. Jahrhundert vielleicht deutlicher auszeichnet als in den beiden vergangenen christlichen Jahrtausenden. Die mit der Hybridität einhergehende Alterität, Ambiguität und Ambivalenz unserer Kultur und Gesellschaft stoßen aber nicht nur auf ungeteilte Zustimmung, vielmehr entstehen ,Gegenbewegungen', die Ordnung und Halt in Form von dichotomischen Lagerbildungen versprechen. Nationalistische und populistische Stimmen rufen in Europa und auf anderen Kontinenten dualistisch geprägte Verhältnisse aus, die das ,Ich` über das ,Wir` stellen. So werden Ost vs. West (Krimkrise), Okzident vs. Orient (radikaler Islamismus), Arm vs. Reich (USA) oder Jung vs. Alt (Brexit) in Frontstellung gebracht, und hierdurch ,Wir-oder-Die-Mentalitäten“ befördert. Letztlich entstehen somit

\footnotetext{
${ }^{583}$ Vgl. zu diesen Diskursen MATUSZKIEWICZ (2015a).

${ }^{584}$ Zur ,Erlebnisgesellschaft‘ im Kontext digitaler Medien vgl. SIMANOWSKI (2008).
} 
agonale kulturelle Muster, die den Konsens hinter dem Dissens verschwinden lassen. In der Zeit, in der diese Zeilen geschrieben werden, steht also durchaus nicht wenig auf dem Spiel. Die (Königs-)Frage ist aber, wie sich diese Probleme lösen lassen. Freilich müssen Lösungsstrategien, wollen sie erfolgreich sein, global angelegt sein. Dies bedeutet aber nicht, dass sie unbedingt nur jene einflussreichen Akteure der weltpolitischen Bühne betreffen. Sie fangen, im Gegenteil, im Kleinen, bei uns selbst an. Digitale Medien kreieren nicht nur neue Probleme, sie machen auch Difizilitäten sichtbar, die in einer weniger vernetzten Welt mit ubiquitär abrufbaren Informationen eher opak geblieben sind. Sicherlich ist die selektive Zuwendung schon immer eine Schwierigkeit der Mediennutzung gewesen, dies intensiviert sich in Zeiten von ,Filterblasen“ und ,Echokammern“ aber noch. (vgl. PARISER 2012) Somit muss letztlich der konkreten Mediennutzung und Medienwirkung seitens der kulturwissenschaftlichen Forschung mehr Aufmerksamkeit geschenkt werden. Dies bedeutet aber auch, sich stärker der Empirie zuzuwenden und weniger in den eigenen Vorannahmen zu verharren. Die vorliegende Arbeit hat dieses Defizit immer wieder moniert und damit betont, dass für viele rezeptionsbezogene theoretische Entwürfe des Kontinuumsmodells deren Tragfähigkeit erst noch empirisch zu ermitteln ist. Wenn sich die Kulturwissenschaften in Zukunft also weniger vorstellen, wie die Welt ihrer Meinung nach sein müsste, sondern sich konkret anschauen, wie sie de facto ist, dann werden die Kulturwissenschaften nicht nur entdecken, dass da eine u.U. ganz andere Welt zu finden, neue Welten zu entdecken sind, sondern die Welt wird auch feststellen, dass da ein Wissenschaftsfeld ist, das Antworten auf Fragen liefern kann, wo andere Disziplinen verzagen. So gesehen ist die Digitalisierung keine Herausforderung für die Existenz der Kulturwissenschaft, sie ist eher deren Chance und das 21. Jahrhundert vielleicht die Hochzeit der Kulturwissenschaft. 


\section{Medienverzeichnis}

\section{Bibliografie}

AARSETH, Espen (1997): Cybertext. Perspectives on Ergodic Literature. Baltimore, MD: The Johns Hopkins University Press.

AARSETH, Espen (2001): Computer Game Studies. Year One. In: Game Studies, 1 (1). URL: http://gamestudies.org/0101/editorial.html (30.06.2018).

AARSETH, Espen (2003): Nonlinearity and Literary Theory. In: Noah Wardrip-Fruin und Nick Montfort (Hg.): The New Media Reader. Cambridge, MA: The MIT Press, 761-780.

AARSETH, Espen (2004a): Genre Trouble. Narrativism and the Art of Simulation. In: Noah Wardrip-Fruin und Pat Harrigan (Hg.): First Person. New Media as Story, Performance, and Game. Cambridge, MA: The MIT Press, 45-55.

AARSETH, Espen (2004b): Quest Games as Post-Narrative Discourse. In: Marie-Laure Ryan (Hg.): Narrative across Media. The Languages of Storytelling. Lincoln, NE: University of Nebraska Press, 361-376.

AARSETH, Espen (2012): A Narrative Theory of Games. In: FDG '12 Proceedings of the International Conference on the Foundations of Digital Games. New York, NY: ACM, 129-133.

AARSETH, Espen (2014a): Ludology: In: Mark J.P. Wolf und Bernard Perron (Hg.): The Routledge Companion to Video Game Studies. New York, NY: Routledge, 185-189.

AARSETH, Espen (2014b): Ontology. In: Mark J.P. Wolf und Bernard Perron (Hg.): The Routledge Companion to Video Game Studies. New York, NY: Routledge, 484-492.

Аввотт, H. Porter (2011): Narrativity. In: Peter Hühn et al. (Hg.): The Living Handbook of Narratology. Hamburg. URL: http://www.lhn.uni-hamburg.de/article/narrativity (30.06.2018).

ABESSER, Bernd (2009): Wer erlöst die Welt? Religion und virtuelle Welten in PC-Spielen. In: Harald Schroeter-Wittke (Hg.): Popkultur und Religion. Best of ... Jena: Garamond, 7988 .

ACKermann, Judith (2017) (Hg.): Phänomen Let's Play-Video. Entstehung, Ästhetik, Aneignung und Faszination aufgezeichneten Computerspielhandelns. Wiesbaden: Springer VS.

ADAMS, Ernest (1999): Three Problems for Interactive Storytellers. In: Gamasutra, 29. Dezember. URL:

http://www.gamasutra.com/view/feature/3414/the_designers_notebook_three_php (30.06.2018).

Alber, Jan und Hansen, Per Krogh (2014) (Hg.): Beyond Classical Narration. Transmedial and Unnatural Challenges. Berlin: De Gruyter. 
AlFERMANN, Dorothee und StOLL, Oliver ( ${ }^{52016): ~ S p o r t p s y c h o l o g i e . ~ E i n ~ L e h r b u c h ~ i n ~} 12$ Lektionen. Aachen: Meyer \& Meyer.

AlighIERI, Dante (1980): Die Göttliche Komödie. Übersetzt von Hermann Gmelin. Stuttgart: Reclam.

ApPerley, Thomas H. (2006): Genre and Game Studies. Toward a Critical Approach to Video Game Genres. In: Simulation \& Gaming, 37 (1), 6-23.

ARISTOTELES (2008): Werke in deutscher Übersetzung. Begründet von Ernst Grumach. Hg. von Hellmut Flashar. Band 5: Poetik. Übersetzt und erläutert von Arbogast Schmitt. Berlin: Akademie Verlag.

Armstrong, Karen (2007): Eine kurze Geschichte des Mythos. München: dtv.

ARSENAULT, Dominic (2009): Video Game Genre, Evolution and Innovation. In: Eludamos, 3 (2), 149-176.

ARSENAUlt, Dominic (2014): Narratology. In: Mark J.P. Wolf und Bernard Perron (Hg.): The Routledge Companion to Video Game Studies. New York, NY: Routledge, 475-483.

Assmann, Aleida und Assmann, Jan (1998): Mythos. In: Hubert Cancik; Burkhard Gladigow und Karl-Heinz Kohl (Hg.): Handbuch religionswissenschaftlicher Grundbegriffe. Band IV: Kultbild - Rolle. Stuttgart: Kohlhammer, 179-200.

AssmanN, Jan (1992): Frühe Formen politischer Mythomotorik. Fundierende, kontrapräsentische und revolutionäre Mythen. In: Dietrich Harth und ders. (Hg.): Revolution und Mythos. Frankfurt am Main: Fischer, 39-61.

ASSMANN, Jan ( $\left.{ }^{6} 2007\right):$ Das kulturelle Gedächtnis. Schrift, Erinnerung und politische Identität in frühen Hochkulturen. München: Beck.

ATKINS, Barry (2003): More than a Game. The Computer Game as a Fictional Form. Manchester: Manchester Univ. Press.

AtTEBery, Brian (2014): Stories about Stories. Fantasy \& the Remaking of Myth. Oxford: Oxford University Press.

Avedon, Elliot M. und Sutton-Smith, Brian (1979a) (Hg.): The Study of Games. Huntington, NY: Krieger.

Avedon, Elliott M. und SutTon-Smith, Brian (1979b): Introduction. In: Dies. (Hg.): The Study of Games. Huntington, NY: Krieger, 1-8.

BaCHMANN-Medick, Doris ( $\left.{ }^{3} 2009\right)$ : Cultural Turns. Neuorientierungen in den Kulturwissenschaften. Reinbek bei Hamburg: Rowohlt.

Bachtin, Michail M. (2008): Chronotopos. Frankfurt am Main: Suhrkamp.

BACKE, Hans-Joachim (2008): Strukturen und Funktionen des Erzählens im Computerspiel. Eine typologische Einführung. Würzburg: Königshausen \& Neumann. 
BACKE, Hans-Joachim (2011): Von der Superhelden-Fiktion zur Meta-Helden-Fiktion. Watchmen und die Dekonstruktion des Heldentums. In: Kritische Berichte. Zeitschrift für Kunst- und Kulturwissenschaften, 39 (1), 5-19.

BAER, Ralph (2005): Videogames. In the Beginning. Springfield, NJ: Rolenta Press.

BAL, Mieke (1981): Notes on Narrative Embedding. In: Poetics Today, 2 (2), 41-59.

BAlZAMO, Elena (2004): Die ätiologische Erzählung. Drei Aspekte. In: Fabula, 45 (1-2), 93101.

BAREITHER, Christoph (2016): Gewalt im Computerspiel. Facetten eines Vergnügens. Bielefeld: transcript.

BARNER, Wilfried; DetKen, Anke und Wesche, Jörg (2007) (Hg.): Texte zur modernen Mythentheorie. Stuttgart: Reclam.

BARTHES, Roland (1988): Einführung in die strukturale Analyse von Erzählungen. In: Ders.: Das semiologische Abenteuer. Frankfurt am Main: Suhrkamp, 102-143.

BARTHES, Roland (2010): Mythen des Alltags. Berlin: Suhrkamp.

Bartholdy, Björn; Brandhorst, Susanne; Breitlauch, Linda; Czauderna, André und FREYERMUTH, Gundolf S. (2017) (Hg.): Games studieren - was, wie, wo? Staatliche Studienangebote im Bereich digitaler Spiele. Bielefeld: transcript.

BAßLER, Moritz (2014): Bewohnbare Strukturen und der Bedeutungsverlust des Narrativs. Überlegungen zur Serialität am Gegenwarts->Tatort২. In: Christian Hißnauer; Stefan Scherer und Claudia Stockinger (Hg.): Zwischen Serie und Werk. Fernseh- und Gesellschaftsgeschichte im >Tatort . Bielefeld: transcript, 347-359.

BATEMAn, Chris; LowenhauPT, Rebecca und NACKE, Lennart E. (2011): Player Typology in Theory and Practice. In: Proceedings of DiGRA 2011 Conference. Think Design Play. URL: http://www.digra.org/wp-content/uploads/digital-library/11307.50587.pdf (30.06.2018).

BAteson, Gregory (22007): A Theory of Play and Fantasy. In: Henry Bial (Hg.): The Performance Studies Reader. Abingdon: Routledge, 141-151.

BAUdRILlard, Jean (1996): The Gulf War Did Not Take Place. In: Contemporary British History, 10 (1), 250-252.

BAUDRILlARD, Jean (2010): Simulacra and Simulation. [Nachdruck]. Ann Arbor, MI: Univ. of Michigan Press.

BeIL, Benjamin (2010): First Person Perspectives. Point of View und figurenzentrierte Erzählformen im Film und im Computerspiel. Münster: Lit Verlag.

BEIL, Benjamin (2015): Game Studies und Genretheorie. In: Klaus Sachs-Hombach und JanNoël Thon (Hg.): Game Studies. Aktuelle Ansätze der Computerspielforschung. Köln: Herbert von Halem Verlag, 29-69.

BeIL, Benjamin; Freyermuth, Gundolf S. und Gotto, Lisa (2015a) (Hg.): New Game Plus. Perspektiven der Game Studies. Genres - Künste - Diskurse. Bielefeld: transcript. 
BeIL, Benjamin; FreYermuth, Gundolf S. und GotTo, Lisa (2015b): Vorwort. In: Dies. (Hg.): New Game Plus. Perspektiven der Game Studies. Genres - Künste - Diskurse. Bielefeld: transcript, 7-18.

BeILEIN, Matthias; Stockinger, Claudia und Winko, Simone (2012) (Hg.): Kanon, Wertung und Vermittlung. Literatur in der Wissensgesellschaft. Berlin: de Gruyter.

Belman, Jonathan und Flanagan, Mary (2010): Exploring the Creative Potential of Values Conscious Design. Students' Experiences with the Values at Play Curriculum. In: Eludamos, 4 (1), 57-67.

Berger, Peter L. (1999): The Desecularization of the World. A Global Overview. In: Ders. (Hg.): The Desecularization of the World. Resurgent Religion and World Politics. Washington, D.C.: Ethics and Public Policy Center, 1-18.

BнAвHA, Homi K. (2012): Über kulturelle Hybridität. Tradition und Übersetzung. Wien: Turia + Kant.

BIERMANN, Ralf und BECKER, Steven (2017): Faszination Let's Play-Videos. Rezeptionsmotive und -merkmale - Eine explorative quantitative Studie. In: Judith Ackermann (Hg.): Phänomen Let's Play-Video. Entstehung, Ästhetik, Aneignung und Faszination aufgezeichneten Computerspielhandelns. Wiesbaden: Springer VS, 161-179.

BlumenBerg, Hans (2006): Arbeit am Mythos. Frankfurt am Main: Suhrkamp.

BÖHME, Gernot (2014): Atmosphäre. Essays zur neuen Ästhetik. Berlin: Suhrkamp.

Bogost, Ian (2010): Persuasive Games. The Expressive Power of Videogames. Cambridge, MA: The MIT Press.

Bolter, Jay David und Grusin, Richard (2000): Remediation. Understanding New Media. Cambridge, MA: The MIT Press.

BÖMELBURG, Hans Jürgen (2006): Frühneuzeitliche Nationen im östlichen Europa. Das polnische Geschichtsdenken und die Reichweite einer humanistischen Nationalgeschichte (1500-1700). Wiesbaden: Harrassowitz.

BRAUN-THÜRMANN, Holger (2002): Künstliche Interaktion. Wie Technik zur Teilnehmerin sozialer Wirklichkeit wird. Wiesbaden: Westdeutscher Verlag.

BRECHT, Bertolt (1963): Leben des Galilei. Berlin: Suhrkamp.

BReITlauch, Linda (2008): Dramaturgie der Computerspiele. Analyse und Bewertung von Wirkungspotenzialen interaktiven Erzählens im Kontext gestaltungsrelevanter Fragestellungen. Diss.: Hochschule für Film und Fernsehen Potsdam.

BUCHER, Hans-Jürgen (2001): Wie interaktiv sind die neuen Medien? Grundlagen einer Theorie der Rezeption nicht-linearer Medien. In: Ders. (Hg.): Die Zeitung zwischen Print und Digitalisierung. Wiesbaden: Westdeutscher Verlag, 139-171.

BudZISZEwSKI, P. Konrad (2012): >Legend of Zelda< Series. In: Mark J.P. Wolf (Hg.):

Encyclopedia of Video Games. The Culture, Technology, and Art of Gaming. Band 1: A L. Santa Barbara, CA: Greenwood, 360-365. 
BÜNGER, Traudl (2005): Narrative Computerspiele. Struktur \& Rezeption. München: kopaed.

BuRKe, D.M. (2011): The Necessity of the Triforce in the Defeat of Ganon. In: Jonathan Walls (Hg.): The Legend of Zelda and Theology. Hollywood, CA: Gray Matter Books, 155-170.

BURKE, Kenneth (1960): Myth, Poetry and Philosophy. In: The Journal of American Folklore, 73 (290), 283-306.

Burkert, Walter und Horstmann, Axel (1984): Mythos, Mythologie. In: Joachim Ritter und Karlfried Gründer (Hg.): Historisches Wörterbuch der Philosophie. Band 6. Darmstadt: WBG, 281-318.

BuURman, Gerhard M. (2005) (Hg.): Total Interaction. Theory and Practice of a New Paradigm for the Design Disciplines. Basel: Birkhäuser.

CaIlloIs, Roger (1960): Die Spiele und die Menschen. Maske und Rausch. Stuttgart: Schwab.

Calleja, Gordon (2009): Experiential Narrative in Game Environments. In: Proceedings of DiGRA 2009. URL: http://www.digra.org/dl/db/09287.07241.pdf (30.06.2018).

CAMPBell, Joseph (1992): Die Masken Gottes. Band 4: Schöpferische Mythologie. Basel: Sphinx.

CAMPBell, Joseph (2011): Der Heros in tausend Gestalten. Berlin: Insel Verlag.

CASSAR, Robert (2013): Analysing God of War. A Hero's Journey. In: Eludamos, 7 (1), $81-$ 99.

CASSIDY, Scott Brendan (2011): The Videogame as Narrative. In: Quarterly Review of Film and Video, 28 (4), 292-307.

CASSIRER, Ernst (2002): Vom Mythus des Staates. Hamburg: Meiner.

Cermak-SASSEnRath, Daniel (2010): Interaktivität als Spiel. Neue Perspektiven auf den Alltag mit dem Computer. Bielefeld: transcript.

Cervantes Saavedra, Miguel de (1969): Der sinnreiche Junker Don Quijote von der Mancha. 2 Bände. Frankfurt am Main: Büchergilde.

CHANDLER, Rafael (2007): Game Writing Handbook. Boston, MA: Charles River Media.

ChANDLER, Benjamin (2009): The Spiky-Haired Mercenary vs. the French Narrative Theorist. >Final Fantasy VII and the Writerly Text. In: Jason P. Blahuta und Michel S. Beaulieu (Hg.): Final Fantasy and Philosophy. The Ultimate Walktrough. Hoboken, NJ: John Wiley \& Sons, 5-19.

CHANG, Edmond Y. (2008): Gaming as Writing, or, World of Warcraft as World of Wordcraft. URL:

http://www2.bgsu.edu/departments/english/cconline/gaming_issue_2008/Chang_Gaming as_writing/index.html (30.06.2018).

Charles, Alec (2009): Playing with one's self. Notions of Subjectivity and Agency in Digital Games. In: Eludamos, 3 (2), 281-294. 
Chatman, Seymour ( $\left.{ }^{6} 1993\right)$ : Story and Discourse. Narrative Structure in Fiction and Film. Ithaca, NY: Cornell University Press.

COLERIDGE, Samuel Taylor (1997): Biographia literaria. Hg. von Nigel Leask. Everyman: London.

Collins, Dwayne (2009): How Can There Be Evil in Hyrule? In: Luke Cuddy (Hg.): The Legend of Zelda and Philosophy. I Link Therefore I Am. Chicago, IL: Open Court, 223232.

CONRAD, Maren (2015): Paradoxe Interaktivität. Zum Potential der Feedbackschleife als integratives Modell am Beispiel des Computerspiels. In: Literatur. Macht. Gesellschaft. Neue Beiträge zur theoretischen Modellierung des Verhältnisses von Literatur und Gesellschaft. Hg. vom Promotionskolleg Literaturtheorie als Theorie der Gesellschaft. Heidelberg: Winter, 79-100.

Consalvo, Mia (2003): Zelda 64 and Video Game Fans. A Walkthrough of Games, Intertextuality and Narrative. In: Television and new media, 4 (3), 321-334.

Consalvo, Mia (2007): Cheating. Gaining Advantage in Videogames. Cambridge, MA: The MIT Press.

Consalvo, Mia (2016): Atari to Zelda. Japan's Videogames in Global Contexts. Cambridge, MA: The MIT Press.

CostikyAn, Greg (2007): Games, Storytelling, and Breaking the String. In: electronic book review. URL: http://www.electronicbookreview.com/thread/firstperson/storyish (30.06.2018).

COURTÉs, Joseph (1991): Analyse sémiotique du discours. De l'énoncé à l'énonciation. Paris: Hachette.

CudDy, Luke (2009a) (Hg.): The Legend of Zelda and Philosophy. I Link Therefore I Am. Chicago, IL: Open Court.

CudDY, Luke (2009b): >Zelda ${ }^{2}$ as Art. In: Ders. (Hg.): The Legend of Zelda and Philosophy. I Link Therefore I Am. Chicago, IL: Open Court, 153-164.

DEGLER, Frank (2009): A Willing Suspension of Misbelief. Fiktionsverträge in Computerspiel und Literatur. In: Thomas Anz und Heinrich Kaulen (Hg.): Literatur als Spiel. Evolutionsbiologische, ästhetische und pädagogische Konzepte. Berlin: de Gruyter, 543560 .

DEWINTER, Jennifer (2015): Shigeru Miyamoto. Super Mario Bros., Donkey Kong, The Legend of Zelda. New York, NY: Bloomsbury.

DINKLA, Söke (2009): Meta Games. Interaktive Medienkunst und digitale Spiele - ein (un)gleiches Geschwisterpaar. In: Kritische Berichte, 37 (2), 88-94.

DAHRENDORF, Ralf ( $\left.{ }^{17} 2010\right):$ Homo sociologicus. Ein Versuch zur Geschichte, Bedeutung und Kritik der Kategorie der sozialen Rolle. Wiesbaden: VS. 
Denson, Shane und JAHN-Sudmann, Andreas (2013): Digital Seriality. On the Serial Aesthetics and Practice of Digital Games. In: Eludamos, 7 (1), 1-32.

DeVAN, Benjamin B. (2011): High Rule? Vintage Virtue in >The Legend of Zeldar. In: Jonathan Walls (Hg.): The Legend of Zelda and Theology. Hollywood, CA: Gray Matter Books, 125-142.

DOMSCH, Sebastian (2012): Freiheit oder Erzählung - oder beides? Zu Konzepten von Erzählung und Spielerfreiheit im Computerspiel. In: Ansgar Nünning; Jan Rupp; Rebecca Hagelmoser und Jonas Ivo Meyer (Hg.): Narrative Genres im Internet. Theoretische Bezugnahmen, Mediengattungstypologie und Funktionen. Trier: Wissenschaftlicher Verlag Trier, 195-207.

Domsch, Sebastian (2013): Storyplaying. Agency and Narrative in Video Games. Berlin: de Gruyter.

Dovey, Jon und Kennedy, Helen W. (2011): Game Cultures. Computer Games as New Media. Reprinted. Maidenhead: Open University Press.

Downes, Edward J. und MCMillan, Sally (2000): Defining Interactivity. A Qualitative Identification of Key Dimensions. In: New Media \& Society, 2 (2), 157-179.

Droogers, André (2012): Play and Power in Religion. Collected Essays. Berlin: de Gruyter.

DRZAIC, Kristina und RAUCH, Peter ( $\left.{ }^{2} 2009\right)$ : Slave Morality and Master Swords. Ludus and Paidia in `Zeldar. In: Luke Cuddy (Hg.): The Legend of Zelda and Philosophy. I Link Therefore I Am. Chicago, IL: Open Court, 65-74.

DugAn, Patrick (2009): A Link to The Triforce. Miyamoto, Lacan, and You. In: Luke Cuddy (Hg.): The Legend of Zelda and Philosophy. I Link Therefore I Am. Chicago, IL: Open Court, 203-210.

Duncan, Sean C. und GeE, James Paul (22009): The Hero of Timelines. In: Luke Cuddy (Hg.): The Legend of Zelda and Philosophy. I Link Therefore I Am. Chicago, IL: Open Court, 85-101.

DÜRRENMATt, Friedrich (1980): Die Physiker. Eine Komödie in zwei Akten. Zürich: Diogenes.

Dworkin, Ronald (2013): Justice for Hedgehogs. Cambridge, MA: Harvard University Press.

Eco, Umberto ( $\left.{ }^{3} 1993\right)$ : Die Innovation im Seriellen. In: Ders.: Über Spiegel und andere Phänomene. München: dtv, 155-180.

EDER, Jens (2008): Die Figur im Film. Grundlagen der Figurenanalyse. Marburg: Schüren.

EICK, Dennis (2014): Digitales Erzählen. Die Dramaturgie der Neuen Medien. Konstanz: UVK.

EigenfeldT-NiELSEN, Simon; Smith, Jonas und ToscA, Susana (2008): Understanding Videogames. The Essential Introduction. New York, NY: Routledge.

Eliade, Mircea (1984): Das Heilige und das Profane. Vom Wesen des Religiösen. Frankfurt am Main: Insel. 
ENGELNS, Markus (2014): Spielen und Erzählen. Computerspiele und die Ebenen ihrer Realisierung. Heidelberg: Synchron.

ENGELNS, Markus (2015): »äußerst unzufrieden« - Entscheidungsstrukturen in Computerspielen als Produkte >individualisierbaren $<$ Konsums. In: PAIDA, 21. Dezember 2015. URL: http://www.paidia.de/?p=6757 (30.06.2018).

Engemann, Christoph und Sudmann, Andreas (2018) (Hg.): Machine Learning. Medien, Infrastrukturen und Technologien der künstlichen Intelligenz. Bielefeld: transcript.

ENSSLIN, Astrid (2014): Literary Gaming. Cambridge, MA: The MIT Press.

ERIKSON, Erik H. $\left({ }^{4} 1971\right)$ : Kindheit und Gesellschaft. Stuttgart: Ernst Klett Verlag.

ERNST, Daniel (2018): Musik als dramatischer und interaktiver Bestandteil im Spielverlauf. In: Christoph Hust (Hg.): Digitale Spiele. Interdisziplinäre Perspektiven zu Diskursfeldern, Inszenierung und Musik. Bielefeld: transcript, 311-324.

ESKELINEN, Markku (2001): The Gaming Situation. In: Game Studies, 1 (1). URL: http://www.gamestudies.org/0101/eskelinen/ (30.06.2018).

ESKELINEN, Markku (2004): Towards Computer Game Studies. In: Noah Wardrip-Fruin und Pat Harrigan (Hg.): First Person. New Media as Story, Performance, and Game. Cambridge, MA: The MIT Press, 36-44.

ESKELINEN, Markku (2012): Cybertext Poetics. The Critical Landscape of New Media Literary Theory. New York, NY: Continuum.

ESPAGNE, Michel und WeRnER, Michael (1988): Transferts. Les relations interculturelles dans l'espace franco-allemand. Paris: Éd. Recherche sur les Civilisations.

FAHLENBRACH, Kathrin und SCHRÖTER, Felix (2015): Game Studies und Rezeptionsästhetik. In: Klaus Sachs-Hombach und Jan-Noël Thon (Hg.): Game Studies. Aktuelle Ansätze der Computerspielforschung. Köln: Herbert von Halem Verlag, 165-208.

FEIGE, Daniel Martin (2015): Computerspiele. Eine Ästhetik. Berlin: Suhrkamp.

FELLELA, Toni (22009): Link's Search for Meaning. In: Luke Cuddy (Hg.): The Legend of Zelda and Philosophy. I Link Therefore I Am. Chicago, IL: Open Court, 45-54.

Flaubert, Gustave (2014): Madame Bovary. München: dtv.

Flood, Christopher G. (2002): Political Myth. A Theoretical Introduction. New York, NY: Routledge.

FontANE, Theodor (2004): Effi Briest. Roman. Frankfurt am Main: Suhrkamp.

FORSTER, Edward Morgan (1974): Aspects of the Novel. Harmondsworth: Penguin.

FRASCA, Gonzalo (1999): Ludology Meets Narratology. Similitudes and Differences between (Video)Games and Narrative. URL: http://www.ludology.org/articles/ludology.htm. (30.06.2018).

FRASCA, Gonzalo (2001): Simulation 101. Simulation versus Representation. URL: http://www.ludology.org/articles/sim1/simulation101.html (30.06.2018). 
FrascA, Gonzalo (2003a): Sim Sin City. Some Thoughts about Grand Theft Auto 3. In: Game Studies, 3 (2). URL: http://www.gamestudies.org/0302/frasca/ (30.06.2018).

FRASCA, Gonzalo (2003b): Simulation versus Narrative. Introduction to Ludology. In: Mark J.P. Wolf und Bernard Perron (Hg.): The Video Game Theory Reader. New York, NY: Routledge, 221-235.

Frasca, Gonzalo (2007): Play the Message. Play, Game and Videogame Rhetoric. Phil. Diss.: IT University Copenhagen. URL:

FREUD, Sigmund (2013): Totem und Tabu. Göttingen: V\&R unipress.

FREYERMUTH, Gundolf S. (2015a): Games - Game Design - Game Studies. Eine Einführung. Bielefeld: transcript.

FREYERMUTH, Gundolf S. (2015b): Game Studies und Game Design. In: Klaus SachsHombach und Jan-Noël Thon (Hg.): Game Studies. Aktuelle Ansätze der Computerspielforschung. Köln: Herbert von Halem Verlag, 70-103.

FRITZ, Jürgen (2011): Wie Computerspieler ins Spiel kommen. Theorien und Modelle zur Nutzung und Wirkung virtueller Spielwelten. Berlin: Vistas.

Fromme, Johannes und Unger, Alexander (2012) (Hg.): Computer Games and New Media Cultures. A Handbook of Digital Game Studies. Dordrecht: Springer.

FroschaUer, Adrian (2016): Der Kampf um die Erzählhoheit. Voice-over-Narration im Computerspiel. In: Martin Hennig und Hans Krah (Hg.): Spielzeichen. Theorien, Analysen und Kontexte des zeitgenössischen Computerspiels. Glückstadt: VWH, 117-136.

FRYE, Northrop (1964): Analyse der Literaturkritik. Stuttgart: Kohlhammer.

FRYE, Northrop und MACPHERSON, Jay (2004): Biblical and Classical Myths. The Mythological Framework of Western Culture. Toronto: University of Toronto Press.

FuCHS, Mathias; FIzEK, Sonia; RuFFINO, Paolo und SCHRAPE, Niklas (2014) (Hg.): Rethinking Gamification. Lüneburg: Meson Press.

FuChS-HeInRITZ, Werner und KönIG, Alexandra (2011): Pierre Bourdieu. Eine Einführung. Konstanz: UVK.

FURTWÄNGLER, Frank (2001): »A Crossword at War with a Narrative«. Narrativität versus Interaktivität in Computerspielen. In: Peter Gendolla et al. (Hg.): Formen interaktiver Medienkunst. Geschichte, Tendenzen, Utopien. [Frankfurt am Main]: Suhrkamp, 369-400.

Gabbrielli, Maurizio und Martini, Simone (2010): Programming Languages. Principles and Paradigms. London: Springer.

GABRIEL, Markus ( 22015$)$ : Warum es die Welt nicht gibt. Berlin: Ullstein.

GABRIEL, Nicole; KAZUR, Bogna und MatusZKIEWICZ, Kai (2015): Reconsidering Transmedia(l) Worlds. In: Claudia Georgi und Brigitte J. Glaser (Hg.): Convergence Culture Reconsidered. Media - Participation - Environments. Göttingen:

Universitätsverlag Göttingen, 163-194. 
GADAMER, Hans-Georg (1999): Hermeneutik I. Wahrheit und Methode. Grundzüge einer philosophischen Hermeneutik. Tübingen: Mohr Siebeck.

Galloway, Alexander (2006): Gaming. Essays on Algorithmic Culture. Minneapolis, MN: University of Minnesota Press.

GAmesCoop. (2012) (Hg.): Theorien des Computerspiels zur Einführung. Hamburg: Junius.

GazZard, Alison und Peacock, Alan (2011): Repetition and Ritual Logic in Video Games. In: Games and Culture, 6 (6), 499-512.

GENETTE, Gérard (1994): Die Erzählung. München: Fink.

GENNEP, Arnold van ( $\left.{ }^{3} 2005\right):$ Übergangsriten. Frankfurt am Main: Campus.

GeERTZ, Clifford (2002a): Deep Play. Notes on the Balinese Cockfight. In: Ders.: The Interpretation of Cultures. Selected Essays. [Nachdruck]. New York, NY: BasicBooks, 412-453.

GEERTZ, Clifford (2002b): Religion as a Cultural System. In: Ders.: The Interpretation of Cultures. Selected Essays. [Nachdruck]. New York, NY: BasicBooks, 87-125.

Gerling, Winfried; Holschbach, Susanne und LöFfler, Petra (2018) (Hg.): Bilder verteilen. Fotografische Praktiken in der digitalen Kultur. Bielefeld: transcript.

GESELlSCHAFT FÜR MEDIENwISSENSCHAFT (2017) (Hg.): Zeitschrift für Medienwissenschaft, 2. Bielefeld: transcript.

GibBons, Alison (2012): Multimodality. Cognition, and Experimental Literature. New York, NY: Routledge.

GIDDENS, Anthony ( $\left.{ }^{3} 1997\right):$ Die Konstitution der Gesellschaft. Grundzüge einer Theorie der Strukturierung. Frankfurt am Main: Campus.

GoERTZ, Lutz (1995): Wie interaktiv sind Medien? Auf dem Weg zu einer Definition von Interaktivität. In: Rundfunk und Fernsehen, 43 (4), 477-493.

GoFFIN, Bettina (2002): Euergetismus in Oberitalien. Bonn: Habelt.

Goffman, Erving (2007): Performances. Belief in the Part One is Playing. In: Henry Bial (Hg.): The Performance Studies Reader. Abingdon: Routledge, 61-65.

GoMes, Renata (2005): The Design of Narrative as an Immersive Simulation. In: Proceedings of DiGRA 2005 Conference. URL: http://www.digra.org/dl/db/06276.21047.pdf (30.06.2018).

GreIMAS, Algirdas Julien (1971): Strukturale Semantik. Methodologische Untersuchungen. Braunschweig: Vieweg.

Grodal, Torben (2003): Stories for Eye, Ear, and Muscles. Video Games, Media, and Embodied Experiences. In: Mark J.P. Wolf und Bernard Perron (Hg.): The Video Game Theory Reader. New York, NY: Routledge, 129-155. 
GrUBER, Angela (2015): The Void - der erste virtuelle Freizeitpark. In: Zeit Online, 8. Juni. URL: http://www.zeit.de/digital/games/2015-06/virtual-reality-the-void-freizeitpark (30.06.2018).

GrÜNBEIN, Durs (2002): Epistel an einen englischen Arzt. In: Ders.: Erklärte Nacht. Gedichte. Frankfurt am Main: Suhrkamp, 131-135.

GÜNZEL, Stephan (2012): Egoshooter. Das Raumbild des Computerspiels. Frankfurt am Main: Campus.

GÜNZEL, Stephan (2013): Bild und Erzählung im Computerspiel. In: Bernd Kracke und Marc Ries (Hg.): Expanded Narration. Das neue Erzählen. Bielefeld: transcript, 381-390.

GÜNZEL, Stephan (2017): Raum. Eine kulturwissenschaftliche Einführung. Bielefeld: transcript.

GUNZENHÄUSER, Randi (2003): Computerspiele als Herausforderung an die Wissenschaften. In: Evelyne Keitel et al. (Hg.): Computerspiele - Eine Provokation für die Kulturwissenschaften? Lengerich: Pabst, 107-114.

HABERMAS, Jürgen (1981): Theorie des kommunikativen Handelns. Band 1: Handlungsrationalität und gesellschaftliche Rationalisierung. Frankfurt am Main: Suhrkamp.

HAHN, Sabine (2017): Gender und Gaming. Frauen im Fokus der Games-Industrie. Bielefeld: transcript.

HAMSUN, Knut (2012): Hunger. Roman. Berlin: List.

HARTH, Jonathan (2016): Zwischen Subjekt und Objekt - Überlegungen zum Status computergesteuerter Spielpartner. In: PAIDIA, 30. Juni. URL: http://www.paidia.de/?p=7705 (30.06.2018).

HARTMANN von Aue $\left({ }^{4} 2001\right)$ : Iwein. Berlin: de Gruyter.

HARTMANn, Martin (2010): Gefühle. Wie die Wissenschaften sie erklären. Frankfurt am Main: Campus.

HARVIAINEN, J. Tuomas (2012): Ritualistic Games, Boundary Control, and Information Uncertainty. In: Simulation \& Gaming, 43 (4), 506-527.

Harviainen, J. Tuomas und Lieberoth, Andreas (2012): Similarity of Social Information Processes in Games and Rituals. Magical Interfaces. In: Simulation \& Gaming, 43 (4), $528-549$.

HASSler-Forest, Dan (2016): Science Fiction, Fantasy, and Politics. Transmedia WorldBuilding Beyond Capitalism. London: Rowman \& Littlefield.

HAVsTAD, Joyce C. und JAHng, Iris M. ( $\left.{ }^{2} 2009\right)$ : The Legend of Feminism. In: Luke Cuddy (Hg.): The Legend of Zelda and Philosophy. I Link Therefore I Am. Chicago, IL: Open Court, 233-244. 
HAYSE, Mark (2011): The Meditation of Transcendence within The Legend of Zelda: Wind Waker. In: Jonathan Walls (Hg.): The Legend of Zelda and Theology. Hollywood, CA: Gray Matter Books, 83-96.

HEINECKE, Andreas M. (22012): Mensch-Computer-Interaktion. Basiswissen für Entwickler und Gestalter. Berlin: Springer.

HeInRICH, Karen (2013): Fan Costuming and Cosplay zu Star Wars und Anime. Die kulturelle Praxis von Fans japanischer und amerikanischer Populärkultur. Heuchelheim: Longtai.

Herte, Michelle (2016): »Come, Stanley, let's find the story! « On the Ludic and the Narrative Mode of Computer Games in >The Stanley Parable«. In: IMAGE. Zeitschrift für interdisziplinäre Bildwissenschaft, (23), 30-42.

Hewson, Martin (2010): Agency. In: Albert J. Mills; Gabrielle Durepos und Elden Wiebe (Hg.): Case Study Research. Band 1. Los Angeles: SAGE, 12-16.

HeYNOLDT, Anke (1998): Die Bedeutung des Sarmatismus für das Nationalbewusstsein und die Kultur des polnischen Adels zwischen dem 16. und dem 18. Jahrhundert. In: Kultursoziologie, 7 (1), 6-57.

HickethIER, Knut (1991): Die Fernsehserie und das Serielle des Fernsehens. Lüneburg: Universität.

HimeKAwA, Akira (2009): The Legend of Zelda. Ocarina of Time. 2 Bände. Hamburg: TOKYOPOP.

HOFSTADTER, Douglas ( $\left.{ }^{11} 1988\right):$ Gödel, Escher, Bach. Ein endloses geflochtenes Band. Stuttgart: Klett-Cotta.

HöHN, Hans-Joachim (2006): Postreligiös oder postsäkular? Wo heute religiöse Bedürfnisse aufleben. In: Renaissance der Religion. Mode oder Megathema? Herder Korrespondenz Spezial. Freiburg im Br.: Herder, 2-6.

HorkHEIMER, Max und Adorno, Theodor W. (1997): Dialektik der Aufklärung. Philosophische Fragmente. Frankfurt am Main: Fischer.

Horn, Charles Joshua ( $\left.{ }^{2} 2009\right)$ : The Triforce and the Doctrine of the Mean. In: Luke Cuddy (Hg.): The Legend of Zelda and Philosophy. I Link Therefore I Am. Chicago, IL: Open Court, 211-219.

Howard, Jeff (2008): Quests. Design, Theory, and History in Games and Narratives. Wellesley, MA: A K Peters.

HuberTs, Christian (2014): Computerspiele lesen. In: Thomas Böhm (Hg.): Computerspiele und Literatur. Berlin: Metrolit, 28-37.

HÜBNER, Kurt (1986/87): Die nicht endende Geschichte des Mythischen. In: Scheidewege, 16, 16-29.

HuIZINGA, Johan (1991): Homo ludens. Vom Ursprung der Kultur im Spiel. 116.-118. Tausend. Reinbek bei Hamburg: Rowohlt. 
HunTer, Justus (2011): On Hylian Virtues. Aristotle, Aquinas and the Hylian Cosmogenesis. In: Jonathan Walls (Hg.): The Legend of Zelda and Theology. Hollywood, CA: Gray Matter Books, 109-123.

Huntington, Samuel (2011): The Clash of Civilizations and the Remaking of World Order. New York, NY: Simon \& Schuster.

HuXLEY, Aldous ( ${ }^{632006): ~ S c h o ̈ n e ~ n e u e ~ W e l t . ~ E i n ~ R o m a n ~ d e r ~ Z u k u n f t . ~ F r a n k f u r t ~ a m ~ M a i n . ~}$ Fischer Taschenbuch Verlag.

INDERST, Rudolf Thomas und Just, Peter (2011) (Hg.): Contact-Conflict-Combat. Zur Tradition des Konfliktes in digitalen Spielen. Boizenburg: VWH.

InGELMANN, Julian und MATUSZKIEWICZ, Kai (2017): Autorschafts- und Literaturkonzepte im digitalen Wandel. In: Zeitschrift für Germanistik. Neue Folge XXVIII, 2, 305-315.

IP, Barry (2011a): Narrative Structures in Computer and Video Games. Part 1: Context, Definition, and Initial Findings. In: Games and Culture, 6 (2), 103-135.

IP, Barry (2011b): Narrative Structures in Computer and Video Games. Part 2: Emotions, Structures, and Archetypes. In: Games and Culture, 6 (3), 203-245.

ISER, Wolfgang (1970): Die Appellstruktur der Texte. Unbestimmtheit als Wirkungsbedingung literarischer Prosa. Konstanz: Universitätsverlag Konstanz.

ISER, Wolfgang (2009): Das Fiktive und das Imaginäre. Perspektiven literarischer Anthropologie. [Nachdruck]. Frankfurt am Main: Suhrkamp.

JÄCKEL, Michael (1995): Interaktion. Soziologische Anmerkungen zu einem Begriff. In: Rundfunk und Fernsehen, 43 (4), 463-476.

Jahn-Sudmann, Andreas und Stockmann, Ralf (2008): Introduction. In: Dies (Hg.): Computer Games as a Sociocultural Phenomenon. Games Without Frontiers - War Without Tears. Basingstoke, NY: Palgrave Macmillian, xiii-xix.

JAMISON, Anne (2013) (Hg.): Fic. Why Fanfiction Is Taking Over the World. Dallas, TX: Smart Pop.

Jamme, Christoph und MatuscheK, Stefan (2014a): Vorwort. In: Dies. (Hg.): Handbuch der Mythologie. Darmstadt: Zabern, 8-9.

Jamme, Christoph und MatuscheK, Stefan (2014b) (Hg.): Handbuch der Mythologie. Darmstadt: Zabern.

JANNIDIS, Fotis (2003): Narratology and the Narrative. In: Tom Kindt und Hans-Harald Müller (Hg.): What Is Narratology? Questions and Answers Regarding the Status of a Theory. Berlin: de Gruyter, 35-54.

JANNIDIS, Fotis (2007): Event-Sequences, Plots and Narration in Computer Games. In: Peter Gendolla und Jörgen Schäfer (Hg.): The Aesthetics of Net Literature. Writing, Reading and Playing in Programmable Media. Bielefeld: transcript, 281-305. 
JANNIDIS, Fotis (2012): Wertungen und Kanonisierungen von Computerspielen. In: Matthias Beilein; Claudia Stockinger und Simone Winko (Hg.): Kanon, Wertung und Vermittlung. Literatur in der Wissensgesellschaft. Berlin: de Gruyter, 321-344.

JENKINS, Henry (2002): Game Theory. In: MIT Technology Review. URL: http://www.technologyreview.com/news/401394/game-theory/ (30.06.2018).

JENKINS, Henry (2004): Game Design as Narrative Architecture. In: Noah Wardrip-Fruin und Pat Harrigan (Hg.): First Person. New Media as Story, Performance and Game. Cambridge, MA: The MIT Press, 118-130.

Jenkins, Henry (2006): Fans, Bloggers, and Gamers. Exploring Participatory Culture. New York, NY: New York University Press.

JoHnson, Carl Matthew (2009): Linking to the Past. Zelda Is a Communication Game. In: Luke Cuddy (Hg.): The Legend of Zelda and Philosophy. I Link Therefore I Am. Chicago, IL: Open Court, 103-117.

JOYCE, James (2012): Ulysses. Richmond: Alma Classics.

JOYCE, Michael (1987): Afternoon: A Story. Cambridge, MA: Eastgate Systems.

Jung, C[arl] G[ustav] (1954): Von den Wurzeln des Bewußtseins. Studien über den Archetypus. Zürich: Rascher.

JunG, C[arl] G[ustav] ('21976a): Gesammelte Werke. Band 9/1: Die Archetypen und das Kollektive Unbewusste. Olten und Freiburg im Breisgau: Walter-Verlag.

JunG, C[arl] G[ustav] ( $\left.{ }^{2} 1976 b\right)$ : Gesammelte Werke. Band 8: Die Dynamik des Unbewussten. Olten und Freiburg im Breisgau: Walter-Verlag.

JUUL, Jesper (1999): A Clash between Game and Narrative. A Thesis on Computer Games and Interactive Fiction. M.A. Thesis: Institute of Nordic Language and Literature, University of Copenhagen.

JuUL, Jesper (2001): Games Telling Stories? A Brief Note on Games \& Narratives. In: Game Studies, 1 (1). URL: http://www.gamestudies.org/0101/juul-gts/ (30.06.2018).

JUUL, Jesper (2004): Introduction to Game Time. In: Noah Wardrip-Fruin und Pat Harrigan (Hg.): First Person. New Media as Story, Performance, and Game. Cambridge, MA: The MIT Press, 131-142.

JuUL, Jesper (2005): Half-Real. Video Games between Real Rules and Fictional Worlds. Cambridge, MA: The MIT Press.

KaCZMAReK, Joël (2010): Gegnerschaft im Computerspiel. Formen des Agonalen in digitalen Spielen. Potsdam: Universitätsverlag Potsdam.

KAERLEIN, Timo (2016): Intimate Computing. Zum diskursiven Wandel eines Konzepts der Mensch-Computer-Interaktion. In: Zeitschrift für Medienwissenschaft, 15 (2), 30-40.

KAERLEIN, Timo (2018): Smartphones als digitale Nahkörpertechnologien. Zur Kybernetisierung des Alltags. Bielefeld: transcript. 
KAMINSKI, Winfried und LORBER, Martin (2006) (Hg.): Clash of Realities. Computerspiele und soziale Wirklichkeit. München: kopaed.

Kent, Steven L. (2001): The Ultimate History of Video Games. From Pong to Pokémon and Beyond - The Story Behind the Craze that Touched Our Lives and Changed the World. New York, NY: Three Rivers Press.

KERSKEN, Norbert (2004): Geschichtsbild und Adelsrepublik. Zur Sarmatentheorie in der polnischen Geschichtsschreibung der frühen Neuzeit. In: Jahrbücher für Geschichte Osteuropas, 52 (2), 235-260.

KIRSCHNER, Heiko und EISEWICHT, Paul (2017): Spielende und ihr Publikum unterhaltungsorientierte Darstellungen des Spielens auf Online-Videoplattformen. In: Judith Ackermann (Hg.): Phänomen Let's Play-Video. Entstehung, Ästhetik, Aneignung und Faszination aufgezeichneten Computerspielhandelns. Wiesbaden: Springer VS, 133144.

KIRSTEN, Karina (2016): Western remediated. Der Wilde Westen als Action-Adventure in Red Dead Redemption. In: Martin Hennig und Hans Krah (Hg.): Spielzeichen. Theorien, Analysen und Kontexte des zeitgenössischen Computerspiels. Glückstadt: VWH, 228-247.

KNIEP, Matthias (2009): Die drei Zeitalter des Superhelden-Comics (Gold, Silber und Bronze). Von der Geburt, Demontage und Wiederbelebung eines amerikanischen Mythos. Kiel: Ludwig.

Kocher, Mela (2007): The Ludoliterary Circle. Analysis and Typology of Digital Games. In: Peter Gendolla und Jörgen Schäfer (Hg.): The Aesthetics of Net Literature. Writing, Reading and Playing in Programmable Media. Bielefeld: transcript, 107-120.

Koenitz, Hartmut; Ferri, Gabriele; HAAHr, Mads; SEZEN, Digdem und SezEN, Tonguc Ibrahim (2015) (Hg.): Interactive Digital Narrative. History, Theory and Practice. New York, NY: Routledge.

KoHler, Chris (2005): Power-Up. How Japanese Video Games Gave the World an Extra Life. Indianapolis, IN: BradyGames.

KoHring, Torben und Sindermann, Markus (2017): Einmal so wie Gronkh sein - Let's Play-Videos in der offenen Kinder- und Jugendarbeit. In: Judith Ackermann (Hg.): Phänomen Let's Play-Video. Entstehung, Ästhetik, Aneignung und Faszination aufgezeichneten Computerspielhandelns. Wiesbaden: Springer VS, 241-255.

KoKKINIA, Christina (2000): Die Opramoas-Inschrift von Rhodiapolis. Euergetismus und soziale Elite in Lykien. Bonn: Habelt.

KONZACK, Lars (2007): Rhetorics of Computer and Video Game Research. In: Patrick Williams und Jonas Smith (Hg.): Players' Realm. Studies on the Culture of Video Games and Gaming. Jefferson, NC: McFarland, 110-130.

KÖPPE, Tilmann und KINDT, Tom (2014): Erzähltheorie. Eine Einführung. Stuttgart: Reclam.

KOSCHORKE, Albrecht ( $\left.{ }^{3} 2013\right)$ : Wahrheit und Erfindung. Grundzüge einer Allgemeinen Erzähltheorie. Frankfurt am Main: Fischer. 
KozINETS, Robert V. (2010): Nethnography. Doing Ethnographic Research Online. Los Angeles, CA: SAGE.

KRACHT, Christian ( $\left.{ }^{4} 2001\right)$ : 1979. Roman. Köln: Kiepenheuer \& Witsch.

KRINGIEL, Danny (2009): Computerspielanalyse konkret. Methoden und Instrumente erprobt an Max Payne 2. München: kopaed.

KRÜTZEN, Michaela ( $\left.{ }^{3} 2011\right)$ : Dramaturgie des Films. Wie Hollywood erzählt. Frankfurt am Main: Fischer.

KÜCKLICH, Julian (2001): Auf der Suche nach dem verlorenen Text. Literaturwissenschaften und Computerspiele. In: Philologie im Netz, 15, 25-42.

KüCKLICH, Julian (2003): Perspectives of Computer Game Philology. In: Game Studies, 3 (1). URL: http://www.gamestudies.org/0301/kucklich/ (30.06.2018).

KüCKLICH, Julian (2007): From Adventure to EverQuest. Narrative Strategies in Computer Games Now and Then. In: Anglistik, 18 (2), 121-140.

KuHn, Thomas S. ( $\left.{ }^{4} 2012\right):$ The Structure of Scientific Revolutions. Chicago: The University of Chicago Press.

KüHn, Simone; Kugler, Dimitrij Tycho; Schmalen, Katharina; WeIchenberger, Markus; WiTt, Charlotte und Gallinat, Jürgen (2018): Does Playing Violent Video Games Cause Aggression? A Longitudinal Intervention Study. In: Molecular Psychiatry, 13. März. URL: https://www.nature.com/articles/s41380-018-0031-7 (30.06.2018).

LANDAY, Lori (2014): Interactivity. In: Mark J.P. Wolf und Bernard Perron (Hg.): The Routledge Companion to Video Game Studies. New York: Routledge, 173-184.

LANGE, Stefanie (voraussichtlich 2018): Enhanced E-Books. Eine Untersuchung zum Leseprozess einer neuen Literaturform. Diss.: Universität Göttingen.

LAUREL, Brenda (1993): Computers as Theatre. Reading, MA: Addison-Wesley Publishing Company.

LeBlanC, Marc (1999): Vortrag auf der Game Developers Conference 1999.

LefeBvre, Henri (2008): The Production of Space. Malden, MA: Blackwell.

LETOURNEUR, Ann-Marie (2016): Grenzüberschreitungen. Vom >Spielen Martin Hennig und Hans Krah (Hg.): Spielzeichen. Theorien, Analysen und Kontexte des zeitgenössischen Computerspiels. Glückstadt: VWH, 174-192.

LÉVI-STRAuSS, Claude (1972): Die Struktur der Mythen. In: Ders.: Strukturale Anthropologie. Frankfurt am Main: Suhrkamp, 226-254.

LÉvi-Strauss, Claude (2013): Die andere Seite des Mondes. Schriften über Japan. Berlin: Suhrkamp.

LILGE, Thomas und STEIN, Christian (2018) (Hg.): Spielwissen und Wissensspiele. Wissenschaft und Game-Branche im Dialog über die Kulturtechnik des Spiels. Bielefeld: transcript. 
LINDSEY, Hal (1986): Die Entrückung. Asslar: Schulte und Gerth.

Loguidice, Bill und B ARTOn, Matt (2009): Vintage Games. An Insider Look at the History of $>$ Grand Theft Autor, >Super Mario‘, and the Most Influential Games of All Time.

Amsterdam: Focal Press.

LOKOWANDT, Ernst (2001): Shintō. Eine Einführung. München: Iudicium.

LuHmann, Niklas ( $\left.{ }^{2} 1996\right)$ : Die Realität der Massenmedien. Opladen: Westdeutscher Verlag.

LuHMANN, Niklas ( $\left.{ }^{5} 2009\right)$ : Einführung in die Systemtheorie. Hg. von Dirk Baecker. Heidelberg: Carl-Auer Verlag.

LyONS, John (1980): Semantik. Band 1. München: Beck.

LyOTARD, Jean-François (1986): Das postmoderne Wissen. Ein Bericht. Graz: Böhlau.

MAGENHEIM, Johannes (2008): Interaktion und Interaktivität im Kontext von Wissenskonstruktion und Nutzung digitaler Medien. Zur Vielfalt des Interaktionsbegriffs. In: Navigationen, 8 (1), 11-41.

MAHNE, Nicole (2007): Transmediale Erzähltheorie. Eine Einführung. Göttingen: V\&R.

ManN, Thomas (1981): Buddenbrooks. Verfall einer Familie. Frankfurt am Main: S. Fischer.

MANOVICH, Lev (2001): The Language of New Media. Cambridge, MA: The MIT Press.

MALETZKe, Gerhard (1963): Psychologie der Massenkommunikation. Theorie und Systematik. Hamburg: Verlag Hans-Bredow-Institut.

MARquard, Odo (2000): Lob des Polytheismus. Über Monomythie und Polymythie. In: Ders.: Abschied vom Prinzipiellen. Philosophische Studien. Stuttgart: Reclam, 91-116.

MARTIN, George R.R. (1996 ff.): A Song of Ice and Fire. New York, NY: Bantam Books.

MARTINEZ, Matias und SCHEFFEL, Michael (62005): Einführung in die Erzähltheorie. München: Beck.

MATUSCHEK, Stefan (2014): Mythos und Mythologie. In: Christoph Jamme und ders. (Hg.): Handbuch der Mythologie. Darmstadt: Zabern, 12-14.

MATUSZKIEWICZ, Kai (2014): Internarrativität. Überlegungen zum Zusammenspiel von Interaktivität und Narrativität in digitalen Spielen. In: DIEGESIS, 3 (1), 1-23. URL: https://www.diegesis.uni-wuppertal.de/index.php/diegesis/article/view/152 (30.06.2018).

MatusZKIEWICZ, Kai (2015a): Religion in digitalen Spielen - Eine Frage des Genres. In: Tim Lörke und Robert Walter-Jochum (Hg.): Religion und Literatur im 20. und 21. Jahrhundert. Motive, Sprechweisen, Medien. Göttingen: V\&R Unipress, 645-666.

MATUSZKIEWICZ, Kai (2015b): Abschied von der >Gangster-Romantik^! Kriminalität im Wandel in >Grand Theft Auto<. In: Thomas-Gabriel Rüdiger und Alexander Pfeiffer (Hg.): Game! Crime? Frankfurt: Verlag für Polizeiwissenschaft, 179-198. 
MATUSZKIEwICZ, Kai (2016): Agency und Interaktivität - zur Kompatibilität von zwei Handlungskonzepten in den Digital Game Studies. In: PAIDIA, Sonderausgabe „Das ludische Selbst“, 30. Juni. URL: http://www.paidia.de/?p=7640 (30.06.2018).

MatuszKiEwICZ, Kai (2017): Wer erzeugt die Geschichte? Mediale und personale Narrationen in digitalen Spielen. In: Maren Conrad; Theresa Schmidtke und Martin Stobbe (Hg.): Digitale Kontexte. Literatur und Computerspiel in der Gesellschaft der Gegenwart. Textpraxis. Digitales Journal für Philologie, Sonderausgabe \# 2. URL: http://www.unimuenster.de/Textpraxis/kai-matuszkiewicz-wer-erzeugt-die-geschichte (30.06.2018).

MÄYRÄ, Frans (2010): An Introduction to Game Studies. Games in Culture. Reprinted. Los Angeles, CA: SAGE.

MATHIAK, Klaus und WeBER, Rene (2006): Towards Brain Correlates of Natural Behavior. fMRI during Violent Video Games. In: Human Brain Mapping, 27 (12), 948-956.

MATTUSCH, Uwe (2000): Adventuregames als Erzähltexte im Deutschunterricht? In: Siegener Periodicum zur internationalen empirischen Literaturwissenschaft, 19 (2), 320-329.

MCGonigal, Jane (2012): Besser als die Wirklichkeit! Warum wir von Computerspielen profitieren und wie sie die Welt verändern. München: Heyne.

MEAD, George Herbert ( $\left.{ }^{10} 1995\right)$ : Spiel, Wettkampf und der (das) verallgemeinerte Andere. In: Ders.: Geist, Identität und Gesellschaft aus der Sicht des Sozialbehaviorismus. Mit einer Einleitung hg. von Charles W. Morris. Frankfurt am Main: Suhrkamp, 194-206.

Mechant, Peter und Looy, Jan Van (2014): Interactivity. In: Marie-Laure Ryan; Lori Emerson und Benjamin J. Robertson (Hg.): The Johns Hopkins Guide to Digital Media. Baltimore, MD: John Hopkins University Press, 302-305.

Mertens, Mathias (2004): Computerspiele sind nicht interaktiv. In: Christoph Bieber und Claus Leggewie (Hg.): Interaktivität. Ein transdisziplinärer Schlüsselbegriff. Frankfurt am Main: Campus Verlag, 272-288.

MichelUCCI, Pietro (2013) (Hg.): Handbook of Human Computation. New York, NY: Springer.

Miller, Frank (1989): Batman. Die Rückkehr des Dunklen Ritter. Hamburg: Carlsen.

MiLlER, J. Hillis (2006): Narrative. In: Frank Lentricchia und Thomas McLaughlin (Hg.): Critical Terms for Literary Study. [Nachdruck]. Chicago, IL: University of Chicago Press, 66-79.

MoITZHEIM, Sebastian (2016): The Legend of Zelda. Spielt das 3D-Fan-Remake direkt im Browser. In: Giga Games, 5. April. URL: http://www.giga.de/spiele/the-legend-of-zeldabreath-of-the-wild/news/the-legend-of-zelda-spielt-das-3d-fan-remake-direkt-im-browser/ (30.06.2018).

MOSER, Christian (2012): User Experience Design. Mit erlebniszentrierter Softwareentwicklung zu Produkten, die begeistern. Berlin: Springer Vieweg. 
MülLER, Christian (2017): Digitale Lesekompetenz in der Grundschule. In: Sebastian Böck; Julian Ingelmann; Kai Matuszkiewicz und Friederike Schruhl (Hg.): Lesen X.O. Rezeptionsprozesse in der digitalen Gegenwart. Göttingen: V\&R unipress, 211-234.

MÜLLER, Ralph (2014): Geschichte vs. Interaktivität. Zur Gattungsdifferenzierung von Hyperfiction und Computergames. In: DIEGESIS, 3 (1), 24-39.

MURRAY, Janet (1997): Hamlet on the Holodeck. The Future of Narrative in Cyberspace. New York, NY: The Free Press.

MURRAY, Janet (2005): The Last Word on Ludology v Narratology in Game Studies. Vortrag auf der DIGRA 2005 in Vancouver, Kanada, 17. Juni.

[N. N.] (2011): The Legend of Zelda 25 th Anniversary Symphony. [Beiheft zur Symphonie$\mathrm{CD}]$.

NAPIER, Susan (2007): From Impressionism to Anime. Japan as Fantasy and Fan Cult in the Mind of the West. New York: Palgrave Macmillan.

NAREMORe, James (1990): Acting in the Cinema. Berkeley, CA: University of California Press.

NaUmanN, Nelly (2011): Die Mythen des alten Japan. Köln: Anaconda.

NEITZEL, Britta (2000): Gespielte Geschichten. Struktur- und prozessanalytische Untersuchungen der Narrativität von Videospielen. Diss.: Universität Weimar.

NEITZEL, Britta (2011): Narrativity in Computer Games. In: Jost Raessens und Jeffrey Goldstein (Hg.): Handbook of Computer Game Studies. Cambridge, MA: The MIT Press, 227-245.

NeITZEL, Britta; NoHR, Rolf und Bopp, Matthias ( ${ }^{32010)}$ (Hg.): »See? I'm real...«.Multidisziplinäre Zugänge zum Computerspiel am Beispiel von 〉Silent Hill«. Münster: Lit Verlag.

Nelson, Theodor H. (2003): A File Structure for the Complex, the Changing, and the Inderterminate. In: Noah Wardrip-Fruin und Nick Montfort (Hg.): The New Media Reader. Cambridge, MA: The MIT Press, 133-145.

NERSINGER, Ulrich (2008): Mit der Computermaus gegen Dämonen und Geheimbünde. Kirche und Religion in Computerspielen. In: Zenit. Die Welt von Rom aus gesehen. 19. Februar. URL: https://de.zenit.org/articles/mit-der-computermaus-gegen-damonen-undgeheimbunde-kirche-und-religion-in-computerspielen/ (30.06.2018).

NEUBERGER, Christoph (2007): Interaktivität, Interaktion, Internet. Eine Begriffsanalyse. In: Publizistik, 52 (1), 33-50.

NeUHAUS, Stefan (2009): Literaturvermittlung. Konstanz: UVK.

Newman, James (2002): The Myth of the Ergodic Videogame. Some Thoughts on PlayerCharacter Relationships in Videogames. In: Game Studies, 2 (1). URL: http://www.gamestudies.org/0102/newman/ (30.06.2018). 
NiESZ, Anthony und Holland, Norman (1984): Interactive Fiction. In: Critical Inquiry, 11 (1), 110-129.

NiTSCHE, Michael (2006): Telling Stories Through Space. The Mindstage Project. In: Lecture Notes in Computer Science, 4326, 61-71.

NoRMAN, Donald (2005): Emotional Design. Why We Love (or Hate) Everyday Things. New York: Basic Books.

OHLENDORF, Wiebke (2015): Artus. Krieger - König - Kunstfigur. In: Dies; André Reichart und Gunnar Schmidtchen (Hg.): Wissenschaft meets Pop. Eine interdisziplinäre Annäherung an die Popkultur. Bielefeld: transcript, 33-60.

PARISER, Eli (2012): Filter Bubble. Wie wir im Internet entmündigt werden. München: Hanser.

PAumgarten, Nick (2010): Master of Play. The Imagination behind Nintendo. In: The New Yorker (20. \& 27. Dezember), 86-94. URL: http://www.newyorker.com/reporting/2010/12/20/101220fa_fact_paumgarten (30.06.2018).

PeArce, Celia (2004): Towards a Game Theory of Game. In: Noah Wardrip-Fruin und Pat Harrigan (Hg.): First Person. New Media as Story, Performance, and Game. Cambridge, MA: The MIT Press, 143-153.

PennebaKer, James W. und Evans, John F. (2014): Expressive Writing. Words that heal. Enumclaw, WA: Idyll Arbor Inc.

PERLIN, Ken (2005): Toward Interactive Narrative. In: Lecture Notes in Computer Science, $3805,135-147$.

Perron, Bernard (2003): From Gamers to Players and Gameplayers. The Example of Interactive Movies. In: Mark J.P. Wolf und ders. (Hg.): The Video Game Theory Reader. New York, NY: Routledge, 237-258.

Perron, Bernard und Schröter, Felix (2016) (Hg.): Video Games and the Mind. Essays in Cognition, Affect, and Emotion. Jefferson, NC: McFarland.

PFISTER, Eugen (2016): Plädoyer für eine argumentenbasierte Debatte zur Wirkung gewalthaltiger Spiele. In: Spiel-Kultur-Wissenschaften, 5. September. URL: https://spielkult.hypotheses.org/1114 (30.06.2018).

Pietschmann, Daniel (2009): Das Erleben virtueller Welten. Involvierung, Immersion und Engagement in Computerspielen. Boizenburg: VWH.

PIRNER, Manfred (2001): Messias spielen. Der Erlösermythos als Computerspiel. In: Religion heute, 48, 260-261.

PRINCE, Gerald (1982): Narratology. The Form and Functioning of Narrative. Berlin: Mouton Publishers.

PRINCE, Gerald (2008): Narrativehood, Narrativeness, Narrativity, Narratability. In: John Pier und José Angel Landa (Hg.): Theorizing Narrativity. Berlin: de Gruyter, 19-27. 
PROPP, Vladimir (1972): Morphologie des Märchens. München: Hanser.

QIN, Hua; RAU, Pei-Luen Patrick und SALVEndy, Gavriel (2007): Posters - Player Immersion in the Computer Game Narrative. In: Lecture Notes in Computer Science, 4740, 458-461.

QIN, Hua; RaU, Pei-Luen Patrick und Salvendy, Gavriel (2009): Measuring Player Immersion in the Computer Game Narrative. In: International Journal of Human Computer Interaction, 25 (2), 107-133.

QuANDT, Thorsten; WimMER, Jeffrey und Wolling, Jens (2009) (Hg.): Die Computerspieler. Studien zur Nutzung von Computergames. Wiesbaden: VS.

QUIDDE, Ludwig ( $\left.{ }^{31} 1926\right):$ Caligula. Eine Studie über den römischen Cäsarenwahnsinn. Berlin-Friedenau: Hensel.

QUIRING, Oliver und SCHWEIGER, Wolfgang (2006): Interaktivität - Ten Years after. Eine Bestandsaufnahme und ein Analyserahmen. In: Medien und Kommunikationswissenschaft, $54,5-24$.

RABY, Mark (2010): Zelda Producer Says Link May Never Talk. In: gamesradar+, 14. August. URL: http://www.gamesradar.com/zelda-producer-says-link-may-never-talk/ (30.06.2018).

Raessens, Jost und GoldsteIn, Jeffrey (2005) (Hg.): Handbook of Computer Game Studies. Cambridge, MA: The MIT Press.

RAFAELI, Sheizaf (1988): Interactivity. From New Media to Communication. In: Robert P. Hawkins; John M. Wiemann und Suzanne Pingree (Hg.): Advancing Communication Science. Merging Mass and Interpersonal Processes. Newbury Park: SAGE, 110-134.

RANKE, Kurt und BREDNICH, Rolf Wilhelm (1977-2015) (Begr. / Hg.): Enzyklopädie des Märchens. Handwörterbuch zur historischen und vergleichenden Erzählforschung. Berlin: de Gruyter.

Rasmussen, Josh[ua] und Rasmussen, Rachel (2011): Freedom vs. Destiny. A Hero's Call. In: Jonathan Walls (Hg.): The Legend of Zelda and Theology. Hollywood, CA: Gray Matter Books, 71-82.

RATH, Brigitte (2011): Narratives Verstehen. Entwurf eines narrativen Schemas. Weilerswist: Velbrück.

RAUSCHER, Andreas (2012): Spielerische Fiktionen - Transmediale Genrekonzepte in Videospielen. Marburg: Schüren.

RAUSCHER, Andreas (2015): Mise en Game. Die spielerische Aneignung filmischer Räume. In: Benjamin Beil; Gundolf S. Freyermuth und Lisa Gotto (Hg.): New Game Plus. Perspektiven der Game Studies. Genre - Künste - Diskurse. Bielefeld: transcript, 89-113.

RAWLINGS, Tomas (2006): Narrative and Interactivity. URL: http://gameresearch.com/index.php/articles/narrative-and-interactivity/ (30.06.2018).

REINERS, Torsten und WoOD, Lincoln (2015) (Hg.): Gamification in Education and Business. Cham: Springer. 
RetTBerg, Scott (2015): The American Hypertext Novel, and Whatever Became of It? In: Hartmut Koenitz et al. (Hg.): Interactive Digital Narrative. History, Theory and Practice. New York, NY: Routledge, 22-35.

RICH, Jason R. (1998): The Legend of Zelda. Ocarina of Time. Berkeley, CA: Sybex Inc.

RIMMON-Kenan, Shlomith (1983): Narrative Fiction. Contemporary Poetics. London: Methuen.

RIMMON-KenAN, Shlomith (2006): Concepts of Narrative. In: COLLeGIUM. Studies across Disciplines in the Humanities and Social Sciences, 1, 10-19.

RousE, Richard ( $\left.{ }^{2} 2005\right)$ : Game Design. Theory \& Practice. Plano, TX: Wordware Publ.

RUTTER, Jason und BRYCE, Jo (2006) (Hg.): Understanding Digital Games. London: SAGE.

RYAN, Marie-Laure (2001a): Beyond Myth and Metaphor. The Case of Narrative in Digital Media. In: Game Studies, 1 (1). URL: http://www.gamestudies.org/0101/ryan/ (30.06.2018).

RYAN, Marie-Laure (2001b): Narrative as Virtual Reality. Immersion and Interactivity in Literature and Electronic Media. Baltimore, MD: John Hopkins University Press.

RYAN, Marie-Laure (2004): Introduction. In: Dies. (Hg.): Narrative across Media. The Languages of Storytelling. Lincoln, NE: University of Nebraska Press, 1-40.

RYAN, Marie-Laure (2006): Avatars of Story. Minneapolis, MN: University of Minnesota Press.

RYAN, Marie-Laure (2014a): Interactive Narrative. In: Dies.; Lori Emerson und Benjamin J. Robertson (Hg.): The Johns Hopkins Guide to Digital Media. Baltimore, MD: Johns Hopkins University Press, 292-298.

RYAN, Marie-Laure (2014b): Plot Types and Interactivity. In: Dies.; Lori Emerson und Benjamin J. Robertson (Hg.): The Johns Hopkins Guide to Digital Media. Baltimore, MD: Johns Hopkins University Press, 395-399.

RyAn, Marie Laure und Thon, Jan-Noël (2014) (Hg.): Storyworlds across Media. Toward a Media-Conscious Narratology. Lincoln, NE: University of Nebraska Press.

Ryan, Richard M. und DECI, Edward L. (2017): Self-Determination Theory. Basic Psychological Needs in Motivation, Development and Wellness. New York, NY: The Guilford Press.

Sachs-Hombach, Klaus und Thon, Jan-Noël (2015a): Einleitung. Game Studies und Medienwissenschaft. In: Dies. (Hg.): Game Studies. Aktuelle Ansätze der Computerspielforschung. Köln: Herbert von Halem Verlag, 9-27.

Sachs-Hombach, Klaus und Thon, Jan-Noël (2015b) (Hg.): Game Studies. Aktuelle Ansätze der Computerspielforschung. Köln: Herbert von Halem Verlag.

Salen, Katie und Zimmerman, Eric (2004): Rules of Play. Game Design Fundamentals. Cambridge, MA: The MIT Press. 
SALLGE, Martin (2010): Interaktive Narration im Computerspiel. In: Caja Thimm (Hg.): Das Spiel. Muster und Metapher der Mediengesellschaft. Wiesbaden: VS, 79-104.

SAPKOWSKI, Andrzej (2008-2011): Geralt von Riva-Saga. München: dtv.

SAUTNER, Oliver (2006): The Legend of Zelda - Wie Legenden entstehen. In: Nintendo WiiUniverse, 9. Dezember. URL: http://wii.gaming-universe.org/features/the-legend-of-zelda-wie-legenden-entstehen/11-1.html (30.06.2018).

SCHECHNER, Richard (1988): Playing. In: Play and Culture, 1 (1), 3-19.

SCHELL, Jesse (2015): Die Zukunft des Erzählens. Wie das Medium Geschichten formt. In: Benjamin Beil; Gundolf S. Freyermuth und Lisa Gotto (Hg.): New Game Plus. Perspektiven der Game Studies. Genres - Künste - Diskurse. Bielefeld: transcript, 357374.

SCHENK, Michael (32007): Medienwirkungsforschung. Tübingen: Mohr Siebeck.

SCHIMANK, Uwe ( $\left({ }^{4} 2010\right):$ Handeln und Strukturen. Einführung in die akteurtheoretische Soziologie. Weinheim: Juventa.

SCHIRACH, Ferdinand von (2015): Terror. Ein Theaterstück und eine Rede. München: Piper.

SCHLICKER, Alexander (2016): Serialität - Spiel - Game Studies. Zu Formen, Distinktionen und Potenzialen der Game-Serie. In: Martin Hennig und Hans Krah (Hg.): Spielzeichen. Theorien, Analysen und Kontexte des zeitgenössischen Computerspiels. Glückstadt: VWH, 193-211.

SCHMIDT-RELENBERG, Norbert (1970): Über Verantwortung. Ein Beitrag zur Soziologie der Alltags-Klischees. In: Kölner Zeitschrift für Soziologie und Sozialpsychologie, 22, 251264.

SCHÖLlY, Reto (2017): Ethos, Charakter und Selbstbezüglichkeit in The Walking Dead Eine Analyse der Persönlichkeitsentwicklung des Charakters Clementine und seinen Reflexivitäten mit dem Ethos der SpielerInnen. In: PAIDIA, Sonderausgabe ,, Serialität oder Computerspiel(e) in Serie: Medien - Theorien - Kulturen “, 22. März. URL: http://www.paidia.de/?p=9422 (30.06.2018).

SCHRIER, Karen und GIBSON, David (2010) (Hg.): Ethics and Game Design. Teaching Values through Play. Hershey, PA: Information Science Reference.

SCHROEDER, Jens (2011): »Killer Games« versus »we will fund violence«. The Perception of Digital Games in Germany and Australia. Frankfurt am Main: Lang.

SChröter, Felix und ThON, Jan-Noël (2014): Video Game Characters. Theory and Analysis. In: DIEGESIS, 3 (1), 40-77.

SCHRÖTER, Jens (2018): Das Holodeck als Leitbild. In: Bildwelten des Wissens, 14, 90-99.

SCHULZE, Gerhard (2005): Die Erlebnisgesellschaft. Kultursoziologie der Gegenwart. Frankfurt am Main: Campus.

SCHULzKe, Marcus (2009): Moral Decision Making in Fallout. In: Game Studies, 9 (2). URL: http://gamestudies.org/0902/articles/schulzke (30.06.2018). 
Schumacher, Heidemarie und Korbel, Leonhard (2009): Game Studies und Agency. Ein Forschungsbericht zu ihrem Verhältnis und ein Vorschlag zu einer neuen Forschungsperspektive. In: Caja Thimm (Hg.): Das Spiel. Muster und Metapher der Mediengesellschaft. Wiesbaden: VS, 55-78.

SCHUPPISSER, Raffael (2014): Von der Simulation zum Text. Narrative Strukturen in Computerspielen. Zürich: Chronos.

SCHWINGELER, Stephan (2014): Kunstwerk Computerspiel - Digitale Spiele als künstlerisches Material. Eine bildwissenschaftliche und medientheoretische Analyse. Bielefeld: transcript.

SCULlY-BlaKeR, Rainforest (2014): A Practiced Practice. Speedrunning Through Space with de Certeau and Virilio. In: Game Studies, 14 (1). URL: http://gamestudies.org/1401/articles/scullyblaker (30.06.2018).

SEARLE, John R. (2000): Sprechakte. Ein sprachphilosophischer Essay. Frankfurt am Main: Suhrkamp.

SeARLe, John R. (2001): Intentionalität. Eine Abhandlung zur Philosophie des Geistes. [Nachdruck]. Frankfurt am Main: Suhrkamp.

SEDA, Roman (2008): Interactive Storytelling im Computerspiel. Adventure Games im Spiegel polymedialer Einflüsse. Boizenburg: VWH.

SEYFERT, Robert und RoBERGE, Jonathan (2017) (Hg.): Algorithmuskulturen. Über die rechnerische Konstruktion der Wirklichkeit. Bielefeld: transcript.

SHEFF, David (1999): Game Over. Press Start to Continue - The Maturing of Mario. With New Chapters by Andy Eddy. Wilton, CT: Cyberactive Media Group Inc.

SHERLOCK, Lee (2009): Three Days in Termina. >Zelda and Temporality. In: Luke Cuddy (Hg.): The Legend of Zelda and Philosophy. I Link Therefore I Am. Chicago, IL: Open Court, 121-131.

SIABRA-FrAILE, Joaquín ( $\left.{ }^{2} 2009\right)$ : Constructing NESpace in `Zeldar. In: Luke Cuddy (Hg.): The Legend of Zelda and Philosophy. I Link Therefore I Am. Chicago, IL: Open Court, 133-149.

SICART, Miguel (2009): The Ethics of Computer Games. Cambridge, MA: The MIT Press.

SICART, Miguel (2011): Against Procedurality. In: Game Studies, 11 (3). URL: http://gamestudies.org/1103/articles/sicart_ap (30.06.2018).

SimANOWSKI, Roberto (2008): Digitale Medien in der Erlebnisgesellschaft. Kultur - KunstUtopien. Reinbek bei Hamburg: Rowohlt.

SIVAK, Seth (2009): Each Link in the Chain Is a Journey. An Analysis of The Legend of Zelda: Ocarina of Time. In: Drew Davidson (Hg.): Well Played 1.0. Video Games, Value and Meaning. Pittsburgh, PA: ETC Press, 297-328.

STAABY, Tobias (2015): The Walking Dead in der Schule - Moralphilosophie nach der Apokalypse. Übers. durch Elisabeth Heeke. In: PAIDIA, Sonderausgabe „Computerspiele und Werterziehung ", 21. Dezember. URL: http://www.paidia.de/?p=6671 (30.06.2018). 
StAnZEL, Franz K. (111987): Typische Formen des Romans. Göttingen: V\&R.

STAPELKAMP, Torsten (2010): Interaction- und Interfacedesign. Web-, Game-, Produkt- und Servicedesign. Usability und Interface als Corporate Identity. Heidelberg: Springer.

Staub, Christoph A. (2011): Der Mythos schafft die Wirklichkeit des Spiels. Mythen in Magic. In: Daria Pezzoli-Olgiati und Thomas Schlag (Hg.): Vom Avatar bis zur Zauberei. Religion im Spiel. Zürich: TVZ, 141-150.

STERBENZ, Benjamin (2011): Genres in Computerspielen - eine Annäherung. Boizenburg: VWH.

Stobbe, Martin und Weigang, Tristan (2016): Relativ Indie. Skizzen zu einer Kultursoziologie des Computerspiels. In: Martin Hennig und Hans Krah (Hg.): Spielzeichen. Theorien, Analysen und Kontexte des zeitgenössischen Computerspiels. Glückstadt: VWH, 94-116.

SÜß, Gunter (2003): Filmstudien und Computerspielanalyse. In: Evelyne Keitel et al. (Hg.): Computerspiele - Eine Provokation für die Kulturwissenschaften? Lengerich: Pabst, 3348.

SUTER, Beat (2000): Hyperfiktion und interaktive Narration im frühen Entwicklungsstadium zu einem Genre. Zürich: update verlag.

SUTTER, Tilmann (1999): Medienkommunikation als Interaktion? Über den Aufklärungsbedarf eines spannungsreichen Problemfeldes. In: Publizistik, 44 (3), 288-300.

SUTTER, Tilmann (2010): Der Wandel von der Massenkommunikation zur Interaktivität neuer Medien. In: Ders. und Alexander Mehler (Hg.): Medienwandel als Wandel von Interaktionsformen. Wiesbaden: VS, 83-105.

SutTon-SMith, Brian (2001): The Ambiguity of Play. Cambridge, MA: Harvard Univ. Press.

SutTon-Smith, Brian (22007): The Ambiguity of Play. Rhetorics of Fate. In: Henry Bial (Hg.): The Performance Studies Reader. Abingdon: Routledge, 152-158.

Švelch, Jaroslav (2010): The Good, The Bad, and The Player. The Challenges to Moral Engagement in Single-Player Avatar-Based Video Games. In: Karen Schrier und David Gibson (Hg.): Ethics and Game Design. Teaching Values through Play. Hershey, PA: Information Science Reference, 52-68.

Tallon, Philip (2011): The Birth of Gaming from the Spirit of Fantasy. Video Games as Secondary Worlds with Special Reference to The Legend of Zelda and J.R.R. Tolkien. In: Jonathan Walls (Hg.): The Legend of Zelda and Theology. Hollywood, CA: Gray Matter Books, 47-69.

Thomas, Tanja; BrinK, Lina; GritTMAnn, Elke und WolfF, Kaya de (2017) (Hg.): Anerkennung und Sichtbarkeit. Perspektiven für eine kritische Medienkulturforschung . Bielefeld: transcript.

THON, Jan-Noël (2006): Immersion revisited. Varianten von Immersion im Computerspiel des 21. Jahrhunderts. In: Christian Hißnauer und Andreas Jahn-Sudmann (Hg.): Medien - Zeit 
- Zeichen. Beiträge des 19. Film- und Fernsehwissenschaftlichen Kolloquiums. Marburg: Schüren, 125-132.

THON, Jan-Noël (2007): Simulation vs. Narration. Zur Darstellung fiktionaler Welten in neueren Computerspielen. In: Andreas Becker et al. (Hg.): Medien-Diskurse Deutungen. Beiträge des 20. Film- und Fernsehwissenschaftlichen Kolloquiums. Marburg: Schüren, 68-76.

THON, Jan-Noël (2008): Immersion Revisited. On the Value of a Contested Concept. In: Amyris Fernandez; Olli Leino und Hanna Wirman (Hg.): Extending Experiences. Structure, Analysis and Design of Computer Game Player Experience. Rovaniemi: Lapland University Press, 29-43.

THON, Jan-Noël (2014): Narrativity. In: Marie-Laure Ryan; Lori Emerson und Benjamin J. Robertson (Hg.): The Johns Hopkins Guide to Digital Media. Baltimore, MD: John Hopkins University Press, 351-355.

ThON, Jan-Noël (2015): Game Studies und Narratologie. In: Klaus Sachs-Hombach und ders. (Hg.): Game Studies. Aktuelle Ansätze der Computerspielforschung. Köln: Herbert von Halem Verlag, 104-164.

Thon, Jan-Noël (2016): Transmedial Narratology and Contemporary Media Culture. Lincoln, NE: University of Nebraska Press.

ThORPE, Patrick (2013) (Hg.): The Legend of Zelda. Hyrule Historia. Milwaukie, OR: Dark Horse Books.

TILGNER, Alexander (2017): Gaming 2.0. Von der Fanproduktion zum Kulturgut - Let's PlayVideos als Schnittstelle zwischen passiver Rezeption und aktiver Partizipation. In: Judith Ackermann (Hg.): Phänomen Let's Play-Video. Entstehung, Ästhetik, Aneignung und Faszination aufgezeichneten Computerspielhandelns. Wiesbaden: Springer VS, 209-222.

Todorov, Tzvetan (1971): The Two Principles of Narrative. In: diacritics, 1 (1-2), 37-44.

TolKIEN, J.R.R. (282015): Das Silmarillion. Hg. von Christopher Tolkien. Stuttgart: KlettCotta.

Tolstoj, Lev N. (2009): Anna Karenina. München: Hanser.

Tronstad, Ragnhild (2001): Semiotic and Nonsemiotic MUD Performance. URL: http://www.cosignconference.org/downloads/papers/tronstad_cosign_2001.pdf (30.06.2018).

TRONSTAD, Ragnhild (2014): Quest Narrative. In: Marie-Laure Ryan; Lori Emerson und Benjamin J. Robertson (Hg.): The John Hopkins Guide to Digital Media. Baltimore, MD: John Hopkins University Press, 409-412.

TUdor, Henry (1972): Political Myth. London: Praeger.

TURING, Alan ( $\left.{ }^{3} 1988\right)$ : Maschinelle Rechner und Intelligenz. In: Douglas R. Hofstadter und Daniel C. Dennett (Hg.): Einsicht ins Ich. Fantasien und Reflexionen über Selbst und Seele. Stuttgart: Klett-Cotta, 59-73. 
TURNER, Victor (2005): Das Ritual. Struktur und Anti-Struktur. Neuauflage. Frankfurt am Main: Campus Verlag.

UtTerback, Camille (2004): Unusual Positions - Embodied Interaction with Symbolic Spaces. In: Noah Wardrip-Fruin und Pat Harrigan (2004): First Person. New Media as Story, Performance, and Game. Cambridge, MA: The MIT Press, 218-226.

VENUS, Jochen (2017): Stilisierte Rezeption. Überlegungen zum epistemischen Status von Let's Play-Videos. In: Judith Ackermann (Hg.): Phänomen Let's Play-Video. Entstehung, Ästhetik, Aneignung und Faszination aufgezeichneten Computerspielhandelns. Wiesbaden: Springer VS, 19-29.

VERSTÄNDIG, Dan und Holze, Jens (2017): It's not just a game - Subversive Praktiken in [der] digitalen Spielkultur. In: Judith Ackermann (Hg.): Phänomen Let's Play-Video. Entstehung, Ästhetik, Aneignung und Faszination aufgezeichneten Computerspielhandelns. Wiesbaden: Springer VS, 225-239.

VOGLER, Christopher ('2010): Die Odyssee des Drehbuchschreibers. Über die mythologischen Grundmuster des amerikanischen Erfolgskinos. Frankfurt am Main: Zweitausendeins.

WALLS, Jonathan (2011a): Introduction. In: Ders. (Hg.): The Legend of Zelda and Theology. Hollywood, CA: Gray Matter Books, 11-15.

WALLS, Jonathan (2011b) (Hg.): The Legend of Zelda and Theology. Hollywood, CA: Gray Matter Books.

WALLS, Jonathan (2011c): Trouble in the Golden Realm. Ganondorf and Hyrule's Problem of Evil in Ocarina of Time. In: Ders. (Hg.): The Legend of Zelda and Theology. Hollywood, CA: Gray Matter Books, 31-46.

WALTER, Klaus (2001): Grenzen spielerischen Erzählens. Erzähl- und Spielstrukturen in graphischen Adventure Games. Diss.: Universität Siegen.

Walton, Kendall (1990): Mimesis as Make-Believe. On the Foundations of the Representational Arts. Cambridge, MA: Harvard Univ. Press.

W ARDriP-Fruin, Noah und MONTFOrT, Nick (2003) (Hg.): The New Media Reader. Cambridge, MA: The MIT Press.

WeBER, Max ( $\left.{ }^{6} 1984\right)$ : Soziologische Grundbegriffe. Tübingen: Mohr Siebeck.

Weber, Rene; Ritterfeld, Ute und Mathiak, Klaus (2006): Does Playing Violent Video Games Induce Aggression? Empirical Evidence of a Functional Magnetic Resonance Imaging Study. In: Media Psychology, 8 (1), 39-60. URL: http://ocw.metu.edu.tr/file.php/85/ceit706/week4/Weber_MP.pdf (30.06.2018).

WESSEL, Craig (2003): The Legend of Zelda: Oracle of Ages. New York, NY: Scholastic.

Wessely, Christian (1995): Auf den Spuren des Mythos in Computerspielen. In: Communicatio socialis, 28 (4), 349-377. 
Wessely, Christian (1997): Von Star Wars, Ultima und Doom. Mythologisch verschleierte Gewaltmechanismen im kommerziellen Film und in Computerrollenspielen. Frankfurt am Main: Lang.

Whalen, Zach (2004): Play Along - An Approach to Videogame Music. In: Game Studies, 4 (1). URL: http://www.gamestudies.org/0401/whalen/ (30.06.2018).

WHITE, Hayden (2008): Metahistory. Die historische Einbildungskraft im 19. Jahrhundert in Europa. Frankfurt am Main: Fischer.

WIENER, Norbert (1992): Kybernetik. Regelung und Nachrichtenübertragung im Lebewesen und in der Maschine. Düsseldorf: ECON.

WIMMER, Jeffrey (2013): Massenphänomen Computerspiele. Soziale, kulturelle und ökonomische Aspekte. Konstanz: UVK.

WIMMER, Jeffrey (2017): »Erfahrenen Gamern sozusagen über die Schulter schauen «. Eine Interviewstudie deutscher YouTube-NutzerInnen zu Let's Play-Videos. In: Judith Ackermann (Hg.): Phänomen Let's Play-Video. Entstehung, Ästhetik, Aneignung und Faszination aufgezeichneten Computerspielhandelns. Wiesbaden: Springer VS, 147-160.

Winterling, Aloys (2003): Caligula. Eine Biographie. München: Beck.

WitTGEnsteIn, Ludwig ( $\left.{ }^{2} 1980\right)$ : Philosophische Untersuchungen. Frankfurt am Main: Suhrkamp.

WodiAnKA, Stephanie und EBERT, Juliane (2014) (Hg.): Metzler Lexikon moderner Mythen. Stuttgart: Metzler.

Wodianka, Stephanie und Ebert, Juliane (2016) (Hg.): Inflation der Mythen? Zur Vernetzung und Stabilität eines modernen Phänomens. Bielefeld: transcript.

Wolf, Mark J.P. (2003a): Space in the Video Game. In: Ders. (Hg.): The Medium of the Video Game. Austin, TX: University of Texas Press, 51-75.

Wolf, Mark J.P. (2003b): Time in the Video Game. In: Ders. (Hg.): The Medium of the Video Game. Austin, TX: University of Texas Press, 77-91.

Wolf, Mark J.P. (2003c): The Video Game as a Medium. In: Ders. (Hg.): The Medium of the Video Game. Austin, TX: University Press of Texas, 13-33.

Wolf, Mark J.P. (2003d): Genre and the Video Game. In: Ders. und Bernard Perron (Hg.): Video Game Theory Reader. New York, NY: Routledge, 113-134.

Wolf, Mark J.P. (2003e): Narrative in the Video Game. In: Ders. (Hg.): The Medium of the Video Game. Austin, TX: University of Texas Press, 93-111.

Wolf, Mark J.P. und Perron, Bernard (2003): Introduction. In: Dies. (Hg.): Video Game Theory Reader. New York, NY: Routledge, 1-24.

Wolf, Mark J.P. (2008) (Hg.): The Video Game Explosion. A History from PONG to PlayStation and Beyond. Westport, CT: Greenwood Press.

WoLF, Mark J.P. (2012): Building Imaginary Worlds. New York, NY: Routledge. 
Wolf, Werner (2002): Das Problem der Narrativität in Literatur, Bildender Kunst und Musik. Ein Beitrag zu einer intermedialen Erzähltheorie. In: Vera Nünning und Ansgar Nünning (Hg.): Erzähltheorie transgenerisch, intermedial, interdisziplinär. Trier: WVT, 23-104.

WoLF, Werner (2003f): Narrative and Narrativity. A Narratological Reconceptualization and its Applicability to the Visual Arts. In: Word \& Image, 19 (3), 180-197.

ZIPFEL, Frank (2001) (Hg.): Fiktion, Fiktivität, Fiktionalität. Analysen zur Fiktion in der Literatur und zum Fiktionsbegriff in der Literaturwissenschaft. Berlin: Erich Schmidt. 


\section{Filmografie}

2012 - Das Ende der Welt (2009): Roland Emmerich. USA.

Alien - Das unheimliche Wesen aus einer fremden Welt. Ridley Scott. UK/USA.

Batman (2005-2012): Christopher Nolan. USA/UK.

Black Dahlia, The (2006): Brian De Palma. D/USA/F.

Citizen Kane (1941): Orson Welles. USA.

Deadpool (2016): Tim Miller. USA.

Dr. House (2004-2012): David Shore. USA.

Eat, Pray, Love (2010): Ryan Murphy. USA.

Elementary (2012 ff.): Robert Doherty. USA.

Forever (2014-2015): Matthew Miller. USA.

Freaky Friday - ein voll verrückter Freitag (2003): Mark Waters. USA.

Game of Thrones (2011 ff.): David Benioff/D. B. Weiss. USA/UK.

Godzilla (1954): Ishirō Honda. J.

Guardians of the Galaxy (2014): James Gunn. USA/UK.

Harry Potter und die Kammer des Schreckens (2002): Chris Columbus. UK/USA/D.

Haus am See, Das (2006): Alejandro Agresti. USA.

Herr der Ringe, Der (2001-2003): Peter Jackson. USA/NZ.

Herr der Ringe, Der: Die zwei Türme (2002). Peter Jackson. USA/NZ.

Herr der Ringe, Der: Die Rückkehr des Königs (2003). Peter Jackson. USA/NZ.

Hobbit, Der (2012-2014): Peter Jackson. NZ/USA/UK.

Hobbit, Der: Smaugs Einöde (2013): Peter Jackson. USA/NZ.

I Am Legend (2007): Francis Lawrence. USA.

Indiana Jones (1981 ff.): Steven Spielberg. USA.

Kampf der Titanen (2010): Louis Leterrier. USA.

King Kong und die weiße Frau (1933): Merian C. Cooper/Ernest B. Schoedsack. USA.

Legend of Zelda, The (1989): John Grusd. USA.

Legend of Zelda, The: Oblivion Rising (2016): Scotty Whitehurst. USA.

Matrix (1999-2003): Lana und Lilly Wachowski. USA/AUS.

Mumie, Die (1999 ff.): Stephen Sommers/Rob Cohen. USA/C/D/CDN. 
Nacht in Rom, Eine (2010): Julio Medem. ESP.

Naruto Shippūden (2007-2017): Hayato Date. J.

One Piece (1999 ff.): Konosuke Uda et al. J.

Parallele II (2014): Harun Farocki. D.

Scott Pilgrim gegen den Rest der Welt (2010): Edgar Wright. USA/UK/CDN/J.

Sherlock (2010 ff.): Mark Gatiss/Steven Moffat. UK.

Silent Hill (2006): Christophe Gans. CDN/F/J.

Simpsons, Die (1989 ff.): James L. Brooks/Matt Groening/Sam Simon. USA.

Star Trek: Raumschiff Voyager (1995-2001): Rick Berman/Michael Piller/Jeri Taylor. USA.

Star Wars (1977 ff.): George Lucas et al. USA.

Star Wars: Krieg der Sterne (1977): George Lucas. USA.

Star Wars: The Clone Wars (2008-2015): George Lucas. USA.

Star Wars: Rebels (2014 ff.): Simon Kinberg/Carrie Beck/Dave Filoni. USA.

Super Mario Bros. (1993): Annabel Jankel/Rocky Morton. UK/USA.

Terror - Ihr Urteil (2016): Lars Kraume. D.

Und täglich grüßt das Murmeltier (1993): Harold Ramis. USA.

Walking Dead, The (2010 ff.): Frank Darabont. USA.

Your Name. Gestern, heute und für immer (2016): Makoto Shinkai. J. 


\section{Ludografie}

Adventure (1976): William Crowther. USA.

Adventure (1979): Warren Robinett/Atari. USA.

Age of Empires Online (2011-2014): Gas Powered Games/Robot Entertainment. USA.

Age of Mythology (2002): Ensemble Studios. USA.

Assassin's Creed (2007 ff.): Ubisoft Montreal. CDN.

Asteroids (1979): Atari. USA.

Asura's Wrath (2012): CyberConnect2. J.

Batman: Arkham (2009 ff.): Rocksteady Studios/Warner Bros. Games Montréal. UK/CDN.

Batman: Arkham City (2011): Rocksteady Studios. UK.

Batman: Arkham Knight (2015): Rocksteady Studios. UK.

Beginner's Guide, The (2015): Everything Unlimited. USA.

Beyond: Two Souls (2013): Quantic Dream. F.

Black Stories (2004 ff.): Holger Bösch. D.

Black \& White (2001): Lionhead Studios. UK.

Bloodborne (2015): From Software. J.

Cluedo (1948 ff.): Anthony und Elva Pratt/Waddingtons. UK.

Cool Spot (1993): Virgin Interactive. UK.

Dante's Inferno (2010): Visceral Games/Artificial Mind and Movement. USA/CDN.

Dark Siders (2010 ff.): Vigil Games. USA.

Dark Siders (2010): Vigil Games. USA.

Dark Souls (2011): From Software. J.

Dark Souls 2 (2014): From Software. J.

Dark Souls III (2016): From Software. J.

Day of the Tentacle (1993): LucasArts. USA.

Demon's Souls (2009): From Software. J.

Destiny (2014 ff.): Bungie. USA.

Diablo (1996 ff.): Blizzard North. USA.

Donkey Kong (1981 ff.): Nintendo. J.

Donkey Kong (1981): R\&D1. J. 
Dota 2 (2013 ff.): Valve. USA.

Driver (2000): Reflections Interactive. UK.

Dr. Kawashimas Gehirn-Jogging (2005): Nintendo. J.

Dragon Age (2009 ff.): BioWare. CDN.

Duke Nukem (1991 ff.): Apogee Software/3D Realms. USA.

Dungeons \& Dragons (1974): Gary Gygax/Dave Arneson. USA.

Elder Scrolls, The (1994 ff.): Bethesda. USA.

Elder Scrolls II, The: Daggerfall (1996): Bethesda. USA.

Elder Scrolls III, The: Morrowind (2002): Bethesda. USA.

Elder Scrolls IV, The: Oblivion (2006): Bethesda. USA.

Elder Scrolls V, The: Skyrim (2011): Bethesda. USA.

FIFA (1993 ff.): EA Sports. CDN.

Final Fantasy (1987 ff.): Square (Enix). J.

Final Fantasy VII (1997): Square. J.

Fruit Ninja (2010): Halfbrick Studios. AUS.

Game of Thrones (2014 f.): Telltale Games. USA.

God of War (2005 ff.): SIE Santa Monica Studio. USA.

Grand Theft Auto (1997 ff.): Rockstar North. UK.

Grand Theft Auto: Vice City (2002): Rockstar North. UK.

Grand Theft Auto: San Andreas (2004): Rockstar North. UK.

Grand Theft Auto IV (2008): Rockstar North. UK.

Grand Theft Auto V(2013): Rockstar North. UK.

Halo (2001 ff.): Bungie/343 Industries. USA.

Hearthstone: Heroes of Warcraft (2014 ff.): Blizzard Entertainment. USA.

Heavy Rain (2010): Quantic Dream. F.

Hidden Agenda (2017): Supermassive Games. UK.

Horizon Zero Dawn (2017): Guerrilla Games. NL.

Hyrule Warriors (2014): Omega Force/Team Ninja. J.

Ice Climber (1984 ff.): Nintendo. J.

Journey to Wild Divine, The (2001 ff.): Wild Divine. USA. 
L.A. Noire (2011): Rockstar Games. USA.

Last Guardian, The (2016): Japan Studio. J.

Last of Us, The (2013): Naughty Dog. USA.

League of Legends (2009 ff.): Riot Games. USA.

Legend of Zelda, The (1986 ff.): Nintendo EAD. J.

Legend of Zelda, The (1986): Nintendo EAD. J.

Legend of Zelda, The: A Link to the Past (1991): Nintendo EAD. J.

Legend of Zelda, The: Link's Awakening (1993): Nintendo EAD/SRD. J.

Legend of Zelda, The: Ocarina of Time (1998): Nintendo EAD. J.

Legend of Zelda, The: Majora's Mask (2000): Nintendo EAD. J.

Legend of Zelda, The: Oracle of Ages (2001): Capcom/Nintendo EAD. J.

Legend of Zelda, The: Oracle of Seasons (2001): Capcom/Nintendo EAD. J.

Legend of Zelda, The: The Wind Waker (2002): Nintendo EAD. J.

Legend of Zelda, The: The Minish Cap (2004): Capcom/Nintendo EAD. J.

Legend of Zelda, The: Twilight Princess (2006): Nintendo EAD. J.

Legend of Zelda, The: Phantom Hourglass (2007): Nintendo EAD. J.

Legend of Zelda, The: Spirit Tracks (2009): Nintendo EAD. J.

Legend of Zelda, The: Skyward Sword (2011): Nintendo EAD. J.

Legend of Zelda, The: Breath of the Wild (2017): Nintendo EPD. J.

Life Is Strange (2015): Dontnod Entertainment. F.

Mad Dog McCree (1990): American Laser Games. USA.

Mafia (2002 ff.): 2K/Hangar 13. CZ/USA.

Magic: The Gathering (1993 ff.): Richard Garfield. USA.

Mario (1983 ff.): Nintendo EAD. J.

Mensch ärgere Dich nicht (1910): Josef Friedrich Schmidt. D.

Metal Gear (1987 ff.): Konami. J.

Minecraft (2009 ff.): Mojang. S.

Monkey Island (1990 ff.): LucasArts/Telltale Games. USA.

Monopoly (1933 ff.): Elizabeth Magie Phillips. USA.

Monster Hunter (2004 ff.): Capcom. J. 
Myst (1993): Cyan. USA.

NHL (1991 ff.): EA Canada. CDN.

Night Journey, The (2010): Bill Viola. USA.

Pac-Man (1980): Namco. J.

Persona (1996 ff.): Atlus. J.

Pikmin (2001): Nintendo EAD. J.

Pokémon (1996ff.): Game Freak. J.

Pokémon Go (2016 ff.): Niantic. USA.

Pong (1972): Atari. USA.

Portal 2 (2011): Valve. USA.

Red Dead Redemption (2010): Rockstar San Diego. USA.

Resident Evil (1996 ff.): Capcom. J.

Silent Hill (1999 ff.): Konami et al. J.

Simon the Sorcerer (1993): Adventure Soft. UK.

Space Invaders (1978): Taito. J.

SpaceWar! (1962): Steve Russell. USA.

Stanley Parable, The (2013): Galactic Cafe. USA.

Starcraft (1998): Blizzard Entertainment. USA.

Star Wars: The Force Unleashed (2008): LucasArts. USA.

Street Fighter (1987 ff.): Capcom. J.

Super Mario Bros. (1985): Nintendo EAD. J.

Super Mario Galaxy (2007): Nintendo EAD. J.

Syndicate (1993): Bullfrog Productions. UK.

Tekken (1994 ff.): Namco. J.

Tetris (1984): Alexei Paschitnow. SU.

This War of Mine (2014): 11 Bit Studios. PL.

Tomb Raider (1996 ff.): Core Design/Crystal Dynamics. UK/USA.

Uncharted (2007 ff.): Naughty Dog. USA.

Uncharted: Drakes Schicksal (2007): Naughty Dog. USA.

Uncharted 2: Among Thieves (2009): Naughty Dog. USA. 
Uncharted 3: Drake's Deception (2011): Naughty Dog. USA.

Uncharted 4: A Thief's End (2016): Naughty Dog. USA.

Uncharted: The Lost Legacy (2017): Naughty Dog. USA.

Until Dawn (2015): Supermassive Games. UK.

Walking Dead, The (2012 ff.): Telltale Games. USA.

Wii Fit (2007): Nintendo EAD. J.

Wii Sports (2006): Nintendo EAD. J.

Wiki Game, The (2017): Alex Clemesha. USA.

Witcher, The (2007 ff.): CD Projekt RED. PL.

Wolf Among Us, The (2013-2014): Telltale Games. USA.

World of Warcraft (2004 ff.): Blizzard Entertainment. USA.

Yu-Gi-Oh! (1999 ff.): Konami. J.

Zork (1980-1997): Infocom. USA. 


\section{Weblinks}

\section{Abbildungen und Bilder}

DeviantArt: Prinzessin Zelda und Link als Paar. URL: http://orig06.deviantart.net/d8be/f/2014/220/3/f/link_x_zelda for_the_love_of_a_princess by_aerisuke-d7uaf8h.jpg (30.06.2018).

GamerGirls: Prinzessin Zelda und Link im Cosplay. URL: http://www.gamergirls.de/wpcontent/gallery/3/aktuell-zelda-cosplay/link_and_zelda_acen_2010_by_forcebewitya.jpg (30.06.2018).

Giantbomb: Prinzessin Peach. URL:

http://static.giantbomb.com/uploads/scale_small/0/7003/204916-peachmp8a.png (30.06.2018).

Imgur: Fangrafik zu den Erwartungen über die Multilinearität in Telltales The Walking DeadSpielen. URL: http://i.imgur.com/4S2ki.png (30.06.2018).

ME.ME.: Meme zur Tötung von Paarthurnax (Freundschaft). URL: https://me.me/i/if-youkilled-paarthurnax-wecantbe-friends-credit-hundi-the-dovakiin-\%E2\%80\% A2elderscrolls-1662084 (30.06.2018).

ME:ME.: Meme zur Tötung von Paarthurnax (Goldene und Bastarde). URL: https://me.me/i/8799370 (30.06.2018).

My Hero: Shigeru Miyamoto als Schöpfer des transmedialen Universums von Nintendo. URL: https://myhero.com/S_Miyamoto_mflandres_FR_2016_ul (30.06.2018).

NexusMods: Esbern and Delphine Head on Table. URL: https://www.nexusmods.com/skyrim/images/67708 (30.06.2018).

Reddit: Ganon aus Ocarina of Time. URL: http://vignette1.wikia.nocookie.net/zelda/images/9/94/Ganon_\%280carina_of_Time\%29.p

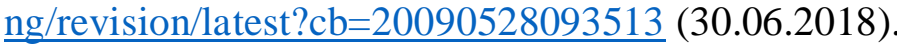

Reddit: Shigeru Miyamoto bei einem öffentlichen Auftritt mit Zelda-Merchandise. URL: http://vignette2.wikia.nocookie.net/zelda/images/8/83/Shigeru_Miyamoto_at_E3.png/revis ion/latest? $\mathrm{cb}=20100605230158(30.06 .2018)$.

Smashbros.com: Bowser aus Smashbros. URL: http://www.smashbros.com/images/og/koopa.jpg (30.06.2018).

Smashbros.com: Prinzessin Zelda aus Twilight Princess/Smashbros. URL: http://www.smashbros.com/images/og/zelda.jpg (30.06.2018).

StrategyWiki: Karte von Hyrule aus Ocarina of Time. URL: http://strategywiki.org/wiki/The_Legend_of_Zelda:_Ocarina_of_Time/Maps (30.06.2018).

Zelda Europe: Shigeru Miyamoto gemeinsam mit den Figuren seiner transmedialen Welten inszeniert. URL: http://www.zeldaeurope.de/include/designs/queen/img/miya_22.jpg (30.06.2018). 


\section{Blogs und Blogeinträge}

Spiel-Kultur-Wissenschaften. URL: https://spielkult.hypotheses.org/1114\#more-1114 (30.06.2018).

The Ludologist: Liste der einflussreichsten digitalen Spiele aller Zeiten. URL:

http://www.jesperjuul.net/ludologist/the-most-influential-games-of-all-time (30.06.2018).

The Ludologist: Sorry, but You Can't Do That. Talk at University of California, San Diego, April 18th. URL: http://www.jesperjuul.net/ludologist/sorry-but-you-cant-do-that-talk-atuniversity-of-california-san-diego-april-18th (30.06.2018).

\section{Fanfictions}

ChloeMorrison: The Legend of Zelda - Fragments of the Old Shiekah. URL: https://www.fanfiktion.de/s/4eceb93000021d8106a01770/1/The-Legend-of-ZeldaFragments-of-the-old-Shiekah (30.06.2018).

Fanfiction: Fanfictions über eine mögliche Liebesbeziehung zwischen Aeris und Sephiroth aus Final Fantasy VII. URL: https://www.fanfiction.net/community/Aeris-X-SephirothLove/5966/ (30.06.2018).

Fanfiction: Fanfictions über die transmediale Welt von The Legend of Zelda. URL: https://www.fanfiction.net/game/Legend-of-Zelda/ (30.06.2018).

MIKATUK: The Legend of Zelda - Ocarina of Time. URL: https://www.fanfiktion.de/s/44f139040000044406a01770/1/The-Legend-of-Zelda-Ocarinaof-Time (30.06.2018).

SKALA: Zelda Ocarina of Time. URL: https://www.fanfiktion.de/s/42a47708000014a806a01770/1/Zelda-Ocarina-of-Time (30.06.2018).

\section{Fanforen, Fanprojekte und Fan-Wikis}

GameFAQs: Thread aus einem Forum über Sephiroths Schuld an Aeris' Tod in Final Fantasy VII. URL: https://www.gamefaqs.com/boards/197341-final-fantasy-vii/55550339 (30.06.2018).

Gamezone: Is The Legend of Zelda: Ocarina of Time Overrated? Another Look. URL: http://www.gamezone.com/originals/is-the-legend-of-zelda-ocarina-of-time-overratedanother-look (30.06.2018).

Qhimm: Thread aus einem Forum über die Bedeutung von Aeris' Tod in Final Fantasy VII. URL: http://forums.qhimm.com/index.php?topic=10706.0 (30.06.2018). 
Reddit: Thread aus einem Diskussionsforum über die Qualität von Telltales Game of Thrones. URL:

https://www.reddit.com/r/gameofthrones/comments/4119dv/no_spoilers_is_the_telltale_ga me_really_that_bad/ $(30.06 .2018)$.

Steam. Diskussionsforum über The Wolf Among Us. URL:

http://steamcommunity.com/app/250320/discussions/0/558752450235742885/?1=german (30.06.2018).

Zelda30tribute: Kommentar der Schöpfer zur Entfernung des Fanspiels aufgrund Nintendos juristischer Intervention. URL: http://zelda30tribute.com/ (30.06.2018).

Zelda Europe: Forum. URL: http://www.zeldaeurope.de/forum/ (30.06.2018).

Zelda-Oblivion: Website des Fan-Filmprojekts Oblivion Rising. URL: http://zeldaoblivion.com/ (30.06.2018).

Zeldapedia: Hauptseite. URL: http://de.zelda.wikia.com/wiki/Zeldapedia:Hauptseite (30.06.2018).

Zeldapedia: Artikel ,Hylian Shield‘. URL: http://zelda.wikia.com/wiki/Hylian_Shield (30.06.2018).

Zelda Universe: Hauptseite. URL: http://zeldauniverse.net/ (30.06.2018).

Zelda Wiki: Hauptseite. URL: https://zeldawiki.org/Main_Page (30.06.2018).

\section{Institutionen, Projekte, kulturelle und kulturjournalistische Websites}

Bavelier Labs: Publikationsliste. URL: https://cms.unige.ch/fapse/people/bavelier/publications/ (30.06.2018).

Game. Verband der deutschen Games-Branche: Hauptseite. URL: https://www.game.de/ (30.06.2018).

Game. Verband der deutschen Games-Branche: Studie zum Durchschnittsalter von Gamern in Deutschland. URL: https://www.game.de/blog/2016/06/07/der-durchschnittliche-gamer-indeutschland-ist-35-jahre-alt/ (30.06.2018).

Charité: Website zum Spielprojekt TRACY als Teil des E-Learnings der Charité. URL: https://elearning.charite.de/projekte/tracy/ (30.06.2018).

Das Erste: Zuschauer-Voting zum Film Terror. Ihr Urteil. URL: http://www.daserste.de/unterhaltung/film/terror-ihr-urteil/voting/index.html (30.06.2018).

GameRankings: Ewige Bestenliste digitaler Spiele. URL: http://www.gamerankings.com/browse.html (30.06.2018).

Metacritic: Ewige Bestenliste digitaler Spiele. URL: http://www.metacritic.com/browse/games/score/metascore/all/all/filtered (30.06.2018). 
Nintendo Life: Aktualisierung der Timeline von The Legend of Zelda. URL:

http://www.nintendolife.com/news/2016/01/the_official_legend_of_zelda_timeline_has_be en_updated (30.06.2018).

The Night Journey: Website zum Spielprojekt The Night Journey. URL: http://www.thenightjourney.com/ (30.06.2018).

Theology.de: Sammlung christlicher Browser-Spiele. URL: http://www.theology.de/theologie/fachbereiche/praktischetheologie/religionspaedagogikon linespiele.php (30.06.2018).

Universität Duisburg-Essen: Publikationsliste Maic Masuch. URL: https://www.unidue.de/zim/services/suchdienste/mitarbeiter.php?tab=Publikationen\&id=50472 (30.06.2018).

VGChartz: Verkaufszahlen zu The Legend of Zelda. URL: http://www.vgchartz.com/gamedb/?page=1\&results=200\&name=zelda\&platform=\&minSa $\underline{\text { les }=0 \& \text { publisher }=\& \text { genre }=\& \text { sort }=\text { GL }}(30.06 .2018)$.

\section{Let's Plays und Youtube-Videos}

10DOTV: GAMESCOM 2011: Cosplay Interviews. URL: https://www.youtube.com/watch?v=n_gxz5JZ6-M (30.06.2018).

112COPYRIGHT: Die Nintendo Story. URL: https://www.youtube.com/watch?v=yJNhbIJ7wAI (30.06.2018).

ACERCODE: The Force Unleashed (PS2) - Quick Time Events. URL: https://www.youtube.com/watch?v=RXThm3uP0Gs (30.06.2018).

AJCARABELLO95: Angry Gamer Rage (Compilation). URL: https://www.youtube.com/watch?v=iqu-fPkqQao (30.06.2018).

ANGTFT: LoZ - Ocarina of Time: Gerudo Valley Waterfall Clip. URL: https://www.youtube.com/watch?v=rv3NOLhLR_E (30.06.2018).

BlueKnightNight: The Legend of Zelda Ocarina of Time: Temple of Time.

URL: https://www.youtube.com/watch?v=Qt1NBnq35xY (30.06.2018).

BoogIE2988: Francis Sucks at Skyrim. URL: https://www.youtube.com/watch?v=cLWrT7qoZaA (30.06.2018).

CAlloftreyarch: GTA V: Controversial Torture Mission(18+). URL: https://www.youtube.com/watch?v=_NrsicTLC5Q (30.06.2018).

CountBleck2009: Legend of Zelda Ocarina of Time Cutscene: Getting the Master Sword. URL: https://www.youtube.com/watch?v=LIbmCd-GPfw (30.06.2018).

COUNTBLECK2009: Legend of Zelda Ocarina of Time Cutscene: Link Meets Ganondorf. URL: https://www.youtube.com/watch?v=v3FSsNA78iI (30.06.2018). 
CRYZENX: Unreal Engine 4 [4.13.1] Zelda Ocarina of Time / Hyrule Field + Download link. URL: https://www.youtube.com/watch?v=FFx38t4ydY0 (30.06.2018).

DennisTheMenaceGr: GTA Vice City Rub Out(killing Diaz). URL: https://www.youtube.com/watch?v=amWjKW2n76U (30.06.2018).

DerSoRbus: Uncharted 4 Gameplay German PS4 Part 1 - Der Anfang vom Ende - Let's Play Uncharted 4 Deutsch. URL: https://www.youtube.com/watch?v=T7pq8HHAzXE (30.06.2018).

DFD_FREE_SPEECH: Paarthurnax' speech about trust. URL: https://www.youtube.com/watch? $\mathrm{v}=$ XpgLDjLwego (30.06.2018).

EMERgEnCy Awesome: Game Of Thrones Season 6 Jon Snow $\mathrm{R}+\mathrm{L}=\mathrm{J}$ and Tower of Joy Explained. URL: https://www.youtube.com/watch?v=OOcD_Mz-VZw (30.06.2017).

ERNIE GONZALEZ: The Legend of Zelda - Timeline. URL: https://www.youtube.com/watch?v=ak8jzShE3Vk (30.06.2018).

GAMER4EVER: Batman Arkham City Ending - Batman vs Joker vs Clayface. URL: https://www.youtube.com/watch?v=6W27Zkh9lng (30.06.2018).

GAMEXPLAIN: Zelda: Wind Waker HD - Final Ganondorf Boss Battle + Ending. URL: https://www.youtube.com/watch?v=p71I8slrgrI (30.06.2018).

GERUGON: Syndicate (1993) \#01 Let's Play German Deutsch. URL: https://www.youtube.com/watch?v=bUED9SD3Zdo (30.06.2018).

HOLLYLP: THE STANLEY PARABLE | Part 5 | Komplettes DURCHEINANDER! (German Deutsch). URL: https://www.youtube.com/watch?v=wD_q0i00_BI (30.06.2018).

ISHKOTEN: Ellie kills David Cutscene cinematic The Last of Us. URL: https://www.youtube.com/watch?v=L7I3ILw_hqA (30.06.2017).

JHNINGAMER: The Legend of Zelda: Ocarina of Time All Cutscenes. URL: https://www.youtube.com/watch?v=FX8YkcOeOfQ (30.06.2018).

JACKSEPTICEYE: The Walking Dead Season 2 Episode 5 (Finale) | THESE ARE MANLY TEARS! URL: https://www.youtube.com/watch?v=9CZ2AKhohI0 (30.06.2018).

KeYsJore: Let's Play Uncharted Drakes Schicksal \#01 Deutsch - Charmanter Grabräuber. URL: https://www.youtube.com/watch?v=ZeDVsNFivkU\&list=PLT5cw0HwssyrsLPmoPBCNw CDUE9j4XQjf (30.06.2018).

KINGDAVIDGAMING: The Beginning of Skyrim (Part 1). URL: https://www.youtube.com/watch?v=5CdoyqsNdaE (30.06.2018).

LogicPRoduction: Ocarina of Time - Kaepora Gaebora's Theme Re-orchestrated. URL: https://www.youtube.com/watch? $\mathrm{v}=\mathrm{ANMsD} 4 \mathrm{UcXUY} \& \mathrm{list}=\mathrm{RDANMsD} 4 \mathrm{UcXUY \# t=0}$ (30.06.2018).

LORE: Bloodborne Lore in a Minute! URL: https://www.youtube.com/watch?v=RmvYgwbTHOo (30.06.2018). 
MAHALOVIDEOGAMES: Legend of Zelda: Ocarina of Time Walkthrough - Hyrule Field. URL: https://www.youtube.com/watch?v=DXJeRYqHvig (30.06.2018).

MARIOVEREHRER: Kaepora Gaebora - The Legend of Zelda: Ocarina of Time [Piano Tutorial] (Synthesia). URL: https://www.youtube.com/watch?v=FbErK0RxAJI (30.06.2018).

MasaeAnela: Let's Play Zelda: Ocarina of Time! - Part 89: »Disguises and Kidnapping«. URL: https://www.youtube.com/watch?v=2YkIEgS2xBA (30.06.2018).

MEgasteakman: Shit Navi Says - Legend of Zelda. URL: https://www.youtube.com/watch?v=iZY5owIvLBI (30.06.2017).

MIKEL: The Legend of Zelda: Breath of the Wild [\#015] - Angriff der Yiga! | Let's Play Zelda. URL: https://www.youtube.com/watch?v=pl6SLnY11CE (30.06.2018).

NICOBBQ: Link is NOT A HERO! URL: https://www.youtube.com/watch?v=9mngY8bIZwE (30.06.2017).

OCTANEBLUE: The Legend of Zelda: Ocarina of Time - Part 11 - Lake Hylia \& Zora's River. URL: https://www.youtube.com/watch?v=4hDa8kLwJos (30.06.2018).

OfFEnsive JaKe: Let's Play L.A. Noire - Part 12 (The Black Dahlia Killer / The Quarter Moon Murders) Walkthrough. URL: https://www.youtube.com/watch?v=WUh-5-JSZDA (30.06.2018).

ORKENSPALTER TV: Pen and Paper Rollenspiel: Was ist das? Ein Crash-Kurs für Einsteiger. URL: https://www.youtube.com/watch?v=H_zLvsvghXc (30.06.2018).

RABIDRETROSPECTGAMES: UNCHARTED THE LOST LEGACY Gameplay Walkthrough Part 1 FULL GAME No Commentary. URL: https://www.youtube.com/watch?v=h_jnaqSN-MU (30.06.2018).

RAJMANGAMING HD: Heavy Rain ,Quick Time Events'. URL: https://www.youtube.com/watch?v=VY6h8FY1EC0 (30.06.2018).

RoB124IN: Let's play - Zelda Ocarina of time - Der Basar - Part 14. URL: https://www.youtube.com/watch?v=IaJ70jeYkEY (30.06.2018).

SARIA: Ocarina of Time 3DS Part 1 - The Beginning. URL: https://www.youtube.com/watch?v=InSUxRBsIK8 (30.06.2018).

Shotana Studios: Hidden Agenda (PS4). Competitive Mode Playthrough Gameplay. URL: https://www.youtube.com/watch?v=VhFB-6b3tu8 (30.06.2018).

STEVEn Heartstone: SKYRIM | Zu den Graubärten (Der Weg der Stimme) - Hauptquest Quest 05. URL: https://www.youtube.com/watch?v=VetpEnQvWjc (30.06.2018).

TECH InSIDER: The Void: Alien level experience. URL: https://www.youtube.com/watch?v=oCXthgLTj3Q (30.06.2018).

The GAMEDEPOT: Heavy Rain: Trial 4: Kill a man to save your son. URL: https://www.youtube.com/watch?v=ZAv7dIKVqBw (30.06.2018). 
TMARTN2: Uncharted: The Lost Legacy - Part 3 - THE SNIPER. URL: https://www.youtube.com/watch?v=HpsZkShCXpM (30.06.2018).

TORJE: The Legend of Zelda: Ocarina of Time Any\% speedrun in 17:42 by Torje. URL: https://www.youtube.com/watch?v=7YdcgFe74RE (30.06.2018).

UberNoobsComeHere314: EXTRA'S - The Cucco Game At Lon Lon Ranch. URL: https://www.youtube.com/watch?v=D5W_6V2Hp3E (30.06.2018).

VAATIVIDYA: Bloodborne's Story Explained! URL: https://www.youtube.com/watch?v=yvB1 Vo87uK0 (30.06.2018).

VAZZ: Elder Scrolls IV: Oblivion (pt1) - Beginning. URL: https://www.youtube.com/watch?v=IKLRq2iNfHQ (30.06.2018).

VINYLTOX: Minecraft Xbox - Creative Mode (Episode 1). URL: https://www.youtube.com/watch?v=XlVwLEvoj2o (30.06.2018).

WASTED LINK: Hyrule Warriors - Zelda and Link | https://www.youtube.com/watch?v=1I_oZAT7C0s (30.06.2018).

WKCW AKKA: Zelda Ocarina of Time - Meet with Sheik. URL: https://www.youtube.com/watch?v=zh6813ehnXQ (30.06.2018).

XaXton Revolution: The Journey To Wild Divine Let's Play Part 1. URL: https://www.youtube.com/watch?v=UUNcPhyCa84 (30.06.2018).

XCV: BEYOND: Two Souls - Alleyway Scene - Accept Offer (Chapter: Homeless). URL: https://www.youtube.com/watch?v=Kx57Hy_GUs0 (30.06.2018).

XCV: BEYOND: TWO SOULS - FULL MOVIE [HD] (Chronological Order) Complete Walkthrough. URL: https://www.youtube.com/watch?v=9qolJTsmmWA (30.06.2018).

XCV: Life Is Strange - Kate Commits Suicide (Episode 2: Out of Time). URL: https://www.youtube.com/watch?v=NqS2ppt3NQU (30.06.2018).

ZELDA DUNGEON-INFORMER: Legend of Zelda Ocarina of Time Walkthrough 01 (1/5) $\gg$ Kokiri Sword «. URL: https://www.youtube.com/watch?v=i9OV4K05EHA\&list=PL8C7A9D9AD3CC39F8 (30.06.2018).

ZELDAMASTER: The Legend of Zelda: Ocarina of Time 3D - Part 30 - Biggoron's Sword. URL: https://www.youtube.com/watch?v=mFMU2NLQF88 (30.06.2018).

ZELDAPEDIAVIDEO: The Creation of Hyrule (Ocarina of Time). URL: https://www.youtube.com/watch?v=r4tHItL1xLs (30.06.2018).

\section{Zeitschriften}

Game Studies: The International Journal of Computer Game Research. URL: http://gamestudies.org/1601 (30.06.2018). 


\section{Glossar der verwendeten Fachbegriffe}

Agency: Fähigkeiten und Möglichkeiten eines Subjekts (situativ und kontextbezogen) zu handeln

Agôn: Nach Roger Caillois eine der vier Hauptrubriken des $\rightarrow$ Spiels: Auf Konflikt und Rivalität beruhende Spiele; bspw. Wettstreitspiele wie Tennis

Alea: Nach Roger Caillois eine der vier Hauptrubriken des $\rightarrow$ Spiels: Zufallsoder Schicksalsspiele; bspw. Glückspiele wie Roulette

Attributebene: Erste Ebene des Kontinuumsmodells. Dient der relationalen Einordnung von interaktivnarrativen Phänomenen und Medien. Verschiedene Perspektivierungen des Gegenstandsbereichs möglich

Avatar: Hybrider Figurentyp in interaktivnarrativen $\rightarrow$ digitalen Spielen. Kann (simultan wie zeitversetzt) sowohl als $\rightarrow$ narrativer Charakter als auch als $\rightarrow$ Spielfigur eingesetzt werden

\section{Designparadigma: Vom informatischen} Konzept des Programmierparadigmas abgeleitet. Verdichtung von bestimmten designerischen Prinzipien und Vorstellungen zu einem leitenden Muster

Designphilosophie: Designerische Leitvorstellungen einer Person oder einer Gruppe von Personen, die sich aus designerischen Idealen und Maximen speisen

Designprozess: Zirkuläre Bewegung zwischen $\rightarrow$ Attribut- und $\rightarrow$ Strukturebene $\rightarrow$ digitaler Spiele. Designteam nutzt $\rightarrow$ interaktiv-narrative Polyvalenzen und $\rightarrow$ strukturelle Äquivalenzen zum Design eines interaktiv-narrativen $\rightarrow$ digitalen Spiels
Diegese: Erzählte Welt; Gesamtheit der fiktiven Entitäten eines $\rightarrow$ Narrativs, die sich auf dessen Welthaftigkeit beziehen

Digitales Spiel: Freiwillige, soziale, kommunikative und wechselseitige Handlung innerhalb eines prozedural automatisierten Systems, die durch eine Schnittstelle ausgeführt wird

Erzähllogik: Bestimmter prozessualprozeduraler Aufbau eines $\rightarrow$ Narrativs oder einer Gruppe von zusammenhängenden Narrativen, der für diese typisch ist

Erzählstruktur: Strukturellsyntagmatische Verkettung von narrativen Funktionen innerhalb eines $\rightarrow$ Narrativs

Figurendesign: Entwicklung und Anlage von Figuren als $\rightarrow$ narrativer Charakter, $\rightarrow$ Spielfigur und $\rightarrow$ Avatar im $\rightarrow$ Designprozess

Gameplay: Rezeptionsorientierte Kategorie, die beschreibt, was Spieler beim Spielakt und in der $\rightarrow$ Interaktion mit dem Spielsystem erfahren und erleben

Handlungsoption: Möglichkeit des Subjekts zwischen verschiedenen äquivalenten oder scheinbar äquivalenten Handlungen zu wählen. Unter ,intendierter' Handlungsoption versteht man dabei jene, die vom Designteam bevorzugt angelegt ist und situativ realisiert werden soll, ohne obligatorisch zu sein

Hybridität: Zusammengehen bzw. Zusammengegangensein von mehreren Entitäten, die sich (temporär und partiell oder vollständig) in Form einer neuen Entität auflösen, die die 
Ausgangsentitäten zwar miteinschließt, sie aber nicht mehr in der vorher vorhandenen Reinform aufweist. Unter ,medialer Hybridisierung' versteht man das Verschmelzen mehrer Medien in einem ,Hypermedium', das andere Medien bspw. remedialisiert. Unter ,attributiver Hybridisierung' fasst man das Zusammengehen diverser Kulturformen und -techniken zu einer neuen Entität

Ilinx: Nach Roger Caillois eine der vier Hauptrubriken des $\rightarrow$ Spiels:

Rauschzustände induzierende Spiele, die physische wie psychische Entzückung bedingen; bspw. der mexikanische ,Día de Muertos“

Interaktion: Wechselseitige, kommunikative (via Medien vermittelte) Handlung zwischen , anwesenden ${ }^{6}$ Akteuren. Entscheidend ist hierbei die kognitive wie handlungsautonome Gleichberechtigung zwischen den Interaktionspartnern. Unter einer, realen Interaktion' werden alle Handlungen des Spielers, die zwar mit Bezug auf das $\rightarrow$ digitale Spiel ausgeführt werden, die aber im ,real-analogen' Raum stattfinden, also als tatsächliche physische Handlung oder Reaktion ausgeführt werden, verstanden. ,Virtuelle Interaktionen' hingegen bezeichnen alle Handlungen des Spielers sowie die Reaktionen des Systems, die im virtuellen Raum situiert sind oder hier ihren Ursprung haben

\section{Interaktion-Narration: Konkrete} Umsetzung der designerischen Anlagen eines interaktiv-narrativen $\rightarrow$ digitalen Spiels auf der $\rightarrow$ Realisierungsebene

Interaktiv: Set aus vom Designteam definierten $\rightarrow$ Handlungsoptionen und designten $\rightarrow$ Interaktionen, die an einem $\rightarrow$ dominanten Spielprinzip orientiert sind
Interaktiv-Narrativ: Ordnende und strukturierende Kraft eines interaktivnarrativen $\rightarrow$ digitalen Spiels auf der $\rightarrow$ Strukturebene, das aus $\rightarrow$ Interaktiv und $\rightarrow$ Narrativ besteht

\section{Interaktiv-narrativ polyvalente}

Elemente: Elemente, die sich interaktiv, narrativ oder interaktiv-narrativ im $\rightarrow$ Designprozess umsetzen lassen wie bspw. Figuren als $\rightarrow$ Spielfigur, $\rightarrow$ narrativer Charakter oder $\rightarrow$ Avatar

Interaktivität: Graduationsfähiges Potenzial von Medien und Phänomenen, $\rightarrow$ Interaktionen zu gewährleisten. Unter ,Ludus-Interaktivität' versteht man eine Form der Interaktivität, bei der sich der Spieler an den Konventionen des Ludus in der Interaktion mit dem Spielsystem orientiert. ,Paidia-Interaktivität ${ }^{\star}$ bezeichnet demgegenüber die Maximierung des Möglichkeitsraumes durch die vollständige Erkundung der $\rightarrow$ Agency und Interaktivität

\section{Interaktivität-Narrativität: Graduell} unterschiedlich ausgeprägte attributive $\rightarrow$ Hybridität interaktiv-narrativer Phänomene und Medien, die auf der $\rightarrow$ Attributebene erfassbar ist

Ludus: Nach Roger Caillois eine der beiden Spielarten des $\rightarrow$ Spiels: Striktes regelgeleitetes und an einem Spielziel ausgerichtetes Spiel

Mimicry: Nach Roger Caillois eine der vier Hauptrubriken des $\rightarrow$ Spiels: Maskenspiele mit anderen Identitäten und Rollen. Imitation von anderen und zuweilen Täuschung Dritter; bspw. Maskenball

Monomythos: Form des mythologischen $\rightarrow$ Narrativs, die Joseph Campbell mit seiner Forschung zum Modell der Heldenreise herausarbeitete 
Mythos: Kulturelle Form, die

soziokulturell dominante Inhalte, Themen und Motive narrativ vermittelt und tradiert, die darüber hinaus aber zahlreiche Funktionen erfüllt, deren ordnende und strukturierende Gestalt für Menschen bedeutsam ist. Deshalb lassen sich Mythen sowohl substantialistisch als auch funktionalistisch fassen

Narration: Prozess der Realisierung eines $\rightarrow$ Narrativs als $\rightarrow$ Plot oder $\rightarrow$ Story. ,Medial' können Narrationen von Medien im Zuge von deren Repräsentation und Vermittlung erzeugt werden. ,Personal' generieren Subjekte bspw. Plots, indem sie bestimmte Entitäten narrativieren

\section{Narrativ: Kulturell verfestigte $\rightarrow$} Erzählstruktur, die auf einer spezifischen Verkettung von Kardinalfunktionen beruht und die auf ein bestimmtes Figurenpersonal sowie Raum-ZeitGefüge zurückgreift. Ist ein Narrativ , eingebettet', dann ist es vom Designer in die mediale Struktur einer Entität integriert, ein emergentes Narrativ wird hingegen vom narrativierenden Subjekt hinzugenommen, um eine (auch nicht genuin narrative) Entität bzw. den Kontakt mit dieser zu narrativieren

Narrativer Charakter: Auch narrative Figur. Figurative Entität eines $\rightarrow$ Narrativs

\section{Narrativität: Graduationsfähiges}

Potenzial von Phänomenen oder Medien, narrativ sein zu können. Bei ,medialer Narrativität' ist einem Medium aufgrund eines eingebetteten $\rightarrow$ Narrativs Narrativität eingeschrieben, wohingegen einem Medium oder Phänomen ,personal' Narrativität zugeschrieben werden kann, indem das narrativierende Subjekt ein emergentes Narrativ hinzunimmt
Paidia: Nach Roger Caillois eine der beiden Spielarten des $\rightarrow$ Spiels: Freies, wenig reglementiertes und tendenziell spielzielloses Spiel

Plot: Realisierung eines $\rightarrow$ Narrativs durch $\rightarrow$ Narration bei der die kausale bzw. $\rightarrow$ erzähllogische Verkettung der narrativen Funktionen maßgeblich ist

Queststruktur: Strukturell-syntagmatische Verkettung von Quests innerhalb der interaktiv-narrativen $\rightarrow$ Spielstruktur

Realisierungsebene: Dritte Ebene des Kontinuumsmodells. Dient der Analyse der konkreten Realisierung(en) der designerischen Anlagen interaktivnarrativer $\rightarrow$ digitaler Spiele durch Spieler. Identifizierung von verschiedenen $\rightarrow$ Spielertypen möglich

Reisemodell des Helden: Auch Modell der Heldenreise $\rightarrow$ Monomythos

Spiel: Freiwillige, soziale, kommunikative und wechselseitige Handlung, die mit Hilfe eines ,Als-ob-Charakters' immersiv in den liminalen Zustand des Zauberkreises als eine raumzeitliche Abgrenzung von der gewöhnlichen Welt einführt und die nicht primär an materiellen Vorteilen in der gewöhnlichen Welt orientiert ist

Spielertypen: Anhand von Spielerpräferenzen identifizier- und kategorisierbare Akkumulationen von vergleichbaren Nutzungsmustern interaktiv-narrativ $\rightarrow$ digitaler Spiele. Unterschieden werden der interaktive, der narrative und der interaktiv-narrative Spielertyp

Spielfigur: Semiotischer Funktionsträger eines $\rightarrow$ Spiels, der gemäß den $\rightarrow$ Spielmechaniken und $\rightarrow$ Spielregeln variierende Rollen übernehmen kann und in seiner Erscheinung sehr wandelbar ist 
Spielmechanik: Charakteristische interaktiv-prozedurale Prozesshaftigkeit eines $\rightarrow$ Spiels, die das Spielen des Spiels umfassend beeinflusst

Spielprinzip: Auch dominantes Spielprinzip. Das Design leitende Muster von wiederkehrenden (interaktiven) Handlung(soption)en, $\rightarrow$ Spielregeln, $\rightarrow$ Spielmechaniken und $\rightarrow$ Spielrhetoriken

Spielprozess: Zirkuläre Bewegung zwischen $\rightarrow$ Struktur- und $\rightarrow$ Realisierungsebene $\rightarrow$ digitaler Spiele. Spieler nutzt die designerischen Anlagen interaktiv-narrativer digitaler Spiele im Rahmen seiner konkreten Umsetzung spezifisch

Spielraum: Raum, in dem sich das $\rightarrow$ Spiel als Spiel entfalten kann und der wesentlich von $\rightarrow$ Spielmechaniken, $\rightarrow$ Spielregeln und $\rightarrow$ Spielrhetoriken konstruiert wird

Spielregel: Fixierte, verbindliche, intersubjektiv erfahrbare und den Handlungsraum absteckende Regeln, die die formale Struktur von Spielen bilden

Spielrhetorik: Persuasives Element von $\rightarrow$ Spielen, das den Spieler dahingehend zu überzeugen versucht, dass es sein $\rightarrow$ Gameplay koordinieren möchte

Spielstruktur: Zentrale Struktur interaktiv-narrativer $\rightarrow$ digitaler Spiele, die aus der $\rightarrow$ Quest- und der $\rightarrow$ Erzählstruktur besteht und im Falle einer ausgeprägten $\rightarrow$ Hybridität die Züge einer Doppelhelix annehmen kann

Spielwelt: Hybrider Welttyp in interaktivnarrativen digitalen Spielen. Kann (simultan wie zeitversetzt) sowohl als $\rightarrow$ Diegese als auch als $\rightarrow$ Spielraum eingesetzt werden

Story: Realisierung eines $\rightarrow$ Narrativs durch $\rightarrow$ Narration bei der die chronologische Verkettung der narrativen Funktionen maßgeblich ist

Strukturdesign: Entwicklung und Anlage von Strukturen als $\rightarrow$ Erzählstruktur, $\rightarrow$ Queststruktur und interaktiv-narrative $\rightarrow$ Spielstruktur im $\rightarrow$ Designprozess

Strukturebene: Zweite Ebene des Kontinuumsmodells. Dient der Analyse der Implementierung der designerischen Anlagen interaktiv-narrativer $\rightarrow$ digitaler Spiele durch das Designteam. Beschreibung anhand verschiedener $\rightarrow$ Designparadigmen möglich

\section{Strukturelle Äquivalenz:}

Gleichwertigkeit bestimmter Elemente interaktiv-narrativer Phänomene oder Medien, die eine Offenheit gegenüber der anderen Seite des Kontinuums erlauben; bspw. die potenzielle Gleichwertigkeit von Spielleiter und narrativer Instanz

Transmediale Welt: Welt, die aus den transmedialen Bezugnahmen diverser medialer Artefakte z.T. unterschiedlicher Medienkanäle verschiedener Produzenten und Rezipienten aufeinander entsteht. Transmediale Welten beinhalten meistens transmediale Erzählungen und ein reges Franchise

Weltdesign: Entwicklung und Anlagen von Welten als $\rightarrow$ Diegese, $\rightarrow$ Spielraum und interaktiv-narrative $\rightarrow$ Spielwelt im $\rightarrow$ Designprozess 


\section{Abbildungsverzeichnis}

Abb. 1: Kücklichs Dreiecksmatrix

Abb. 2: Modifizierte Dreiecksmatrix

Abb. 3: In-Game/In-Engine, Thomas Hawranke, 2013

Abb. 4: Kontinuumsmodell

Abb. 5: Makroperspektive

Abb. 6: Mesoperspektive

Abb. 7: Mikroperspektive

Abb. 8: Modifikation des Modells der Heldenreise

Abb. 9: Mikro-Mikroperspektive 